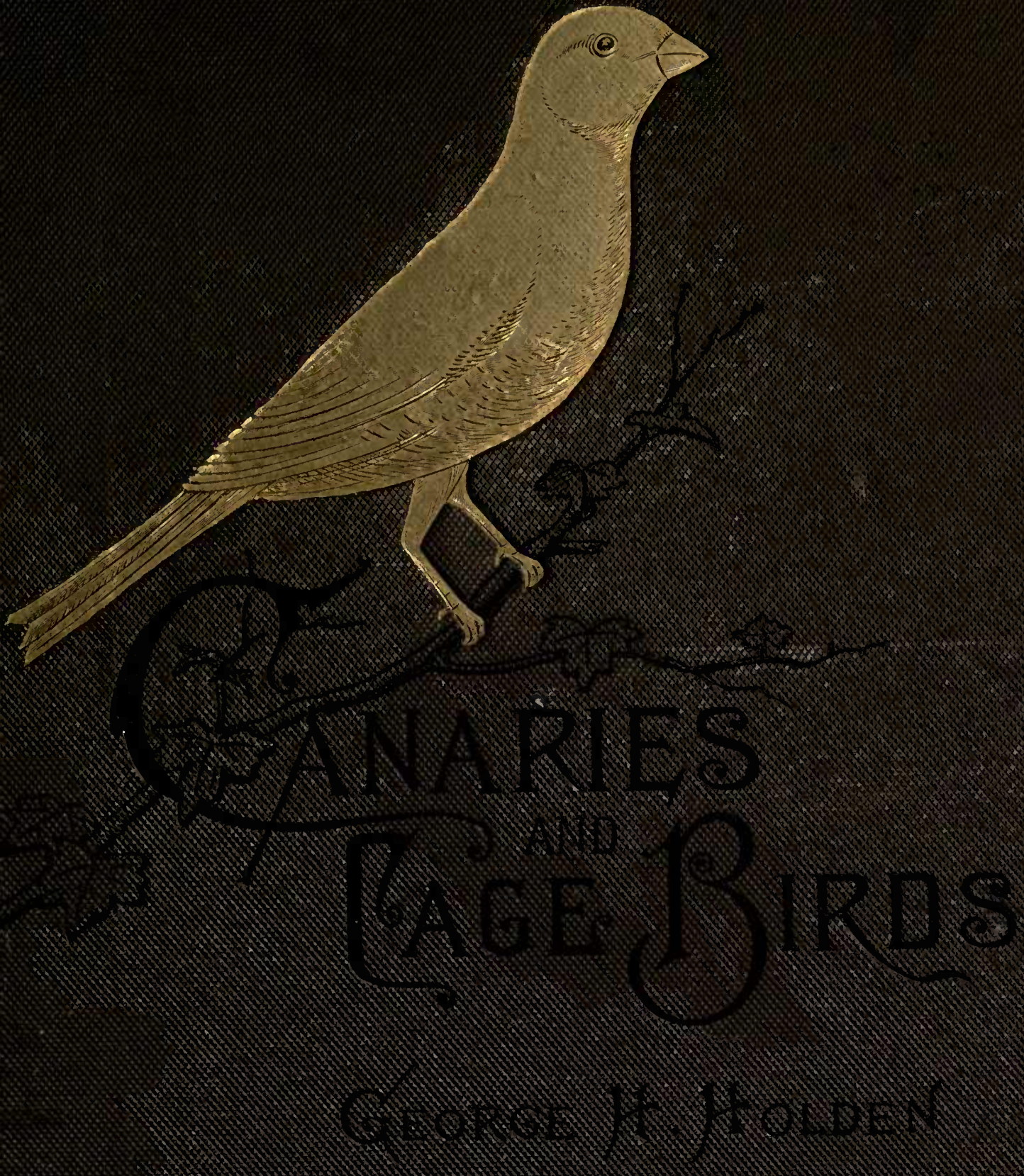




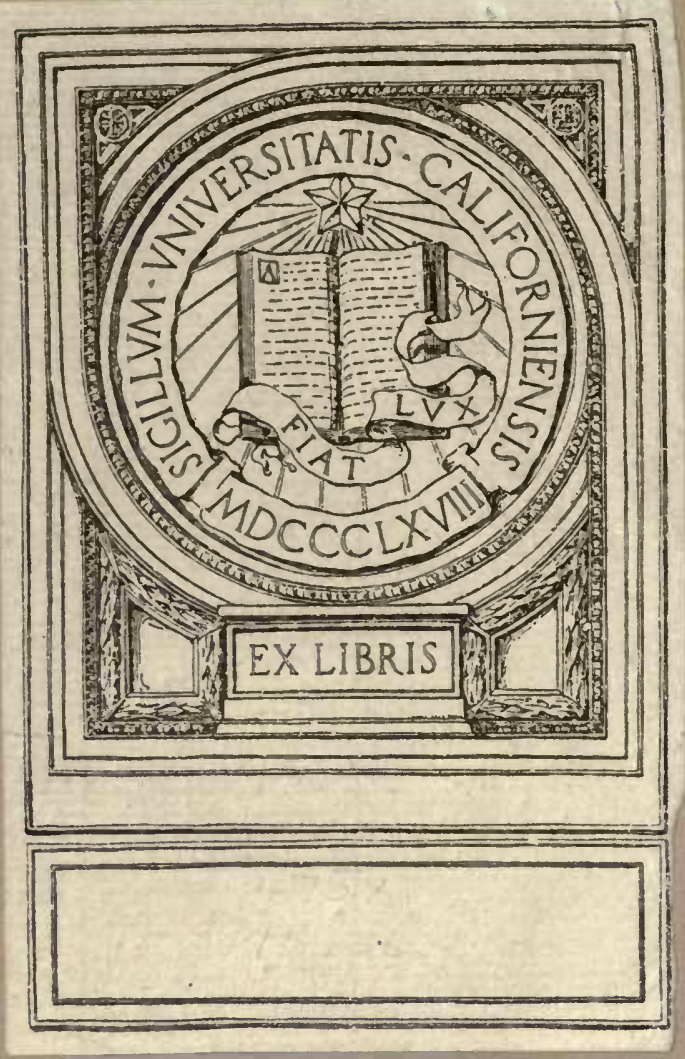




$$
\text { allo. } 0=
$$


300

megl 





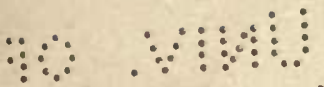

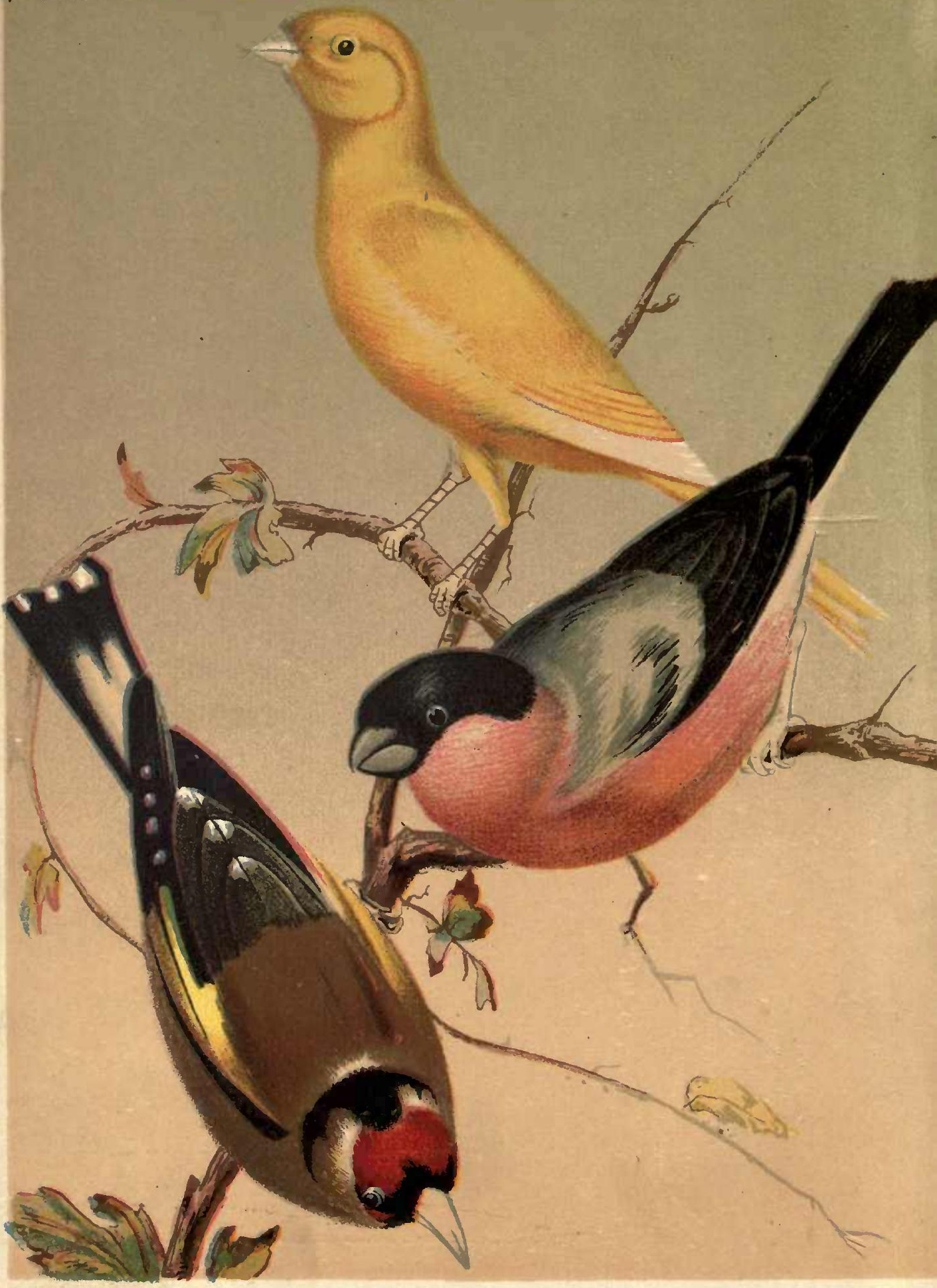




\section{CANARIES AND CAGE-BIRDS}

THE FOOD, CARE, BREEDING, DISEASES AND TREATIIENT

ALL HOUSE BIRDS

\section{BIRDS FOR PLEASURE AND FOR PROFIT}

BY

GEORGE II. HOLDEN

AUTHOR, IN PART, OF "HOLDEN'S BOOK ON BIRDS"

Second qed ittion

PUBLISHED BY GEORGE H. HOLDEN

240 SIXTH AVENUE, NEW YORK

9 BOWDOIN SQUARE, BOSTON, MASS.

37 NORTH MAIN STREET, PROVIDENCE, R. I. 
Copyright, 1888 ,

BY GEORGE H. HOLDEN.

$\because \because \because \because \vdots$

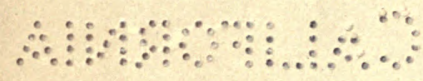

PRESS OF

ALFRED MUDGE \& SON,

Bostox. 
JUDGE PETER S. WHEELOCK, BOSTON, MASS.,

Who, in A NOTE PERMitTING THIS INSCRIPTION, WRITES, "IN EARLY BOYHOOD I USED, AT EVERY OPPORTUNITY, TO SIT AT THE EDGE OF THE WOODS, AT NIGHTFALL, AND HEAR THE BIRDS SING THEMSELVES TO SLEEP,"

THIS BOOK

IS AFFECTIONATELY DEDICATED. 



\section{INTRODUCTION.}

This work is designed to be a help to those who keep birds for pleasure, or breed them for profit. The greater part of the space devoted to each bird contains the essential facts respecting his food and care. The two subjects, food and care, being thus fully written up, it can be readily inferred that the subject usually combined with them, namely, diseases, would require little attention. And the author would like to sharply outline this fact for each reader, that if "Food and Care," as indicated for each bird, are properly read, "Diseases " will not prevail.

But there always will be some sick birds requiring attention, and they must not be neglected; for this reason these pages contain a large number of recipes, many of which have been used for years with success, and are now for the first time publisherl.

The articles on Canaries, Mocking-birds, Parrots, Finches and Nuns, and our native wild birds, have been made very complete; and it is hoped they will prove especially valuable. The direetions for mating and rearing many kinds of birds not generally bred here in eages, such as the smaller seed-eating birds, as well as the soft-billed birds, and Paroquets and Parrots, are drawn from the experiences of European breeders of wide reputations, and with due regard to the habits of the birds in their wild states.

An attempt has been made in each article to indicate the peculiar traits of the bird, and this idea has been expanded in the several comparative tables. Buyers unfamiliar with the different birds will find in the tables suggestions which will aid them in selecting desirable specimens.

The black-and-white illustrations of birds have been drawn with care from lifesubjects.

The colored plates were made under the author's own supervision, and exactly represent in color and outline the subjects portrayed.

We are indebted to Mr. W. W. Caldwell of Boston for several good poems; to 
Mr. Albert J. Holden of New York for the tuneful arrangement of each of the Bullfinch melodies; and to $\mathrm{Mr}$. John Gourley, jun., of Boston, for valnable assistance in the preparation of the manuscript.

Only fragments of widely separated hours have been seized from an exacting business located in three cities, and devoted to this work, in which no pretence is made to any literary style; but, if the book is a real he'p to bird-keepers, the author will have the pleasure of seeing its aim fully accomplished.

G. H. H.

\section{THE SECOND EDITION.}

In this edition there are forr more pages of colored plates, making twelve in all. The Parrot article has been rewritten, with especial reference to the taming, diseases, and treatment of these valued birds.

Many new styles of canary cages, with the drawer bases, and the larger cages, in new designs with brass bases, are illustrated in the new list of lower prices.

G. H. H. 


\section{CONTENTS.}

PAGE

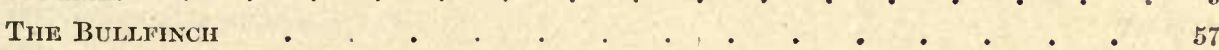

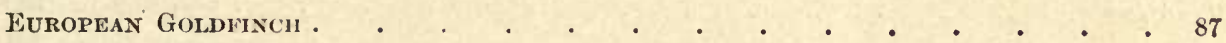

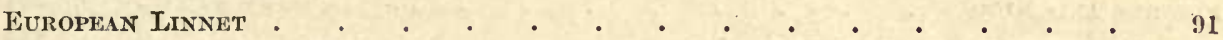

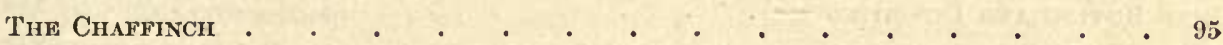

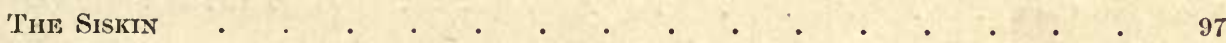

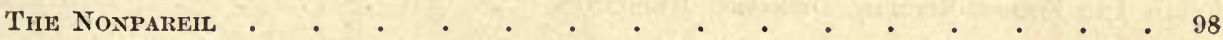

THE INDIGO BIRD • • • • • • • • • • • • • • 100

THE Yellow-BIRd . . . . . . . . . . . . . . 101

AMERICAN Red LINNET • . . . . . . . . • . . . 103

The Snow Bunting . . . . . . . . . . . . . . 104

JAVA SPARROWS . . . . . . . . . . . . . . 105

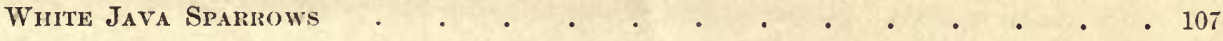

Cardinals . . . . . . . . . . . . . . 110

Grosbeaks . . . . . . . . . . . . . . . . 115

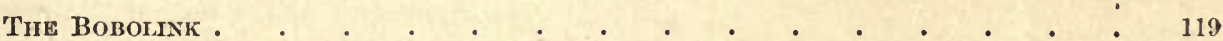

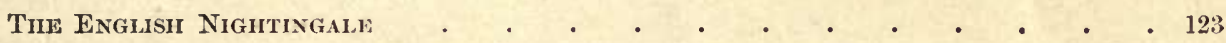

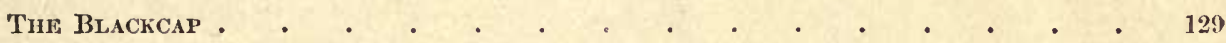

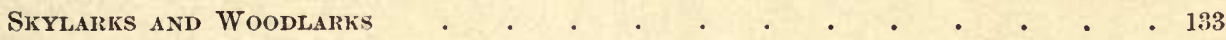

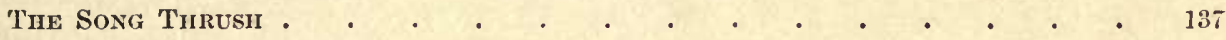

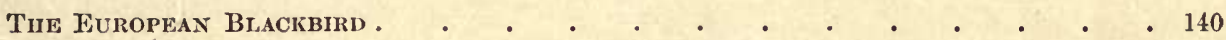

The Stone Thrusil • . . . . . . . . . . . . 143

The ENGLisil Staring . . . . . . . . . . . . . 145

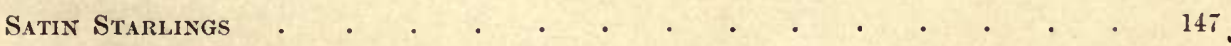

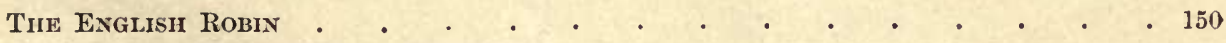

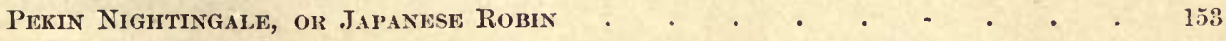

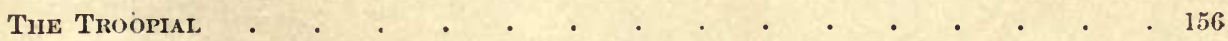

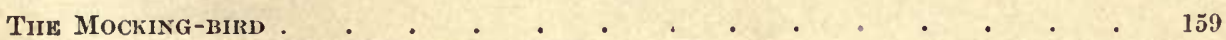

Brown Tirrasher axd other American Thrusirs . . . . . . . 166

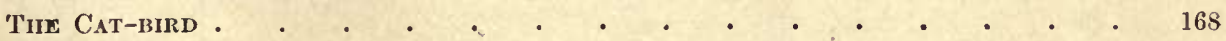

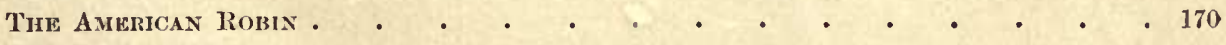

The Blue Robin • • • • • • • • • • • • • • • • 173 
PAGE • • • • • • • • • • • 171

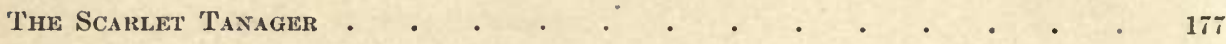

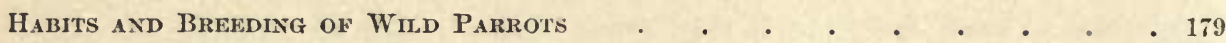

African Gray PARrot and other Parrots . . . . . . . . . 183

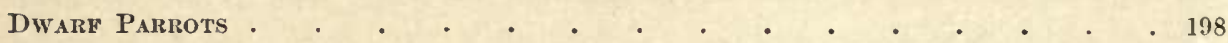

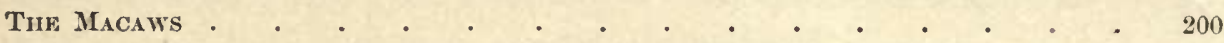

The Cockatoos . . . . . . . . . . . . . . . . . . . 203

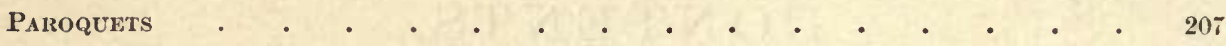

African, Madagascar, and West-Indian Paroquets . . • . . . . 211

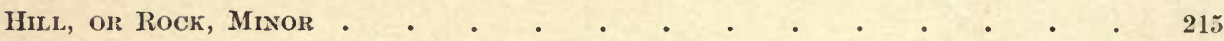

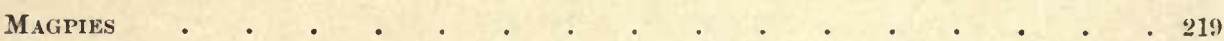

RAVEN, CROW, ROOK, JACKDAW . . . . . . . . . . . . . . . . . 223

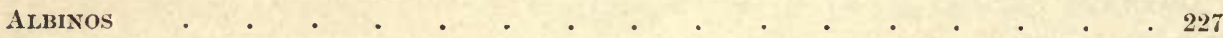

Toucans . . . . . . . . . . . . . . . . . . . . . . . 230

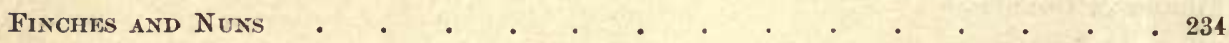

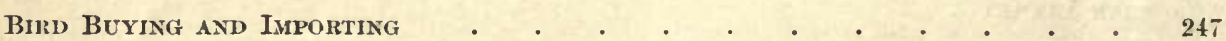

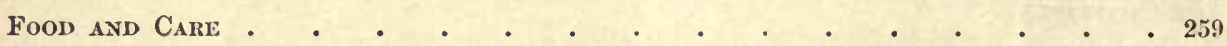

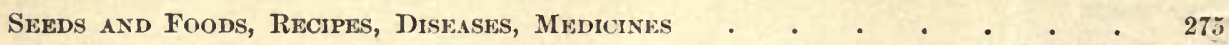

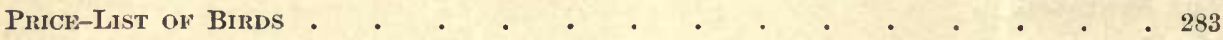

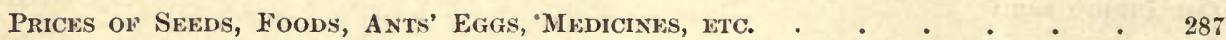

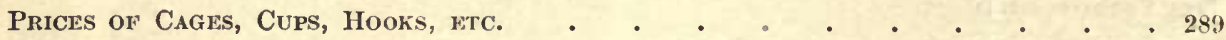

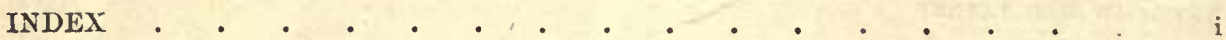




\section{LIST OF ILLUSTRATIONS.}

AUSTRATIA PATOQU⿴囗十 PAG

Australian Paroquets

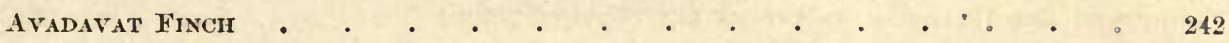

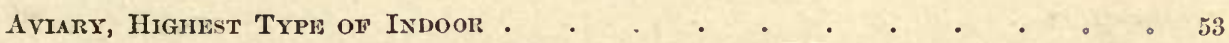

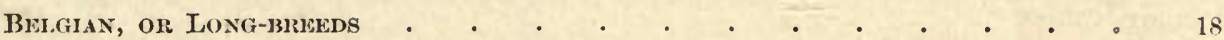

BLACKCAP (Colored Plate) . . . . . . . . . . . . opp. 154

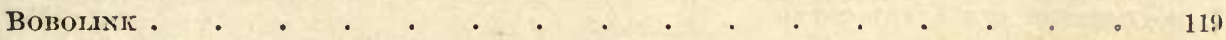

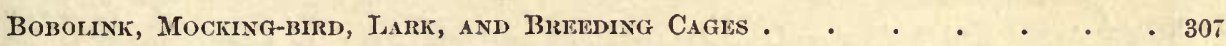

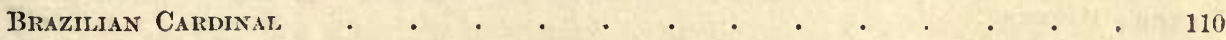

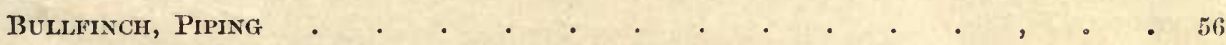

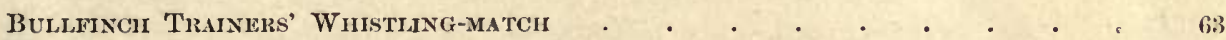

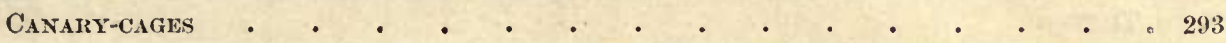

Canary, Crested, Caymnne-Fud, and Golden-Spangled Iazard (Colored llate), opp. 45

Canary, Goldfinci, and Bullfincir (Colored Plate) • • • • . Frontispiece

Cardinals, Red axd Gray (Colored Plate). • • • • • • . . opp. 111

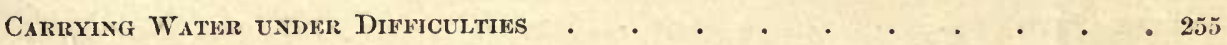

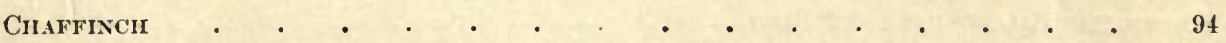

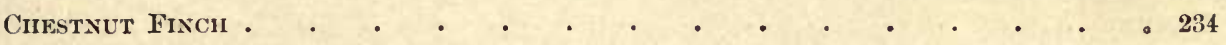

Cockatoos ${ }_{6}$.

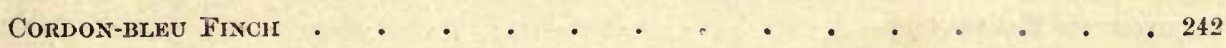

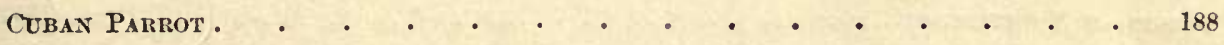

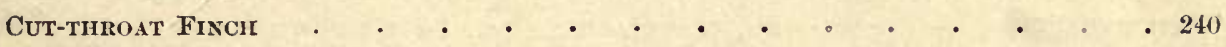

DIAMOND SPARROW . • • • • • • . . • • • . . . . . 234

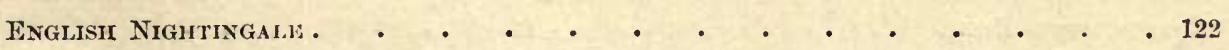

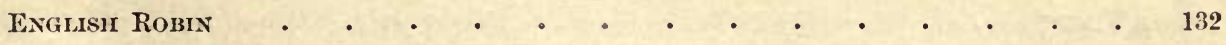

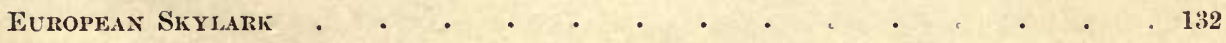

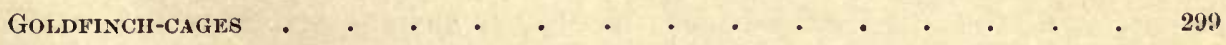

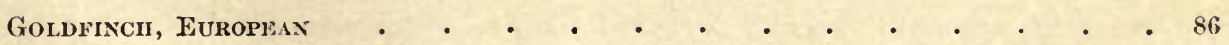

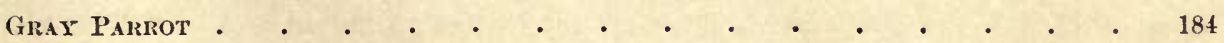

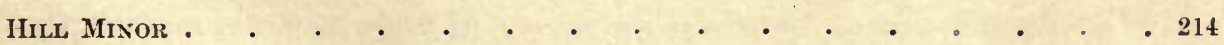

HOOK AND CUPS

LiNNet, EURopeax • • • • • • • • • • • • • 86

IONDOX FAKIR • • • • • • • • • • • • • • • • 251

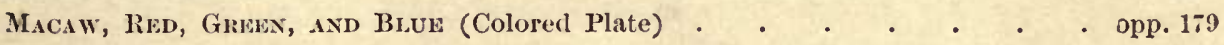


Magr'e

MagPhe Fixch

MOCKING-BIRD

Mouse aNd SQu

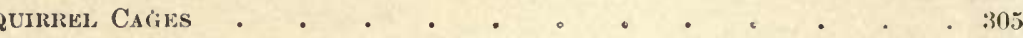

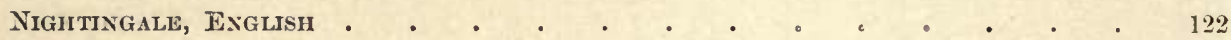

Nigitringale, Europeax (Colored Plate) • . . . . . . . . opp. 154

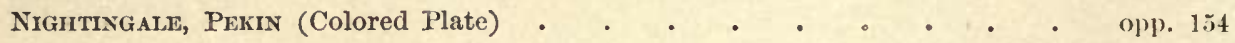

Nigittingale, Virginian . . . . . • • . . . . . . 110

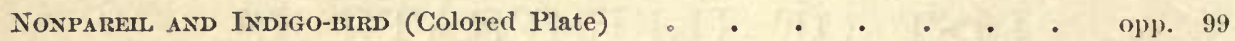

ORANGe Bishop Finch

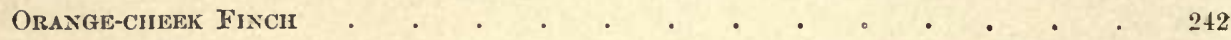

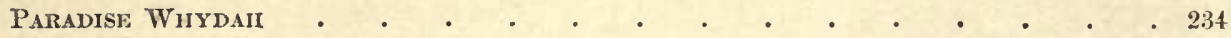

Paroquet, Cardinal, Mocking-ibird, axil Aviart Cagles . • • • • $\quad 300$

Paroquets, Red-Headed axd Australiax (Colored Plate) • • • . . opp. 207

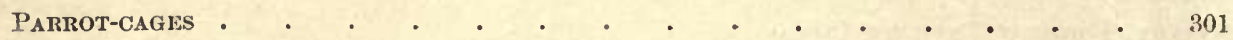

Parrot, Cuban .

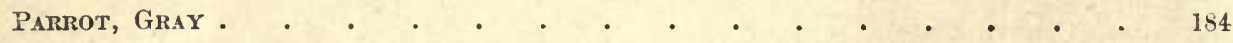

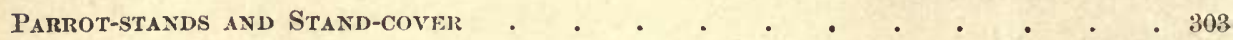

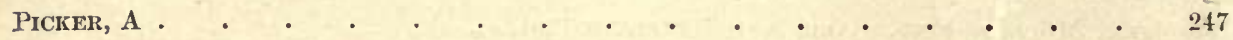

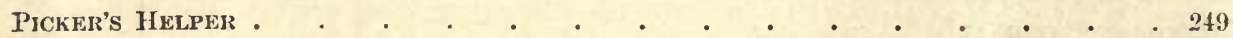

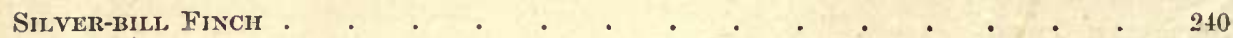

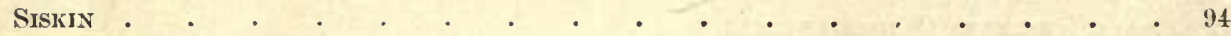

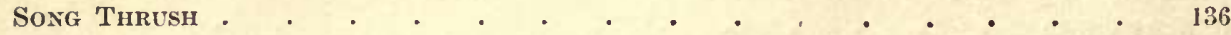

South Ankrican Troopiat (Colored Ilate) • • • • • • • . opp. 157

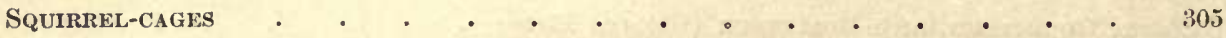

St. Andreasiberg Canali . . . . . . . . . . . . . . . 13

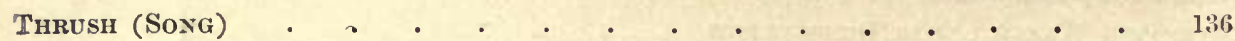

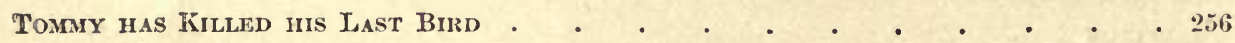

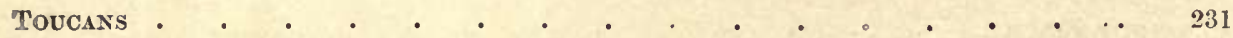

Trap-cage, Spring, Hooks, Elevatol, Ciraix, axd Guards • • • . 308

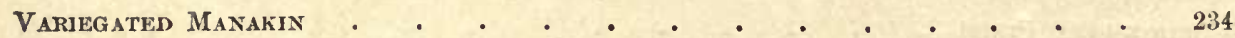

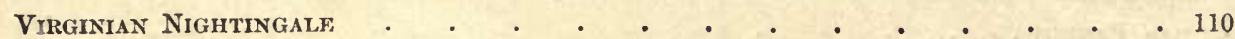

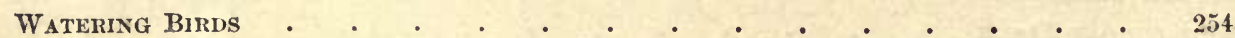

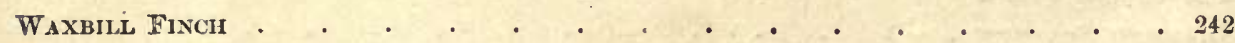

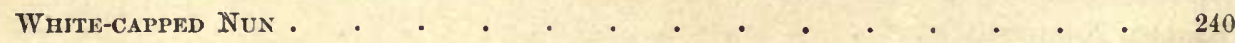

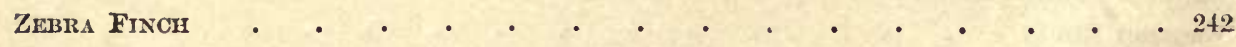




\section{HOLDEN'S}

\section{CANARIES AND CAGE-BIRDS.}

\section{CANARIES.}

'Tnese birds are now so widely known and universally kept, that any formal introrlnction of them as a family is certainly unnecessary. 'There are, however, individual menbers of this large family - foreigners - which are strangers to most of us ; and these it will be our pleasure to so plainly present to you, that not only the name, lut general traits, of each may be understood. This article will treat, then, of most of the varieties which have sprung from the original wild stock; the diseases. to which the birds are subject, and the treatment of the same; the care and food; and the methods of breeding in the countries where the different classes exhibit the best strains of blood.

The Canary has been known as a household pet since the commencement of the sixteenth century. His original colors were green and gray; and he was an inhabitant of the island whose name he bears, whence the-species were brought to Europe in large numbers. Easily domesticated and bred, he became at once the cage-bird to which the most care was given, and upon which the greatest attention was lavished. It is related by the older authors, that the island of Elba was the first European ground on which a Canary found resting-place; having flown thither from a ship bound to Leghorn, which foundered near the island. 'This theory is unworthy of belief, as a crew of a foundering ship would probably attend to other duties than that of opening a thousand eages, and allowing the birds to escape ; and a small number would not be sufficient to form the basis for the extensive bird-trapping which is reported to have taken place on the island. The first Canaries were brought to England on regular ships plying between English ports and the south of France.

They are at present found in a wild state in some of the islands off the coast of Africa, but are rarely brought to civilized conntries, owing to their inferiority in every way to the domesticated birds. 'The superiority of the latter class over the wild birds has been brought about by the watchful study which has been given them in the various countries which have made the subject of Canary-raising a specialty. Canaries have at the present time a nationality; each breed being easily distinguished from the others by the varions sizes, shapes, colors, and songs which they distinctively have. 
The main classes may be enumerated as follows : the German, the English, the Belgian, the French, and Hybrids. From these classes spring numberless distinct varieties, which have marked and fixed characteristics. In the English class, there are no less than eight of these varieties.

'The Germans were probably the first to give the matter of Canary-breeding any special attention; and, although the first to take up the subject, the birds which they raise, even to the present day, probably bear the elosest resemblance, in shape, size, and color, to the original wild Canary, of any class raised. 'This is due in a great measure to the inattention paid to breeding birds for color and distiuctive shapes or sizes, the German breeder's chief aim being the song which his bird is capable of producing : to this he directs all his skill and attention, and at the present time is far ahead of all other breeders in this respect. If he has sacrificed beanty and imposing size, he can point with pride to his one chief excellence, which indeed is the most attractive quality for which birds of any breed or class should be kept. The German's model is the nnpretentious-looking Nightingale; and he evidently bears well in mind the old saying, "Fine feathers do not make fine birds."

The German class of Canaries may be subdivided into three varieties, - the Harz-mountain, or common German, Canary, the St. Andreasberg, and the Campanini ; the latter being a new class of birds, which has sprung into existence from the continued efforts to produce a higher grade of trained singers. The Harz Momtains are the home of the German song Canary; and in this and contiguous districts, as well as in Hanover, Hesse, Berlin, Thuringia, and Tyrol, this elass of Canaries is bred to the number of thousands annually. Owing to the immense numbers bred, the chance for voice-culture is not so great as in the case of the other German varieties, when smaller numbers are raised, and greater care exercised on each particular bird. To meet the immense demand for these songsters, thousands are annually exporter to all quarters of the globe ; and the common German Canary is the best known of any class of Canaries raised. The ease with which they may be bred has made them great favorites wherever introduced. The song, although not so choice as the highest of his class, is sufficiently sweet to charm all except those whose judgment in bird-music is most highly cultivated.

The Harz-mountain Canaries are bred in common breeding-rooms ; and although the birds do not receive the care and attention paid the higher class of song-birds, and which must be given the fancy colored or shaped birds, - owing to the picked strains of blood and the ehoice markings in feathers which must be employed in the latter cases, - they are the most prolific of breeders, and for this purpose deservedly popular with beginners in bird-raising. The natural song of the Harz Canary is very pleasing, loud, and varied; and, in addition to his own song, he occasionally introduces the notes of the Nightingale, and the notes of other swectnoted songsters which abound in his native hamlets. The entire song forms a pleasing combination, and no two birds' songs are alike : to be sure, the perfect rollings and trills of his better-edueated brothers are lacking; but his song withal is very sweet, and, until the better grades are heard, applanded as the perfection of Canary song.

It has been often said, that it is cruel to eage and confine Canaries. With the class of people who argue in this way, I do not agree. The Canary bears to the race of birds about the same relation as man to the animal family. For generations 
back the Canary lats known no habitation but that of the eage; his domestication has been made almost complete: and in most cases, when he escapes, or is turned loose on the wicked world, he is most anxious to return to his home again : missing the care and attention which any bird-keeper would naturally bestow on him.

The Harz-mountain Canaries are divided into different grades; the usual rule being, the fewer number reared at any one breeding-house, the better the class of songsters. When wholesale breeding is indulged in, the tendency is to lessen the variety and sweetness of the notes. Your dealer, if an importer, usually has the birds selected according to the breeding-places; and it is well to note the difference.

The St. Andreasherg Canary takes his name from his native village, which is perched in the summit of the Harz Mountains, and a favorite resort in summer for invalids suffering from troubles of the lungs and throat. Its pure, braeing air is medicine for the lungs of a man, and exercises a wonderful transformation in the tone of the Canary which bears the name. Added to this, years of patient and constant training and sehooling in cultivating the Canary's voice to the highest degree of perfection have justly placed this class at the head of the school of singing Canaries. The amount of education which a well-trained singer of this class is obliged to undergo would scarcely be believed. Since the increase of exportations, owing to the great demand for them since they were introduced into other countries, the training-places have been extended to various other localities in the Harz Mountains, the teachers being taken from St. Andreasberg; and at the present time very ehoice grades of these silver-throated singers are bought in many places besides that famous village. The St. Andreasberg Canary, in his native breeding-place, is fed on plain rape-seed, and twice a week on the egg and Zwieback mixture.

The methods employed in raising a brood of nestlings, to become artists in their line, are interesting; and the amount of patience expended can only be accounted for by the intense love of the German for his hobby, added to the remuneration obtained. In St. Andreasberg, the principal revenue of the village is derived from Canary-raising. 'The St. Andreasberg Canary's notes were originally obtained by placing a Nightingale in the breeding-room of young birds. The natural, cleartoned voices quickly blended the song in with their natural notes: then the most promising pupils were culled out, and trained still further, by means of other songbirds. After three or four seasons of this kind of training, the Canary was ready for the position of teacher, and placed in the schoolroom as instructor for the young beginners. Years of this sort of training gradually raised the St. Andreasberg's song to the highest state of perfection. Look into one of these schoolrooms, and see the school-teachers' boxes draped over to prevent their singing until the proper hour. The young birds in another room are quietly feeding, and chirping in the sunlight. The cloth covering of the teacher's box is raised in front, so that a little light may be admitted; and, after a few preliminary touches, he suddenly bursts forth into such a flood of melody that the listener is fairly enraptured by the delightful sounds. The young birds leave off feeding, and appear to be as delighted as the human audience, and manifest their pleasure by endeavoring to imitate the song which is heard. But there is a sad failure, for many days elapse before even a few notes are sung in perfection. After weeks of this training, the young birds are separated; and any of them which have the least semblance of harsh or broken 
notes are quickly put where they will not injure more proficient pupils, and their training is then continned until the bird-raiser satisfies himself that further perfeetion cannot be attained. No two bird-raisers have teachers for the young birds which have voices exactly alike; and, by the interehange of teachers for the instruction of the young, the voice is still further eultivated. It requires a praetised ear and an immense amount of experience to select the highest class of birds. The choicest birds, when sold to the dealers, are beard separately, and each separate note recorded. The foreign buyer of the St. Andreasberg Canaries is obliged to visit the breeding-places as early as July, before the birds are fully feathered, and pay in advance for them, to be delivered when fully instrueted. The breeder retains three or four of the choicest, as instruetors for the following season.

It is elaimed, that, after all the care which is lavished upon this class of Canaries, only about ten per cent of the entire number raised are juclged to be perfect by the eonnoisseur; and under no circumstance is a bird perfect in song when he has less than six-months' training. 'The highest-prized notes are learned by the quiet birds; for the more excitable birds are apt to beeome nervous, and break into sliarp, detached notes, which impair the song. To produce these best songsters, the breeder must give close attention to a multiplicity of things, - among others, the amount of light which they receive, the kind and variety of food given, and the proper voicetraining : most necessary of all is it to earefully eull all naturally sharp or liarsh voiced birds, as soon as their faults are noticed, from among the young brood.

The objeet to be attained in the best-trained bird's song is to get the greatest combination of various difficult trills and odd notes, and the excellence consists in the performance of them. Lond or harsh notes are not desirable, and the bird uttering them is quiekly rejeeted. The length of the song, combined with quality of voice and a continued repetition of the varied strains, are the qualities which mark the perfect bird. Short notes, no matter how sweet or soft, are not regarded as worthy of merit. The Nightingale-notes, when sung solely, are not prized as highly as those of a bird which combines certain lengthened trills or passages of melody. The perfect birl's song should be like an endless stream, the finish and commencement of his song not being pereeptible. Some of the eloicest birds lave a compass of four octaves, and will exeeute the various passages in the most perfeet style; but no matter what strains, notes, or combinations he has mastered, it is always desirable that the beginning and the finish of the song shonld be the softest notes of all. The trills and other notes should be fully gone through, and the passing from one note to another should be an imperceptible glide.

The notes, trills, and combinations number twenty-five or more; the best known and highest prized being the water-bubble, deep roll, bell, flute, warble, whistle, and the numberless trills. These are all varied, and form an endless number of combinations: as one bird may commence his song with an entirely different note or trill from another; and, when both birds' songs are listened to, they appear to be entirely different. Although the same notes are gone through with, they are sung in an entirely different order. An enthusiastic lover of the St. Andreasberg Canary describes his song as follows:-

"A few days ago, in climbing a mountain on the west side of the Hudson River, near Catskill, weary and thirsty, I unexpectedly found a spring welling from a rock. 
tures; and, at the sound of his quiet voice, turmoil and strife, and all that race, are put to flight."

Owing to the large prices paid in Germany for the highest elass of the best trained and perfect songsters, it was deemed inadvisable to import any to America ; as the original cost of the birds, combined with the large attending expenses of collecting and shipping them, would not warrant the risk incurred: but, within the past two years, small lots have been received, and, owing to their superior excellence and perfection in song, have been christened the Campanini Canary. This grade of bird is the same as the birds used as instructors in the village of St. Andreasberg, and are bought only after being put to the severest trials. 'They are heard separately, before leaving Germany, by the most expert judges of Canary song; and the least fault or false note reduees them from the highest grade. To hear a Campanini Canary perform his varied and perfect song for the first time is a revelation, even to those supposed to be judges of bird-music. This grade of Canary never loses his song, owing to the thoroughness of the training received: but they should be kept in a separate room, away from any harsh or loud songsters; as such birds have a tendency to gradually mar the purity and mellowness of the notes. 'They will perform sufficient bird-music to please even the most exacting.

Our artist has transferred, as nearly as may be possible, the shadow of our bird for your inspection; but no engraver's knife, be its point never so fine and never so cumningly directed, can furnish any adequate idea of what the St. Andreasberg is. Only his own voice can do him simple justice.

The German Canary is about five inches and a lialf in length, and varies in color from the elear yellow to the briglit green. As mentioned above, no attention is paid to the depth or purity of eolor, the principal object souglit being the soug; but the colors and combinations of colors are almost as numerous as the birds themselves, and comprise the mealy, the jonquil, dark green, dark mottled, light mottled, dark and light crested, in clear or mottled colors, and the prized cinnamon.

The St. Andreasberg and Campanini Canaries are somewhat smaller, varying in length from four inches and a half to five inches. The eolor of these birds is, as a rule, of a lighter shade than the common German Canary. The inferiority in size cloes not have the least effect on the throat-power. Why the best singing Canaries should be the most insignificant in size is something which cannot be accounted for, but may be diue to the purity of the breed; for the genuine St. Andreasberg Canary, in his own village, is never erossed with any other. An inquiring buyer, on being shown a St. Andreasberg Canary, remarked, "What a dirty, insignificant-looking ehap he is! How is it that he eosts so much?" The salesman had no need to answer the question. The bird himself answered it far better than any human tongue eonld, and, in performing his melodious reply, seemed conscious of the fact, that, although small and not gorgeous, his voice made up for any deficiencies in appearance.

To the breeders of Canaries, no matter what the variety may be, the St. Andreasberg and Campanini Canaries cannot be surpassed as vocal instruetors for the young. 'There is no necessity for breeding this high grade to produce good songsters. Place one in a room with young Canaries, able to feed and eare for themselves. and the result will amply repay the advaneed price given for the instructor. It 
should not be forgotten that the Campanini was originally a teacher of young Canaries, and, though in a foreign land, is not apt to forget his ealling.

The selection of the male from the female Canaries of the German breed is a difficult matter, and cannot be made to a certainty except by an expert in the subject. Of course, if your bird sings a long, free song, you may be quite certain it is a male; for, thongh occasionally a female sings, the notes are rather short and disconnected. The principal points in judging are the size of the head and its color. The head of the male bird is broader than that of the female, and flatter on the crown : the head of the female is inclined to be round, particularly on the crown. The colors of the German male are always deeper on the head, particularly around the beak and eyes. In the green-colored variety the shade on these parts is nearly olive green. In the female birds the colors are lighter, the pure-green female having a grayish tinge throughout. In the deep-yellow bircls the head of the male is always of a deeper tinge than the remainder of the body; while, in the female of this color, gray or light-colored spots or streaks will be noticed, particularly on the back. These are the points for picking young Canaries, before they have commenced to sing, depended on by the best German judges. It requires practice, and the consequent handling of a great number of birds, to become an expert in the selections. In the spring of the year the difference in the sex is more easily distinguished. By catching the bird in the hand, and gently blowing the feathers from the belly and vent, the lines in the female will be observed to be preserved and rounded, forming an oval: in the male bird, the lines are straighter, and the body more like a cone.

There is a knack in catching and holding a bird when an examination, for any cause, is desired. In catching a bird, first remove the perehes from the cage, and (lo not make a promiscuous rush for the bird, but wait until he alights in a good position, and then make a sharp, decisive pounce, and, when you lave him, be sure and hold him. To examine either back or breast, lay him in the palm of the luand, with the thumb across the neck. It is impossible for him to escape or be injured when held firmly but gently in this manner. To hold a bird securely without ruffling his plumage, take the tips of the wings and the tail between the thumb and fingers.

The age of a Canary camnot be accurately determined: but, after the first year, the scales on the legs become coarser and larger, increasing as the bird grows older; and the claws also lengthen: but, when the bird's claws and legs are carefully attended to, it would puzzle any but the most expert judges to accurately determine the age.

A question frequently asked by the buyer's of German Canaries is, "Will the bird sing by gaslight?" This question cannot be accurately determined by the dealer before a trial. As a rule, this desire is easily brought about by covering the cage, except at intervals for feeding, throughout the day, and uncovering it in the evening when the room is brilliantly lighted. In this way the bird becomes gradnally accustomed to the artificial light; and, as darkness deprived him of his desire to sing (luring the day, he pours out his pent-up) melody when he sees the light. After a few days' training of this sort, the difference in the natural and artificial lights is not noticed; and he will sing as freely by one as by the other. As a rule, the 
Campanini birds are natural night-singers, owing to the darkness which they are aecustomed to when performing their duties as instructors. German Canaries differ in the constancy of song. Some sing only at odd periods throughout the day; while others sing so constantly as to excite alarm for their safety, as they are apt to overdo the matter; and cases have been frequently cited where the bursting of the internal organs has been occasioned by the vigor and strength which they put into their inusical performances. 'This can only be accounted for by the natural ambition of the bird. Canaries bred from the same parents vary in temperament just as the members of a family of the human race are apt to : one is lazy, and don't care to sing; while another is full of ambition, and not happy unless he is at it all the time. Sometimes the laziness is occasioned by the richness of the food given. Offer rich food and plenty of dainties, and the bird will repay you by becoming so lazy and polite that he will not think of annoying you with the noise of his song. He has convinced himself that bird-music is positively disagreeable to you.

A little advice may be introduced here, which applies to the treatment of other birds as well as Canaries. Find out as nearly as possible the exact amount of seeds the bird eats daily: when this is determined, add a slight quantity over tle amount required, and feed this amount as nearly as possible daily. In case too many seeds are given, he will be sure to select the richest, and leave the rest. 'This constant eating of the richer seeds is apt to impair the song. When extras, like hemp, are given, they should be fed separately.

The German Canaries are certainly the choice birds when song is the quality sought for; and the numbers of the Harz-mountain birds make the prices, as in natural consequence, low. They are equally as tough and hardy as any variety, and as long lived. If the common care and rules for feeding are observed, there is 110 danger of their losing their sweet songs.

So strong is the desire of the German breeders to breed as many birds as possible for the market, that the breeding for numbers is forced by means of artificial heat; and the diseases to which the German Canary is subject are mostly those of the throat and lungs, induced by changes to damper or colder climates. For this reason, the old, threadbare advice, "Do not hang your bird in a draughty room, or anywhere that a possible draught can reach him," must be repeated here, and carefully regarded if you would keep your bird in health and song Hang your bird in a room which has an even temperature, which may be as low as $40^{\circ}$, or as high as $75^{\circ}$; the bird will become accustomed to either, and sing equally as well in one as in the other: but sudden changes must be avoided. Another serions cause of complaint is the rumpled, dumpish appearance of your German bird. After being purchased, and brought home, he is transferred from his prison-like quarters to the handsome, roomy brass cage which you have prepared for him. You are, no doubt, surprised at the change which a day has wrought in him, and also surprised to see that he does not seem inclined to eat, and lay it to homesickness, caused by the absence from the large number of birds with which he has always associated. If not looked to in two or three days, the newly made purchase will be rearly for dissection, which will reveal the canse of his death to have resulted from starvation. 'The starvation is easily explained. By examining the little wicker cage in which the bird has been exported, and in which he was when bought, you will see that the 
seed-box and watering-pot are inside the eage, and within his easy reach: your brass cage has the eups hung on the outside, with small, narrow apertures, through which the bird is obliged to poke his head in order to reach his seed and water. As he has never been aceustomed to this mode of reaching his food, and endeavors to find it in vain, the only results can be slow death, or a disease resulting from overeating after he has found his food. The above evil luckily does not frequently happen; as some birds, seemingly possessed of more instinct than others, readily find the cups, and eat and drink at once from them. It is, however, well to watch the bird after being changed into such a cage, and notice whether or not he eats. In case he does not eat within a few hours, place the seed and water in small vessels inside his eage, and then accustom him to the ones hung on the outside. It is always better to procure cages with the eups so arranged that the openings to them will be on the inside.

The different classes of Canaries are brought up and fed on about as many different kinds of seeds, and the seeds to which the bird has been accustomed are the ones on which to feed him. The Germans religiously believe in the superiority of the German summer rape-seed, and feed it to their birds when fresh or new. This seed is not heating, and an excellent voice-promoter. When he eats solely of this, it has the effect of keeping the song down to a mellow state: when the more heating seeds are fed, they are apt to produce the sharper notes, and have the effeet of making the bird sing too constantly, which is not desirable in the lighest class of song Canaries. When sent to other eountries, it is the custom to vary the diet by the addition of other seeds, such as canary and millet, being fed in equal proportions with the rape. This has been proved to be an excellent plan of feeding, as the ehange of air and habitation seemingly necessitates a change to more stimulating food. At different seasons of the year, the food may also be changed : on consulting the articles on "Food and Care" for the different months, the best foods may be noted. In England the breeders of German Camaries follow the plan of feeding adopted with their own Canaries; 1.e., of adding to regular seeds, sugar mixed with egg. This is not advisable, however, as has becn proved by the inferiority of the German birds bred in England to those bred in Germany. The German method of feeding the young birds daily on a mixture of grated hard-boiled egg, mixed with Zwieback, or hardened German bread, is the best. When Zwieback camnot he obtained, grated bread will do. When the birds grow older, there is no need of feeding the egg-mixture so often. The quantity given at a time should he in proportion to one hard-boiled egg mixed with an equal quantity of bread, for eight birds. The above foods should form the principal daily diet of all German Camaries. For treatment in ease of sickness, consult the articles on "Food and Care," and "Remedies for Diseases."

\section{THE BELGIAN, OR LONG-BREED, CANARY.}

This breed of Canary is of ancient Duteh origin, and in some parts of the world is the highest prized of any class of Canaries known. They are bred for shape and position chiefly, song and color being minor qualities. The bird, as he originally appeared, was merely a long, slender bird of the Canary breed ; but persistent breed- 


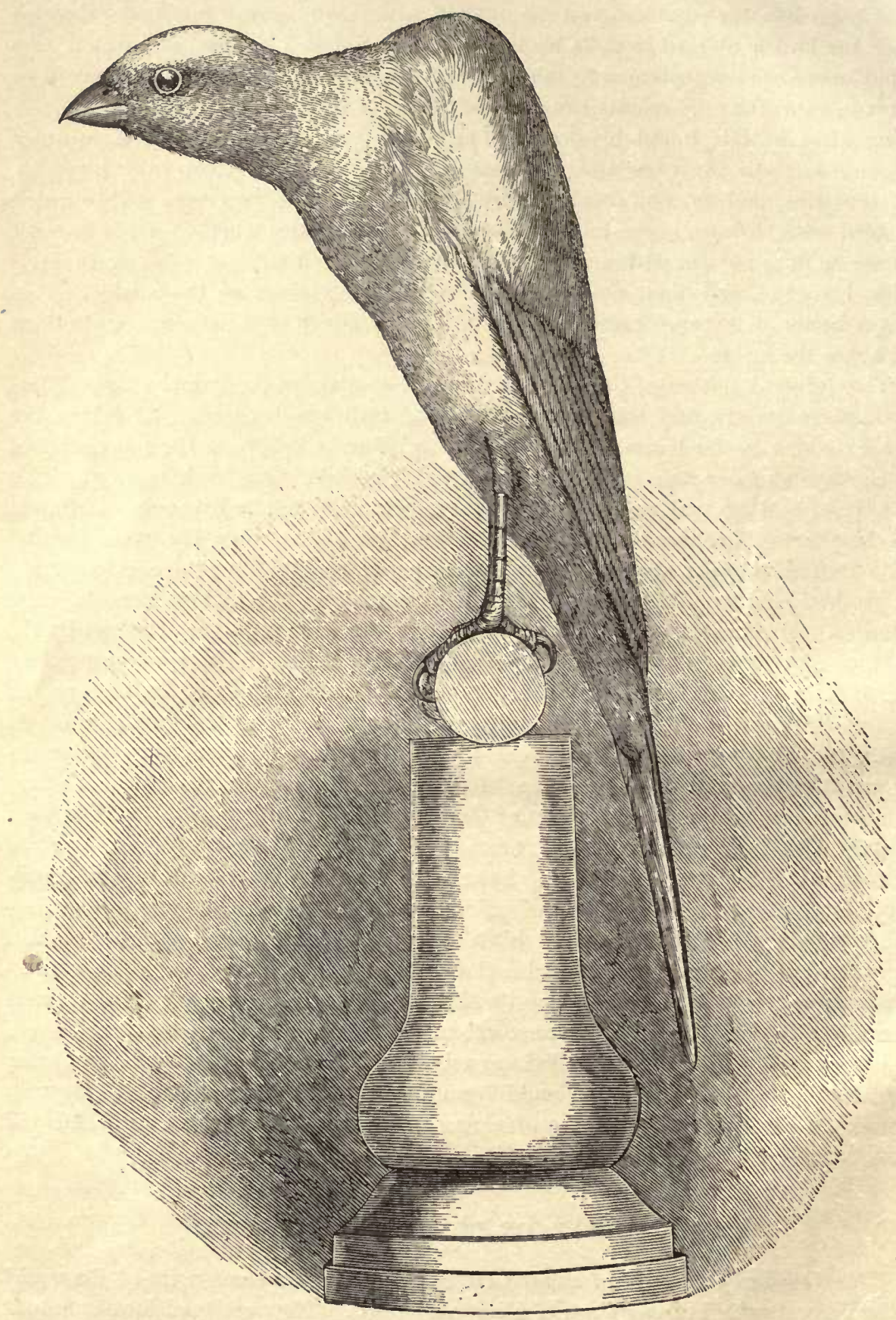

The Belgian Canary. 
ing and training has brought him to his present perfect shape. This, in a great measure, was brought about by the numerous guilds, or clubs, formed for the purpose of breeding Canaries to a perfect shape. Throughout Belgium clubs were formed; and each club had a special object in view, and embraced every thing in art or sport, bird-raising being one of the things.

Each ornithological club now has its bronze model, which is supposed to be the shape a perfect Belgian Canary should be ; and every member strives to breed and train, as nearly as possible, his living choice to the shape of the bronze cast.

The Belgian Canary is the thorough-bred of the Canary family, and, like the thorough-bred race-horse, shows his breeding in erery movement. This is due to the amount of care, and picked strains of blooded stock, used in the breeding. 'The bird's head, particularly, should be noticed, as showing high cultivation; the large, intelligent eye, and very small, snake-like head, being the best evidences of ligh blood.

His shape, when at rest, should conform to a right angle. A line drawn from the crown of the haad to the tip of the shonlders should form one side, and a line from the tip of the shoulders to the tip of the tail should form the other side of the angle. There are, besides these, numerous minor points, such as shape and size of the head; a flat and very small head being considered the best. The tail should be lengthy and slender, and not too broad, nor too forked. The shoulders should be compact, without too much of a hollow between them. The breast should have a good depth, but not be too broad. The upper side of the neck should be a nearly straight line from the shoulder, and not have the appearance of a camel's neck. 'The purity or fineness of feather, not the depth of color, is the quality sought after in plumage. Nearly all are light yellow; but some are deeply mottled in gold and green, and these are highly prized by the English fanciers. The legs should be straight, and the thighs well feathered. A knock-kneed or bowlegged Belgian, no matter how fine he may be in other respects, is not an object of beauty.

There are numerous styles of the Long-breed family; but the only recognized pure Belgian Canary, in his native country, is a fac-simile of the illustrated model. A brood of young Belgian Canaries are a gawky-looking set of creatures, and an amateur would pass them by without notice. They tumble around in about the sa.se manner as a very small boy taking his first lesson on a pair of very long stilts. As they develop, this unsteadiness passes away; but still, the full-blooded Belgian, when viewed in any position except when on his perch, is an awkward-looking fellow at the best. When hopping along the bottom of the cage, pecking at his seeds, his movements are such as might be made by a two-legged camel moving rapidly, if such an animal can be imagined.

It is from his pose when excited, that the most points may be seen. When in position he is judged according to his merit, and then all the prominent points are brought out to the fullest extent. The Belgian is the blue-blood of the Canary family, and should never be excited without cause. For this reason, a fancier, when entering an exhibition-room, uses as much care as a person would in going into a sick-room. The bird, when exciter, strives to do his utmost in gaining a perfect position; and for this reason he should not be excited without cause. He 
gradually learns the meaning of the seratch or tap given as a signal for him to assume his best position; and when given too often, without a reason, his inclination to obey is likely to cease. Some writers claim that training, as well as highbreeding, has much to do with perfect position; but this statement is open to adverse criticism. The breeder, when entering the room to show off his best birds. gently lifts the eage by the bottom with one hand, and taps or scratehes with the other the bottom of the cage : and, at this signal, the bird's appearanee is changed ; he grasps the perch with a firmer grip, and throws himself upward as though he would push his shoulders out of joint; he moves from side to side, heaving with excitement; and sometimes, in his endeavor to get in the best form, he appears to lose his balance, and the tail sweeps under the pereh until he resembles three sides of a square. These actions and this shape are the best evidence of his perfect training. It is said that a Belgian breeder had to invest all his spare money in wooden shoes, he wore so many pairs out shuffling his feet on the floor of the breedingroom while training his young birds. 'The breeding-coops for the Long birds are as varied as they are numerous, and exhibit different degrees of cleanliness. Some of the breeding-places are kept scrupulously clean and neat, while others are like miniature pig-sties; yet the latter, in many cases, seem to turn out as good birds as the former, which goes to disprove the idea that the Belgian is not a hardy bird. I would not, however, recommend trying the experiment of breeding Canaries on the pig-pen plan; because Canaries are not apt to thrive like swine.

The full-blooded bird is sensitive and nervous, and, therefore, easily excited; but, if kept properly and quietly, he makes as desirable a cage-bird as can be found. A Belgian breeder would as soon think of putting his hand in the fire as of catching a thorough-bred Canary. The birds are never handled, but, when changed from cage to eage, are guided from one to the other by means of a stick, which they obey as readily as a trained horse does the whip. The slightest unusual object is the cause of exciting a bird of this class to an astonishing degree. A visitor, when entering a Canary-room, should remove his tall silk hat; as it is apt to put the birds in a flutter of excitement. It is even stated that an irate Duteh breeder "dropped" one of these hats over the wearer's ear because of the eraze it produced among his pets. A red smoking-eap has thrown a first-class bird into fits, from which he never recovered. This class of birds, as may be supposed, is rarely seen outside of the country in which they are bred and reared, because of the value attached to them for breeding and exhibition purposes. It is not for the money value of any prize he may take in competition that a Dutch breeder seeks, but the honor attached : for a prize won gives his elub additional fame; and this means to him, later on, value in a commercial sense when he wishes to dispose of his birds. It is this very club-strife for the highest standard which has brought out the perfect breeding; each member being determined to outdo every other in the club, and each club endeavoring to excel every other club.

When the young birds are hatehed, the perch should be a few inches higher than the nest; as, by the formation of the bird, it is much easier for the female of this breed to feed the young brood from an elevation than on a level. It is also well to have the perch raised from the seed and water cups in the same manner. The young birds are given about the same food as any other breed of Cauary. 'The 
hard-boiled egg is made into a paste by being mixed with pulverized cracker moistened with water. One enthusiastic breeder always chewerl the egg and eracker, and fed the young birds himself in addition to the feeding they received from the mother. He was fond of strong liquor, and was an inveterate smoker, but, for the space of five months, abstained from the use of intoxicating drinks and tobaceo; so that the saliva, mixed with the cracker and egg, would not injure the yomng birds. 'The Canaries he raised were never dissipated.

It has been mentioned that the Belgian breeder pays no attention to color in breeding. Color is of no importance to him as long as he can breed the coveted style. The birds are usually of a yellow, or mealy, color; and only a few are mottled. All the ordinary colors night be obtained with the best shape; and if the English breeders wonld only take hold of these Canaries, and breed for color, a grand class would be produced.

A unique style of travelling-cage, used for the Belgian Canary, may be mentioned here; and it would be well to adopt it when it is found necessary to carry a bird from one city to another. It is made of a round board, about eight inches in diameter, to which is tacked a small cloth, or duck bag with the bottom eut out, and fastened at the top by means of draw-strings. Air-holes are cut in the sides of the cloth. 'This eage may be laid down or hung up without any injury to the bird.

The Dutch exhibition-cage is always the same, cone-shaped, open on all four sides, and raised, on four legs, about three feet from the floor. By the use of this cage, the bird is not unduly excited when he is to be exhibited for position; as it may be raised without eatching hold by the top.

The three-quarter and half breed Belgians are birds which have been extensively exported, and are in great demand among American bird-fanciers. They combine much of the beauty of the full-blooded Belgian and the song of the German, and make a most desirable cage-bird. They were originally produced by mating a thorongh-bred Long bird with a large-sized song Canary, the progeny being called three-quarter breerl birds. A pair of three-quarter breed birds mated produce the half-breed. Although not so handsome as the three-quarter-bred, the Half-long birds are large and fine-looking, and, in many cases, most excellent songsters. Americans are not as well posted in the fine points of bird-breeding as the scientific fanciers of Europe. With us bird-breeding is comparatively a new matter, while in Europe they have been breeding the Canary for at least two hundred years. We do not produce as good birds, becanse we rlo not start with the best stock. Genuine first-class Canaries of any specie may always be imported in their seasons, and may be as easily bred here as in their native countries. Shonld an American fancier wish to breed the best full-blooded or three-quarter birds, he can always procure the proper stock, and will be satisfied with the perfection attained from birds of his own mating.

Colors may be produced as easily as style and size; and, where one has the three qualities, the breeding may be called scientific.

The Belgian Canaries, of all classes, are bought in large numbers by the English dealers, who separate the birds into the different grades after arriving in England. 'The best grade brings high prices for breeding purposes, and the rest are sold for collections. 
The chief cities in Belgium, where the Long Canary is seen at his best, are Antwerp, Ghent, and Brussels ; and the yearly exhibitions in those cities are largely attended. A few of the rules governing one of these societies are given below.

The meeting is always fixed on some special Sunday, which is decided upon six months before the exhibition occurs.

Article I. - There shall be a prize of honor given, of the value of thirty francs.

ART. II. - Each member has the right to enter from one to four birds.

ART. III. - Four experts shall judge the birds, but no expert shall be an owner of a bird entered for competition.

Arr. IV. - The four societies having the greatest number of entries shall have the right to elect an expert, but no town shall elect more than two. The fifth expert shall be a stranger to the town.

ART. V. - No bird shall be entered for competition that is more than one year old.

ArT. VI. - All competitors must attend the distribution of prizes. Those absent, whose birds have won prizes, will be fined to the extent of a fourth part of the value of the prize. An excuse will be entertained from those absent on account of sickness.

'These exhibitions have not that spirit of avaricions gain prevailing in them which is seen in other countries; and when honor, first, is the prize to be gained, the care and attention paid to the breeding of birds is much greater than when merely money enters into the contest.

The Belgian Canary is fed on the regular mixed canary-seed, but should have, at least twice each week, a mixture of grated hard-boiled egg and cracker. Great care should be given the young birds : when first hatched out, they should receive daily the egg-and-cracker mixture; this should be fed to them until they are three months old, as it is very strengthening : and, when a young bird starts out strong, he is apt to live longer, and keep free from disease. In other respects, the Belgian Canary requires only the same care that any other Canary receires. They are just as easily kept and as hardy as any other breed when the proper rules are observed.

Owing to the peculiar shape of the Long-breed Canary, his cage should be roomy, rather high than otherwise : and, when lung in a room, he should hang at least six feet from the floor; as his shape can be seen to much better advantage.

The pure Long-breed Canaries are imported about the first of December and until April, and the three-quarter-bred Canaries are on sale during the same time.

The half-breed are imported earlier in the season, and may be found in the shops from October until May.

A cage, eleven inches by fourteen inches on the base, and seventeen inches high, is the best size for the Long Canary. This style makes a good cage for a pair.

A round eage, ten inches in diameter and twenty inches high, makes a desirable cage for a single singer.

\section{ENGLISH CANARIES.}

The English Canaries include more varieties than any other known breed. They embrace the Norwicl, or Deep Gold, Canary, the London Fancy, the Gold and Silver Lizards, the Scotch Fancy, the Yorkshire, the Manchester, or Lancashire: and these different classes are subdivided by cross-breeding, whence spring many lesser-known tribes. 'The breeding of the different classes requires a vast amount 
of patience and skill, and is the best evidence of the science to which Canary-breeding has been reduced. It is the result of years of careful study, and shows that the English have, perhaps, a more thorough knowledge of the anatomy of the bird and his plumage than the German has. 'The Euglish and German methods of raising Canaries are widely different, and must necessarily be so ; since the former seeks size and feather, - physical culture, - while the latter strives for voice-culture. The Germans follow their taste for music, and breed birds only for music; while the English tastes are shown in their devotion to high color and imposing physique. The Englishman accomplishes his object by patiently breeding from generation to generation for the deepest golden color possible to attain, and, later still, further deepening the brilliaut color by artificial means. In some sections of the country, breeders pay all attention to the development of size in Canaries; and, as the result, the Manchester Coppy of to-day stands forth as the giant of the Canary family.

The Norwich Canary is the general favorite of the breed of English Canaries, and is the most extensively bred of any of them. He is easily recognized as a brilliantly illuminated edition of the deep-yellow Canary, and takes his name from the city of Norwich, where for generations he has been bred and cultivated; and, at present, every artisan in the city las his brood to care for, the taste being further fostered by the extensive patronage of the wealthy classes throughout the country. Careful breeding is a remunerative employment, as fine birds are well paid for. The Norwich Canary is larger than the German, his usual length being about six inches. He is a very solid, substantial-looking fellow; and his compactly built figure and handsome golden coat give him a very attractive appearance. Owing to the nature of the breeding, he is naturally much hardier than any other variety known: heat is not considered a necessity in the breeding-rooms of the English Canaries; and only at the moulting season, when extra care is required, is artificial warmth allowed. A strong incentive to breeding these Canaries is the competitive exhibitions which are annually held in all the breeding-centres of England. Every attention is pald to the size of the bird, the texture of his feathers, and, most of all, the depth or brilliancy of his color. The Norwich Canaries may be divided into three classes: the clear yellow, a bird which has no foreign color on his entire body; the mottle, or variegated, which is a combination of yellow and green, or dark-brown colors; and the crested, which may again be subdivided into clear or mottled. It is not necessary to go into the details of the depth of color, or silkiness of the feathers ; as they would not probably interest our amatenr breeders. The highly-bred crested variety is a very interesting class : in some cases, when bred for years for perfection of crest, it appears to be something unnatural; the size and proportions being perfect. The crest hangs over the eyes so as to partially obscure the bird's sight. As a songster, the Norwich, as now bred, is not equal to the German Canary; nor can this be expected, owing to the inattention paid. to his song. $\mathrm{He}$ is, however, susceptible to an easy training: and I have heard many Norwich birds, when hung in a room with a well-trained St. Andreasberg Canary, copy his best notes in all their perfection ; giving, of course, more strength to the sounds, owing to the fact, perhaps, that he is a much larger, heavier bird. The same observation applies to all other breeds of the English Canaries.

The London Fancy, and both kinds of Lizard Canaries, it is said, are of the 
oldest blook, and, although unlike in appearance, are closely allied. 'This is proven by the fact that both breeds of birds, when nestlings, resemble one another very elosely: after shedding the first feathers, the appearance is, however, widely different. The London Fancy male bird, when in full plumage, should have the entire head, breast, and back of the same color's as those of the mealy, or buff, Norwich, with wings and tail black or dark green: this variety of bird is not so stoutly built as the Norwich; he is more slender and elegant in shape. He is not so popular at present as the Norwich, owing to the energy displayed in breeding the latter, and the greater care which is required to breed the London Fancy in all his perfection of markings.

The Gold and Silver Spangled Lizards are justly in the foremost rank of "feather" birds in their native country: they certainly present a most beautiful appearance in their gayly decked spangies, and clear, shining gold or silver caps. It is elaimed that the Lizard is the direct offshoot of the original green Canary of the Canary Islands, and, by the careful and judicious selection of strains, the clearly defined spangles were finally obtained. The Lizard is mentioned as the spangled bird in the oldest known treatise of birds we have. The color-line in the Lizard breed is strictly drawn between the Gold and Silver; the spangles in either case being overeast throughout with the rich gold of the Norwich bircls, or the silver of the mealy class. The Gold-spangled Lizard is the favorite of this class, as his richer colors are much more striking. The most important point in the selection of a good Lizard is perfection of the head. The eap of the bird is one of his distinctive features. A perfect eap must be bounder by a line commencing at the tip, of the beak, and passing over the tip of the eye, ronnd to the back of the head, in the same plume, and returning in the same way on the other side: it must not come lower than the eyes, and the boundary-line at this part should be a hair-line of clearly defined feathers. The cap is clear in color, and may be either clear yellow or light gray, which defines the elass to which the bird belongs. The color of the eap also regulates the color on the body, and the tinge which overcasts the spangles will always be found to be of the same color as that of the eap. The outline of the eap must be clear and unbroken, and its entire surface free from a tinge of dark feathers. 'The slightest intrusion of dark feathers on the cap constitutes the class called broken caps, and any intrusion of the cap itself into the dark feathers of the neck is called the run eap. The classes are more familiarly known, however, as the plain and broken caps. The spangled appearance of the birds is eaused by the development of the feather. A description of the feather of the Lizard Canary will explain the canse of the peculiar appearance of the plumage. 'The soft, silky portion of the feather next the quill is blue black; as the feather grows ontwarl, the color changes, the centre becomes blackish brown tinged with a lighter shade. the central color increasing in.depth till it reaches nearly to the extremity of the feather, where it expands into a circular form, and is nearly as black as possible; the edging of the extremity of the feather is fringed with a very narrow borlering of the same color of the cap, which may be either gold or silver. The lapping of the feathers over one another where so many shades of color are observable constitutes the appearance of spangling: the shorter feathers, as those of the head and breast, are more closely spangled than the longer feathers of the wing. In perfect 
birds, the appearance resembles a chain, with the links continuous and perfect. The clearly defined spangles must be decided and unbroken throughout the body: splashes or breaks in the spangles or wings throw the bird out of the perfect class. As in all other cases, in a nest of young birds perhaps there will be but one or two specimens which could be called perfection : for, no matter how carefully the selection of the parents was made, the splashes or foul spots will show ; this may be due to defects in earlier generations : but crossing perfectly marked birds for continuous years will probably obviate this, and the result will certainly be foretold before the birds are hatched from the eggs.

The whole appearance of the Lizard Canary is essentially dark; the beak, legs, and claws following the same color. The appearance of the Lizard should not be hazy or indistinct; the spangles should be clear, bright, and regularly arranged; nor should the gold of the gold-spangled class be mixed with the colors of the silver spangled, or vice versa. In size the Lizard Canary is more uniform than the other classes, measuring about five inches and a half in length. He is easily known by the peculiar markings and snug-looking cap, and the class is an interesting one for the purpose of breeding. They are easily bred, and of good value when well marked.

We now come to a different set of elasses in the English Canaries; i.c., of shape and size, color being a minor quality. The Scotch Fancy is probably the most remarkable-looking Canary of any known variety, - even more curious in formation than the Belgian. The Belgian is bred for the clearly acute angle which the different parts of his body form, while the Scoteh Fancy is bred for the curves which his body forms. In shape the bird resembles a half-circle: and, if the enthusiastic breeders of Scotland continue their efforts in the same directions, the half-circle must become a whole eircle; and the methods of perehing, flying, etc., will have to be revolutionized. We mean no disrespect to the rugged Highland breeders. This variety is their choice and funcy, and they should be allowed their indulgence. The mania for breeding these birds in the districts to which the strictest attention to them is paid exceeds that of the Belgian breeders, and the proud possessor of a prize-winner is looked upon as a skilled engineer in his profession. It requires, indeed, a skilled artist in bird-breeding to produce perfection.

The Scotch Fancy Canary, judging from its form, is most likely an offshoot of the Belgian; and, as in the other classes of English Canaries, the shape nas been perfeeted by the persistent breeding of birds to obtain the nearest approach to a certain model or standard.

The head of the Scotch Fancy Canary should be flat and snake-like, - a very important point, which is only brought about by the extrene care exereised in his breeding; the neck, unlike the Belgian's, should form the connecting curve between the head and shoulders; the shoulders should not be prominent, but elose together, and have the appearance of the Belgian's shoulders, with the corners planed off ; the back and tail form a sweeping curve, thus making the different parts of the body form an are. If a line were drawn from the tip of the beak to the point of the tail, the figure would represent a half-cirele. The bird is slender and elegant in shape, and his carriage graceful and dignified. His legs are long and straight, and appear to be set in his body on the principle of a shank on a diamond scarf-pin. 
'The colors of the Scotch Fancy are a secoudary consideration, and not brilliant, like those of the previous classes. The Scotch breeder seems content to obtain perfection in shape, and let his English neighbors bear off the palm in the color-line. The colors are the same as those observed in the common breed of Canaries, ranging from the clear green to the pale yellow, or mealy. The Scotch Fancies, like the Belgian pure breeds, have no crested birds among them. To the superiority of the female Scoteh Fancy birds, the breeders do not pay so much attention. Of course, a high class of birds must be used in breeding ; but all the minute points are developed in the males.

The bird-shows held in Seotland are even more elaborate than those of Belgium, the task of the judges being more severe; and the amount of handling and judging which a prize-winner is obliged to undergo is something amazing. The worthy judges, too, deserve a word of mention. A pure labor of love with them is this task of handling and testing some eight hundred eases; and the amount of skill required in properly giving every bird his exact dues would put one of our highpriced modern court judges into college again in order to learn his lessons over.

The Yorkshire Canary is another edition of the birds bred for shape and size; and, as the angular and curved editions are provided for, it is no more than proper that a class of admirers should be found for something in the line of straight birds. 'The Yorkshire is the class which depends for his beauty on the straightness of the lines of his body, the compactness of his build, and fineness of his feathers combined. The Yorkshire, like the Scotch Fancy, is supposed to be an offspring of the Belgian. The head of the Belgian bird, if placed in an upright position, and not hung down as though ashamed of himself, forms the main line of beauty in the Yorkshire Canary. A line drawn from the top of the head to the tip of the tail should be a perfectly straight one, the body should be slender and elegant in appearance, the feathers as compactly arranged as those of a duck, and their texture of the finest quality. These form the main points in the Yorkshire Canary's excellence. He is a larger bird than the Norwich, being from six inches and a half to seven inches in length. No particular attention is paid to the colors; although they are usually of a deeper shade than those of the common Canary, and may be clear or mottled. The Yorkshire bird is never bred in the crested class.

'The giant in the English class, and, in fact, of the Canary race, is the Manchester Coppy, - a bird remarkable for the size of both its body and crest. This class of birds is bred almost exelusively in the manufacturing districts around the city of Manchester, from which the bird derives his name. Wherever seen, this class is always admired for its noble proportions and majestic bearing. A startled beholder, on first seeing one, said that "he looks more like a yellow Pigeon than a Canarybird." His pedigree cannot be certainly traced ; but it is most probably of the ancient Dutch order, which is always a respectable and sure covering for any thing of doubtful origin. The breed of the bird is most jealously guarded in the districts from which he originally appeared, and no other foreign strains or crosses are allowed to be crossed with him. 'The word "Coppy," which is also a part of the bird's name, signifies erest, or topping - an ornament with which the birds are, as a rule, decorated. The largest birds of this class often measure eight inches in 
length. They are very compactly built, with no deviation in shape, being of the straight-back order. The figure is well-proportioned and strongly made. He is massive, graceful, and as sprightly as the smallest Canary. The cap, or crest, which he wears, is in just proportion to the size of his body, and is remarkable for the exactness and regularity of its formation. All the feathers radiate to a common centre, each feather being in its exact place. It is not knotty or curly, and presents a striking appearance, and an oddity not observed in any other class of Canaries. It is much larger than the erest of the Norwich bird, and has a style of beanty which the Norwich bird's crest does not possess. It is mucl clearer in form than that bird's, and surpasses it in the clearness of the yellow color, which appears to be a difficult object to procure in the crested class. The crests of the Manchester may vary in color, and run in gray, ticked, and dark shades. The main points in the standard of excellence in this class are size of crest, size of bird, and shape.

This class is also bred without the crest, and is then called the Plainhead.

The colors are the same as in the other classes, - sometimes as deep as the Norwich, but usually of the buff, or mealy, variety.

This majestic and massive bird forms one of the highest-prized eage-birds, and, when better known, will take a foremost place in the list of Canaries. He should have the largest-sized Canary cage : and, if he fills it by his great dimensions, he wili offset it by filling the house with his song; as his voice fully corresponds in power with his size.

\section{THE FRENCH CANARY.}

The French Canary is an edition of the Belgian, and, although not so finely bred for position and style, retains the main characteristics of that breed. The French are bred throughout the manufacturing districts of France, and the English hobby of compactly arranged feathers is knocked to pieces by the exact opposite arrangement in the Frencl breed. The feathers on the breast, belly, and sides resemble miniature wheels of feathers pinned on to the bird, and present a fluffy, odd appearance, and impress one with the idea that the bird ought to bathe, and straighten them out. The chief object in breeding these birds is, to obtain this remarkable disarrangement of the feathers: the more wheels obtained, the higher prized is the bird. The placing of the feathers resembles that of the crest of the Manchester Coppy, and, when neatly formed, give him the look of being "coppied" all over. This bird measures about seven inches in length, and, as a rule, appears in plain yellow feathers throughout.

The English and French breeds of Canaries are fed in their native countries on the plain Sicily or Spanish canary-seeds; and, when a mixture is required, a few hemp-seeds are added. This kind of feeding is a torture for the German breeder to witness, and he is sure the birds will die if fed thus for any length of time. But the vigorous constitutions of the birds scem capable of withstanding any luxury showered upon them, as this sort of feeding in our country would certainly be so considered. I find that the English Canaries, when imported to America, thrive much better on the regular mixed seeds, rape, canary, and millet, than on the plain seer given them in their own country; but no amount of argument or reasoning will 
convince the British breeders that such is the case: they have followed this fixed style of feeding for generations back, and cannot be induced to think any other feeding correct. The young birds are fed daily on the egg-paste, which is made of hard-boiled eggs and bread crumbs, mixed in equal proportions, with the addition of a little sugar or maw-seed. The old birds are given the above mixture once a week, in some cases twice. The diet is also oceasionally varied by feeding clickweed, water-cress, and sweet apple. The English birds are also giren freely milletseeds on the ear, and an occasional Sunday dinner of raw, scraped beef.

\section{CAYENNE-FED CANARIES.}

We now come to the Cayenne, or artifieially colored, class of Canaries; and, as they are the last products of seientific attention and feeding, it is no more than proper that they should oceupy an important place in these papers on the Canary. The Csyenne-fed Canary of the present time is as far ahead of his plain-coated brothers, if the comparison may be permitted, as the electric light is of the oldtime tallow-dip.

The first intimation on the subject of eayenne feeding was obtained by a trifling accident, just as many greater discoveries are disclosed in the same manuer. There certainly must be some law which governs nature in bestowing the various colored lues which adorn the feathers of the bird-nation; but what that Iaw is, cannot be defined. The fact, that in the earliest stages of the growth of the feathers of the Canary, as of all other birds, these were not feathers, but simply little tubes in which the blood circulates, and which eventually develop into what we call feathers, led to the supposition that the coloring matter was manufactured in and deposited by the blood. This theory eventually took hold of the minds of the breeders; and various somethings were fed, in order to develop the colors which they contained. Experiments were made with saffron, cochineal, port wine, and beet-root; but all were ineffectual. At last, by the veriest accident, the simple coloring agent was discovered to be cayenne pepper, - the very article which every bird-breeder has oceasion to use in his breeding and moulting rooms as well as on his own table. Who the lucky discoverel was, is not known; but he jealously guarded the secret, and for two years, at the great bird-shows throughout England, made his find pay, by taking all the cash-prizes, and bearing away all portable property in the way of special prizes. He also made the real hard workers in the natural colored breed of birds gnash their teeth with rage at their easy downfall, and puzzled the learned juclges of birds, and chemists in their analyses. It is also true, that the naughty discoverer endeavored to palm his wares off as a new strain of blood; but who would not have done the same if placed in his position? 'This diseovery was verily a comet in the sky of Canary-breeding, and for a time the one absorbing topic. The first birds of this class which were produced bear no comparison in color to those which are now seen : they were at first a pale reddish color, but careful researches with the food have been followed by the present brilliant results. When the first published account of the secret was written, it startled the entire Canary world of breeders; but the eurious breeders of deep natural colors, whose labors in that direction had brought the golden Canary to its high standard, struck off into a new 
path, and bent part of their energies in the new direction, and studied the various grades of cayenue, and modes of feeding it, until the brilliant red, almost approaching scarlet, is as easily produced as the rich golden was before. 'The depth of color' varies with the grade of pepper fed; and, in order to obtain the best results, only the best kinds must be used. To take the common cayenne, as used for table purposes, and feed it to your bird, will, to be sure, have some effect; but the color produced will pale before the searlet of the highly fed bird.

It has been a matter of speculation as to whether cayenne pepper, when fed Canaries, would be injurious to them or not. It is well known among even the most disinterested keeper of Canaries, that pepper, as an agent for the promotion of health and preventive of disease, cannot be surpassed, and that the entire Canary family readily eat it when prepared for them. Small quantities can, therefore, have no evil effect. " But can the feeding be overdone?" is a question often asked. We think it can, as too much use of it is apt to endanger the healthy action of some of the more delicate organs. It has been proved that birds may be as highly colored on a judicious use of the food as by over-feeding. Because the bird is fond of the pepper, and eats it greedily, it is no reason why he should live on it entirely, any more than your child, because she sometimes craves candy, should be fed on it alone.

To begin with, obtain only the best grade of cayenne pepper, which is imported expressly by the bird-dealers for this purpose. There are various methods of feeding it, but we recommend this simple plan: with one grated bard-boiled egg, mix an equal quantity of grated sweet bread or German Zwieback, and add a heaping teaspoonful of the eayenne pepper. 'The whole shonld be thoroughly mixed together: then sprinkle it with a little granulated sugar, and feed as the bird appears to like it or thrive on it. 'The above are the proportions used, but the quantity to feed a certain bird must be gauged by the bird's appetite; usually two large teaspoonfuls of the mixture is sufficient for one bird per day, but no rule can be for a certainty observed in the matter: the watchful breeder will notice how his bird thrives, and accordingly increase or lessen the quantity. While the feeding of the cayenne mixture lasts, feed the regular seeds sparingly; about half the usual quantity being sufficient. It is, of course, understood that the cayenne mixture should be fed in a separate cup from that which is used for the seeds.

'The feeding of eayenne should be eommenced with the young Canaries to be colored, at the age or seven or eight weeks, because it is necessary that the process should begin while the feathers are in the state as described in the beginning of this article; continue feeding until the birds are thoronghly monlted; perhaps a daily dose for two weeks over the period would surely set the colors. Heat is a powerful assistant in moulting Canaries, and, when employed in the eayenne process, will be found to be a great aid. 'The birds which have seen their first year are usually put on the mixture as early as June, and the feeding continued in the same manner as for young birds.

At the head of the class of Canaries which should be bred for the production of brilliant colors, stands the Norwich Canary; for, while his beautiful golden coat seems handsome enough without further polish, his color is eminently fitted to produce the richest results in Cayenne Canaries. Next to him stand the Lizards and the London Fancy: these are also capable of taking the cayenne better than the 
average class. The Gold-spangled Lizard, when well peppered, is a beautiful speeimen of this class of feeding, and greatly admired. The handsome, gay spangles stand out from the rich red in bold relief; and the cap, when fully colored, sets the bird off to great advantage. Why these three elasses of birds slould show the effects of the pepper more than any others, cannot be easily accounted for. We often hear the complaint, "I have fed the pepper as directed, but my bird isn't so red as the ones you show." There may be many eauses in explanation of this. 'The eayenue may not have been properly administered, or may be of poor quality ; and, ehief of all, perhaps the bird is not capable of showing the effects of it. Sometimes, in a nest of three or four birds, one of them will show no eolor whatever when fed on pepper-diet. Why does this happen? Something must be wrong in the circulation of the blood which will not transmit color. This is the only explamation which at present can be given: perhaps the futme will clearly reveal the eauses. If you have tried your bird on the food, and do not suceed in coloring, the cause may lie in the fact that he eannot be turned red. 'The proper' colors, then, to select for coloring, are the deep yellow, - the deeper the eolor naturally, the deeper artificially. This is the rule, which, like all others, would not be a rule unless there were exeeptions to it. The deep yellow, with slight markings, also show handsomely: the deep-yellow body and green erest also show well. The darkgreen birds are not so suitable for coloring, the dark shade of the body being an unpleasant contrast to the red. Buff, or mealy, birds, when well colored, show to splendid advantage; exhibiting the brilliant red, which is frosted by the gray or light natural colors. In no class of Canaries do the females exhibit the depth of color which the males possess, therefore the eolors are never so brilliant. The female Canaries are rarely colored, as they are mostly used for exhibition or aviary purposes.

In song, the Cayenne Norwich ranks as high as any of the English birds ; and, the pepper being a throat invigorator, his voice is remarkably elear, and free from any hoarseness. Like the other classes of English Canaries, he is exceedingly tough, and ean withstand a great degree of cold. This is not because of the amount of pepper he has concealed beneath his jacket, as many would suppose, but beeause his English breeding makes him so. He starts ont in life a remarkably healthy bird, and so continues if proper attention is paid him. He may be fed amnually on the pepper-food, as the moulting season comes around; and some of them seem to look forward to the feeding-time as anxiously as a boy to Fourth of July. If properly fed, he will preserve his brilliant coat until he lias run his natural course. It is safe to say, that, for a heautiful eage-bird, he eannot be surpassed by even the most brilliant songsters of the tropies.

\section{THE AMERICAN CANARY.}

This variety eannot be traced to any distinet origin. He descends from an astonishing number of elasses ; and his ancestors, in most eases, lay about as mueh claim to thorough breeding and nobility of race as the traditional yellow dog. The German and English breeders are eager to rear the highest elasses of finely bred birds, but their great enthusiasm is never felt by the Ameriean bird-fancier. 
If he produces a nest of yellow Canaries, he is satisfied. Our fanciers' indifference in regard to the stock bred from, no donbt largely arises from not understanding how much better a good breed of birds is than a poor breed. While it is true that many bird-fauciers of England, Germany, and other bird-producing countries, when settling in America, bring with them their love for breeding Canaries, they find so little enthusiastic competition, and so few admirers of what a fine bird should be, that they gradually drop the hobby.

It certainly gives one pleasure to be able to point to a choice songster, and say that he was bred and reared by one's own hands ; but, when praised and flattered by some well-meaning friend into making a present of the pet, the fun is found to be less paying than ever.

There is a class of enthusiastic breeders in some parts of the country, whose number's ean be very easily counted, who pay the greatest attention to the Belgian breed of Canaries. These fanciers breed from the finest stock possible to obtain. Herein is the great secret of success in all branches of bird-breeding. These faneiers really succeed in producing birds of as good shape and position as the purely imported article. When this is the ease, the breeder easily obtains a paying market for his stock. This seems to be the only class of birds to which any attention at all has been given. 'The importation of the finely colored Canaries, and highest class of songsters, commenced at a comparatively recent date; but, if their breeding here is taken up with the same enthusiasm that the amateur breeders of England exhibit, there is no reason why good birds should not be bred with profit as well as pleasure. The finest stock can be easily obtained; and, when the facilities of importing are so great, if one does not see the best, he can easily order just what. is wanted. To be sure, an article branded with a foreign stamp has a certain superior value in some people's eyes over the home-manufactured goods; but, if some of the energy always displayed by the genuine Yankee is devoted to birdbreeding, it is safe to say, that it would be but a matter of very few years before he could enter into successful eompetition with the best stock in Europe.

The usual breeds of American Canaries, as now seen, have no fixed length, shape, color, or song. The birds are a kind of combination, which eannot be explained. As before mentioned, the main idea here seems to be to get a Canary; and, a Canary once obtained, the breeder is satisfied. These American Canaries, when offered for sale in the shops of importers, find no sale at a remunerative price; as they bear no comparison to the fine-voiced Germans, or to the elegant colors and shape of the English and fancy breeds.

The one recommendation to which the American Canary may lay elaim is, that, as a rule, he is an exceedingly hardy bird: this hardiness is due to the elimate. Birds reared from the ehoicest imported parentage also quickly become acclimater, and sickness is very rare among them.

In conclusion, we wonld, recommend the breeder of Canaries to begin and continue with only the best stock, and he will then be sure of rearing fine birds: thus the laughter which his efforts have heretofore provoked will quickly cease if only the most common rules and proper care are observed.

Is there any exception to the proverb, "Like produces like"? 


\section{HYBRIDS.}

The breeding of this class of birds has received as much attention as has been given to any class known. Good Hybrids are splendid birds, and when finely bred, for color markings, make probably the handsomest cage-bird bred in natural colors. The great charm in Mule-breeding is the uncertainty which attends it : no fixed rule can be followed for the production of the highly prized white Mules. The rules regarding the selection of proper breeding material are numberless, but each successful breeder of this class of birds religiously guards the secret of his successes ; and the stock from which he has obtained his prizes can no more be bought than his right arm. 'The scareity of proper material for muling purposes is well known, and white or clear Mules of any variety always repay the breeder in a manner which justifies him in keeping the secret to himself.

The most common class of Mules is the Canary-Goldfinch breed. The utmost attention must be paid to the selection of the female where the light colors arc desired. The clear-yellow hen, which has descended for generations back from the same clear color, is the most desirable for this class of Mule-breeding; and we may here note, that even ninety ont of a hundred of these elear yellows will throw the dark type of Mule. The proper female to mate for the purpose ean only be founc after numberless trials in breeding, or by purchase from some fancier known to he possessed of this class.

If the common or dark class of Mules is desired, any good breeding-female Canary will do. After procuring the proper material on the female side, it is necessary to obtain the proper Goldfinch. The Goldfinehes vary as mueh as the female Canaries: some breeders like the slender, snake-headed variety; others seek points in the color. and select the varicty known as the Cheveral, or white-bellied class; while the majority look for the white-legged variety. 'The German Goldfinches are the liest to breed from ; for they are larger, stronger birds than the English, and throw a much finer class of Mules. When used for breeding purposes, the Goldfinch should be caged early in the fall. and domestieated as much as possible until May, the usual time for breeding. It is well to rear a brood of Canaries from the female Canary which is to be used, so as to accustom her to her duties. 'The rules for breeding Canaries apply to Hylorid-breeding.

The male Goldfinch mated with the female Canary is the proper pair for breeding Goldfinch Mules. When the female Goldfinch has been mated with the male Canary. most unsatisfactory results follow. The colors in the Goldfinch Hybrids vary from the pure white - the color which every breeder tries to obtain - to the very dark. The valnes which the different classes have vary with the colors.

Another handsome type of Mules is the Linnet-Canary. The same rule applies in the selection of the female Canary, the pure yellow being preferred to the mealy. The Limnet should be as clear colored as possible, and the larger he is the better the class of Mules. Either the English or German brown Linnet is preferred. I have seen Mules of this class without a single dark feather on any part of the head or body, yet so distinetly Linnet in shape and size that the origin conld not be mistaken. All Mules generally unmistakably show their origin lyy the shape of head. 
while the beak and the bird's actions are the same as those observed in the males from which they spring. 'The Canary quality is seen in the shape of the body. Characteristics of both of the parents are distinctly observed in the Mule. Mules which have songs different from the Canary are eagerly sought for. Such songs may be tanght the Mules by placing them, as soon as they are able to utter notes, within hearing of the bird whose song you desire them to imitate.

Other varieties of Mules are obtained, althongh not so satisfactory as the above, by pairing the female Canary with many of the seed-eating varieties of songsters. An uneommon specimen of Mule-breeding was obtained by mating a male Bullfinch with a female Goldfinch, the result being a beautiful combination of shape and colors. It is said that this class of Mules is as easily bred as the others, the main point being to thoroughly domesticate the birds before pairing them.

'The treatment of Mules is the same as that given Canaries: they should have the mixed seeds and the usual varieties of food given the Canaries. They may also be colored by means of the cayenne mixture, and the light-colored varieties change to elegant colorings when so fed.

\section{TRICK CANARIES.}

The tricks which a Canary may be taught are almost numberless; and, owing to their natural tameness, they may be recommended for the above purpose over any other class of birds known. The methods of training Canaries vary, and I know of no fixed rule to lay down. Sone trainers commence with kindness, others with starvation and ernelty, - two widely different starting-points, you will say. 'The bird, as in all cases of training animals, must know but one master; and that master, in order to thoroughly train his bird, must completely gain the bird's confidence. When the confidence is once gained, teaching and training are easy. Patience is every thing in training a Canary to the highest point of perfection. Notice how quickly a Canary will choose from among the members of a family his speeial favorite. Be assured the choice was not made by any lottery arrangement, but was made because the bird was treated kindly. Show your bird any special favor daily, and you will be surprised to see how quickly he will repay you by endeavoring to please you with his song. Gain a bird's confidence and affection first, and he will learn as many tricks as you are willing to teach him.

The older authors assert that hunger is the chief means of gaining a bird's confidence, and usually the starting-point. I think it a eruel method when the opposite means are just as easy. 'To recount the tricks which a well-trained bird is capable of performing would be useless here, as, no doubt, the majority of the readers of this article have seen performing-birds of this class. 'The hardest branch to teach is probably arithmetic. Trainers in France devote their energies to mathematics: and a troop of birds has been seen there, each member of which had to do some special example in figures: and the intricacies of the various tables of multiplication, subtraction, and division were eleared away as easily as could be done by the prize-members of a school. When Canaries are trained to perform tricks, it is, of course, essential to feed a dainty now and then as a reward. If not too lavish in the use of these, the bird may be kept in song as well as if he were not trained. The pre- 
vailing idea that a trained bird loses his song because he is learning tricks is not so : the loss of song can almost always be attributed to the rich food which is apt to be given in large quantities as rewards.

\section{PIPING CANARIES.}

Canaries may be taught to pipe a tune in the same manner as a trained Bullfinch, but the great trouble lies in the fact of his forgetting the air when brought into the presence of natural singing Canaries. The Canary has a natural varied song which the Bullfinch does not have : and, when trained to pipe musie, he must be kept out of the reach of Canary voices; as his natural song is recalled, and the artificial notes neglected. For this reason the difficulty in obtaining a well-trained Canary is great; and, when one is found, he must be given a room to himself, and out of the reach of the vocal influence of any other Canary. When a Canary is well taught, the voice is exceedingly flutelike and elear. The lessons are given in the same manner as to the piping Bullfinch ; and it is necessary to be able to properly whistle the air, or to play a bird-organ which has it, in order to keep the bird in perfect tune. As may be imagined, it is exceedingly difficult to procure a piping Canary in a bird-shop, for the constant din from members of his own elass would utterly ruin his artifieial notes. These Canaries are always imported to order when one is desired.

\section{TALKING CANARIES.}

No doubt, to state there is such a class, provokes an incredulous smile: nevertheless, believe it or not, Canaries have been trained to talk. You may say you are a great traveller, have had thousands of Canaries in your care, but never heard a Canary speak, all of which may be true. You are not one of the favored few ; for it may be safely said, that very few have ever heard one.

When a talking-bird is mentioned, most persons naturally expect to hear or read something about a green parrot, - one of the smaller, insignificant parrots, to which they might listen for seventeen months, - could life last so long under such circumstances, - and never hear him utter an intelligible word, - a bird with a shriek, that, heard unexpectedly, would terrify the stoutest heart. There are many species of birds that talk; and, likely, as we become better acquainted with the feathered tribe, many more kinds will be added to an already long list. A friend, living in Eastern Massachusetts, has a Canary, a real tame bird, of her own raising, which often used to perch on her work, fight the fingers that refused him caresses, pull the thread from her needle, and finally alight in such a position that no more stitches could be taken. This bad conduct elicited sharp remarks of assumed displeasure. "Peter! Peter! fly for your life!" But Peter, like Peter the Great, would not understand what fly meant: he preferred to stay and fight. After several days' repetition of this mimic contest, imagine the surprise caused by the bird alighting in his usual battle-ground, and saying plainly, "Peter! Peter! Fly! Fly!"

Many authentic cases of the above kind are on record. Many owners of pet Canaries, who name their pets Dickie, are surprised, after repeating the name many 
times in succession, to hear the exact imitation which the bird produces: his natural, sharp call-note enables him to repeat this word with probably greater ease and distinctness than any other which could be given; but, when once able to eall his own name, he is easier fitted for more advanced training in this direction. Short, shar'p words of the above description are more easily mastered by him than others, owing to the high squeak of his voice. A lady is the best trainer for a Canary, as she can naturally pitch her voice at about the desired key. In London a lady gained quite a notoriety, and considerable money, by attending to this branch of training. Young Canaries, just beginning to sing, are the best for this purpose.

\section{DISEASES OF CANARIES.}

Most authors, writing on Canaries, start with the subject of sicknesses and diseases. They commence with a sick bird, and end with a healthy one. I think it much the better plan to commence at the opposite end, and, believing your bird to be a healthy one, trust that he will continue so; but if, from any cause, sickness attacks him, it is well to know what to do. First, in becoming owner of a bird, find out as nearly as possible just how your bird has been brought up, and continue bringing him up in the same manner. In the numerous chapters devoted to special breeds of Canaries, it may be noticed that the degrees of temperature to which they were accustomed varied almost as much as the breeds of birds themselves; ranging from the hardy English birds, some of which endure the cold as well as poultry, to the very warm class, bred in the hottest of rooms. Take an English bird, and change him to the hot temperature to which the bird of the other elass has been accustomed, and the difference would be as marked as that of dropping a newly imported Esquimau in the vicinity of the equator. To be sure, a bird may become gradually accustomed to the change; and it is during the process of acclimating him that great care must be exercised. An ounce of prevention, etc., most aptly applies to the Canary race; and as the bird is naturally a hardy fellow, even in the breeds brought up in high temperatures, the diseases should be few if common care is given.

A few hints will be given here, which have been omitted in some of the articles devoted to "Food and Care."

It is unnecessary to repeat here the precaution of absolute cleanliness; I presume every lover of birds has grown heartily sick of looking at this piece of advice, and hearing it repeated : but to keep your bird's food, water, and cage elean, is to insure his health; to neglect them, is the sure means of bringing on disease. The length of time which a disease of some sort may be warded off, is gauged only by the vigor of the bird's nature. 'The selection of the proper cages, with proper' feed and water cups, is also essential. The cups should be so arranged as to be easy of access for the bird's head; and the bathing-dish should be shallow, and large enough to prevent the bird from injuring his plumage in his vigorous plunges. A bath-dish which is too deep is apt to make the unlucky bird-owner think he is the possessor of a race of suicides, from the number of floating dead which will be the result of such negligence. This will particularly be the case when young Canaries attempt to bathe in dishes too deep for the purpose. 
A word about perches suitable for the Canary's foot. 'The proper size should be - when of the same diameter throughout - about twice that of a common-sized lead-peneil. Perehes which are too small are a source of constant misery to the bird. You will always notice in the ease where the perch tapers at the ends, that the bird chooses the centre or thickest portion as his natural resting-place, on account of the rest which it gives his feet.

The Canary natmally follows the old adage, "Early to bed," etc. He will, in the early hours of the evening, go to roost, putting his head beneath his wing, evidently with the intention of letting it remain there, unless disturbed; and he will also as eagerly seek the early sunshine. Hang the cage, therefore, where the rising sun will reach him; and the effeet will be worth many bottles of medicine to the sick bird, and renewed strength to the healthy one. Heat, if not obtained naturally, must be had artificially, where there are sick birds, or in the breeding-room. The young birds require it, as do also the weakened systems of the old. Mice are a source of torture to Canaries, and oftentimes succeed in frightening healthy birds into sickness, and even death: you will oftentimes perceive your Canary drooping and sickly in appearance from no apparent cause ; and this is provoking in itself, beeause of the care you have given him. If there are mice in the house, and any possible chance for them to reach your Canary cage or room, rest assured they will get there. Bird-seeds are as delicions to them as the best brands of cheese; and they will enter the cage in the dark, and succeed in making your bird as sick as the most ambitious bird-doctor could desire. The only remedy is, to hang the eage out of possible reach, and, in the ease of the breeding-room, to effectually bar them out by means of zinc. If you disregard the mice, the larger enemies, rats, will follow ; and, instead of nursing sick birds, you will be burying dead ones. Insects are another pest, and worse even than miee, for they are more stealthy, and do not leave such visible traces of their visitations; but they sueceed in so completely torturing the bird, that his life is gradually consumed. Students who make the study of msects a specialty say, that there are two classes of them which annoy the Canary: one class is composed of those which remain on the bird's body throughout the entire twenty-four hours, and the other of those which seek the bird's body only at night, and remain in the crevices of the cage and perches through the day. The two are closely allied, and their differences can only be detected by the most powerful of microscopes. In order to thoroughly rid your bird of both kinds, - for where one class is known to be, the other is most sure to follow, - use the German Inseet Powder, the ouly sure kind. It must be thoroughly dusted over the bird's body, under the feathers; and a thorough eleansing of the cage must follow. If the cage is of brass, the effectual way is to have it refinished, and the perches renewed. If insects appear in the wooden breeding-cage, the birds should be removed if possible; and the cage should receive a thorough coat of varnish, after first being: washed with soap and warm water, and the joints and crevices treated with a solution of bichloride of mercury. Only tightly jointed breeding-cages should be used : the old, rickety, loosely constructed affairs should be discarded. For this reason, when purchasing a breeding-cage, buy only the best; as they are not thrown together, but neatly jointed and varnished. When the presence of insects is suspected, if the crevices and joints are inspected, a little white deposit resembling 
flour will be noticed; this is a sure sign, as the deposit is the eggs of the insects : wherever observed, the varnish-brush must be applied. A stroke with a brushful of varnish will eatch them in a trap from which escape is impossible. In case where a large room is used for breeding, before putting the birds in, it should be most thoronghly cleansed, and whitewashed or painter. With elean utensils, and clean, healthy birds, at the start, you will have insured freedom from these pests.

The different nests used are here worthy of mention. It has been said, that, give a pair of Canaries only half a chance, and they will breed and hatch on the bare floor. How true this is, I do not know ; but eertain it is, that some astonishing specimens are reared in the rudest affairs possible. In the German district, the little wicker eage with the front detached, and a nest of moss, serve the purpose : this is fastened to the front of the breeding-eage, and the parent birds fly in or ont at will. The English nests are made of different materials and of different shapes, the most primitive being a leather cup of the desired size; and another is a sort of basket made by sewing stout manila cord in the desired form. In Norwich the nest is made of wood, square in shape, with a back-board, which is used for fastening against the wall. In still other parts of England, the perforated tin or wire netting nests are used. The materials used for lining vary greatly, and may be either felt, moss, jute, dried grasses, or deer's hair. 'The latter substance and the perforated tin or wire nest are the best for all practical purposes. It is better, perhaps, all things considered, to allow the Canary to do its own building: to be sure, it is most certainly a fact, that years of domestication have impaired the architectural skill of the Canary; this is proved by the fact that no two build nests exactly alike: however, it is best to leave them to their own resources. 'There is apparently no difference in the health of birds reared in the most eleverly constructed nests, and of those which are reared in nests which at best may be called mere apologies.

The breeding-cages should be of sufficient size to allow the young birds, when able to fly, plenty of space; for the strength thus gained is of great benefit to the health when the birds grow older. The ailments to which young birds are subject are few if bred from healthy parents. The last brood of the season is apt to be siekly, when, as a natural cause of impaired strength in the parents, the weakness is transmitted to the young. The birds of the late broods should be separated from the earlier, healthier birds, and their constitutions built up by means of plenty of fresh air and sumshine, and rich feeding on egg-mixtmre and green stuffs.

Indigestion. - During the earlier part of their existence, young Canaries spend a great deal of time in sleep. This is perfectly natural; but when they are observed to be sleeping more than the usual time, and when the bird has the appearance of a puff-ball, it should be taken in hand at once. The disease in early youth is generally incligestion, arising from unwholesome or stale food, such as the eggmixture or green food permitted to grow sour in the cage; or it may arise from overeating of delieacies which have been introduced into the eage. Whatever the cause, the bird should be caught, and a couple of drops of eastor-oil dropped down his throat; or the drinking-wated may be removed from the cage for two hours, so that the bird will have a desire for it when returned: then float a few drops of codliver oil on the water. Either of the above will afford almost immediate relief. The bird shonld then be renoved to a dry, warm place, and fed on crushed hemp for a few days. 
Wasting. - Another cause of complaint among the German young Canaries is the wasting away of flesh, which comes from feeding too much plain rape, and not enough rich, stimulating food in addition. The bird, if examined, will be found to be almost a complete skeleton. Warmth and rich diet will prove beneficial in this case.

Temperature. - A young bird should not be too suddenly changed to a colder room; for the result will be an inflamed, red appearance of the reins on the body. Birds thus affected should be treated as for wasting.

Surfeit. - This appears in young birds of from a month to six weeks old, and is caused by gluttony. Alum or a little common salt dissolved in the drinking-water is recommended. 'The food should consist of bread and Canary-seed soaked in boiled milk; and the bird should be allowed a bath in tepid water, after which he should be thoroughly dried. Feed sparingly on millet-seed for a few days.

Constipation. - It is often found, on buying a young Canary freshly imported, that it shows signs of constipation by a frequent twitching of the tail. A German authority prescribes the following: Take a piece of soft, stale bread, and soak it in eream that has stood over night; take the bread out, and allow the cream to adhere to it; sprinkle with a little maw-seed, and feed at once. Do not allow the mixture to remain too long in the eage, as bad effects are sure to follow. This is a mild close and a speedy cure.

The ailments to which the entire Canary race are subject are no more than could be expected of birds kept in elose confinement. The canses of diseases may be divided into five classes: (1) The most common diseases result from exposure, or from draughts of cold air when birds are hung in a warm room; (2) From badly ventilated rooms, or from being lung where the foul air, emitted with hot, burnt gas. reaches them; (3) Too much unwholesome food, and the feeding of too many dainties ; (4) Sour or stale food, and foul drinking-water : (5) Contagion.

The medicines used in the treatment of Canary diseases are few and simple : the chief requirement in most cases being a change either in air, temperature, food, or water.

The chief diseases are troubles of the lungs or chest, and may result from a variety of eauses, - from dampness, dranghts, cold after bathing, or slight chills during the moulting season.

Consumption. - The first result is a cold, which, if not cared for, develops into consumption. Some birds are more easily affected than others, which is eaused by the hereditary charaeter of this complaint. This illness must not be confounded with asthma : the latter may be deteeted by the periodic attacks of wheezing. The symptoms are about the same : in both cases there is a wheezing sound, and the bird is more languid that usual. These symptoms continue day and night. The treatment should consist of building up the constitution by means of nourishing foorls. The egg-mixture and an abundance of green stuffs should be given. A small dose of castor-oil, when the disease first shows itself, will be found very benefieial. Keep the patient in a temperature of $70^{\circ}$ to $75^{\circ}$. The water should be changed often, say twice a day, and should have dissolved in it a small piece of gum-arabic, and a little glycerine added. A drop or two of cod-liver oil will also give great relief.

If the above treatment does not afford relief, stronger remedies must be used. 
The drinking-water must be turned into a cough-mixture, which may consist of twenty drops of paregoric added to the drinking-cup of water ; or another good mixture is made by adding to the drinking-water five drops of muriate of morphia, a teaspoonful of glycerine, and a morsel of gum-arabic. 'The bowels, if not opened sufliciently by the glycerine, should be kept moderately open by the addition to the water of about as much carbonate of magnesia as will lie on a ten-cent piece.

Asthma may also be of hereditary form, and, if not attended to when first noticed, will develop into a chronic disorder which is incurable. The symptoms are familiar to any who have had any considerable experience among Canaries: there are the quick, short gasps of the bird at night, most painful to listen to, as well as the puff-ball appearance of the body. The natural causes are sudden draughts, improper foor, or overfeeding and indigestion. The food and treatment should be the same as for consumption, care being taken to change the green food every day. In cases of long standing, a few grains of iodide of potassium added to the usual drinking-water is recommended. Tonics which contain iron in any form are also very strengthening, and may be given to the amount of fiftecn or twenty drops daily to the drinking-water.

Loss of Voice. - This is a frequent complaint among song Canaries, caused by exposure to cold, or from overstraining the vocal organs by too constant song. A couple of drops of castor-oil should be administered in the beginning : then add ten drops of paregoric, a small teaspoonful of glycerine, and a small piece of rockcandy to the drinking-water. The food should be richer than the usual daily food: in addition to the seed, add a portion of grated hard-boiled egg, dusted with cayenne pepper. When attended to at once, this complaint is easily cured.

Diarrhœa is caused by giving too much green food, or food which when fed is too wet, or is decayed. Bad drinking-water is another frequent cause, as are also stale or musty seeds.

Exposure to cold, which results in sending the blood to the internal organs, is another cause. 'This disease may be detected by the watery state of the excrement: the disease is very weakening in its effect, and, if not attended to, quickly causes the bird's death. The bird should be changed into a clean, dry cage ; or, when this is not to be obtained, let the cage he is in be cleaned thoroughly, frequently changing the gravel, which should be warmed and dried before being strewn in the eage-bottom. Hang the eage in a warm, well-ventilated place. Change the food by giving the bird light biscuit or stale bread soaked in new milk, to which a little prepared chalk and a little powdered loaf-sugar may be added. Should this fail, fifteen drops each of elixir of vitriol and tincture of opium may be added to the driuking-water. When the case develops into bloody diarrhœa, which is seen by the bloody nature of the excrement, it becomes a serious disease, and one difficult to check. A good mixture is, to add to a wineglassful of water fifteen drops of tincture of laudanum, thirty drops of wine of ipecacuanha, and three of four grains of nitrate of potash.

Watchful care is required after the bird las recovered from the diarrhœa; and daily egg-food added to his usual seed, and iron tonic to his water, is required to build him up.

Constipation is caused by an error in the bird's food: too much egg and 
pepper to a bird not nsed to it, being a cause, is easily detected by the uneasiness of the bird, and the thick, ruffled appearanee of the feathers. A few drops of castoroil usually affords relief. The permanent eure is effected through the food: in summer, fresh green food should be given daily; and a mixtme of egg, raw, grated earrot, and sugar, in the winter, or when fresh green food eannot be obtained, is an effectual remedy.

Inflammation of the Bowels. - This is a disease of which numberless Canaries die, while they may be treated for another ailment. The disease is caused by overeating too stimulating food, or from unwholesome diet of sour food: bad drinking-water is also frequently the cause. Careless bird-keepers leave the care of their birds to more careless servants; and the drinking-water becomes tinged with a green mucous matter, which is rank poison. The symptoms are languidness, the bird rarely stands upright, but rests with his body on the perch, and does not eare to sing. If the invalid is eaught and examined, the lower part of the abdomen will be found to be of a color varying from a rich to a dark red, according to the stage of the disorder.

The diet should be changed as in all other cases : cleanliness is most essential, and the same preeautions should be taken as in cases of diarhœe. Dip a camel's-hair brush into warm turpentine, and paint the inflamed abdomen, and open the bowels, if eonstipated, by giving three drops of castor-oil, ten grains of each of the tinctures of opium and belladonna; and a few drops of gum-arabic added to the drinking-water should be the daily drink until a cure is effected. The food shonld be of the lightest description : light biscuit soaked in milk, and frequently changed, should be the main diet. A little brandy may be added to the drinking mixture as a last resource if the bird is about to be given up, although we wonld not recommend it unless the case seems almost beyond hope. Stimulating foods and tonics must be given during convalescence.

Inflammation of the Liver. - This is an almost incurable disease, and is sure to follow the overfeeding of dainties, such as hemp-seed, sugar, plum-cake, etc., and too high temperature. The symptoms are the restless actions of the bird: he is nervous, hot, and thirsty, and evidently suffers great pain. 'The absence of wheezing indicates there is no lung trouble, and the natural color of the bowels betrays no symptoms of inflammation.

Commence by giving three drops of castor-oil: when the bowels have been acted on, put daily in the drinking-water fifteen grains of tincture of opium and a teaspoonful of dandelion juice. When the pain bas subsided, omit the opium, and continue with the dandelion. The diet should be of the lightest kind, and digestion must be aided by the regular iron tonic. When the bird is fully cured, feed on only the plainest seeds ; the German summer rape-seed forming the main part of the mixture.

The bath need not be omitted in any of the above cases, except when the siekness is very severe.

Epilepsy, or Fits. - This is caused by too rich food, overeating, or too frequent mating, any one of which causes a suspension of the heart's action ; or it may be caused by fright, which is often the case when a bird is caught too suddenly. When the bird is attacked, hold the cage in the fresh air, and gently sprinkle the sufferer with a few drops of cold water. 
Another and frequently fatal cause arises from hanging the bird in the hot, blistering sun. In sueh a case smelling-salts are required in addition to the sprinkling of cold water. The diet must be carefully regulated ; and plain seeds, alternated with cracker's and milk, should be the food. Tonie should be given daily.

Cramps are caused by filthy eages, or from confining the bird in a cage much too small for him : they may also come from indigestion. 'They may be eured by adding a few drops of laudanum to the drinking-water. If in the legs, which may be noticed by the nervous contraction of both members, the best cure is, to immerse the legs in warm water, and hang the cage in a warm place.

Bathing too frequently will cause birds to have cramps, and a third attack is sure to prove fatal. One bath a day, or a bath on alternate days, is frequently enough.

The Pip is a small swelling which appears on the bird's rump. It may be easily cured by gently opening the swelling with a sewing-needle. A little cold cream should be afterwards gently rubbed over it. Feed the bird on mild food for a few days.

Surfeit in old birds is indicated by a slight eruption on the body, and an extending baldness on the head. It is caused by an abrupt change in food, or by continued plain diet. Add a few grains of Epsom salts to the water, and give a daily feeding of green stuffs. A little lemon-juice added to the drinking-water is also very beneficial. The heal should be rubbed with any simple ointment.

Pimples, or Obstruction of the Rump-Gland. - This is a gland which forms part of the structural economy of every , bird, and is intended for seereting the oily substance required to render the plumage supple, and impervious to wet. 'The bird presses this gland, which is situated just above the rump, with its bill, and the oil oozes out; if this is not done frequently, the opening is apt to get clogged: and, there being no vent for the increasing contents of the gland, it gets hard and inflamed. If you see your bird sitting about with its tail bent downwards, and often turning its head to peck at the hinder part, where the feathers will most likely appear ruffled, suspect that this is the ease; and if, on examination, you find it so, rub the gland with some fresh butter and sugar mixed together, at the same time clearing and enlarging the aperture with a needle or sharp knife. Some persons cut off the gland altogether, but this is a bad plan ; for, although it effeets a cure, it deprives the bird of a useful organ, for want of which at the next moult he will probably die. Beclistein recommends a salve of litharge, white lead, and olive-oil, to remove the obstruction; and Tscheiner, another German naturalist, states that this evil may be remedied by puncturing the gland, compressing it frequently, bathing the bird with a syringe, and plucking ont some of the tail-featluers. In the renewal of the feather's, aceumulated fat is absorbed, and the gland sufficiently relieved to resume its functions.

Yellow Gall is indicated by a small ulcer or a number of them around the head and eyes. If the bird has been fed on plain food, change to something more nourishing. The ulcer's should be eut, and anointed with any simple ointment. The following remedy for this complaint has also been suceessfully tried. Make a strong solution of sugar of lead with rain-water, saturate the ulcers thoroughly, and bathe the parts, wherever sore, three or four times per day. 'This will effect a cure in from four to seven days. 
Giddiness. - This cannot be called a disease, but is merely a disagreeable habit which the bird has of twisting and turning the head, and continually looking up and backwards. The best remedy is, to use a cage covered on top.

Cancer. - This disease is oftentimes fatal. The cancer is a warty, yellowish protuberance, which appears at the base of the bird's bill. It sometimes attacks the feet as well. It is caused by filthy cages or filthy food, which gradually poison. The parts affected should be bathed frequently in a strong solution of alum and water, which will tend to dry up the warts, and canse them to fall off. After this use olive-oil or glycerine for healing purposes. Keep the cage as clean as possible, and hang in a warm position. Feed the bird only on plain food.

Contagious Diseases. - These arise from overcrowded bird-rooms, where the air becomes so foul that disease must surely be the result. Bird-owners who own only a few birds are not usually affected by it. In appearance a bird may be perfectly healthy and in song; yet the disease lurks in his system, and results fatally unless speedy means are taken to check it. When the disease appears among a snall number of birds, it may result from unclean or poisonous drinking-water, and is shown by numerous ulcers on the head and body. In other cases the disease is noticed by the short gasps of the bird, as though in great distress. As soon as noticed, all cages in the room should be thoroughly cleaned and disinfected, and the seed, water, and bath cups thoroughly cleansed. Keep the birds in the purest atmosphere possible: sunshine is also good. Feed such birds on plain seeds, with a little maw-seed in the mixture. Green food and egg-mixture should not be given during the run of the disease. Add to the drinking-water a teaspoonful of brandy and a few drops of paregoric: float this mixture with a little cayenne pepper. The above remedy has resulted in complete recovery when the disease was promptly attended to. If allowed to run without checking, the result will be surely fatal.

Wounds are usually the result of acciclents, caused by the bird getting his feet or claws entangled in some parts of the cage. They may also be caused by coming in contact with the edges of broken seed or water vessels. When the accident happens to the feet, the bird should be carefully caught, and the feet bathed with warm water: the wound should then be bathed with some healing remedy, such as a solution of five grains of sulphate of zine in an ounce of water, or touch the wound with a piece of wet alum. When the wound is on the body, bathe the part with warm water first, and with the sulphate-of-zine solution afterwards. The above should be applied about twice every day.

Sore Feet are a result usually of filthy cages, or from improper attention to the legs and feet while the bird is growing old. If the cause is filthy cages, clean the feet thoronghly by soaking them in warn water, remove all particles of dirt which adhere to them, and, after wiping dry, anoint with glycerine or some other simple ointment until fully healed and healthy. Meanwhile keep the cage as clean as possible. If the soreness is caused by not removing the scales which grow on the bird's legs as he gets older, take the bird carefully in hand, and anoint thoroughly the affected parts with some softening lotion, such as cold cream, and, after two or three days' application, gently remove the scales by means of a sharp knife. When they are all removed, anoint daily with the ointment until cured. 
The claws of Canaries sometimes grow very long and hooking, and need to be cut. Hold the bird up to a strong light, and cut the claws with a sharp pair of scissors, avoiding hitting the vein in the claw.

'The bill, or beak, may grow so long that it is almost impossible for the bird to pick up his food. Usually only the upper mandible needs to be cut back, and should be left of natural length, and, of course, longer than the lower. After being cut with the scissors, the round edge may be scraped off with a knife; and the end of the bill should not be left blunt, but should be brought, by scraping, to such a point as it naturally would have.

Accidents to the joints may sometimes occur from the bird getting caught in the bars of the cage; and a wrench will cause, sometimes, a painful inflammation. Bathe the afllicted part with a solution of hot water, and a few drops of tincture of opium.

Broken Legs. - In case of a broken leg, draw the leg ont slightly, taking hold just below the break, then, with fingers and thumb, press the ends of the break into position. Shear the feathers off for a half-inch each side of the limb if necessary, and wind a couple of times around the break a piece of cotton cloth threequarters of an inch wide, and secure it with thread. Take two half-inch splints of pine, each one-sixteenth of an inch thick, and one-eighth of an inch wide; place one splint inside the leg, and the other ontside, and secure them firmly in their places by thread; remove the perches, place the seed and water in the bottom of the cage, and trust to nature to effect a healing.

When a bird gets mangled beyond possible recovery, it is evidence of the kindest heart to administer chloroform. 'To do this, make a paper horn large enough to hold the bird; let six drops of chloroform drop into the bottom; put the bird in, and close the top of the horn. His suffering is ended. Death is painless and instantaneous.

The prevention of disease is worthy of far greater praise than any possible display of skill can be that attempts to control the flame of fever kindled by sheer carelessness.

'To prevent diseases in birds, use the best quality of seeds, clean, fresh water for' drinking or bathing, coarse, flinty gravel, cuttle-bone, and fresh green stuff. If these are supplemented by light, airy rooms, where the bird may have one or two hour's of sunlight each day, and regular attention, your bird, if fairly well bred, will be subject to few diseases.

\section{BREEDING-BIRDS.}

Canaries may be bred either in aviaries or in separate cages. The aviary method can be followed by those who have no definite purpose other than the pleasure to be derived from general observation. "We may sum up," says Blakston. " the advantages of the aviary system briefly, by saying that it involves only a small amount of care and attention ; the birds being left pretty much to take care of themselves, to choose their own mates, and make their little world inside the wires as much as possible like that ontside. The observer has nothing to do but watch the goings on of the little republic, which will develop much that is beautiful. In the 
aviary, there is the disadvantage of indiscriminate pairing, rendering it impossible to breed any distinct variety; though this may not be any objection to those who, as long as they breed something, and have the pleasure of seeing it grow, care little what that something may be."

In putting a pair alone in a separate eage, special colors, sizes, shapes, and, it can be added almost with certainty, desirable songs, may be obtained. To our' general breeder, it matters little, usually, whether his young birds are clear or mottled, have a dark cap or are ticked, since he has the pleasure of raising the birds. be the color what it may, and the added pleasure of making many friends happy. whom he may favor with gifts of pets. Birds mate in cages any time from January on until June, and birds once mated will breed until September. A case is known where a pair of Canaries hatched a brood each month during the year. 'This pair reared that year a total of forty-two birds. You will join us in exclaiming this was a clear case of cruelty to animals.

A cage for breeding may be made of brass or wood; but the former keeps freer from insects, and on this account is greatly preferred. For a single pair of birds, it should be not less than $8 \times 10$; and $9 \times 12$ or $10 \times 16$ is better. The wood-frame and tinned-wire cages, with solid wood backs, are very convenient; because they can hang up against the wall, or set on a shelf against the wall. A position against the wall, about eight feet from the floor, and with a southern aspect, seems to be correct. A breeding-cage ought not to swing. 'These wood-frame cages are $10 \times 14$ or larger, and are constructed with a movable platform, containing one or two nest-places. Food and water bottles hang in wire rings at either end, on the outside of the cage. The nests are wire, and lined with cotton-wool flannel. Deer's hair is furnished the birds, so they may arrange the interior of the nest to suit thenselves.

Gravel should be strewn in abundance on the draw ; and a bit of old plastering, from an old building, should be partially crushed, and furnished in small quantities daily. When this cannot be obtained, crushed oyster-shells may be substituted. Birds thus provided for seldom lay soft-shell eggs.

The daily food should be equal parts of German summer rape, Sicily canary, and millet seeds mixed, and, for one pair of birds, one-third of both parts of a hardboiled egg, with which has been mixed a thimbleful of pulverized cracker, or cracker-dust, and a very little maw-seed every other day, or oftener if it seems needful ; give sweet apple or lettuce or celery, and, in a special disl, a thimble of maw or poppy seed. Birds which are to be mated ought to be fed as above stated for . two or nore weeks previous to mating.

It is a good plan to let the pair hang within sight of each other, and become acquainted, before being put in the cage together; for love at first sight is still rare enough to be noteworthy. After the birds have been fed and watered, and had the bath, and the cage has been cleaned, unless they really need something more to eat, or some ailment requires attention, leave them to their own resources for their pleasure. Too close attention, and frequent taking down of the cage to show the pair to callers, has separated many mates, and ruined prospects that gave fair promises of a large and beautiful family.

I don't say, that trying to breed birds contrary to every suggestion given above 



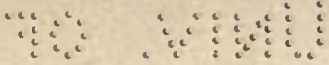

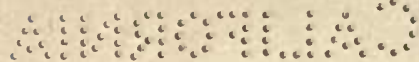

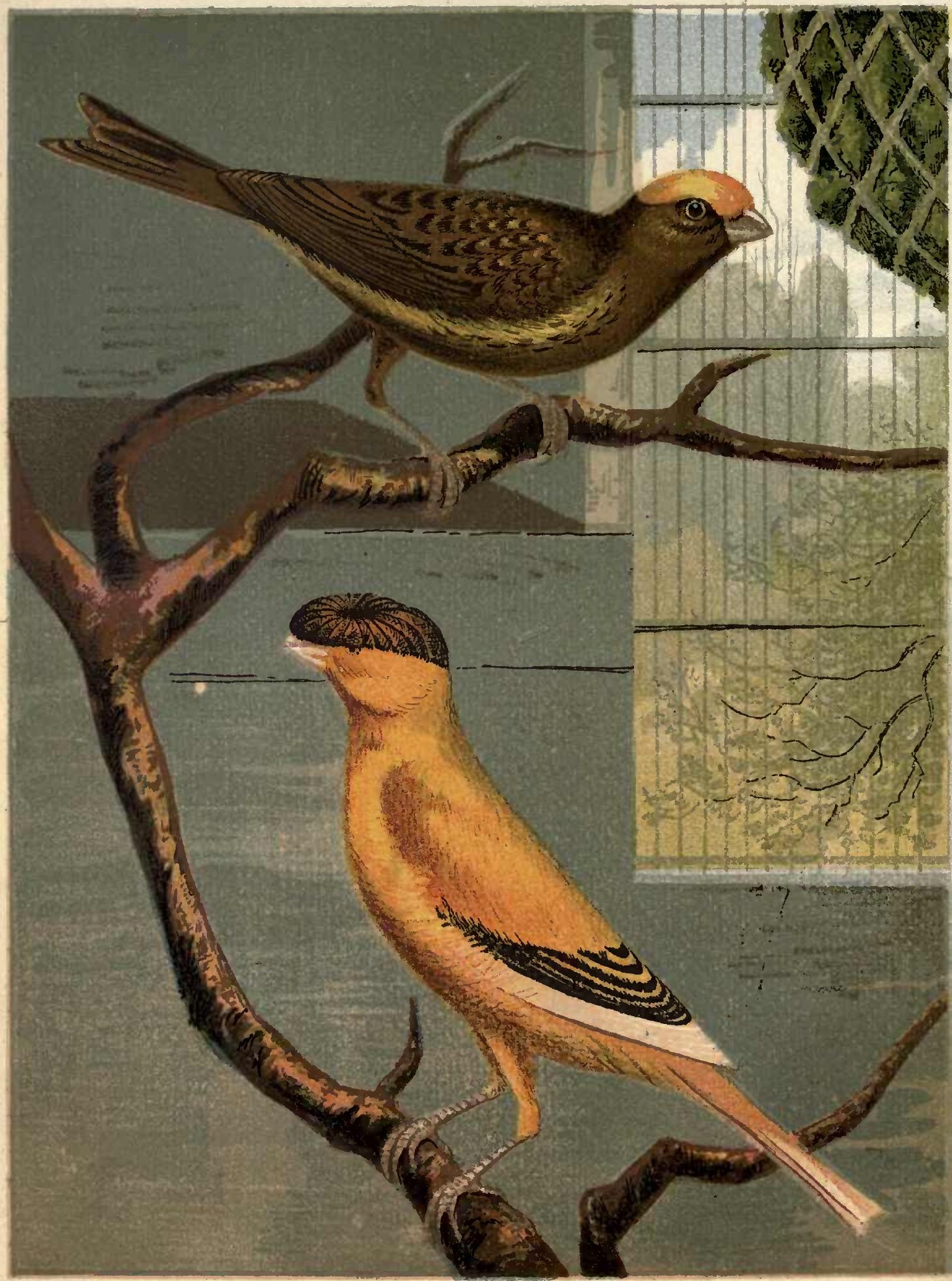


will result in failure; but if the suggestions are followed, and you nse a pair of good birds, great sucess is altogether probable, utter failure impossible.

Having thus given a general ontline on the two methorls of breeding, and information in regard to suitable eages and proper food for pairs of birds, we shall try to state in detail how to mate two Canaries, and take care of them. There must be a starting-place in breeding birds, as in every thing else; so suppose we mark the plice, in order to recognize it in a second visit. "Like produces like." It is a very disagreeable "old saw;" but as it is about the worst one known, and will likely, before we are through, worry us more than any other could, why, let it stand to mentee and harass us.

Recall the maxim above, and commence to breed with the very best stock you can obtain. "Seeure good birds," writes Blakston, "but never mind the age if they are only healthy. When a year old, the eoek birds look out eagerly for mates; and the hens are equally anxious for the duties of maternity, and, if left to themselves, would lay nests of unfertile eggs, and sit on them till hope died out in deelining health and strength. We have never found that age added one iota to their experience, or that youth was conneeted with any lack of knowledge."

If one wishes clear deep-yellow birds, let deep-yellow, unmarked birds be mated : if eimnamon, colors are desired, mate a deep gold-colored male with a elear green female, or mate two cinnamon birds. Mottled or splashed birds may beget clear yellow colors from some clear yellow ancestry back two or three generations, but generally they produce a mottled progeny. Colors and sizes are generally reproduced, but voices or songs are never reproduced. The young birds that sing like their father do so beeause they hear only his song. A young Canary will learn the notes of a Lark or Nightingale or Virginia Redbird as quickly as the song of a Canary, and when thus taught is, of course, much more valuable. Both of a pair may be erested birds; but in that case some of the nestlings may have very poor crests, and usually the erests are imperfect in shape. To obtain the largest and best crests, mate a Crest with a Plainhead.

'The largest birds with the best erests are the Lancashire Coppies, bred in Rochdade, Ashton-under-Lyne, and other towns in England: the Coppies bred in Manchester, Eugland, are equally famous. These two varieties are alike in size, shape, and eolor and crest, and are the longest and largest breed of all Canaries. The Norwich, England, Canaries, both Plainheads and Crested birds, are large, strong birls, and, in respect to high eolors, stand at the head of the list.

Those who like to breed short, compact birds will select the German variety : all of the German Canaries are the same size, but the St. Andreasberg breed are trained singers. Ordinarily there is no difficulty in mating birds: when you decide on the shapes and colors desired, put the par together. 'The probability is, that, when the birds are first put together, they will quarrel; but it is not always the case. It arises from the fact, that the male bird is always the first to make advanees towards a more intimate acquaintance; and the female, as is fit and proper, with becoming modesty repels them. If he be a bird who has spent the winter wisely in studying bird-nature, he will commence by admiring the nest, and giving lis opinion on things in general, and will coax the female witl presents of dainty morsels, and a display of polite gallantry; but if he begins at once to be too familiar, and the first 
song he sings is, "Oh: name the day, the happy day," she will thrash him, or try to do so. But it is the same old, old story over again; and we all know how it ends. In a few days they will have settled matters to their mutual satisfaction, and then begins the serious business of life. It is not, however, always so. Some females take a settled arersion to a particular male, and will never pair with him. In such a case change the female.

The first indication of the birds having come to an understanding is the male feeding his mate. As stated above, give the pair daily, in addition to the rape, canary, and millet seeds, mixed in equal parts, one-third of both parts of a hardboiled egg, grated on a coarse grater, and mix with it a thimbleful of pulverized cracker, and half a thimbleful of maw or poppy seeds; furnish them with small quantities of old plastering erushed, or erushed oyster-shell, to prevent laying softshell eggs.

It will sometimes happen, that, the day before a female lays, she will be seen in the morning in the most complete health, her feathers elose and compact, wings tucked up, and nothing to indieate the presence of any disarrangement; but in the afternoon she will be found apparently about ready to go home. She seeks a eorner of the cage, panting violently, and squats on the ground with wings outstretched. feathers all ruffled, head thrown back, eyes elosed, in a state of entire prostration, the picture of complete misery. On the following morning, if she should not have laid her egg, something must be done. Take her gently in the left hand, with her head towards the little finger, and the tail projecting between the thumb and first finger, and holding her in this position over the steam of boiling water, in a narrowneeked jug, expose the vent freely to the aetion of the steam. Let her have a good vapor-bath, and then, with a bluntly pointed little stıck, drop one or two drops of sweet oil on the vent. Gently replace her in the nest, and the egg will soon be laid, even if it be not dropped in the jug. Early attention to a case when the bird is egg-bound is of utmost importanee. On no account must the egg be broken, or the consequenees will be immediately fatal. The removal of eggs as laid may be made or not. If removed, they should be returned to the nest on the afternoon of the day the third egg is laid. The female then goes to the nest at night, lays her fourth egg in the morning, and generally eommenees to sit so elosely that the date of hatching may be reckoned from the fourth morning. She will sit thirteen days, and hateh punetually to an hour. But, if the eggs should not break at the time expected, let the bird remain undisturbed three or four days.

The egg-and-cracker paste is continued, of course, during the setting, for the old birds to feed the nestlings with. In a case where the young are deserted by the old birds, or are not fed enough, eut a hard-boiled egg in halves, and, after moistening the yolk with saliva, serape up some egg with a little flat stick, making it very moist, about the consistency of cream, and, wherever there is a suspicion of an empty erop, give the young bird a good feed. With young birds, if in place of full erops, plump breasts, and heavy abdomen, you find every feature dwarfed, it is time to commence artificial feeding, as above. The egg-trongh should be filled two or three times every day with fresh egg and green food, lettuce, chickweed, and water-eress also given fresh frequently. Fresh food will often induce the mother to feed the young when nothing else will. 
When the young birds are four or five days old, the breeder may find then some day with the down all gone, or tangled and natted with moisture. 'This is an indieation of the female having begun to sweat them, by sitting too elosely. Sometimes this will continue, no matter what is done; but it ean often be stopped by removing the male from the eage, and thus compel the female to leave the nest quite frequently for food. If the male ean be put in an adjoining compartinent of the same cage, where he can feed the female through the wires, he will incessantly call 'her to come and feed; and these invitations she cannot refuse. The chances are, that on returning to the nest she will feed the young.

Should the female forsake her young, they may be put with the other chicks, where, generally, they will have good care.

If, when the young are a week old, the nest is infested with insects, a nest, as nearly as possible like the one in use, should be prepared, the birds transferred, and the old nest destroyed.

lieep the young birds confined in the nest if possible until they are three weeks old, by which time they are as large as their parents, and can use the perch. If, now, the female inelines to pull the feathers from the young birds, they may be put in a eage with the father-bird, who will continue to feed them as long as it is necessary. If, meantime, one wishes the pair to start a second brood, the male should be put with his mate a short time night and morning: when the third egg has been laid, he ean be removed altogether, and put in charge of the young birds. Young birds of the same age may be kept together quite a long time: but, if the young of different ages are put together, the older birds are liable to pick the feathers from the younger; and, if such a course is continued, it will have serious results.

When the young first try to eat seeds, they will grow faster and thrive better if given canary seeds, rape, millet ; and some hemp, crushed for them in a coffee-mill, is added. Where it is not convenient to so erush it, the seed may be moistened some to soften the hulls. So far the difficulties and dangers arising in breeding Canaries lave been pointed out: the pleasure and satisfaction afforded in watching the growth of the young, their tameness, bright, playful ways, and astonishing intelligence, wonld require still larger space.

After one or two nests of Canaries have been reared, one may take a goodbreeding, light-colored female, and mate with some of the Finch family early in May. It is not necessary that the female should have been mated previously to being mated with the Goldfinch: but, as the Finches do not mate until May, the fenale Canary can be used up to that time; and such use is generally beneficial. For Mule-breeding, seleet a female that throws variegated birds : for if, when mated with a Canary, she throws dark birds, when mated with the Finch the progeny will he still darker; and thus the great object sought for-high color - will not be attained.

In selecting Goldfinches, nearly every breeder follows some whim of his own which he is sure is the foundation of his suecess in raising handsome birds; so there are a great many theories as to what requisites a Goldfinch should possess. One statement which appears to have an extensive backing is, that the bird should be a Cheveral, - a Goldfinch which has the distinction of a white streak from the base of the lower bill down the breast; but this is a mere statement, and not an argument, 
since many of the handsomest Mules ever shown were bred by men who never owned a Cheveral.

The male Finch and female Canary are usually mated; and the reason is, that, from such an alliance, there is a greater chance of obtaining Mules resembling the Canary, and also beeanse the female Canary, being more domesticated, is likely to be a more reliable mother: but the female Goldfineh will breed readily in confinement mated with a male Canary, or with a Goldfinch, or even with a Linnet, Siskin, or Bullfinch. Since such Hybrids are usually very dark, they are not considered valuable, and are seldom bred.

Select the Goldfineh early in the season, so he may be well tamed, and, in April, feed with stimnlating diet, such as egg, maw-seed, eanary and rape seed, and hempseed. When the last tinge of black has disappeared from his beak, and it begins to assume that delicate, transparent pinky-white color, it is time to think of putting him with his mate. If there are several Goldfinehes, they may be mated with the females just the same as Canaries; but, if there is only one bird in prime condition, he may be "run" through six or eight cages. He need not necessarily be allowed to remain long with each bird. If permitted to settle down with a single mate, he will be very attentive, and at once accept the responsibilities of his position, nursing and feeding in a most exemplary manner. There is some risk in leaving an untriecl bird with the female after she lays; as he may be inquisitive, and try to find out what the egg-shells contain. If he shows such a disposition, he must be taken from the cage before the egg is laid: after it is removed from the nest, he can be returned.

Hybrid-breeding is fascinating, and has great charms, as its results are so uncertain : the probabilities are, that all the Mules will be dark, ordinary-colored birds; the possibility is, there may be among the nest of fledglings a single brilliant-colored bird, - a bird whose wealth of white and gold is worth years of experiments to obtain.

Bullfinehes mate with Canaries, and sometimes a handsome bird is obtained; but in this cross brilliant colors are not sought for so mueh as fine song. The Bullfinch has a mellow, subdued note, produced through his wide throat; and when the Mule has the Bullfineh form and size, and is a singer, his tones are most delightful. 'The brightest colors are obtained by mating the male Bullfinch with a light-colorect female Canary; but as the female Bullfinch is very tame and a good setter, and is more likely to mate than the male, the Mules are oftener bred from her and a male Canary.

Linnets and Siskins can also be mated with Canaries, and these and the Bullfinch may be managed the same as Goldfinches. Nestling Mules should be fed the same as nestling Canaries, with the paste made of hard-boiled egg-both parts - and cracker-dlust: crushed hemp-seed, and rape-seed soaked, so the hull is soft, should be given when they are two to three weeks old.

Canaries, like unfeathered bipeds, have their particular fancies; and the male you propose to mate, perchance may have set his affections elsewhere. If matters are going on all right, place in the cage, where it may be easily seen and got at, some deer's hair, washed very clean, and put lined wire nests, of the size and shape of a bird's nest, in the platform of the cage; these the birds will most likely proceed to line with the materials supplied for the purpose: should they not, you had 
better do it for them, pressing the hair gently and evenly down all round the sides ; the rims of the nests should rest firmly on the platform of the eage. Notwithstanding all your care and attention, you will sometimes find a first egg laid away from either nest, in one of which you must gently place it; and most likely the second will be laid by its side. Some persons adopt the plan of removing the eggs as they are laid, and putting ivory balls in their place, and then restoring them all together to the nest, that the young may be hatehed at the same time; but the policy of this is very questionable : there is great (langer of breaking the eggs; and it gives unneeessary disturbance to the old birds, which, in the management of their domestie matters, should not be interfered with unnecessarily. We have said that the Canary has his fancies. When you are mating him with two hens, he wll sometimes be very ardent and loving towards one of them, and neglect the other altogether. When this is the ease, it is best to put the neglected hen in one division of the eage by herself until the other begins to lay, then place the male with her, and keep him there until she does the same, after which the sliding-door may be left open, as there is no louger any oceasion for keeping the birds separate. Seven or eight days after pairing, the first egg is generally laid, and each day after another, until the whole number, four or five, is laid. In about thirteen days from this time, the young ought to make their appearance; wait another day, and, should there then he no signs of hatching, take the eggs carefully from the nest, keep them for four or five minutes in lukewarm water, and then replace them. It is well before doing this to hold them up to the light ; as, if they are semi-transparent, they are bad, and may be destroyed. This experiment may be tried when the eggs have been set on eight days only; and the nother-bird, perhaps, may be saved some unnecessary trouble, and loss of time. Sometimes a hen will lay three or four eggs, and then desert the nest. If those eggs are examined, they will generally be foumd bad: by what secret instinct is the bird informer of this? Some hens will eut their eggs; and some turn them ont of the nest, and break them. In the former case, it is generally hunger which drives the bird to do it; to prevent this, food should be prepared over night, and placed where she ean easily get it: in the latter ease you may be pretty sure that your hen is a hasty, impatient bird, that will not endure the drudgery of attending to her offspring. If she hatches them, they will most likely be served as the eggs were, or left to perish of hunger: such a bad mother should not be used as a breeder. Before deciding on this, however, examine the feet of the birl ; as this overturning of the nest will sometimes occur from the elaws being dirty and clogged, or the nails too long.

As soon as the young are hatehed, Beehstein recommends that a small jar should be placed besicle the common feeding-trough eontaining a quarter of a hard-boiled egg, minced very fine, with a piece of white bread previonsly soaked in water, and squeezed dry; and with this another jar, containing rape-seed which lias been boiled and well washed, to remove the bitter taste from it: these should be prepared fresh every morning. It sometimes happens that a young mother is so over-careful and anxious about the eggs not hatched, that she will not leave the nest to feed the young birds which are out; and so they get starved. If you keep a register of the laying of the eggs, you will know exactly when the hatehing ought to commence. Let plenty of food be placed close to the nest over night, and observe if she gets off 
to take it in the morning, when you feel assured she ought to have her first chick out of the shell. Should she not do this, nor the cock carry food to her, take her gently off the nest, and let her see that there is plenty of food, and one or more little bills gaping for it. Her maternal instinct will inform her what she ought to do in the case; and, having once fed her young, she will continne to do so: the coek will most likely also follow her example.

While incubation is going on, take eare that the room is kept quiet: even the violent shaking of a door may, it has been asserted, injure the young in the shell. When these are hatched, the male bird generally takes upon himself the responsibility of providing them with food, as if to give the hen a little rest after her heary duties. Should you find, as is sometimes the ease, that the young are insufliciently fed. administer a little food, prepared of cracker grated fine, and crushed rape, mixed and moistened, when wanted for use, with a little water, and yolk of egg. Alout four quills full of this is sufficient for each nestling at the time: the frequeney of its administration must depend upon the quantity of food given by the old birds ; if you have to bring up the young altogether by hand, ten or twelve times a day will not be too often. 'The young Canaries are almost destitute of plumage until they are about twelve or fourteen days old, at which time the hen bird usually begins to prepare for a second brood, and has often bnilt her nest and laid her egg's before the first are fully fledged. According to some anthorities, Bechstein among them, the growth of the feathers is promoted by the immersion of the young birds in a bath of lukewarn water ; this renders them, however, extremely liable to get a chill : and it is best, if you observe any backwardness in the development of the plumage, to take an atomizer filled with warm water, and, standing at some distance, let a gentle spray fall over mother and young. It las been found, that when a male Canary has paired with two females, and one of them has died after laying, the other hen has recered the chicks into her nest, and sat and tended on them as if they had been her own, even repulsing the attentions of the cock, that she might be enabled to do so.

After the thirteenth day the young birds ean generally feed themsclves, and when a month old may be taken from their parents altogether : they may then be placed in a good-sized store-cage, or in small separate eages, as Beclistein recommends, and fed with their ordinary food, with which a little soaked rape-seed has been mixed.

Canaries may be mated up to the middle of May or the first of June, and, after they are once mated, will breed until September ; and some pairs breed every month in the year. If a pair are worked too hard, they will be of little value at the end of the season. A choice pair of birds ought not to rear over three broods in a season, and the limit might better be set at two broods.

Those who enjoy breeding fancy-colored Mules should arrange to put the pairs together in May. As stated above, Goldfinch, Linnet, Bullfinch, and Siskin males may be mated with the female Canaries. To that list of names, some American native birds may be added, including the Goldfinci, or Yellow-bird, the Bobolink, the Nonpareil, and the Indigo-bird. Males of each of these mate during the month of May, and slould be put in prime, fresh eondition for use by the 15th of that month. Do not expect that all you have to do is comprised in the formal 
introduction of Mr. Finch to Mrs. Canary, and, on the other hand, do not chaperon the birds too closely. A pair of birls in good physical condition, an abundance of high feel - like eggs, etc. - to warm the blook, a temperature varying from $66^{\circ}$ to $70^{\circ}$, and a quiet corner seeure from the obtrusion of strangers, - these are essentials. 'The pair may not evince a disposition to mate for a week or ten days; they will likely fight some; but let them remain together, and, doubtless, in two to three weeks from the time of rumning them together, you will have the first evidence of their mating in the egg in the nest. Any of these young Mules should have the same fool and care as young Canaries, - boiled egg and cracker-dust mixed, at first, and afterwards rape-seed, soaked so the hulls are soft, and milletseed treated the same way.

The Goldfinch-Canary Hybrid is bred usually for high color; while the LinnetCanary, Bullfinch-Canary, and Bobolink-Canary Hybrids are expected to be extra songsters.

The Bullfinch-Canary Hybrid is somewhat thicker in form than a pure Canary, has handsome colors, and a song that partakes largely of the mellow notes of the Bullfinch. He is elegant in form, sprightly and graeeful in movement, and possesses many of the characteristies of the Bullfinch.

The Bobolink-Canary Hybrid is the largest of all, and is less frequently seen than the others. Weeks of patient work are well expended if one can rear only one singer of this variety. 'This Hybrid is a large, handsome, finely formed bird; and his song is one of the inost delightful in the whole range of bird melody.

The Linnet-Canary Hybrid is a grayish-green bird of ordinary Canary size, and has a sprightly, very sweet song: it is the Canary's song with all the harsh, choppy notes eulled out, and each trill and turn seemingly cultivated to the highest degree.

The Siskin-Canary Hybrid is an indifferent singer, but is vivacious, and, like the Siskin, quite a gymnast in the eage.

The Nonpareil-Canary Hybrid, next to the white Goldfinch Mules, is the most showy of all the crosses. The beautiful violet head and the mealy-yellow body form rich contrasts with the glossy golden green and purple shades of the back and wings. Not all the Mules are elegantly marked, but the fine ones are so magnificent that they well repay all the eare and patience necessary to obtain them.

'The Indigo-Canary Hybrid, when he has the Indigo's eolors, is a beantiful bird: his song is a pleasing mixture of whistling and singing. A few insects, in addition to the seed, are very acceptable to him.

In addition to the regular seeds, these Mules should have daily a few spiders, ants' eggs, or meal-worms : they are bred especially for the showy colors, and not much singing is expected from them; but some of them are even better singers than the ordinary Canaries.

In breeding Mules, it is the custom to run one male through the eages of three or four females; but never allow the male to remain with the female up to the time of laying, for fear of the eggs being broken. As stated above, the Mules are handsome when bred from mealy or very light colored females. The lighter the female, the whiter the Mules are apt to be.

All of the birds used for Hybrid-breeding ean be found in the shops during the winter and spring months. The regular Canary-breeding eages are used. 


\section{THE INDOOR AVIARY.}

The indoor aviary should have a warm aspect, and be well protected from draughts; and if it is a conservatory, or similar glass erection, it must be well sladed from the strong sunlight, and protected, as far as possible, from all extremes. 'The bird-keeper should remember, that, under a more pampered system, the birds will lead a more artificial existence, and be more liable to feel the injurions effects of external influences. The most important consideration of all is, to effect a thorongh ventilation, with a complete exclusion of draughts ; for dranghts eause the deaths of more Canaries than many people imagine. Too much attention eamot be paid to this, and our instructions on this point are most emphatic.

Having selected a suitable room, proceed to furnish it by placing in it a number of "Christmas-trees," small firs of different sizes, which, if obtained at al nursery, can be moved in the autumn, and will, if carefully raised and well potted, live the year through, by which time they will be about done for. In selecting the trees, choose substantial plants with flat, spreading loranches, and arrange them tastefully on such stands as ean be extemporized for the purpose, singly or in clumps, filling up cormers, arranging them, in fact, in any way and every way, in doing which there is scope for the exercise of much taste. Aroid, however, placing them so that any part of the room cannot be got at if desired ; for old birds as well as young are apt to flutter away into inaccessible corners, and make no effort to release themselves from positions not dangerous in themselves, but from which they seem to think escape hopeless.

In addition to the trees or shrubs, a few fantastically shaped branches (from which all loose bark must be removed, so insects may have no breeding-place) may be arranged in rustic fashion; and any old gnarled stumps or roots may le utilized in a similar way. The branches are not intended for nesting-places, but only as perches. Nothing is more out of eharacter in a room such as we are deseribing than long, straight perches; but a substitute must be provided. Canaries are not always on the wing, but will not often visit the floor except to feed, or on other matters of business. The trees themselves are not suitable for perching on, mless they should lave fairly substantial branches; and, therefore, some comfortable resting-places must be provided. The birds will soon find these ont for themselves : and the object of using the branches we refer to is, that the whole may look as natural and attractive as possible. If, in place of such an arrangement, one or more long perehes he used, the result will be, that the birds will generally be seen sitting in a row, in not very picturesque fashion, on the topmost bar, to which they will always immediately retreat when any one enters the room. 'To obviate this, all natural ledges, such as the tops of architraves over doors and windows, must be rendered untenable, and more tempting places offered. The birds will most certainly please themselves in their selection of resting-places; and the thing is, to make their cloice comfortable for them, and pleasing to our own taste. It takes a great many birds to fill a small room, and a place may appear tenantless while a score or two of birds are perched up aloft somewhere out of sight. Virgin cork, in rarions shapes, may also he used : but a strict wateh must be kept for insects : and, npon their appearance, the pieces infested 


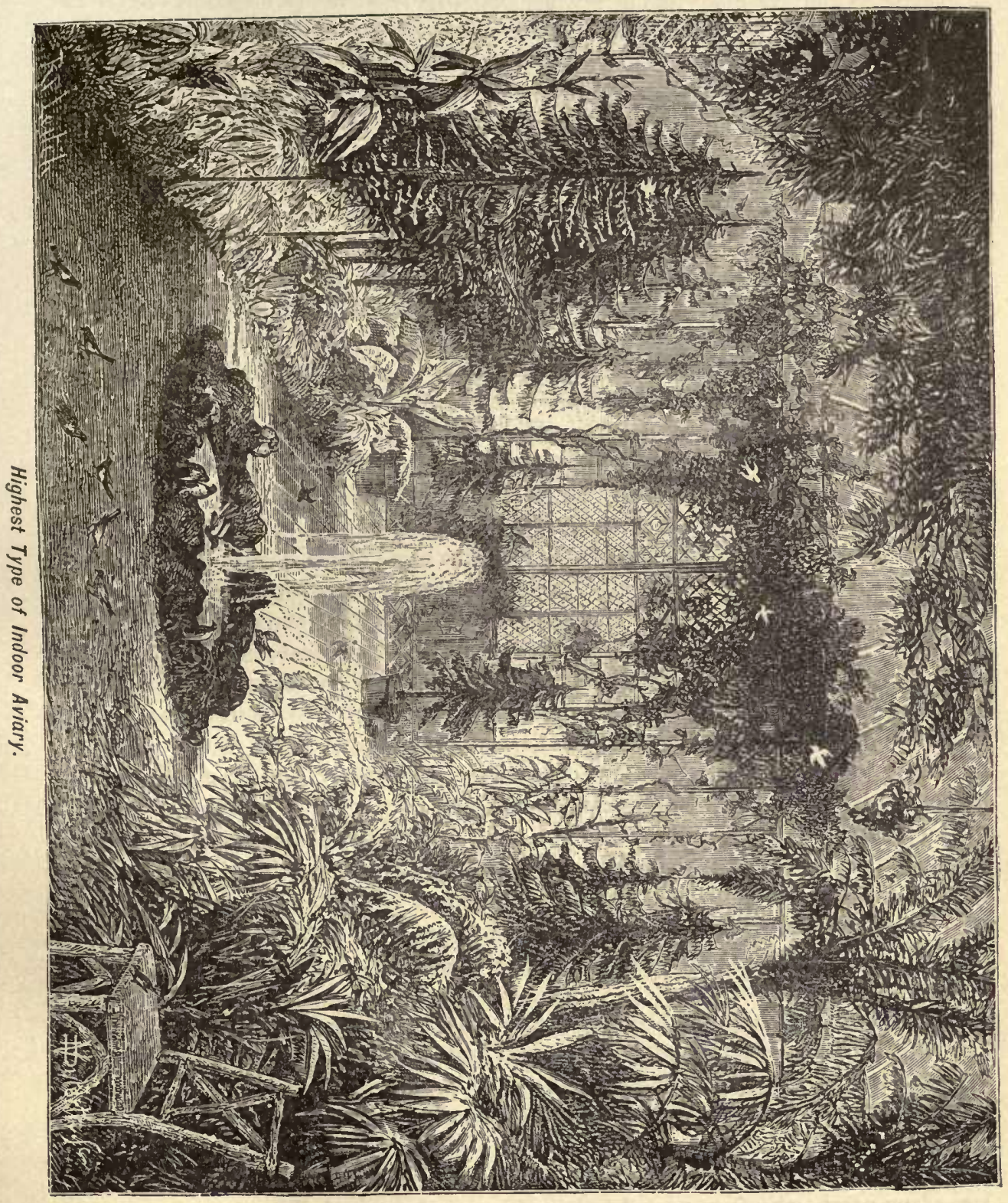


should be inmersed in boiling water for fully ten minutes. Should any of these smaller arrangements be taken up for vesting purposes, and be found to harbor insects, give them a touch of oil on the places affeeted. 'The danger of harboring parasites is the only objection to the use of cork and similar material, though the risk is exceedingly small in a room where there is good rentilation. Ordinary nesting-boxes are out of place in a well-furnished aviary, but those east in a rustie mould might be used. The birds select their own nesting-places in which to build, and not a little amusement will be derived from notieing the impossible corners some will fix on. The slightest projection will suffice for one, and he will spend a great amount of time and labor in constructing the nest under circumstances of selfimposed difficulty. Not unfrequently some place will be chosen on which it may seem almost impossible a nest eould rest; but you will find that the Canary is not a bad arehiteet, and generally turns out to be the best judge of a site. Domestication, however, has impaired this wonderful instinetive building faeulty; and it will be seen that some will make attempts which turn out perfectly futile, while other's will commence to build on a foundation manifestly sandy, in which case it may be well to supply a nest-box if the bird has shown a determination to settle in that spot.

Furnish a good supply of nesting material, such as fibrous roots, and long, fine, dry grass from the hedge-side, plenty of moss, and, if it can be had, the coarser kind of lichen; also soft cow-hair, which can be had from any tan-yard : or deer's hair, which is always kept in stock at the better class of bird-shops; a supply of soft feathers will also be appreciated, as will also some rabbit-down. The hair and these latter materials are best packed in small nets, and snspended in positions where the bird ean. get a pull at them : if allowed to lie about, the finer stuff will nearly all be wasted. These are the materials which ought to be supplied; but there are some which ought not to be admitted on any account, such as cotton, wool, or other long, tough stuff, which can become entangled in the feet. Wool beeomes twisted around the feet in a most dangerous way; and, as it eannot be so readily perceived in a room as in a small eage, a bird may suffer exceedingly, and even lose its toes, before the cause of the misfortune be discovered.

To complete the furnishing, we might add a small rustic chair, placed in the most retired corner, in which the observer can sit quietly, and watch the busy world at work around him, to do which the only requirement really necessary is, that you do sit quietly, when it matters not if you have a nest within a foot of your elbow, or even built on the back of your chair, things will go on just as unconeernedly in your presence as in your absence.

A few items, all important in their way, have to be inelucled in om inventory. The floor should be strewed with elean sand, and a supply of old lime rubbislı will be found eonducive to the general health of the birds.

In country-places, where they can easily be obtained, thin sods will be a great acquisition; and almost every part of them will be turned to some good purpose. All work and no play does not suit a Canary any more than the youth in the legendary poem, who is reported to have been made very dull by the process ; and birds, like other animals, are fond of amusing themselves. Nothing entertains them more than giving them something of this kind to piek and pull to pieces, which they will do with many a resolute tug; and it is this attention to little wants, 
which may not, perhaps, be absolutely necessary, that goes to make up the sum of their happiness.

In such an aviary a great variety of birds live in harmony, thrive and sing. With the Canaries may be included, either pairs or single birds, all the small A frican Finches, the Japanese Nuns, the Australian Paroquets, African Love-birds, Bullfinches, Goldfinches, Linnets, Siskins, Chaffinches, Cardinals, Nonpareils, Indigoes, Bobolinks, and almost any of the seed-eating birds not larger than the Cardinals, most of which will breed.

CANARY TABLE.

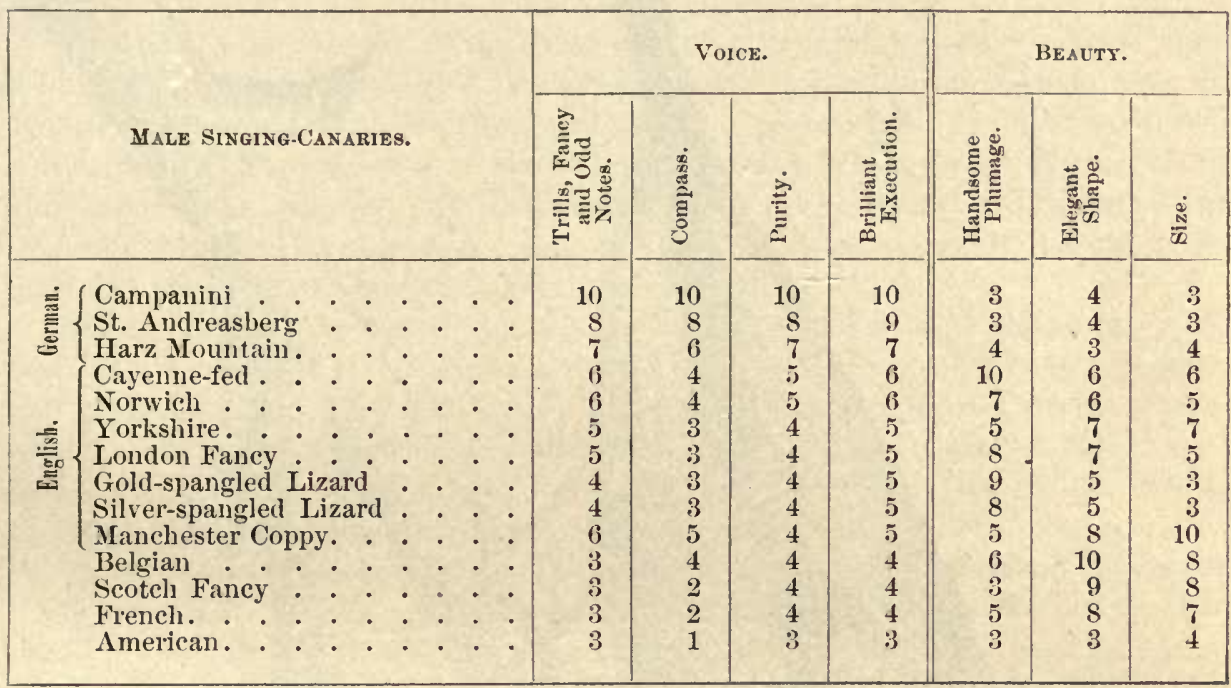

The above table is designed to contrast the merits of Canaries of the varions breeds. While one breed exhibits a high standard as song-birds, another takes first rank by the beauty of the general appearance, which includes size, plumage, and shape. The table is not offered as an authority, but shows my experience with the varieties named.

The highest point attained in any one division is quoted as ten, which, if given in the seven particulars, would make a total of seventy points; and a bird obtaining seventy points would be considered perfection.

It is impossible to attain perfection, in both divisions of the table, by any one variety of bird. In each class it may be observed, that the highest points recorded are made by birds specially bred for the particular point or points in question, excepting the American Canary. Each class is bred for a special object, and the number ten is placed against his best quality: while the breeders of separate classes may consider the table hardly a fair one, inasmuch as their own favorites suit their special tastes, and should, in their estimation, have the highest points; yet they must honestly confess, that the table is made out in an unprejudiced manner: because I, though a born Yankee, have justly marked the Canaries bred in America the lowest of all. 


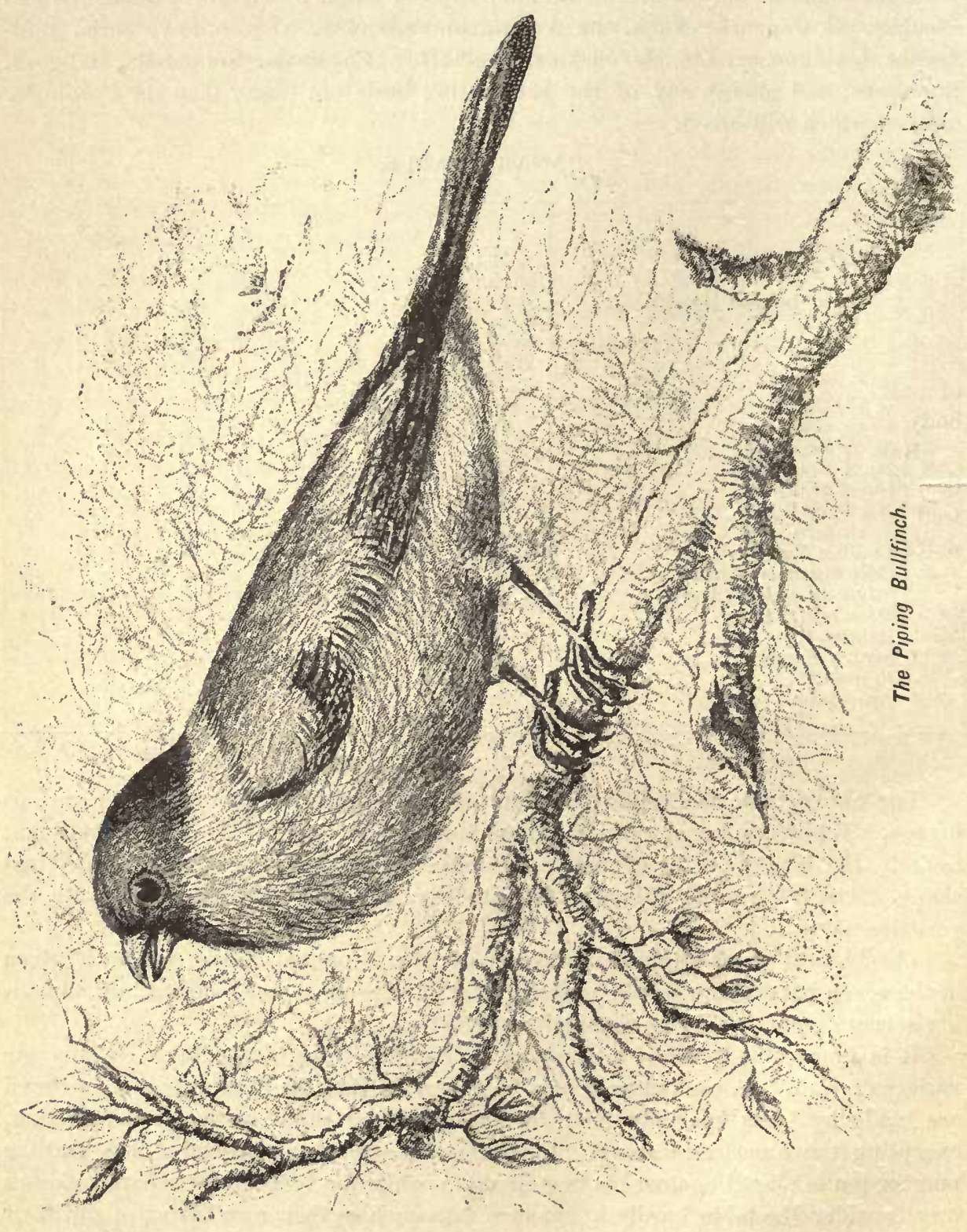




\section{THE BULLFINCH.}

Tuis bird is the favorite of the entire race of trained birds, and is beloved alike for his gentle manners and great accomplishments. Indeed, even when in his wild state, he appears more docile than his brothers of the forest. Volumes have been written about his proficiency in music, and his clever tricks when trained. He is known throughout the world of bird-lovers as the most delightful and most favored of petted birds. His appearance is striking, and the various pretty colors of his body and his well-rounded figure make him very attractive.

Bullfinches vary greatly in size. The German Bullfinch, which is probably the best known, is about seven inches in length; the beak is one-lialf inch in length, well rounded, black, thick, and short; the feet are very slender and black; the top of the head, the eircle around the beak, the chin, and upper part of the throat, form a beautiful hood of shining, velvety black; the upper part of the throat, shoulders, and back are a handsome shade of steel gray; and the rump is white; the breast and upper part of the belly vary from a beautiful crimson to a handsome shade of bright chestnut. All the colors darken as the bird grows older. The larger wing-feathers are a brilliant black, tipped with reddish gray; and the centre feathers are ashen gray. The tail is forked, and blue black in color. This entire combination of colors is charmingly blended, and the whole coat shines with the lustre of silk. The body-feathers just below the wings have a fluffy or fringed look, which is a handsome addition to the bird's appearance. 'The Bullfinch is somewhat thick in proportion to his length; and while the slender elegance is lacking in his shape which is so much admired in some birds, his chubby, cunning appearance is such as to make him a favorite at once. The female Bullfinch is easily distinguished from the male, as she is smaller; and there is, as well, a marked difference in the color. The breast and belly in the female are of a dun or dusky gray color, and the back is a darker shade of the same color.

There are other rare varieties of the Bullfinch; although I think the appearance is due to cross-breeding, when in a wild state, with some other variety of bird, or from unnatural confinement, and improper feeding when in captivity.

The Gray Bullfinch is grayish white throughout, with a few dark spots on the borly or back.

The Black Bullfinch varies in color from coal black to a dusky tinge throughout the body: the Black Bullfinches are usually females. This color, it is said, is due to hanging the bird in a dark place when young, or to feeding too much hempseed: although the first theory does not seem to be correct, from the fact that the trained Bulffinches are always brought up in darkened eages or boxes while going 
through a course of training; and they retain their natural colors. I incline to think the black is most probably a freak of nature, a phenomenon which may happen in any class of birds.

'The Mottled Bullfinch is a natural-colored bird with white spots throughout the body.

The Hybrid, or Mule, Bullfinch is the result of mating the Bullfinch with some other seed-eating variety, usually the Canary or Goldfinch.

The size of the Bullfinch varies greatly; the largest size coming from the more northern portions of Europe, usually Sweden or Russia.

The common or medium size, the well-known Bullfinch which is used for training purposes, comes from Germany, and the central parts of the Continent.

The smallest is the English Bullfinch, the best variety for breeding Hybrids.

When wild, the Bullfinches feed on the seeds of trees and shrubs and grasses. They find no firm friends in the farmers, as their fondness for the buds on young fruit-trees is great. When caught, the Bullfinch is at once contented in his eage, and will commence to eat as soon as food is offered. This makes him a great favorite for performing purposes, and for making a faithful pet. By a little deprivation in withholding his seed and water, and forcing him to take them from the hand, he will readily become as tame and playful as any pet dog could be.

The following methor is described as the lightning way of training a freshly caught or wild Bullfinch: Accustom him to the cage for a day or two, by feeding him as you would any caged bird : then catch him carefully, and fasten a narrow strip of cloth around his body and wings, so that he cannot beat himself against the eage. His food is then put into a small bag, to which a small bell should be attached, and his water poured into a vessel which has also a bell attached. It is better to let him eat for a day or two with the seed and water dishes in the eage, approaching, however, when he is observed eating. Then remove the dishes, and accustom him to spring to them in the hand whenever the bell is rung. Hunger will control him greatly, and he quickly learns to fly whenever he sees his master approaching with food. After feeding from the hand a few times, he slonld be carried around the rocm on the finger; care being taken to retain a firm hold on the feet, so that he cannot escape. This course of training accustoms him to his trainer, and in a surprisingly short time he will fly at the word of command. He may be taught the trick of kissing by withlolding his drinking-water from him for about half a day, and giving him saliva from the lips.

Bullfinches, if caught when old, are greatly prized for their brilliant colors ; because, to a certain extent, the colors are dimmed by confinement in cages, where the sunlight and air are, of necessity, some of the time excluded.

They are very tender, loving birds, which is shown by their extraordinary attachment for their mates, both when at liberty and in confinement. Their attention and devotion to their masters or mistresses is such also as is shown by. no other variety of bird known. This does not wholly spring from the artificial training which they receive, but is a part of their natures. When in a wild state, they constantly fly in pairs; and, if a pair is kept in captivity, they are seen constantly billing and cooing in the same manner as a pair of turtle doves, and kissing one another with the frequency of a pair of long-parted lovers. 
In a wild state they hatch twice a year'; and they may be bred in eonfinement as easily as a pair of Canaries, and requre the same care and treatment when mated. The female Bullfinch, and at good breeding male Canary, will mate easily; and, although the offspring are not very attractive in appearance, they are fine singers.

'The male Bullfinch, if mated with a female Goldfinch, produces beautifully colored bircls ; but they are so rarely found, that it would pay a bird-breeder to devote attention to this branch of breeding. If one wishes to obtain the proper Bullfinches for instruction, it is better to procure the home-made article; i.e., buy a male and female Bullfinch, and mate and breed them at home. When the young birds are hatehed, remove them from the nest, and bring them up by hand, and follow the German instructor's method given farther along in this article.

Both male and female have the same natural notes, which are a suecession of soft, low call-notes, intermixed with harsher notes, which resemble the squeaks of an unoiled door-hinge. For this reason the Bullfinch, if taken for training purposes, should be removed from the old birds at an early age; so that he will acquire none of the harshness which is so apt to spoil his artifical training. 'The female Bullfinch is as capable of being taught a course of musie as the male; and, although she is rarely given a thorough edueation, it is by no means infrequent to see her industriously edueating herself from her better-taught brother; and, when this occurs, the self-made musieim is a thorough scholar.

The following is a description of the methods by which the trained Bullfinches are bought and taught. They are usually trained in Hesse, Germany :-

The journey from Hanover, Germany, to Cassel, in summer, is delightful; as the many European tourists who have enjoyed it can testify. From Cassel we go to Bebra, thence to Fulda : there we leave the cars for a jaunt of eight hours in a post-coach, so called, but which really is a hay-cart. With aching bones, and apparently paralyzed limbs, we try to alight, and succeed in tumbling to the ground; this is Angersbach : near by are an unlimited number of dorfs, or very small villages; ehief among them are Lauterbach and Storndorf, distant from one another a walk of two and a half hours. 'The trip made in winter', as it must necessarily be when buying piping Bullfinches, is a severe one; for the region is very desolate, the snow deep, and aceommodations at the inns not exactly the same as at our New-York Windsor. The bill of fare at the inns has the first page covered with print, but the most exact translation reveals only the name of the louse and its proprietor; the second page informed us there were bread and beer and eheese; the third page was somewhat like the seeond, cheese and beer and bread; the fourth page, ah : here we shall find the names of refreshing viands; but close inspection and a "Baedeker" stated beer and cheese and bread, _- "bitter bread mit der Carryaway seeds in it." Would that the "Carryaway" were true. The meal proved to be a strong one, and the appetite was more than satisfied. A little Limburger cheese goes a great ways, if not farther. But let us turn to a more pleasing subject.

'The Bullfinch is taken from the nest in the early spring, when fourteen days old. and thoronghly tamed before being given his elementary lessons in whistling. By regularly feeding from the hand, he becomes rery tame, and strongly attached to his master, whom he soon begins to regard as a substitute for his mother. When taken from the nest, he is allowed his liberty for two or three days in order to ac- 
custom him to his new mode of life, and afterwards put in a small wicker cage, so commonly seen in the bird-shops. This cage is set into a box of dimensions just allowing its admission, and having a small swinging-door in front, which is kept closed, except during lesson-hours. A professional trainer's house has, as its chief furniture, probably fifty or seventy-five of these study-boxes, placed in rows around the wall, as far apart as the space will admit. As the houses are usually one room en-sute structures, the space separating the boxes is limited. When a trainer has two or more rooms, the number of airs tanght accords with the number of rooms; for only one air can be taught in a room, as the birds would get two songs mixed. But a bird having learned thoroughly one air is taken to another room, and taught a second piece.

The Bullfinches vary in intelligence the same as persons; some birds having surprising faculty for learning, while others are so mulish, or dull, that no amount of training will call forth even a single musical note: hence a trainer's success depends on securing intelligent birls. From twelve birds taken out of the nest, and put in training, should six prove intelligent enough to learn a tune, the trainer thinks himself fortunate. While some have the ability to learn three airs, others in the same room, under the same instruction, acquire but a portion of a single air. A trainer is quick to perceive the difference in his pupils; and the most promising are selected, and thoroughly taught.

The lessons are given five times each day, and at each lesson the air is whistled through from beginning to end : it is never whistled in parts. Some of the scholars commence by catching a portion at a time, and from constant repetition gradually acquire the entire air: the lessons cannot end here, but must be repeated day after day, even after the birl whistles the song perfectly, in order to thoroughly fix it in his memory. Some of the pupils appear to waste valuable time, and, like many wise men, are content to listen. These get their lessons as regularly as the most promising ones, but the only sign they give the trainer are the chirps of recognition. After four or five months of untiring care, they delight the teacher by piping the air complete: these are held at the highest value, as they remain fast, i.e., never forget; and are the ones always sought after by the Bullfinch lover.

The trainer commences the lesson before breakfast by opening the bird's stall, and bestowing a few pet names (the smartest birds being usually inflicted with a large number), and in a slow, crooning tone repeating the name over and over: at the same time the trainer sways his head slowly from side to side until he hears the call of recognition. The swaying continues as long as the bird continues to pipe: then the box is closed, and the trainer passes to the next bird, and so on until each one has received his lesson.

The trainers, or professional whistlers, are shoemakers, tailors, or schoolmasters: the latter always produce the best-trained birds; their education, however slight, fitting them exactly for the task. I can safely say that the Bullfinch pupil always gets more thorough care and severer lessons than the boy pupil; for the schoolmaster's labor with the birds is more remunerative and satisfactory, as lie has no slow-paying, bad-tempered parents to satisfy, because these scholars have not been trained up properly.

The music formerly taught was of the old style of German hymns, and slow- 
time popular songs; operas and waltzes being unknown in the region. The birds were taken to London by enterprising dealers, and, as soon as their beautiful qualities beeame known, were in great demand: the music, no matter how slow or uninteresting, whenever rendered by a Bullfineh, was very enjoyable. But coustant repetition in music tires; and, as the birds became better known, sprightly English melodies were whistled to the buyers, who, on returning to Germany, whistled them to the trainers for the birds to learn. If the buyer did not mix his music witl too mueh beer, he could render it tolerably well ; and the bird taught these sprightly songs, when sent to the London market, would have a double value.

The buyer of the trained Bullfinehes is usually a German, who buys for large American importers. His lot is by no means a happy one, as the Bullfinch teacher has about as much patience in holding out for a great price as he has in teaching; and, since the birds must be bought for the Christmas market, the buyer's trip into this bleak and desolate country is made in dead of winter. Here is deep snow and piercing winds, and temperature that quickly freezes ears and fingers, and, worst of all, the three meals of "Limburger." Aneas' agonies in founding "Troy" seem, in comparison, sweet pleasures.

The buyer is usually a jolly fellow despite all he undergoes, and drinks beer, and flirts with the untutored maidens, in a most business-like manner. Generally well known in the district, he is a most welcome guest; he indulges in no preliminaries on arrival, but is at once conducted to the nearest trainer's house : and "Hannschen" - little "Hans" — is coaxed to pipe, but, like our "smart" baby, is stupidity itself, and will not perform even half rate. As the buyer has no time to lose, and plenty of deep-snow pedestrianism in view, his patience quiekly ebbs ; and the trainer resorts to all sorts of devices to detain him, and make the bird pipe. 'The daily swaying to which the bird is so well accustomed produces no effeet, pet names are lavished all to no purpose, tempers are lost on both sides, and little Hannschen is cursed and recursed. As a last resort the box is closed, and we retreat outside the door: then the little raseal is evidently delighted with the fight and his victory. Standing ontside, the trainer takes two large, rusty keys, or similar artieles, and rubs them together, in order to produce a low, harsl sound ; Hannschen, thinking himself alone, always responds in a low, sweet voice, piping his full song with spirit and fine expression.

The price for the first bird is carefully considered, as this regulates the marketprice for the dorf. After completing the bargain at the first house, Hannsehen is quickly transferred to a wicker eage, and elosely eovered, to protect him from the biting wind. The buyer is then escorted by the owner of this house to a neighbor's : it may be four rods, or perhaps two miles, distant. 'The two German trainers converse in a dialect peculiar to that country, so as not to be understood by the buyer, himself a German, who vainly tries to get the thread of the conversation; but the only words intelligible to him are, "whistling" and "Bullfinch." When trainer number two is posted on the prices, a sale is made; the invariable rule being, to obtain the price which the first bird eommanded. When a bird is found extra fine, a higher price is demanded and given. A trainer's word should be carefully weighed and found correct before being taken for literal truth. The character of the "Father of his Country" may exert in America a great and good influence; but in Germany they ask, "Who vas Shorge Vashington?", 
After leaving each house, your train of followers is inereased by one: for, when a bird is bought, the former owner eonstitutes himself one of the guard of honor: and you are thus eseorted from house to house. The distriet is sparsely settled ; and in early winter few birds are far enongh advanced in training to pipe the air without a break, therefore special care has to be exercised in selecting only those most thoroughly taught. A great many miles have to be walked, and the buyer has performed a hard day's work if he finishes in the evening with ten birds.

The day which the buyer selects for his coming is celebrated as a holiday; and the men interested in the training forego all work, and don their Sunday clothes, and give themselves up to the pleasure of a trip from dorf to dorf, comparing notes. and exchanging their views on the different birds and trainers, making it a sort of annual market-day. The taverns are not forgotten on the route; and, by the time work is completed, the majority of the party feel quite happy, and are altogether funny. At the completion of his day's work, the buyer always puts up at the nearest Wirtchschaft. 'This, in the evening, is the rendezvous for all the natives. All shapes and sizes are represented, with costumes antique but not unique; the "abbreviated" jacket and "high-water" pantaloons predominate; eaps with abbreviated peaks, and some without any, form a diminutive head-gear, which, in some eases, seem lost amid the long and bushy unkempt locks. 'The guests'room at these wayside imns is by no means elaborately furnisherl: a few very plain board benches and tables, and a high sileboard in a corner for bottles and glasses, and the regulation porcelain store, complete the list. The walls are devoid of decorations. After finishing the lunch, the trainers compete for the bottle of whiskey which the inn-keeper has offered. Our sketch of the Whistling Match is made just as the last competitor has "struck an attitude:" he is not quite so fully under the influence of the ardent as is the party in the background, who feels as if the wall must be propped up. This tailor and famous trainer last year taught forty Bullfinches to pipe "Polly Perkins." He is minus two front teeth; so, when he arose to compete, the gentleman on the right ridiculed the idea of his trying for the prize : but, placing two fingers where the teeth were missing, he whistled with such accuracy and sweetness and smoothness, that all agreed he was easily first. So he had the pleasure of calling the bottle his, and of treating the rest.

Great attention is now paid to the popular English airs ; and, as the attention of the American bird-lovers has been strongly attracted toward the trained Bullfinches, American airs are becoming popular with the Bullfinch trainers. The "StarSpangled Banner" and "Yankee Doodle" hare been tanght with great sneeess. Before many years the inhabitants of the Bullfinch district expect to have a railroad put through ; and by that time we may expect to have "Pinafore." As it is now, the bird-importers, if given the sheet-music before the regular training season commences, will furnish a bird trained to order.

It is much better to have a trained bird to pipe one or two long songs thoroughly than to liave his number credited with three airs, when perhaps he ean pipe at most only parts of each. A Bullfinch which pipes three perfect songs is, indeed, a rarity, and seldom obtained. Birds which pipe two good songs thoroughly are lighly prized; and, when they remain through the season perfeet in the songs which they have been taught, they are not apt to forget them through a life of years. Of 


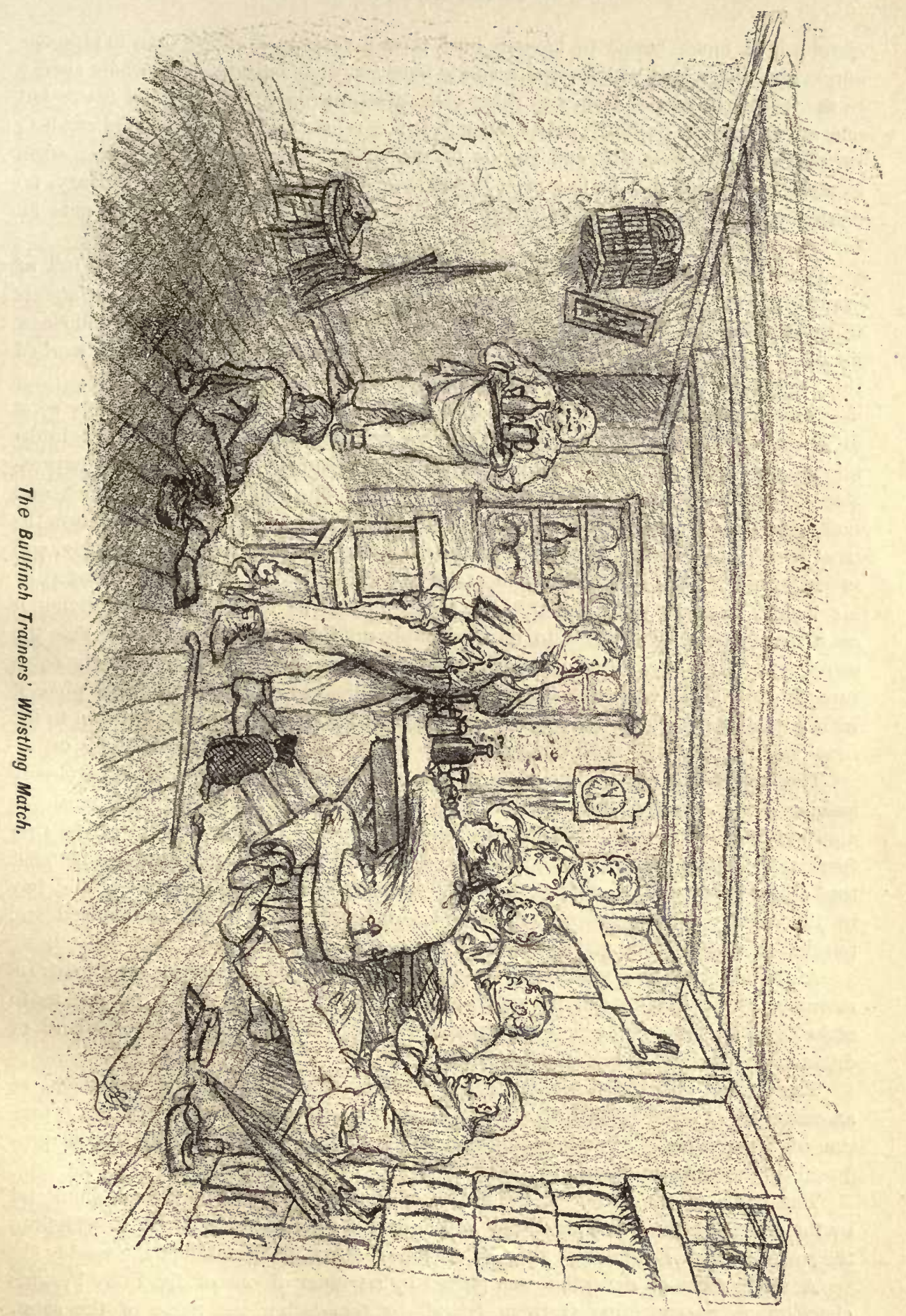


course, it is much better to have a bird pipe a variety of songs than to pipe one single air; but a bird which pipes a single long air, seemingly puts his whole energy to the task. In music, as in any thing else, constant repetition generally tires : but one never tires of Bullfinch music, though it is a repetition of the same old strains; for the soothing sweetness and pathos of the voice, and exquisite rendering, seem to make one forget that he has ever before heard the piece. On the contrary, no matter how often the bird pipes, if he is a good performer he always gets an encore.

The whistling of the trainers of these birds is wonderfully sweet, and full of expression, and no more to be compared with the attempts of the amateur streetwhistler than the voice of an operatic star can be compared with the buzz-saw music of the street-solicitor of alms. Long and continued repetition has worked this effect, and its full charm is rendered complete by the pupil's sweet roice.

Some Bullfiuches pipe sweeter than others: one bird will pipe through his song in a manner which makes the music appear dreamy and far off, meanwhile intermingling the most beautiful trills, giving his song most delightful and correct expressions. Another will pipe his air throngh in a manly, business-like manner, shake and nod his head as if asking, How do you like it? Want any more? He will perform the most frivolous love-ditty, or a piece of the most classic music, carefully, sweetly, and in exact tune; always performing his task satisfactorily. An encare demanded by his master is never disregarded. He seems to feel as much delight in giving it as it causes those who listen to bim, probably not forgetting at the same time the usual reward of hemp-seed. To hear a number in a bird-shop pipe at the same time is laughable: each one thinks his own particular song the best, and pipes it with an air of determination; seeming to think, that, if he took time to listen to his next-door neighbor, he would be tempted to learn that song in addition to his own.

The abstracted expression of a visitor on entering a bird-store, and carelessly looking about, hearing for the first time a Bullfinch perform his pathetic music, is amusing in the extreme. Although he may be standing directly in front of the performer, the music appears to come from a distance. Not imagining for a moment that a bird is capable of such an accomplishment, he will suspiciously eye the boy in the vicinity, and peer into all possible hiding-places, looking as amused and puzzled as though some good joke were being played on him.

A trained Bullfinel which had been hung in a child's chamber on Christmas morning, as a Santa Claus gift, piped his beautiful melody in such a manner as to make the little innocent believe she once more slept, and was soaring in the land of dreams, or listening to real angels' songs.

The trained bird which was concealed in a beautiful bouquet, and suspended as an ornament at a celebrated dinner-party, made a decided hit, and was the sensation of the evening. Many cumning anecdotes might be related of the effects produced by the music rendered by these birds.

The name of the author of the ditty "Polly Perkins" has been made immortal by the efforts of the whistling tailor and a few of his colleagues, who, in whistling the songs to their Bullfinches, thereby circulated the song throughout the world.

A sharp piece of deception was played by a trainer of one of the Polly Perkins class on an unsuspecting German friend, by translating the name of the song, 
"Polonius Perkins." A new air commands a higher price; and while, to be sure, the music of Polly Perkins. by any other name would sound as sweet, it would not sound for as much money. It is better to train a Bullfinch by a soft, flute-like, natural whistle; as the tone as then rendered by the bird is much sweeter. The flute is a favorite instrument used in teaching, but a bircl-organ is sometimes called into use : the natural whistling is best ; and, although the organ is a very good instrument to repeat the melody to the bird so that he may not forget it, I would not (specially recommend it for use in teaching.

In order to thoronghly train the Bullfinch, whistle in exact time, and always in tive same key, the air which you intend he should learn. Repeat the whole of it at regular intervals during the day: and the bird will, as a rule, soon commence to practise it, the first attempts being very crucle: a great amount of patience must be exercised in this branch of training; and, in order to become a perfect trainer, one must never lose patience at the obstinacy of his pupil. A Bullfinch, when thoroughly trained at home, will never forget his lessons, as those sometimes do who go through the bustle and disadvantages of travelling a long distance: instances are known where Bullfinches, which have lived in the same house where they have been trained, have remained in perfect song through life, which lasts from ten to twelve years under proper care.

The German trained Bullfinch, during the training period, is fed only on plain German summer rape-seed. His life, when caged in the small cages used for training, is of a sedentary nature; and, as a consequence, he is apt to grow fat and lazy : therefore rich food of any lind is withheld. When transferred into a larger eage, such as should be used for him when thoronghly trained, after he no longer requires daily instruction, the foor should be varied; althongh then care should be taken that the food be not too rich.

The great trouble with all trained Bullfinches, when petted and well trained, is, the consuming of too many dainties, which are given him for showing his accomplishments. 'The owner may thoronghly understand the eare and treatment of the bird, but good-natured friends and orer-kind servants usually abound in the honses where trained Bullfinches are kept; and, as a result, the bird is slyly rewarded with those dainties which he loves so well, but which, for his own welfare, should not be given him. It is from this cause that the principal diseases which attack him arise.

The Bullfinch's main daily food should be the best quality of fresh German summer rape-seed, varied about three times each week by the addition of about one-half dozen grains of hemp-seed at a time. A piece of sweet apple hung between the bars of the cage about twice a week is a relish for him. The apple should not be allowed to stand longer than a day, as it is apt to grow stale. A piece of lettuce, water-cress, or sweet berries of any kind, may be given at intervals; but they must be fresh when given, and taken away before they grow sour or stale: frequently diseases of the digestive organs arise from the use of stale green stuff.

When the rape-seed cannot be procured fresh, it should be thoroughly soaked, and squeezed dry : $m$ this case the seed-cups must be daily washed and thoronghly dried. The water must be given fresh daily; and about twice each week the cups should be thoroughly cleaned, so that any collection of stale green food or mucus 
will be rinsed out, and the possible poisonous effects guarded against. A bath may be given daily, or less frequently when desirable.

All birds, when reared from the nest by hand, are necessarily fed on food which is unnatural to them in the wild state; and many writers on the subject elaim that this is a means by which their lives are shortened. I do not think this is so in the case of this particular bird. As mentioned above, delicaeies must not be given too freely.

A cage ten or twelve inches long, with the perehes so arranged that the bird can easily hop from one to the other, - hopping is his usual mode of locomotion, is the proper size. A plentiful supply of dry, coarse gravel, sprinkled daily on the bottom of the eage; good, plain, wholesome food; and the bird hung in a warm, dry plaee, free from any draughts of air, - and you have the preventives of the usual diseases which attack him.

During the moulting season a little extra care shonld be given the trained Bullfinch. At this period all song-birds, as a rule, partly or wholly lose their songs; and the rule applies to the cultivated voice as well as the natural one. The better way to moult the Bullfineh, so that he will lose none of his accomplishments by forgetting what has been taught him; is, to moult him in a darkened place, and feed on nourishing food. Cover the cage with a black cloth, and hang it in a place where fresh air will reach the bird: he should daily receive his lessons in the same manner as originally given him. He may only respond by his vote of recognition: but, nevertheless, the lesson constantly repeated will be borne in mind; and, as soon as his new feathers spring out, he will commence to gladden his tẻacher's heart by piping bars of the air in which he was formerly so proficient. As soon as he has finished his moult, and regained his full strength, his vocal powers return; and lis rendering is as perfect as in his early days. The moult, or season in which Bullfinches remain out of song, lasts from the beginning of July until the latter part of August. During this period some Bullfinches pipe through their entire song or songs, other's only parts of the song. 'The bird should be incited to pipe, for then the chances of perfect restoration of the voeal powers and the retaining of the song are greatly inereased; but, when the lessons are faithfully given hm, there is no danger of a loss of song.

During the moulting period the bird's strength should be kept up by means of stimulating food. Feed on the soaked rape-seed squeezed dry, a few grains of hemp-seed every other day, and daily a portion of green food, which should be changed and kept fresh while he is feeding from it. A little iron tonic, or a drop or two of sherry wine, put into his drinking-water about once a week, will prove very strengthening, and keep the bird from drooping. After he has safely passed through his moult, he may be put on his regular diet, and kept in health the entire year.

The diseases which attack the Bullfinch are diarrhœa, constipation, epilepsy, asthma, or lung troubles, surfeit, melancholy, and corpulency.

Diarrhœa is caused by overfeeding of green food, by filthy drinking-water, or unwholesome rape-seed. This, like the appearance of all other diseases to which the Bullfinch is subjeet, is noticed by the cessation of the song, and the drooping, wearied look of the bird. The excrement will be of a watery, whitish appearance. 
His food should be of the best rape-seed soaked, and squeezed dry; and a strip of raw, fat pork, plentifully sprinkled with cayeme pepper, should be hung in the cage. His drinking-vessel must be thoroughly cleaned, and replenished twice each day with fresh drinking-water. During the run of the disease, green foods and fruits must be withheld from him. A little crushed hemp may be given daily, to assist in restoring his weakened constitution. He should be hung in a warm, sunny place: and the gravel shoukd be frequently renewed. For medicine, at first give him a few drops of castor-oil, which will thoroughly remove from his system any traces of poisonous regetable matter. Add daily to his drinking-water a few drops of paregoric, or in severe cases laudanum: continue the treatment until a change is noticed in the appearance of the bird. A small cup of boiled milk, in which a portion of light biscuit or stale bread has been soaked, may be placed in his cage, and will act as a mild stimulant. After the run of the disease, the hemp-seed may be increased to a daily ration until he is perfectly restored. When it is not desirable to use hemp-seed, the egg-and-cracker mixture, as given the Canaries, is very beneficial.

Constipation is cansed by unwholesome diet. The bird may be easily relieved by administering a few drops of castor-oil for a few days, and feeding daily on fresh green food or sweet apple. Do not feed any seeds but the fresh rape cluring the continuance of the clisease.

Epilepsy, or Fits, is eaused by frightening the bird in endeavoring to roughly catch him out of the cage; or he may be easily frightened by the appearance of some intruder in the shape of a cat or other formidable animal. Or the disease may come from overfeeding of dainties in the sugar or candy line. The Bullfinch is a very sensitive bird ; and, although used to caresses and handling, he must never be handled in a rougl manner, especially by persons to whom he is not acenstomerl.

When epilepsy occurs, - which may be told by lis painful struggles and convulsions in the bottom of the cage, - he should be at once removed to the fresh air, and earefully sprinkled with cold water. As soon as lie revives, liang the cage in a quiet place: it would, perhaps, be advisable to cover it over for a few days. Feed on wholesome, fresl food. When the disease resolves itself into a chronic clisorder, it is exceedingly difficult to cure; and severe cases lave been helped by clipping one claw close enough to draw blood. Overfeeding of dainties will result in this painful disease; and, when such has caused it, the bird's diet must be at once changed, and only the plainest of food used.

Asthma or Lung Troubles result from the usual canses, - hanging the bird in dranghts of air, or an abrupt change of temperature. It is first noticed by the hard breathing and convulsive gasps. The little patient should be ance remover to a warm place, and a few drops of glycerine and a tiny piece of rock-candy should be added to his drinking-water. The food should be of the most generons nature during the run of this complaint. If not attended to, it will gradually develop into consumption, - a disease which eannot be cured in Bullfinches.

Surfeit is caused by rich food, and shows itself by the appearance of a yellow ulcer or vilcers on the head. A change to plain, wholesome food is at once recommended. Add daily a little iron tonic to the drinking-water. The ulcer should be opened witl a sharp knife or needle, and the puncture should be daily bathed with 
a solution of sugar of lead and water: glycerine or cold cream is also recommended.

Melancholy, or Decline, is a gradual wasting away of the bird. If taken in the haud, and the feathers blown from the body, he will have the appearance of a mere skeleton. He will sit for hours on the perch, and be drowsy; appearing as though he had lost all his friends, and didn't want any more. This complaint usually makes its appearance in the mating season, May. 'The bird needs hearty, stimulating food, and a great deal of petting. These will work greater cures than any medicine. Feed liberally on hemp-seeds or the egg mixture, and add tonic to his water. Give him more than his daily allowance of caresses, and he will come around in due season. When these fail to satisfy him, it wonld probably be well to procure a mate, and hang her within calling distance for a short period.

Corpulency is the result of the fattening powers of hemp-seeds, too frequently given by over-kind friends to a willing victim. 'The bird thus overfed will in the course of time be a literal ball of butter. He is then so handsome and lazy that he is utterly unfit for use when regarded from a vocal stand-point. If the bird does not sing, and appears lively and well, you should examine him. Blow the featliers from the body, and a clear white mass of flesh will be seen to cover the entire front of it. He should be put through a thorough course of training and dieting in order to reduce him to his proper weight. It would be better to allow him the freedom of the room for a few hours daily, so that he may fly, and exercise himself. The hemp-seeds and other fattening foods should be gradually withdrawn, and replaced by plain, soaked rape, with boiled milk and cracker at rare intervals. 'The iron tonic may be also added to his water. It takes considerable time, and requires much fortitude on the part of the fond owner, to reduce the diet of the favorite, to say nothing of the appeals of the favorite himself for his restoration of privileges. But these things must be done if health is to be restored: otherwise the bird will be utterly unfit for any thing except, perhaps, to hand him down to the cook, to be served up as a piper on toast.

Hoarseness often results from change of climate, or from eatehing a slight cold. It may be easily cured by adding a small lump of rock-candy and a few drops of glycerine to the drinking-water.

The Claws and Beak often need clipping, and may be attended to in the same manner as those of the Canary.

The above are all the diseases to which the Bullfinch is subject; and it perliaps is unnecessary to repeat that plain food and water, and a little necessary attention. are all that is requisite to prevent the appearance of most of them.

Below may be found the titles and some of the music which Hannschen is usually proficient in : there are, of course, many more which are regularly taught: ancl the sheet-music may be found at the regular bird-shops. Whether it be the lively love-ditties or the inspiring American airs, he will be found at home in the rendering of either. A complete change of nationality takes place when he has been tanght the foreign airs; and the naturalized American Bullfinch will betray his knowledge of his new-found sphere by the Yankee sparkle of his eye, and the desire to lead you to believe that he is eapable of reading the music at sight. 


\section{ENGLISH SONGS.}

1. Blue Bells of Scotland.

2. Champagne Charlie.

3. Daughter of the Regiment.

4. God save the Queen.

5. Polly Perkins.

6. Robin Adair.

7. Star-spangled Banner.

8. The Chimney-sweep.

9. The Last Rose of Summer.

10. The Mouse-trap Man.

11. 'The Rat-catcher's Daughter.

12. Within a Mile of Edinboro'.

13. Yankee Doodle.

\section{TITLES OF THE GERMAN MELODIES, AND THEIR TRANSLATIONS INTO} ENGLISH.

1. Ach Mädchen erhöre mich bald. Listen to me, sweetheart.

2. Ach wie schon bist du. How fair thou art.

3. Blau blüht ein Blümlein. Blue blossoms a flower.

4. Bei Wagram auf den Theresienfeld. At Wagram on the Theresienfeld. (Battle Song.)

5. Das clu mein Schätzchen list? Will you my sweetheart be?

6. Der alter Reiter und sein Mantel. The old warrior and his cloak.

7. Der Pabst lebt herrlich in die Welt. The Pope leads a merry life.

8. Die Miulle im Thal. The mill in the valley.

9. Die Wacht am Rhein. The watch on the Rhine.

10. Du bist verricht mein Kind. March onward fearlessly. (March: Opera "Fatinitza.")

11. Du bist wie eine Blume. Thou art so like a flower.

12. Du, du liegst mir im Herzen. Thou art ever in my heart.

13. Ein Herz das sich mit Sorgen qualt. My heart is troubled with sorrow.

14. Ein Strüuschen am Hut. A flower for my hat.

15. Frisch auf zum fröhlichen Jagen. From the merry chase. (Hunting Song.) 
16. Hinans in the Ferne.

Away to the woorls. (Hunting Song.)

17. Ich weiss ucht wos soll es bedeuten.

I do not know the reason why. (Song of Fairyland.)

18. Ju lustig ben ich clas ust wahr.

Yes, indeed, I am happy.

19. Jetzt ist Zeat und Stunde.

Now is the time and hour.

20. Hom' herem m dre beste Stube.

Come in and be merry.

21. Mïdel schan mir un's Gesicht.

Look me in the eye, maiden.

22. Maler, mal' mu mem Liebschen.

Painter, pieture my sweetheart.

23. Mit dem Pfeil und Bogen.

With bow and arrow. (Hunter's Song.)

24. Morgen muss ich fort von hier.

'To-morrow I must away from here.

25. O bleıb bei mu?

Ol, stay with me:

26. O du lieber Augustin!

Augustine.

27. Verlegenheit.

Embarrassment.

28. Was kamn schöner sein, was kann eller sein.

What ean prettier be, what ean nobler be?

29. Wein, Weibe, und Gesang.

Wine, women, and song.

30. Wenn die Schwalben heimuärts Hiegen.

When the swallows homeward fly.

31. Wenn ich ein Vögelein viàr.

I wish I were a tiny bircl.

32. Wir winden dir den Jungfermkranz.

We bind for thee a brilal wreath.

33. Z' Lauterbach hab' rch mein Strumpf verioren. I lost my stocking while going to Lauterbach.

34. Der Wagen des Herren Patrick Duffie. Paddy Duffy's cart.

TITIES OF TWO SONGS COMBINED, PIPED BY ONE BIRD.

1. $\{$ Blau blüht ein Blumlein.

\{ Polly Perkins.

2. Der Pabst lebt herrlieh in die Welt.

YO du lieber Augustin :

3. $\{$ Star-spangled Banner.

\{ Ach wie schön bist dur.

4. $\{$ Die Wacht am Rhein.

$\{$ Hinaus in die Ferne. 
5. $\{$ Wir winclen dir den Jingfernkranz.

The Mouse-trap Man.

6. $\{$ Der Pabst lebt herrlich in die Welt.

\{ God save the Queen.

7. $\{$ Yankee Doodle.

7. $\{$ Aeh Mädchen erhöre mich bald.

8. $\{$ Du bist wie eine Blume.

\{ Blue bells of Scotland.

9. $\{$ Ich weiss nicht was soll es bedeuten.

(Mit dem Pfeil und Bogen.

10. \{ Das du mein sehätzchen bist.

\{ Jetzt ist Zeit und Stunde.

11. $\{$ Du bist verricht mein Kind.

\{ Bei Wagram auf den Theresienfeld.

12. $\{$ Friseh auf zum fröhlichen Jagen.

(Ein Herz das sieh mit Sorgen quält.

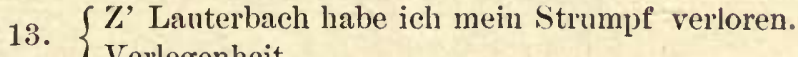

$\{$ Verlegenheit.

14. $\{$ Fin Sträuschen am Hut.

'The Chimney-sweep.

15. Daughter of the Regiment.

\{ Du, du liegst mir im Herzen.

16. $\{$ Within a mile of Edinboro'.

Kom' herein in die beste Stube.

17. $\{$ Vergiss mein nicht.

\{ The Rat-catcher's Daughter.

TITLES OF THREE SONGS COMBINED, PIPED BY ONE BIRD.

1. $\{$ Blau blüht ein Blümlein.

1. $\left\{\begin{array}{l}\text { Frisch auf zum fröhlichen Jagen. } \\ \text { Walz. }\end{array}\right.$

2. Der Pabst lebt herrlieh in die Welt.

2. Hinaus in die Ferne.

O du lieber Augustin :

3. $\left\{\begin{array}{l}\text { Ein Herz das sieh mit Sorgen quält. } \\ \text { Jungfernkranz. }\end{array}\right.$

Galop.

4. $\left\{\begin{array}{l}\text { Die Wacht am Rhein. } \\ \text { Vergiss mein nieht. } \\ \text { Polly Perkins. }\end{array}\right.$

5. $\left\{\begin{array}{l}\text { Was soll es bedeuten. } \\ \text { Mit dem Pfeil und Bogen. } \\ \text { Polka. }\end{array}\right.$

6. $\left\{\begin{array}{l}\text { Du bist verricht mein Kind. } \\ \text { Die Mithle }\end{array}\right.$

(verlegenheit. 


\section{BULLFINCH MELODIES.}

\section{DU BIST WIE EINE BLUME.}

(Thou art so like a Flower.)
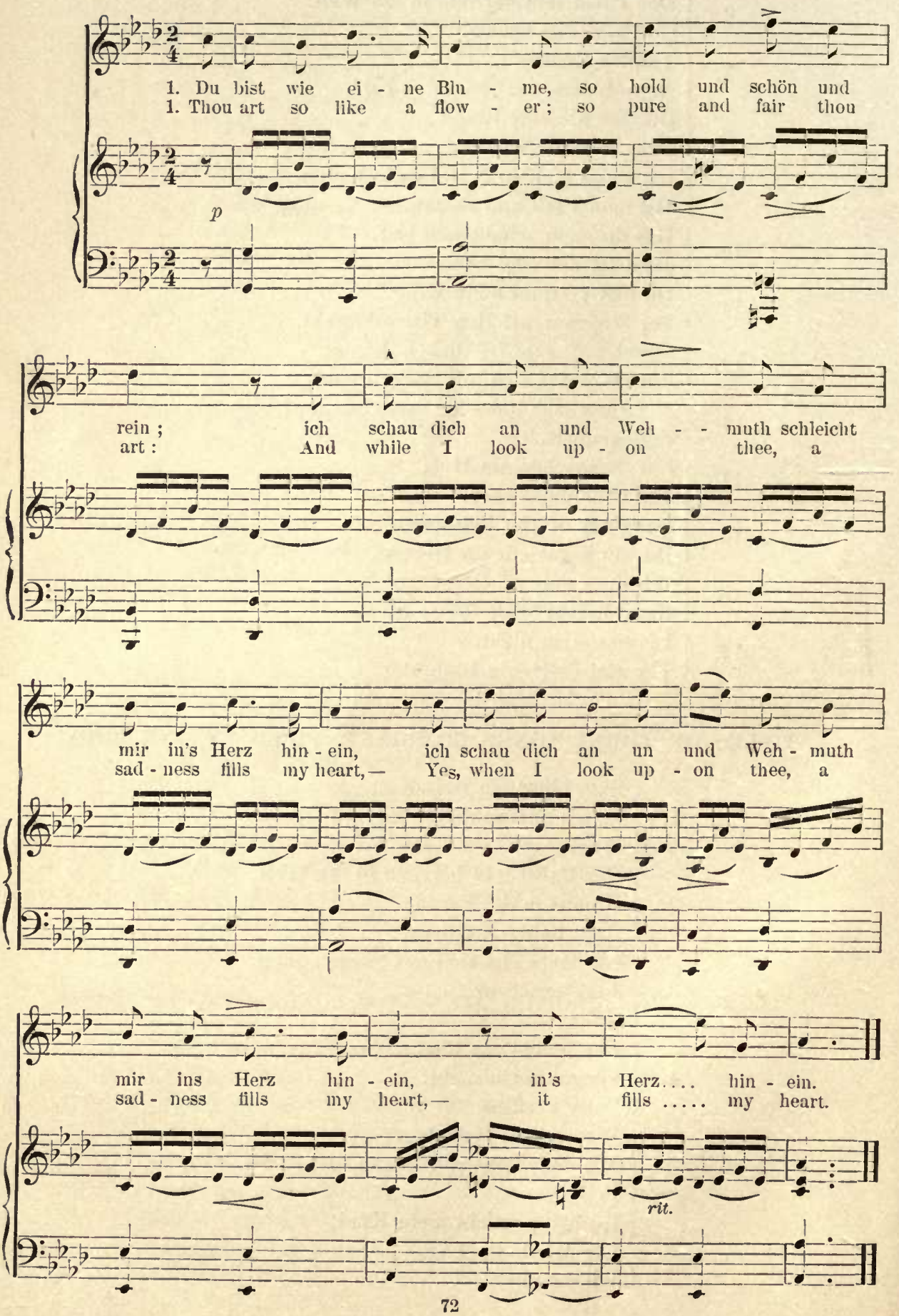


\section{THE BLUE BELLS OF SCOTLAND.}
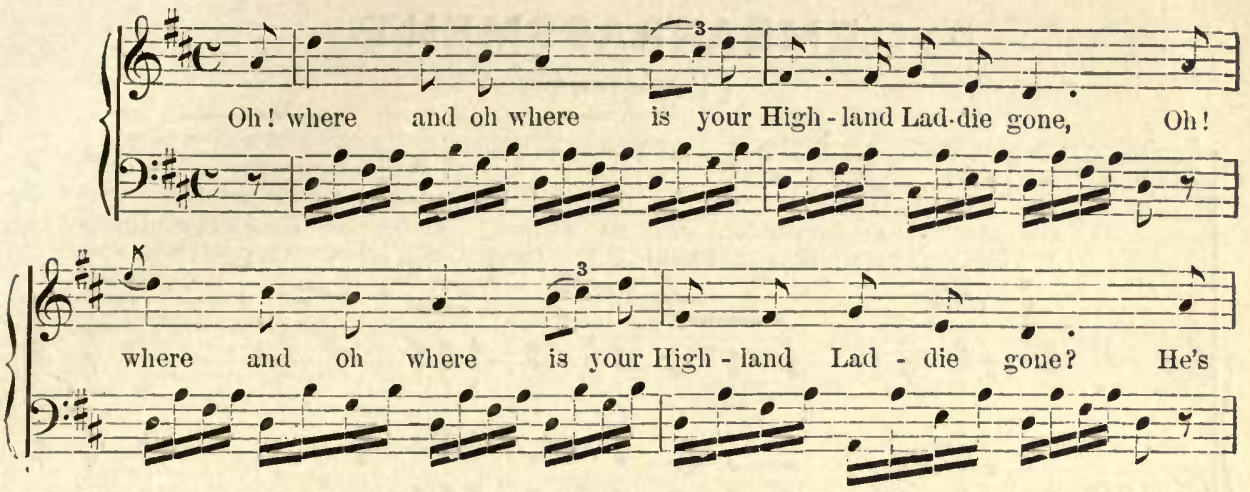

$1(02$ gone to fight the French, for King George up-ou the throne, And its

$\begin{cases}3 & 1\end{cases}$

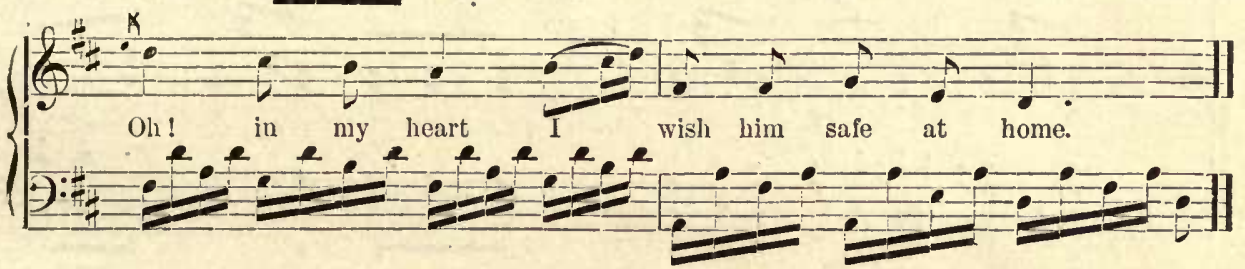

\section{HOW CAN I LEAVE THEE?}

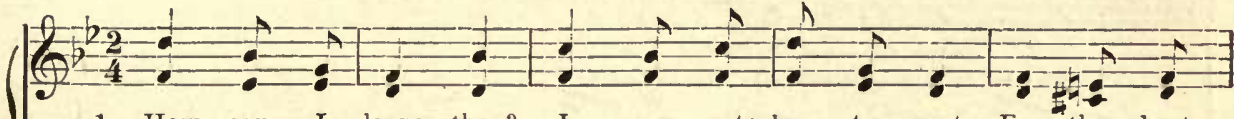

1. How can I leave thee? I can - not bear to part, For thou hast

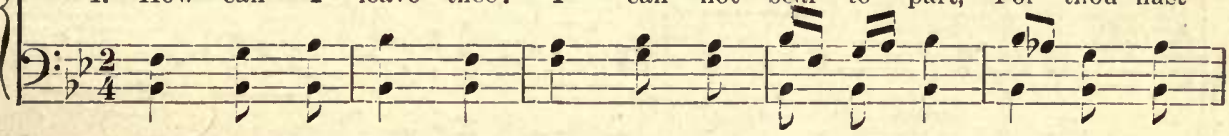

$\begin{cases}\text { my whole heart, Dar - ling, be - lieve! Thou hast this soul of mine, } \\ 9:-2\end{cases}$

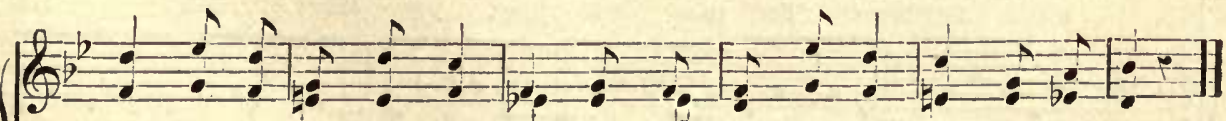

'Tis al - to - geth - er thine, None oth - er can I love. But thee a-lone.

(9:b-: : 


\section{BULLFINCH MELODIES.}

\section{EMBARRASSMENT.}

\section{(Verlegentieit.)}
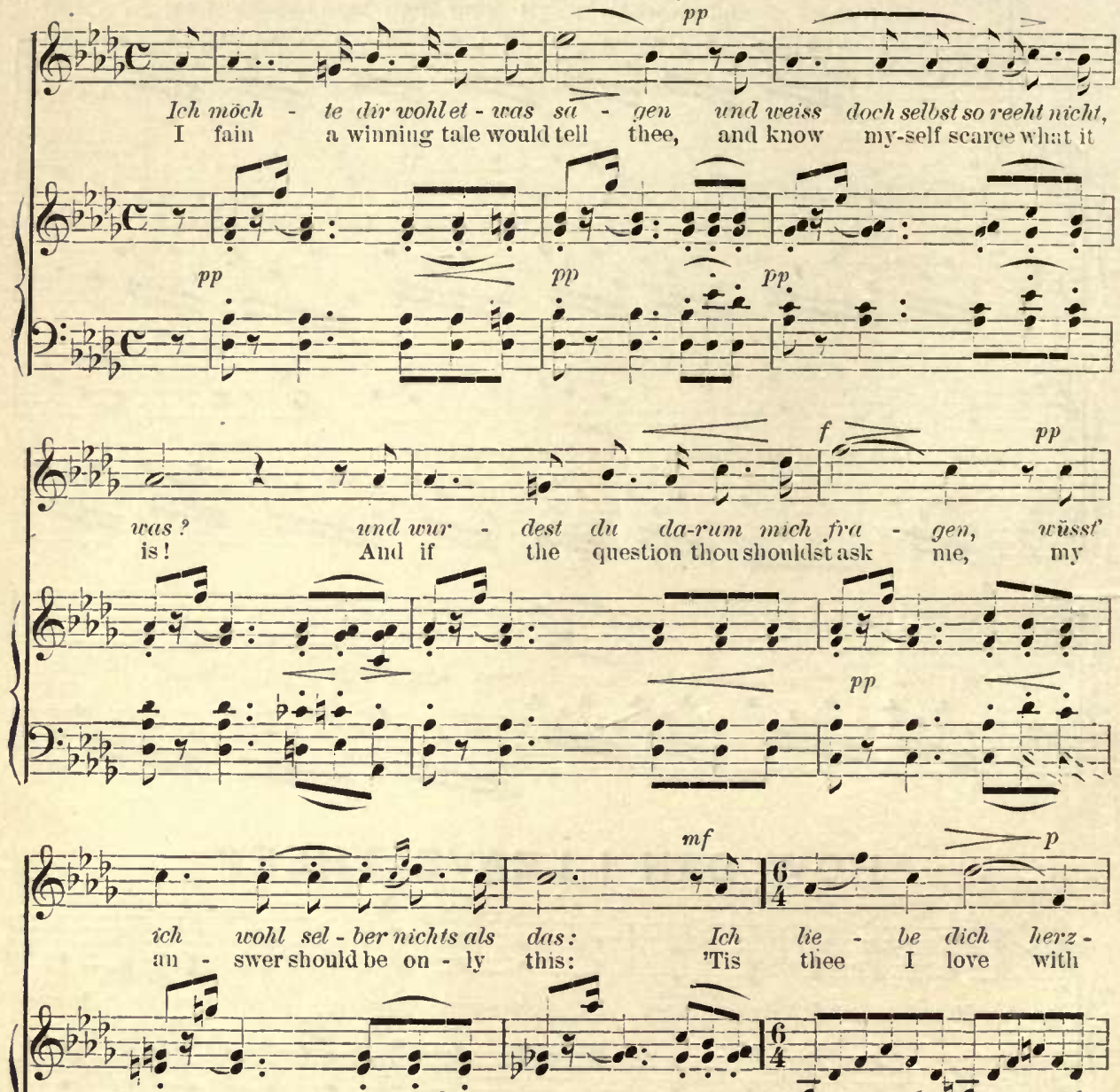

Soco rit.

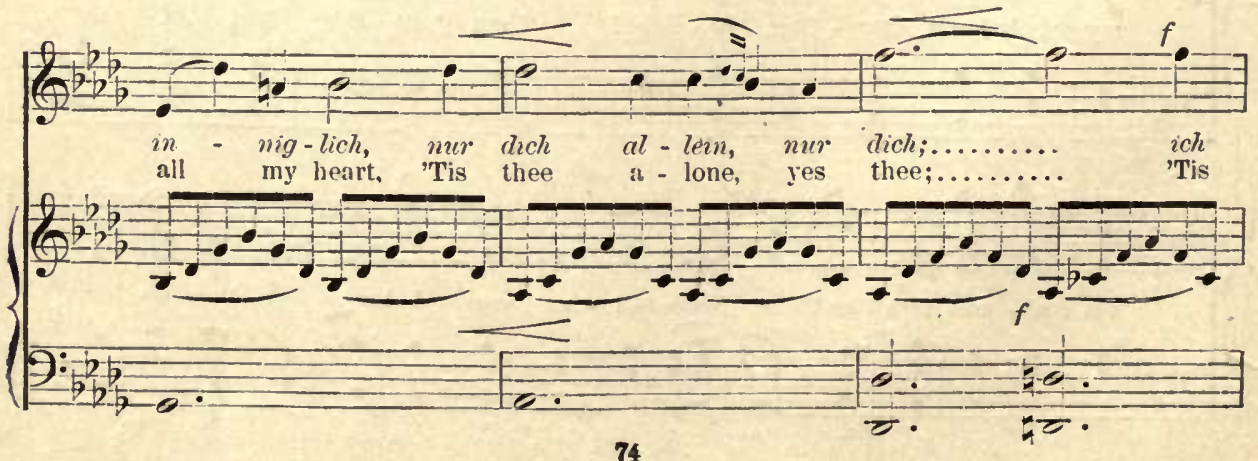


VERLEGENHEIT. Concluded.

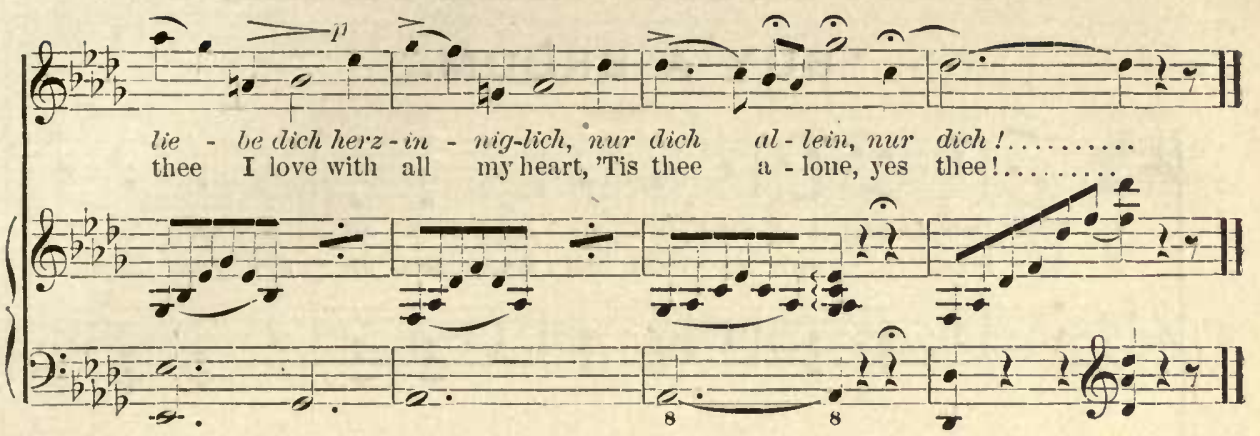

DER SCHÜTZ.

(The Archer.)
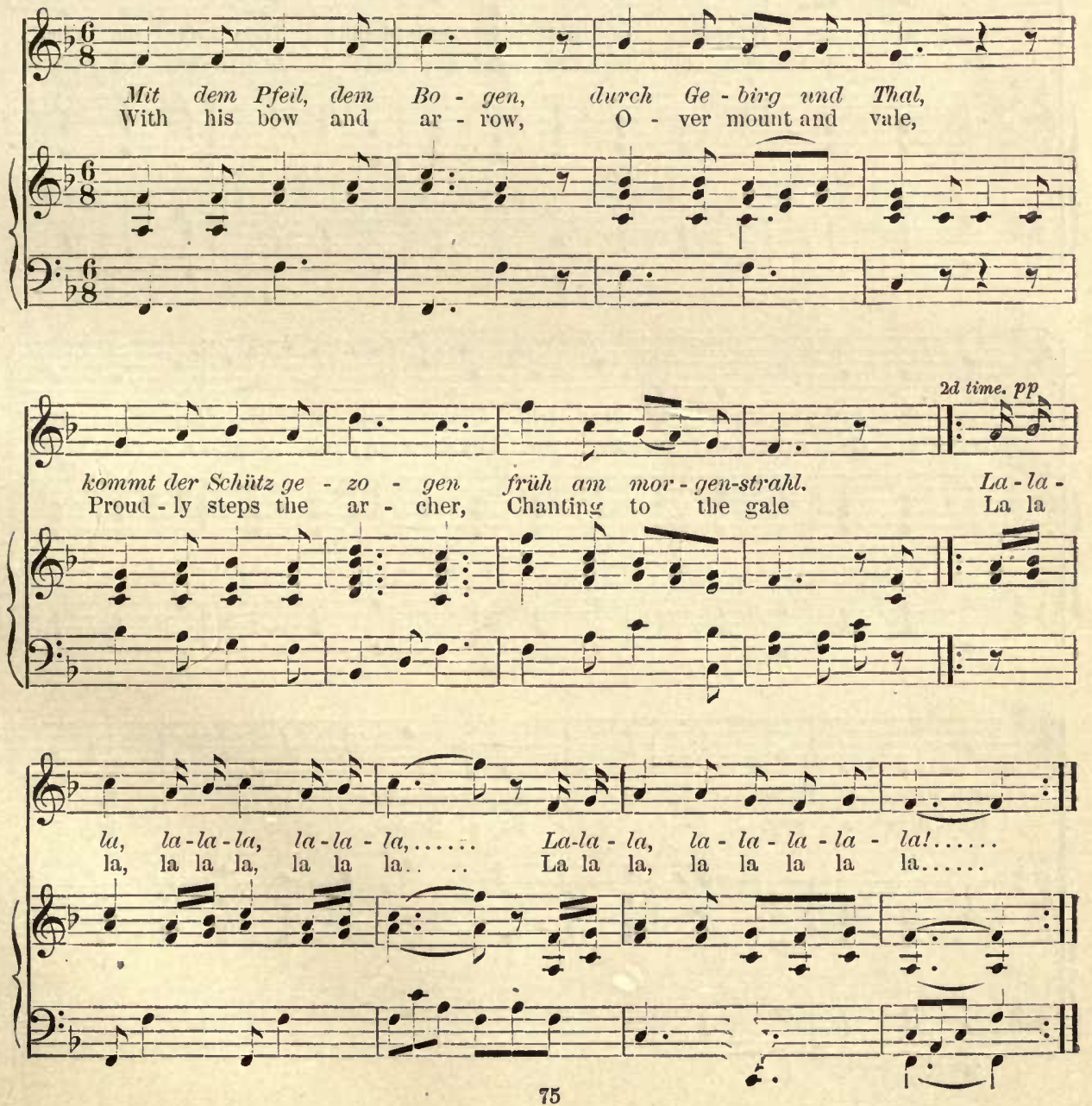


\section{BULLFINCH MELODIES. BUY A BROOM.}
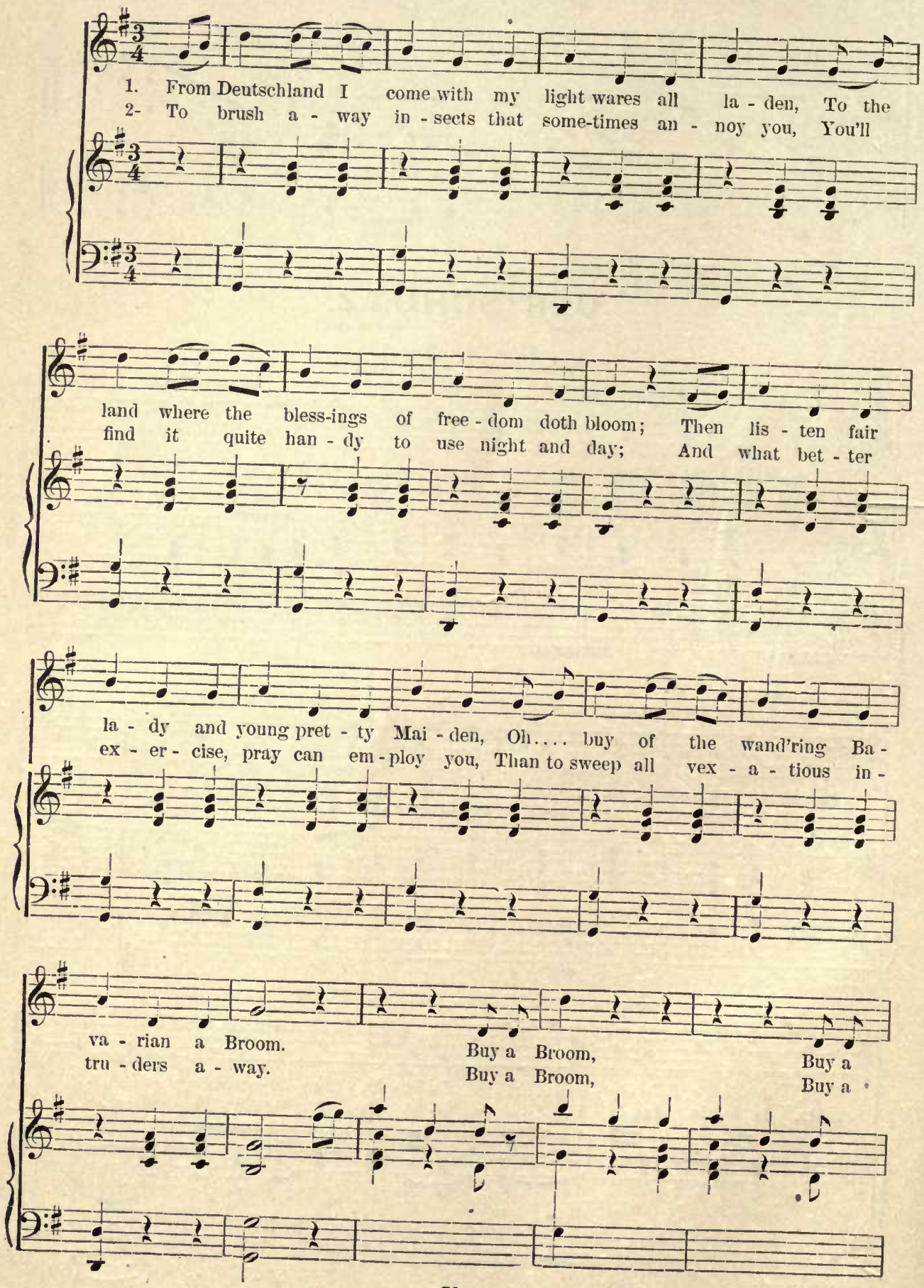
BUY A BROOM. Concluded.

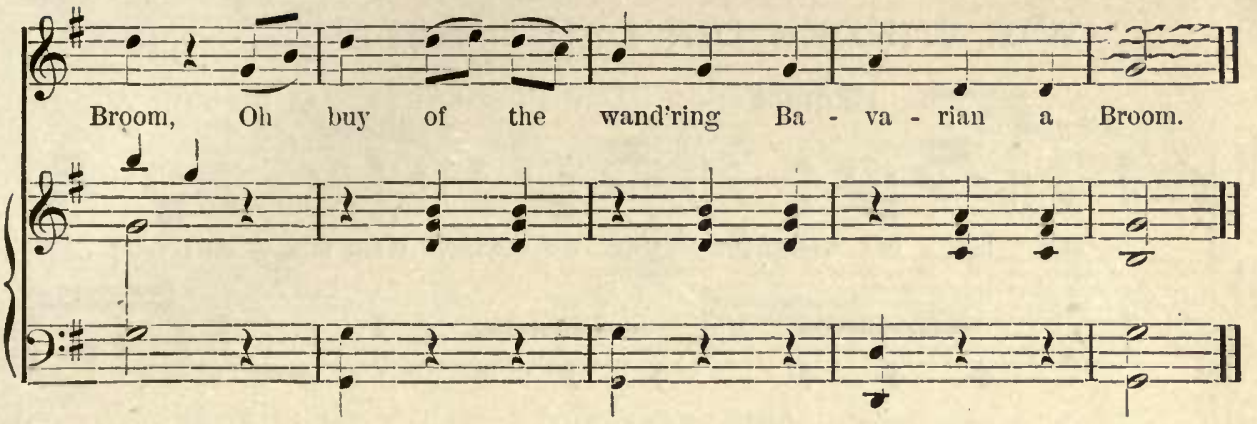

THE MOUSE-TRAP MAN.
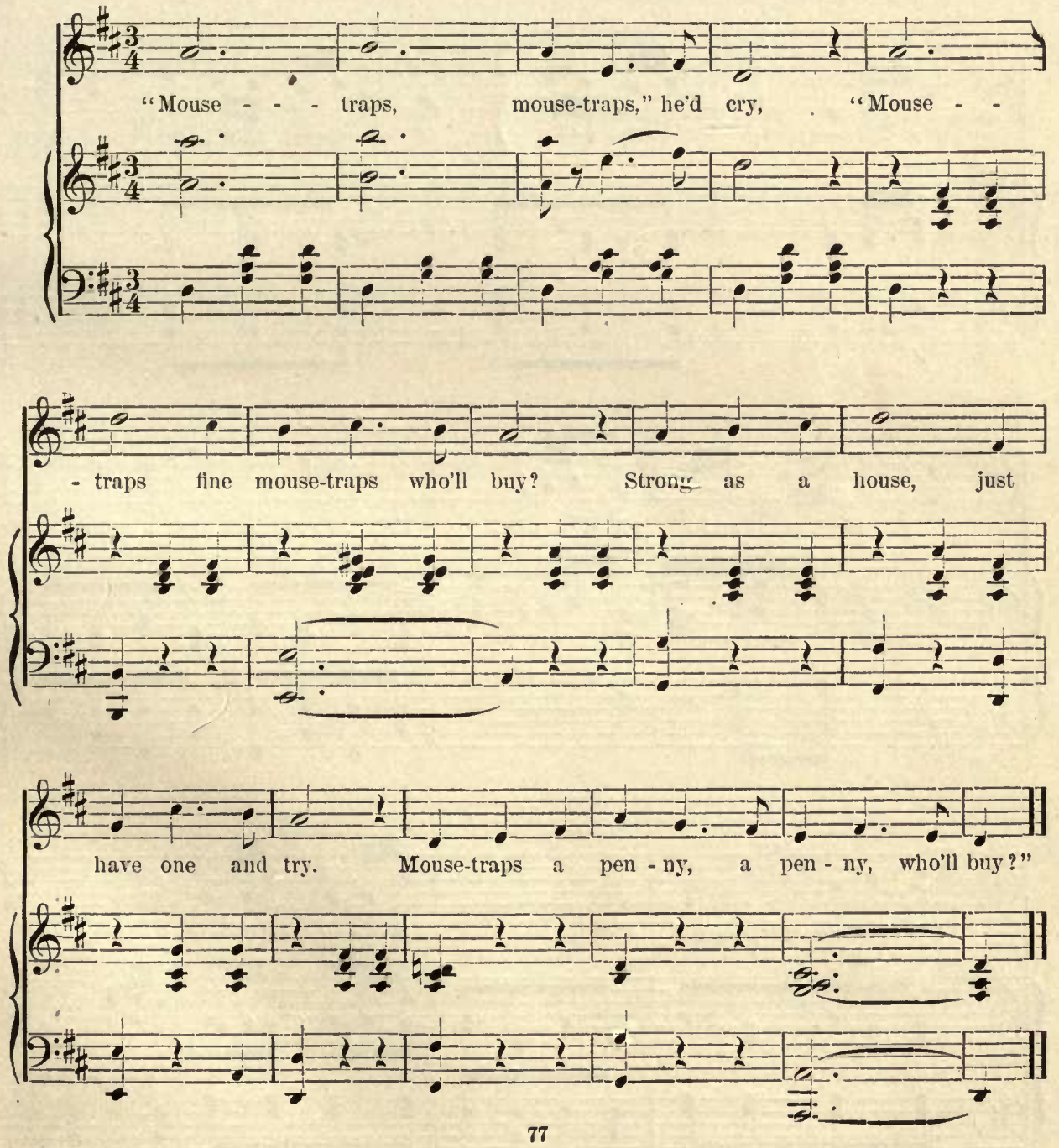


\section{THE BRIDAL WREATH.}

(WIR WINDEN DIR DEN JUNGFERNKRANZ.)
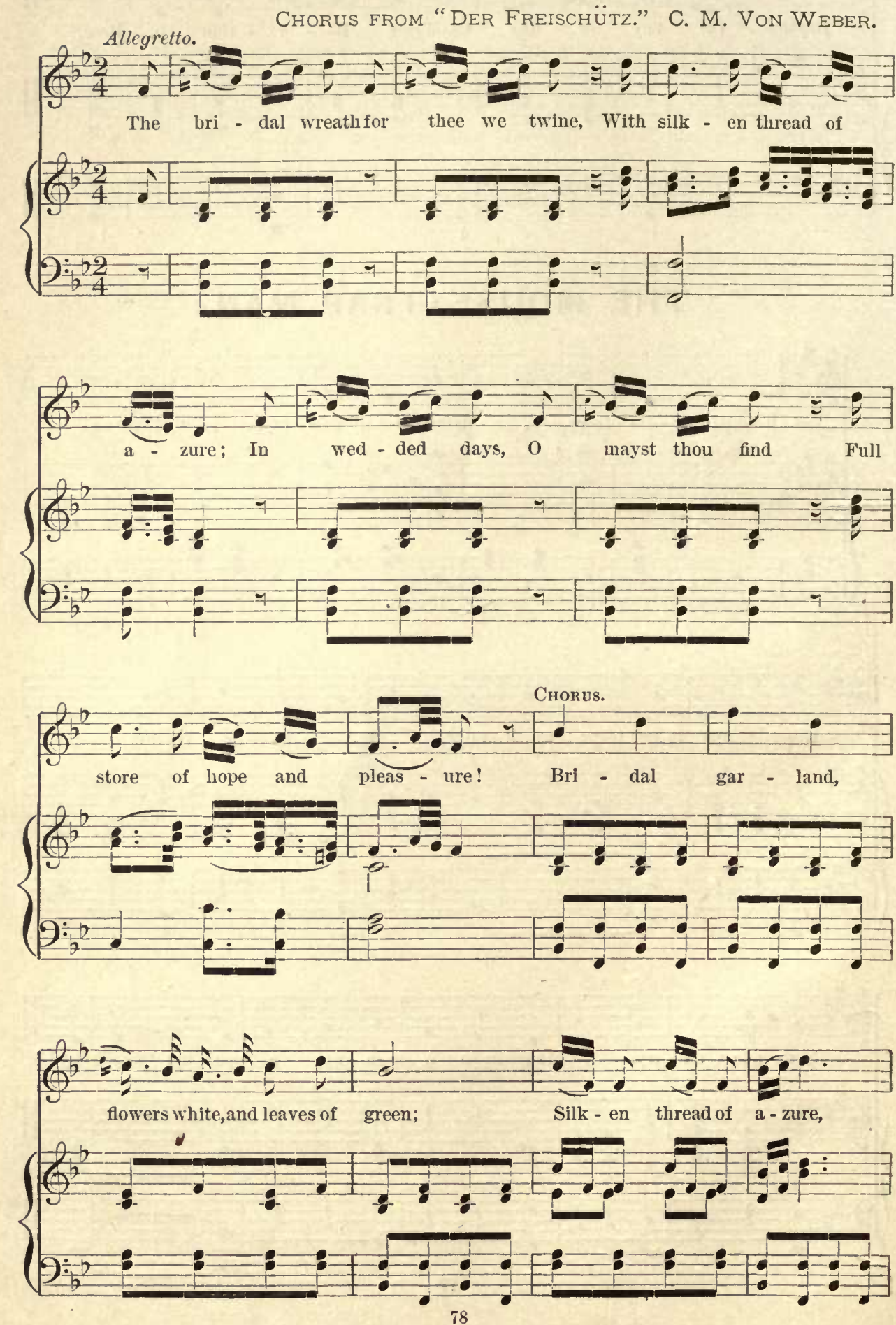


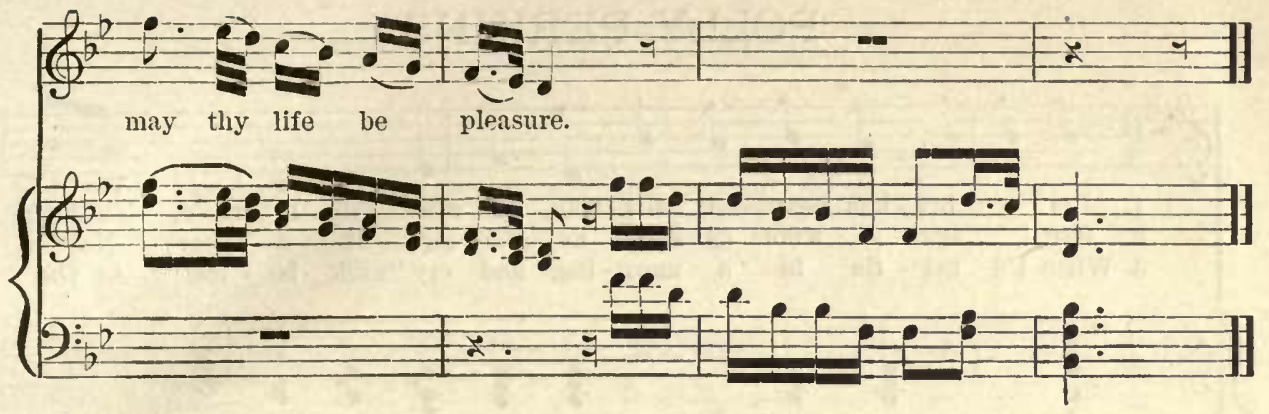

THE OLD WARRIOR TO HIS CLOAK.

(DER ALTE REITER UND SEIN MANTEL.)

VOLKSLIED OF THE 18TH CENTURY.
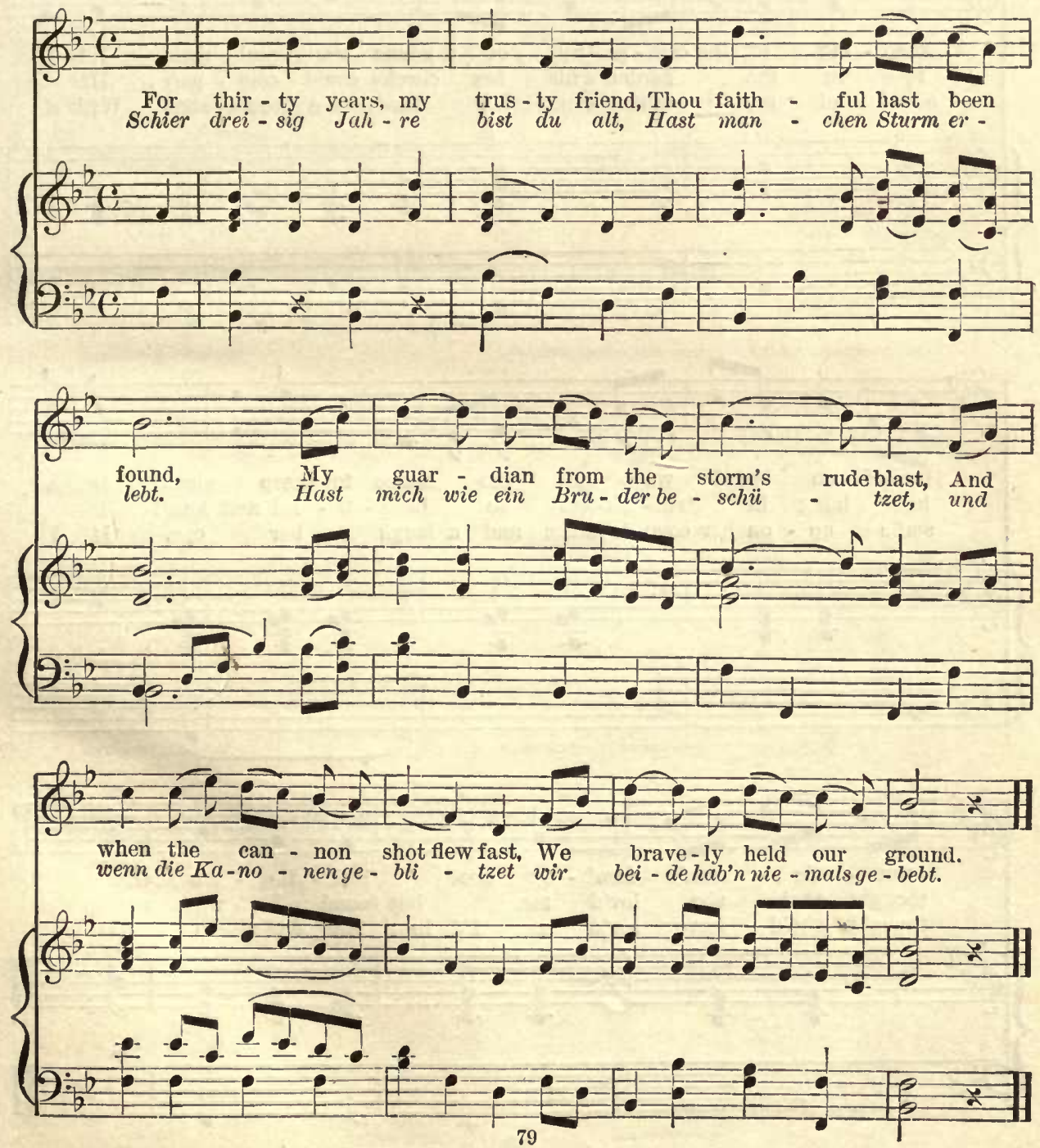


\section{POLLY PERKINS.}
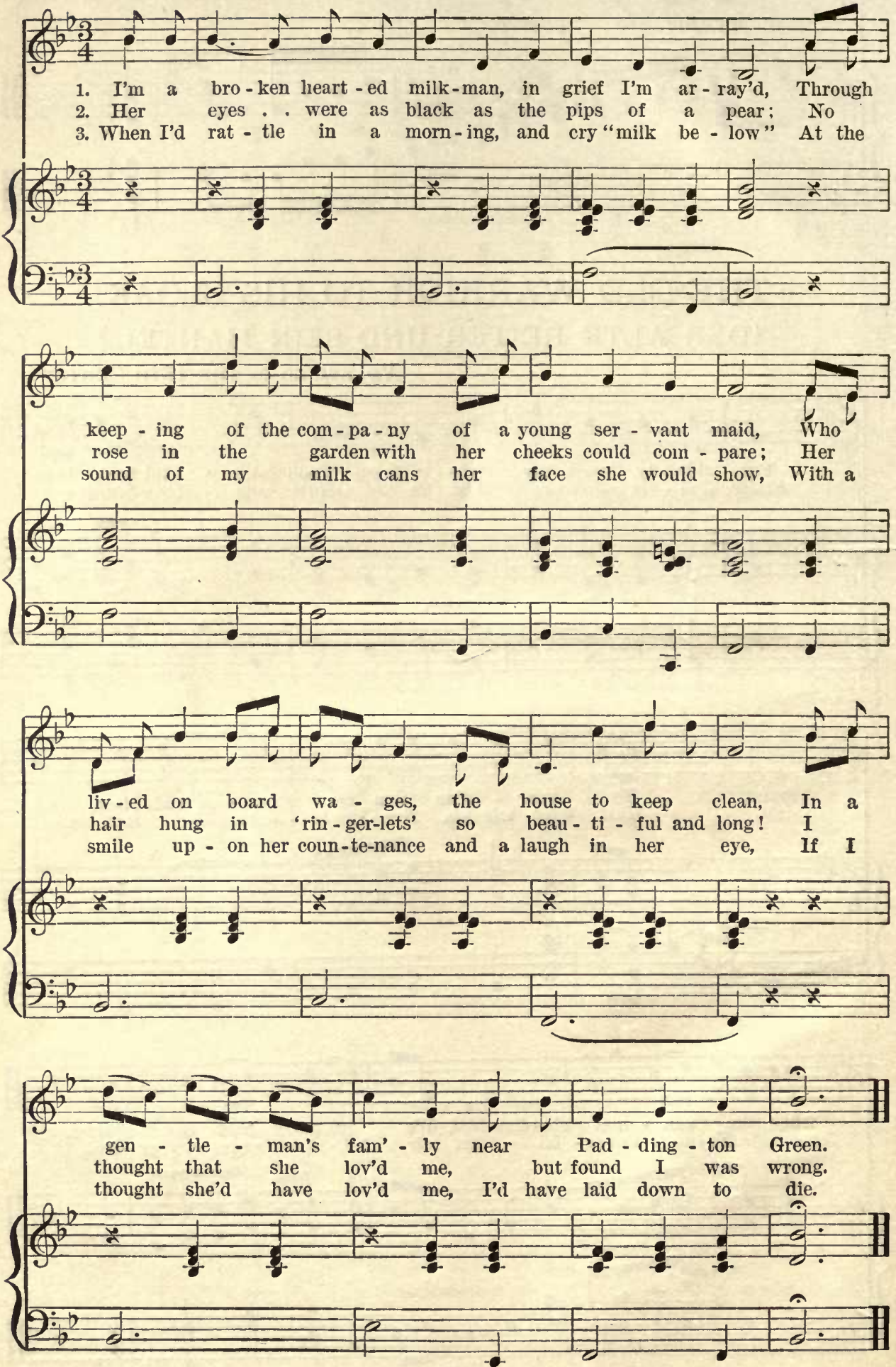
FATINITZA, MARCH AND CHORUS.

F. VON SUPPE.

Tempo marziale.

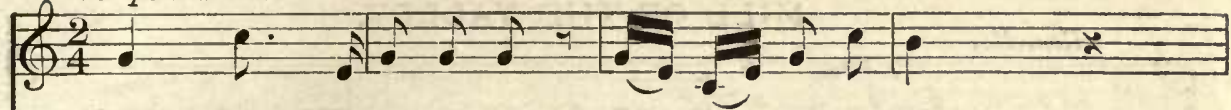

March for - ward fear-less-ly; Now thy val - or prove:

$\left\{\begin{array}{l}\frac{2}{4}+2 \\ 4\end{array}\right.$

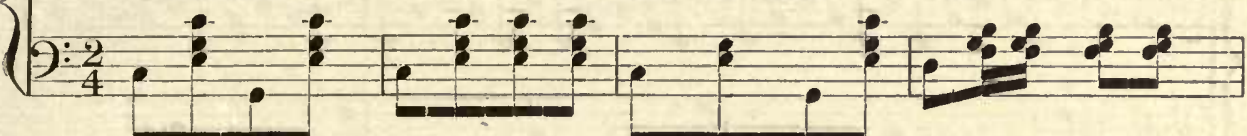

Q

That stand - ard bear - er free Lead-ing thee is love !

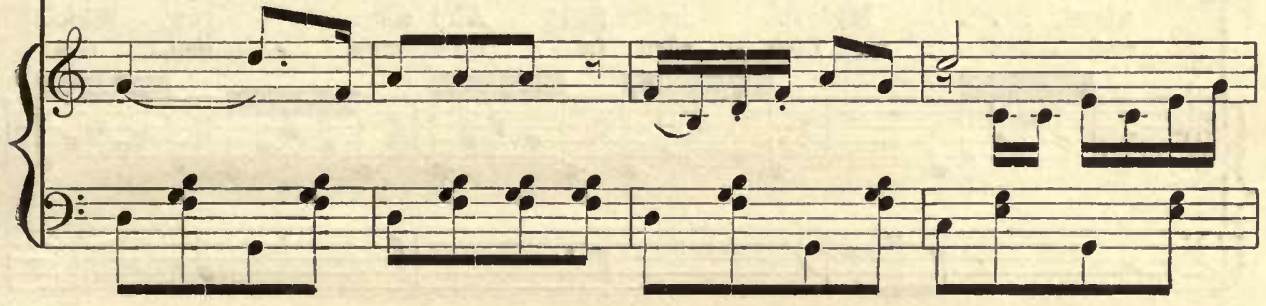

Q

For - ward, withsword in hand; Smite the hos - tile band !

A

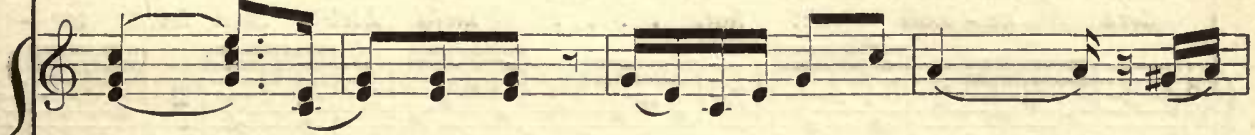
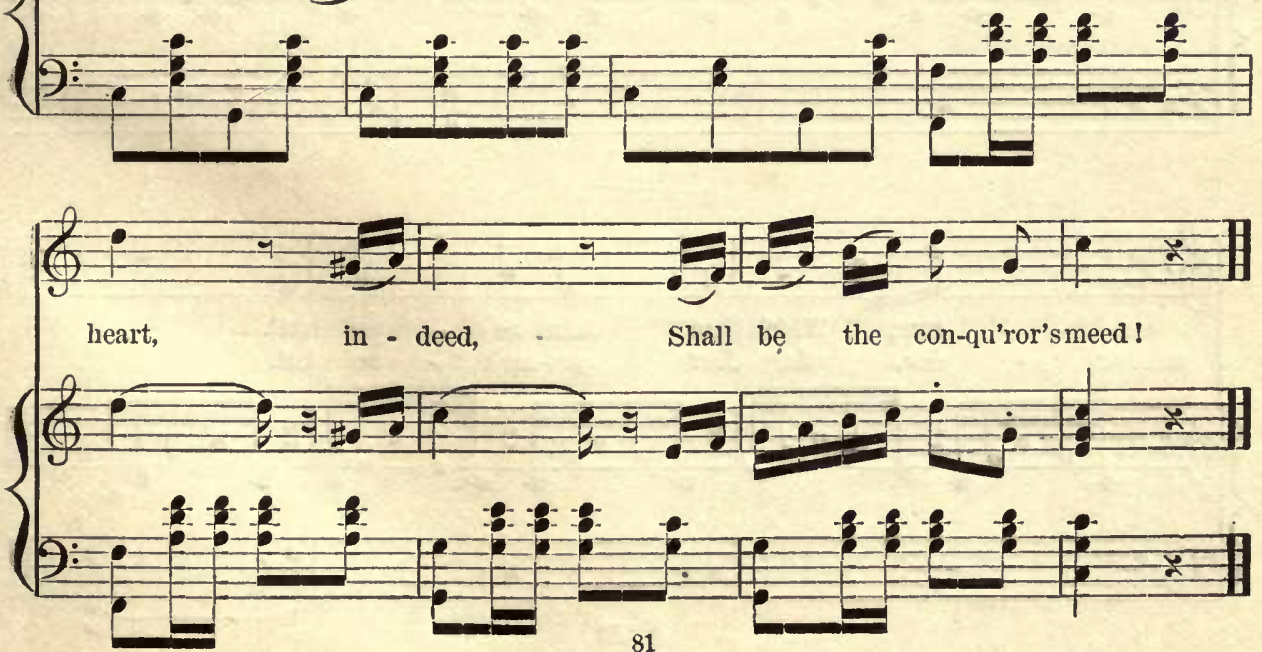


\section{THE BROKEN RING.}

IN EINEM KÜHLEN GRUNDE.
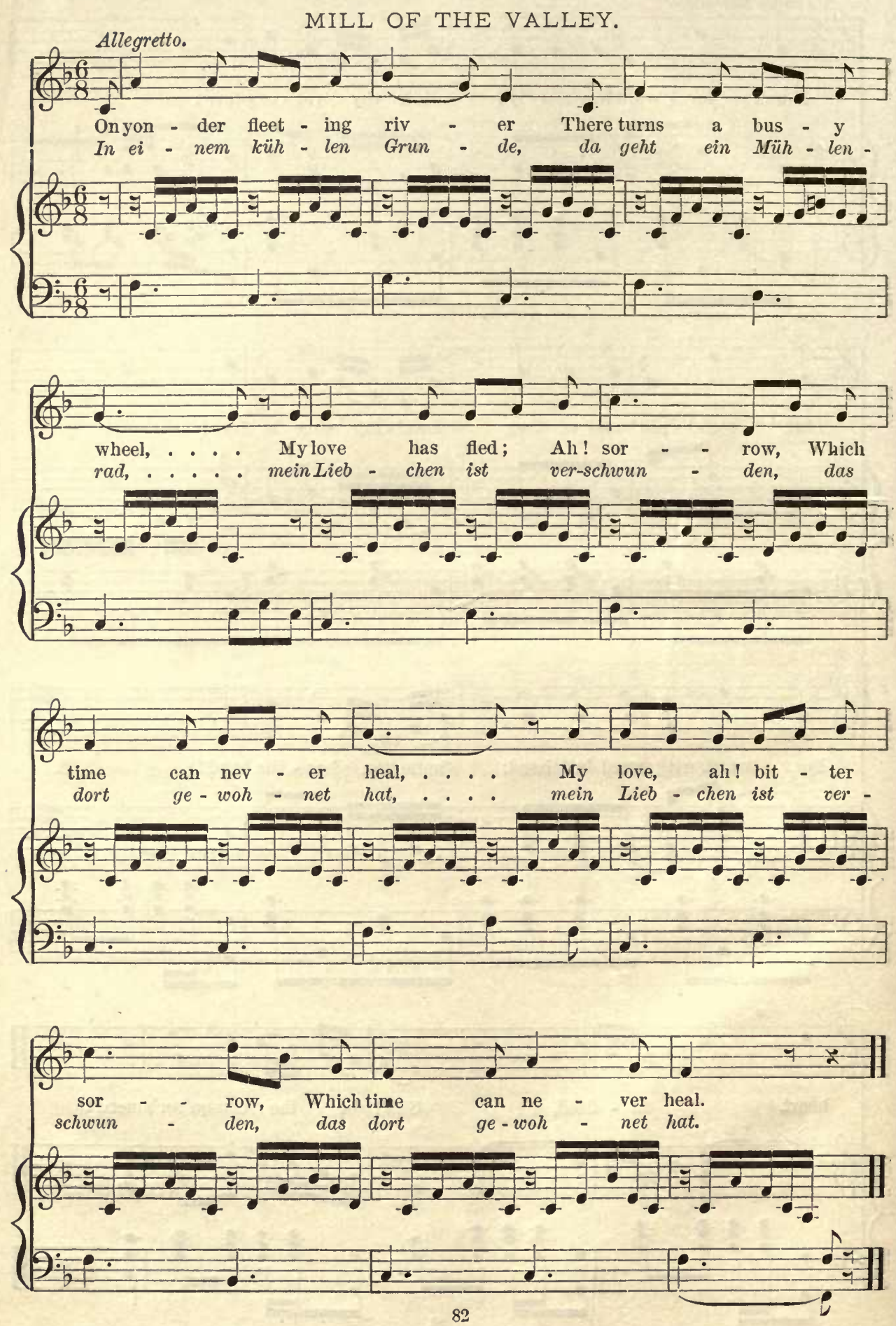
HUNTSMAN'S MARCHING SONG.

A. Methfessel, 1813.
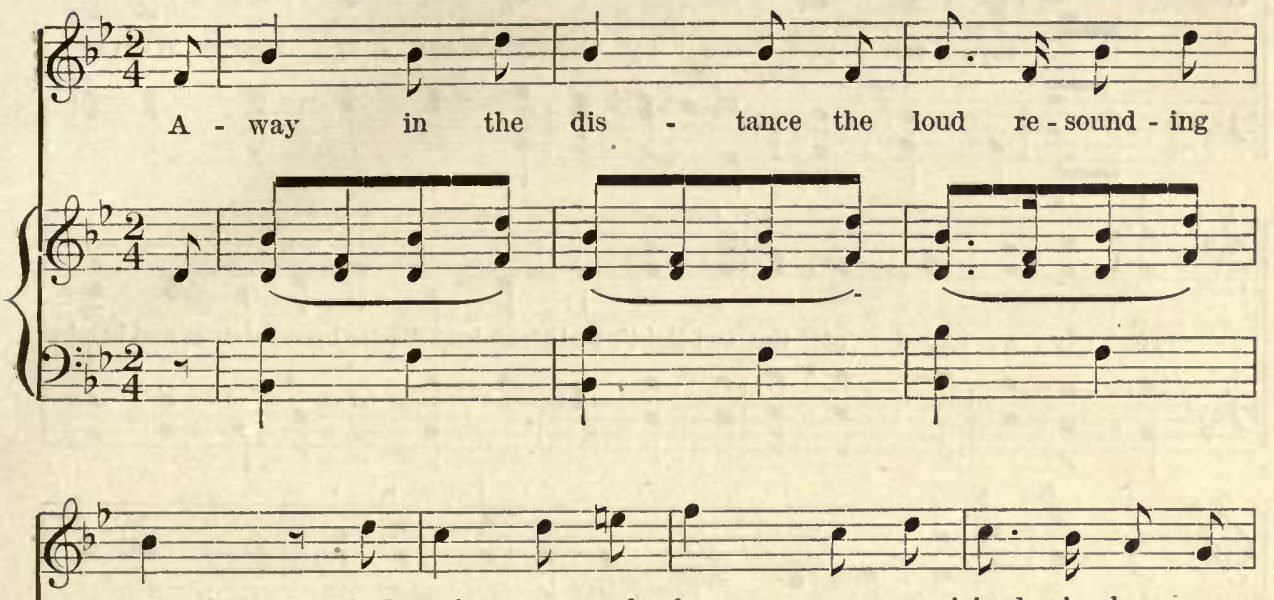
horn And voi - ces of free - men are joined in hap - py
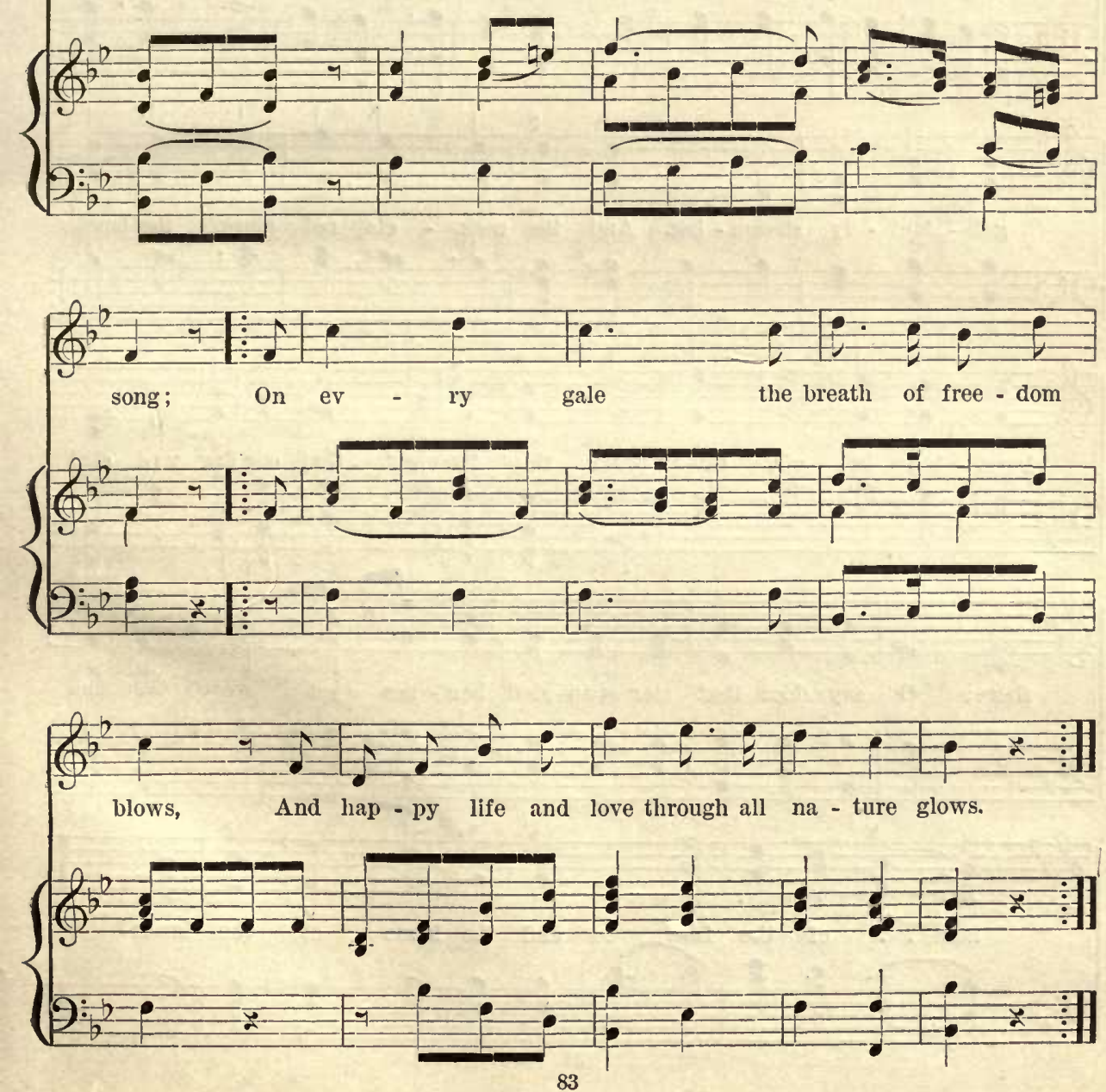


\section{THE STAR SPANGLED BANNER.}
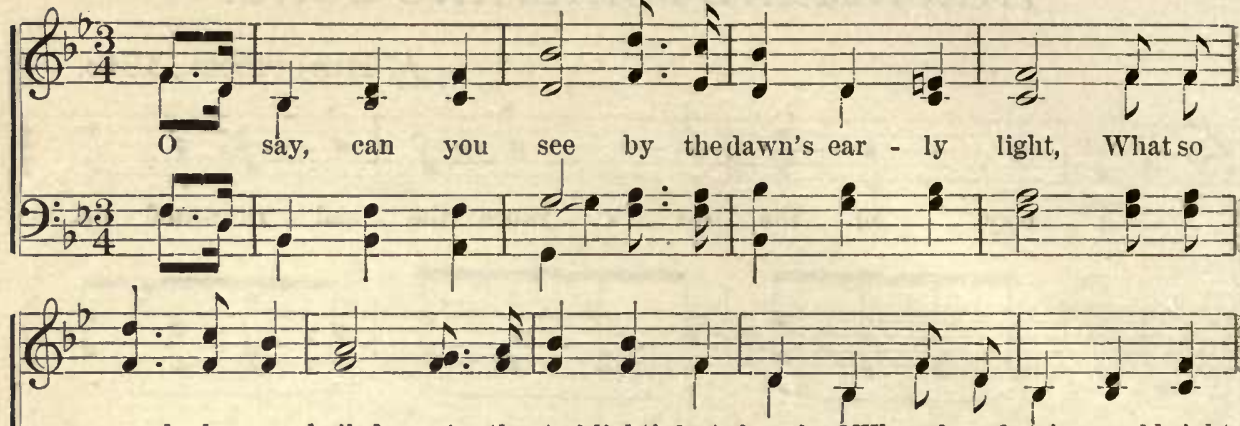

proud - ly we hailed at the twi-light's lastgleaming? Whose broad stripes and bright

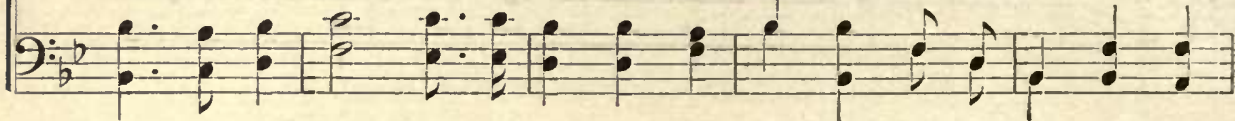

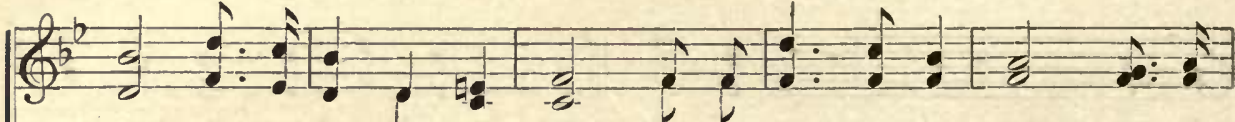
starstliroughthe per - il - ous fight, $0^{\prime}$ er the ram-parts we watched, were so

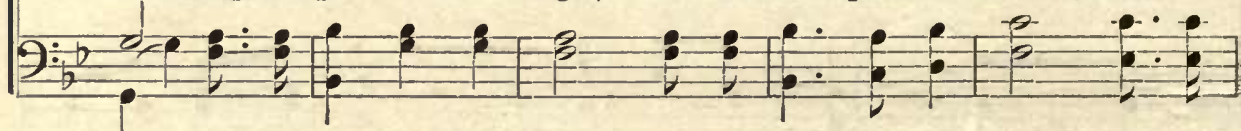
(4) gal - lant - ly stream - ing. And the rock - ets red glare, the bombs

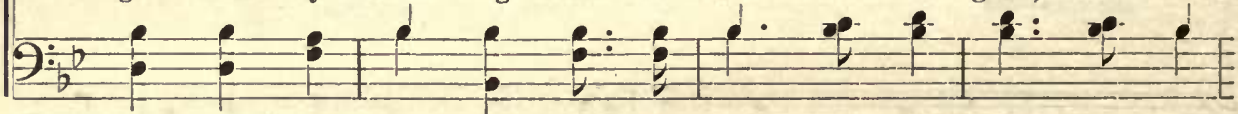
$\left(\frac{1}{2}+\cdots\right.$ burst - ing in air, Gave proof thro' the night that, our flag was still

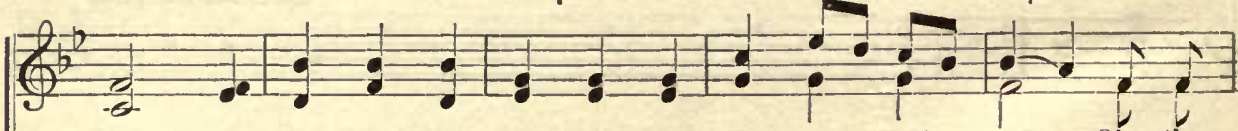
there; 0 say does that star span-gled ban-ner yet wave O'er the (2) of the free. and the home of the brave? 
HUNTER'S CHORUS.

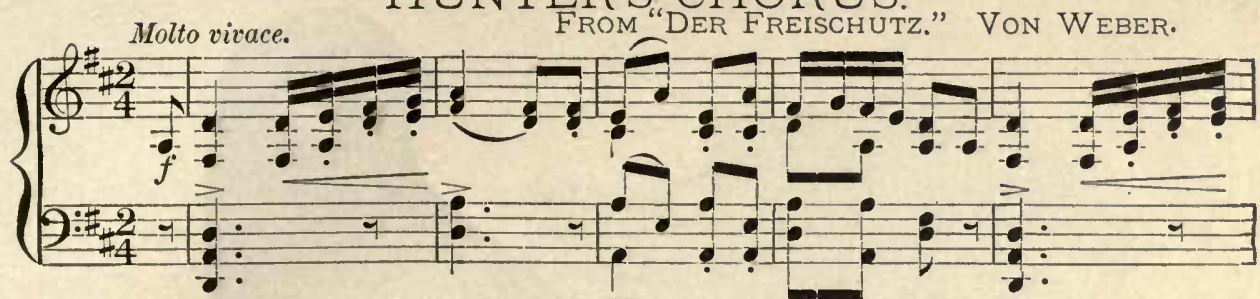

The joy of the hun - ter on earth all sur -
Wasgleichtwohlauf Er-den dem Jä - ger-ver -

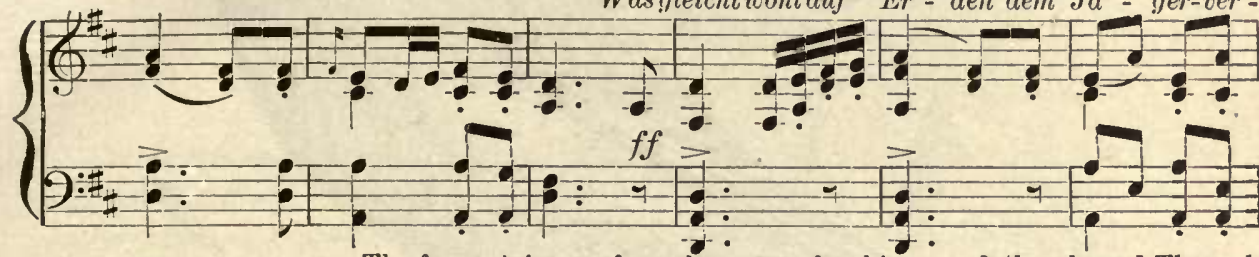

pas - ses, The foun - tain of plea - sure for him doth a-bound,Through gnï - gen, vemspru - delt der Be - cher des Le - bens so reich? Beim

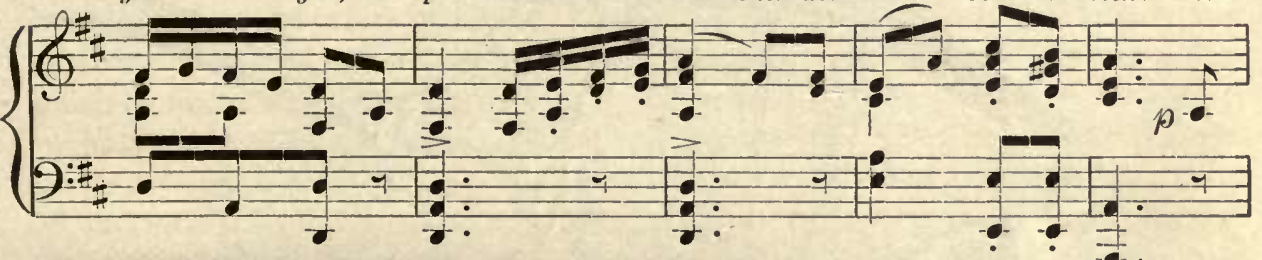

wood and through flood, where the stag flits and pas - ses, He flies in pur - suit while the Klan-ge der Hör-ner im Gru-nenzu lie - gen, den Hirsenzu ver - fol-gen durch

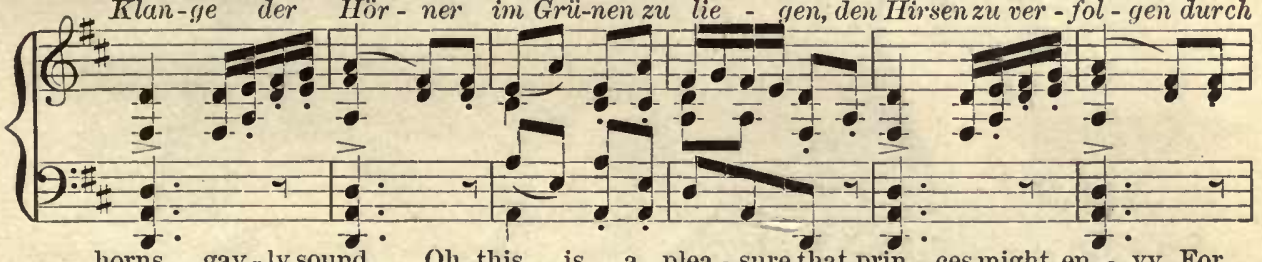

horns gay-lysound. Oh, this is a plea - sure that prin - ces might en - vy, For

Dic-kicht undTeich, istfürst-li-che Freu-de, ist männ-lich Ver-lan-gen, er -

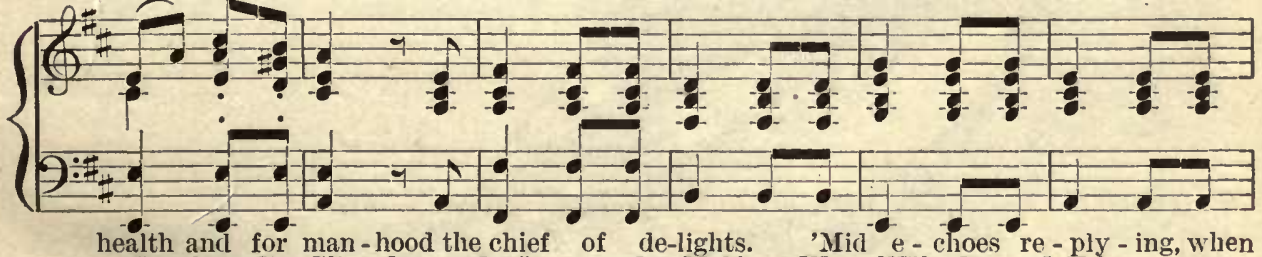

health and for man-hood the chief of de-lights. Mid e-choes re-ply-ing, when
stär-ket die Glie-der und wü - zet das Mahl. Wem Wäl-der und Fel - sen uns

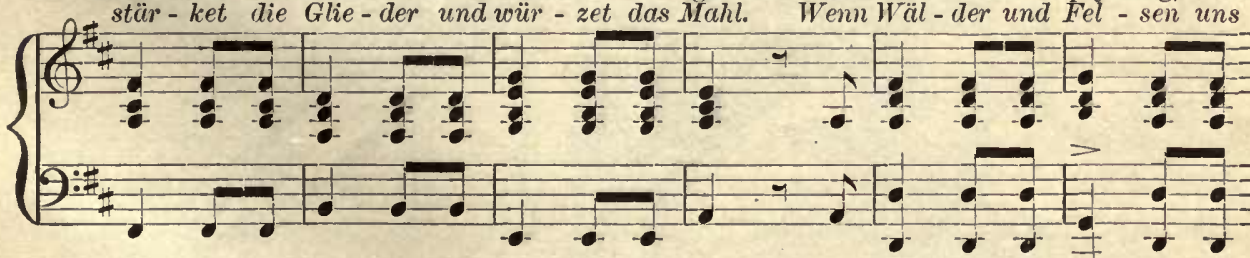

day-light is $d y$ - ing, To rest and the wine-cup our la - bor in-vites. hal - lend um - fan - gen, tönt frei - er undfreud'-ger der vol - le Po-kal.

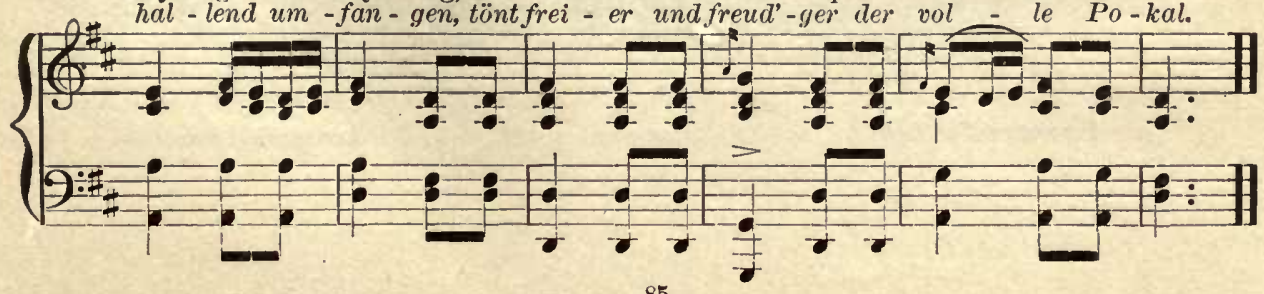




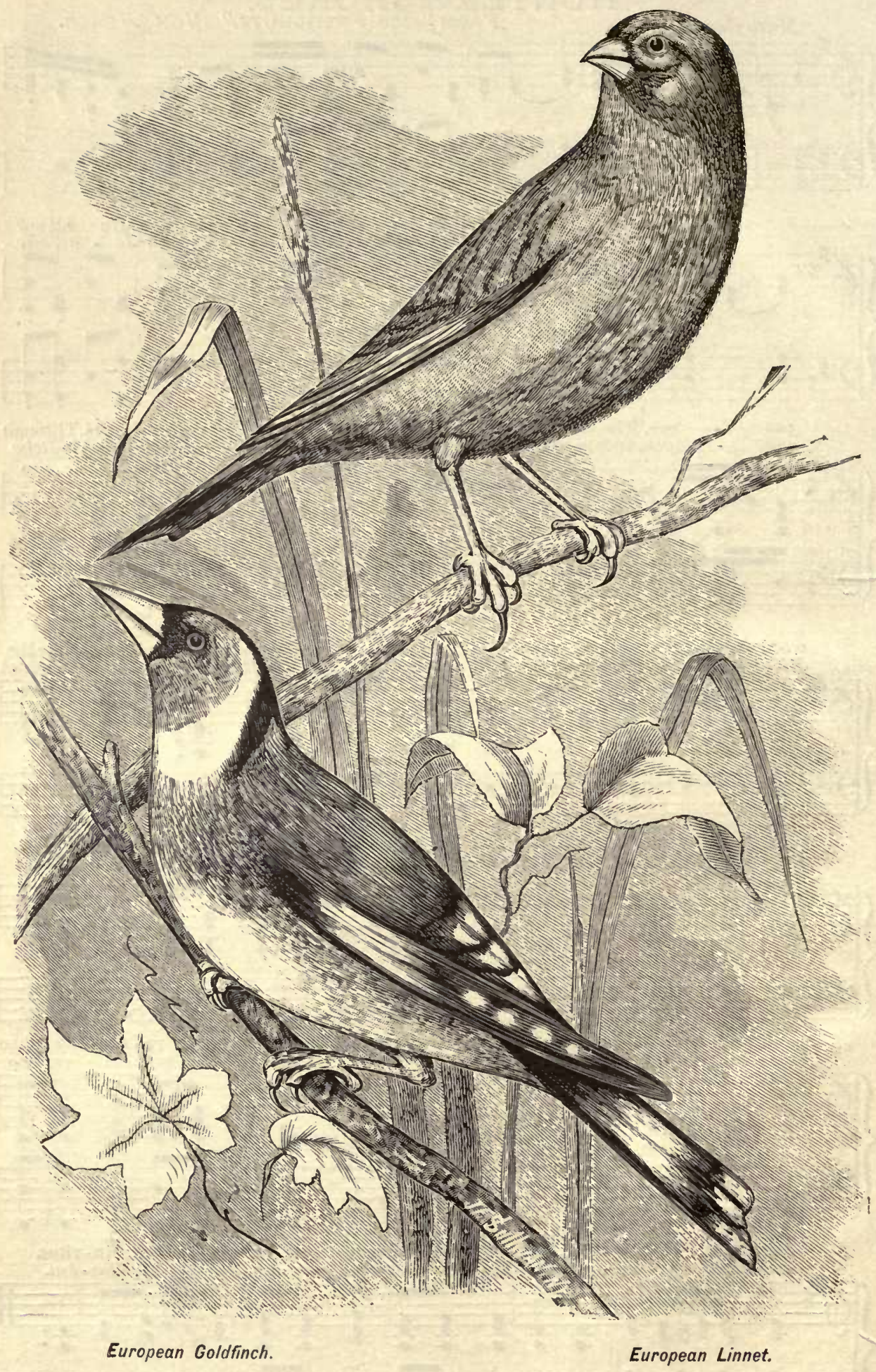




\section{EUROPEAN GOLDFINCH.}

OF all the cage-birds with which we are acquainted, the Canary holds first place; and the Goldfinch ranks a close second. His beautiful plumage, sprightly actions, docile ways, and pretty song, make him a favorite wherever he appears; and he is probably better known than any imported cage-bird except the Canary. The beantifully blended colors of his velvety coat are remarkable for their brilliancy and number; while his hardiness, when caged, is unsurpassed; and the readiness with which he mates with other varieties of birds makes him one of the most interesting subjects for use in the breeding-room. The ease with which he may be taught numerous and difficult tricks makes him an especial favorite with another class of bird-lovers. In fine, his many qualifieations are not combined in any variety of bird with which we are acquainted. 'The Goldfinch is about five inches and a half in length ; the beak is conical, and very sharp and whitish, with a horn-colored tip; the feet are brown and slender; the front of the head is bright scarlet, and a broad band of the same color encircles the root of the beak; the top and back of the head are a brilliant black; the cheeks, and upper part of the neck, are pure white; the top and nape of the neck are a beautiful brown; the rump is white, tinged with brown; the sides of the breast are light brown; the middle of the breast and belly are whitish gray, tinged with brown; the thighs are grayish; the wing-feathers are velvety black, with white tips; the middle wing-feathers are edged on the outer plume, for about an inch, with bright yellow, which, in eonjunction with the yellow tips of the hindmost large coverts, produces a beautiful effect. The tail is black, and tipped with whitish spots. The female Goldfinch closely resembles the male in size, and markings of plumage, the only perceptible difference being the small size of the scarlet band on the head. Much discussion has arisen as to the points by which the male is distinguished from the female. A certain, and the only sure, point by which they are known from one another is in the difference in colors of the fore-arm of the wing. If the bird is taken in the hand, and the wing outstretehed, the tip of the fore-arm will be observed to be velvety black in the male bird, and of a rusty brown in the female. It is contended by some authors, that the difference in the size so often seen in Goldfinches is caused by the unfair share of food which the first birds hatched receive. I think that this theory is doubtful, and $I$ attribute the difference to the country or district in which they are reared. The birds are, to be sure, all of the same genus : but the conditions of climate and food result in the larger growth of some birds over that of others ; as, for instance, the German Goldfinch is larger, and, of course, higher prized, than the English.

There are many varieties of the Goldfinch, caused by the difference in markings 
or colors of the plumage, and by breeding with other varieties of birds. The lighest. prized of these varieties are the scarlet-headed, which has the entire head colored in rich scarlet or crimson : there are no other markings to mar the brilliancy of color on the head. This is a very rare and beautiful variety. The white-breaster Cheveral, or King Goldfinch, has a pure white breast, and clear white ring around the neck. This variety is highly prized as a breeder of white or handsomely marked Goldfinch-Canary Hybrids. The white-legged variety is esteemed for the readiness with which he mates with the female Canary. The black Goldfinch is a variety which is obtained by keeping the bird in close confinement in a darkened room. The Goldfinch Hybrids are in some cases very beautiful birds, and exhibit a wonderful variety of markings and color. The pure white is the highest prized; and the color's range from that of the above specimen to the very dark, and are varied by elegant spots of brilliant crimson or yellow throughout the plumage. 'The Goldfinch is found throughout Europe, and in the summer season frequents gardens, groves, and even mountainous districts which are not altogether uncultivated. It. is not a migratory bird, but collects in flocks in antumn, and makes excursions in search of food; forsaking districts where suow is too deep, for others where theclimate is warmer.

The nest of the Goldfinch, like the birds themselves, is a marvel of neatness and beauty, and is usually built in an apple or pear tree. It is semi-spherical, and composed of moss, lichen, and fine root-fibres, ingeniously woven together, and lined with wool, hair, or thistle-down; the whole structure being remarkable for strengtl, and the skill with which it is constructed. 'The female lays, once a year, five or six pale-green eggs; and the young, if taken before they are fully fledged, are easily reared by hand, and make the most desirable class for teaching tricks, or for easily acquiring the Canary-song, which is greatly admired when poured forth from the throat of this débonnaire little stranger.

Goldfinches are sociable little fellows with the strangers of the field, and never quarrel among themselves, which can rarely be said of even the best-conducted families of birds or men. They are of great service to the farmers aud gardeners, and, with the aid of their sharp, strong little beaks, do effective work in the destruction of innumerable insects. Their chief food in a wild state is thistleseeds, of which they are very fond. The Goldfincli is easily trapped by placing a bundle of thistles in the vicinity of limed twigs. After capture they take very readily to confinement; and after some few flutterings, and ineffectual attempts to escape, they resign themselves to their fate, and in a few days eat the seed which. is offered, and contentedly give themselves up to the pleasures of civilized life.

The Goldfinch, when caged, sings throughout the year, with the exception of the moulting season. His song is on a ligh key, and real agreeable, and contains many warbles, trills, and twittering notes, which are intermingled in a most cliarming manner. The bird, during the continuance of his song, is in constant motion ; and these lively movements, combined with his graceful form, delicately blended colors, and sprightly song, make him one of the most attractive bird-objects with which a home can be adorned. A flock of flasling, dazzling-coated Goldfinches, when seen disporting themselves among the trees, combining their sweet voices into a great chorus, free to go whither they will, brightens the most dreary scenes of nature. 
The effect which one of these little gems of nature, flying wild near London, produced on the mind of a poetic, dreamy lover of the bird, is deseribed as follows : -

"Take this old rustic settee, and place in the shade of the bow-apple tree, and let's forget there's such a building as the London National Gallery : ah ! we do forget, and even Landseer's Dogs are out of Memory's Avenue for the nonce, as from a hiding in the shrubberies a song, now a double song, floats. 'How delightful!' she exclaimed : those staccato notes, then the trills, now the disconnected warblings ; a strange intermingling of varied notes, so striking in contrast, and yet, as a whole, so admirable, - like a necklace of frosted gold and diamonds alternating, each adding beauty to each. Now the singer hops into sight, - a Goldfinch, beautifully marked and ornamented."

In addition to his beautiful qualities above described, his intelligence is something wonderful, and is but rarely equalled in any variety of the bird-race. After once overeoming the bird's natural shyness, and obtaining his confidence, the task of teaching the cumning and even difficult tricks which he is capable of learning to perform is an easy matter. The bird must be taught to know but one master, and as soon as acquainted with him, by means of a dainty, in the shape of hemp-seed, will gradually eat from the hand: and the successive tricks of teaching him to eat from the mouth, and to climb the ladder, by making him perch on the forefinger of one hand, and climb to that of the other, by raising it above the one on which be is perched, and so on, until he has mounted many rounds, will be succeeded by the more difficult ones of firing off miniature cannon, and playing a tiny barrel-organ, in which he places himself on duty in the treadmill to produce the harmonious sounds. Feigning death, and feeding himself, and furnishing his own drinkingwater, by diawing his seed from a trough supplied with a quantity of it on a tiny wheelbarrow, and drawing his drinking-water from a miniature well, placed beneath the platform of his cage, in "Old Oaken Bucket" style, by means of a small chain attached to a thimble, - these and many other difficult tricks he performs with apparent pleasure; and the training which he undergoes interferes in no way with his pretty song. He bears the same relation to the bird-race, in his special line of training, that the trained Bullfinch bears to it in the art of music.

When thoroughly trained, the Goldfinch thinks but little of his freedom, and evinces his displeasure if his master does not attend to his daily duties in the way of caresses, and bestowing upon him his usual dainties. He will perch on his owner's finger, and insert his sharp little beak between the lips in search of a hidden hemp-seed; although he may perform this pleasant trick with due respeet to the one whom he loves, if a stranger should attempt it with him, he would be apt to administer such a vicious dig on the lip with his needle-lıke beak, that the stranger would think that the blow was given for the purpose of sewing his lips together.

In confinement the Goldfinch should be fed on maw or poppy seeds, mixed with a third portion of either hemp or canary seeds. Lettuce, sweet apple, or ripe fruits of any kind, shonld be given him three times each week: he is also fond of scraped beef, which may be given about once a week. The daily bath is the Goldfinch's greatest luxury; and he enjoys his plunge, and the after arrangements of completing his toilet, with the greatest pleasure. He is a proud little fellow; and the dis- 
placement of any of his gay feathers is as quickly noticed as a speck of dust on the eoat of the most fastidious dandy.

'The proper' cage for a Goldfinch should be high, and either round or' square, and of the regular Canary-cage size; because he likes to leap and climb upward, and always utters his sweetest song from the highest perch of his eage. As an aviarybird the Goldfinch has no equal; his handsome plumage, his sociable ways, and constant motion, making him one of the most attractive birds which could be used for this purpose.

In the breeding-room he again ranks next to the Canary; and when a good specimen, which breeds the rare colors so eagerly sought for by the anxious birdbreeders, his value is greatly enhanced. A full article on the breeding of Goldfinch-Canary Hybrids may be found in the article on Canaries.

Goldfinches may be mated and successfully reared in cages in the same manner as Canaries. The best birds for the purpose are those which have been caged for two or three seasons. Some breeders claim that the white-legged variety are sure to mate and breed. Why this should be, I do not know; but it is certain that the attempt very often succeeds.

The progeny of birds which have been bred and reared in cages are the best materials with which to effect sure results, as their domestication makes them breed more readily.

If moulted in a dark room, or where the sunshine is wanting, the bright colors of the Goldfinch are apt to become dull ; and after a second moult the bird will totally lose his most brilliant colors: therefore, when moulting season arrives, the cage should be hung in a sunshiny place, and the bird supplied daily with green food or fruits.

He is not subject to many diseases. Epilepsy usually is caused by fright ; decline is the result of too much plain food; and giddiness results from eating too much maw-seed.

Epilepsy may be cured in the same manner as advised for Canaries.

Decline is cured by changing the diet to rich food, such as lettuce, apple, or fruits, and raw, scraped beef.

Giddiness may be treated by withdrawing the maw-seed, and feeding on soaked plantain or millet-seeds until the bird has recovered.

Diarrhœa and Constipation should be treated in the same manner as advised for Canaries.

The Goldfinch, if properly cared for, will live caged for twelve or sixteen years, and in his old age will lose none of his sprightly melody, graceful motion, or beautiful color. 


\section{EUROPEAN LINNET.}

THIS sweet-voiced little songster is justly held in the highest estimation by all lovers of cage-birds, and, next to the Canary and Goldfinch, is probably the best known of the smaller songsters. His sprightly, melodious voice, docile ways and extreme hardiness when eaged, make him a great favorite. Although his plain brown garb camnot be termed handsome; yet in some eases, when lie appears as the Redpoll, the sleek plumage is greatly admired when adorned by the handsome crimson of the forehead.

The Linnet inhabits most of Europe and Northern Asia, and, during his migrations, appears also in many parts of Africa. The plumage of the bird varies greatly at different ages aud seasons of the year, - a fact which not only mixes the family up in the greatest confusion, but is also the cause of both numberless mistakes by ignorant bird-dealers, and of great errors in works of ornithology. The family of Linnets, in these eases, are divided into three classes, which are made separate species from one another, as the Brown Linnet, the Greater Redpoll, and Yellow Linnet. By numerous and careful observations it is proven that thesc three are one family; the variations in the colors of the plumage occurring at different seasons of the year, and at the particular ages at which the bird is seen.

A male Linnet at three years of age, when he has attained his full plumage, and is known as the Redpoll, may be described as follows: The forehead is blood-red, the rest of the head reddish ashen gray, spotted on the poll with black, and on the cheeks, the sides of the neck, and around the eyes, with reddish white. The feathers of the upper part of the back are rusty brown: the lower part is mottled with gray and white. The tail is forked and black; the four external feathers having on each a deep margin of white, which, in the two centre feathers, is. narrower, and tinged with red.

After the antumnal moulting, the red on the forelead disappears, and the same hue on the breast becomes less conspicuous: the colors, however, recover their brilliancy in the course of the winter.

Males of one year old have no red feathers on the head; but, instead, the black spots are more numerous. The breast is light rust color throughout: the rust color of the back is also spotted with dark brown and reddish white. Such birds are known as Brown or Gray Linnets.

After the second moulting, specks of blood-red may be observed on the under sipe of the reddish-gray feathers ; and the red of the breast is concealed only by the broad, yellowish white margins of the feathers. These birds are called Yellow Linnets. Bird-sellers sometimes give the name of Yellow Linnets to those birds 
in which the red on the breast and forehead is replaced by a bright orange : this is merely the effeet of old age, or sickness during moulting. Such birds are often the finest songsters; but they are, as a rule, remarkably shy and wild, and usually die of grief, from which it must be inferred that the birds are very old. As a general rule, the older the bird, the redder the color on the head.

Those birds which have been deprived of their liberty when young never acquire the beautiful red color on the head and breast, but always resemble the one-year old, or Gray Linnet.

No variation of color is observed in the female Linnet; she is somewhat smaller than the male; and the colors on the breast and back are of a much duller cast, and more gray than brown.

The Linnet, in a wild state, breeds twice a year; the female laying each time five or six eggs. The old birds feed the young from the erop, and, when the whole brood is taken, will continue to do so in the cage.

The devotion which the parent birds show their young long after they are able to provide for themselves is remarkable, and it is related that a pair of these birds continued the care of their captured nestlings for a long time while the cruel bars of the cage separated them.

The Linnet is chiefly prized on account of his beautiful song. In the interior of England, where the perfeet song of the trained Canary lias not penetrated, the Linnet is the highest prized of all song-birds : and singing-matches are regularly held among varions owners of the best song Linnets, one contesting bird only singing at a time; the requirements of song generally being for variety and number of notes, length of rolls or runs on the same notes, and length of time without breaks within the time fixed upon, which is decided by appointed judges.

'The Linnet's song ranks very high. His tone is mellow, his notes very sprightly, artfully varying into the plaintive strain, and returning again to the sprightly, with the greatest address and most masterly execution. During the contimuance of the song, certain clear or sonorous notes recur, which is ealled the Linnet's crow ; and the song is esteemed in proportion to the frequeney with which these notes are sung.

'The Linnet's song greatly varies; while in some eases the notes are sung in a masterly manner, in others the song falls greatly below the most commonplace song-bird. The difference is accounted for in the training: the Linnet is as susceptible of a thorough training as the Canary; and if taken from the nest when young, and placed within hearing of a first-class songster of his own variety, he will become one of the same kind. He will also copy the notes of the Nightingale, Lark, or any other highly prized song-bird, with remarkable precision, and rivals the trained Canary in that respect. It is also elaimed, that Linnets have been trained to pipe airs in the same manner as the trained Bullfinch.

Another claim which the Linnet has, as a superior cage-bird, is the ease with which he may be trained to perform numerous trieks at the word of command; and his intelligence in this respect ranks as high as that of the Goldfinch or Siskin. If his plumage were as beautiful as that of the Goldfinch, he would fairly outrank that little favorite in popular estimation.

'The Linnet's many attractive qualities are not so well known to the bird-faneiers 
of this country as to those of Europe: the birds of this species which are usually sent here are those which have been trapped, and are consequently wild and shy when placed in an open cage. The best class of Linnets are the trained nestlings, which are now regularly imported to this country in small numbers; and it is safe to say, that, when their many beautiful qualities are known, they will quickly displace many of the now more popular songsters.

The beautiful wild song of the Limnet is best described in Burns's popular verse :-

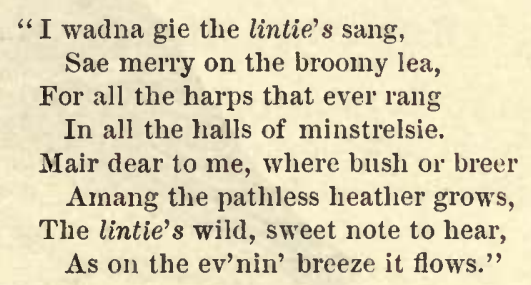

The Linnet is probably the hardiest bird of any of the smaller class of songsters. He is not apt to eatch cold ; as his tough North-of-England, or Scotch, constitution fits him to withstand many of the hardships which other cage-birds could not undergo: in fact, his toughness may be compared to that of the song 'Thrush or Blackbird.

The Hybrids reared from a Linnet and Canary comprise, sometimes, most beautiful varieties, varying from the clear milk-white specimen to the gray variety. The birds of this class are very highly esteemed, on account of the ease with which they lear'u to sing the Nightingale's song, or the trained notes of any other bird.

In pairing birds for Hybrid-breeding, the male Linnet and a female Canary, which are known to breed white Hybrids when mated, generally reproduce beantiful specimens.

Linnets may also be successfully paired in cages, and bred in the same manner as Canaries. When Linnets of this class are obtained, they may be taught in the same way as young Canaries, and will probably surpass them, after thorough training, in purity and fine quality of the voice, owing to the natural, flute-like tone.

If the Redpoll is moulted in the sunlight and fresh air, the beautiful crimson on the head will in no way be diminished in depth of color. All birds of brilliant colors, when moulted in dark rooms, are apt to lose the depth of color : pure air and plenty of sunshine are essential in these cases.

The cage which should be used for the Linnet is the regular Canary size. Trapped Linnets should be placed in covered cages until they recover from their shyness: otherwise they would be apt to pine away and die from the continued efforts to escape, and exposure to unaccustomed objects.

The food, care, and treatment of Linnets are the same as given for the Canary.

If properly cared for, the Linnet will thrive in a caged state, and remain in constant song from twelve to fifteen years. 


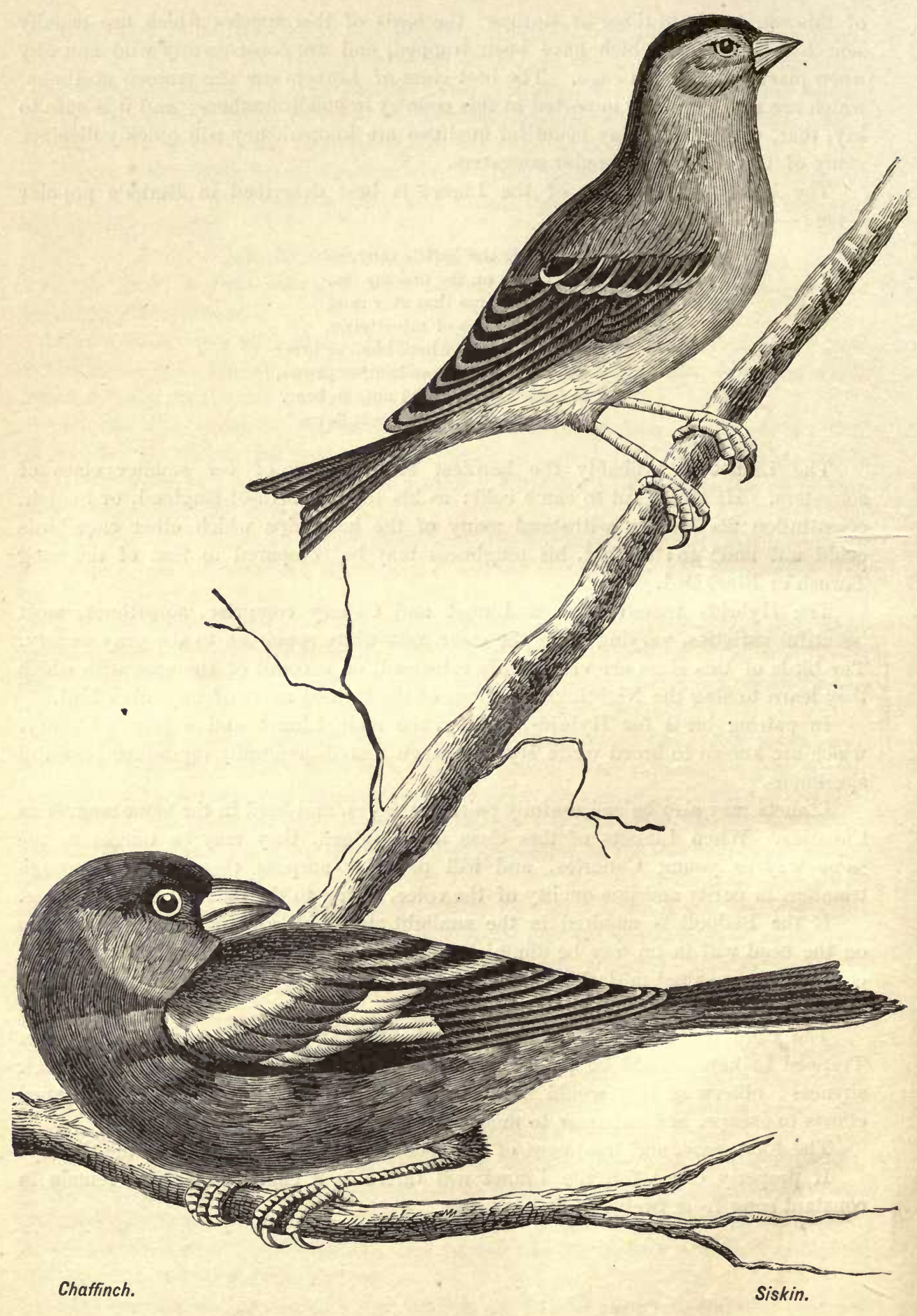




\section{THE CHAFFINCH.}

'Tn: Chaffinch is an oldly eoated, sprightly fellow. In order to hear his song in perfection, one must visit the eountry where he is so highly respected. That must be a valuable bird when a poor man cheerfully gives up his cow in exchange for one known to be perfect in song. Yet it is said that instances of the kind are not infrequent in 'Thuringia, where the bird is prized above all songsters. He is not so highly esteemed in America, because one is rarely imported of the above value. In England singing-matehes are held by owners of these birds, in order to decide their respective merits. In eertain parts of Germany one is rarely heard in his wild state in perfect song, because of the craze for them. Bird-trappers will travel miles for them, and spend many weary hours in endeavoring to trap one if he ventures near where his song may be heard.

The Chaffinch is about six inches and a half in length. The beak is conical, and is white in winter' but, at the time of mating, it turns blue, and remains so until moulting season. As the birl commences to sing at the time of mating, the color of the beak is an indication as to whether the bird is in song or not. The cheeks, throat, breast, and belly are a reddish chestnut brown, tinged with a lighter shade toward the vent. The forehead is black, the nape of the neck grayish blue, and in old birds a darker shade of blue. 'The upper part of the back is ehestnut brown, tinged with olive green: the lower part of the back is light green.

The female, being smaller, is easily distinguished from the male; and the bright colors on the upper part of the male's body are replaced by a grayish brown, and on the breast by a reddish gray. The Chaffinch is an inhabitant of all parts of Europe, but is most common in Germany. They are migratory birds, and begin to arrive in March; the males arriving some time in advance of the females, which has gained for them the name of bachelor birds. 'This earlier arrival is also taken advantage of by the bird-eatehers, who are sure of not encumbering their traps with unmarketable females. The lird's chief value, undoubtedly, lies in his song, which is distinguished from all other birds' by the near approach to the articulation of speech. The natural wild song is greatly enhanced by instruction, which the bird is obligel to undergo in order to become perfect: one of these trained singers is often hung in a room with a number of young birds, which receive a regular course of instruction, and are afterwards perfected still more if they are capable. Bechstein enumerates no less than thirteen different varieties of song which these birds are able to produce, some singing as many as four of them. 'The highest prized of all the songs is termed the "double trill" of the Harz. It consists of five long passages, or strains, and ends in a double-syllabled word, which is dwelt upon at 
considerable length. This song is not wholly natural, hut partly so. In order to be perfect, the bird should be tanght it: it is said that a bird which can interpret this song in all its perfection may be taught to speak, as the different syllables require a distinct pronunciation. The entire list of songs are designated by names which the bird pronounces, or is supposed to pronounce, in the course of his song. This bird, unlike a majority of trained birds, never forgets what has been taught him; his song returning to him in all its completeness after the moulting season. When a trained singer is placed in a room for the purpose of instructing younger birds, the room should be darkened; as the younger birds learn much more readily than when too much light is given.

In some parts of Europe, in order to make the Chaffinch sing by night as well as day, he is put in a totally dark room for a few days, in order to accustom him to find his food: he is then deprived of his sight by means of a red-hot needle passed through the pupils of the eyes, - a heartless piece of conduct, which cannot be too severely condemned.

The Chaffinch may also be taught a variety of tricks, although not as easily taught in this respect as many of the other Finches. He is noted for the beauty of the construction of his nest. He may be paired with a female Canary in breeding season, but Hybrids of this variety are rarely seen.

The proper food for the Chaffinch is the mixed canary-seed, varied occasionally by a few grains of hemp: too much hemp should not be given; for although it does not injure the song, as in ease of a great many seed-eating birds, it makes them fat, and subject to disease. A piece of sweet apple, or green food of any kind, should be given occasionally as a variety, and to aid them in digestion. A mealworn is a dainty, and two or three every week will keep the bird in perfect song. The daily bath should not be neglected. A larger cage is required for the Chaffinch than for the Canary; the best being the brass cage $11 \times 13 \times 17$, or wood framed, tinned wire, $9 \times 14$.

In sickness this bird should be treated the same as the Canary.

\section{SONG.}

FROM TIIE GERMAN OF GEIBEL.

Birdling, whither now, I pray?

"Southward far I wing my way."

There the sun shines warm and clear,

'Tis the winter of the year.

Birdling, when on mottled wing,

'Mid the linden-leaves you sing.

Where my gentle love doth dwell,

Tell her, that, by night and day,

Lives she in my heart alway;

Tell her that I love her well.

And the flowerets of the plain,

Kiss them o'er and o'er again. 


\section{THE SISKIN.}

'Turs is a diminutive, green-colored fellow, very unpretentious in color, and is very well known in our larger eities by the number of them which form the stock in trade, or, rather, the brains, of numerous itinerant venders of fortunes (never bad ones) on street-corners. 'The bircls are usually seen in a long box-cage, with a trough attached, containing a number of envelopes ; and, on the payment of a trifling fee, one will poke his head throngh the bars, and select the envelope which contains the written secret of your future life. He is one of the easiest of birds to teach simple tricks ; and whether it is in performing the feat of firing off a cannon mauy times his size, or drawing his tiny bucket of water for his daily drink, le performs them in such an accommodating manner as to leave the impression that he enjoys the performance as much as does the spectator. It is chiefly for the ease with which he learns to perform that he is prized. Siskins are very numerons throughout Europe, where they remain the entire year. He is four aud three-quarters inches in length. The top of the head and throat are black; the neek and cheeks green; the back, green, speckled with black; the under part of the neck and the breast are greenish yellow; the belly and vent whitish yellow. 'The wing-feathers are black, bordered with yellowish green: the tail is forked. 'The female is paler' in color, and is without the black on top of the head. They are favorite birds to mate with Canaries; and haudsome specimens are produced where the male Siskin is bred with a high-colored female Canary, although success is more certain if mated with a female green Canary. The male birds combine both beauty and song to a marked degree.

The Siskin should be fed on poppy or maw seed, mixed in equal proportions with plain canary-seed, and occasionally a few grains of hemp, the latter as a reward, when the bird is in training. He is remarkably free from disease, his chief ailment being epilepsy. He lives eaged to the age of about eight years. The song is quite pleasing, being a combination of pretty elirps, and is given throughout the year. 'The bird is sociable, and, as he is not of a quarrelsome disposition, is quite an attraction for the aviary, where he has room to display his gymnastic qualities. The regular Canary-cage is the most suitable for him. 


\section{THE NONPAREIL.}

The Noupareil, or Painted Bunting, is a gayly plumed little bird, and, as lis first name indicates, unequalled. Indeed, it would be difficult to find such a blending of beautiful colors in any other songster. His shining coat of red, blue, and gold, as it glitters in the sunlight, each color seemingly more beautiful than the others, calls forth admiration from the most careless observer. The Nonpareils breed in our Southern States, and in the summer season they are caught in large numbers. Louisiana is a favorite haunt with them, where they are great favorites with the French inhabitants, who, true to their native instincts, admire any thing which is gayly dressed. 'This bird is not by any means the lowest in the list of song-birds ; for his melorlious warble, given in a low, concise manner, adds much to his other attractive qualities. He is very easily domesticated, and, after a few days' confinement, appear's reconciled to his new mode of life. Pairs are very easily mated, and require no more eare than the mating of a pair of Canaries. If the same attention and interest were taken in breeding this class of birds as are taken in breeding Canaries, they would, no doubt, become much more popular than at present: whatever inferiority they have in song is more than made up by the richness and beauty of plumage.

It is a pleasing operation to wateh the numerous changes which the feathers undergo before the birds attain their full colors. The Nompareils arrive in the Southern States from the warmer latitudes about the latter part of April, and raise two broods in the breeding season, which lasts until July 1. The young birds of botl sexes, during the first season, are a fine olive-green color on the upper parts, and pale yellow below. 'The female undergoes no material change in color afterward, except becoming a darker shade as she grows older. 'The male birds, on the contrary, are three seasons in obtaining their full variety of colors. In the second season the blue on the head begins to show, intermixed with the olive green : the red also begins to make its appearance in spots which dot the breast. The third season the bird attains his full beauty, and blossoms forth in his beautifully intermingled colors, blue, green, and scarlet. When in full color the head and neck are violet, the upper part of the back bright green, the lower part of the back and the rest of the borly a bright red: the tail is brownish red. From the above description it may be seen, that, until the second season, it is next to impossible to tell the male from the female; and, no doubt, many an unsuspecting buyer lias been astonished and delighted at finding the bird which he bought for a female Nonpareil bloom out in any thing but feminine-bird colors the following season. The ease with which the Nonpareil is trapped makes his stoek very numerous in the birdmarket in the season, which lasts in the Northern States from May until September. 
He 
萡

…

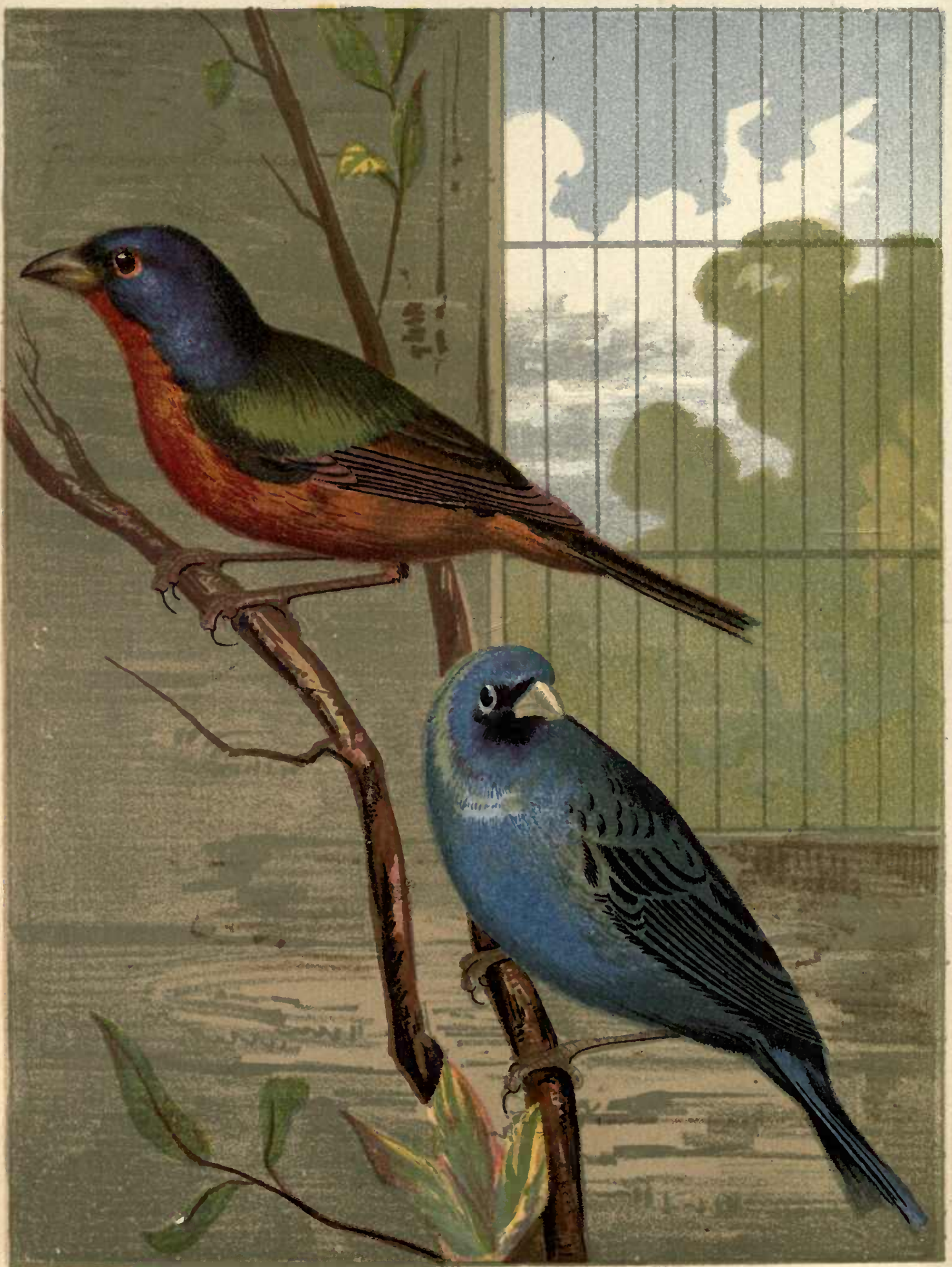


The method of trapping Nonpareils is, to place a stuffed specimen or a painted plaster-Paris imitation in a trap-cage: his brilliant feathers attract the attention of the passing flock, which pounce upon him, and spring the trap; thus making prisoners of themselves. In this manner thousands are caught every spring, mostly by negroes, who make an easy living while the game lasts. 'The Nonpareil begins to feed immediately after heing eaged, which is contrary to the usual habit of trapped birds. He may be bought as cheaply in the Northern States as in the Southern, because the great numbers sent North are usually traded off for Canaries and other imported birds, which cannot be sent direct to the Southern States; thus making the cost in reality but little above the original price in their breeding-places. Many a Northern lady, while visiting the ortunge-groves of Florida in the winter season, becomes enchanterl with the beautiful appearance of the Nonpareil as seen in his wild state, and offers some wily negro a tempting prize for the capture of one. The negro, who is always ready to please this class of customers, easily procures one, and charges the price which he usually procures for a dozen from the bird-dealer. The lady, not being a bird-fancier, takes unusual care to transport her charge safely to lier Northern home, and exhibits him as one of the rarities and beauties of the Southern elime. If she chances to take the trouble to visit the nearest bird-shop, she will see how easily she could have saved the trouble, and one-half the original cost, by buying at home.

The Nonpareil is very easily tamed : he is passionately fond of flies and insects, and readily learns to take them from the hand. This should be the first step towards his regular course of training, when training is desired. In their wild state, the regular food is rice, various kinds of insects, and different varieties of seeds.

They are largely exported to the various European countries, where of late years they have become great favorites. In some of the zoölogical gardens, notably at Antwerp, they are bred with great success. At Havre and Paris immense numbers of them are sold yearly.

A great deal of fault has been found by the lovers of these birds, owing to the change of color which they undergo while moulting. If eare is not exercised during the moulting period, the bright dress is apt to become a dull orange hue. If the bird is given plenty of room, and a daily bath, and all the sunlight that can be possibly proeured, he will come out as brilliant as though he moulted in his wild state. Sunlight is the chief requisite in moulting birds of a natural bright plumage; and, when plenty of it is given, there need be no fear of their losing any of their gay colors.

The Nonpareil has been mated with the Canary; and although this species of Hybrid-breeding has been rarely attempted, no doubt if the same attention was paicl to this kind of eross-breeding that is given the regular Goldfinch-Canary cross, the result would more than repay one for the trouble. The Nonpareil will live in confinement about ten year's, and should be fed, when caged, on plain canary-seed, or plain canary-seed mixed in equal proportions with millet-seed. The daily bath should never be neglected, as it seems to be a special necessity with him. His diseases are few, constipation being the chief : although a seed-cating burd, he should be fed insects and worms as regular as the soft-food birds; when this is done, he keeps remarkably free from disease, and will live many years. 


\section{THE INDIGO-BIRD.}

This beantiful and favorite American songster is well known in all parts of the United States. He is among the first to make his appearance in the spring-time, and his merry warble in the fields and orchards is always a welcome sign. His (locility and beauty make him a universal favorite; and whether in the aviary, or eaged in single blesseduess, he appears equally happy. His pure, handsome blue color makes him a striking object when viewed in contrast with the various colors of a well-stocked aviary; and, as he is one of the most sociable of birds, he is always sought after when a nice collection is desired.

The Indigo-bird is about five inches and a half in length. The beak is a dark lead color, and the feet are brown. In the spring-time, when in perfect plumage, the entire color of the male is rich deep blue, being most brilliant on the top of the head and neck, the wing and tail feathers being slightly tinged with brown. When the bird assumes his winter coat, the blue on the body is tinged with brown, and the breast is speckled with whitish spots. The female Indigo-bird is easily distinguished from the male; the entire plumage being a dusky blue intermingled with brown, which color she retains the entire year.

The song of the Indigo-bird, although not so loud and varied as some, is very agreeable, and, when caged alone, is constant, except through the moulting period. He is a very apt scholar, and is one of the favorite trick-birds. He may be taught as readily as the English Siskin or Goldfinch, and his efforts in firing off cannon and drawing water make him a great favorite with those fond of this class of birls. Like the Nonpareil, he is largely exported, and, being a Northern bird, is somewhat better adapted to withstand the cold climates.

His food should be the same as that of the Nonpareil. The same treatment also applies to both. Cross-breeding has been attempted with the Canary, but with poor success; the colors being disappointing.

'The Indigo-bird lives usually in confinement, when carefully looked after, about seven years. The regular Canary-cage is best adapted for him when it is desired to keep him alone. When kept in an aviary he is apt to live longer, owing to the freedom and greater variety of food which he obtains. 


\section{THE YELLOW-BIRD.}

'THERe are very few bird-fanciers, or, in fact, the most indifferent olsservers of the bircl-race, but what have admired the smartly dressed, intelligent Y ellow-birl. He rejoices in a surprising variety of names; being known as the American Goldfinch, Thistle-bird, New-York Siskin, and called by the misehievous bird-trapping urchins, The Shiner. He is a pretty little fellow; and whether performing any of the numberless tricks which he is capable of being taught, or simply eaged on account of his pleasing manners, he is always the same unassuming bird, which trait has won for him his many friends. His cheapness is one of the least of his many virtues.

These birds are found in abundance throughout North America. The Yellowbird is about four inches and a half in length, of a rich lemon color, fading into white on the rump and rent. 'The wings and tail are black, the former being edged and tipped with white: the fore-part of the head is black, the bill and legs of a reddish cinnamon color. 'This is the summer dress of the male; but in September the yellow gradually changes to a rich tint of brown olive, and the male and female are then nearly alike.

They build a very neat and delicately constructed nest, which they fasten to the ivigs of a tree, covering the ontside with pieces of moss or lichen, which they find on the trees or fences. 'These they glue together-with their saliva, and afterwarts line the inside with the softest downy substances they ean procure. The young males do not attain their perfect plumage until they are one year old, wanting during that time the black on the head; and the white on the wings being of a cream color. In the month of April they begin to change their winter dress, and about the middle of May appear in a coat of brilliant yellow.

During the latter part of summer they are constant visitors in the gardens and orchards, seeking the seeds of which they are so fond, and dislodging them from the husks in a very adroit manner.

The song of the Yellow-bird is a pleasing suecession of short notes or twitters, and greatly resembles the song of the European Goldfinch, but somewhat weaker ; as it appears to come from a distance, although the bird may be perched on the hand. When perched together in flocks, and singing their morning concert, the sounds produced are not at all unpleasant to listen to, and form a sort of harmony extremely new and original.

The Yellow-bird bears a striking resemblance to the Canary, the chief difference being in the size. Attempts have been made to mate the male Yellow-bird with the female Canary; and, although in some cases the result has been successful, the progeny were not of sufficient value to make the investment a paying one. 
The Yellow-birds are probally trapped in larger numbers than any of our native birls, and in the large cities in the proper season may be seen exposed for sale in any of the principal markets or on street-corners. Unlike the majority of freshly trapped birds, they take naturally to the eage, and eat readily as soon as food is offered. The seeds which the Yellow-bird eats in lis wild state are the lettuce, thistle, and hemp. In confinement he will thrive on maw or poppy seeds, millet and canary mixed, which should he varied oceasionally by the addition of a few grains of liemp.

It is probably owing to the great frequency with which they are seen in thieir wild state that they are not more frequently seen in the eages of bird-lovers. They make most desirable eage-birds, and the number of tricks which they are capable of learning eannot be surpassed by the best-educated birds known; and they rank ahead of the European birds of the same class in the intelligence displayed. To show what they are capable of doing, the following feats are related of a troop of trained Yellow-birds which travelled for many seasons throughout the country. They were a source of wonder wherever exhibited, and the means of considerable revenue for their owner. The troop consisted of eight birds: one appeared dead, and was held up by the claws or tail without exhibiting any signs of life; the second stood on its head with its claws in the air; the third imitated a Dutch milkmaid going to market with pails on her shoulders; the fourth mimicked a Venetian girl looking out of a window ; the fifth appeared as a soldier, and mounted guard as a sentinel; the sixth acted as a cannoneer, with a cap on its head, a musket on its shoulder, and a match in its claw, and discharged a small eannon. The same bird acted also as if it lad been wounded. It was wheeled away in a barrow, to convey it, as it were, to the hospital, after which it flew away before the company. The seventh turned a windmill ; and the last bird stood in the midst of fireworks, which were discharged all around it, without betraying any signs of fear. The usual tricks of making them draw water from a well by means of a thimble attached to a string, and drawing their seed in a diminutive wheelbarrow, are commonly seen.

They make very sociable aviary-birds, and live in perfect peace with the remainder of the family. Their natural tameness permits one to allow them the freedom of the room, and they betray no fear at the approach of their master: after a few lessons in taking seeds from the hand, they gain confidence, and become apt pupils, learning quickly the more difficult tricks.

The different styles of eages in which they may be seen are numerous and varied. The poor owner who cannot afford a costly brass cage will be apt to make an aged basket or box, with a woven-string front, answer all purposes. The best styles of eage are the round or square, painted, or all brass Canary-cages.

When these birds are dumpish or sick, feed crushed hemp. Keep them warm, and acld a few drops of paregoric to the drinking-water. A bath may be given every day. 


\section{AMERICAN RED LINNET.}

Turs bird is a charming songster, and a rival of the Englishman of the same surnane. He is commonly seen in our Northern woods in the summer season. The colors of the male, after attaining the full plumage, are red or rose color, most intense on the head, mixed with dusky streaks on the back, fading to white on the belly and vent; wings and tail dusky, with reddish edgings. The females and young male birds have no red or bright colors on their plumage, but resemble some of the Sparrow tribe: they may be recognized by the short, stout bill. While the male birds are changing their colors, they show every gradation between the colors of the opposite sexes, and frequently show saffron or bronzy tints throughout the plumage. They are naturally tame, and delight to build their nests near the habitation of man. 'The length of the Red Linnet is about five inches and a half. The male bird sings throughout the year, and is a most desirable songster to cage ; being exceedingly tough, owing to living in the Northern climate. The treatment and care should be the same as for Canaries. Linnets are trapped in large numbers, but rarely bred in confinement.

Throughout the Northern States is also found a Gray Linnet, a larger specimen than the Red, resembling in appearance the coloring of the Sparrow race. This bird also makes a most excellent songster and good cage-bird.

Other varieties of the Linnet family are the Redpoll and Pine Linnet, both good specimens. The members of the Linnet family are all noted for their toughness, and the ease witl which they may be tamed. They all require the same care and treatment as given to Canaries. 


\section{THE SNOW BUNTING.}

Tuis bird bears the same relation to the bird-race that the Esquimaux do to the human race. It appears to be a fact, that, unless icebergs are around, the snow Bunting is not happy. He is an inhabitant of the coldest and most dreary climates, and is unknown in latitudes where snow does not abound. He is chameleon-like regarding the color, which includes any thing from the clear white to the dusky brown; the most common colors seen being the winter dress, - a mixture of white on the body and head, the wings being brown or dun colored. In summer the plumage changes to a tawny brown.

In the districts of Siberia, Russia, and Greenland, where game is scarce, the Snow Buntings form one of the chief articles of diet. They are found in swarms in these sparsely settled regions, and it is a matter of surprise to see how they are able to exist where sufficient food must be so scarce. They are the subjects of numberless legends, and are known in our own country as the harbingers of severe cold weather. 'They become very tame, and easily get acquainted with the inhabitants of a household who have been kind to them. They will make daily ealls in search of bread-crumbs or seeds which have been seattered for them. They are harmless birds, and are not often seen caged; although they are easily trapped by means of horse-hair loops. As their desire for freedom is so great, it seems a pity to keep them caged. 'They form one of the few picturesque scenes of a dreary winter, and should be allowed to remain in their native places.

When in confinement they will eat almost any kind of seeds, oats, or breadcrumbs. The warmer temperature to which they are naturally introduced when caged does not appear to affect them.

The song 'of the Snow Bunting is a series of whistles, some of the varieties being recorded as most excellent songsters. 


\section{JAVA SPARROWS.}

Every one who writes of the Gray Java Sparrows mentions the fact that they are well-known cage-birds, and this is indeed true. Probably no foreign cage-bird is better known here than this sleek, handsome, inquisitive-looking fellow. To be sure, beyond his well arranged dress and docile ways, he has no special recommendation; yet it is always a pleasure to look at one, or a number of them, chatting away as lively as a lot of blooming maidens arrayed for a matinée.

The Java Sparrow's chief object in life seems to be to keep elean, a virtue which a great many sweet singers do not possess; and this, likely, makes him the farorite with many admirers. He is an amusing bird, and is much sought after as a pet for children and invalids. His short chirps are not disagreeable, and will in no way be a disturbance in a sick-room; while, socially, his company is very enjoyable.

He derives his name from the island of Java, in which place, and other EastIndian countries, large numbers are captured, and brought to European and American ports by sailors. The care given to a very large number of them during a voyage is very slight; as they are hardy birds, capable of withstanding all degrees of heat and cold, and thrive on unhulled rice alone. They are called in their native countries Rice-birds, and are as common as the English Sparrows in our own land. They do immense damage to the rice-crops, and are a source of constant annoyance to the inhabitants, who endeavor, by means of movable scarecrows, very ingenious in construction, to deter them from destroying the crops. But like our native torment, the Crow, they become accustomed to the various devices used, and wink at such meaus of intimidation.

The Java Sparrow is about five inches in length: the beak is very strong and large, and is of a beantiful rose color, with the appearance of being modelled from wax. The middle of the breast and belly are a handsome shade of slate color, and the upper parts of the body are a somewhat darker shade of the same color. On the cheeks are clear white spots ; and the throat and face are black, with a satin-like sheen; the feet are reddish brown.

There is no cage-bird so easily kept as the Java Sparrow : he is like the Chinese in his frugality; rice being his only food, and a daily bath his principal luxury.

He may be easily taught numberless amusing tricks, such as feigning death, playing soldier, standing on his head, etc.

In London a favorite trick-cage is used for the Java Sparrow : it is a common wooden cage, with a large revolving-wheel for one side, and is fitted with perches arranged in the form of a circular ladder; inside the wheel a music-box is concealed. The Sparrow is trained to jump from one rung of the ladder to another, 
ancl the wheel acts in the same relation to the music-box as a crank to a liand-organ. As the bird hops, the music-box plays, and continues playing until the bird is quiet. 'The birds always seem to enjoy the music, and need no urging to make them perform their pleasing duties.

The care of Java Sparrows is easily explained. 'Their focit should consist of Paddla, or unhulled rice, and occasionally some plain canary-seed. The daily bath should not be neglected. The Sparrow's silken coat retains its bright appearance throughout the year: in fact, so snug are the feathers, that his plumage does not seem to consist of separate feathers, but a single block. After lus daily plunge, the water drips off his back as though running from an oily surface. It is always better to keep the Java Sparrows in pairs, although they thrive very well when separated.

The best eage for a pair is the brass cage $10 \times 13 \times 15$, or the wood-frame timued-wire eages $9 \times 14$ to $12 \times 24$.

The common-sized Canary-cage is suitable when it is desired to keep only one bird.

They also live peaceably in a large aviary. 


\section{WHITE JAVA SPARROWS.}

These are among the most striking birds when kept in a large collection. The beantiful, clear white, silky plumage, set off to good advantage by the clear rosetinted beak, gives the White Java Sparrow an appearance which at once arrests the attention of any observer.

The clear white color is another evidence of the superiority of the scientific breeding of the bird-fanciers in China and Japan. How the change of color from the gray to the white was obtained will probably never be known. Some writers assert, that the birds were originally bred in rooms where nothing but white color was seen; and, in breeding dlown from generation to generation, the white variety was gradually obtained. Jacob, a son of Isaac, changed the color of cattle by this method. That is a convenient way to account for the Sparrow's transformation. Other writers assert, that the gray variety was fed on clialk, which changed the plumage. One story is probably as truthful as the other; and, as nobody knows for a certainty, it is better to let the matter remain a mystery. It is, however, certain, that the White Java Sparrows are not of the Albino race; as they lack the pink eyes always seen in the various specimens of that race. They may also be bred in confinement, and produce progeny of the same color, which is an impossibility with any Albino bircls.

The Japanese make a business of breeding the White Java Sparrows ; and each pair has a small cage, in which is placed a perch and nest. By careful and stimulating feeding, they are made to lay freely; and, as soon as a brood is hatched, the old birds are placed in another cage, where they continue hatching and breeding. 'The young are brought up by hand, being fed on a scalded vegetable decoction mixed with millet-sced.

It is an easy matter to breed White Java Sparrows in this country, and, besides being easily done, much more remunerative than Canary-raising. Put a pair in a common breeding-cage with a straw-basket nest, and furnish materials, which may consist of pieces of straw, hay, hair, or fowls' feathers; and they will commence to build as readily as a pair of Canaries. The period of incubation lasts about the same length of time as required for Canaries. When the young are hatched, feed on egg-paste mixed with millet-seeds or crushed hemp. When full grown, the birds are as hardy as the gray variety, and require the same care.

The White Java Sparrows are usually seen in aviary collections, where they always keep by themselves, and never molest the other inmates.

It requires an expert to tell the difference in the sexes of the birds of either variety, they resemble each other so closely; and when ordering a pair from a 
distance, for breeding purposes, they should be ordered from a reliable dealer. The same-sized cages should be used for the White as for the Gray. Java Sparrows.

The mottled white and gray Java Sparrows, although very handsome in appearance, are not so highly prized as the pure white: the streaky appearance is probably due to some defect in the breeding.

Java Sparrows live to be twenty years of age.

TABLE OF BULLFINCHES, GOLDFINCHES, ETC.

\begin{tabular}{|c|c|c|c|c|c|c|c|c|c|c|}
\hline & \multicolumn{5}{|c|}{ Vorce. } & \multicolumn{5}{|c|}{ ATTRACTIVE QUALITIES. } \\
\hline & 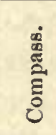 & 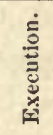 & 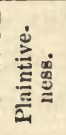 & 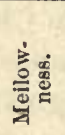 & 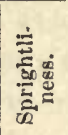 & 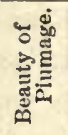 & 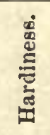 & $\frac{\stackrel{\Delta}{*}}{\frac{\pi}{2}}$ & 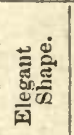 & 䲻 \\
\hline Bullfinch (trained) . & 10 & 10 & 10 & 10 & 10 & $s$ & 8 & 6 & 8 & 10 \\
\hline Goldfinch (European) & 6 & 6 & 4 & 4 & 9 & 9 & 8 & 4 & 7 & 9 \\
\hline Limmet (European). & $\tilde{5}$ & 6 & 5 & 6 & $\dot{8}$ & 5 & 9 & 5 & 5 & 7 \\
\hline Chaffinch .. . & 5 & 4 & 5 & 6 & $\bar{t}$ & 6 & 8 & 7 & 6 & 6 \\
\hline Siskin. . . & 3 & 3 & 2 & 2 & 7 & 5 & 8 & 3 & 5 & 8 \\
\hline Nonpareil : : & 3 & 3 & 4 & 3 & 5 & 10 & 6 & 4 & 7 & 6 \\
\hline Indigo-bird . & 4 & 4 & 4 & 4 & 6 & 8 & 6 & 4 & 7 & 6 \\
\hline Limnet (American) & 5 & $\tilde{5}$ & 5 & 6 & 7 & 5 & 8 & 6 & 5 & 6 \\
\hline Yellow-bird (American Goldfinch) . & 3 & 3 & 2 & 2 & 7 & 6 & 6 & 3 & 6 & $s$ \\
\hline Java Sparrow $\cdot \cdot \cdot \cdot \cdot \cdot \cdot \cdot$ & 2 & 2 & 0 & 0 & 2 & 8 & 9 & 5 & 6 & 7 \\
\hline Bullfinch (untrained) & $\overline{2}$ & 2 & 2 & 2 & 2 & 8 & 8 & 6 & 8 & 10 \\
\hline
\end{tabular}

The above table is arranged with one hundred as the highest standard of excellence, - fifty points for the voice, and fifty for attractive qualities. These figures are given, rather as representing my individual opinion, and are not offered as an unvarying standard. 


\section{CARDIN A LS.}

Tre Red Cardinal, Cardinal Grosbeak, Redbird, and Virginia Nightingale are some of the more common names applied to the bird whose full figure is shown in the cut. He is a large, strongly built bird, measuring eight inches in length. His brilliant searlet coat and jaunty pointed erest easily distinguish him from the other American bird-vocalists. The following is an exact deseription of the male bird's plumage. The entire upper parts of the body are of a dusky red; the sides of the neek and head, and the lower parts of the body, are of a brilliant vermilion color; the ehin and lower forehead are velvety black. The head is ornamented with a high, pointed crest, which the bird can raise or lower at pleasure. The bill resembles a beautiful piece of coral in color, and is very thick and powerful, which renders it easy for him to break the hardest kinds of grain or seeds, and which gives him the title, in some places, of "corn-cracker." The legs and feet are a light clay color. The female is of a brownish olive or drab color, of a deeper shade in the upper parts of the body than in the lower: the tips of the tail-feathers, the wings, and crest, are a dull red.

The birds of this species are found in immense numbers throughout the Southern and Western parts of the United States, but are rarely caught north of Pennsylvania. There were formerly odd cases where these birds bred as far north as Nora Scotia, but it was probably the result of a pair escaping from a cage. Although a very hardy class of birds, - being capable of withstanding the rigors of a Northem winter as well as any cage-bird, - they scem to naturally thrive better in the Southern States, where they are trapped in immense numbers. Early in May, in that climate, they build their nests in cedars or in laurel bushes. The outside is constructed of small twigs, and tops of dry weeds, and within are slips of vinebarks : the whole is lined with stalks of fine grass. The female lays four eggs, and there are usually two broods in a season. These birds breed in large cages or rooms if furnished with bushes and other suitable material. The male is often used to rear nests of young Canaries deserted by their parents. He may be put into a eage with a nest of very young Canaries, and will feed then as carefully as any female Canary possibly could, and watch over them as tenderly as though they were his own. He antieipates their every want, and gives them instruetions, not only in flying, but in singing songs very different from the ordinary Canary-song in style, modulation, and notes. He has patience inexhaustible. The young, uneultivated pupils struggle hard to catch his notes, and their renderings of the songs he whistles sound very odd : a listener is often compelled to laugh at the many ineffectual attempts the Canaries make before they succed in singing well even the first bar of his "Wake, Brothers !" 


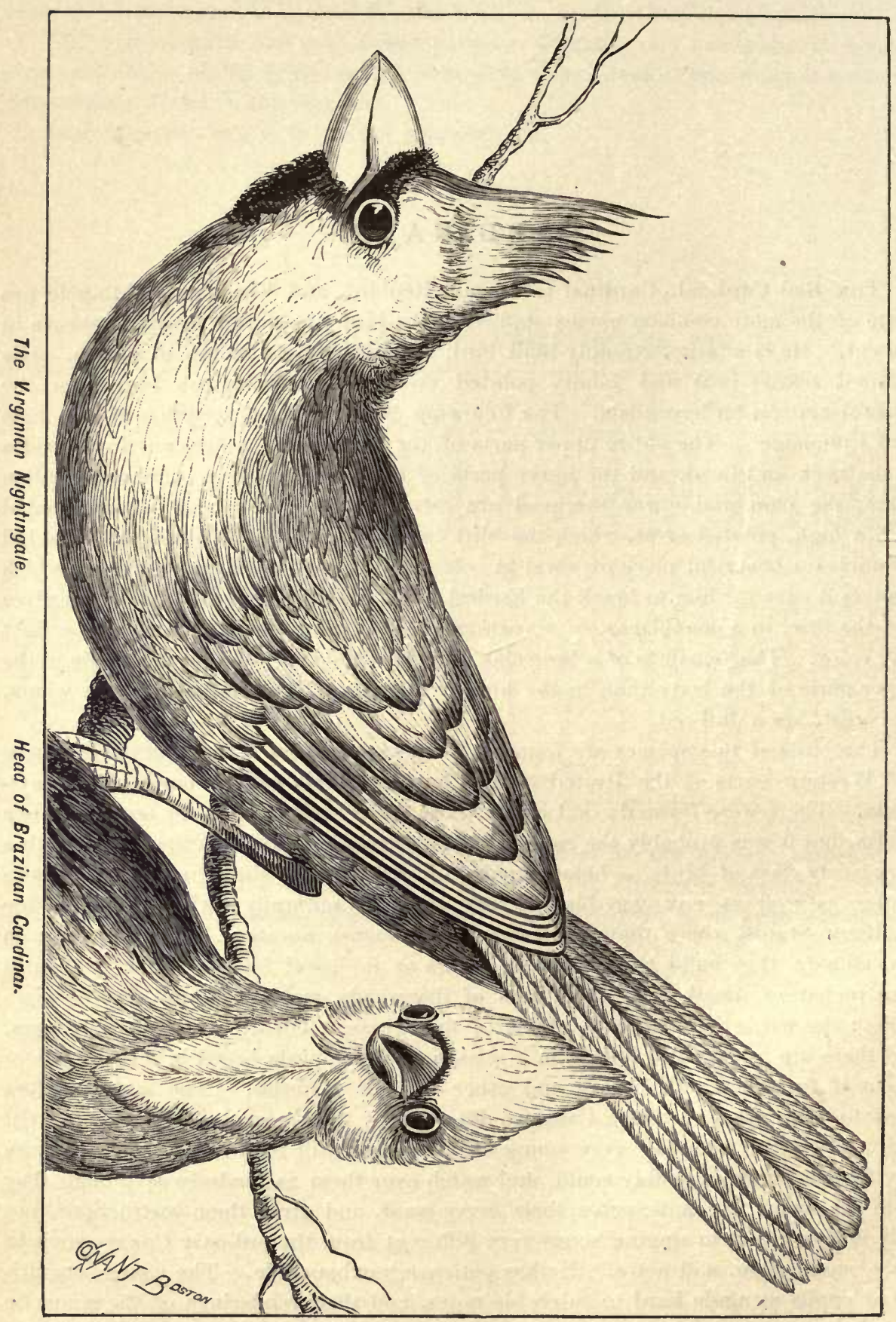


With all his compassion for Canary orphans, toward his own speeies, in his breeding season, he is violent and pugnacious, and delights in a grand rough-andtumble fight. Place a mirror before his cage, and the gestieulations of the tenant will be truly linghable; yet with this he soon becomes so well aequainterl, that, in a short time, he takes no notice whatever of it.

Cardinals are rarely raised from the nest; as they are so easily taken in trapeages, and domesticated, that the trouble of rearing by hand is unnecessary. Like the Mocking-bird, his very love for fighting makes him an easy victim for the wily negro bird-trapper. A bird of some other species, if placed in a trap-cage, will quickly attract the Cardinal's sharp eye; and his furious pounce is followed by his sure eapture. The birts are also canght by means of birt-lime. When taken from the trap-cage, his powerful beak is often used to such good effect on the hands of his eaptor, that he sometimes makes his escape, and at others is the means of breaking his own neck. The Cardinal's beak is capable of inflicting a severe nip, and is given so quickly and with such force, that the victim in his alarm endeavors to jerk his hand away from the bill. The bird has a disposition like that of the bull-dog, and hangs on with true grit: and, when the hand is pulled away, the bird retains his hold; and the sudden jerk is the means of breaking the chords of the neck, and the result will be a lingering death. Whenever eatching a bird which has a disposition like the Cardinal's, it is better to eateh him so that the thumb and forefinger will encirclc the neck elose to the head: it is then an impossibility for the bird to bite. If by any chance he should obtain a hold on the flesh, never pull the hand away; as the result oftentimes proves fatal. It is much better to grin and bear it for a while, even if the nip should be at the tender flesh between the fingers. 'The bird always. gradually releases the hold on the flesh, and then a safer method of holding him may be tried. The Virginia Cardinal, like all brilliantly colored birds, is apt to lose to a certain 'extent the richness of plumage when eonfined in a cage for a number of years. This may be remedied by eareful attention during the moulting season: if placed in a good, airy place, where an abundance of sunlight may be had, the bird will moult out, and look as brightly as if freshly canght.

He is a hardy bird, easily kept, and sings nearly the whole year, being especially lively on dark days. He sings in the evening as well as during the day. Many admirers of the bircl declare that the females sing even better than the males. To this we hardly agree: the female's song is very sweet, and has some mellow notes not found in the male's voice; but it has neither the variety of notes nor the attractive and brilliant arrangement of them that the male possesses.' Among domesticated birds, which are bred altogether in eages, the plumage of the female is as handsome as that of the male; but among wild birds-particularly those having brilliant eolors - one general law exists, that the male has always more elegant colors than the female; and it is equally true, that the male is the better singer. 'The females of only a very few species sing at all. Whether one wishes to breed them, or not, it is usually the ease that a pair of Redbirds, male and female, is kept together during the whole year. Under these conditions, it is stated, the male sings more; and as the female, too, sings well, there is a continuous round of delightful melody.

Somc writers elaim that the Redbird surpasses, in singing qualities, every other 
American songster, and insist there is only one bird in the world which is his superior. Probably this decision was reached under peculiarly happy circumstances. Given a fresh June morning, a meandering stream in one of Virginia's lovely valleys, shut away from the bustling strife and grinding care of business, with the Blue Mountains seeming to lift you up on their high shoulders out of the narrow rut of daily toil, so you are in a half-conscious, half-heavenly state of mind; then let a flock of gorgeous Cardinal-colored birds flit among the green cedirs and greener laurel, some perching on the topmost boughs, while others seek the dense slade beneath the laurel. The whir of many wings ceases; not a leaf rustles; one hears only his own heart beating : then two shrill call-notes startle; and this signal of the leader is followed by a concerted melody, in which every songster joins. All about, down from loftiest cedar-tops, and up from beneath the dwarf-lamels, the songs are poured in choral floods that sweep away judgment, and leave only sentiment to exclaim, "This birt is a Nightingale!",

But thrusting aside all sentiment, and with calmness comparing this bird's song to that of other greatly admired bird-vocalists, we find, though he may not stand first on the list, he is a most superb second. And when one considers the low price at which he is sold, compared with the amount asked for other songsters, it is easily seen why the bird is so great a favorite, and is so generally kept.

They are great favorites in the European countries, where thousands are annually sent.

In their wild state they associate with Snow-birds, Sparrows, and numerous other varieties. Their food consists of Indian corn, rice, and oats; they also eat apples or cherries, of which they are specially fond; they dig through the fruit. and delight in cracking the hard stones; they also devour large quantities of msects of various kinds.

In confinement the Cardinal should be fed on unhulled rice or paddy, mixed in equal parts with hemp or canary seeds. He should daily have a piece of apple, or other ripe fruit or green stuff of some sort; and two or three times each week, in addition to his regular seeds, he should have a portion of the prepared Mockingbird food, and two or three meal-worms. Raw, grated beef is also beneficial, and serves as a change. The frequent changes in food are necessary to keep him in good health and song; and, if carefully observed, he may be kept caged to an old age. He is exceedingly fond of bathing, and the claily bath should not be forgotten.

When first caught, and placed in a cage, the Cardinal is very timid; for this reason the cage should be kept covered on the top until the bird becomes acquainted. When newly eaged he should have very rich food, such as canary or liemp seed. Mocking-bird food, and plenty of green stuff, becanse lis efforts to escape and his timidity cause him to waste away: therefore rich feeding is necessary. He should hang in a quiet place about eight feet from the floor: after a little time he gets aceustomed to the new morle of life, and will eagerly seize a meal-worm from the fingers. After two or three months of cage-life he may be allowed to come out of the cage, and will entertain with many tricks and playful ways.

The ailments to which the Virginia Cardinal is subject are few, as the bird is naturally very hardy and long lived. 


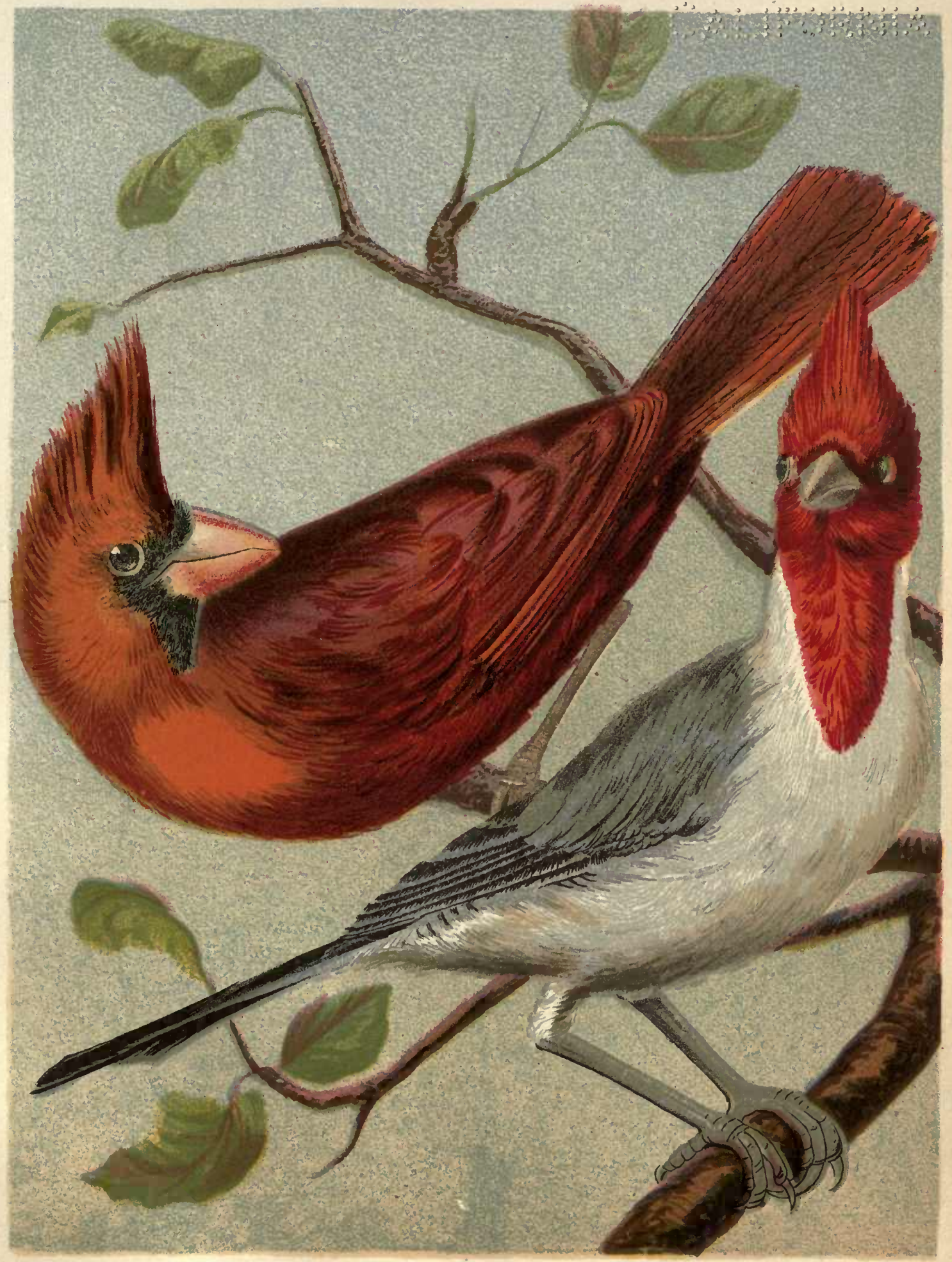

Red Cardinal, or Virginia Nightingale
Irxaiiian,

or Gray, Cardinal. 


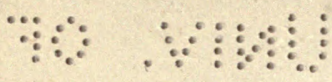

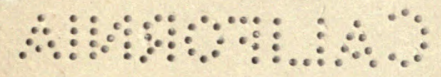


Melancholy, or wasting away, is eaused by the absence of sunlight, or from being confined in a cage too small for proper exercise. Pure air and sunshine, a roomy, clean cage, and plenty of rich food and green stuffs, will effect a cure quicker than any medicine.

Cramps are also frequently seen in this class of birds: they are caused by too frequent bathing, or by bathing in a cold place where the proper aids, sunlight or warmtl, for drying off, are wanting. 'I'his complaint may be detected by the bird lying on the bottom of the eage, having apparently lost the use of his limbs. He shonld at once be removed to a dry, warm place, a quantity of sand or gravel should be warmed, and strewn on the bottom of the cage, and a dose of sherry wine should be administered. A preventive of this disease is, to always hang the bird in a sunny exposure or near the stove while he is taking his daily bath.

Constipation may be easily cured by giving a few meal-worms dipped in castoroil, and afterwards an abundance of fresh green food.

Diarrhœa is cured by mixing a half-teaspoonful of brandy with the drinkingwater.

A large cage is necessary for the Cardinal; as lie is a very sprightly bird, and exceedingly fond of keeping in constant motion.

'The Gray, or Brazilian, Cardinal is exten-

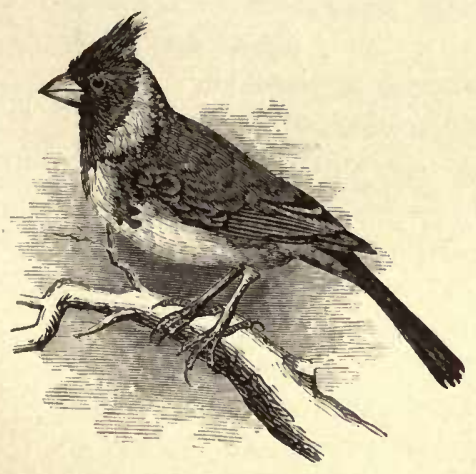

Brazilian Cardinal. sively seen throughout South America; and, if his appearance is not as brilliant as the Virginia Cardinal's, the contrast in the various colors of his body make him altogether a very attractive birl. Flocks of these birds frequent the inhalsited portions of Brazil, and their regimental uniforms of red caps and gray coats give them a very soldierly look. They are very sprightly birds, easily become tame, and the delightful melody of the song is eliarming.

The Brazilian Cardinal is seven inches in length; the upper parts of the body and tail are dusky gray; the lower parts vary from clear white to pale gray; the head and crest are brilliant scarlet; the beak is conical, and white in color. The female greatly resembles the male; the difference being in the dark shade of gray on the breast, and the lighter shade of scarlet on the head and crest. The bird was formerly very little known as a cage-bird; but, as soon as his beantiful qualities became known, they were extensively exported. His notes are not as loud as those of the Virginia Cardinal, but the real music is as sweet. His habits and food when eaged are the same as those of the Virginia Cardinal.

Althongh these birds are imported from a very warm climate, they endure well the colder temperature of the North, and are subject to few or no diseases. 'Their constant activity may partially account for the fact that these birds enjoy long lives, free from the illness to which so many of the tropical birds are subject when confined to high latitudes.

Pairs breed readily in a roomy aviary if furnished a bush in which to buíld a 
nest, and suitable small sticks, fine, dry grass, and deer's hair, for the construction of the fabric. Egg and potato is good food for the nestlings, but it may be varied by giving dry prepared Mocking-bird food, with raw carrot grated and mixed with it. Millet-seed soaked so it can be crushed easily between the fingers is also good food dluring the first four or six weeks of the nestling's life.

The Green Cardinal is also imported from Brazil, but is rarely seen in New York. He is sometimes called the Black-crested Cardinal. Though not so showy in feather as his more brilliant consins, he is a very pretty bird, is gentle, and is more fond of human society than either of the others is. His breast is a light green, back and tail green and black in stripes, and the crest a rich, clear, coal black. He is a little larger than the Gray Cardinal.

The proper cage, food, and care are the same as for the other Cardinals. 


\section{GROSBEAKS.}

\section{THE ROSE-BREASTED GROSBEAK.}

TuIs is a class of birds rarely seen eaged; although they are very attractive in plumage in most eases, and very hardy in a caged state.

The Rose-breasted Grosbeak is probably the best known, and is more frequently seen throughout the southern New-England States than any other part of the Northern United States. The males are charming songsters, and the demand for them lately has greatly increased. The delightful song, combined with the brilliant plumage, accounts for this growing popularity: moreover, it is rare to find the combination of music and beauty existing to such a high degree in any other of our American birds.

The Rose-breast is a very shy bird, and cautiously conceals his nest in the thickest shrubbery and underbrush ; so that it is exceedingly difficult for the most skilful of the bird-catchers to eapture specimens. 'The birds inhabit only local parts, and in no place are they widlely distributed. The favorite haunts of these beantiful birds are in the thickets near the rivers and streams of Massachusetts and Connecticut.

The male Rose-breasted Grosbeak is eight inches and a half in length: the whole upper parts are black, except the second row of wing-eoverts, which are tipped with white. 'The chin, neck, and upper part of the breast are a brilliant black; the lower part of the breast and middle of the belly are a handsome tint of rosecolor; the tail is forked and black; the bill, like all the race of Grosbeaks, is conical, very strong, and pure white; the legs and feet are light blue. The young males have at first the plumage of the females, but the rosy tint appears after the first moult.

In the female the upper parts of the body are streaked with brownish stripes; and the under parts are of a dusky tinge, and lack the rosy tint observed in the male.

The bird migrates South in the fall of the year, and passes the winter in Louisiana, Texas, and Mexico, and in May, or in the early part of June, returns to New York and the New-England States to breed. Before the habits of the bird are understood, an ornithologist might think he would hunt through the woods until he saw a speeimen ; but, as long as he was in motion, not a Grosbeak would be seen. 'The bird's favorite abode is in large forests, where he seeks the densest shade and gloomiest retreats : and, if you would study him in his home, take a luncheon with you; so, if he is not in when you first call, you can await patiently several hours, 
say until sunset, for his return. Then you hear a clear, mellow whistle, and imagine some farmer's boy, who is "turning the cows" in a distant pasture, is tuning his pipe; but nearer and elearer it sounds : and soon the gorgeous bird, hopping from tree to tree, and whistling all the while his harmonions melody, shows his rosecolored shield on a white and black ground. A shout of delight almost eseapes you ; but smother it ! for this is ouly the leader; and, if he is frightened away, all his follower's will fly. On come the flocks with heavy, elumsy hops, straying here and there, aimlessly, seeming to eare not where they may alight, but giving all attention to the softer modulations of the songs, putting in a rest here and there, as though they expected the very trees slould be their claque.

The bird may be called an "evening" Grosbeak, as he sings during the stillness of the night also; and the notes at these hours are even more mellow anci delightful.

The song greatly resembles that of the South-Ameriean Troopial: the rich, mellow notes are whistled in a manner which greatly and pleasantly surprises one unaequainted with the bird.

The Grosbeak readily aceommodates himself to eage-life; and, although a little timid when first eaught, he quiekly becomes aceustomed to his new life, and later pipes as merrily as in his native thiekets. It is a matter of wonder among birdfanciers that he is not more commonly kept caged. It eannot be said of him, as of the Bobolink, and many more of the native birds, that he is too common: on the contrary, he is seldom heard near the habitations of man; because he enjoys seelusion. Of late years the appreciative bird-fanciers of Europe have noticed the many merits of the Rose-breast, and large numbers are exported in pairs for breeding in the Zoölogieal Gardens. It is not known whether or not they will breed readily in cages. If in the proper situation, where they would be safe from intrusion, and could enjoy the seclusion which their nature seems to demand, they could probably be as easily reared as any other elass.

The Rose-breasted Grosbeak, when eaged, has many of the Bobolink's eharaeteristies: he is a merry fellow when well aequainted, and, if given too many dainties, will beeome as fat and lazy as his more rollieking neighbor of the open fields.

His food, when he is first eaged, should eonsist of the plain canary-seed, as the natural timidity and consequent wasting away must be overeome by rieh feeding; as he beeomes better aceustomed to his eage, unhulled rice may be added. Afterwards his daily food may consist of a mixture of unhulled rice, eanary and hemp seeds. A portion of Mocking-bird food may be added two or three times each week. He is very fond of green food, apples, or any ripe fruits. A meal-worm or spider may be given him occasionally. Care should be taken that too much food should not be given him at one time : it is better to give him a fair portion of food rather than too much, beeause he has a great desire to eat constantly ; and from this fault his prineipal disease arises.

$\mathrm{He}$ is exceedingly fond of bathing, and his daily plunge is always keenly enjoyed. When hung in the warm sunlight, he will dive in and out of his bath with the vigor and earelessness of a $\log$; and he has no sooner plumed and dried himself than he plunges in for another ducking; therefore it is better to withdraw the bathdish as soon as he has had a fair wash. 
His cliseases are few, and ehiefly arise from high living. The symptoms of disease may be observed by the absence of song and the dumpish appearance of the bird. He is careless of any thing which goes on around him. When these actions are observed, the bird should be hung in a warm exposure, and fed on the plain, unhulled rice, and a daily portion of green food. A few thops of castor-oil may be alministered at first.

His diseases are those which are usually observed in the seed-eating elass of birds. His eage should be roomy: and, when the weather permits in summer, he may be hung ont doors; as sunlight and fresh air are a great boon to him.

If properly cared for, the Rose-breast will live in eonfinement six or eight years, and be in song about ten months of the year. When all lis qualities are considered, he is, without doubt, one of the most desirable of cage-birds.

Nuttall, the great ornithologist, claims the Grosbeak is melodious the entire night, pouring ont flools of song as varied and enchanting as those of the English Nightingale, and adds that he is the only rival of the Mocking-bird. An opinion such as the above, when given by so eminent an anthority, must rank the bird high $n$ in the list of native songsters.

\section{TIE PINE GROSBEAK.}

This is the largest specimen of the Grosbeak family, and extensively inhabits the northern portions of the entire globe. They are handsome birds, and but little is known of their habits in a wild state; as they come from the most barren countries, and, when visitiug the civilized parts of the world, appear to seek the most secluded portions. Indeed, it is said that they are so little experienced in the artifices of man, that, if a hunter approaches the trees on which they are perched, they never offer to stir, but will stare at a gun destined for their destruetion withont thinking of flight, even should one of their companions be shot down from the same branch. The elumsiest kind of a trap is all that is needed to catch the unsuspicious little wanderers.

The most tonching tales are told of the affection shown by the Pine Grosbeak for its mate. On one occasion three out of a party of four had been captured, when, to the astonishment of the trappers, the fourth hopped along, and crept into the net to share the fate of his fellows. It must not be imagined that these birds are really foolish; for experience soon teaches them its lessons, and they become distrustful, shy, and cautious.

The Pine Grosbeak is eight inches and a half long; the head, neck, breast, and rump are earmine, tinged with blue; from the nostrils a black line runs as far as the eyes; the feathers of the back and upper wing-coverts are black, edged with red; the tail is forked, and marked like the wing feathers.

The prevailing color of the female is grayish green, tinged here and there, especially on top of the head, with pale red or yellow.

The beak resembles that of the Parrot, the upper mandible hanging some distance over the lower. This formation enables it to elimb skilfully from branch to branch on the trees. Its flight is very rapid and undulating, and it hovers for some time before perehing. 
The voice is exceedingly flute-like and expressive, and not as loud as the Rosebreast's. The song is very varied and pleasing, on account of the soft and clear notes. During the clear summer niglits, in its native haunts, he sings throughout the night in such a charming manner that one is compelled to stop and hear the song through again to make sure it is not the utterance of that master singer the English Nightingale on an escapade. On account of these night-serenades, the bird is called, in his native lands, "The Watchman." 'The Pine Grosbeak, in addition to his splendid voice, has many other good qualities. Owing to his gentle, confiding temperament, he may be easily tamed if properly treated. He becomes in a few days accustomed to confinement, taking food readily from the hand, and will allow himself to be stroked, and carried around the room, all the time piping his happiness and content. Owing to the ignorance of bird-keepers, the Piue Grosbeak when eaged is always kept in a warm room. This surely proves fatal; for, when so kept, he will waste away, and die in a very short time. If shut up in too warm a place, they will climb uneasily around the eage, and open their beaks, and pant, showing how unbearable the heat is to them. It is therefore better to keep them in an unwarmed room, or hung ontside the house. In confinement the plumage loses its brilliancy, and after the first few months' confinement the bright carmine changes to a yellow. In a wild state the Pine Grosbeak subsists on the seeds of the fir-tree.

When eaged, they should have the same seeds as the Rose-breast. If kept in a cold room, they will live for some three or four years, and sing throughout the entire year.

The line Grosbeak is often met throughout the New-England States, where he has received the name of Evening Grosbeak.

\section{THE BLUE GROSBEAK.}

Unlike the Pine Grosbeak, this bird is an inhabitant of the warmer regions of the globe, but like him, and, in fact, all the members of the Grosbeak family, seeks retired haunts. He is rarely seen in the northern parts of the United States. Owing to his timidity he is not easily eanght. As a eage-bird the Blue Grosbeak is not a success: he has no song whatever, the only note being a single call-note. He has very beautiful plumage, which is kept with the neatness of the Java Sparrow's. The Blue Grosbeak is six inches long; the whole upper parts are a rich purplish blue, more dull on the hack, where it is mixed with dusky streaks; the wings are black, tipped with brown and blue; the breast is a beautiful dark blue, and the face black; the tail is forked and black.

The female is of a dark drab color tinged with blue throughout. The young male birds do not attain the full color until the second spring moulting. In confiuement the Blue Grosbeak should receive the same care and treatment as the Rosebreast. Being used to a warm climate, care should be taken not to expose him to the cold which the Pine Grosbeak needs and is capable of enduring.

There are some twenty other varieties of the Grosbeak family, which inhabit the various parts of the globe; and all of them may be distinguished by the peculiar conical formation of the beak. 


\section{THE BOBOLINK.}

Likw all inischievous, merry fellows, this jolly reveller has his losts of friends aud a number of enemies. His friends may be divided into elasses, - those who enjoy his mad, merry musie, his jaunty, showy coat, and sprightly ways, and those who have no taste for musie; but who have excellent appetites, and crave Bobolinks on toast.

His enemies are the farmers, whose plentiful rice-erops are left in sad plight by his mereiless raids : meanwhile Robert grows fat and lazy on the results of his pillage.

The Bobolink, when seen in his most showy plumage, is a very attractive bird, and, like all eareful lovers, exhibits his best coat only during the days of courtship.

The plumage of the male Bob-

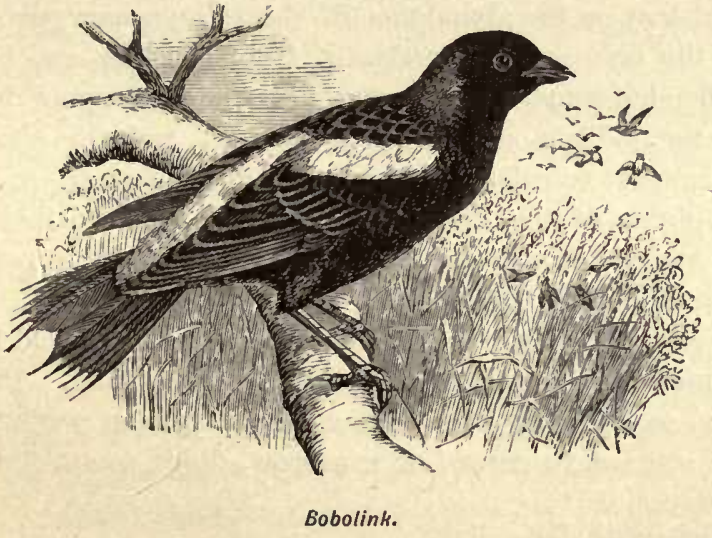

bird while ascending the stalks of the reed.

After the breeding season, or about the month of August, the plumage of the male ehanges ; and he gradually assumes the same garb as worn by the females and young birds. The colors then are : yellowish brown above, brownish yellow below; upper parts and sides below streaked with black; wings and tail dusky, with pale edges of the feathers. The male, after having changed plumage, cannot be distinguished from the female. The lengtl of the Bobolink is seven inches and a half.

Early in May, in the Northern States, the Bobolinks' merry chorus is heard ; and, if you walk abroad for an hour amid the fresh fields and pastures, you are greeted, not only from every rail in the fence, but every sighing breeze bears its burden 
of music. Whole flocks strew the way with such a tangle of melody and jangle of music, that your steps are checked, and you listen in admiration to the fullest outpourings of song. The revelry continues until Robert is sobered by the cares of family matters.

Whilst Master Robert, attired in his jaunty spring costume, bubbliing over with exhilaration, is attending to nothing but his own sweet appearance and noisy voice. Mrs. Robert is engaged in a more substantial manner, and is thonghtfully tying knots in the grass, to trip the unwary feet of her future lord and master.

Bobolinks' nests are concealed in the luxuriant herbage of meadows with sueh instinctive care for their safety as to be difficult to find, except by accident. In the Western country the saying is, that an Indian can hide behind three blades of grass : the hiding capabilities of a tuft of grass is best illustrated by the screening of a Bobolink's nest, not only from observation, but from actual search. 'The female is said to employ some artifice in arranging the spires of grass about the structure. In New England she commences to lay about the first of June, and lays four or five eggs, bluish white marked with irregular chocolate-brown spots.

Before the summer season is over, the former jolly, handsome fellow assumes the shabby dress of his mate; and, as thongh ashamed of limself, he takes his journey south with his numerous progeny, and travels mostly by night during the migration, to elude observation ; and by the latter end of August, or the first of September, the final clink-link-a-link is heard, and he is seen no more until the return of spring. On reaching the Southern States he assumes the vanes of Reed-bird and Rice-bird, and there grows fat and lazy on the abundance of the antumn harvests of rice and oats. It is there that the non-musical portion of Bols's friends, and his injured enemies, join forces ; while shot-guns, cannon, and all sorts of weapons for extermination, are brought into use. Then sad slaughter comes; and the shotriddled imnocents hang head downwards, voiceless, in the fowl market-places.

It appears that the breeding-places of the Bobolinks are in the more northerly latitudes, and that they merely migrate Sonth for the purpose of finding more abundant food and a more congenial climate.

Robert o' Lincoln is one of the few birds which may be transferred from field to cage, and, in the process, lose none of his sprightly ways and inspiring song. Put him in some small, rusty old cage, so confining that he can only step from perch to floor, and let him be thrust into some dark corner of a narrow, dingy room, it all matters not to him : his

$$
\begin{aligned}
& \text { "Bob-o-link, Bob-o-link, } \\
& \text { Spink, spank, spink," }
\end{aligned}
$$

is sure to be heard, given with the same vim as though he entertained a king in a palace, or were free to swing

"On briar and weed,

Near to the nest of his little dame, Over the mountain-side or mead."

In his wild state, during the spring and summer seasons, the Bobolink subsists almost wholly on insects; later in the season the food is seeds and grain: le is, however, not in the least a dainty fellow, but will thrive and grow stout on the 
poorest of foods. When caged, the principal seeds given him are the canary and umhulled rice mixed; as the canary-seed is very fattening, too mueh of it should not be given him : aud, when he is noticed to be in a gouty condition, the canary-seed should be withdrawn, and only the unhulled rice fed. He his a most voracious appetite, and overeating is the cause of all his diseases : therefore, when giving him his daily seeds, feed only in small quantities. He enjoys all the physieal eomforts you may offer, aceepts greedily any dainties, tumbles lazily into the bath-tub, rolls ont again in a seemingly contented frame, and sings himself dry in the sumniest spot he can find. Then he ploughs through the gravel, finds a piece that he thinks is heavy enough to hold down that last too solid luncheon, swallows it, then siugs again.

Time seems very precious to the Bobolink; he makes the most of every moment: lie eats many hearty meals during the day, and each one is apparently enjoyed more than its predeeessor; but, when he is not eating, he is singing.

The chief ailment to guard against is gluttony, - his habits of eating: if too much and too rich food is given him, it will interfere with his song, and render him fit only for the cook's hands. The Bobolink, when caged, cannot possibly obtaiu the exercise which is necessary to keep him from growing fat; and, therefore, the simplest food, and no dainties, should be given. He will obtain supply enough from the plain food to make up for any defieiency in the dainties. $\mathbf{A}$ good-sized eage should be given him, and a plentiful supply of gravel furnished.

The daily bath should not be neglected; because, with all his lazy habits, Robert is an extremely clean bird, and delights in a fresh dress every day. He is not a fit inmate for an aviary; because, with his love of eating, he would quickly starve the other inmates out of prison.

For breeding purposes he is rarely used; and, until the farmers find a method of partly exterminating his almost numberless race, he will probably be allowed to choose his own native breeding-place.

The eheap cost of the Bobolink, combined with his sociable manners and charming song, certainly render him a very attractive eage-bird; but his very numbers, and domestieated habits, when wild, guard him against trapping for this purpose: he is rarely seen caged in the country villages or towns. What need of caging one when before every house a whole chorus, continually changing, is heard day after day? In the city bird-shops they may always be found, and are always greeted as old friends when the country folk pay a visit to the town.

Many amusing mistakes are made by the change of plumage of the Bobolink, and many people who only know him in his spring suit are surprised at his comparatively shabby condition when seen in his winter garb.

An old friend, who supposed himself to be a bird-fancier, was induced to buy one in this condition of plumage: and although be insisted that the bird was a linnet, - an absurd mistake, by the way, - he finally bought him, and, because the bird did not sing in two days, opened the window, and permitted the bird to fly; thus losing a fine songster, to say nothing of a most delicions meal.

It was some time before the earlier naturalists could be induced to accept the theory that the male Bobolinks changed their plumage and resembled the females in the autumn ; although they could not, at the same time, account for the heartless conduct of the males in deserting their mates, and seeking unknown regions. 


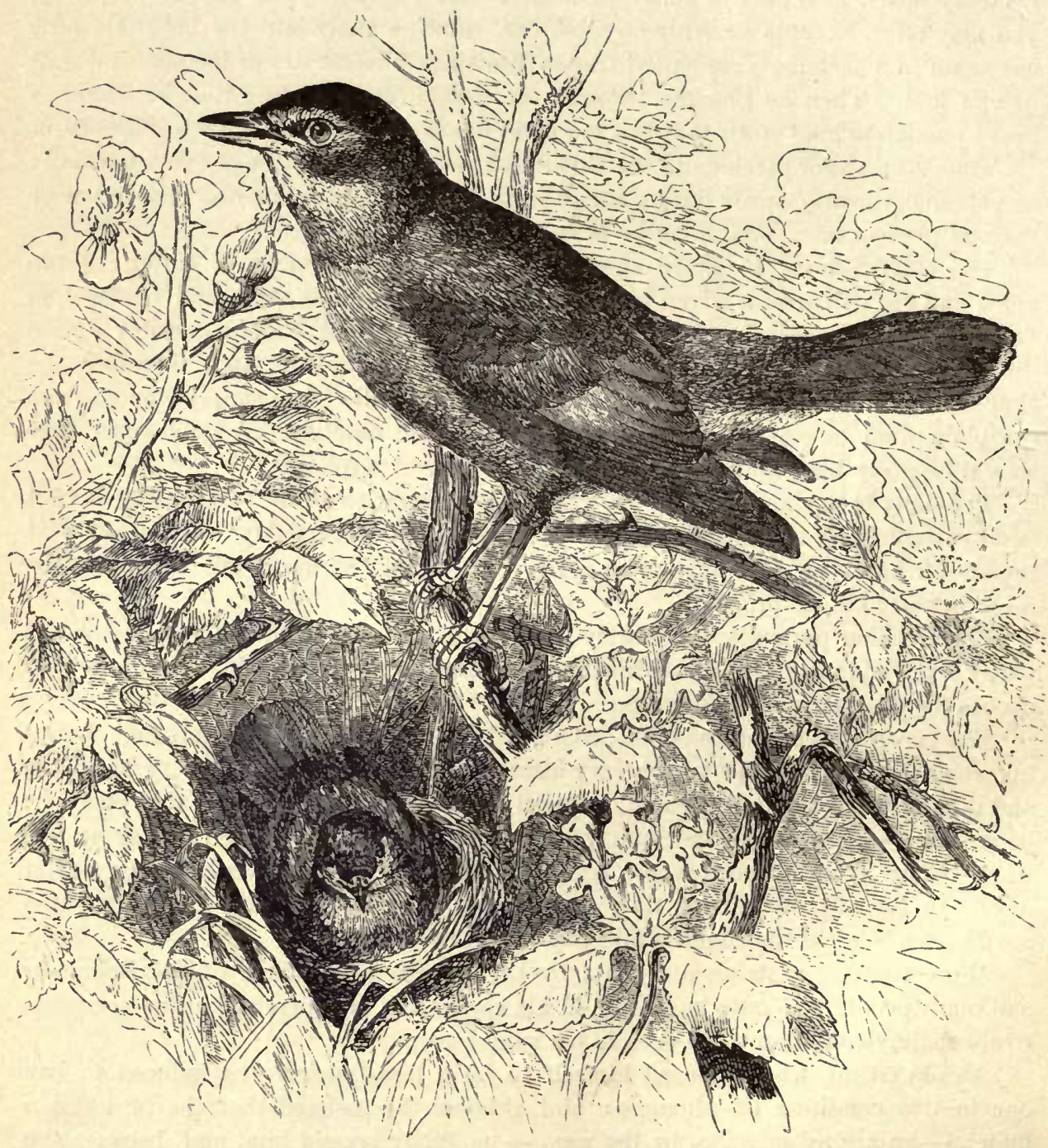

The English Nightingale. 


\section{THE ENGLISH NIGHTINGALE.}

Probably no known song-bird has been so lauded and praised as this master of all songsters. His plain colors are not in the least attractive, but his magnificent voice has no equal. Although very unpretending in color, and insignificant in size, he is universally known as the "King of songsters." Each class of song-birds has its special admirers, and each class is heard with pleasure as long as the Nightingale remains silent. Some of the numerons favorites are admired for the beautiful tone, others for the softness and purity of the voice, and still others for their delightful trills and warbles. The Nightingale combines all these charming qualities, and adds more; for lie seems to monopolize all the perfections of melody and voice.

The Nightingale measures about six inches and a half in length. The whole of the upper part is reddish brown; the breast a dull white, shading into brown; and the throat and belly pale gray; the tail is reddish brown, long and rounded.

The Nightingale is met with over the whole continent of Europe, from Sweden to the Mediterranean, and over a large portion of Central Asia as far north as the middle of Siberia. He also visits North-western Africa in the course of his migrations. Woods, groves, and leafy forests, in the immediate vicinity of water, afford the favorite retreats of these most musical, most melancholy songsters. In such localities they live, each pair within its own especial domain, which, although small, is jealously guarded and boldly defended from all intrusion. Some parts of Southern Europe are especially frequented by these delightful birds. Spain, in particular, is extremely fortunate in this respect; and in certain districts their enchanting voices ale heard from every bush and herlge. 'Tlue declivities of Sierra Morena may be literally described as an extensive Nightingale garden.

The flight of the bird is undulatory ; but, though light and rapid, it is rarely sustained beyond a short distance. 'That these birds, however, are capable of great exertion while on the wing, must be evident to any one who has witnessed the endeavors of two contending rivals in love-matters to drive each other from the field.

No sooner have the Nightingales arrived at their nesting-places in Europe, about the micldle of April, than their songs are to be heard almost incessantly. Some pour forth their trilling notes through the long, bright night, just as the American Mocking-birds whistle during the moonlight nights of spring-time and early summer ; but generally they sing only in the daytime, except during the breeding season, when the desire to please and attract their mates renders the male birds exeited and restless. 'The nest, built in some hollow in the ground, or in the roots or stump of a tree, is made of leaves, dried grass, bits of bark and roots, and lined with finer grass and horsehair loosely put together. There are five eggs in a nest, and only 
one nest in a season, unless the eggs or the young get destroyed, in which case there is a second laying. The moulting season commences in July, after which, when the birds are in new, full plumage, the antumn migrations begin. These journeyings are accomplished in families or small parties, the birds flying with great rapidity to very distant countries. In April they re-appear in Europe, the males about two weeks in advanee of the females, and at once seek their former haunts, and greet the old homes in joyous strains.

The Nightingale is easily captured with a trap. When taken from it, his first food should be of the richest quality. He should be carefully fed by liand the first few days, in order to accustom lim to the new kinds of food in confinement. The' birds caught in the early spring are preferable to those caught later; as they beeome quicker accustomed to the eage, and sing during more months in the year. The song of the Nightingale has been beautifully deseribed in all languages. When wild, his rocal superiority over all other songsters of the grove is easily apparent. When challenged to a contest, he will fill a whole valley with his varied and beautiful lays, full of the richest melodies. The song of a fine Nightingale includes twentyfour different strains. His enchanting floods of music are well described by Buffon as follows :-

"He commences with a lralf fearful prelude, in low, undecided notes, as if trying the capabilities of the instrument, and intent on arresting the attention of the hearers. By degrees he becomes more decided, his courage and his inspiration inerease, and soon the full harmonies of his incomparable throat are ponred fortl. - sonorous bursts, light, hovering shakes and trills, in which ease and purity are united; a subdued inward murmur, whose place in the seale the ear seeks in vain, but which is all the better adapted for a background to the clear. distinct notes ; runs, as rapid as lightning, uttered with amazing power, and often even with a tasteful ruggedness ; mournful cadences, hardly separable from one another, yet full of expression : enchanting, penetrating tones, the veritable sighs of love and pleasure which rush from the heart, and speak to the heart, so that the heart overflows with emotions. and sinks in delightful languor. In the passionate tones, it is as impossible to mistake the expression of the feelings of love, as not to detect in the more artful, though perhaps less expressive, strains, the desire to entertain and please his mate, or to celebrate his victory over some jealous rival of his happiness and fame. The notes already heard are enjoyed again in the eeho which hovers about the ear, undisturbed by any new impression; ; and, if the admired passage be not repeated when the bird recommences his song, it is replaced by another so beautiful as to efface the wish for a repetition of the first."

One chief reason why the Nightingale surpasses all other birds in song is, that he sings at night. While all other song-l)irds are silent, he sings at the highest pitch of his strength, and in a voice which is rivalled by no other; while he far excels all other birds in the flute-like quality of the voice, and in the uninterrupted duration of the warble, which sometimes lasts twenty seconds. It has been ascertained that the Nightingale's voice may be heard at the distance of a mile, which is as far as the human voice can reach. It is remarkable that so loud and clear a voice can come from so small a bird, but it has been demonstrated that the larynx of the Nightingale is proportionately stronger than that of any other bird. 
There is a great difference in the voices of Nightingales, just the same as in it great many elasses of song-birds. This difference eamot be easily aceounted for: it may be that the teaching of the inferior-singing Nightingales has been defective; in other cases, where the Nightingale is reared in forests where various song-birds abound, he has been excited by rivalry or jealousy to perfeet his own song to the highest degree: and these peculiarities may be transmitted from generation to generation. The same conditions of rivalry do not exist in all. the different parts of the world which the Nightingale inhabits, therefore there is the difference in the roices of birds of the same species which grow up under different eireumstances. This rivalry of the choice songsters extends to the small distriets where they are trapped, and bird-lovers of one distriet may claim a superiority for the birds of their own country orer these of a neighboring one. Many disenssions have arisen as to the relative merits of the English Nightingale and the American Mocking-bird. It is admitted that both hirds are the leading representatives in song of the eountries which they represent. Perhaps the discussion will never be fully decided; for it is almost impossible to compare the songs of the two birds, they are so unlike in style. The Nightingale probably rivals the Moeking-bird in the power, brillianey, and quality of the natural notes; but, while a mimic in a small degree, he camnot bear comparison with the Mocking-bird in this respeet. As the styles of the songs are so widely different, it would, perhaps, be as well to allow them to stand, each as a representative of a style peeuliarly his own, and not bring them into competition.

A Nightingale is often indueed to sing in confinement by the jealonsy ereated by being hung near some other constant good singer. The rivally thus created puts the king to his best efforts; and by this means he is kept in song many months in the year, when otherwise he wonld be silent.

The Nightingale, when kept in good health and spirits, remains in song about eight months of the year. The song is not sung with the same zeal throughout the entire period of singing: it is during the mating season the song of the bird is the most beautiful. In the wild state, owing to the migratory character of the bird, and the absence of song at certain seasons of the year, he is heard only about three months out of the twelve. The foor of the Nightingale, when first eaged, should be of the most nourishing kind possible. He is an exceerlingly sensitive, nervous bird; and stimulating food is a necessity to him. 'The Nightingale paste, as given in "Recipes," is the best food. When first confined, he should also daily have in addition, for about two weeks, three or four meal-worms. Gradually add the regular prepared Mocking-bird food to the mixture, so that he may become accustomed to it. To feed nothing but the prepared food and carrot at first, would be the means of bringing on, perhaps, a fatal sickness. After he has been gradually induced to eat the prepared food, the mixture may be withdrawn ; and ants' eggs, scalded until soft and swollen, should he daily added to the prepared food and carrot. The meal-worms should not be given too freely when he is accustomed to the prepared food; but two or three at a time, twice or three times each week, is sufficient for him. In addition to this, a great variety of other food may be given him. Currants thoroughly soaked, and placed on top of the food, are a healthy and attractive dish. Ripe berries or fruits in their seasons, may be frequently given as a change, although they should not be allowed to grow sour or stale while remaining in the eage. Of live 
insects he is exceedingly fond ; and spider's, grubs, or worms of any kind, are eagerly devoured by him. His appetite is enormons, and he will easily devour and cligest as mueh food as a bird twice his size.

He is a very tencler-footed bird; by this I mean that his feet, if not properly attended to, become easily diseased : therefore an abundanee of dry, fresh gravel should be eonstantly kept in the bottom of the cage. His feathers are very soft, and beeome easily damaged from contaet with the wires of the eage; and if, when first received, his plumage is damaged from being eoufiued in a eage of too narrow limits, he should daily receive a shower-bath of tepid water. The perches should not be too elose together, and kept far enough from the wires of his eage so that he may not break his tail-feathers. In countries where the bird's eare is best understood, he is eonfined in a eage about 18 inehes long, 8 inches deep, and 13 inches higb. The baek may be of wood: and, whether the top is of wood or wire, it should be lined with eloth; so the bird, in flying up, shall not injure his plumage. The bath should be freely given; as his plumage requires daily dressing and arranging, owing to its texture, and the ease with whieh it beeomes soiled and spoiled if not frequently bathed.

The eage should be hung in a sunny exposure, free from all draughts of air: under these conditions the bird's life is prolonged. He is a much hardier bird than he is thought to be; and, if rich food is freely given, his ehances of life are as good as those of any eage-bird.

The Nightingale breeds easily in eonfinement; and the principal objects which insure suceess are, plenty of room, quiet, and an abundanee of egg-food, insects, and worms.

The diseases to which the Nightingale is subject are, chiefly, constipation, diarrhoea, eolds, asthma, deeline, or melaneholy.

Constipation is eaused by sour food, or feeding too mueh prepared food without any addition or ehange. The drooping appearanee of the bird, and his eonstant uneasiness, betray this. Administer three or four drops of eastor-oil in the beginning, and let his daily rations of worms be soaked in oil before being fed him. Feed an abundance of soaked ants' eggs, and green foods, until he is thoroughly cured. Too mueh prepared food should not be given until some time after the eure is assured.

Diarrhœa comes usually from filthy drinking-enps, to whieh particles of vegetable matter have adhered and grown poisonous. Owing to the aloundance and ehanges of food whieh is given the Nightingale, the drinking-water easily becomes impure; for this reason frequent cleansing of the eups is absolutely necessary. Diarrhœa is noticed by the watery exerement. The bird should be put on food whieh eonsists of hard-boiled egg, grated earrot, and the prepared food in equal parts, the whole thoroughly sprinkled with maw-seed. Put a few drops of laudanum or paregorie in the drinking-water, and lie will be relieved in a short time by this course of treatment. His food should afterwards be of the richest charaeter.

Colds and Asthma result in lianging the bird in clraughts of air. If taken in time, before the disease becomes too firmly seated, he may be eured : if, from negleet, the disease is allowed to eontinue, it is clifficult and almost impossible to cure. Only the richest foods must 7 e given; and the bird should be liung in a warm, dry 
place, the cage being covered at night. Add glyeerine and a small piece of rockcandy daily to his drinking-water.

Decline, or Melancholy, is caused, first, by neglect, or ignorance in feeding the hird: the ignorance consists in giving the bird only the plain prepared food with no change, which causes a gratual clecline, or wasting away of the body. It may come, secondly, from natural causes diring mating season, or from the absence of songbirds in the vicinity. 'The Nightingale is fond of rivalry ; and birds, if lunng in his neighborhood, are welcome friends. Rich food in abundance, and a little extra attention, are usually the remedies for this disease.

'The Nightingale's feet require frequent attention, and should be examined at least once a week, and, if they have a dirty or cloggerl appearance, should be carefully cleaned, and bathed in warm water. Bathe afterwards with glycerine if the feet appear sore.

In the past three or four years the sale of these birds has greatly increased, because lovers of the grandest and sweetest bird-music have learned how to so care for the performer as to elicit from him most charming melodies. He has a natural song, and, like the American Mocking-bird, is also a mimic. His eage may hang by itself in a less frequented part of the bird-room; but, the more singers there are in the same room for him to contend with and surpass, the wider will be his range of voice.

When carefully attended to, the Nightingale will live in good health and song to the age of fifteen years.

\section{TIE ASS YND THE NIGHTINGALE.}

FROM TIIE RUSSIAN OF KRILOV.

An Ass a Nightingale espied,

And shouted out, "Holloa! holloa! good friend I

Thou art a first-rate singer, they pretend:

Now let me hear thee, that I may decide.

I really wish to know - the world is partial ever -

If thou hast this great gift, and art indeed so clever."

The Nightingale began her heavenly lays,

Throingh all the regions of sweet music ranging,

Varying her song a thousand different ways, -

Rising and falling, lingering, ever changing,

Full of wild rapture now, then sinking oft

To almost silence, melancholy, soft,

As distant shepherd's pipe at evening's close ;

Strewing the wood with lovelier music; there

All nature seems to listen and repose;

No zephyr dares disturb the tranquil air;

All other voices of the grove are still,

And the charned flocks lie down beside the rill.

The shepherd like a statue stands, afraid

His breathing may disturb the melody; 
His finger, pointing to the harmonious tree, Seems to say, "Listen !" to his favorite maid.

The singer ended; and our critic bowed His reverend head to earth, and said aloud, -

"Now, that's so-so; thou really hast some merit: Curtail thy song, and critics then might hear it. Thy voice wants sharpness: but, if Chanticleer Would give thee a few lessons, doubtless he Might raise thy voice, and modulate thy ear; And thou, in spite of all thy faults, mays't be A very decent singer."

The poor bird -n silent modesty the critic heard, And winged her peaceful flight into the air, O'er many and many a field and forest fair.

Many such critics you and I have seen :

Heaven be our screen! 


\section{THE BIACKCAP.}

Turs well-known forest musician, praised alike in poetry and prose, has been probably as much written about as the acknowledged king of songsters, - the Nightingale. His marvellous voice and imitations place him at once in the foremost rank of feathered songsters. He is best known as the "Mock Nightingale," and by enthusiastic Europeans is placed on an equal footing with the American Mockingbird. In many of the small villages of Germany, he, of all birds, is the favorite. Bechstein says of his song, "If lis song have less volume and be not so distinct as that of the Nightingale, it is purer and more flute-like in its tone, more connected, and has almost as many varieties of notes."

It is surprising that so small a bird as the Blackeap is capable of uttering such a volume of song. When singing he sits perfectly still, and pours forth strain after strain, producing the most delightful musical climaxes.

The Blackeap is about five inches and three-quarters in length, of which the tail measures two inches and one-quarter. 'The beak is born blue; the iris chestnut brown; the cheeks, and back of the neck, are light gray ; the upper part of the body and wingcoverts ashen gray; the under part of the body very light gray, inclining to white on the throat and belly; the pen and tail feathers are dark brown, edged with the color of the baek. The top of the head is surmounted by a round jet-black eap, from which he derives his name, and by which he may be easily distinguished from other birds. In Germany he is nieknamed "The Monk."

The female is a trifle larger than the male, and may be distinguished from him by the color of the cap, which is a ehocolate brown : other parts are also tinged with brown.

The plumage of the Blackeap is very soft and silky, which accounts for the usual poor condition of the feathers when a large number are imported together.

The Blackcap has his home all over Europe, and migrates about the middle of September, being one of the first of European birds to migrate ; for this reason they are kept in the birl-shops only at certain seasons of the year. In confinement the Blackeap will sing the greater part of the year, ceasing only during the migratory fever in Mareh and September, and a short period during the moulting season, which may be in either July or August.

The chief requisite for keeping the Blackcap in song is, careful attention to his food, and the utmost cleanliness of his eage. "My Blackeap has not sung since I bonght him," is a chronic complaint with the purchasers of these birds ; and "I hought him on the recommendations of the number of books I have read about the superiority of his song," says another. "I believe it is a fraud to sell a dumb bird 
for a large price !" ejaculates a third party. Certain it is, that, for an excellent sougster, the Blackeap has given rise to more complaint than almost any other variety of eage-bird; and he is a constant subject of communication between bird buyers and sellers. 'The bird's silence is easily accounted for'; as, unless the Blackcap is tenderly eared for and looked after, he certainly will not sing. A greater variety of food must be given him than almost any other kind of bird. If a few precantions are observed, he will sing as readily as any bird, and once in song will remain so.

In his native woods he feeds altogether on caterpillars, flies, and insects, and is also foud of the virions wild berries which abound. 'This should not be forgotten when he is eaged : to feed him sinply on the regular Mocking-bird food is not sufticient; he must have in addition a varied diet of fruit, insects, or berries, which should be always kept in store for him. When the proper conditions are observed, and a little more attention than is commonly given cage-birds is paid him, he will thrive in contentment, and will live to be twelve or sixteen years of age, singing nearly constantly. The Blackeap is au unusually clumsy bird, considering his small size; and as he hops along the bottom of his eage, with his body almost touching the ground, his awkward movements are surprising. His cage should be cleaned daily, and a plentiful supply of dry gravel shonld be given him ; as one of the bird's chief ailments is swelling of the feet, which is always eaused by inattention, and neglect to properly clean them. When the cage is not carefully sanded, the bird's feet become clogged ; and a hardened mass gradually grows on them, which, if not attended to, will cause the feet to swell, and in the course of time utterly ruin them. When the first sign of dirt or clogging is noticed, the bird should be carefully caught, and the lumps of dirt softened in lukewarm water : after thoroughly softening, they must be carefully removed, not pulled off. The feet, should then be earefully dried; and an application of glycerine should be made, in order to remove any soreness of broken skin whieh may have occurred in the operation.

The Blackeap is also subject to a disease closely resembling consumption in the human being. It is a gradual wasting away, or decline. He may be noticed sitting on his perch, with ruffled feathers, and his head under his wing, and at times eating an enormous amount of food. This is the result of an unnatural diet, where no change of food has been given, which impairs the digestive powers. The most effectual remedy is, to put a rusty nail in his drinking-water, and force him to swallow a spider, which acts as a purgative, and, as soon as any perceptible, recovery is noticed, to change the food as much.as possible.

Epilepsy or paralysis is caused by want of exercise : when the bird is attacked by it, dip him once or twice in the coldest water procurable, and allow him the run of a larger cage than he has been used to. This disease sometimes terminates fatally, although, when carefully attended to, may be cured.

The Blackeap is usually fond of his daily bath ; and, when it is regularly indulged in, he usually enjoys his full complement of feathers : but, when the bath is not taken, it is often the case, owing to the softness of his plumage, that his feathers are broken, and have a disordered appearance. In this ease he should be showered daily for a week with lukewarm water.

His regular food should be the Mocking-bird food, as prepared for all soft-bill birds. His bill of fare outside of this is almost inexhaustible, and any thing new in 
the way of dainties is always welcomed by him: he is epicurean in his tastes, and will be apt to sulk if his whims are not gratified. In the different seasons he, may be fed on inseets, beetles, eaterpillars, or spiders. $\Lambda$ stoek of meal-worms should be kept for him. Ants' eggs soaked in boiling water until they swell may be placed, a few at a time, in his prepared food daily: common dried eurrants soaked in the same way may be at times substituted for the ants' eggs. Fresh berries of all kinds, and fresh fruits or green vegetables, are relished by lim. It is an easy matter for any one to obtain some of the above-mentioned foods, as it should be borne in mind that change of food is necessary for him.

When the proper food is furnished, althongh the trouble of feeding and attention is somewhat greater than is usually the case of the average cage-bird, he will not belie his reputation as a song-bird, and will fully justify all the praises that have been written of him.

'The Blackeap requires a somewhat larger cage than the Canary; the best one being the brass eage $10 \times 13 \times 15$, or the wood frame, tinned-wire one, size $9 \times 14$.

\section{SONG.}

I never heard the herald Lark

Pour forth his matin lay,

As, rising from the shadows dark

Into the golden day,

Up, up he mounts on tireless wing,

Bearing his tuneful offering.

I never heard the Nightingale,

Deep hid within the grove,

Trill out his song o'er hill and vale,

In ecstasy of love,

Till all the rustling leaves are still,

And softer runs the list'ning rill.

Yet, hearing thee, I seem to hear

The Lark at dawn rejoice,

And in the gloaming, silver-clear,

The Nightingale's sweet voice;

And unawares the quick tears start,

Such perfect rapture fills my heart.

IV. W. Caldwell. 


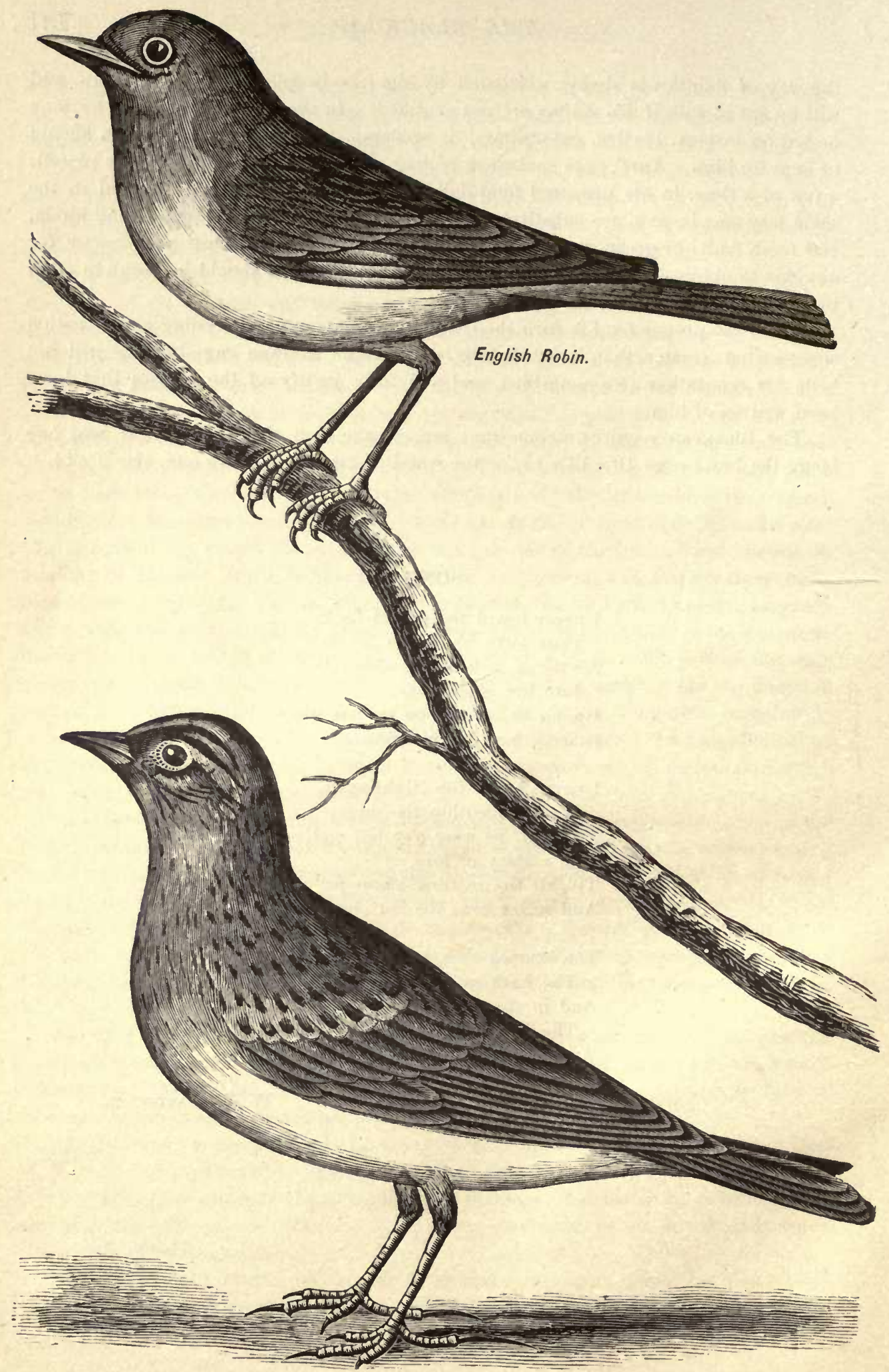

European Skylark. 


\section{SKYLARKS AND WOODLARKS.}

'THE Skylark, a bird about which so many poets, good and bad, have written, is a common-looking little fellow, about six inehes in length, and, like a majority of the most noted songsters, very unpretending in color. 'The beak is dark brown above, and pale yellow brown at the base: the feathers at the top of the head are dark brown edged with paler brown, and, being rather longer than those on the rest of the body, form a erest, which the bird elevates at pleasure, but ehiefly when in full song. The cheeks are pale brown. The upper part of the body is varied with three shades of brown; the centre of every feather being darkest, and shading off to the onter edge, giving the bird a spotted appearance. The tail is brown, with white outside feathers; the throat and upper part of breast pale brown, streaked with darker brown; and the belly a pale yellowish tint. The legs are strong: the hind-claw is the longest, and very straight. This peculiar formation of the foot is an easy way for an amateur to distinguish the bird.

The Skylark is an inhabitant of most parts of Europe, and is also foumd in Asia and Africa, and being a tough, hardy bird, and able to withstand the hardships of a bleak winter, is found in eountless numbers throughout the parts he inhabits. There is certainly no eage-bird so mniversally kept in Europe as the Skylark. No matter whether in a rude box-eage he hangs before the lowly eabin of some poor peasant, or in a gilded cage he swings in some narrow, foggy London street, he seems perfeetly contented, and pours forth his joyous melody in an endless stream. His song is especially esteemed for its wonderful power and brilliancy. To be heard and enjoyed to the fullest extent, it must be heard on a clear morning, when he rises to loftiest height, on pinions unconfined. As he mounts skyward, he performs an entire original opera, wonderful in its diversity. He is the only performer required, his scope in music being seemingly unlimited, his small pipe pouring forth every sound that ean be musically expressed. He is, in faet, a grand church-organ in a condensed form. His first flight commences in lively music, and is gradually deepened into the more serious passages, his voice being modnlated as he ascends. As he rises higher and higher, and distance softens the notes, the music seems to vary and become mellow, until at his utmost height, and a mere speck in the heavens, one ean almost imagine himself listening to the mellow trills of some far-off, aged, soft-noted instrument. The old saying, "Distance lends enchantment to the view," may be in the ease of the Skylark ehanged to "Distanee lends enchantment to the hearing." The Lark performs his grand finale as he descends, ceasing almost entirely when almost to the ground. He is most appropriately named by a wellknown poet, "the musical eherub." The song of the Skylark is peculiar to itself, 
and is made up of a variety of swcet notes uttered in quick succession, to which he keeps time by the vibrations of his wings.

'The Lark's nest is built on the gronnd, hidden in a mass of flowers or thick grass ; and he always approaches it stealthily, an act in strong contrast to his bold flight. The eggs are four or five in number, of a grayish color speckled with brown. The mother of a brood of young is not easily frightened away, and may be caught by the hand before she is forced from the nest.

The Skylark does not perch in trees, but rests on the bare ground. The peculiar shape and length of the claws was a matter of inquiry among naturalists, as he does not use them for scratehing. The nest is liable to be injured, placed, as it is, in the grass; and the parent birds use their elaws to move the eggs to a place of safety. 'The length of the claws enables the bird to walk with much greater ease through the grass, acting on the same principle as a snow-shoe on the foot of a man.

The Skylark is probably the hardiest cage-bird known : true to his joyous nature, he is happy in all sorts of weather, and contented with almost any kind of food. The richest food which can be given him, and in which he delights, are insects of all kinds : he will also feed on seeds and oats, of which he is very fond. His prineipal food should be the same as for all soft-bill birds, - Mocking-bird food and raw, grated carrot; and a variety of fresh vegetables should always be given him. He is very fond of them; and as they serve as a good change, and keep him in good song, they should be freely given. Of all birds of passage, he is the earliest to arrive, and, owing to his varied bill of fare, can sulosist on most any thing, even should the coldest weather set in.

From the foregoing it may be seen that the Skylark is a most desirable eagebird, easily cared for, naturally very tame, and one of the best and most delightful of songsters. If taken from the nest, and placed in a room where other birls in full song may be heard, he easily acquires their notes. It is asserted by one of the best authorities, that a Skylark hung in a room with a Nightingale had learned his song to perfection, and whistled it in addition to his own natural notes. The young Larks when taken from the nest are easily reared, and make the best cage Larks; as they are very tame when reared by hand. When taken from the nest, the young Larks should be fed on bread and milk mixed with a little poppy or maw seed : if ants' eggs ean be procured, they wonld be preferable.

The female Skylark is somewhat smaller than the male, and is distinguished from him by larger and more numerous dark spots on the back and breast; the groundcolor on her breast being much lighter than on the male bird.

Skylarks may be easily bred in confinement, owing to their natural tameness. They should be given a large room, with an abundance of sand. A quantity of dry grass and hair should be given them, from which to construct a nest. With these materials they will build, first scooping out a hollow in which they make the nest. The.female lays twice a year four or five gray eggs spotted with brown: the period of incubation is from fourteen to eighteen days, and the young birds are hatched out about the first of May. At this period the parent birds should be given plenty of meal-worms, insects, poppy-seed, and crushed oats, or crushed hemp and barley groats, or bread-crumbs: these should be varied with the regetahle diet, such as water-cress, lettuce, or cabbage, and lean meat chopped into fine pieces. The above 
food should be given to all Larks, whether they are breeding or not; as it improves the song, makes them livelier, and keeps them free from diseases. An abundance of gravel and a sod also should be given. The Lark is a bird which never bathes: he dusts himself in the same manner as barnyard fowl, and, when any degree of cleanliness is observed, is remarkably free from insects. He should always have some fine sand in his eage for this purpose: fresh sand should be put in the eage at least once every two days.

If good song is desired, the Lark should be eaged; as he is more apt to sing at his best than when allowed the freedom of a room: if kept in a room, particular care should be taken as to cleanliness; as he is sure to get his feet entangled in such substances as hair, string, ete., which wonld oceasion the loss of his claws, or canse lameness and disease in the feet.

The usual and best cage for the Skylark is peculiar in shape, and specially made for him : it is a cottage-shaped strueture, with a semieireular front revolving on a pivot. A piece of eloth is stretched across the top of the eage. The Lark in eonfinement does not forget his natural desire to soar, and for this reason the eloth is used to prevent his injuring hinself. The revolving front should be always furnished with a fresh sod, on which the Lark delights to roam, seeming at home, and upon which his best efforts are heard. Perches are not neeessary, and should never be put in the eage.

He will pace from one end of the eage to the other, stretehed to his full height, with fluttering wings, pouring forth his song, and seemingly as contented as if roami.g his own native heatl. When the weather permits, he should be hung outdoors, as it seems to enliven him; and, as he is not so susceptible to colds as other eagebirds, this may be freely done without injury to him. A good Skylark probably remains in song longer than any other wild bird known.

The Woodlark is about three-fourths the size of the Skylark, and bears a striking resemblanee to him in eolor and habits. He is not so hardy a bird as the Skylark, being used to warmer climates. His song, aceording to some authors, is superior to the Skylark; and he is oftentimes rated as second to the European Nightingale. The song is very flute-like and melancholy. He is rather shy, and does not like to sing when in company. It is therefore best to always hang him outdoors.

Woodlarks are not as numerous as Skylarks, and are not so well known; but, when the song is once heard, they are acknowledged the equals of the more general favorite. The Woodlark perches, contrary to the habit of the Skylark, and sings in confinement only when perched. In his wild state he sings when almost out of sight on outstretched wing, oftentimes warbling for an hour in this position.

His food and treatment are identieal with those of the Skylark. The diseases to which Larks are subject are usually the same that affect all soft-bill birds, and the treatment should be the same. They are subject to one speeial disease of the skin: a part or the whole of the body is puffed up by an accumulation of air beneath the skin ; this is easily remedied by pricking the skin with a needle to let the air out.

The square eages suitable for them should measure $8 \times 10$ or $9 \times 14$, and are usually made of tinned wire and black walnut. 


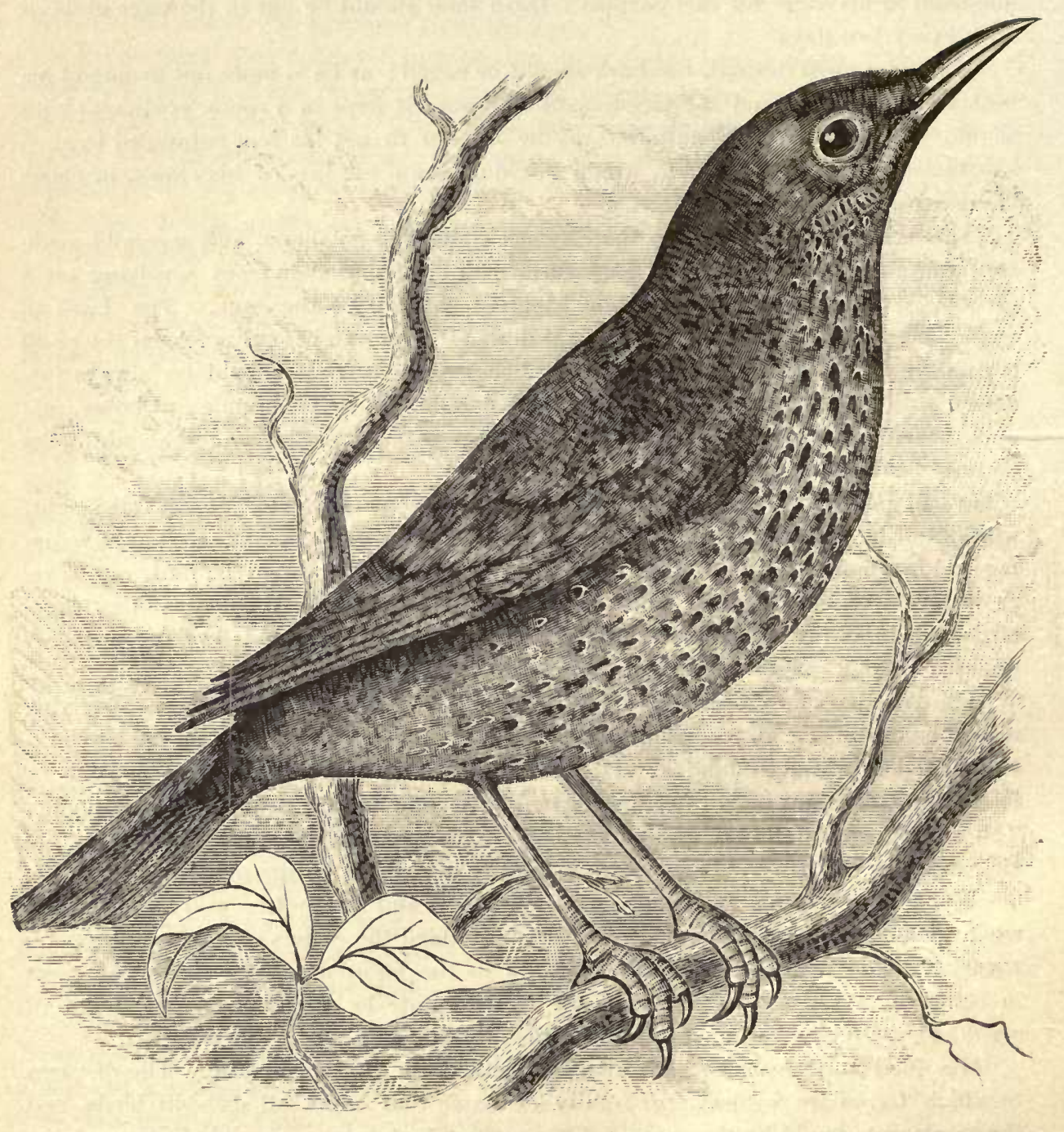

The Song Thrush. 


\section{THE SONG THRUSH.}

Tne members of the 'Thrush family number about one hundred varieties, and inhabit all parts of the globe. Of the entire number, probably the Song 'Thrush is the best known: he is a kindly, intelligent-looking fellow, who pours forth his mellow song with as much vigor in his rucle latticed cage before the hut of the poor peasant as when free to fly over quiet glebes or in shady wood. There is no bird which has the affectionate regard of the poorer classes of bird-lover's so fully as the Song 'Thrush. Added to his great powers of song are his hardy qualities and handsome mottled plumage.

The Song Thrush measures about eight inches and a half in length. 'The npper part of the body is a rieh olive brown; the throat light yellow, with a black stripe down each side; the sides of the neck and breast light reddish yellow, covered with numerous dark-brown heart-shaped spots; the belly is white, with darkbrown oval spots; the outer wing-feathers have orange spots on the tips; the immer wing-feathers are light orange. In the female several little streaks are substituted for the black lines on the throat; the breast is a pale whitish yellow; and the orange spots on the wing-feather's are smaller than in the male. Thrushes build in small pine or fir trees, and prefer to build in the neighborhood of a stream or brook: The nest is formed of fine twigs or roots, and lined with mud. 'The female lays from three to five eggs, and, when wild, rears as many as three broods in a season.

The Song 'Thrush is the earliest breeder of all British birds, which accounts for his commencing to warble so early in the year: the songs of all birds in a state of nature are called forth by the impulses of courtship ; and they are, of course, nothing more than the outpourings of love.

It is said in general, that the notes of soft-billed birds are finely toned, mellow, and plaintive; those of the hard-billed species, sprightly, eheerful, and rapid. 'This difference proceeds from the construction of the vocal organs. As a larger pipe of an organ produces a deeper and more mellow-toned note than a small pipe; so the windpipe of the Nightingale or of the Thrush, which is wider than that of a Canary, sends forth a deeper and more mellow-toned note. Soft-billed birds also sing more from the lower part of the throat than the hard-billed species. 'I'his, together with the greater width of the tube of the soft-billed birds, fully accounts for their soft, round, mellow notes, compared with the shrill, sharp, and elear notes of the Canary and other hard-billed songsters.

The 'Thrush sings nearly the whole year, but in the spring his song is particut larly fine: he is often ealled in England the Ousel. Tennyson refers to him in the lines, - 
"From the woods

Came voices of the well-contented doves. The Lark could scarce get out his note for joy, But shook his song together as he neared His happy home, the ground. 'To left and right The Cuckoo told his name to all the hills; The mellow Onsel fluted in the elm; The Redcap whistled; and the Nightingale Sang loud, as though he were the birl of day."

Every one who has listened to the Song Thrush will agree with the poet's idea, that the song is mellow and its tones flute-like. 'There are many kinds of birds one may hear, and afterward feel that the song was incomplete, - something was needed to make it perfect; but listen to the Thrush, and, ere he has finished, you are impelled to exclaim, What perfectuess! It is a most satisfactory performance ; and the only thing one can desire is, that the bird repeat, and repeat again, his inspiriting, restful, heaven-bestowed melody.

"There is a blithe, bluff heartiness," writes Swaysland, "about the song of the Thrush, that carries with it a certain feeling of rusticity, which makes it peculiarly attractive in a town, bringing, as it does so forcibly, remembrances of those green fields and shady hedgerows where, beside some rippling stream, he builds his nest."

The flight of the Song Thrush is remarkable for its swiftness and grace; and the birds are very adroit in hopping over the surface of the ground, or climbing about the trees, aided by their wings. They are capable of springing with remarkable facility to a distant branch. Their sight is so keen as to enable them to detect the smallest insect at a great distance; and their sense of hearing so delicate as to warn them of the approach of danger long before it has been perceived by other inhabitants of their native woods, who at once seek safe shelter when they hear the warning cry of their more acute and vigilant companions. To this superior sagacity is, no doubt, attributable the eager desire exhibited by Thrushes to investigate any new or striking object: they, however, take good care to keep at a safe and respectful distance, even while carrying on their examination with the most eager attention. While they are such active birds, unlike most birds they do not accompany their notes with any description of movement or gesticulation, but sit perfectly quiet and almost motionless during the whole song. One male has no sooner perched himself on a conspicuous branch, and commenced singing, than he is answered by all those in the neighborhood ; as they hurry to the spot to join in the performance, and share the admiration they evidently expect it will excite.

When caged, he is deservedly one of the greatest favorites, especially with the foreign bird-fanciers, his beautiful song bringing to mind the scenes and sounds of the old-country wildwoods. The first inhabitant of a bird-shop which a freshly arrived English or Irish emigrant is sure to seek is his favorite Song Thrush, or Mavis as he is familiarly called. The traveller will relate new and fabulous stories of his powers of song, and the cage tenanted by one of his farorites is certain to receive a dainty from his hands.

It oftentimes is possible in the crowded tenement districts of a large city to see a Song Thrush hanging before the window, night and day, in all sorts of weather, the 

roof of the cage forming his only protection. His hardiness is proverbial, and his remarkable constitution seems capable of enduring any degree of cold. His melodious voice will delight whole streets by its loudness and pleasing variety: and, while the voice is very loud, it is always clear and agreeable; in this respect the SongThrush when eaged cannot be equalled.

In a wild state the bird subsists on berries of various kinds, and is a greedy devourer of almost any variety of insect food. One of his chief delights is that of cracking a cockle on a stone, and dexterously withdrawing the meat, which is a delicious morsel for him.

When caged, the prepared food is the bird's regular dict, subject to the changes as given for all soft-bill birds. The changes of diet, and the remedies for diseases, are the same as those of the Mocking-bird.

A number of small pebbles or stones should be placed in the cage, to supply the want of the cockles which he enjoys cracking in his wild state. He will pick up a pebble in his beak, and beat a tattoo with amusing rapidity on the bottom and against the wires of his cage.

The eage should be roomy, twenty-four to thirty inches long; and, if the bird is accustomed to remain outdoors, he should have all sides of the cage except the front protected. With this precaution the cage may be permitted to hang outdoors at all seasons, except the most severe.

With even common care and attention the Thrush will live in good health and song to the age of ten or twelve years. 


\section{THE EUROPEAN BLACKBIRD.}

Trrs is a deservedly popular bird with all classes of bird-lovers, and one which combines with his own sweet natural song most remarkable powers of imitation. 'The Bullfinch has a great rival in the Blackbird; and, if the latter were more widely trained, he would, no doubt, surpass even the perfeetion of trained song supposed to be attained only by the Bullfinch.

The deseription of the male Blackbird's phumage is easily written: it is black throughout, and shines with a beautiful velvety lustre. The beak is an ineh long, and almost black until the bird is two years oll ; and then it beeomes a brilliant orange, showing in a marked manner against the jet-black plumage of the body : the eyelids are also of the same brilliant color, and surround a bright, full brown eye. He is ten inches in lengtl, and well proportioned.

The female Blackbird is so differently marked from the male as to lead most persons to suspect that they are an entirely different speeies. 'The head, neek, and baek are dark brown; the throat and breast are rust eolor; the belly pale brown. The Blacklird is a member of the 'Thrush family, and is often ealled the Black Thrush, and greatly resembles the Song 'Thrush in many of his habits.

The Blackhird is very shy in his wild state, and is not easily trapped: the favorite birds of this class are the nestlings. If these are taken at an early age, and earefully reared, they become practiced musicians, and will not only imitate the songs of other birds placed within hearing, but will pipe operatic songs in a perfeet manner.

Blackbirds are very intelligent, and their devotion to their young is remarkable. A pair oftentimes snceeeds in driving away a cat which attemps to devour a nest of their young. They also have, in a measure, the cunning and mischief of the Crow ; although they are not so destructive to the farmer.

Many amusing aneedotes are told of the Blackbird's singular attachment for animals: he rearlily becomes attached to the house dog or eat; and, although the latter always has one eye on the pet Canary, he never seems to think that his friend the Blackbird would make a more substantial meal. 'The bird will peek at the cat's tail, and take a ride in perfect safety on the dog's back, and will battle with any intruder who may dispute him in these aequired rights.

The natural song of the Blackbird is very flute-like and melodious, and, thongh not so varied as the Song 'Thrush's melody, is more rich aud mellow. He commences his song very early in the morning, and sings late in the evening: and it is said that

- he is a rival of the famons Moeking-bird as a night songster. They appear to put forth all their efforts during the continuance of a rain-storm, and at no other time is 
the Blackbird heard to whistle so well. Would it not be well, then, to have a cage arranged with a sprinkler attachment, so, when the Blackbird alighted on his perch, the flood would pour down upon him?

In addition to his qualities as a songster, he forms a favorite dish for epicures ; and Blackbird on toast, or within a crust, is as well known and delightful to some admirers as his charming song and playful ways are to others. He seems to have been a special favorite in olden times, when the rage for dainties in the shape of frieasseed birds' brains and tongues was at its height. It is said, that, when this absurd mania was in full sway in Italy, the Blackbirds were fed on grapes and other rich fruits, so that their delicious flesh was still more delicately flavored. The Blackbird, when eaged, is a very neat and attractive-looking fellow ; and, without laying claim to gaudy plumage, his two simple, striking colors and trim shape give him a very "dressy" appearance.

He is a hardy bird, as his early life spent in the fields through winter and summer tends to make him so. When eaged, this training is at all times apparent; and. like the mischievous boy, he is never so much at home as when outdoors. Hang your Blacklirel ontiloors, and he will quickly make himself heard throughout the house as well as up and down the street. Like the 'Thrush, he is eapable of enduring all sorts of weather: and if the eareless owner forgets to cover the cage to protect him from the clriving storm, or leaves him hanging outcloors all night, it does not appear to affect him; the next day he will sing as well as ever, and look his master in the eye with a don't-do-it-again expression. He is an espeeial favorite with the linglish bird-lovers, and his homely wieker eage may be observed hanging beneatlı the window-sills of dozens of houses throughout all quarters of the larger cities. He appears to bear the same relation to the class of larger birds in England that the Mocking-bird bears to the American birds. His powers of mimiery, although not as great as those of the Mocking-bird, are very well developed. He will intermix with his song the Rooster's crow and the Hen's cackle; and it is even said that he can successfully imitate the dog's bark, although this seems to be somewhat out of his line. The Blackbirds which have been reared by hand from the nest are the only ones capable of performing these imitations; as their early associations were away from the old birds, and where they were deprived of hearing the natural song. If taken from the nest before they are able to fly, and earefully reared, the training may be developed into remarkable results. In training the Blaekbird to pipe a song, proceed in the same manner as indicated for the Bullfinch; the natural whistle being the better way, although his strong, melodious voice is well fitted to copy exactly the notes of a flute. In Germany and England shoemakers and artisans who have to perform their lahors at home, oftentimes while away a weary hour, and add profit to their industry, by teaching a young Blackbird to perform some galop or air from a comic opera. The Blackbird, unlike the Starling, does not mix in any harsh, guttural notes with lis operas; as his own natural notes are of an entirely different nature from the Starling's. If he performs the song which has been tanght him, and adds a few of his own notes as a finishing touch, the effect is all the more pleasing, and takes away the unpleasant feeling of hearing a too oft repeated good story. Blackbirds have been taught to pipe many of the airs which appear in the list of Bullfinch music. Tlie Blackbird's voice bears no comparison to the Bullfinch's. 'The dreamy, 
soft tone in the voice of the Bullfinch, which affords such great pleasure, is absent; and in its stead is heard the elear, mellow pipe, just like the notes of a well-played flute: and, although the two styles of music are widely different, each bird has his own class of achirers, who think that the music as performed by their own favorite is the best.

The Albino Blackbirds are a remarkable class. 'This freak of nature seems to favor the Blackbird more than any other known speeies, and the appearanee of some of the members is quite puzzling. In some parts of Ireland the Albino, or White lBlackbird, is held in great veneration; and, when one is seen in a flock, he is not allowed to be harmed: in fact, the religions superstition which proteets birds of this class would prove dangerous to anybody who should be found guilty of eatching one of the birds.

Sometimes the entire body is pure white: in other cases the wing or tail feathers only show the white. It is not related that the flesh of the White Blackbird is any more delicious or tender than his colored brother's : but it is certain that they are greatly sought for as eage-birds and speeimens for museums.

English Blackbirds have become great favorites in America; and residents of foreign birth, who do not forget his pleasing song when he roamed the fields with which they were so well aequainted, admire him above any other imported cage-bird. He does not lose any of his pleasing notes when caged, and sings even more constantly during the year than when at liberty. Owing to the Blackbird's size, he should have as roomy a eage as possible, and ample bathing facility. In fine spring or summer weather he may always be hung outdoors; and then his cage should be covered, to proteet him from the rays of the sun.

The Blackbird lives in confinement, when properly cared for, from eight to ten years. The trained birds of this class are not apt to forget their music; but, during the moulting season, it is better to whistle the air to them daily, so that they will remain perfect pipers.

The Albinos require the same care as the common Blackbird : only in the ease of complete Albinism, or where the eyes are pink, the bird should be hung where a strong light will not reach him; as it would tend to weaken the eyes.

The food, care, and treatment for diseases, are the same as given for the Song. Thrush. 


\section{THE STONE THRUSH.}

Turs bird, although very little known as a eage-bird, is a splendid songster, and fairly rivals his better-known brother, the Brown 'Thrush. He inhabits but a limited portion of Europe, chiefly the southern parts, and rarely appears in the northern portions. He is commonly found in the mountainous or rocky districts, hence his name. Alpine travellers have often noted his handsome appearanee, and have oftentimes been at a loss to find ont his name, owing to his extreme rarity in a eaged state.

In his amusing postures and movements he greatly resembles the Starling, and, like that bird, is also able to imitate the human voice, and to learn to distinctly pipe a complete tune.

The Stone Thrush is about seven inches and three-quarters in lengtl, of which the tail measures two inches and three-quarters. The beak is black, with yellow corners, and about one inch long: the feet are very strong and black. The head and neck are grayish blue, lighter in old birds than in young ones. The upper part of the back is dark brown, sometimes clonded with a lighter tinge, the middle a beantiful white. The breast and belly are dark orange, the latter being spotted or clouded with white more or less distinetly according to the time of year. The vent is a pale yellowish red; the wing coverts darkish brown, with white points ; the quillfeathers very dark brown or blackish, the hinder ones somewhat lighter, whitish at the points, and having a narrow white border on the farther side : the tail dark yellowish red, with the two centre feathers grayish brown.

The female has the upper part of the body dark brown, the feathers being bordered with grayish white; the rump is rust colored, with a similar edge; the chin white ; the front of the neck, and all the lower parts, a dirty orange, with brown and white wavy lines; the tail is somewhat lighter than that of the male.

When in a wild state the Stone Thrush digs under stones after worms, these being dainties in which he delights. His principal food when wild being inseets, they must be freely given him when caged; as withont them he is apt to become sick and waste away.

The Stone Thrush, when taken as a nestling, is remarkably docile and very playful : he becomes the tamest of eage-birds, and in the process of becoming tame loses none of his charms as a sougster.

His natural song is remarkably melodions; and, while not so loud as the Brown Thrush's song, the variety is equally as great. The Stone Thrush may be safely recommended to any bird-lover who desires a night-songster, as he sings as freely by gas or lamp light as he does by daylight: he sings about ten months of the year. This bird is rarely caught by means of traps or limed twigs, but is taken from the 
nest, and reared by hand. Only a few are imported; but, when one is introduced into a household, he immediately takes rank as one of the most delightful of pets.

His food in confinement should be the prepared Moeking-bird food ; and he should have an abundance of insects and meal-worms, as it is on this class of food that he subsists when wild. A few berries in their season, and fruits of different kinds, should be given as a change; and these will generally keep him free from diseases.

He is naturally a strong, hardy bird, and in the summer season should be hung outdoors in the sunshine. Like all his class, he is fond of his daily plunge : he also delights to play with stones or pebbles, taking them in his beak, and hammering them on the bottom and sides of his eage. Such pebbles should be given with the gravel, which should be plentifully sprinkled on the bottom of his cage. He usually lives for ten years.

The regular wood-framed or brass Mocking-bird cages are the best for him. He is kept for sale in the bird-shops the entire year. 


\section{THE ENGLISH STARLING.}

A merir-making clown is our well-known English friend, made famous by writers of prose and verse.

Although the Starling's natural song cannot be classed with that of the Nightingale, he makes up for this deficiency by his numerous laugliable tricks, his great tameness, and great power of mimicry. All points considered, he is one of the most attractive of cage-birds. As for a cage for him, it is not neeessary : for, after being with you a few days, he is not satisfied unless he has the full run of the louse; and you may rest assured every thing which comes under his shar') glance must pass the closest inspection. He is always a great favorite, and has been the subject of many good, bad, and indifferent stories. His glistening purple plumage gives him a handsome appearance; but his walk as he goes across the floor cannot be considered studied or graceful, being a compound of a duck's waddle and the roll of the typical old salt.

His roguish eye flashes out the intelligence which he displays by his aptitude for learning to pipe entire tunes, he being the trained Bullfinch's great rival in this respect. He learns to talk also, and it is recorded that one has spoken sentences with as many as ten words in them.

He is probably one of the easiest kept cage-birds known, as his appetite is by no means as dainty as it is unlimited. He will eat almost any thing in the shape of bird-food ; and, if put in an aviary with other birds, his greediness, if not satisfied with sufficient food, would tempt him to turn cannibal, and devour one of his messmates, - a trait of character which his intellectual talents and simple ways would not lead one to suspect. They live, however, very anieably when a lot are put in one cage together; and their antics are strange and very conical.

The Starling is about eight inches in length: the beak is one inch long, very slencler and pointed, and pale yellow in color. The entire body is of a blackish cast, tinted with bright purple and green. The feathers of the head, and back of the neek, are tipped with reddish white, those on the back with a light rust color, and on the outer part of the body with clear white, which gives the bird a comely, speekled appearance. In the fenale the spots are larger than in the male, and the beak is of a brownish color.

The Starling inhabits all parts of Europe. from March until October, and breeds in large numbers, in almost any place on which a nest may be built. He considers the eaves of a house as much his property as a tree in the woods.

It is singular to wateh a flock of Starlings abont to retire for the night: they will wheel about the thicket or spot which they have selected to settle on for the night 
with great accuraey; suddenly, as if by a note of command, the whole flock turn their sides to the spectator, and, with a great whirring noise, the whole front and shape of the troop is altered. No body of well-trained soldiers could better wheel or countermarch than a regiment of Starlings.

They are very plucky birds, which becomes the war-like movements deseribed; and it is related for a fact, that a cat, who ventured to attack a nest of young Starlings, was so pestered and annoyed by a troop which the male bird hastily summoned, that he was obliged to forego his tender meal, and run for safety.

In Germany the peasants treat the Starlings like domestic pigeons, taking the young from the nest before they are fledged; this induces the parent birds to breed as often as three and four times in a season : the last nest, however, is left undisturbed, so as to increase the stock, and induce the old birds to return to the same nest the following season. The same nest is used year after year, being cleaned out as soon as taken possession of.

A Starling, when caged, should be fed on the prepared Mocking-bird food, as given to all soft-billed birds. Of dainties he is extremely fond, and, if allowed to roam in the dining-room, will quickly display his epicurean taste by eating only the best, leaving the common food for the rest of the boarders. He will eat insects of all kinds, also fruit and grain : therefore it will be seen that his wants may be easily satisfied. A change of food is always desirable, and from the above varieties a change can be easily had.

He is an amphibious bird, and no other bird that I know of delights more in taking a batll. He is like the Newfoundland $\log$ in his way of bathing: he will plunge in and duck around, and, when he comes out, seems to take pleasure in scattering the water as far as possible while shaking himself dry. He will stand for hours pluming himself and making his toilet, chattering and singing in the most amusing fashion.

The young Starlings are easily trained to whistle an opera-air : but, in order to do this, they should be kept in a room as free as possible from noises of any kind; as they are apt to mimic them, and mix them with the music. The air should be whistled once through five or six times daily, or, better still, be played on a birdorgan. They do not require so long a course of training as the Bullfinch, for they learn to pipe a complete air in two or three months. They often pipe two, and sometimes three, airs.

The Starling should have the roomiest of cages and an abundance of fresh gravel daily. If given any sort of attention, you may have an amusing, interesting companion, who will live for many years. 


\section{SATIN STARLINGS.}

Inere is a race of birds with which, probably, one bird-fancier in one hundred is aequainted; and yet the Glossy Starlings are the most gorgeous eage-birds knowu. Words fail to show the brilliancy of the plumage, and the painter's brush cannot adequately represent it. The wonderful dark brilliant hues of which the plumage is composed reflect the rays of light like a eluster of diamonds. Added to all this gorgeousness, the birds have the spirit of acute mischief and the usual high degree of intelligence in the Starling family. They are extremely hardy, and live in eonfinement longer than the average long-lived cage-bird. The entire family are uatives of the different portions of Afriea, a land which is noted for its brilliant-hued birds. Very little is known here of the bird in a caged state, although they have been successfully bred in various parts of Europe ; but, when their lively dispositions and playful ways become better knowu, they will undoubtedly outrank many of the favorites of the present time.

There are four varieties of the Glossy Starlings, all noted for their flashing hues and splendor of color. In each class some one brilliant color predominates, while all the remaining colors blend with such effect that it is often difficult to tell at a distance just what the ehief color is. Their dispositions connect them with the Starling family, and their colors with the Birds of Paradise : in fact, they seem to form a connecting-link between these two families.

While all parts of the countries to which these birds belong are enlivened by their presence, they take up their residence principally in rocky districts in the immediate vieinity of men's dwellings, where they disport themselves, and lend an embellishment to the tropical scenery which travellers are never weary of extolling. They are, without exception, lively, bold, and noisy in their demeanor, and always travel in large flocks, and live very sociably. They have, however, enemies among other elasses of birds, with whom they live in a state of constant warfare. Their movements are light and active, and their dispositions exceedingly sagacious and intelligent. Some of the species have a very agreeable song; while others have the harsh, guttural notes of the English Starling. 'They breed twice each year, laying each time five or six eggs.

The bronze-colored Satin Starling, an inhabitant of the northern part of Africa, possesses an attire of extraordinary lustre, which glitters in the rays of a tropieal sun. The plumage is bronze-like in tint, except upon the sides of the head, the lower part of the belly, and wings, which are a beautiful indigo blue. This speeies is about ten inches in length, of which the tail measures three inches. The Bronze Starlings are to be met with in large numbers in their native lands. They are brisk 
and lively; and the flight is very peculiar, being distinguished by a noiselessness that plainly indieates the velvety softuess of the wings. Their song resembles that of the English Starling: Nature seems to lave been so lavish in her charms on the decoration of the bird, that she deemed attention to the voice or other particulars unnecessary. Those who have seen the Bronze Starling in his native woods describe him as flashing upon their astonished sight like a bright and unexpected gleam of sunshine, the feathers reflecting every ray of light as does. a looking-glass. This species is the largest of the Satin Starlings, and is ealled by some authors the Longtailed Glossy, or Satin, Starling. He possesses many of the characteristies, when placed in confinement, of the mischievous Magpie; and he will pursue a gold ring, or any ornament which is of the same order as his metallic brilliant dress, around the room with the same zeal and playfulness of that prince of mischief-makers. It is hazardous to place this species in a cage with other birds, as the cannibalistic propensities of his native land seem to possess him.

The Golden-breasted Satin Starling is eight incles long. In the male the forehead and upper part of the head is bluish green; the neck, throat, and belly are of a darker shade of the same color; the rump is brilliant steel blue; the thighs are rust red. The female's plumage does not show the lustre of the male bird's, and it is intermixed with a brownish tinge. Although the plumage of this species suffers in comparison with that of the others, yet it is sufficiently brilliant to exeite admiration whenever seen in company with any but his more lustrous-hued brothers.

The Superb Satin Starling may be eertainly regarded as the most magnificent nember of the entire group. This species inhabits the most unfrequented parts of the African continent, and is of the same size as the Golden-breasted Starling. On the top of the head the color and lustre resemble burnished gold; the upper part of the back is metallie green, each feather being tipped with a brilliant silky black spot; the front of the throat, the upper part of the breast and tail, are indigo blue, with a diamond-like gloss; exeepting a white band upon the breast, the remainder of the body is a lustrous red. The above is a combination of colors which may be found in some rare varieties of birds, but in no other bird are the brilliant lustre and beautiful gloss apparent to such a degree as in this dazzling creature.

These birds are met with in considerable numbers in Soudan, where they are always seen flying about in large flocks. They seem to be endowed with more than the average gifts allotted to the bird race; for, in addition to the intense brilliancy of the plumage, they have a very pleasing song. They are the best songsters of any of the above classes. During the day multitudes of these gorgeous creatures may be observed disporting themselves with great vivacity, running in small parties over the ground in search of food, or seeking repose and shelter from the mid-day sun amongst the branches of the trees, on which they perch also morning and evening whilst the males pour forth their matin or vesper songs. Should the party be alarmed. they do not seek safety in flight, but hide among the foliage until they can renture forth from their places of concealment. During the whole time they are in search of food the entire neighborhood is kept in a state of bewildering confusion; each one rying with every other in trying to make the most noise, simply for the sake of ereating an uproar. The Superb Satin Starling is very rarely seen outside of its own country ; as their capture, owing to their methods of hiding, is extremely difficult. 
As a specimen for the taxidermist's collection, the Superb Satin Starling is a dangerous rival of the Bird of Paradise. 'The three varieties described above form a group; as they resemble one another in many respects, sueh as formation of body, and shape of head and feet.

The Green Satin Starling is the most closely allied to the European Starlings of any of the Afriean family, and one would at once recognize him by his saney eyes and playful ways as an illuminated edition of his mischief-loving English brother. II may be taught all the tricks, and trained to pipe, in the same manner as the kuropean Starling. These birds are met with over a large portion of Africa, but they prefer the mountainons districts. They resemble the other members of the family in their morle of life, but are very quiet eompared with them. They are the most frequently eaged of any of this class of Starlings, and lay claim to merits possessed by very few eage-birds. The colors are of a dazzling nature; and although of no great variety, as observed in the other three varieties, the simple ehange of light is suffieient to make them appear to have all the gorgeous shades of the rainbow. The plumage is a rich violet over the whole of the back and throat as far as the breast; and the under parts are a lustrous bluish green or greenish blue, according to the light in which the bird is seen. The male and female are colored alike. If one wonld see the Green Satin Starling in all its dazzling splendor, the tropical forests which they hamt must be visited. When in flight, instead of the violet line, the baek shimmers in the sun like burnished gold; and only when brought down with the gun are the real colors discovered. 'The following is a description of one of these beautiful birds which had been caged for some time : -

Ben had all the playfulness and ingenuity of the Starling family, and, in addition, exquisite plumage, smooth and glossy like satin, and flashing all the fires and hines of a perfeet-eut diamond. One caller would say, "What a beautiful green he is !" then a companion, interrupting, "Why, to my eyes he is a deep blue!" Each was right, for the slightest change in the points of observation made the bird seem a different eolor. Could one clip off a yard of rainbow, condense it, and run it through a bird-shaped mould, he might prodnce something somewhat like Ben in color; but even this extract of rainbow would be inferior to the Starling's lorilliant plumes. The adage, "Gay birds have no song," will not hold true in this case; as I unhappily discovered at three o'elock every morning. The bird was restless and uneasy when away from me; so each evening he would walk or hop quite demurely throngh the hall, and wait on the hat-tree quietly until my lateh-key clieked in the lock; then, strutting along in a most piquant way, he would peck my shoes, fly to the extended hand, and refuse to leave me; so strong was his attachment that I felt compelled to have a little perch constructed, and each night this had to be placed in my room; at three o'eloek in the morning either his notes would arouse me, or else, plaeing the end of his very long bill between my lips, he would open his beak quickly. The sensation was terrible : but the bird loved me, and whistled, when I bade him, a sweet song; so I overlooked the one bad trait that for me meant misery, but to him expressed affection.

When confined, the African Starlings should have the same care and treatment as given for the English Starling. They are equally as hardy, and will live caged from eight to ten years. 


\section{THE ENGLISH ROBIN.}

Agarss a dark background of heartlessness, criminal deeds, and ferocity, as portrayed in the "Babes in the Woods," the Robin of Europe stands forth painted in the attractive colors embodying gentleness, kind actions, and whole-souled sympathy. The author of that stirring tale indicated only partially, however, the endearing qualities of the Robin, not touching at all upon the bird's vocal attainments, which are to us equally as interesting a study as are his mental traits. In writing, as that author probably thought, only for such readers as were familiar with the Robin, and daily heard and saw flocks of them, he treated particularly of the noiseless and unembodied qualities which are usually unobserved by the multitude.

The respect in which this little favorite is held in England has been transmitted to all lands, and the Robin Redbreast abroad almost takes the place of a national bird. If he has not been seen by our readers, he has been sufficiently written about to make him appear as an old acquaintance. He bears no comparison in size or color to the American Robin, but, like him, is held only in the highest estimation.

In length, the Robin is about five inches and three-quarters; the beak is dark brown ; the head, neck, back, tail-coverts, and tail, are of a yellowish olive-brown ; the greater wing-coverts are edged with buff ; over the base of the back, around the eyes, and covering the chin, throat, and upper part of the breast, is an orange red, bordered with bluish gray down to the wings ; the lower part of the breast, and the belly, are white.

The female is somewhat smaller; and the color on the breast is paler than in the male, resembling yellow more than orange. The young males resemble the females vory closely, and clo not attain the perfect deep color on the breast until the second year.

There are also Albino varieties of the Robin, some being wholly white, and others are mottled : the mottled class are very attractive in appearance.

The Robin is met with in large numbers throughout Europe, and in some parts of England they are seen as frequently as flocks of Sparrows. 'The European countries must certainly be regarded as the Robin Redbreasts' home, since during their migrations they do not cross its southern boundaries.

The Robin's nest is placed in holes in the ground, or in hollow trunks of trees, at no great elevation, and is formed of moss, stalks, and leaves, woven together and delicately lined with hair, wool, and feathers. Should the margin of the eavity in which the nest is placed not project in sueh a manner as to form a sheltering cover, a roof is constructed, and an entrance made in the side. The eggs, which are of a yellowish white marked with reddish-yellow spots, are from five to seven in 
number: these are laid about May. The parents brood alternately during a fortnight. They feed the nestlings assiduously with worms and iusects, and diligently instruct them in song, and tend them for a week or ten days after they are fully fledged: they are then permitted to go forth into the world on their own account, and the old birds prepare at once for the introduction of a second family.

The Robin is a very sprightly little bird ; and it is no wonder that lis social, fearless liabits when wild have made him the great favorite he is. He may always be met with close to the houses in country villages, hopping nimbly from bush to bush abont the fields and gardens in search of spiders, worms, and beetles, on which he cliefly subsists during the summer season. Some few do not eare to chance a southern journey; and remain near their old haunts during the winter months, and depend upon the various winter berries, or upon the good graces of their friends, the gardeners, as a means of support.

The Robin Redbreast is familiar to Europeans from earliest childhood, and is looked upon as one of their earliest acquaintances. The fabled story of poor Cock Robin's death and burial is the basis of many stories told of him in prose and poetry. In the different countries of Europe he has procured as many different pet names. In Norway he is known as "Peter Bonsmed," in Germany as "Tommi Guidet:" in England he is called plain "Bob."

Wordsworth best deseribes the esteem in which he is held, as follows:-

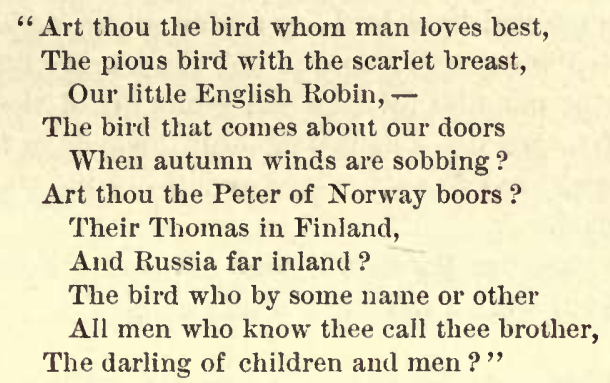

The song of the Robin is ranked very high by some authors; and the excellences of his volce have, in some cases, been placed on an equal footing with the Blackeap. His many endearing qualities and social traits, and being heard under peculiar conditions, probably account for this ligh recommendation. Although his song cannot be compared with the Blackeap's, yet for sprightliness, compass, and plaintiveness he stands very high in the list of cage-birds. Like the American Robin, he is so commonly seen wild, and is such a universal favorite, that he is not so frequently seen caged as some of the rarer specimens, that cannot be compared with him in song or playfulness.

Althongh living in constant peace with mankind, and always remaining friendly with him, the Robin is an extremely pugnacious fellow with members of lis own race, or with those of any other which dispute him in any way. Battles among them are frequently seen, in which one or the other is killed: their ferocity is likened to that of game-fowl.

The pugnacity of the bird is taken advantage of for the capturing of others of 
his species. If a Robin Redbreast is tied by the leg inside a small eage, and the door left open, only a short time will elapse before one of his kind is attrated by his flutterings. An immediate attack is the eonsequence, which results in an easy capture for the bird-eateher; as the Redbreast is intent only on the destruetion of his brother, and unmindful of any danger that may threaten himself.

Many amusing anecdotes are told of his kindly disposition when eaged, which are in direet contrast to his fighting qualities when wild. The following account shows his kindly nature when his opponent was unable to do just battle:-

Two male Redbreasts were captured, and confined in the same eage. From the moment of their imprisonment they seemed to have laid aside their amiable and social demeanor: morning, noon, and night they squabbled, and pecked each other, and fonght with a raneor which plainly showed that they each grudged every atom of food or drop of water obtained by the other. 'This state of affair's was at last brought to an unexpected termination: one of the captives bloke his leg, and forthwith the conduet of his companion clsanged; he at once took the helpless invalid under his charge with as mneh tenderness as if he had been one of his own children, and fed and tended him until the limb was completely restored. After the invalid was strong and well again, neither of the birds showed the slightest inclination to resume hostilities.

The truly parental affection which they exhibit towards the young of entirely different species is mentioned by a bird-lover who put an unfledged Linnet into the eage with a Robin Redbreast. No sooner did the hungry little stranger begin to clamor for food than the parental feelings and sympatliy of the Robin were aroused : he at once bopped off to procure a dainty mouthful, which he placed tenderly in the youngster's gaping beak, repeating the performance until the eravings of hunger were completely satisfied.

It is aiso related that the Robin will take care of a negleeted nest of young Canaries, and rear them with a devotion which cannot be surpassed by the most eareful of mothers.

The song of the Robin when eaged is as agreeable as his sweet notes when in a wild state. He is a very constant singer, and he remains in song about ten months of the year.

The bird is more easily eared for than the Canary, and, with proper food and treatment, lives many years: he thrives on regular prepared food, most keepers preferring to use the dry food with grated, raw earrot mixed with it. A few ants" eggs soaked, and mixed with the food daily, and one or two spiders or grasshoppers, are of benefit, and will be eagerly devoured. When the bird has diarrhoea a spider or two is the best cure. Attacks of indigestion are cured by giving spiders or oiled meal-worms.

A pair of Robin Redbreasts may be as easily mated as a pair of Canaries, requiring the same-sized breeding-eage and nesting material, and plenty of rich food, whieh should be meal-worms, spiders, ants' eggs, egg-paste, and fresh fruits or berries, and the dry prepared food with carrot. These may all be fed after the young are hatched. 'Two nests may be reared in a season. 


\section{PEKIN NIGHTINGALE, OR JAPANESE ROBIN.}

The above bird, of which but meagre accounts are written, is known also as the Japanese Robin, the Chinese Nightingale, and East Indian Sun-bird. As a cagebird, the Pekin Nightingale commends itself as one of the most attractive in the entire list, on account of his sprightly song, his lightning, graceful movements, and his exceeding hardiness. The bird is an inhabitant of the Oriental countries, where large flocks dart among the trees of the groves and forests. They are favorite birds, even in their own countries, where their delightful, mellow calls, dashing movements, and flashing colors, add greatly to the charming Oriental scenery. The Eastern eountries are noted for breeding gorgeous-hued birds, but no bird imported from there combines the attractive qualities of this universal little favorite. The Pekin Nightingale is about five inches and a half in length. The upper parts of the body are brownish olive; the breast and throat are a brilliant shade of orange; the wing-feathers are bronze-colored tipped with orange, and the tail-feathers rusty black barred with white feathers; the beak is long and slender, and of the same brilliant color as the breast; the eyes are large, black, and very expressive, and are surrounded by a ring of white. The female Nightingales and the young males are distinguished from the old males by the dull colors instead of the bright tints observed in the male; while their backs are grayish bronze, and their breasts are lemoncolored.

The nest is a very neatly constructed affair, and is usually built on "low trees or shrubs. The female lays four bluish eggs, and hatches ont two broods in a season. The male and female sit alteruately, luatching the eggs in twelve or thirteen days.

The importation of these birds during the past few years has been very great; as the demand for them, where their attractions as cage-birds were revealed, inereased more rapidly than has been the ease with any wild bird known to bird-sellers. They may be bred easily in confinement, and the large zoölogieal gardens of Europe in a great measure supply the extensive call for them by breeding them in large numbers. It is said that the largest part of a mestling is his eyes ; and when these are seen, as the youngster peers over the side of the nest, they appear to be of unnatural brilliancy and size.

The rapidity of movement with which the Pekin Nightingale darts around his eage caunot be described, and is surpassed by no other bird. "Now you see him, and now you don't," is strikingly illustrated by his lightning moves; this activity is one of the bird's chief charms : and if he should be compared to the mopish, lazymoving songsters whieh are better known than he, whose praises are sung by all writers on birds, the Pekin songster would at once elaim first attention. 
The song is a curious combination of sprightly, mellow notes, which are uttered with such precision and in such clear tones that the hearer thinks he is roaming the wildwoods, listening to a chorus of wild songsters, each pouring forth his best songs in his endeavors to outdo all others. 'The song can be deseribed partially by saying it is a wild tangle of joyful melody, and combines the beautiful, plaintive tones of the English Nightingale, and the sprightly, curions jangle of our own Bobolink; and it is sung in a manner which is in keeping with the bird's restless movements. As soon as the Pekin Nightingale commences his song, he keeps time with his marvellous springs and jumps; and, during the continuance of the song, a stranger to the bird would be puzzled to know whence the delightful notes eame. His joyous warble is heard at all hours of the day, and by gaslight as well, and never becomes monotonous. The ever-changing songs of the birds of the wildwood always delight the ear by their pleasing variety, and such is the effect of the varied notes of the Pekin Nightingale.

The bird is an accomplished gymnast, and can turn somersets and stand on his head with an ease which would make a professional acrobat envious. His contortions and evolutions are as bewildering as they are langhable; and an owner of one, no matter how long the bird may be in his possession, will be constantly amused by new tricks. As a household pet, the Nightingale of Pekin cannot be surpassed; and, after a few lessons in training, he becomes so tame, that it is unnecessary to confine his dashing movements within the narrow limits of a cage. He may be allowed the run of a chamber, and will successfully elucle the craftiest efforts of the eat to eatch him. His large eyes are ever on the alert; and if it needed to prove the saying, that a sharp-eyed being can see around corners, or look in fourteen different directions at the same time, one should observe the ease with which a Nightingale will observe the approach of a strange object. All the tricks which are usually taught birds of any class may be taught him; and the readiness with which he learns to perform them cannot be excelled by that prince of performers, the English Goldfinch. Offer him a dainty in the shape of a meal-worm, and, when he thinks you are not looking, he will snatch it from between your fingers with a rapidity that will cause you to search the floor, thinking you had dropped it. He. becomes very tame, and quite affectionate toward his master; and nothing delights him so much as to have his cage-door opened, and the privilege extended him of perehing on the master's shoulder or head.

If a stranger of his own kind is placed anywhere within calling distance, the call-note of one is answered immediately by the other; and with animated eyes, and expressive movements of the tail and body, his delightful song is poured forth with his best efforts, only to be answered by his newly found rival. 'The chorus is enchanting ; and no moment of silence is observed, except for feeding, as long as the birds are near enough to hear each other's soug.

"A bird which can sing and won't sing must be made to sing" is an old saying, probably uttered before birds were discovered; and the only case to which it applies is that of the Pekin Nightingale : place a song-bird of any kind within hearing distance, and, if a single note is uttered by him, the Pekin Nightingale immediately imitates the song, and also sings his own. It is said that it is only necessary to stand a Chinaman in front of him, and the recognition of his countryman is sufficient to force the bird to his best efforts. 


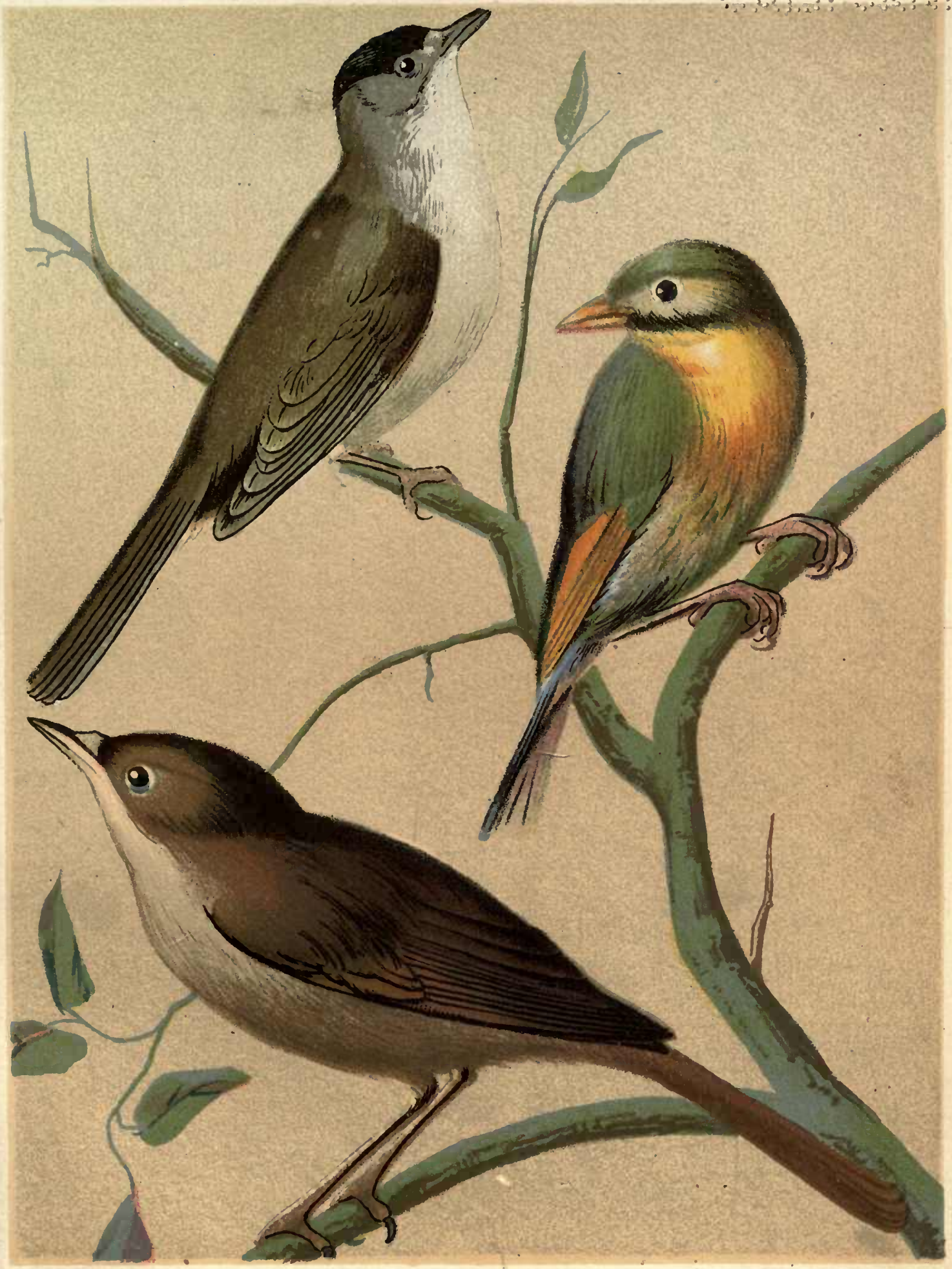




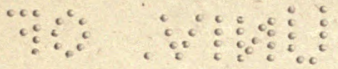

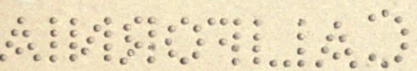


The toughness of the bird, when caged, is astonishing; and the bird-hospital is rarely visited by him from any cause: he is capable of withstanding neglect and carelessness to a greater degree than the toughest of English Thrushes. His simple food, and a bath as a luxury, seem to content him; and he passes his lays in constant song and flitting movements with a pleasure which exists only in creatures of delightful dispositions.

The food of the Pekin Nightingale, when wild, consists mainly of insects and worms, which he is very expert at catching: if allowed the freedom of a room during the summer season, he will speedily clear it of flies.

In confinement, the Pekin Nightingale should be fed on the prepared Mockingbird food, and insects and meal-worms may be given him frequently: as a cliange from this diet, feed soaked ants' eggs or currants, and occasionally a piece of sweet apple, banana, or the green food such as is usually given birds.

The bath is seemingly lis greatest luxury, and he enjoys it with enthusiasm : as long as the bath-dish contains any water, just so long will the bird continue his bathing; he will dart in and out of his bath with the same lurry which he exhibits in all his motions. He keeps up lis song while bathing, and interrupts it only when his beak is full of feathers, while pluming himself. He takes especial pricle in pluming himself after a bath, and his handsome appearance is thus greatly enhanced. It is better to allow the bird to bathe but once daily, as too much bathing is apt to bring on cramps.

The Pekin Nightingale is as sociable with birds of a foreign class as he is with his own brothers; and he is not in the least pugnacious, but may be safely put in an aviary collection. If kept alone, the bird should have a cage $10 \times 12$ or $10 \times 14$; as lis active movements demand it.

The diseases to which the bird is subject are few, and usually brought on by more than the average amount of carelessness. He is a hearty eater, and too much rich food tends to bring on the usual diseases observed in birds of his class. Constipation results from plain feeding, or filthy drinking-water, and may be cured by feeding him a comple of meal-worms dipped in oil. Sickness in the Pekin Nightingale is quickly observed by the absence of his sprightly movements, or the dulness of his eyes; and, whatever disease the symptoms indicate, should be treated the same as advised for Mocking-birds.

In the moulting season, the bird should be hung in the sunlight; because, if moulted in a darkened place, the bright colors are apt to lose their brilliancy.

With an average amount of care, he will live in constant song, except during the moulting season, from ten to twelve years.

As a cage-bird he cannot be too highly recommended; and, during a long experience in business, I have heard less complaint about this bird than any other in the long list. 


\section{THE TROOPIAL.}

'Turs handsomely eolored songster is the best known of South-American songbirds, and is one of the greatest favorites of the bird famly. As soon as he becomes an inmate of a household, he installs himself as one of its settled members. 'This he easily does; beeause lis quaint, comical tricks are as amusing as his rich, full, mellow notes are pleasing.

He belongs to the family of Starlings, a tribe of funny fellows, whose members number more than one hundred, and have dwelling-places in many of the countries of the globe. He has the richest natural song of any of his species, but his power of mimiery is rather inferior to that of some of his cousins. He becomes so tame and playful, that a lover of his once said, "He is the cheapest bird to buy, because he requires no cage. I would as soon think of my pet dog flying away as SouthAmerican 13ill.,"

Troopials are sometimes ealled Hang-Nests in South America, because they suspend their artfully woven nests from the branches of trees. 'These nests are very cleverly construeted, and display a weaver's intelligence in their manufacture. They are made of a material like hemp or flax, and are woven into a fabric not unlike coarse cloth. The nest is very singular in formation, and somewhat resembles a large pistol hung from the branch of a tree by the butt: the entrance is at the muzzle, and the nest in the butt. The entrance to the nest is at the side, probably for the protection of the young birds from the attacks of snakes, which are eonstantly on the watch for them. 'The parent Troopials will fearlessly attack snakes, and compel them to sneak away: this they are abundantly able to do, as they are plucky, powerful birds for their size; and the long, strong, sharp-pointed beak forms a most desirable weapon.

The Troopial measures about eight inches in length, and is a powerfully built bird, with very strongly made legs and claws. The plumage of the male, when full grown, is very brilliant. The head, wings, and upper part of the back, are velvety black. The lower back and body vary in color from a bright orange to a handsome shade of lemon. A white streak through the wing serves as an additional ornament. The tail is orange and black. The female Troopial has a dull brownish eolor in place of the brilliant black in the male. The beak is long and pointer, and black in eolor.

The Troopial, although not so gracefully built and as sprightly in movement as some of his gorgeous-plumed eompanions of the South-American forests, is, withal, a beantifnl bird. He inhabits the tropical forests of South and Central America, and lives lnxmiously on the abundance of fruit and insects which are easily found 

there, and dwells in undisturbed splendor and ease until captured, and civilized in our drawing-roons and parlors. He soon becomes very tame, and devoted to his master or mistress, and is a friend to anybody who is friendly with him: this is due to his fondness for high living, and any one who is kind enough to present him with a sweet banana or orange will have his name put down on 'Troopial's visitinglist. It is too true that he is somewhat of a glutton: his love of sweetmeats is his great folly, and is the chief cause of his ailments. He is, however, a remarkably healthy bird, and lives to a ripe old age; cases being knowu where a specimen has lived twenty years in confinement. Troopials are very easily cared for'; since their appetites are unlinited, and they are quite capable of eating any thing on a modern bill of fare. In taking care of them, vary the food as much as possible. Let the prepared Mocking-bird food, mixed with grated carrot, form the principal diet: this should be varied at times with fruits of all kinds. He is particularly fond of bananas and oranges, which should be ripe. These may be supplemented by grapes, cherries, apples, pears, or, in fact, fruit of any kind, which is sweet and ripe; and occasionally a few meal-worms, spiders, or grasshoppers should be given them, as they are insectivorous in their wild state. Occasional favors in this line of dainties will cause this feathered epicure to cut a new antic, or perform a new trick, with a readiness which well repays the slight trouble of extra feeding. Where insects cannot be had, a few morsels of scraped raw beef will be found beneficial. It must be borne in mind, that the principal cause of the 'Iroopial's diseases comes from overfeeding, which is only counteracted by giving a variety of fruits and insects.

One of his chief delights is the daily plunge: he is a very clean bird, and in many instances will bathe his water away before finding out that he has forgotten to take a drink. He should be given a bath daily, and an abundance of fresh gravel should be kept in the cage. It is a good idea to keep a few small-sized pebbles in the bottom of the eage; as he is a very inquisitive fellow, and will turn them over and play with them with as much ardor as a child at work dissecting a sawduststuffed baby : these serve to amuse him, and keep his attention from the feast: It is much better" to allow the 'Troopial the run of the house or' a room than to restrain him in a narrow eage: to be sure, he may do some little mischief by giving the pussy a sly poke in the ribs with his sharp beak, or displace some small article of value in his efforts to discover something new to eat; but, beyond this, his freedom is harmless. He is not easily frightened, and the appronch of a stranger does not disturb him: he is not like the best baby in the house in respect to showing off before company, but will display his accomplishments with as much good-nature before a crowd as if he were simply amusing his master. He is very fond of walking along the ground, and his peculiar rolling motion resembles an old sea-dog ashore after a three-years' cruise. As 'Troopial rolls along the floor, he closely inspects every thing which happens in his way, and will carefully turn over and pry into it, and hop along until something else attracts his attention. A Troopial should always be kept in a cage by himself ; as, if kept in a cage with other soft-food birds, he would be apt to divide the food served up into two parts, the rich and the poor. with more than even chances of reserving the rich food for himself. Mr. Troopial is a good-natured and very sociable fellow, but unselfishness is not one of his virtues. 
It is well to provide a piece of sod in which he can dig and exercise his beak; as in some eases, from too close confinement and consequent lack of exereise, serious deformities oceur in the beak and claws.

'The Troopial's song is exceedingly lieh and mellow : his notes are never harsh, and not so loud as to be disagreeable. He has no great variety of notes in his song; but every one is distinct, and ean always be heard with pleasure. One set of notes is somewhat like the Cuckoo's song withont the mournful tones.

Troopial is an early riser, and his cheery melody may be heard early in the morning if he is hung out of dools : when kept indoors he is not so apt to be musical until some of the family are stirring. Troopials are not like men : they are all the same even-tempered and good-natured boy-like birds, with exactly the same song. Some are, of course, better trained than others; but it comes from more attention and care.

A young lady once visited us with a pet Troopial; ten years of warmest friendship had they passed together; tears stood in the young lady's eyes, beeause her friend was ready for the taxidermist's hands. She espied in a eage a Troopial which had just the same voice, the same spirit of mischief in his eye, and the exact walk of her departed friend. On being told the price, she quiekly decided to replace her former pet with the one before her; and in a short time she was as happy as though her old lover earessed her again.

Troopials may be bred in confinement; the prineipal obstacle to suceess being their greed, which eauses them to negleet the young, and lay again. 'This may, in a measure, be overeome by hiding the food under about one-quarter inch of gravel, so that the rich food is not continually before their eyes; this compels them to dig to obtain it; and then, as a rule, they take better eare of the young birds.

The Troopial is not subject to many diseases, constipation being the prineipal one, overfeeding and no variety of food being the eause. When a bird is thus attacked, feed plenty of ripe banana or orange : if this does not effect a eure, open the beak, and pour three or four drops of sweet or eastor oil down the throat. If the legs and elaws should become too hard or sealy, they should be rubbed with glyeerine until softened. If the conditions given in regard to variety of food are adhered to, there will be no danger of sickness. For a cold, feed boiled milk with bread sprinkled with pepper, and keep the bird warm.

Troopials are kept in stock at all seasons of the year.

Suitable cages are the regular Mocking-bird style, the largest size being best for them. 


\section{THE MOCKING-BIRD.}

Tris extraordinary feathered musician surpasses all birds known, both in sweetness and compass of roice, and is acknowledged by eminent English authority to be the master of their belored Nightingale. His plumage, though not brilliant, is not unhandsome; and his beautiful, well-proportioned figure amply makes up for the lack of bright colors. His graceful, rapid movements and intelligent eye would attract one's attention, even though he were unacquainted with the bird's power of mimicry.

The full length of the bird is about ten inches. The throat, breast, and belly are gray; the back is generally a darker shade of the same color, except when newly moulted, then it is somewhat lighter; the wings and tail are nearly black, the coverts being tipped with white; the bill, legs, and feet are black; the breast of the young birds, before the first moult, is spotted like that of the Thrush.

He inhabits the United States from New England to Florida, but of late years has been found ehiefly south of Pennsylvania: he is migratory in the Northern States, but a permanent resident of the Southern. A warm climate, and low, swampy conntry, seem desirable to him. He is, therefore, found in larger numbers in the Southern States that are contiguous to the ocean.

The time at whieh the Mocking-bird begins to build varies according to the degree of latitude. In the warmer Sonthern States he commences to build early in April ; farther north, much later. He prefers a dense thicket, and builds his nest in either a bush or tree, but rarely higher than eight feet from the ground. The nest is made of dry twigs, light sticks, and withered weeds intermixed with straws, wool, or tow, the whole being lined with fibrous roots. There are usually four and sometimes five eggs in a nest: they are a light blue with large brown specks. The female sets fourteen days, and hatches two broods in a season. She is extremely jealous of her nest, and will allow nothing to approach it. The young birds are taken from the nest when three weeks old, and-fed by hand. They are very hardy birds, and rarely pine away and die from the loss of the mother. They are easily reared by hand, and should be fed at frequent intervals on a mixture of hard-boiled egg and potato, in the proportion of two parts of potato to one part of egg: they are very fond of berries of all kinds, huckleberries being a farorite dish. Insects and spiders, of which they are extremely fond, seem to strengthen them, and prove the best medicine which can be administered in ease of sickness. As the bird grows older, a portion of the prepared Mocking-bird food should be added to the egg-and-potato mixture : this aceustoms him to the food which will be his ehief diet after he is six months old. Many prefer the hand-raised nestlings to the young trapped birds: to be sure, the trouble of raising is greater; but the attach- 


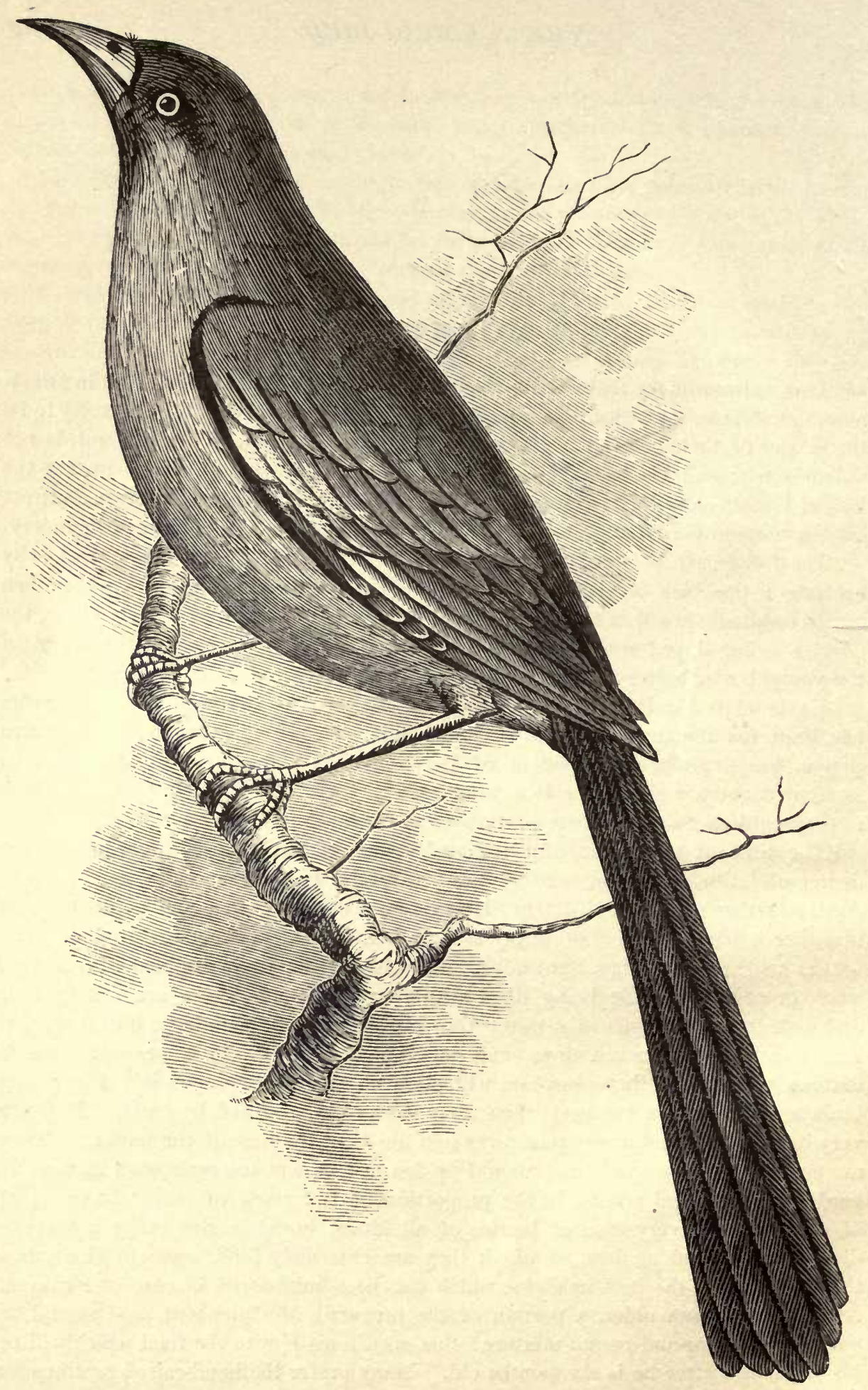

The Mocking-Bird.

(Natural size.) 
ment for you which the bird forms by feeding from your hand is well sliown in afteryears by his willingness to learn a tune or tricks from the one who has been so kind to him. The young trapped birds are easily eanght as soon as they are strong enough to fly.

The device of a lazy negro is, to lie under some shady orange-tree, sleeping, with one eye open, with clistended jaws, and having an imitation spirler fastened on a spring bound to one of his teeth. The Moeking-bird, which is very expert at eatching insects, darts at the prey, and is in turn eaught in a trap. It takes long practice to beeome perfeet in this particular braneh. Another way is, to place a call-bird in a trap-eage. The Moeking-bird is the most pugnacious of all birds, and this very vice makes him the easiest eaptive of all the feathered tribe. He is ever on the alert for a fight, and will attack a much larger bird for the pure fun of fighting, and comes off victorious throigh sheer dash and pluek.

The young birds are sold in large numbers in the months of June, July, and August. Savannah and New Orleans are the principal Southern depots to whieh the birds are brought for shipment North. The negroes are usually the trappers, and many obtain their living from trapping: their well-known love of robbery does not eonfine itself to the narrow bounds of hen-roosts; for they do not scruple to steal baek the very Moeking-birds which they have sold, if the chance is given them. The next morning they sell the stolen property again for new-trapped birds. with a little huckleberry juice rubbed on the white of the wing; for the reddisl mark, they say, is a sure indieation of the male bird.

The large number of birds eaught makes the price reasonable enough to be within the reach of every one. If the Mocking-bird is judged according to his real merit, he would, undoubtedly, be the eostliest of birds.

He eommences to sing at the age of seven or eight weeks; the first notes are low and unfinished; but, as he grows older, his voice inereases in volume and eompass ; and his aptitude for learning is greatly developed. His natural song is sweet, bold, varied ; and, in his native woods, he surpasses every competitor. He is the great artist: the other songsters of the grove are only the chorus. During the utterance of his soug he appears to be in a perfect eestasy of delight : his eonstant, graceful motion, expanded wings and tail, and flashing eye, add to the musie a vivaeity and elegance of rendering given only by this wonderful bird. His notes are sweeter in his wild state than in eaptivity, owing to absence of harsh noises, which he so often hear's when eonfined in the habitations of man. He loses none of his power or energy of song in confinement, and his opportunities for mimicking are much enhanced by the variety of the new sounds which he constantly hears. He improves every chance offered him, and takes as much delight in imitating a buzz-saw or rusty pump as he does in initating the sweetest of flute-notes. II repertoive is unlimited : he will repeat any thing, from a snatch of the latest grand opera to the infinitesimal twitter of the Humming-bird. He sings the songs of other cage-birds with a superiority altogether mortifying to them; his clueks oftentimes can make the lost chicken forget its mother; and, so exaet are the meows of rage, he compels the Thomas cat to imagine somebody has trod on his tail.

A German gentleman, followed by his pet poodle, was very much annoyed while hurrying along the street at hearing the whistle given which is so commonly 
used to call a dog. The dog was a foolisb creature, and ran whenever called by a whistle. The man and the dog were both puzzled as to whence the eall eame, but both concluded that a very small boy some distance away was the whistler. 'The (log ran, delighted to have found a new friend, but was in turn whistled baek by his master. The whistle was repeated from the opposite direction; and the gentleman followed, venting his wrath on the innocent boy, who bad probably not learned how to whistle, remarking, "Dat de poy he vant to shteal mein dog." The cause of all the trouble, a Mocking-bird perched out of sight, was delighted at the mischief he had caused.

The bird is a ventriloquist as well as a mimic, and will, at times, canse his voice to seem to come from any point except the one at which he may be.

Words fail to adequately describe his wondrous song. Both in his wild and domestic states, as soon as the moon rises be eommences bis beautiful melody. 'The hunters in the Southern States, as soon as they hear the Mocking-bird commence to sing, know that the moon is rising, and the night-chase may begin. An English writer, in comparing the Nightingale to the Mocking-bird, concedes that the latter's natural notes are equally as melodious as those of his own "King," but that the song is marren by the harsh sounds which are occasionally introduced. One of the chief charms of the bird's song is the novelties which he is ever introducing: he does nothing by rule, and never sings the same parts twice in succession.

A great many people, while on a Southern tour in winter, wishing to bring back a remembrance of the pleasant times enjoyed, beeome infatuated with the song of the Mocking-bird, and, in most instances never having been lovers of bird-music, are totally at a loss to account for the difference between the Mocking-birds which they hear when at home, and those charmers in their native clime. There is no difference whatever in song: to be sure, the circumstances are more favorable, and consequently impress a mind which has never developed a taste for such music; but the difference in price is enormous. A bird of the first quality may be bought at a lower figure in the Northern States than in the Southern, for the reason that the Southern people are lovers of their songster-kings, and, becoming attached to them, do not care to part with them. The same grade of bird may be bought in Northern cities as in the Southern, and at a lower price in the North, for the reason above given.

A Mocking-bird is probably the easiest trained of all songsters : his remarkable intelligence in a great degree accounts for this. He will incline his head to one side, and listen to every strain whistled to him, and, after hearing his lesson, will repeat it to himself, always interpolating the oddest of notes, trying to give one the impression that he does not care about his teacher. But he is very diligent, and repeats over and over every thing whistled, and, in a remarkably short space of time, gives perfectly one, two, and even three, tunes. To hear a well-trained birt go over his tunes. with an odd cackle or crow as an encore, is very laughable. He may become very tame, and be taught numberless tricks, which do not in the least interfere with his singing.

The young Mocking-birds of the first brood are the ones selected as choice birds; for they are, as a rule, hardier, tougher birds than the later brood.

The selection of nestlings is attended with great care on the part of bird-dealers. 
The difference in the sexes is distinguished by certain marks on the wing-feathers; but the best judges are at times puzzled by peculiarities in the markings, and their decisions are erroneous. In appearance, the male exactly resembles the female : but the female rarely whistles ; the only noise which she is usually capable of uttering is a harsh note of alalm or defiance. 'There are eases, however, where Mockingbirds, most excellent songsters, were proved to be females by the eggs found in their cages. Sometimes the exact markings of the male Mocking-bird are seen to perfection in the female bird: this, however, is rarely the case. The highest type of a perfectly marked male Mocking-bird is called the four-feather bird. The bird known as the three-feather bird is also considered perfect. The above titles relate to the number of primary feathers of the wing, - feathers which have perfectly shaped white markings. 'To examine the wing of the Mocking-bird, to distinguish the sexes, catch the bird firmly in the left hand, and extend either wing to the fullest extent with the right, looking at the wing on the upper side; the white coloring will be observed to be lougest on the feathers nearest the tip of the wing; the extent of white coloring gradually diminishes on the feathers nearer the body, and in the case of the perfect-marked male bird resembles somewhat the segment of a circle, and in some localities has received the name of half-moon. The three longer primaries which have the white color will be found to have no dark markings, or splashes, intermixed with the white. If the white markings are splashed, or do not extend directly across the feathers, the bird may be a female. In rare eases, four of the feathers are unmistakably marked.with clear white; and these are considered perfect-marked birds, and recognized as males to a certainty. The birds which have two feathers and a half clear, the two longer white-colored feathers perfect, and a splash, or dark mark, on the white, on one side of the quill of the third feather, are generally males; though females are sometimes so marked. 'The white color on the feathers of the female bird will be found to be splasherl, and irregularly marked throughout. The birds which have broad wing-feathers are preferred to those with narrow feathers. A little practice in handling a number of both sexes will easily make one familiar with the markings. The female Mockingbird sings little or none, and is of use only when breeding is desirable: and, if the Mocking-bird which you possess has always been a "silent songster," the better way, rather than to wait with expectations never to be fulfilled, is, to have the bird examined by an expert; and, if it proves to be a female, the expense and trouble of feeding will be saved by presenting her to some worthy friend, or, if the weather is warm, allowing her to go free. She may be used for the purpose of breeding.

Mocking-birds have been suceessfully bred in confinement; the chief requirements being plenty of room, good, sunny exposure, and rich food. There are many eases on record where the same pair have bred for years in suecession. For breeding purposes the hand-raised nestlings are preferred, as their long domestication is apt to make them less shy.

Mocking-birds, during the first season, do not attain the full song, and are termed young birds: after the second spring, there is a marked improvement in the purity and compass of the voice. 'The three-years' old birds are considered the prime songsters, and at that age and afterwards should be heard at their best. There is a marked difference in the quality of the voices of different Mocking-birds, 
and the intelligence seemingly varies as much as in the human race. It is elaimed that birds of one section of the Southern States are superior to those reared in another. The birds which come from Louisiana, Florida, and Texas are claimed to be the finest whistlers. It is certain that birds which come from these States are larger and bardier than those hatched in the more northerly sections. The handraised nestlings from the more southerly sections arrive North about June 1, and are considered the prime birds of the young stock.

Mocking-birds are very tough and hardy, and with good eare live to be twenty years of age. 'They sing all the year except during the moulting season and two weeks of the breeding season. They are easily monlted; the ehief care being to keep them out of dranghts while shedding, and to feed an abundance of fresh. green food and insects. The cage should be carefully kept elean, and plenty of gravel strewn on the bottom, so as to keep the feet in order. 'They are very fond of hathing, and should daily be given the tub. 'The prepared food, either moist or' dry, should be the regular diet. When the dry food is used, grated, raw carrot must be mixed with it. For variety, feed the potato-and-egg mixture, with a little Indian meal or grated carrot added. They are also fond of ripe fruits and berries, which are very nourishing and healthy for them. During the seasons when these cannot be obtained, soaked or scalded ants' eggs or soaked currants should be added to the daily portion of food. A meal-worm or two may be given daily. Spiders or insects of any kind are aiways welcome to them, and may be frequently given as a change of diet. Frequent changes of food keep birds of this class in the most perfect condition and song. 'The Mocking-bird is a very sprightly bird, and possessed of a most voracious appetite: variety in food, and live insects, are, therefore, essential to proper keeping. The bird-keeper who is continually fussing with his Mocking-bird, giving him an odd dainty now and then, is always known to have the healthiest and best song-bird.

The diseases to which Mocking-birds are subject are few, and result, as a rule. from inattention to the diet, or from colds caught by careless exposure. The diseases may be more easily cured by building up the constitution by means of rich feeding than by administering medicines.

Constipation results from unwholesome food, and is eured by giving three drops of eastor-oil daily for three days. Insects, meal-worms, and green food, should be fed in abundance until the bird is thoroughly cured.

Diarrhœa is eaused by foul drinking-water, or by feeding stale or sour green food or fruits. Add three drops of laudanum to the drinking-water for a few days, and change the food to stale bread soaked in boiled milk, sprinkled with cayeme pepper. Feed, in addition, a mixture of grated, hard-boiled egg, carrot, and soaked ants' eggs : too much green foods and insects should not be given during the run of the disease.

The Pip is a disease caused by cold, or feeding too much plain food: it may be noticed by the white color or scale on the external skin of the tongue, beginning at the tip, and extending down near the fork at the base. As soon as noticed, this scale should be carefully removed by means of a sharp knife, commencing operations at the part near the base, and peeling the scale off to the tip of the tongue. 'Then feed only the richest foods : a drop or two of glycerine dropped on the tongue 
will prove beneficial in healing the injured part. This disease will be observed to have almost the same outward signs on the bird that asthma has on the Canary.

Blindness is catsed by hanging the bird too high in a poorly ventilated room, where the foul air of burned-ont gas, or the poisonous fumes of a kerosene-lamp, will reach him: these cause partial or total blindness. 'The bird should be removed to fresh air, and fed on the richest diet. When blindness sets in, it is almost impossible to arrest the course of it ; although the bird may afterwards live in perfect health and song for many years.

The Beak and Claws of the Mocking-bird frequently need clipping and sharpening, which should be done in the same manner as recommended for the Canary.

The Legs also require frequent attention: as the bird grows old, the scales which form should be removed, and the legs anointed with glycerine, or some other healing lotion.

Mocking-birds should have the largest-sized cages; as they are exceedingly spry, and delight in flying about. When hung in the open air, it is better to protect them from the strong rays of the sun, or from sudden summer storms, by covering the top of the cage with a piece of light canvas. 


\section{BROWN THRASHER AND OTHER AMERICAN THRUSHES.}

It would appear, from the very few Brown Thrashers which are seen in a caged state, that the beauties of the song are unknown. The Thrasher is as common as any American bird known, and, when in full song, is even a rival of the great Moeking-bird. An imported bird of the same name brings treble the price of the domestic bird, and yet the song is no better. It must be true in this ease, that the article with a foreign brand has the value, whether worth it or not.

The Brown Thrasher is known by the name of the French Mocking-bird in Maryland, a name which is in no way misapplied. He is the largest of all American Thrushes, being eleven inches and a half in length. The whole upper parts are a rich reddish brown; the tail very long and rounded, and of the same color; the lower parts are yellowish white; the breast and sides are beautifully marked with long, pointed spots of black, running in ehains; the bill is very long and stout, the upper mandible overhanging the lower. The female may be distinguished from the male by the smaller number of spots on the breast, and the duller eolor on the back.

The Thrasher's song is a delightful variety of whistling-notes; and on a clear day he may be easily heard at a distance of a half-mile chanting his charming song, which drowns all insignificant warblers into silence. 'The notes bear a great resemblance to those of the European Song Thrush; and, if not as mellow, they are louder and more varied, and the whole a more brilliant work. He is indeed one of our most welcome spring visitors, and, to a lover of the beautiful in nature, one of its most striking objects. He is a very sagacious bircl ; and his powers of reasoning, which can be seen by his many acts when he is in a state of domestication, are something remarkable. The Brown Thrasher, owing to his size, should have the largest-sized Mocking-bird eage, and be fed in the same manner as all soft-bill birds.

\section{THE WOOD THRUSH.}

This species measures eight inches in length, and the colors resemble those of the Brown Thrasher. He is a bird rarely seen, being content to be listened to. His voice is described as being something wondrous in power and compass, and he is frequently compared to the great European Nightingale. Like him, he pours forth his melody in the evening. He is comparatively little known as a cage-bird, although it is maintained that he sings equally as well in confinement as in his native state. He inhabits the whole of Nortl America, and arrives in the northern parts about April 20, and announces his arrival in a most emphatie manner by the 
beauties of his song, which are best described by the eminent naturalist, Mr. William Bartram.

"Almost every country has its peculiar and favorite songsters ; and, even among the rudest nations, the cries and songs of birds are listened to, and associated with their general occupations, their superstitions, or religion. In America the Wood Thrush appears to hold a rank equal to the Nightingale or Song Thrush of Europe: like the latter, he may be oftentimes seen perched on the summit of a topmost branch duriug a warm, balmy evening or morning, pouring forth in rich melody his full voice, and will produce asscciations which would recall to a foreigner the warblers of his own land."

When eaged, the Wood Thrush should be treated as the other varieties, in order to keep him in full song. A variety of insects should be kept in stock for hin. The small-sized Mocking-bird eage is most suitable for him.

\section{THE GOLDEN CROWNED THRUSH.}

This species is six inches long; the upper parts, except the crown of the head, are a rich yellow olive; the tips of the wings are dusky brown; from the nostrils a black strip passes on each side to the back part of the head, and above these strips on the head lies a bed of brownish orange; the sides of the neck are whitish; the breast is handsomely marked with pointed spots of black or deep brown. The female has the orange on the crown considerably paler. This bird inhabits the woods, but, unlike the two former eminent members of the Thrush family, has no song of any consequence; it being composed of a few shrill notes, repeated in rapid succession. He is used as a foster-parent for birds of other varieties who deposit their eggs in the Thrush's nest. The foster-mother performs the part of a faithful nurse to the foundling left to her charge. The Golden-Crowned Thrush can live in a smaller-sized cage than the other two varieties, the largest-sized Canary-cage being best adapted for him. Food, eare, etc, are the same as for the other Thrushes.

\section{THE WATER THRUSH.}

This bird, so called from his partiality to rivers and small streams of water, is colored exactly the same as the Golden-Crowned Thrush, with the exception of the crown. He is about six inches and a half in length. His ehief food in his native state consists of aquatic insects.

He is a charming musician; and, when perched on the banks of a solitary strean, his expressive, silvery tones, beginning very high and clear, and falling until they can searcely be heard, make a very impressive song. His food should daily consist of insects, meal-worms, and soaked ants' eggs, in addition to the prepared food. His cage shonld be the same as for the Golden-Crowned Thrush. 


\section{THE CAT-BIRD.}

Tirs well-known and agreeable songster is very numerous in the United States, and is probably known by everybody who is a dweller out of the city. He is a bird not commonly seen eaged, although why is not very clear; for, though he is not a gaudy plumaged bird, his song is much more pleasing and varied than the majority of cage-pets.

The Cat-bird measures nine inches in length, and, when seen at a distance, appears to be nearly black; but, on close examination, he is found to be slate color, very deep on the upper part of the body, and a lighter shade below. The upper part of the head, as well as the legs and beak, are black. He has very large black eyes, which are always on the watch for the ripest cherry or grape. He cannot be ealled a popular bird in his native haunts, because his appetite always ealls for the richest and best in the fruit-line. This makes him rather unpopular with the farmer, who does not care to barter the most marketable goods for bird-musie, no matter how good the latter may be. The boys are early prejudiced against him, and are taught that it is no sin to destroy him. This lesson is not forgotten in mature years: so that, when the bird-loving young lady of the house suggests the Cat-bird as a desirable singer, she is at once reminded that no praise shall be given him; as he is an old-time enemy. The antipathy against him in early years is continued through life.

In his wild state he is quite a tame bird, and may be easily approached; and, as third-generation hats and bad imitations of scarecrows have no terrors for him, the only way to prevent him from reaching the richest fruit is with the gun. Then, again, the cause of his unpopularity is about the same as in a great many other eases: some people do not like him just because others hate him.

The Cat-bird is a very sprightly songster, and resembles the Mocking-bird in many ways. He is always up before the break of day, singing his song with great clearness while hopping from perch to perch in seareh of food. He is quite a mimic in his way, and endeavors to imitate all the odd sounds and notes he may hear. He seems to study, and, if not at first successful, gives up only after many repeated efforts. His natural notes are short and sweet, and are interspersed with the tune of the wandering back-yard musician, after whom he is named. In his wild state, when first heard, it is difficult to believe that some poor orphan cat has not gone astray in the bushes, so exact are his imitations of the animal's voice. He is not at all afraid of anybody; and, whether in the woods or in his cage, he gives out his song freely and boldly, no matter how closely one may be standing to him.

$\mathrm{He}$ is a very playful bird, and may be easily taught a number of tricks; and, 
owing to his mastery of the sounds known only to the cat family, he becomes quite a comedian in his efforts to anuse his friends and disconcert puss. He is a very eareful parent; and, when his young are in danger, he will boldly attack a snake, and compel him to beat a retreat. If any one imitates the squeaking of his young, he will fly to and fro with hanging wings and open mouth, sceming to implore one not to annoy his suffering brood: this happens only in the breeding season. 'The Cat-bird is most numerous in the Southern States, and flies North as the season grows warmer. It is thought that they winter in the same degree of latitude as Florida.

His food and treatment is about the same as that of all soft-bill birds. The prepared Mocking-bird food, and raw, grated carrot, mixed is given : and, owing to his great love for fruit in his wild state, a variety of it should be furnished; always feed him the ripest, as he is used to it when he himself selects it. His diet may be varied by feeding him Indian meal and milk, which will keep him free from disease. In addition, feed him insects and raw beef. His cage should be the regular Mocking-bird size, the brass cages being preferable to the wooden. After being caged for a short time, he becomes used to the confinement, and will live many years. The best season to trap him is after the breeding-time, which continues until about June 1. When caught then, he is not so apt to pine away. If taken at the proper time, there is very little difficulty in rearing him. 


\section{THE AMERICAN ROBIN.}

THE respect which is entertained by crerybody for the beloved Robin extends to no other bird known. The pilfering boys, who make a specialty of robbing birds' nests, have sufficient regard for the egg of the Robin to pass it by without molesting it. This universal regard for him has been handed down from generation to generation, and he is probably the one exception in the bird family for which the farmer cherishes any friendly feeling. His raids upon the insects and bugs which infest the orchards, and destroy the fruit-trees, make him a valuable ally to the fruit-growers and agriculturists. He is so familiar to everybody, that a description of him seems hardly necessary. He is nine inches in length; the bill is strong, and of a deep yellow color, sometimes black or dusky near the tip; the upper parts of the body are clark olive gray, becoming black on the head, and blackish on the tail : the under parts of the body to the vent, in adult birds, are a beautiful shade of chestnut; in the younger birds, the chestnut color is paler, or variegated with white or gray; the throat is streaked with white and black; and the under tail-feathers are white, mixed with gray. The wing-feathers are dusky brown, mixed with ash, which is the color of the back. Feet blackish, the soles yellowish. 'The eyes are dark brown. Very young birds are speckled above and below, each feather being spotted. The females are more ash-colored, and the black parts are of a dusky tinge. The Robin is a summer resident, and may be found in abundance everywhere. His cheery song is heard as early as March; and he remains in our Northern clime until the middle of November, and individuals may be found at times thronghout the winter. They breed in immense numbers, while their comparative immunity from harm certainly helps to increase the race. Their nests may be found anywhere, the favorite situations being in trees, and in the orchards; though they are sometimes placed under the eaves of the honses, and may be even found in bushes, or on the ground. The nest is a bulky structure, mostly composed of mud, and lined with fine vegetable fibre. The eggs are four or five in number. plain greenish blue, and occasionally speckled. Two or three broods are reared in a season: the first eggs are laid in April. The enormous amount of insect-food devoured by young Rolins is of incaleulable benefit to the crops.

As a songster, the Robin has few superiors among our native birds; but he is so common, that the idea of caging him is rarely thought of. If he were a foreign bird, and had to be imported to the country, he would undoubtedly take a foremost place in the list of eaged songsters ; but it is too often the case, that superior home attractions have no rank when placed alongside of inferior imported ones.

Here is our dear Robin Redbreast, and no one wants him at any price. Puff 
him in all the funny, eatching " ads ;" let the best salesman go into eestasies over the bird's delightful pipings, tameness, amiability, acuteness in learning tricks, and eapabilities of piping any air played or whistled to him; still he is refused. The shop that once owns a native Robin will continue to own one for many years unless the bird gets accidentally injured, or is kindly permitted to fly abroad. But there is one exception. If possible, let there be a customer to whom the bird is unknown: let the bird be called a "Chinese Orangiphant," and a sale at once is made. Surely a rose is sweeter by any other name. The writer has no Robin Redbreast for sale, but knows how companionable the bird is, and how capable of learning, if tanght in youth, the "Star-spangled Banner," or the "Bridal Wreath," playful tricks and pantomimes. The bird is entitled to some consideration on aceount of being a home manufacture; but, more than this, he is both a finer musician and more delightful eage-bird than many of the emigrants, of which most of us know less, and in respect to which, in purchasing, we take our ehances. 'The world is not growing conservative: "chances" have been in rogue ever since Eve used Satan's horn for a fruit-picker, and are in vogue to-day more than ever before.

The Robin is a beautiful songster, and his musical notes resemble greatly those of the Thrush; in addition, he is a constant singer, and sings during the greater part of the year; a hardier bird is not caged. He may be oftentimes seen hung before the window of a house, endeavoring to shelter limself from the severest of storms, and consoling himself for the carelessness of his master by singing in lis sweetest manner. Naturally very tame, - even when wild, as he builds his nest in summer, and seeks shelter in winter, near the habitation of man, - what better qualifications would the most eritical bird-lover wish?

The young sehool-boys, and the old boys who have been to school, smack their lips when thinking of the delicious dish known as Robin pot-pie; and the attentive city business man often wishes he could go back for a day to old times, and enjoy the favorite dish. The flesh of the Robin is a tender morsel, and highly esteemed; and owing to the good eare he lavishes on himself and children, and the rich diet of which he partakes, his body is always found in the most satisfactory condition for a meal. In former times the slaughter of Robins for this purpose was something immense; and, during the sportsman's period, the eities poured out professionals and amateurs in scores for the purpose of killing Robins for the markets. Some liumane person determined to put a stop to the reekless slanghter. The fruit known as poke-berries is a favorite food of the Robins. The juice of the berries is of a beautiful crimson, and they are eaten in such quantities by the birds that their whole stomachs are strongly tinged with the same color. A paragraph appeared in the public press, intimating, that, from the great quantities of these berries which the Robins had fed on, they had beeome unwholesome and even poisonous food, and that several persons had nearly died by eating of them. The strange appearance of the entrails of the birds seemed to corroborate this account. 'The demand for them ceased almost instantly, and motives of self-preservation accomplished more than all the pleadings of humanity.

They are exceedingly fond of gum-berries; and, when a tree is found covered with this fruit, a flock of Robins is sure to be found also: the sportsmen lave easy work in shooting them at this time. 
If taken for cage-purposes, the better way is, to take a nest eontaining the entire brood, and rear them by hand; although the parent birds plead most piteously, and do not care to have their offspring so ruthlessly adopted: but the young birds themselves take kindly to the operation ; and, if sufficient food is given them, they appear to be perfectly content. A nest of young Robins are most voracious eaters, and it is a wonder how the old birds can supply them with sufficient food : they are ready at any hour of the day for a mouthful; and, if it is not supplied, their wants are quickly made known. When taken from the nest, a paste should be made of equal parts of hard-boiled egg, boiled potato, and soft bread: this mixture may be given them in the shape of pellets, and afterwards washed down with a drop or two of water dropped from the tip of a small stick. As the birds grow older, prepared Mocking-bird food may be added to the mixture; and, when of sufficient age to feed themselves, the regular food and care, such as is given all soft-billed birds, should be given tliem.

- They are subject to the same diseases as the Mocking-bird. No amount of dainties or insects seems to injure them. They are a wonderfully hardy race, and rarely ever appear sick. Cases have been known where they have remained in cages for twenty years, and appeared as sprightly and as full of song at that age as they did when first confined. 'The Robin's usual method of taking himself out of the world is completed by the aid of the eat, which animal has a keen taste for the bird's juiciness.

Robins should have large-sized cages; although they get along in almost any thing in the shape of a cage, and require plenty of gravel and bathing-water.

Dainties for them may consist of fresh meat, insects of any kind, berries or fruit. They readily learn tricks ; for their appetites are so great, that they will do any thing to obtain dainties.

I would say in conclusion, that, should anybody want a cheap bird, a hardy bird, a fine-singing bird, and a handsome bird, the male Robin fills the entire combination. 


\section{THE BLUE ROBIN.}

Turs merry harbinger of spring is always a welcome visitor, on account of his many pleasing ways, pretty plumage, and delightful song. His first notes are heard on the approach of spring. He is a well-known bird in all sections of the United States, and is one of the first of the migratory birds which appear among us. He is not a shy bird, and is a great friend to the farmer, who repays his usefulness in killing the tronblesome insects and bugs by allowing him full use of the orchards and lands, and not permitting him to be molested.

He commences his courtship as early as February ; and the female lays as many as six eggs, and hatches two or three broods each season. The young birds at the age of twenty-five days are fully colored out. The Blue Robin is about six inches and a half in length, and the male is easily distinguished by the beautiful sky-blue tint of the entire upper parts of the body.

The throat, neck, and breast, and sides under the wings, are pale chestnut: the belly is dusky brown. The female is distinguished by the paler shades all over the body.

The early song of the Bluebird is an agreeable, merry, oft-repeated warble, which is extremely pleasing: it is uttered with outstretched, quivering wings, which gives him a very interesting appearance. In the fall, as he is about to leave the haunts he has loved so well, his song changes to a single melancholy note, which seems to show low depressed he feels at leaving home. He resembles greatly in manners the favorite Robin Redbreast of Great Britain. In Great Britain he is known by the name of "Blue Nightingale ;" in Germany "The Cottage Singer," owing to his love for building near country-louses.

He is an expert at catching insects, and seems to delight in training his young in the art. Blue Robins may be easily bred in eonfinement. As they are not shy birds, all that is required is a roomy cage, and materials for nest-building, which may consist of old twigs, dried grasses, or old pieces of rope ; and, as they are very prolific, a Mormon family is quickly aequired. All the zoölogieal gardens of Europe breed them so extensively, that there is no need of exporting them to supply the demand. The Blue Robin's food is the prepared Mocking-bird food, with raw, grated carrot, and insects or meal-worms, varying it oceasionally with a little scraped, raw beef. He is rather a voracious bird, and requires a large-sized cage, with plenty of gravel, which should be frequently changed. He is very fond of the bath-tub, and a bath is always looked forward to as a daily luxury. With careful attention he will live for many years in confinement, and is naturally so tame he prefers taking a dainty from the hand to having it mixed with the common food.

IHis ailments are few, and are usually those which attack all soft-bill birds. 


\section{BALTIMORE AND ORCHARD ORIOLES.}

These birds, supposed by early writers to be of the same species, are of two distinct families.

The Baltimore Oriole, or Golden Robin as he is familiarly called, is a migratory bird, and is found in the Northern States early in May. Pairs build their nests usually in the tops of the apple-trees or in weeping willows, and prefer to build adjoining some farmhouse. It is said that he is so named because his colors are those of Lord Baltimore, the founder of Maryland. He is a well-known bird, and always a weleome visitor ; for he is so handsome in his gaudy, striking colors, and his mellow song is pleasant music.

He is about seven inches in length; the bill is almost straight, tapering to a point, black, and sometimes lead color. The head, throat, and upper part of the back and wings, are satin black in color; the lower part of the back, and the rump and whole under parts, are brilliant orange, which deepens into vermilion on the breast; the black on the shoulders is also divided by a band of orange; the outer edges of the wing-coverts are white; the tail-feathers under the coverts are orange. When the tail is expanded, it appears like a pyramid of black supported on an arch of orange. The tail is slightly forked. The legs and feet are light blue.

The female is distinguished from the male by the color: the brilliant black in the male is a dull black color in the female, each black feather being shaded with greenish yellow; the bright orange is replaced by a dull yellow.

The male bird changes his color as he grows older, and appears in his most beautiful colors in his third year. His colors deepen after his first year.

The Oriole resembles the human family in regard to individual differences. A great contrast is seen in the manner of building the nests, and the neatness displayed in the work of finishing them. It may be that age educates them, and makes them expert in the art of building, just as it changes their colors and makes them more beautiful. A wonderful ingenuity is shown in the construction of some of these nests. 'The materials used are flax, hemp, tow, wool, or any thing of like character; and all is woven and sewed through with long horse-hair. In looking at the neatness of the work, one almost siglis to think how handy it would be to have a few well trained in the art of daming stockings and repairing boys' trousers. They are very particular in the selection of materials for the construction of their nests, and the careless country-maid oftentimes rues the loss of a skein of fine silk which chances to be left where $\mathrm{Mr}$. Architect can easily find it. He thus puts the products of man to good use.

The song of the Baltimore Oriole is a clear, mellow whistle, repeated slowly, and 
with a plaintiveness which is very interesting. It has not the wildness and exquisite rendering of the Mocking-bird, but appears to be the whistle of an abstracted man, who, when asked what he was whistling, replied that he didn't know.

The Baltimore Oriole inhabits the entire North America, and is often seen among the trees of the large cities: his flashing eolors and plaintive song, as he flits : among the branches, appear in strange contrast to the dull roar and whirl of city-life.

His food should be the Mocking-bird food, prepared the same as for all soft-bill birds. He is particularly fond of caterpillars, bugs, and beetles, which, wherever found, shonld be saved, and brought home for him. 'The want of insects is the prineipal cause of disease; as the birds are always used to them in the wild state, and, in fact, live on them almost entirely. The usual cage sickness prevails when the bird is first put in confinement: they are apt to pine, and, if not given some little attention, are almost certain to die. For this reason live insects should be fed them daily until accustomed to their new state of life.

It is commonly thought that the young cannot be taken from the nest and successfully reared, but this is erroneous. It is better to take the entire brood under charge at the same time: they need plenty of attention and care, and should be fed as often as they make known their wants. Prepare a boiled potato, and mix with about one-half the quantity of hard-boiled egg, to which should be added a small quantity of the prepared food: this should be fed in small pellets, one or two being sufficient at a time. Keep the birds in a warm place, and there will be no danger of losing any of the brood. The birds taken from the nest will be found hardier and more suitable eage-birds than the trapped birds.

Suitable cages for Baltimore Orioles are the small-sized brass or wood-framed Mocking-bird cages.

\section{ORCHARD ORIOLE.}

This Oriole is not very widely known as a eage-bird; although, owing to his chameleon-like nature of changing color, he has been the subject of fierce arguments among the leading naturalists. The male Orchard Orioles and the female Baltimore Orioles are often mistaken for one another; as, at a certain age, the Orchard Oriole greatly resembles the female Baltimore. They are, however, of two distinct families ; the Orchard Oriole being smaller, and more slenderly shaped, as well as differing in the mode of building the nest.

The Orehard Oriole arrives later in the season than the Baltimore, and does not inhabit the country farther north than Maine. The female Oreliard Oriole is six inches and a half in length, and always remains the same color. She is a yellowish olive, with a brownish tint on the back: the wings are a dusky brown. The young male bird eorresponds nearly to the above description. The second season he appears with a brilliant pateh of black marking the throat, and slight reddish stains mark the sides and belly. 'The third season he appears in his perfect dress, and a very attractive fellow he makes. A velvety black appears over the whole upper part of the back, head, wings, and tail ; while the breast and lower wingfeathers are a bright chestnut color. It may thus be seen, from the varieties of costume in which he appears, that it is a rather difficult matter to believe that he is. 
one and the same party. He is even as clever in the manner of constructing his nest as the Baltimore.

He derives his name from the frequency and numbers in which he is found in the orehards. He is a good friend to the farmer, and saves many a penny in his destruction of blossom-loving bugs and eaterpillars. He will never molest the fruit when he can find insects to subsist on.

He is a sprightly, interesting bird; and, although his notes are not as mellow as his close relation's, there is a confusion about them which is quite bewildering and charming.

Whenever he is given the run of an orchard, and not molested, he becomes quite sociable in his nature, and shows his confidence by the numbers of his relations, which he seems to delight in introducing.

They are somewhat hardier than the Baltimore Oriole when eaged, not seeming to pine for freedom, and when taken from the nest are very easily reared, and commence to sing at a very early age. They have a very curious habit of moving the head in a snake-like manner when observing any thing, which is quite interesting to wateh.

The food and care should be the same as that described for the Baltimore Oriole, and the cage the same dimensions. 


\section{THE SCARLET TANAGER.}

TuIs magnificently coated visitor is perhaps best kuown from being seen mounted in the taxidermist's shop, or as a striking ornament on an expensive hat. $\mathrm{He}$ is the most handsomely plumaged bird which inhabits our woods. Always extremely shy, it is a difficult matter, even for the most experienced bird-trappers, to eatch him. His gaurly feathers, his own worst enemy, make him a bird much sought for as an addition to the aviary. It is asserted by some authors, that he is a difficult bird to keep alive in captivity; but my own experience is, that, if proper care and food are given, he will live a strong and vigorous bird many years.

The male 'Tanager is about seven inches in length. The whole body and head are of a deep, brilliant scarlet, and the wings and tail a beautiful velvet black, making a striking and elegant contrast. The female's colors are very unlike the male's, being green in the upper part of the body, and yellow below : the wings and tail are brownish black, tipped with green.

'Tanagers first make their appearance anong us early in May, and migrate South as early as Angust, making the shortest eall of any of our visitors. As soon as the male is ready to depart for his winter home, he changes his showy coat for a more sombre-colored travelling-dress, which renders him less liable to the attacks of the beanty-loving bird-fancier. His plumage ehanges to a greenish-yellow color almost resembling that of the female.

It is a matter of diseussion among leading naturalists whether the Tanager which regularly visits us is a native of Brazil. Wilson asserts that he is not. I am of the opinion that he is.

If he eannot lay elaim to being the king of American songsters, he certainly can to being king of American beauties. His colors, as seen among the bright green leaves of our forests, certainly form one of the most attractive sights of rural seenery.

His song; although unpretending, is not unpleasant. He combines the mellowness of the Oriole's notes with a simple, pleasing note of his own, repeated at short intervals. It is sung in a manner after that of a ventriloquist; for, although he may be at a eonsiderable clistance from you, the notes appear as though coming from a point directly above. This is, no doubt, a power bestowed on him as a protection from the danger to which his brilliant colors expose him.

$\mathrm{He}$ is a bird which is highly prized in France, a eountry noted for its preference for gaudy-colored birds; and hundreds of them are annually exported thither. He is a very shy bird in his native state. rarely approaching a human habitation, and very quiet and inoffensive in his manners. 
His food in eaptivity is the prepared Mocking-bird food, and raw, grated carrot, to which should be daily added bananas and oranges. Figs he is very fond of ; and they must be freely given, especially when he is first caged. Insects, meal-worms, and dried eurrants soaked in water, should also be given. Ants' eggs mixed with cayenne pepper as a change are also benefieial. It is in the variety of food given him which is the great secret of keeping him alive and in health. He is fond of a daily bath, and, when lung in the bright sunlight after a plunge, delights in pluming his handsome feathers.

The regular Mocking-bird cage is the proper-sized cage.

If carefully attended to, and kept warm in the winter season, he will long form a very interesting addition to any eollection. 



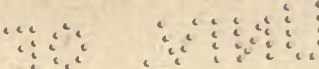

a.

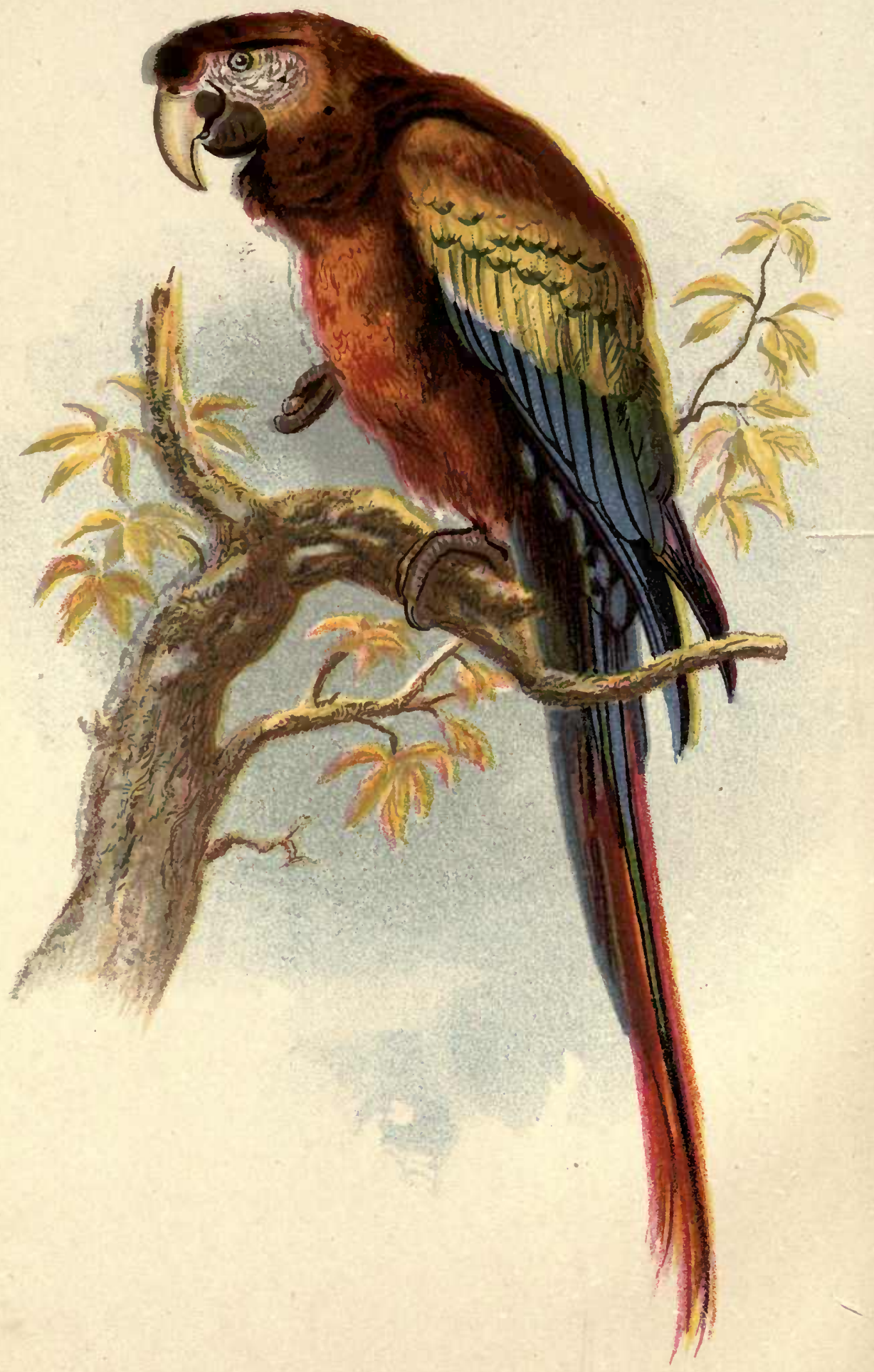




\section{HABITS AND BREEDING OF WILD PARROTS.}

Maxr diseussions lave arisen among bird-owners relating to the question of breeding Parrots in captivity. A description of their mode of life and breedingplaces when wild will, perhaps, prove interesting, and at the same time answer the question so often asked. In breeding Parrots, a great diffieulty to be surmounted in the cases of the largest and best-known species, suel as the Gray, the Mexiean, and the Sonth-American varieties, is the distinguishing of the sexes. There is no known method of distinguishing the male from the female of the abore species of Parrots. As far as can be observed, the male and female of all the above rank equal in intelligence: the eolors are similar, and both are the same size. How, then, is the gender to be determined? The only answer to the question is, to determine the difference in sexes by observation. After a Parrot is thoroughly acelimated, it will be observed to have the natural restlessness common to all birds during the latter spring montlis, the season which seems to be the regular breeding-time for all classes of birds. In order to successfully select a pair of Parrots of the species mentioned above, it is necessary to observe the attention which is paid by one member to another during the breeding season; where large numbers are kept $\mathrm{m}$ the same apartment. A male bird will usually select his mate, and bestow caresses and attentions on her, and act in the same manner as a pair of Canaries do. Separate the pair from the rest, and place them together in a suitable apartment for breeding purposes.

In the smaller varieties of the Parrot family, which embrace also the Paroquets, and in many of the large, brilliant-colored specimens, some distinguishing mark in the plumage is relied on to show the difference in sexes; as, for instance, the male Australian Paroquet is distinguished from the female by the difference in colors on the fleshy excrescence at the base of the beak: the color of the male's being dark blue, that of the female's white. In the African Love-bird, or Red-headed Paroquet, the common way of distinguishing the sexes is thought to be the difference in the intensity of color on the head, the male being supposed to have a more brilliant color than the female: this rule is, however, uncertain; as the young males greatly resemble the females in this respect. The sure mark is on the inside of the wings ; the inside of the male bird's wings are a beautiful shade of deep blue; in the female the color of the inside of the wings is plain green. The Macaw is also another instance where the sexes may be distinguished by the difference which exists in the coloring of some part of the body. On the inside of the wing of the male Red Macaw, near the outer edge, the color consists of a beantiful red: in the female the color is plain drab. A long list miglit be enumerated, but the above distinguishing marks do not appear to extend to the plainer-eolored and better-known varieties. 
All classes of Parrots appear to travel in troops in their native woods; and, in many instances, they build regular settlements in mountainous districts, so inacessible that it is impossible to dislodge them. While travelling from one place to another, each male selects his mate; and lie takes it upon himself to protect her. and feed her, and always appears with her, no matter where the flock may go.

It may be mentioned, that Parrots are more destructive to the crops in their native countries than any other class of birds. The multitudes which assemble upon the fields, or alight on the fruit-trees, devour all they can upon the spot, bite off still more, and carry away as much as possible up into the trees, in order to try to peaceably fill their never-filled stomachs. When they make their appearance in the orchard, they search every tree that is in fruit, and pluck such as may be ripe, bite a bit off, and, if it does not exactly suit their very refined taste, throw it down upon the ground, and take another instead. While feeding they generally climb the branches from helow upwards, and, as soon as they get to the top, Hy away to another tree, sweeping over the ground without ever moving their wings. Arrived at this second tree, they renew their work of destruction as before.

After having satisfied their hunger in this manner, they go in search of water to drink, and, according to the observations of travellers, do not refuse salt or brackish watei. Besides occasional rain-baths, which they enjoy hugely, they will bathe in lakes until they are soaked throngh. 'They also enjoy playing in the sand, like forls, and will travel great distances in search of it.

'The incubation of these birds takes place during the months that correspond in their native lands to our spring. The larger kinds appear to lay but once a year, and then only two eggs; though some of the smaller kinds, such as the Australian Paroquet, are exceptions to this rule, inasmuch as they will regularly lay from three to four eggs, and in some cases from six to nine, twice, or even three times, during the year. Parrot-eggs are generally white, smooth, and round. Holes in trees are favorite nesting-places of these birds, but not exclusively so: some American species will lay in holes in the rocks; and the Indian parrots, in crevices in old buildings, pagodas, monuments, or houses.

Audubon assures us that several females will lay in one nesting-place, but this is considered doubtful; although Parrots prefer breediug in large settlements. An extensive traveller, speaking of a large settlement of breeding Parrots in Sonth America, says, "These several settlements must be very astonishing to those to whom they are new. Fancy yourself alone, about mid-day, wearily approaching a precipice, believing yourself to be perfectly alone, that deep silence reigning around you that always indicates noon in these tropical regions, when all animals seek repose in sleep; a kind of growling strikes your ear ; suddenly you hear the Parrot's cry of warning, answered by many others, and, before you are awake to your true position, are surrounded by swarms of these noisy birds, flying about in a close circle, and in evident anger, threatening to strike you. From all the innumerable holes upon the face of the rocks, little round heads are protruding, looking comical enough; and those that do not come out unite their screams to the general uproar. Every opening indicates a breeding-loole, that has been excavated by its owner in the clay met with between the strata of the rocks. At times many hundreds may be counted." 
These colonies are so eunningly situated, that it is impossible for beasts of prey to approach them.

In general, it is in old trees that Parrots make their nests: but, as it is not always possible to find the trunk of a tree whose hollow has been excavated by some friendly Woodpecker, the Parrots are foreed to excavate their own nesting-places; and then it is that they show what available instruments their beaks can be. It is the female which makes this hole; at this work she proves herself most skilful; she hangs like a Woodpecker from the bark, and gnaws the wood away, one shred after another', until the dwelling is completed. The hole is the principal matter ; the nest does not need much making; a few chips picked up from the ground are sufficient as a bed on which to deposit the eggs; even a hole that leaves much to be desired in the way of convenience will content these very easily satisfied parents. The female generally sits alone, and is fed and entertained by her mate during the whole period of incubation.

The brooding season of Parrots varies: among some varieties it lasts eighteen days, and with others as long as twenty-five days. The young are perfeetly helpless when they leave the egg, but their growth and development are very rapid. At first they are very imperfectly fledged; but in from five to six days the feathers begin to sprout, and they open their eyes within ten days of their birth. 'The foor is always softened in the parent's crop before it is put into the beak of the young bird. The parents are very courageous in defence of their young. Some species will attach themselves with great tenderness to deserted birds, not merely to those of their own family, but to any helpless orphan, even though belonging to another species.

Parrots attain their full beauty of plumage, and commence laying, by the time they are two years old. The Gray Parrot, during the first year, is almost black thronghout; the beautiful crimson of the tail not making its appearance until after the second moult. The Mexican, or Double Yellow-head, does not commence to color out on the head until two years of age.

From the above facts it appears that it would not be a difficult matter to breed Parrots successfully in confinement. It has been tried in the large garclens of Furope with success, where, of course, every facility for the purpose is supplied, and where large numbers are always on hand, from which to select the proper material. The better way is, to breed a number at once; as one of the elements of suceess in breeding Parrots is, to form, as nearly as possible, a settlement which corresponds in a measure to their natural manner of breeding. Always select birds two years of age, or over. A large room should be selected for the purpose, which should be kept at tropical heat at all times; plenty of sumshine is very essential ; and a trunk of a small tree, with a number of loles with small openings, would serve the purpose of nests ; shavings, or small chips, are suitable for building material. 'The floor' should be strewn with sand; as, when not disturbed, Parrots of all kinds like to scratch and burrow in it, after the manner of barn-yard fowls. It is necessary to have openings made to the room, tlirough which the food may be put, so as not to disturb the sitting birds. The food should be of the richest description during mating and breeding season, and should consist of plam hemp-seed, bread soaked in cream, soaked Indian corn, and ripe fruits of all kinds. 
During the period of incubation the birds must not be disturbed. As soon as the eggs are hatched out, the young birds are most carefully looked after by the parents : outside aid, except in furnishing nourishing food, is not necessary. When the birds are of sufficient age to eat alone, they should be taken from the room, and reared by hand; as, when allowed to roam along with the older birds, they are apt to become wild, and not so easily tamed. Hand-reared, nestling Parrots are the highest prized of all for training purposes.

When entering a breeding-room for the purpose of separating the young from the old birds, it is necessary to go well prepared; as the parent birds, in their rage, are capable of inflicting severe wounds. In a breeding establishment in France, devoted to breeding Afriean Gray Parrots, whenever it is found necessary to enter the room, the attendant is clothed in a leather suit, and has his face and head protected by the same material, and his eyes are protected by a pair of strong spectacles.

This branch of bird-breeding is the most remunerative of any, and promises to become very popular. 
u

o 


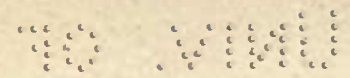

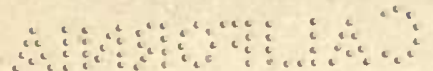

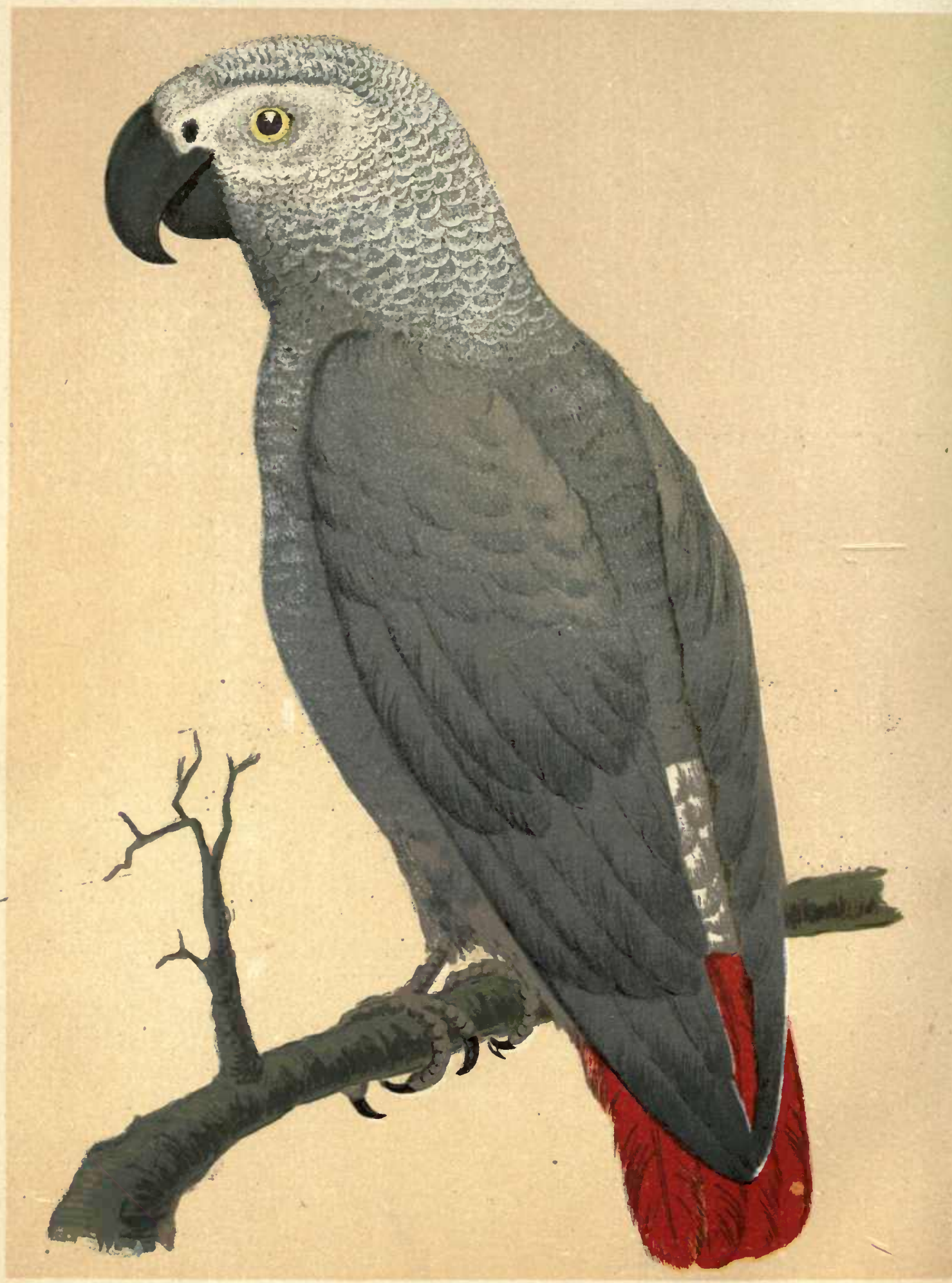




\section{AFRICAN GRAY PARROT AND OTHER PARROTS.}

Agarss no other class of birds does mankind express such deep hatred, and upon no other does he bestow so muel affection, as upon the Parrot. If any one should ask me, "Are Parrots like any other animals?" I would reply, first, "They are very like monkeys," and add quickly, "and very like men." It is because of this manly-monkeyish quality, which brightens and lightens many of our otherwise dull and heavy hours, that the Parrot has won his way, figuratively and literally, from the huts of the wild negroes and Africa's tangled forests into the drawingrooms of dignified judges and learned divines.

One other quality which endears the bird to his owner is his reflexiveness: we speak in some unusual tone, or laugh heartily, or utter a witticism; and on the morrow, at the opportune moment, the Parrot laughs our laugh with a fidelity that startles, and conjures up ghosts and ghouls; or "he reads so closely the line" of wittieism, that roar jostles roar. Then, because he is monkeyish, we grasp him, and call him brother. Mimicry and delicate flattery have great influence with all, and the parrot is only a mimic and a flatterer.

As there are about three hundred and fifty different varieties of Parrots, it would be impossible to give, in a paper of this nature, even a brief sketch of any great number of them; so the article will treat particularly of those generally kept caged in this eountry.

The Gray Parrot, so called, has only two colors, - the tail a deep red, and the rest of the plumage an ashen gray, though the bare places about the eyes have almost a whitish color. This bird is regarded as the most intelligent of all parrots. It is eertain that he can learn all sorts of words and long sentences; and no vowel or consonant, or any combination of any number of them which forms an English word, presents difficulties of pronunciation which he eannot, with attention, overcome. One more certainty may he noted: he never forgets a word or sentence once learned. He may hear you say to a summer vișitor, "Come, Smith, let's go to Mount Washington ;" and next year, or in two years, whenever Smith calls again, rest assured, is soon as the bird sees him and hears his voice, your invitation, in your very tone and manner, will be repeated.

The bird is a native of the west coast of Africa. Negroes take the young birds from the nests, and also trap and suare the older ones, and sell to the captains or mates of trading-vessels. Some are brought here via England ; but these are generally of poor quality, and refuse to live " just a hundred years to a day:" the best are imported on barks plying between the West Coast and Boston; these seem to become partially acclimated in transit, and also learn to talk some, as the thrifty 


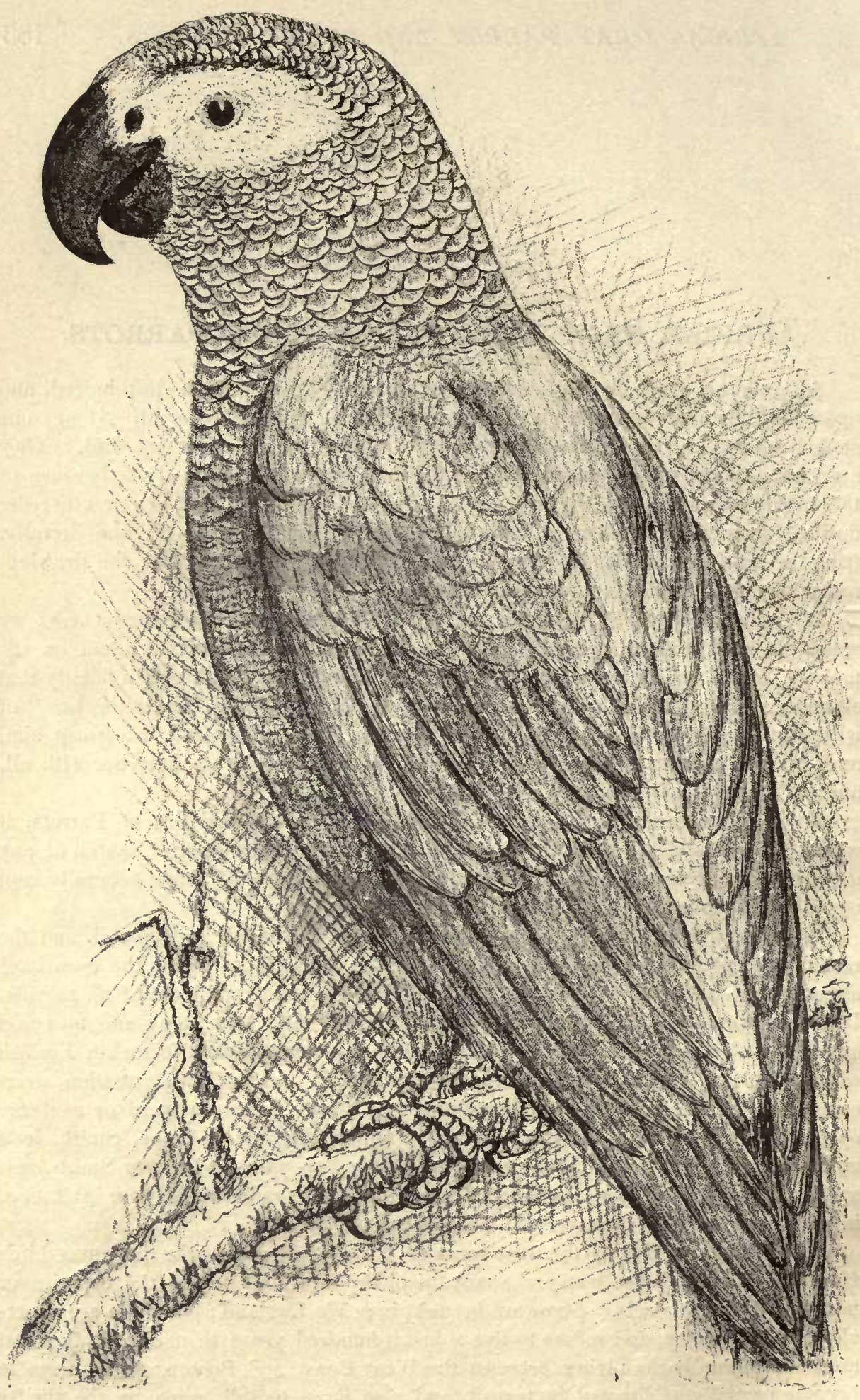

The Gray Parrot. 
New-Fnglanders make time between the "reefings" to give the birds regular lessons: a few hours' instruction each day, where one has a fair-sized class, often gives the captain a better return than the wage of a voyage. 'This especially is the ease if the captain happens to indulge in profanity; as Parrots quickly learn short words spoken with emphasis, and profane Parrots command high prices. 'The more cultivated and pious the buyer, the higher the price for the profane Parrot. This is a statement in favor of the buyer's piety; for he abhors to swear limself, and, like the famous Quaker, will pay roundly any time for a few wellselected oaths and curses. On the other band, a bird which ean repeat any of the catechism, or a prayer, is generally owned by some fellow too lazy or too wieked to say his own prayers.

Capt. $\mathrm{X}-$, on one of the barks sailing between Boston and the West Coast, brought a bird on his last trip that was a genius in spelling: with a ringing tone, as though he enjoyed each letter, and was conscious of great mental superiority, he would spell slowly, "D-o-g, dog;" and inmediately bark, "Bow-wowwow ;" then repeat gruffly, like a ventriloquist, and in imitation of a large Newfoundland, "D-o-g, dog ; bow-wow-wow, wow-wow-wow !"

Jim was also a wonderful bird: at times he was very polite, - "Good-morning, reverend sir!" Then he would threaten, _ "Be off, you rascal! are you going liome, or not?" or if the person was dressed shabbily, and a hard-looking character, he would shout, "I'll punch you, and make you sick!" Some of these gr'ay birds ean whistle very sweetly long runs and several bars from operas: they seldom sing, though I lave heard of one or two that conld sing short pieces. . All Gray Parrots learn to talk and whistle if they are instructed, and the number of sentences and songs acquired depends solely on the opportunities each bird has. Different birds vary in the quickness with which they learn a sentence or a song, just as scholars differ in intelligence. Some birls learn to talk a great deal, and to whistle but little; while others learn a new song in three or four days, but take as many weeks to learn a long sentence. 'It takes from six to ten weeks for a young bird to become aceustomed to a new place: if, during that time, he has had an hour's lesson daily, and has become tame enough to allow his head to be scratched, he will then try to talk, muttering an unintelligible jargon, seemingly for his own edification. When this has been going on for a few days, the teacher will think he heard the bird say Jim, or Tim, or Cumbo, whatever the name may be: soon he is assured by the bird speaking out plainly. From this point on, advance is rapid. Parrots seem to learu faster if instrueted in the early morning hours, and for an hour or two before dark. If you wish a bird to learn a special sentence, he must hear that sentence over and over again; but he will learn to talk without special instruction if placed where he daily hears conversation.

The kindergarten plan, or object-teaching, is indorsed by all Parrots : they need to see and hear dog, crow, hen, erying-baby, popping champagne-cork, or oșculatory indulgences, only a few times before an exact imitation is given. Any talking-bird's voice - be the bird Magpie or Raven, Jay or Parrot - is naturally deep toned and gruff : therefore, when teaching a bird, speak in a clear, ringing tone, pitched in a rather ligh key; in that way the bird's voice will be worked up above its usual gruffness, so any one can understand just what he says. For the 
reason above given, a child's pet talker generally has a sweet roice, and can be readily understood.

\section{MEXICAN DOUBLE YELLOW-HEAD PARROT.}

This bird is classed next to the Gray in intelligence and capability, and is preferred by many on account of his great tameness, and the ease with which he will learn to sing as well as talk.

The Mexican is the operatic star of the Parrot family; his natural voice being sweet, clear, and ringing. Many ladies, who own the best Parrot in the world, relate marvellous stories of the repertoire which her pet Mexican is capable of rendering ; and the list includes in some cases a range of airs, from the opera "Where was Moses when the light went out?" to a Boston sabbath-school hymn. 'The Mexican is seemingly intelligent enough to discern the different styles in which the music should be rendered, giving a faithful representation of either the true operatic artist, or the religiously inclined old lady.

The Mexican Parrots, unlike the other varieties, excepting the Cuban, are rarely ever trapped, but are taken from the nests when scarcely fledged: thus any natural wildness is unknown to them in this condition, and they are quite ready and willing to go to the kindergarten. In the spring of the year the regular bird-buyers for the New-York bird-houses visit Mexico, when the natives collect the Parrots in large numbers from the nests, and display.them for sale in the market-places. The birds thus taken in a season amount to thousands, and these wholesale seizures threaten a scarcity in the future. The Mexican Parrot, after receiving his first plumage, is of a beautiful clear green color throughout the body, with a pale orange forehead and scarlet-tipped wings; his feet are very strong, and white in color; the beak is white; and the tongue is also of the same color, a mark which distinguishes him from a closely allied specimen bred from a full-blooded Mexican and the Half Yellow-head. The Mexican is somewhat larger in size than the African Gray, and measures about fifteen inches in length. As the bird grows older the orange color of the forehead deepens, and extends over the head ; and the very old birds are seen with the entire neck and head clear yellow, with a plentiful sprinkling of yellow feathers through the green on the back, and a gradual spreading of the scarlet on the wing-tips.

The young Mexican birds, when brought to the northern parts of the United States, become easily acclimated, and for this reason, in the estimation of Parrotlovers, have the advantage over the Grays. It is a fact, that the baby Mexican Parrots, when first brought to the market, usually command better figures than the young Grays ; although, when fully trained, the Gray Parrots are given the preference.

The Mexican Parrot, after going through a course of training, is certainly a most amusing fellow, and mingles his odd and witty sayings and his comic songs in a most ludicrous manner. For the piously inclined I would recommend them; because, unlike their wicked gray brethren, they are not so apt to shock one with careless profanity. The natural sweet voice of the Mexican Parrot does not seem fitted to utter the coarse oaths, which, in order to be given expression and meaning, should be said as gruffly as possible. He is eminently fitted as a nurse for the 
infant, and will often perform the mother a service, and at the same time amuse her, by sweetly singing the babe asleep. 'To hear' a well-trained Mexican Parrot attempt to accompany the piano with one of his nursery songs is something startling. Stand behind the door, and listen, but do not look; although you may be sure the bird is doing the singing, the cleverness and clearness with which it is rendered will cause you to doubt your own ears and eyes.

The Mexican will also imitate to the life any of the various animal sounds he may hear. He will daily cause the mother of a baby to run in alarm at hearing the cry of her infant, and cause her to smile at seeing her prodigy laughing in glee at his imitator instead of finding him on the floor with a broken nose. The praises of the Mexican Parrot could be indefinitely prolonged: he certainly ranks closely on the heels of his only superior, the Gray, and in some instances far outstrips him in his versatility. When the young Mexicans are first brought to the markets for sale, it is commonly supposed that the beak is not sufficiently hardened to properly crack the uncooked Indian corn. The chief food, therefore, consists of Indian corn boiled to a soft state : this is indeed a most excellent food for any species of Parrots, as it has not the heating or fattening quality of various other kinds of food commonly given. The soft food retains sufficient moisture, so it is not necessary to give water in addition. The principal food for the Mexican should be the boiled Inclian corn, - which will repay the slight trouble taken in getting it ready by the health which the bird will enjoy, - and bread or eracker soaked in coffee. He may also be fed in addition the regular Parrot food, a description of which will be found in the paragraph on the subject at the end of this article.

Ripe fruit, such as bananas, oranges, or apples, may be given at intervals, and are hugely relished. The usual complaints which affect all classes of Parrots prevail among the Mexicans. A prevalent disease among them is purging, or romiting the food, which is caused by improper or stale food, or by too sudden change of diet, which weakens the stomach, and causes the vomiting of all food which may be given. This complaint will usually be remedied by administering a few drops of brandy diluted with two parts water. Keep the bird warm, and feed only the boiled corn and bread with coffee for a few days.

A great treat for the Mexican, or, in fact, any variety of Parrot, is millet-seed in the ear, Indian corn on the stalk, oats, corn, barley, or wheat in the ear. In the summer season, when green corn is ripe, give him an ear now and then; and he will enjoy it greatly.

Give your bird plain, healthy food, and not any sweetmeats, plenty of sunshine when possible, and a shower-bath when the weather permits; and he will repay you by recounting to your children, when you are dead and gone, your many virtues and kindnesses. The Mexican Parrot, although not as long lived as the Gray, has been known to live to be sixty years of age : unlike the Gray, he cannot conceal his age, but, as a venerable patriarch, in his last years shows a coat of colors which rival those of a French dowager.

\section{THE CARTHAGENA PARROT.}

This bird is striving with the Mexiean for fame as a singer and talker. He is gentle and quiet, very intelligent, and has a most retentive memory. He learns: 


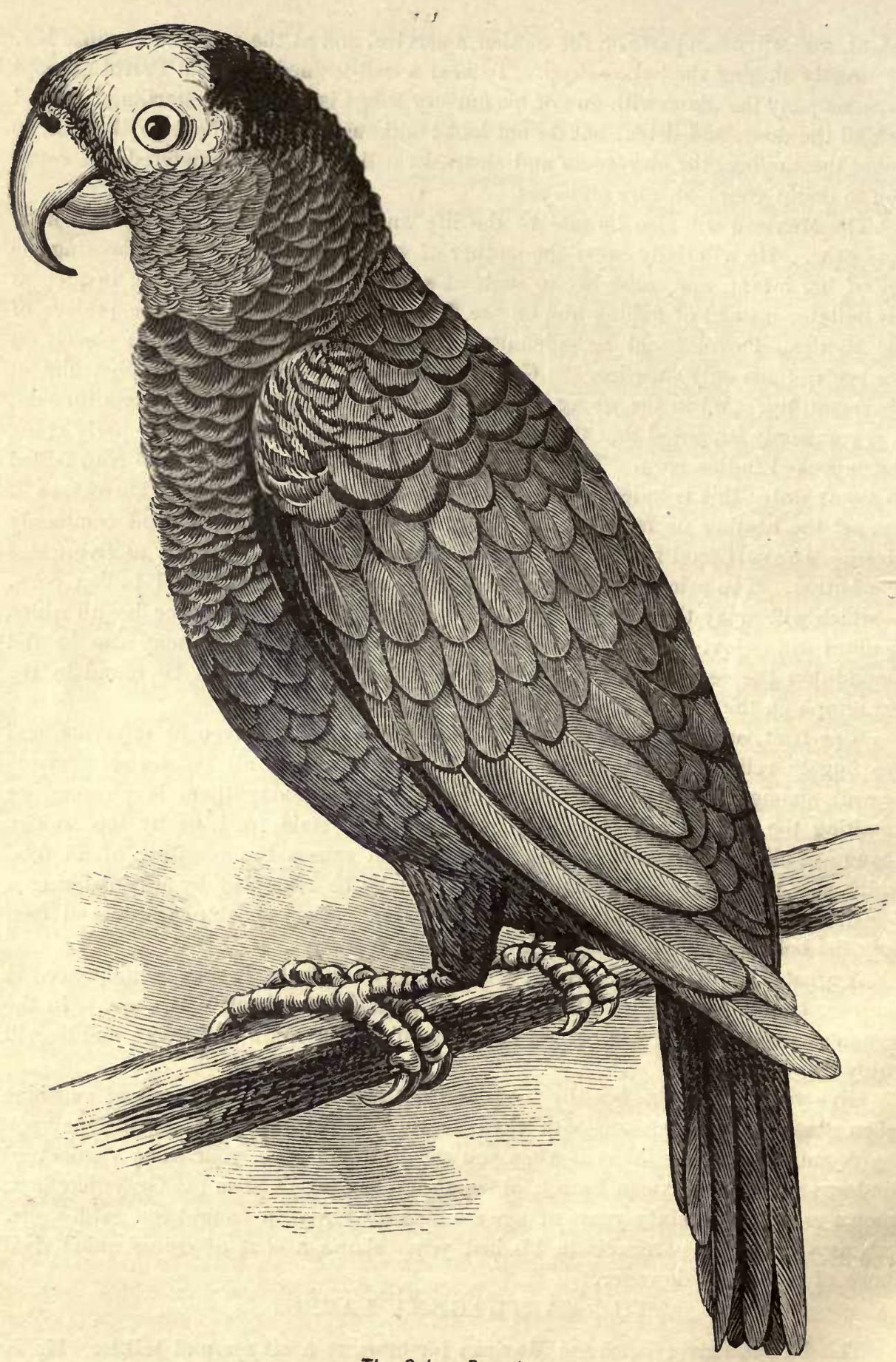

The Cuban Parrot

(3/4 Natural Size.) 
quickly a song with the words, and then seems to enjoy being in a quiet corne: where he can rehearse freely and without interruption. At such times "funuy blood" seems to course vigorously through his vein of humor, and furnish, unconsciously of course, a roaring farce. He also learns to whistle airs. As a learner whose lessons show off to advautage, he will please any possessor. He is about thirteen inches long, has liglit-green body plumage, except on the back of neck, where there is a yellow spot the size of a silver dollar. The wings and tail have green and parti-colored blue and red feathers. His food and care are the same as for the Mexican. He is a strong, hearty bird, and lives from fifty to seventy-five years.

\section{THE AMAZON PARROT.}

This bird takes next rank in the list of talkers. He is a native of the upper portions of South America, not quite as large as the Mexiean, but equally as beautiful in appearance; his brilliant head-dress of blue and vermilion, and searlettipped wings and party-colored tail, making him a very attractive bird. With the exceptions above noted, he is plain green throughout: the beak, tongue, and feet are black. He is an apt scholar, althongh sometimes inclined to be noisy, and readily learus to talk and sing. The Amazon is usually trapped, and when confined is fed on the parrot-seed and water.

\section{THE BRAZILIAN OR BLUE-FRON'T PARROT.}

This bird is easily distinguished by his plain green body and sky-blue forehead: he is somewhat smaller than the Amazon, and sometimes makes a good talker. His food is the same as the Amazon's.

\section{THE MARACAIBO PARROT.}

This is a smaller bird, abont the size of the Cuban, and resembles the Mexiean greatly in appearance. He appears to be a small edition of the latter, and takes a foremost rank in the list of talkers. His food shonld be the same as that of the Mexican.

The Half Yellow-head is commonly confounded, by inexperienced persons, with the Mexican Parrot; but he is not so large; and may be easily distinguished by the black beak and tongue. IIe sometimes makes a most excellent talker; but, as a rule, he does not rank as high as any of the earlier-named birds.

The Lories are a class of brilliantly colored Parrots, and are mostly caged on account of their gorgeous plumage. They rarely ever learn to talk, although they have the virtue of knowing how to keep quiet. The food, care, and treatment should be the same as that for the Parrot family.

\section{CUBAN PARROT.}

This Parrot is classed among the tamest and quickest to learn of all the birdspeaking family. Owing to the wide-spread demand for them, this article has been 
written to point out more definitely their specially attractive qualities. The two very evident reasons why the Cuban is such a favorite are his gaudy plumage and his low price. But these two reasons do not seem to us to account for the demand that absorbs ten thousand Parrots of a certain variety; while there are sold, probably, not a full thousand of all other varieties combined. 'That is a trite saying, "It is hard to teach an old dog;" but it applies with especial foree to any ereature who would learn a new tongue. It is pretty generally agreed, that a native Ameriean can lear'u to speak French more fluently if he commences in childhood than if he undertakes to aequire the language in middle life; and we shall, refrain from absurdly undertaking to make you believe that our Parrots are smarter than your best baby.

The Cubans, when imported, are some of them not yet old enough to be in full feather, ranging in age from two to four months. 'They are too young to know even what fear is, and in some instances cannot feed.themselves. 'They are young, they are tame, they are parrots, - mimies, and good listeners. Fvery word and every sentence spoken to them fall on a new, never-before-occupied brain. This accounts for the fact, that, after a two-weeks' tutelage, the bird may exclaim in mock-derision, "Bah! I hate that Mr. Flanders!"

These birds are captured before they are old enough to fly from the nest, and are brought to New York during the latter part of June and in July, in shipments of six hundred to fifteen hundred birds. Some dealers immediately select promising birds, and put them out with trainers for instruction: but the great proportion is sold as soon as they arrive, buyers preferring to train the talkers to suit themselves; many elaiming that the regular trainers give too much Sunday-school instruction, and not a sufficient variety of oaths and double-entendres.

As stated above, the birds are very tame, being too young to know how to be cross, and may be handled at once with impunity. If handled carefully, and not teased and annoyed, they remain tame, and, of course, learn faster than birds that are abused or tortured so they are in constant apprehension of bodily danger. These birds sell for $\$ 4, \$ 5$, and $\$ 6$ each.

The docility of Parrots, the facility with which most kinds can be accustomed to cage-life, and the talents they possess of imitating the human voice, and pronouneing words or sentences, have made them favorite cage-birds, and suffieiently explain, that, when America was discovered, they were found domesticated by the natives. The first American Parrots, probably these Cubans, that were exported to Europe, were carried by Columbus when he returned on his voyage of discovery, and were with him when he held his solemn entry in Seville, March 31, 1493.

In Cuba and other West-Indian lstands, Parrots are used for soups and other highly prized dishes; it is said that a stranger, lunching in a restaurant there, feels somewhat apprehensive when he hears a waiter shout, "Two Cubans on toast;" but his fears are allayed when it is explained that the two Cubans are only Parrots.

This bird is about twelve inches long. The upper parts are green, with a band of white above the beak; the throat and upper part of breast are bright searlet; and the wings and tail-feathers are blue, green, and scarlet intermixed, making the bird one of the most beautiful of the gorgeous-colored birds of the tropics.

His food is the plain hemp-sced, with oecasionally some unhulled rice mixed 



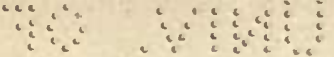

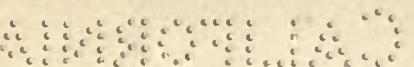

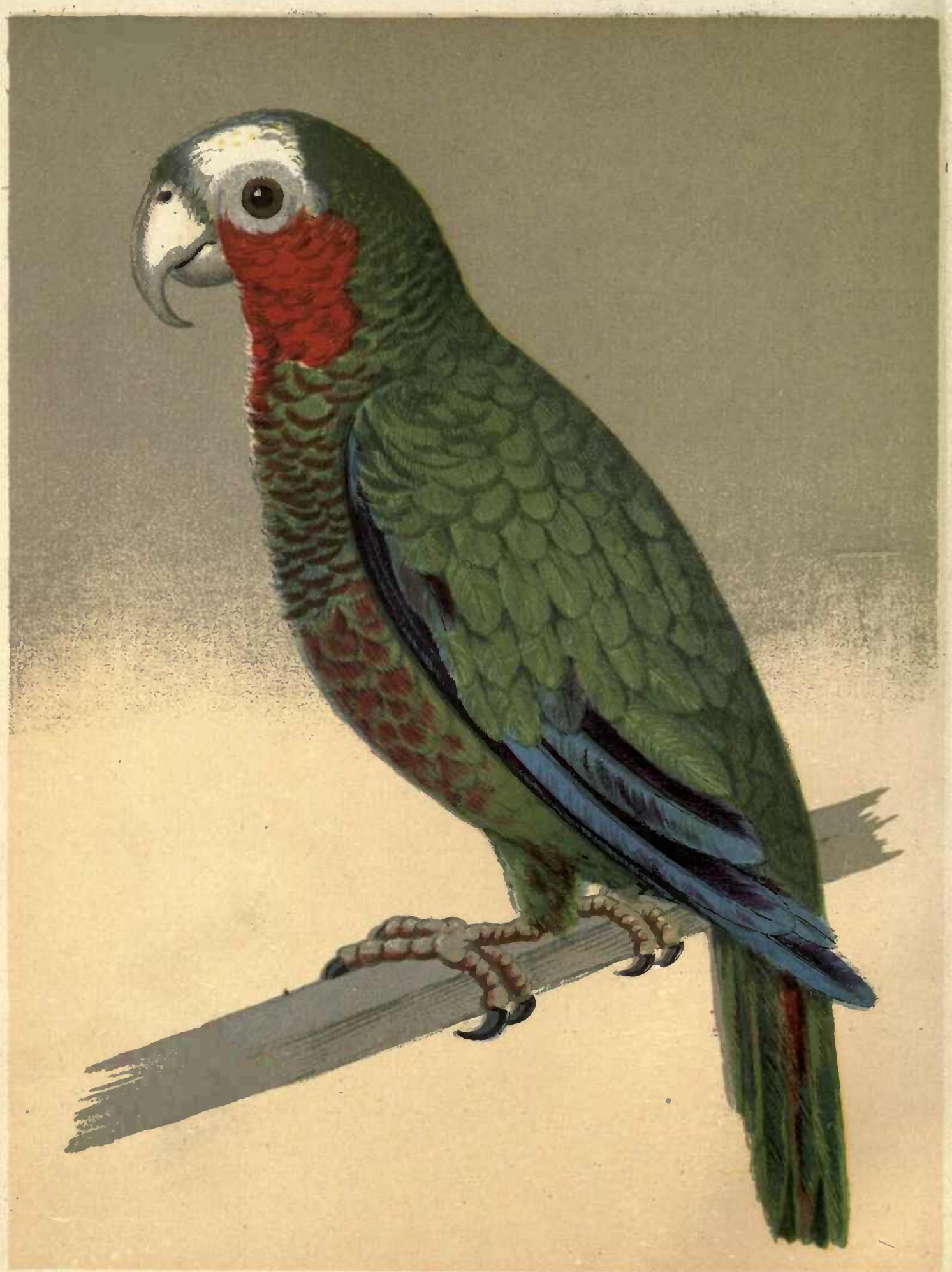

Cuban Parrot. 
with it: some of the birds prefer the regular mixture of equal parts of hemp-seed, unhulled rice, and cracked corn. Each should have, in addition to the seeds, daily, stale bread soaked in coffee. The eage-base should be well strewn with coarse. gravel.

Birds do not differ at all from ehildren respecting the need of regular and systematic instruction. If you are interested in having a bird talk intelligently, give him intelligent instruction. What advancement can be expected in a child who is given French in five-minutes' lessons once a week, mathematies for seventy-seven seconds fortnightly, with Sanserit crowded in as a sort of condiment at dinner-hours? but such a method, or want of method, is the one pursued in teaching a creature which caunot even articulate; yet the bird is expected to learn, not only to enunciate distinctly, but also to reason correctly if not abstrusely. If a proper method of instruction is followed, there is no imaginary fixed line in intellectual progress beyond which a Parrot of ordinary ability may not go. Many cases could be cited to prove this statement if it were deemed necessary; but you will have the best proof if you take a baby Parrot, and follow out in detail the outlines of the progressive course hinted at above.

'There is no known method of making a talking Parrot speak, and it is as impossible to compel one to speak as it is to compel some garrulous people to keep silence. As a bird talks most when in a fairly quiet place, and not in the presence of strangers, it is seldom one ean be heard in a bird-shop where there is a constant racket, and a continuous procession of new faces. The better plan, if you wish to buy a talker, is, to consult the seller's list of birds and the memoranda of sentences, songs, imitations, and other accomplishments each Parrot has, and then buy the bird on the seller's guaranty in the bill, that, if not satisfactory in four or six weeks' trial, he may be exchanged for another. It takes four or six weeks for a bird to get aceustomed to a new home and new faces so he will talk freely.

\section{METHODS OF 'TAMING PARRÓTS。}

Some trainers tame Parrots by force. With hands encased in strong doeskin gloves, the tamer seizes the bird by the legs, pulls it out of the cage by foree, withont heeding its screeching and biting, holds it firmly on the forefinger of the left hand, with the thumb over the feet, and s'rikes it with the right hand until it yields to its fate and becomes tame and quiet. For this, courage is, before all things, necessary, besides skill and patience, and indifference to the pain, which, in spite of the gloves, the bites of the bird may cause. In order to break a Parrot of the habit of biting, he should be struck with the forefinger, or a pencil, on the beak whenever he attempts it. Food should be withheld for some hours each day while the bird is being tamed, and he will the sooner become docile.

Some trainers who follow the above method begin with the bird in the morning, and devote the whole of each day, and sometimes the hours after sunset, for four or five days, and thus the bird's timidity or defiance are conquered, and it becomes tame from hunger and weariness. Other morles of taming may be slower and occupy more time, yet they have the advantage of establishing more friendly relations between the trainer and the bird. In these quieter methods it is necessary, when giving food, or in approaching the bird at any time, to be quiet and friendly, and to 
avoid, before all things, frightening it by sudden and hasty entrance. In all intercourse with it no violence or ontbreak of temper should be allowed. Parrots may be spoiled by excitement; they should never be teased in joke or earnest, nor umecessarily threatened or punished. Punishment should be used only under certain conditions, after the bird's disposition is thorouglily understood.

In taming them. let there be undisturbed quiet, and always keep an equable, kindly temper. At first, for a week or two, the bird should be left unnoticed. It will soon learn that no danger to its life is intended, its shyness will pass away, and it will begin to observe its surroundings. Soon an "inquiring mind" will be shown, and it will distinguish one member of the family from another, and friend from foe. It will then begin to grow fond of any benefactor, and you have only to avail yourself of some knack to tame the bird rapidly. Take away the food or water, or both, for some hours; then hold these out, or some titbit of which the bird is fond, in order to accustom him to taking food from the liand. He soon becomes used to this, comes voluntarily on the finger, allows his head to be scratched and stroked, till at last you may caress and fondle it as desired. As soon as it can be safely done, feed the bird moistened bread or seeds, from your lips, and his attachment for you will be great and constant, and endure for life.

\section{TEACHING PARRO'TS.}

Read with care all the preceding pages on Parrots, and before the instruction commences try to understand your pupil and gain his friendship. Some pupils are stupid, and some, while not stupid, learn slowly.

There is also a difference in teachers; some do not know all things and can teach tolerably well, while others, of wider information, have no faculty of imparting abundant knowledge to others. Those who have taught Parrots for me, and make a specialty of teaching birds, adopt the following plan : All food and drink are removed from the Parrot's cage at night after the evening meal, and instruction commences at daylight; the bird is then wide awake, and the stomach is not overloaded with food. 'The cage is covered with a dark cloth, if necessary, to get the bird's undivided attention, or left uncovered, as seems best for the special bird. Then the sentence is repeated, or the song, words and music, sung several times, and when a sufficiently long lesson has been given or a perfect imitation attempted, reward the bird with a few seeds or some harmless titbit of fruit or peanuts, then continue the lesson, and again reward good imitation. The bird will learn faster during the early hours, or about sunset; but he may be taught at other times also. Every morning, on first going into the room where the Parrot is, and every evening, as well as several times during the day, one word, first very distinctly pronounced, should be said to it clearly and sharply, and, if possible, all drawling and lisping or other mispronunciation avoided. A full-toned word, with the vowel "a" or " 0 ," and also with a hard consonant, sucl as " $k$," " $p$," " $r$," or " $t$," should be chosen, and hissing sounds avoided. While the Parrot is learning to speak treat it kindly, so that it may gain confidence; and, in particular, it must not be terrified, nor made nervous and shy, but kept quiet and attentive, in order that it mav intelligently heed the teaching it receives. The teaching should not, indeed, consist of merely training 
the Parrot to speak certain words, but everything said must awaken in its mind a distinct perception. For this it is necessary it should have some conception of time, place, space, and other circumstances. "Good moruing!" should be said early; "Grood evening!" or "Good night!" late. "How do you do?" and "I am glad to see you!" on arrival, and "Grood by!" on going away. One should knoek, and then call out, "Come in!" Count out titbits to the bird, "one, two, three," or names, " "ut, almond, apple." Later on it should be praised when it is good and oberient and scolded when it is obstinate or will not obey. An intelligent bird soon comprehends such things, and it is often really astonishing with what sharpness and eertainty it learns to know and distinguish under such cireumstances. In teaching the Parrot to sing one or more songs, or to whistle airs, care must be taken that only one key be used for each song.

The Parrot should at first be taught easy words, and progress by degrees to more difficult ones. From time to time the lessons should be reviewed, all that the bird has hitherto learned should be repented, and only when it is quite certain that it has all this well mastered should new words be repeated to it. In reviewing, there must be no prompting while the bird practises if it stop in the middle of a word, or a wrong pronunciaton of the word may be learned. Wait until the bird has ceased to speak, and then pronounce the word or sentence clearly once more. Constant practice is necessary not only for the bird which is being trained, but also for finished speakers; and it must be borne in mind that no advancement in any kind of learning means there will soon be a falling off, and that Parrots, as well as those men who possess "giant intellects," are ever forgetting or confusing what has been learned. Teaching gradually, step by step, will certainly insure the Parrot becoming a good speaker.

\section{FOOD, CARE, AND DISEASES OF PARRO'TS.}

Food. - For nearly all Parrots when over four months old the regular food is equal parts of cracked corn, unhulled rice, hemp, and sunflower seeds. Probably nine Parrots thrive on this mixturewhere one will do better on some other variety. It is necessary to wateh each bird and withhold whatever may be for him indigestible or otherwise harmful. Stale bread or cracker, soaked in a little water or in coffee, plain or with milk, is good. Coffee is the usual drink, but for some birds water is better; others are made sick by drinking water. A piece of cuttlebone the size of a walnut should be given daily; six to ten peanuts may be given; all other nuts are likely to be injurious. Apples, oranges, bananas, red-pepper pods, and lettuce may be given, selecting the kind which is good for each bird. Keep an abundance of silver gravel in the cage. Greasy fools, meat, bones, butter, and table dainties almost always cause diseases, which take a long time to cure. There is one Parrot in, say, ten thousand, which can eat from the dining-table and still live. With proper attention to the food, cleanliness, and cage of the bird, it will seldom be necessary for you to consult the articles on diseases.

Cages for Parrots should be of suitable size to allow plenty of exercise, on which largely health depends. The Cuban, and others no larger, may be kept in a cage twelve or thirteen inches in diameter, though for even these the larger cages 
are better; but grays, and others that size, must have the largest cages, fif teen inches in diameter, or eighteen to twenty-four inches long. Parrots allowed the flight of a room, unless it is given solely to them, are apt to eat something injurious, and, with so much exercise, do not learn or talk as much as when confined to cage or stand.

Bathing. - A few Parrots bathe naturally in water, but the majority take only sand batlıs. A bird keeps in much better health if given a bath one to three times a week through the year, according to the needs and health of the bird. Use from a pint to a quart of tepid water in which a teaspoonful of borax has been dissolved, spraying the bird with the half-pint atomizer. If a teaspoonful of wine is afterwards thrown on the bird with a small atomizer, the plumage will become glossy and beautiful.

Diseases. - The principal indication of the state of health is in the condition of the excretions. In a thoronghly healthy Parrot they consist of two parts : a thickish dark-green and thinish white substance. Whenerer both parts run into one another, or one preclominates, - when the excretion is all greenish gray, slimy white, or watery, - the bird is no longer quite healthy. Any severe internal disease of Parrots is difficult to cure, because it is hard to make a proper diagnosis. Again, the disease and its remedy may be understood, and it may not be possible to use the remedy because the bird will not take it voluntarily, and if force be used, that is of itself harmful. When the remedies cannot be mixed with a small quantity of soaked bread, and eaten, if the bird will not voluntarily take the munmixed, the only alternative is to treat the bird like a young child, "opening his mouth and holding his nose."

Influenza, Cold in Throat, Nose, or Mouth. - Symptoms: Sneezing; slimy yellow discharge from the nostrils, which become encrusted; shaking of the head; a sleepy, puffed-up appearance. Put the bird at once in a warm place, near a stove if possible. Add to the regular seed a few bird peppers; into a glass of water put ten drops of aconite, and every hour pour a teaspoonful down the bird's throat. Second remedy : Let the bird inhale tar vapor, putting the tar in a bottle, - one part of tar to twenty-five parts of hot water, - and hold under the nostril, rub the beak and throat externally with a solution of chlorate of kali, one part, and tweuty parts of hot water ; cleanse the nostrils and the beak with a feather dipped in salt water, and then moisten them with the oil of almonds.

Catarrh in the Air Tubes. - Symptoms: Hoarseness, coughing, rapid breathing, and rattling in the throat. Treatment: Administer something sweet, cuch as honey or pure licorice juice. Mix a half grain of chloricle of ammonia to one teaspoonful of clarified honey and fifty drops of fennel water. Give a half or a whole teaspoonful several times daily, using judgment in each case as to quantity and frequency. Second remedy: Mix thirty drops of extract of dulcamara with one half pint of water, and give a half or whole teaspoontul twice daily; and let the bird inhale the tar vapor. Only tepid water should be given, and the mouth, far back into the throat and the nostrils, should be smeared with a solution of salicylic acid, one part to three hundred parts water.

Inflammation of the Lungs. - Symptoms: Difficult, short, or wheezing breathing, with open beak, hot breast, melancholy, want of appetite, perceptible 
ferer, eoughing, discharge of yellow phlegm, sometimes streaked with blood; a gasping sound, particularly at night. Treatment: Warm air, but moistened by water sprinkled about eage. Make pills of from two to five grains of carbonate of ammonia with bread, and give one every three hours; or, instead of the pills, one to two grains of nitre, for a dose, dissolved in water.

Indigestion.-- Symptoms: Want of appetite; hard brown exerement, in small quantities ; apathy. Causes: Unsuitable or bad food, and consequent disturbed condition of the digestive fluids. Treatment: Light food, a plain diet of unhulled rice and a few sunflower seeds, but little green food, some salt, and tepid drinking water ; a teaspoonful of lnkewarm Bordeaux wine, with a small piece of sweet almond or: walnut, is good. Put into the cup of drinking water a teaspoonful of lime-water. Do not feed dainties from the table.

Inflammation of the Stomach. - Cause: Stale or otherwise bad food; icy-cold drinking water; cold in the stomach; eating poisonous substances, or wet green herbs, or swallowing bone, little stones, etc. Symptoms: Want of appetite, thirst, choking, and vomiting, slimy, and even bloody, excretion, shirering and weakness; often the belly appears swollen and red. Treatment varies according to the cause. Quiet; warm poultices held against the belly; also sand.as warm as is pleasant to the hand, which must be kept at the same temperature; give a solution of tannin, two parts to one hundred parts of warm water, two or three times daily, and of Glanber's salt one half grain for a dose, in water, for a purge, two or three times daily. Second remedy : A teaspoonful of pure glycerine daily, using also the solution of salicylic acid one part to three hundred parts water, giving ten drops three times a day.

Diarrhœa arises from various eauses, and appears as a symptom in different diseases. Read the article above under "Diseases," and see how the excrement varies from the description there given; if it becomes whiter, yellower, or more slimy, if the feathers ${ }^{-}$under the tail stick together, and if the vent looks swollen or inflamed, then there is a cold in the intestines, and the remedies given under "Inflammation of the Stomach" should be used. If the excretion is whitish green or chocolate colored, and of a sour, bad odor, with loss of appetite, while the crop is full, and there is great thirst, then there is severe inflammation of the stomach. Treatment: Do not check the purging; keep warm; give rice water and caleined magnesia with water; feed only plain unhulled rice. Second remedy: Feed the unhulled rice, giving at the same time a half cracker soaked in brandy, on which sprinkle a little red pepper. In severe cases pour down the bird's throat a teaspoonful of boiled milk with five drops of paregoric every three hours.

Bloody Discharges. - Give a teaspoonful of hoiled milk with four drops of landanum in it every three hours. Feed no fruit or green stuff, and do not allow the bird to drink water unless it is impregnated with iron.

Dysentery. - Treat as for diarrhœa, and give also from half to one teaspoonful of eastor-oil, with ten drops of honey; if the excretions be blackish, give, in addition, half to one teaspoonful of port wine one, two, or three times a day. The sticky feathers under the tail should be bathed and washed with warm water.

Costiveness, Constipation, arises from a disturbance of the digestion. Symptoms: Continued effort to void excrement; tilting the hinder part of the body ; 
ruffled feathers; want of appetite. Treatment: First use warn oil - castor-oil and olive-oil in equal parts - by dropping it into the rent or passage from the head of a pin ; by this means, after several repetitions, large masses of excrement pass away. Also a simple water injection may be used, by means of an india-rubber ball with a thin glass pipe having a rounded point. Give ten drops of castor-oil with one half teaspoonful of honey once or twice daily. Feed hemp and sunflower seed in equal portions.

Vomiting and Choking are seen in several conditions of disease, and can only be cured by their removal. However, vomiting of ten occurs merely from mintal excitement, fright, anxiety, etc., and may have but little significance, being only a passing attack. It also occurs when the stomach is overloaded, or after indigestible food has been eaten; but even then it is generally not dangerous. - See "Inflammation of the Stomach."

Convulsions and Fits are the result of disorders of the brain or other organs. The Parrot suddenly shrinks together, with violeut twitching, beating of the wings, or twirling around; or, it begins to tremble, totters, rolls the eyes and then the head, falls down, and writhes violently. Causes: Orereating of hemp-seed or other rich food; confinement in too small a cage; being kept too warm, either by fire or in the sunshine; seclusion from mate. Remedies: Change of food, much green food and fruit, coolness, fresh air, change of place. When the attack comes on take the Parrot in the hand and hold it upright, so it may not injure itself, but maly find relief.

Rheumatism and Gout. - Symptoms: Loss of appetite; fever ; swelling of the joints of the wings and feet, which are at first hard, very red, hot, and painful, and then become soft, and contain a fluid of mingled blood and pus. Treatment: Warmth and dryness; when the swellings are inflamed and hot, cool with vinegar and water; if hard, rub with spirits of camphor, or smear with diluted tincture of iodine mixed with spirits of wine, one part to fifty parts. Wrap them up in warm woollen rags; if the swellings suppurate, eut them open, taking care not to do it too soon; press them, and then rub with a solution of carbolic acid, one part acid to fifty parts water. Give, in all eases, an internal dose of salicylic acid, one part acid to three hundred parts water.

Diseases of the Feet. - When the feet of birds are neglected inflammation may be set up under the crust of dirt, with suppuration, and larger or smaller ulcers. Treatment: Bathe the foot at once in warm water, cooled with water; smear the sore places with diluted glycerine, then thickly cover with fine starch powder. Repeat this treatment every day; the cure will soon be complete. In obstinate cases use lead ointment, or, if the wound be moist, vintment of carbonate of lead; then the foot must be put in a little leather bag and this firmly tied, because the ointments are poisonous to the bird.

Plumage Diseases, Insects. - Where the plumage is poor in consequence of parasites, use the German insect powder, dusting it thoroughly throngh the feathers. Next day the plumage should be washed with warm water, soap, and a brush, and then rubbed thinly with olive-oil. The cage must be cleaned with soap and water, and scalded with hot water; then dust with insect powder. If bald spots come on the bird, and scales and scabs form, they also are probably due to 
some animai or vegetable parasite. Treatment: Rub the bare place with soft soap, and trenty-four hours after wash with warm water, and cleanse as much as possible with a soft brush, and then rub with balm of Peru.

Self-Plucking, or Pulling the Feathers, is one of the worst diseases of Parrots. Cause: Improper food; too much hemp-seed, meats, or bones, and too close confinement. Preventive Measures: A constant supply of wood to gnaw, also sand; avoid all titbits and unnatural food; feed sunflower and unhulled rice. Amuse the Parrot, and give wooden spools or a strong china doll to play with, and keep in a large eage. Treatment: Spray with tepid water and glycerine, half teaspoonful of glycerine to teacup of water, several times each day ; smear the places with tincture of aloes or infusion of tobacco leaves, - one ounce to half pint of water, or other bitter fluids. Puff insect powder through the feathers if it is needed. It is also a good plan to put the bird into new surroundings. Some keepers have had good results by reducing the quantity of food by degrees, till at last the bird got only a third of its customary allowance, wlren it became quite drooping, and left off the habit. Read "Plumage Diseases," above.

Tongue Splitting. - Parrots are never "tongue tied" ; and it is unnecessary and barbarous to cut the side cords or split the tongue.

Warmth. - A Parrot when quite sick should be wrapped in a small blanket and kept near the heat. A temperature of ninety to one hundred degrees is often very beneficial.

Paroquets and Dwarf Parrots are treated in disease the same as Parrots. 


\section{DWARF PARROTS.}

These diminutive members of the Parrot family include several varieties, and inhabit different countries of the globe. They are among the most vivacious and docile of the entire race, and by their pretty tricks, loving ways, and great intelligence, are fast winning popular favor. The poets could not have heen aware of the strong love that exists between a pair of these beautiful little creatures, or they would surely have selected them as their models of ideal tenderness.

The Dwarf Parrot measures about seven inches in length. The prevailing color of the body is green, the upper parts being of a beautiful deep shade of that color, and the throat, belly, and under parts, of a yellowish tinge of the same color. The tail is very short and square. The quills of the wings are short, and, when the latter are closed, reach to the end of the tail.

These Parrots inhabit the forests and groves of South America, and build their nests in the holes of trees, which have been hollowed out by the industry of the Woodpecker. They usually hatch three small, rounded white eggs. The derotion shown the female by the male during the period of incubation is rery tender and touching. He attends to all her wants, and guards the nest, when not in search of food, with a care rarely seen in any other member of the bird race. The birds in their native haunts travel in troops, and visit the gardens of settlers as flocks of sparrows do in our country. They settle in great numbers upon the trees, and nibble at the fruit, meanwhile keeping up a brisk whistling, which is very confusing when uttered by a myriad of them, but, when heard as given by a single bird, sounding very musical.

The Dwarf Parrots live in their wild state in the same manner as any variety of the Parrot family. Their beaks enable them to climb readily; but they are casily approached, and, when captured and confined, seem to forget the loss of their freedom, especially if they are kept for a short time with their mates.

Their habits, when caged in pairs, are worthy of study and admiration. A pair will eat togetler, and share the same bath; and, if the male bird utters his cry, his mate will instantly join him, and seemingly ask all sorts of questions in her tender solicitude. Should one of a pair fall ill, the other takes the post of a faithful nurse, and tenderly cares for its partner, feeding it, and performing all the duties which sickness render necessary.

Unlike the Paroquets of all kinds, with which the Dwarf Parrot is often confounded, the birds of this class will live separately, and thrive as well as when kept paired. The affection which the bird showers on its mate is lavished on its owner when it is kept singly. They never seem wild, even when selected from a newly 
caught lot, but appear to be wholly unfitted by their tender natures to repulse a caress or kindness.

The Dwarf Parrot learns to speak as readily as any of the most intelligent of the Parrot race, and his tiny voice is as sweet and flute-like as that of a child. The words which he may liave been taught to speak are uttered very distinctly, and are clearly understood. He learns to speak long sentences, like the Gray Parrot, and displays that birl's aptitude in saying the right things at the proper time.

As a pet for the family, the Dwarf Parrot stands, perhaps, at the head of the whole bird-list, - certainly at the head of the Parrot-list. He becomes attached to anybody who offers him little dainties, or strokes and caresses him. He is always a great favorite with ehildren, and appears to know that he bears somewhat similar relations to his own race that children do to theirs, and therefore loves to associate with his peers. He will play hide-and-go-seek with a party of children, and enter into the sport with an ardor equal to that of the most playful boy. He does not require a cage, and should be allowed the freedom of the room: this may be allowed him in safety; as he is not at all destructive, and does not care to take the ehance of obtaining his freedom. He will salute his master at daybreak with a eheerful "Good-morning," and add "I trust you are quite well," and act dissatisfied until taken on the finger, and had a caress or kiss bestowed on him.

Sometimes Dwarf Parrots are kept paired; this does not interfere with their powers of speech, as the male and female learn to speak with equal readiness; and a conversation carried on by a pair of well-taught birds is sometimes most enjoyable. When caged they should have plenty of room; as they delight to climb around, and are as much at ease hanging head downwards as when standing on a perch.

Unlike the rest of the Parrot family, they are fond of bathing, and enjoy a bath as well as the most fastidious songster. While performing their ablutions they utter their miniature ehirps of delight, just like a party of small boys mastering the art of swtmming.

In their wild state, they subsist chiefly on fruits and small seeds.

When caged, the best mixture is equal portions of canary and hemp seeds. A piece of sweet apple or ripe fruit should be frequently given them.

They are seldom attacked by sickness, and live from fifteen to twenty years. Constipation, or any otler mild disease, should have the same treatment as recommended for Canaries. 


\section{THE MACA W S.}

Tuese magnificently colored birds are the largest of the Parrot species, and are alike famed for their beanty and intelligence. There are three varieties of them, easily distinguished from one another by the differences in colors. Of these, the Scarlet, or Red-and-Blue, Macaw is probably the best known. Of the same nature as other Parrots, they are equally as mischievous in their ways ; and when not tamed, and carefully confined, the range of destruction may include any thing in house-furnishing from a teaspoon to a piano-leg. A jeweller who owned a Maeaw once had several watches cleaned out on time. The large, powerful beak is indeed a dangerous weapon, as was fully verified by the Down-east boy, who, when inclueed to put his finger in a Macaw's mouth to feel for his eye-tooth, quickly withdrew it, exclaiming, "The euss can bite like a hoss!" Although naturally destructive in his habits, and possibly not a friend of some lady member of a family whose piano he attempted to devour, the Macaw is withal a very sociable bird, and will attach himself to his master with the fidelity of a dog: indeed, he seems to hear the same relation to the race of birds that the Newfoundland does to the dog family.

His intelligence is remarkable; and when tamed, - an easy matter by the way, - and trained to talk, he is held in the highest estimation. His voice, owing to his size, is naturally very gruff : although, when brought within the range of children's or ladies' voices, he quickly imitates them; and the different tones are committed to memory, and uttered at the right moment. The street-vender of oranges and fruits, and the buyers of old rags or bottles, are special favorites of his ; the tones of voice employed by these artists being, in his estimation, the standards of excellence as high tenors and sub-basses. Many times in the course of a day he will bring the busy housemaid, desiring to buy or sell, to the window or door, only to be laughed at by the mischief-loving bird for her pains.

His loud, gruff squawks are easily stilled if a sufficient supply of food is kept before him; if hungry, he will make himself heard in a disagreeable manner, which has probably given him the reputation of not being a desirable house-bird; but when he has sufficient food, which he can peek at, at his leisure, he will always remain in good-humor: and whether it be in singing a song, which shonld be pitched in a very high key, in his amusing bass voice, or vending imitation or'anges, he remains as solemn looking as a hypocritical deacon. If a pair of spectacles were placed on his ample nose, and a red bandanna put in his claw, he would, indeed, make a model-looking sensational preacher.

The Maeaw's age, like that of a well-preserved, hair-dyed old gentleman, it is impossible to tell. After attaining full growth, the younger members resemble the 
old veterans. Certain it is, however, that Macaws attain the greatest age of any known species of eage-bird; it being on record, that one lived in a royal family for more than a hundred and fifty years.

The Scarlet Macaw is about two feet and three quarters long, of which more than one foot belongs to the tail. His stretch of wing's is enormous, being abont four feet. The head, throat, breast, and belly are scarlet: the feathers of the neck and upper part of the back have a greenish edge, which becomes broader lower down. The niddle and lower regions of the back, the rump and lower taileoverts, are a beantiful sky blue; the upper feathers of the wings are scarlet; the middle, hinder, under, and shoulder feathers green, the latter shaded with red; the front wing-coverts are ultramarine on the outer web, and on the inner pale red. The same is the case with the inner wing-coverts: the middle tail-feathers are more or less red, the inner web of the quills black. On the naked, flesh-colored cheeks, which look as though powdered with white flour, are five or six rows of little pencil-shaped red feathers, implanted near the nostrils, and ranged around the eyes. 'The beak is very large and prominent, and is of a clear horn color, black at the point and edges, as is the lower mandible: the eyes are yellowish white, the feet blackish gray, and the claws brownish black. The two sexes are alike in color: the young birds are more delicately tinted than the old ones.

The Macaws are found in the swampy forests of South America, where they are industrionsly pursued by the natives, for the purpose of making ornaments from the beautiful plumage, and for the flesh, which is said to be very delicate. The birls always fly in flocks, and, if separated, always pair off, the male bird ever remaining by the side of his mate.

The Blue-and-Yellow Macaw is a very beautiful bird, of the same size as his scirlet cousin. The prevailing colors are a handsome shade of bluish green abore, and orange below. He inhabits the northern parts of South America. His habits are the same as the above.

The Green Macaw is smaller than the preceding specimens, being only two feet in length. The prevailing color of the entire body is grass green; over the forehead passes a thick band of bright red feathers; the tail-feathers are very long, being bright red at the roots, and tipped with blue. The Green Macaw is not so often seen as the other two.

Macaws should be fed, in confinement, mostly on moistened food, bread or crackers soaked in milk being the main food; they will also eat corn, nuts of all kinds, and fruits, such as bananas, oranges, or apples ; they are very fond of these, and should be given some daily. The food should be always kept before them, and whenever eaten should be at once replenished: if not, they will make it known by a succession of squawks, continued until their desires are gratified. Meat, sugar, or sweetmeats are very unwholesome for them, and will cause them to pluck the feathers out in such a manner as to completely destroy the plumage. This is a liabit due to a disease of the skin, caused from feeding as above, and when once practised cannot be cured. Macaws drink but very little, owing to the moistened condition of the food. They are very hardy birds, and are rarely attacked by disease. Diarrhea is the principal complaint with which they are affected. When this is noticed, soak the bread in sherry wine or brandy, which should be cliluted with water. 
When it is desired to eage them, eages only of the largest size and strongest construction must be used; as the powerful beak is capable of demolishing almost any thing short of brick and cement. A special cage is made for Macaws, of brass and iron. A stand is much more desirable, however; as it allows more freedom, and does not hinder the bird from moving around with his unwieldy rudder, which is a source of constant trouble to him when caged. The regular Parrot-stands, with or without cage-covers, are used. A common stand may be made of gas-piping, in the shape of the letter $T$, which would do very well. It is better to set this style of stand on a circular zinc base, which should be plentifully sprinkled with sand or sawdust.

Macaws are very fond of a bath, which should be given in the form of a showerbath. A favorite way is, to attach a lawn-sprinkler to the hose, and play it directly on him. He will manifest his pleasure in loud, ear-piercing shrieks of delight, and shake himself dry with the vigor of a dog. This should be done only in summer: in winter, lukewarm water may be showered on him from a sprinkling-pot.

A handsomely matched pair of Scarlet Macaws, very tame and talkative, were valued by their owner at a thousand clollars. 


\section{THE COCKATOOS.}

Is an exhibition where there are a thousand birds competing for attention, one attracting by his gay plumage, another by his sweet song, a third by his quaint carriage and flight, the largest and evidently most delighted throng of spectator's will be found surrounding the cage containing the Cockatoos. These birds are distinguished by their compact body, short tail, and large, broad beak, with the upper mandible terminating in a strong hook. The tongue is fleshy and smooth, the region of the eye bare, and the head ornamented with a crest which, in the case of most species, lies flat, but can be erected at pleasure.

The plumage is very striking, either on account of its pure white color' or' very delicate tints.

The Cockatoos are found principally in Australia, and also in the Molueea Islands and New Guinea. They eongregate in enormous flocks of fifteen hundred to five thousand birds, and fly over the fields, presenting, with their brilliant colors, a beautiful spectacle.

Australia is pre-eminently the realm of the Cockatoos. And, indeed, it is the paradise of birds. Of the many families of birds belonging to it and the adjacent islands, none are more important or character-

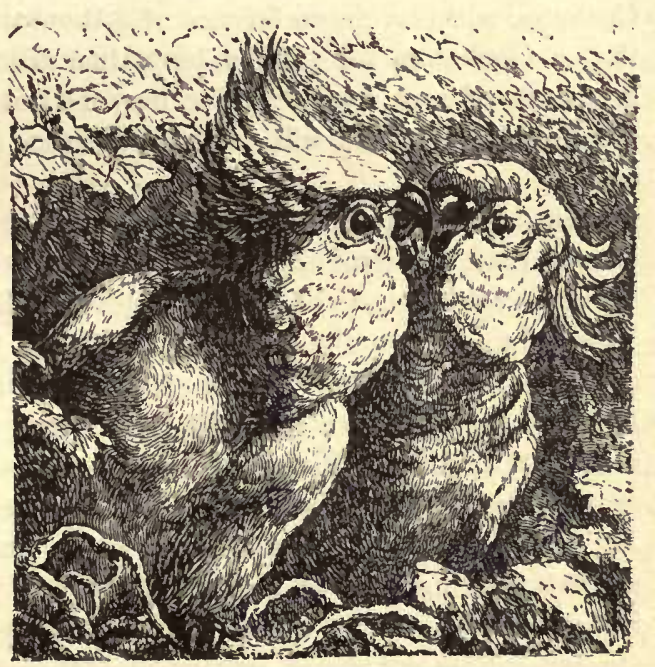

Cockatoos. istic than the Cockatoos and Paroquets. Among the green foliage of the gum-trees Cockatoos sparkle like living Howers, and the rose-colored Paroquets display their searlet plumage among the yellow-bloomed acaeias. The bright-hued Lories mingle with the other birds, and hover about the honey-sweet blossoms. There the Cockatoos fiy abont the streets of the towns and villages, or infest the roofs and court-yards of the houses. When the Australian farmer gathers his harvest, hundreds of these birds throng his fields and farm-yards. To the traveller the speetaele is very pleasing and beantiful; but the farmer whose grains they trample and consume has sworn (leep vows of hatred. and slaughters the gay pilferers without pity and without remorse. 
years old. Cockatoos are cared for and treated the same as other members of the Parrot family, and require the regular Parrot eages or stands. The latter are more generally used, as on them even the largest birds can raise their crests.

TABLE OF THE PARROT FAMILY.

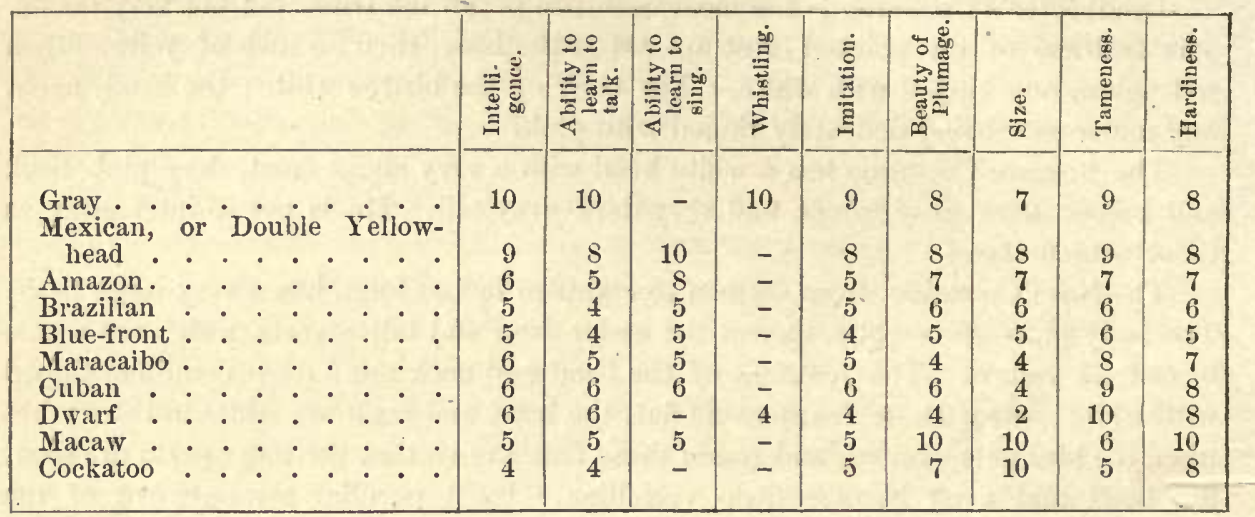

The above represents a comparative table of the excellences of the principal members of the Parrot family. Ten is the maximum figure under each heading, and the total number of points is ninety. These figures are based upon observations made while the writer owned large numbers of the birds named. In some exceptional cases, a member of one of the classes which stands low in the list may combine many of the accomplishments credited to the leading classes. 
Hu

A mb 


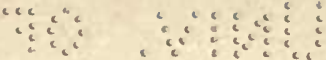

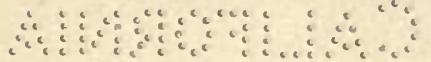

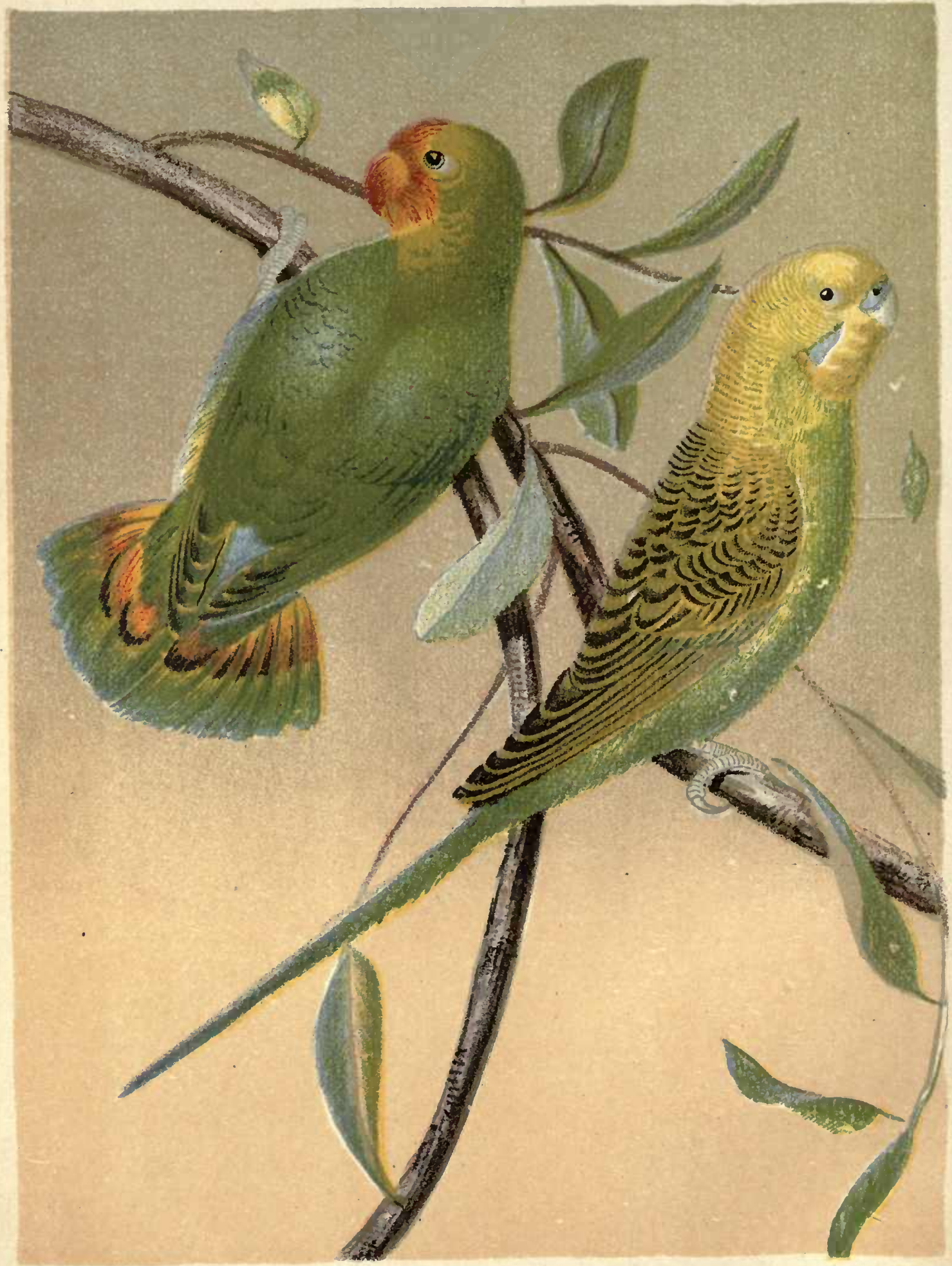




\section{PAROQUETS.}

True Undulated Grass Paroquet, or Shell Parrot, called in America the Australian Paroquet, is one of the handsomest and most enjoyable of cage-birds.

These Paroquets spread over immense districts in Australia, feeding on the seeds of the tall grasses, but breed only in the southern parts, provided the springrains of September and October produce a sufficient erop of grass-seeds. In ease of a drought in the sonthern part of the eountry, the birls migrate north, where tropical storms produce some amount of grass and seeds. It thus happens, that, in districts where one year thousands of Grass Paroquets are caught, not one is ever seen in another year if drought oceurs.

In size, the bird's body is about as large as a Canary's: the tail is very long, so that the full length of the bird is between nine and ten inches. The body is slender and elegantly formed, the tail long and graduated, the wings comparatively long: and pointed, the beak moderately large, with a long, curved point. The feet are long, and the toes slender, the outer one being longer than the inner.

The beautiful grass-green color that predominates in the plumage is prettily marked : the whole of the mantle - that is, the back of the head, neck, top of the back, shoulders, and wing-coverts - is pale yellowish green, each feather being edged and spotted with black or brown, more finely on the head and neek than on the back ; the under side is of a beautiful, uniform green. The parts of the face - that is, the fore part of the head, vertex, and throat - are yellow bordered, and spotted with four bright blue spots, of which those upon the cheeks are the largest, while the others look like three little round drops. The wings are brown; the outer weh of the quills dark gray, spotted with greenish yellow; the tail, with the exception of two middle blue feathers, is green. The female is distinguished from her mate in being somewhat smaller, and by the different color of the nostrils ; the male's being deep blue, while the female's are a light grayish green.

Only within a few years have these birds been at all plenty. In 1840 Gould succeeded in taking the first live pair to England; and, between that date and 1850 . single pairs sold at the extravagant price of thirty pounds. At the present writing, May, 1882 , it is difficult to obtain in America the birds that are imported from Australia; as thousands are now bred in different parts of Europe, the greatest numbers being bred in the Zoölogical Garden in Antwerp.

On the plains of Australia, the Undulated Grass Paroquets live on grass-seed; and in confinement they eare for little else than canary-seed, and nothing agrees with them so well.

To tame them is a diffieult task, for the simple reason that the birds are entirely 
indifferent to dainties; and we have no means to tempt their confidence, or to reward them for their meeting our overtures half-way. 'They will not touch sugar, and are not greedy after meat; we may withhold water, and they do not mind it in the least; the only thing they absolutely want, and which we cannot leave them without, is canary-seed, to which we may add a little millet. The only way to tame the bird,

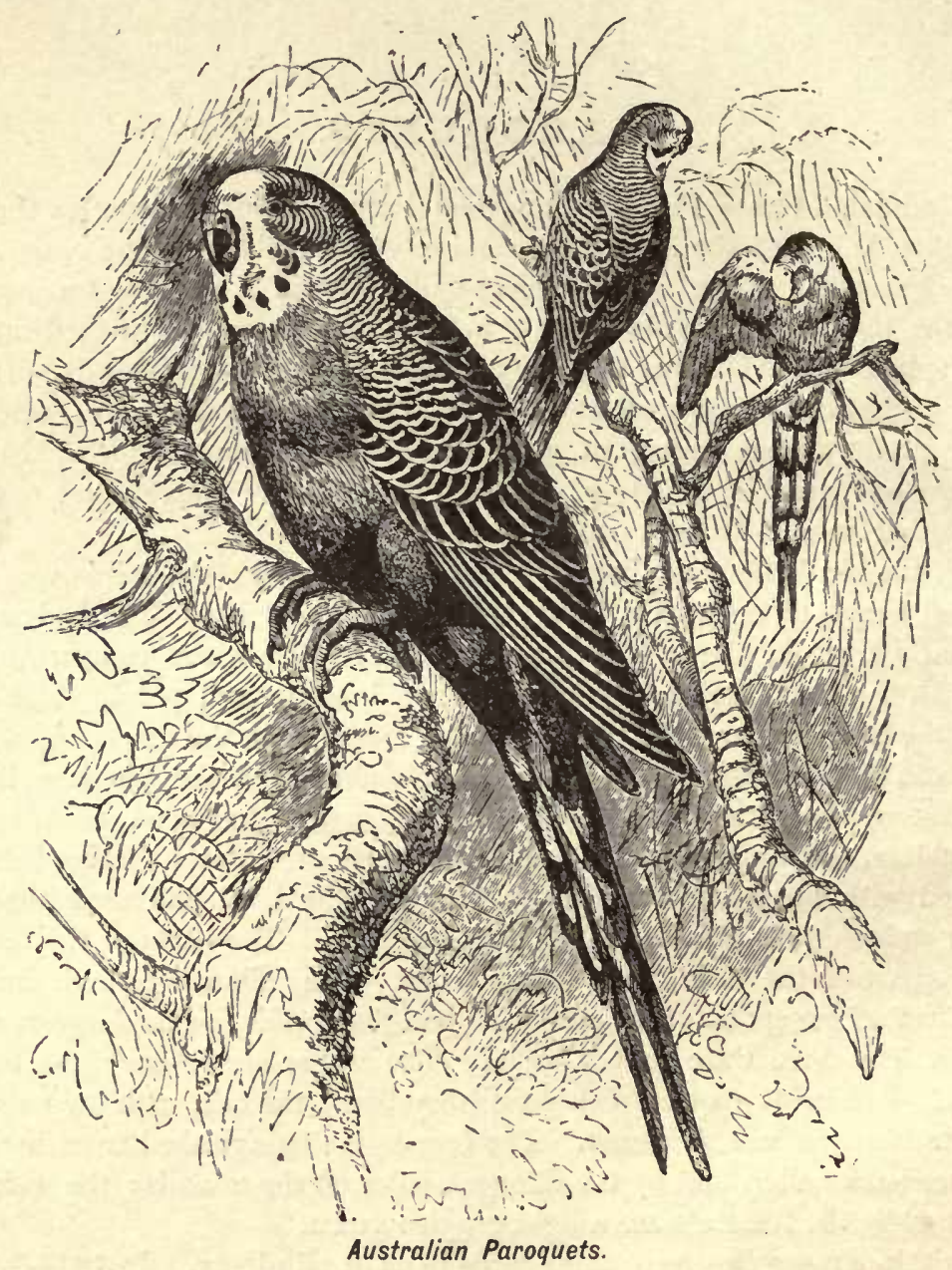

therefore, is by perseverance in regular feeding by the same hand, accompanied by a little coaxing.

These Paroquets never talk, but frequently learn to imitate the song of the Canary and other birds.

It is very easy to breed the Grass Paroquets in confinement. In their natural state, they breed in holes of old trees, or any other cavity; and all that is required is an appropriate nesting-place. Some like the husk of a cocoa-nut, others a hollow $\log$ of wood. They will lay four to seven white eggs on the bare wood, or on a few 
chips of wood, and hatch them in about twenty days, the young remaining about five weeks in the nest.

Some breeders feed the nestlings on egg-food, other's use egg and potato, while a third authority recommends only canary and millet seeds. In breeding, either a single pair should be kept in a cage, or a large number of pairs may be put in a room. Where several pairs are put in a large eage, there are very few young bircls raised ; for some spiteful old "hen " will break most or all of the eggs. 'The newly hatched young are grayish brown, and get in full color only when the feathers are fully grown. 'The pairs breed freely nearly all the year round, when they have onee commenced.

While they may be kept ont in open-air aviaries all the year, and will withstand the cold weather, it is necessary, in order to breed them, to keep them in a temperature ranging from seventy to eighty degrees, or higher.

While, like all other birds, they are very amative under certain eonditions, if these conditions, one of the most important of which is heat, do not exist, they do not seem to care to mate. An aequaintanee had a pair which he kept confined out of doors, and they had never built a nest. He could not understand the reason of this: but when he loaned them to a friend, a noted breeder, the latter put them in his regular breeding-room in a high temperature; the result was, a mating on the third day. Six eggs were laid, but the temperature was kept at ninety-five degrees; and so much attention was given to producing the eggs, that no time was reserved for hatehing them. Both birds seemed to agree that sitting was stupid business. So fond of each other are these birds, that either will die in defence of its mate or home; and so neeessary to each is the giving and receiving of affeetionate regard, that, if a pair is separated in mating season, neither of them will live many days.

It is necessary to be personally acquainted with these lovable little creatures, and to have observed them during the performance of their parental duties, to be able to understand the enthusiasm with which they are regarded: it is only during their pairing-time that we become fully conscious of their many merits. "The male," says Devon, "is a morlel husband; and his mate is a model mother. He devotes his whole attention to his ehosen one, never heeding another female, though she be in the same general nest with him: he is always zealous, devoted, and ardent, - indeed, shows the utmost affection towards his partner. Perched upon a twig before the opening of the nest, he sings her his best song, and while she is sitting prepares her meals for her, and feeds her with as much zeal as pleasure. He is neither dull, quiet, nor sleepy, like many other husbands, but always cheerful."

One hard fact, known to the initiated, rather. weakens Mr. Devon's argument respecting the male's great fidelity: it is, that the male selects a new partner each breeding season.

Of late years, varieties of the Undulated Paroquet have been bred with increasing frequency. Some pure yellow birds have been bred in Antwerp; eren a blue variety has been obtained; and one breeder, earefully selecting the largest pairs, has now a regular breeding of very large birds. It is suggested, that, with a few years more of eage-breeding, there will be produced as many varieties of this particular kind of Paroquets as there have been of Canaries bred from the one kind of original stock. 
The larger specimens are sometimes kept singly when caged, but it is always better to keep them paired. In no other class of birds is the grief at losing the mate so tenderly expressed and slown as in that of the Paroquets.

Probably the best-kuown valriety of Paroquet, after the Australian or Grass Paroquet, is the Afriean Love-bird. This handsome specimen is readily known by the bright orange color of the head: the remainder of the body is clear green, with the exception of the tail, which is tipped by spots of orange and black. The tail, which is short, is spread out like a small fan when the bird is exeited, and gives him an extremely pretty appearance. This specimen of Paroquet is about six inches in length, and inhabits the forests of the eentral parts of Africa. 'They always fly in large flocks, and when perched in long lines make a striking appearance indeed : they sit so closely together, that they appear like one unbroken mass, instead of thousands of individuals. They are a very hardy class of birds, and thrive in perfect content on canary and millet seeds.

It is commonly supposed, that the means of distinguishing the male from the female is by the color on the head ; the male is thought to have the brightest colors; this is usually the case: but the certain way of ascertaining is, to examine the inside of the wings ; the entire inside of the male bird's wing is of a brilliant violet black; while the female bird is plain green, the same eolor as the remainder of the body. It is said that this varicty of Paroquet eannot be bred in confinement. Whether it has been attempted in a scientific manner I do not know : however, I know of no reason why they could not be bred as easily as any other specimen. They make very pretty and desirable pets; being used, in addition to aviary purposes, for the sick-room, where they become great favorites, their tender affection and noiseless ways affording pleasure to an invalid. They are also great favorites with children, and become so tame and playful that their presence in the nursery is absolutely essential.

They are not fond of dainties, their every desire being centred in the plain canary-seed, which should be their ehief food. For a change they may be given French millet, or even hemp-seeds, mixed with the eanary-seed. The most suitable cage for parrs is the all brass, $10 \times 13$ size. The Red-faced birds larely ever bathe, although they remain in perfect plumage throughout the year. They take great pride in arrangiug the feathers, pluming and stroking one another with great frequeney. It is a good idea to give them a slower-bath of lukewarm water at intervals, which will greatly add to the beaty of the feathers. When allowed their freedom, they rarely attempt to escape, seeming to appreciate the favor granted then.

The diseases to which they are subject are few, the chief being decline, which is - usually brought about by the loss of a mate or by old age. They will stand a good degree of cold weather, being somewhat hardier in this respect than other members of the family, and are thus suited for the outdoor aviary.

When attacked with sickness, which shows itself by the rough, disordered appearance of the feathers, and hiding the head beneath the wing, the bird should at once be removed to a very warm place, and fed on crushed hemp : a few drops of sherrywine should be added to the drinking-water ; and, when it is not voluntarily taken, the bird should be caught out of the eage, the beak gently opened, and the dose administered with a spoon. 
'The Madagascar Love-bird, or' White-headed Paroquet, is another common variety: they are much sought after as cage-birds, and, although not as handsomely colored as the Red-faced Love-bircis, are, withal, very desirable cage-birds. They are not quite so large in size as the Red-face, but equally as hardy and capable of being as well trained. They breed freely in confinement, which fact has made them great farorites with the class of fanciers who like to breed odd speeimens.

The uniform color of the body is plain green, and the neck and head of the male bird is a pale silver-gray : the female is green throughout, being a somewhat darker shade on the head than on the remainder of the body.

Pairs construct their nests in a curious manner: they will tear wood into small strips, and, placing the strips in the middle of their backs, will bear them to the hole selected for the purpose. As these bits of wood fall from their backs a number of times duriug their flight, or in entering the nest, great assiduity and patience are exhibited in the course of coustruction.

The food and care should be the same as that of the Red-faced Love-bird.

The West-India Paroquet is a soeiable, plain-colored little fellow, being naturally tamer than almost any other specimen of his class. He is about the size of the Madagascar Love-bird, plain green throughout; the elges of the male bird's wings are tipped with a beautiful tint of dark blue: the female bird is plain green throughout.

I have heard Paroquets of this class that were most exeellent talkers. 'They are probably the most diminutive speech-makers kiown: they are brought from the West Indies and South Ameriea at certain seasons of the year, in large numbers, and are quickly disposed of ; as they are the cheapest of any class of Paroquets, and probably the most intelligent. I lakl a promising specimen of this variety, who rejoiced in the name of Tommy.' His great failing was his intense love of butter. Tommy would forego any pleasure for the sake of it, and, if not closely watched, would indulge in a bath of it for the sake of having a stock of it on hand : after rolling in it, he would sit on his perch, and draw his beak throngh his feathers, and plainly betray the great pleasure his favorite dish gave him. His greed for the article was the meaus of his death, as it bronght on a skin-disease which conld not be cured.

There are a great many other kinds of Paroquets commonly kept, for which the treatment and care are the same as given for the above three kinds. The limited space of this work prevents a fuller enumeration. 


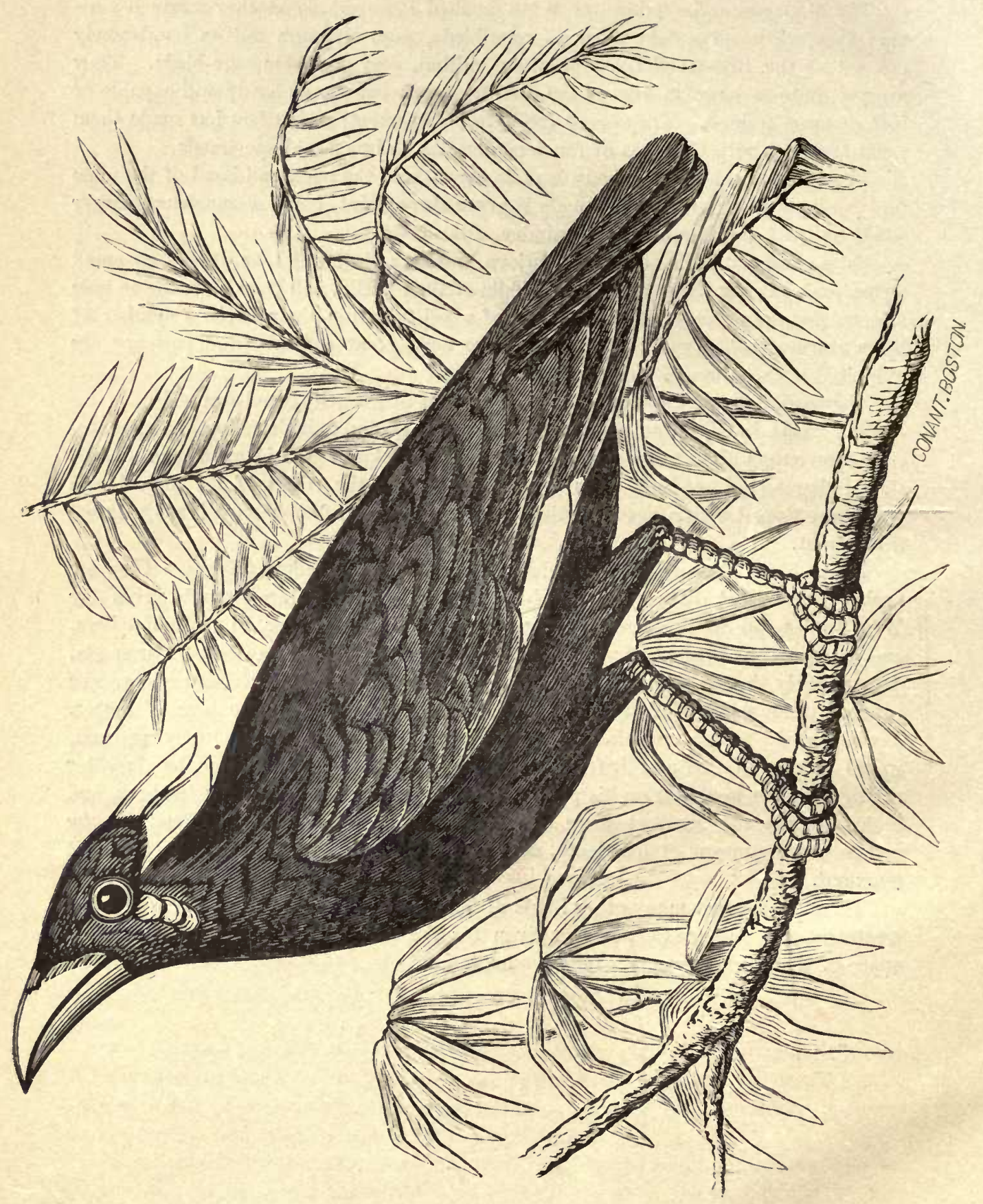

The Hill Minor 


\section{HILL, OR ROCK, MINOR.}

'THIs bird has a different name in every book that refers to him. Some writers call him the Mina; others, the Mino; while Bechstein gives him the full title of "The Minor Grackle."

The Hill Minor, or Musical Grackle, is ten inches long, and about the size of a small dove.

'The plumage is glossy, and of a rich black, shading into violet and purple, according to the light and position the bird is placed in, in reference to the observer. 'The wings and tail are black, the former having a broad bar of white formed by a series of quill-feathers tipped in such a manner as to show a solid color. Appended back of the eyes, and passing over the ears, are bright yellow fleshy flaps ealled caruncles. The naked space under each eye is bright yellow. The beak is a deep orange, and the feet are yellow : the eyes are a beautiful hazel, and express, in a trained bird, great intelligence.

Many authorities class the Minor in the Starling family, and perhaps not incorrectly. He certainly closely resembles that family of birds in both his physical and mental qualities : especially is he akin to the Common Starling in lively manners and inquisitive disposition. In the estimation of persons familiar with both birds, the Minor is considered a plainer and better talker than any of the Parrot species. His powers of imitation ean be so highly developed as to render him a most interesting study if not a real companion. Not ouly is it my own experience, but also the experience of bird-lovers in many widely separated countries, that the Minor, more than any other bird, acquires mental traits quite like any one with whom he may for some months be brought in contact.

A lady friend, who was for many years a missionary in the East Indies, had a Minor. which she kept in the chapel. At certain seasons of the year all the children of the neighborlood were accustomed to enter the chapel at six o'cloek in the evening, and intone the Lord's Prayer and the Ten Commandments. Judge of the lady's surprise one evening, when the children were later than usual, to hear her Minor commence with the prayer, and not stop until he had repeated it and the commancments.

Excepting the human family, this is the only talking species which will reply when spoken to. The finest-talking Parrots are generally silent when one wisles them to talk; and, the more they are urged to speak by being questioned, the more silent and attentive they become. Not so with the Minor, for he is ready to talk with every one who will listen. A famous bird kept in a down-town hotel in New York a few years ago, was well known to all frequenters of the locality. When 
any one came into the office, he would ask, "Will you have brandy and water?" and, to a second person, "What shall I mix for you, sir?" adding, "Please make mine straight." It is said that bird could speak two humdred words, and would answer correctly any ordinary questions pertaining to himself or the office.

A Minor which the writer owned some years ago detested a series of questions: and, if any one persisted in repeating a question once answered, he would eurse and swear, and fly about the eage as though in a great passion. 'This bird possessed. in sn extraordinary degree, a sweet, clear voice for whistling, and seemed to take great pleasure in rumning the chromatic scale, giving the full tones and the intermeliates, both ascending and descending, with perfect accuracy.

A well-known New-York journalist possessed a bird of this class, which accompanied him around the world, and was his constant companion in his various wanklerings. The bird, which was a present from a lady friend, possessed a fine musical and spiritual education. He could whistle several hars of operas, and repeat various selections from the good Book when first presented; but constant association with evil-mouthed servants cansed him to deviate from the straight path, and he became a living example of the effects of bad company. Minors, like Parrots, easily learn bad language: whether they are sinners by nature, as vicious boys are, I do not know; but it is most certainly a fact, that two bad words are learned with pleasure when one good one is a hard study.

The owner of the above Minor, being desirous of showing his bird's accomplishments off before a religious lady, was putting him tlurough his course of instruction, and had reached an interesting part of the conversation, when the bird, espying the friendly servant, abruptly changed the course of remarks by dwelling on subjects disagreeable and most untimely.

He horrified his hearel's by yelling, "Take out your false teeth!" "Pull klown your vest!" and sundry other phrases not at all becoming in such a good bird. His subsequent presentation to a Sunday-school teacher betrayed the regard of his former owner for his friend. But his new owner, on taking the bird, concealed in the breast of his coat, to the church, had no occasion to be thankful for his gift. He expected to show naughty boys how even a bird could repeat the general confession; but the Minor electrified the congregation, and startled the good preacher. by politely asking him to wipe off his chin.

All Minors do not make talking-birds, but whether or not one will learn to talk may usually be determined by the attention which the bird pays his teacher: when once trained to speak a word or two, the remainder is an easy matter. The words first taught him should be easy of pronunciation; and the words "Mino" or" "mother" are usually the first which he is capable of pronouncing, as they seem to exactly suit his style of voice. When talking, the Mino's enunciation of the Indian and English languages particularly is plain; and the inflexions are correct if the teacher has done his full duty. His imitations of various animals are remarkably clear and correct, and his whistle is marvellously pure and sweet. A Minor which had been hung as an ornament in a wealthy man's window rendered the owner of a dog, and the dog himself, two crazy beings by his mocking whistle.

He is a natural mischief-maker, and his tricks at hide-and-go-seek when he finds a shining article will rival those of the Crow family in their eunning. Tie a gold 


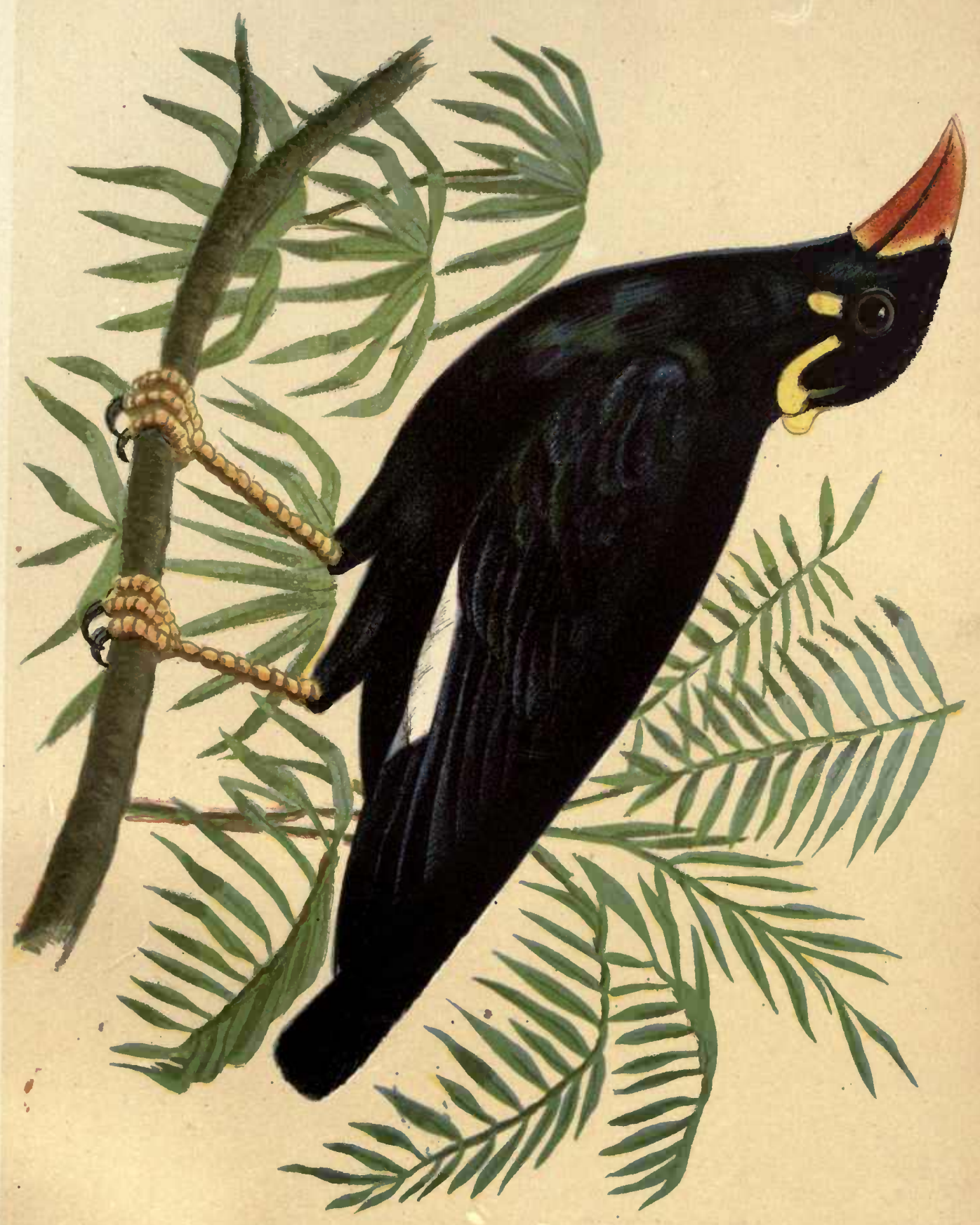




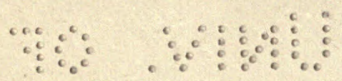

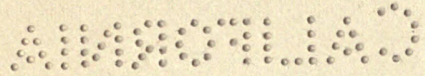


ring, or any shiny article, to a piece of string, and attach it to his cage, and he will play with it for hours: it gives him as much delight as the infant has who tries to make two dogs out of one by separating the animal's tail from his body.

When confined in the elimate of England or America, so much colder than that of his native land, the bird needs a more hearty diet than the boiled rice. He will eat almost every thing, but keeps in the best condition on the regular prepared food. If the moist variety is used, raw carrot should be grated, and mixed in with it, at least once a week. Lean, raw beef, scraped fine, may be given twice a week. There is little danger of overfeeding: after the bird has partaken of a large meal of his regular food, he will accept and thoroughly stow away any number of mealworms, spiders, grasshoppers, and other insects. It is quite worth while occasionally to give him an extra "spread" of this kind, to see the look of sweet resignation and ineffable happiness his eountenance will display. As with men under like outward pressure, it is then really that a strong sense of his own greatness seems to ery out for reeognition. Only web-footed birds are more foud of a plunge than is our Minor. The tub, too frequently offered, is almost sure to result in eramps for the bird. Let him bathe, not more than onee a day, and every other day is still better. Let an abundance of gravel be strewn in the eage to help him digest the heavy meals. 'Two or three hours of sunshine will have a tendency to keep his plumage glossy and brilliant. With proper treatment he will live from fifty to seventy-fire years. The only ailments to guard against are constipation and indigestion, which are eured by feeding banana or orange. In some cases a dose of olive-oil is necessary.

The Minor sometimes alarms lis owner by attempting to stow away in his erop a pebble of larger dimensions than ean be swallowed. If not attended to, the bird might gradually choke to death. A ease of this kind demands prompt action : eatch the bird, and, holding him firmly in the hand, administer a strong dose of eastoroil, meanwhile rubbing the bird's throat gently in order to work the obstruetion into the erop. His diet should, for a few days after, consist only of the richest foods. The difference in the sexes of Minors cannot be clistinguished by any difference in their capabilities of learning: males and females seem to equally possess talking powers. Minors are not plenty, for only one or two speeimens at a time are imported by the sailors. No regular importation of them takes place; but single specimens of young birds, or birds which have a partially acquired education, may be found for sale oceasionally.

The Mud Minor, so called to distinguish him from the Rock Minor, is an inhabitant of the same countries as the other variety, but lives only in marshy or swampy tracts of ground, and is of the same nature as our native marsh-birds. Although I have seen several specimens, not a single bird seems to possess the vocal powers of the Rock Minor. They are somewhat smaller than that bird, and lack his brilliant plumage. The beak: and feet are of a pale yellowish color, and the entire body is of a dusky green color.

Only the longest enges, twenty-four to thirty inches long, with perches arranged to permit long jumping for exereise, is proper for either class. Gravel should be used for the purpose of keeping the cage clean, as well as to aid the bird's digestion. 


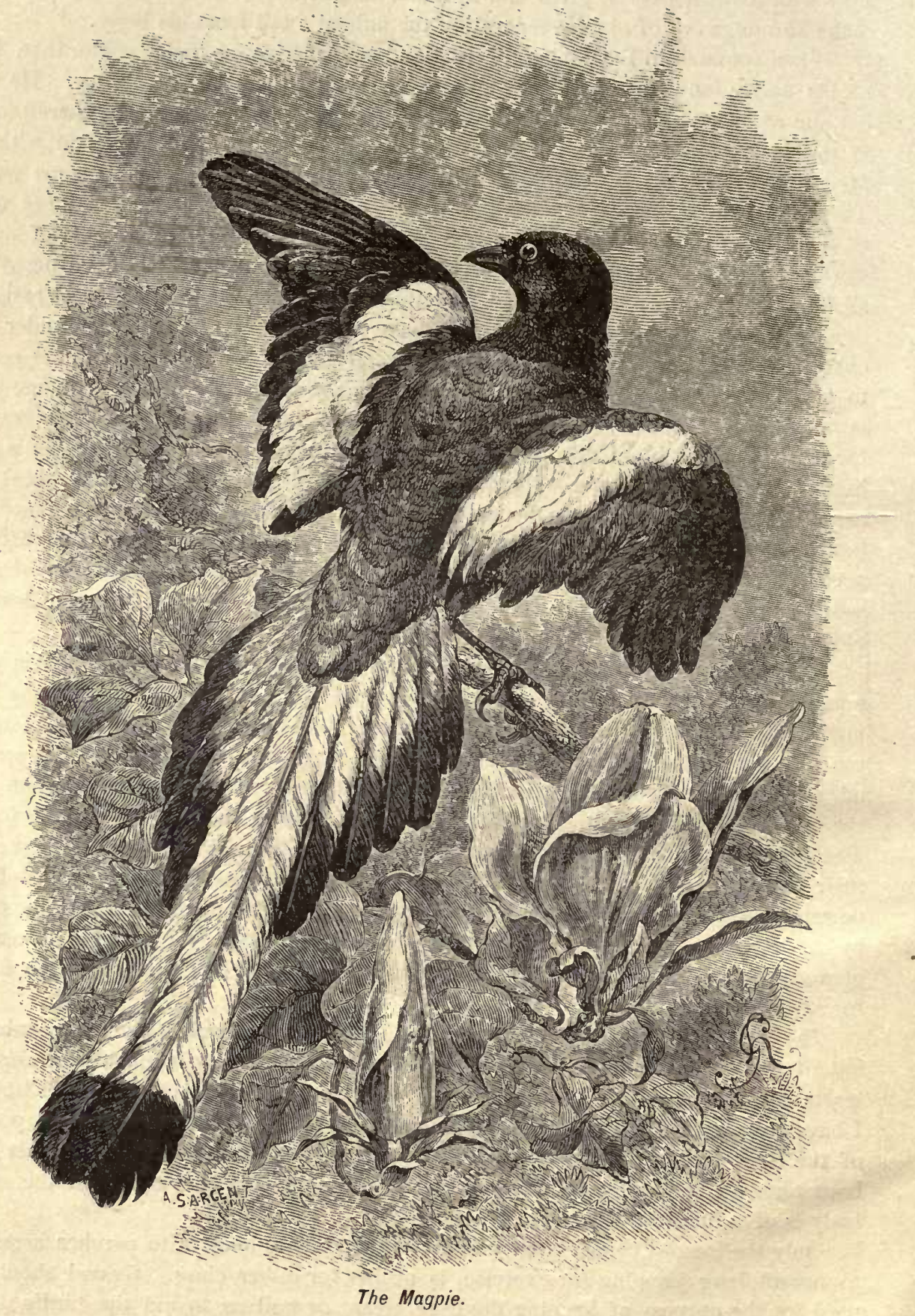




\section{A G P I E S.}

Truese clowns or monkeys of the bird-race are found in large numbers in many parts of the globe; and, although divided into numerons classes, they are alike in being very intelligent, and combine with it a large amount of mischief. Magpies, when wild, have all the cunning and mischievous qualities which exist in our well-known neighbor, the Crow. The Magpie has a great many virtues, which in a manner offset his destructive qualities; while his many droll tricks and talkative disposition make him respected in bird-circles. As a humorous pet, when confined where he can do no injury to articles of jewellery or bric-ci-brecc, he has no equal. He has been made the subject of verse and prose, certainly since the time of Chancer. His sedate walk was frequently referred to as worthy the imitation of the prourl wives of ye olden time, while the many anecdotes which have been related of his crazy antics would fill a funny story-book.

The species of Magpie most commonly seen, and which is represented in the plate, is about the size of a Pigeon, but more slender in shape, and having a long tail, the entire length of the bird measuring eighteen inches. 'The colorings of the plumage, although simple, are very handsome; because they are so uniquely arranged, and blend so charmingly. The black and white are exceedingly clear; and the conical tail is tipped with a purple tinge, which passes into steel blue.

In the European countries the Magpie is well known, and, more than any other wild bird, frequents the habitation of man. By his depredations in the fields and poultry-yards he has incurred the hatred of farmers, who take all opportunities presented of lessening his numbers. His humorous tricks are any thing but laughable to the honest tillers of the soil, and poultry-fanciers ; as he will sit with impunity on the head of the most skilfully constructed scarecrow, and, in his tender solicitude for the welfare of a brood of young chickens, eat them in order to protect them from future dangers.

The Magpie builds its nest on trees close to human habitations, and generally lays four or five whitish-green eggs. The nest is a marvel of its kind, and, besides showing an immense amount of ingenuity in its construction, is built on the plan of a fortress. It is surrounded by thorns, which serve as a means of defence against egg-robbing boys, and has a small entrance in one side just large enough to admit the occupants ; so that a liberal use of a stout knife or an axe is necessary in order to obtain the eggs. The nest is covered with a dome of thorns, respecting which a curiously quaint fable is told.

As a bird-architect, the Magpie is grand master of the craft, and the Rook a very poor nest-builder. Once the Magpie undertook to initiate the Rook into some 
of the higher secrets of architecture. When the lower part of the nest was made, the Rook, so the legend states, seeing it to be so far very like his own, said in his conceited way, "I see nothing wonderful in this : I knew it all before." - "Well! if so, be off to do it: you want no teaehing," said the Magpie in a rage, and would never after show him how to roof a nest, to put in a doorway, to floor it with clay, or to earpet it with hair and wool. So the Rook still has his old uncovered, unlined nest.

The anecdotes which are related of his thieving propensities and trieks are amusing, and show an amount of mischievous intelligence which would searcely be believed unless one is thoroughly aequainted with the bird.

When taken from the nest, and reared by hand, the Magpie becomes as tame and affeetionate as a pet $\log$, and will be found continually at the heels of his owner, looking for a gentle stroke or earess, much after the manner of an overfed kitten. He is often difficult to get rid of, and will follow his master through the country, in and out doors, displaying lis affectionate regard so far that he beeomes a veritable plague. When a bird has become so thoroughly tamed, it is always better to seeure him where he will not be at liberty to follow; as his attentious and mischievous pranks often place his master in embarrassing situations.

It is related of one which was a great pet in an Euglish family, that he found a malicious enjoyment in pecking at the unprotected ankles of little boys not yet arrived at the dignified age of werring shoes and stockings and long trousers, and was such a source of annoyance, that a vigilance committee was selected from among their number; and they had nearly completed their plaus for his execution when he was forcibly detained in his eage until the trouble was over. He was a terror to the female servants of the household; and they were forced to pass his hiding-place armed with a broom, in order to protect themselves from his attacks. One of the servants, having neglected this preeaution, was actually found sitting on the floor with her dress gathered closely around her feet; the Mağpie triumphantly pacing around her until aid was brought, and the bird driven away.

It is also related of one which had a great penchant for biting to pieces any papers that came in his way, probably because he lad perceived people valued them, that one Sunday morning, after the family had returned from ehureh, the rector found his study strewn with pamphlets, torn newspapers, and sermons that seemed to have been thoroughly digested; so that he thought, until the marander had been discovered, thieves had actually been in the house. If your rector has turned the barrel of sermons over, to deliver them again, give him a Magpie.

Another Magpie was smuggled into the chapel of Oxford College, and remained perfectly quiet until the service had begun, when he gravely stalked up the aisle, bowing, and saying, "Pretty Maggie! Pretty Maggie wants a glass of whiskey!" much to the amusement of the innocent (?) students and the discomposure of the worthy divine.

It is said that Magpies are capable of counting; and a funny anecdote is told of one which could eount three, but not four. The bird in question was found guilty of stealing chickens from the barn-yard, and it was thereupon resolved to shoot him. A man hid himself in a lut near the bird's nest for this purpose; but the bird observed him, and flew away; nor would he return until his enemy had departed. The 
next day two men entered, and one eame out; Mag was not to be cheated; he waited nutil the second left also. Then three went in, and two came out, with the same result ; finally four then entered, and three came away ; and the bird went back, and was shot, which proved how far his powers of counting extended.

A Magpie never seems to be happy unless he possesses a hiding-place wherein to deposit his ill-gotten goods, and he always displays great uneasiness if any one approaches his treasure-cave.

Many a trinket has been snatched from a lady's jewel-case by a tame Magpie, and securely hidden away in his safe-deposit vault. Nests have been found containing thimbles, scissors, gold rings, silver spoons, bracelets, and many other articles of value, evidently stolen to use as decorative bric-ì-brac, and perhaps, also, that the young Magpies may early be taught by object-teaching to become adept pilferers.

In Ireland, Magpies are called Protestant birds; beeause they came there in the reign of Queen Elizabeth, and because they are chiefly found in the chicken-rearing, English-peopled part of the island.

As a bird of omen the Magpie, or a number of them, suggested the old couplet, -

"One for sorrow, two for mirth,

Three for a wedding, and four for a birth."

The bird eannot be surpassed as a clown, and seems always to be bubbling over with fun. If his depredations can be guarded against, he is altogether enjoyable: he seems to take pleasure in entertaining children, and apparently really thinks out new and striking funny parts, that delight by their quaintness and originality. He talks and laughs, and does the hide-and-go-seek, all so childlike, that a listener who did not see the bird would say there were only a number of five-years'-old girls running and screaming. No matter how bright and quick-witted the children may be, our Magpie is always the leader, the children the followers.

Magpies which have not been reared from the nest are not as capable of learning how to speak as the nestlings, or those which have been reared by hand. When brought up by hand they easily acquire the power of speech in the same manner as a Parrot, and the resemblance which the Magpie's voice bears to the lruman voice is very striking. In some parts of Germany and England they are regularly trained, and placed as attractions in the inns of villages, where they often startle a eustomer by telling what he should drink, and by making remarks on the extent of his purse, or ehaffing him sharply on his personal appearance.

The bird should at first be taught words with a few letters, and which slould be uttered in a sharp and distinet tone: such words as "Mag," "Crow," "Hello," "Jack," are the best. The Magpie learns readily; and, as soon as he finds out the reward which awaits him after his lesson, his ambition to become a trained linguist often cools the ardor of the teacher giving the lessons.

It is also a sad fact, that, no matter how well taught a Magpie may be, his monkeyish disposition remains with him; and, if asked where some missing article has been concealed, his answers are such as to lead one to suspect that he would be a good subject for court-business in the way of a paid witness. The above are the 
leading characteristies to popular favor which are possessed by the bird known as the Euglish Magpie.

The Australian Magpie is a bird of which little is known; but, wherever seen, he is regarded as the most intelligent type of his race. He is as large as the Raven, and similar in shape; and his colors are like those of the English Magpie. His disposition is like his English cousin's, but his powers of speeeh are much greater; and, when well tanght, he is as good a specimen of the talking-bird as the best-trained Parrot. His sociability eannot be surpassed; and, on entering a lousehold, his first acquaintances are the $\log$ and eat, which either peaceably become his friends, or are fought into submission. His innocent ways deceive even the most cunning eat; and, if pussy endeavors to take a quiet afternoon nap, her slumbers we sure to be interrupted by wide-awake Mag. He will pull the cat's tail in a most annoying manner, and is never detected as the assailant; because, after committing the act, he is always engaged in some innocent work, such as pluming his feathers, or eating his humble meal. Many anecdotes might be related which would surpass those given of the English Magpie. One is especially worthy of mention : A family in Maine owned a very tame and talkative Australian Magpie; and whenever they had eallers the servant was instrueted to lock the bird in a closet, as his unseemly remarks were very inappropriate at times. 'The spiritual adviser of the house made his weekly eall one afternoon; and the servant, according to instructions, put the bird in a eloset reserved for him, which happened this day to be in the room used as the reception-room. The minister had seated himself, just after the mistress of the house had greeted him cordially, when a voice, which seemed to come from the wall, half angrily, half beseechingly, cried, "Say : Hello! I know you: that racket won't work. I'll tell the master." 'The holy man startled violently, and was greatly diseoneerted and somewhat alarmed, but was finally quieted by the explanation of the mistress of the house, that it was only a bird, and he was shut in the eloset. The bird was afterwards consigned to the cellar when a caller was announced.

Magpies are very easily cared for, and really require no cage: but as much freedom as possible should be permitted. Any coop or large-sized eage is sufficient to restrain them when it is necessary to punish them for some ill-timed trick. The food nay be as varied as that enjoyed by the human family. The principal article should be the prepared Mocking-bird food; besides this lie will live on almost any thing; bread, meat, and seraps from the table, are relished; and he is sure to secrete a quantity, to guard against future want. The family who owns a Magpie can safely go away without providing for the bird, as his larder always has a neverfailing supply.

When confined in a cage it is always better to furnish him with a bright or glittering object suspended on a string; as his mischievous tendeneies are thus diverted, and he will play with the object in preference to following more destruetive pursuits.

The Magpie, then, may he considered one of the most amusing and hardy of the bird-race. His maladies are few, and easily cured. He may be set at liberty at all seasons of the year, and usually lives his allotted days, which last from fifteen to twenty years, having an amount of fun greater than that enjoyed by any other living creature. 


\section{RAVEN, CROW, ROOK, JACKDAW.}

THe above quartet of Ethiopian comedians is known in both the New and Old Worlds. Their mischievous pranks aud sagacious tricks entitle them to the leading places in the line of birds whose acts are amusing. 'They are all naturally very tame, and seem to delight to be near the habitation of man. Their thieving propensities are known to everybody who has been unfortunate enough to give them the opportunity to steal. They seemingly know the difference between gold and brass, and, like all clever rascals, give the preference to the former. 'There are, no doubt, more amusing and almost impossible stories related of these four birds than any other four in the bird-calendar.

'They are not the proper birds to place in an aviary; because of the numerons chances it would afford them of hiding the smaller birds in undiscoverable places. 'They are often caged when young with a view of teaching them to speak, which is sometimes successful.

'The Raven, of all birds, is most widely distributed over the surface of the globe. He measures two feet in length, of which the tail measures about nine inches. The whole bird is a deep black color, the upper part being tinged with purple, the lower part and tail with green. The beak is high, round, and shaped like a dagger. The tongue is very broad, which accounts for the ease with which he learns to speak. Some persons in Europe eut the string of the tongue, with a view to facilitate the utterance of sounds; although I think the operation entirely unnecessary, aud nothing more than an ancient, useless custom.

The Raven builds his nest in the highest trees of a wooded country, almost inaccessible to the hands of the egg-stealing youngster. The young, in order to be tamed, should be taken from the nest when about fifteen days old; and as they will eat almost any thing in the shape of meat, fish, or scraps from the table, the difficulty of raising them is slight. In Germany they are favorite birds with innkeepers, who conceal them in cages where they may be heard; and it is sometimes amusing to witness the amount of fun one will eause by calling a stray guest a thief, or some other favorite pet name. When allowed to roam at liberty, which is the proper way to keep one, he will become strongly attached to his master, following him around like a pet dog, hopping along to hin when called, and always remembering his own name. He is a very dignified-looking fellow, although he cannot conceal his roguish eye; and his quiet way and sedate walk are no evidences of his true character. He seems to delight in mischief-making, the same as a boy, and merely does it out of pure love for it. He will make chums with the cat or dog, always to their sorrow. If Mr. Raven is around, a nap for the eat is out of the question, even if 
she sleeps with one eye open, for he will give her a sly dig with his beak : and pussy will look around in surprise; and, never suspeeting treachery on her friend's part, she may try it over again, only to receive another sharp blow, and is finally obliged to give up in disgust.

'The bird always has a safe-deposit vault securely hidden, where any olject which he chances to take in his daily wanderings may be found if one is lucky enough to find out where the safe-deposit vault is. One of these nests, when turned out, will be found to contain an amazing amount of bric-ì-brac: and one need never be surprised to find any missing jewellery there; it may contain any thing, from a lady's gold bracelet to a boy's marble.

In ancient times the Raven was held in high estimation for his supposed prophetic faculty. Then the Raven must have enjoyed life hugely; as he was not allower to be harmed, and lived only on the best fare. He is the subject of Edgar Poe's well-known poem. 'The Raven lives to a great age, although he does not turn gray in the process of growing old. The Raven, if turned loose, will take eare of himself, and, unlike the majority of enge-birds, requires little or no attention : his food may eonsist of almost any thing that is eaten at the table. He is also fond of live mice and insects. When a feast is spread for him he never says "nevermore."

'The Crow is a rascally, sly fellow, insensible to the effect of perfectly manufactured men made especially to arouse his fears when in the vicinity of eorufields, and seemingly innocent of the amount of harm which the numerous shot-guns, always in readiness, would have on him. He is known, probably, better than any other bird in our country. Owing to his sagacity in avoiding traps set for him, and his well-known powers of scenting gunpowder, his numbers are ever on the increase, and will probably so continue.

He is the farmer's ehief enemy; although it has been urged in the Crow's defence, that if the number of worms, eaterpillars, and grubs and mice, which he destroys, were put to his eredit, he would not be found to be so harmful to man after all.

The Crow resembles the Raven in appearance, but is not so large: when fullgrown he measures about one and a half feet. The whole plumage is black, with a tinge of violet on the lower part of the body. He inhabits the woods and fields. and in his wild state lives on insects, worms, carrion, mice, grain, and fruit.

Crows become very tame, and, when certain that they will not be molested, will gather in large troops in the barn-yard in seareh of food. When kept in eaptivity they are very funny; and it is interesting to sit in a corner, and wateh the manœuvres of one when be thinks you are not looking. They may be taught numerous tricks, which they readily learn; and if kept in a eage for a few days, and fed lightly. and then given some speeial dainty, they seem only too willing to repay the kindness by readily receiving instruction. When a knock is heard at the door, the pupil may be taught to alight on the latch, and by his weight raise it, so that a visitor may enter. He will then greet the ealler cordially, as any well-mannered Crow shoukl do. He learns to fairly articulate words, although not so profieient as the Raven in this respect. His love for thieving is on a par with that individual, however; and his look of injured innocence, if aceused of such a crime, is langhable to behold. Many amusing anecdotes are related of this eunning bird. The old story of the 
ancient philosopher who was killed by a Crow dropping an oyster on his head, mistaking it for a stone, is corroborated by the celebrated Watt, who relates, that a Crow caught up a crab, rose with it to a considerable height, dropped it, not on the head of a modern philosopher, who might have fared quite as badly as the ancient one, but on a stone, and then descended to his feast.

He learns after a while to distinguish the different members of the family, and even learns how to tell time, provided the meals are set punctually. With all his f:ults, the Crow is not such a bad fellow: he is, to be sure, no friend of the agriculturist, who would prefer any other singing pet to him; but when tame, and placed where his depredations are not felt, he is as well thought of as any of his kind.

The Rook belongs to a most numerous tribe in Fingland, where he has been the subject of much study by naturalists. The birds live in a semi-domestic state in that country, and build their nests in the immediate habitation of man, and even in the erowded cities. They are probably the most brilliantly colored of any of the members of this family. The glossy black coat is resplendent with purple, blue, and green shadings. The Rook, like his brother the Crow, has an intense dislike of guns, and will take inmediate flight at sight of one. He is a very social bird, which is a natural trait with the entire family.

It was the subject of much discussion in England, whether the Rooks were beneficial or hurtful to the crops ; and an extensive experiment was tried in some of the largest farming districts: a reward was offered for every Rook's head, with a view of exterminating them from the entire district, owing to their depredations in the cornfields. It was the means of driving them entirely from the neighborhood: and for the succeeding three years the erops failed entirely, owing to the destructiveness of bugs and inseets of various kinds. As a consequence, the farmers were obliged to restock their farms with Rooks, as allies to keep in cheek foes otherwise irresistible. He is the earliest abroad of all birds; and, when the dew is on the ground, he may be seen searching after worms and insects. He is almost as large as the Raven, being nineteen inches in length, and resembles that bird greatly in his curious anties and mischievons pranks.

The Jackdaw, probably the favorite of all the tribe, is somewhat smaller than the Rook, being fourteen inclies in length, and is easily distinguished from him by the light-gray featlers on the head and neek. The body is black, the feathers on the under side being somewhat paler than on the upper. He is a great friend of the Rook's ; and, wherever one is found, the other is sure to be. He builds his nest in the crevices of tall buildings or spires, and sometimes inside of chimneys, regardless of the sinoke. It is related, that one pair bronght so many sticks together while building their nest inside a chimney as to stop it up entirely. He is a droll fellow. and will pay attention to the slightest things which go on about him. He will observe you closely when drawing your wateh from your pocket, and, if on intimate terms, will do all in his power to let you know that he can do it equally as well. 'The striking of a match pleases him immensely; and one of these bircls which had become very tame practised the feat so thoroughly, that, after burning himself severely, he finally completed his experiments by setting the house a-fire in the middle of the night. 
The Jackdaws form the outside of their nests with slender twigs or sticks, and line them with any thing soft, - pieces of lace, worsted, or frills of any kind. These articles he is abundantly able to procure in lis numberless wanderings, and he has great dexterity in slipping clothes-pins when nobody is looking. It is. related, that, in a botanic garden in Eugland, the valuable plants were labelled by means of slender wooden tags. The country in the vicinity was inhabited by numerous Jackdaws, who, to save the labor of seeking after twigs for their nests, utilized the labels in the grounds. They ntilized them so well, that, in one chimney alone, no less than eighteen dozen were found. It must have been a mixed-up day for the gardener's.

He does not seem to be so destructive a bird as the Rook and Crow, which probably accounts for the esteem in which he is held. He is not so dignified as the Raven; but he is a lively fellow, strutting about, and chattering with the most consequential of airs. His food and care are the same as the rest of the members. of the family. If any of the above birds are kept in confinement, they require the largest-sized cages (probably a coop would be better); but it wonld be too bad to keep one caged, were it possible to allow him lis liberty, as in no case when they become tame do they ever attempt to take French leave.

They should be taught words with only one or two syllables. They learn to articulate words with long vowels better, and some of these they speak as clearly and distinctly as the best-trained Parrots.

COMPARATIVE TABLE : TALKING-BIRDS O'THER THAN PARROTS.

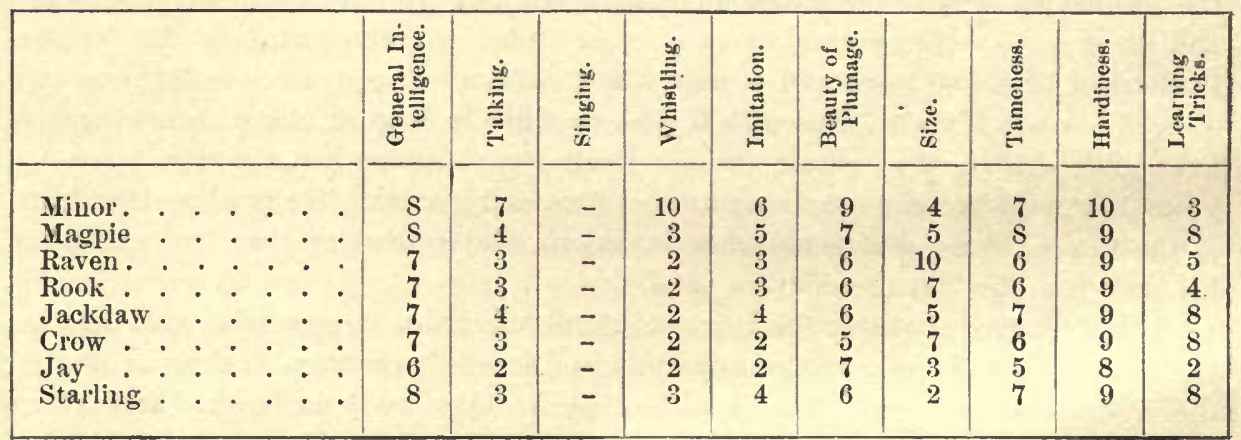

A brief inspection of the above table will show, that in these birds we have an intelligent, beantiful, and liardy lot, capable of learning many tricks, and of becoming, in a limited way, masters of the English language. While they are none of them great musicians, they are, in other respects, most interesting members of the feathered tribe; and an acquaintance with any one of them is sure to ripen into admiration, and usually into mutual affectiou. 


\section{A L B I NOS.}

Tris name is applied to a class, including members of the human race, animals, and birds, having a remarkable peculiarity in the physical constitntion. No doubt, many of our readers are familiar with the pink eyes and snow-white hair of the human class, as exhibited by show-men throughout the country, but are unaware that the same freak of nature extends to the bird family.

Scientists claim that the peculiar appearance arises from the absence of coloringmatter, which is ordinarily deposited in the outer layer's of the epidermis, and affects the entire body, the appearance continuing through life. 'The skin is milk white or pearly in color ; and in the bird family the feathers are of the same color, being very soft and silky in texture. The peculiar distinguishing mark of the Albino is the pink eyes; although a number of the bird family are naturally white in color, - a striking instance being the White Java Sparrow, - only the Albinos have pink eyes. The pupil of the eye is bright red, and the iris pale rose. This change in the eyes is also attributable to the absence of coloring-matter. Albino birds do not have so sharp sight as other birds, and they eannot bear a strong light : otherwise the Albino is as strong and hardy as any other member of his special elass.

Many writers on the subject of Albinos claim that all are weak and enervated, but their ohservations probably did not extend beyond the human family. Any lack of vigor or strength in Albino men or women of the museums probably comes from the natural indolence arising from having nothing to do but merely to sit day in and day out as curiosities. Such a life must induce weakness and inertia. Darwin, among other writers, elaims that Albinism is hereditary in the human race, and cites several instances in support of his theory: other writers claim that this is not so, but that the peculiarity is merely a freak of nature, and is apt to occur in every race. The subject in the case of birds has never been fully treated upon. I know of no case where Albinos have been born when the parent birds bred in confinement. and the instances where the birds are seen in a wild state are remarkably few.

Albinos in olden times were held as objects of religious worship. The white clephant in India is held in the highest esteem of any animal known. It appears, that. in the case of animals and birds, the Albino is regarded as an object of veneration by the rest of the flock; and they follow him, and regard his every whim. In some cases the peculiar appearance, or whiteness, is seen only in spots on the body, giving a beautiful speckled appearance: but there are true Albinos; becanse Albinism, as above mentioned, is betrayed by the appearance of the eyes. Many bird-lovers have, no doubt, witnessed this freak of nature in the most common of our wild bircls. particularly in some specimens of the many flocks which inluabit the parks and 
squares of our great eities. Albino specimens, both the clear white and the speckled varieties, may be seen among these birds.

The most remarkable specimens of this class of birds appear in the birds which have the jet-black plumage, as in the ease of the Crow and linglish Blacklirel. It appears that the Black family are blessed with more than their share of Albinos: such complete transformations as appear in these eases are hard to be believed. The White Crow, to be sure, loses the mischievous twinkle of the eye, which is a characteristic of his black brother; but he ean hoe out a cornfield, smell gumpowder, or make friends with the searecrow, equally as well as the other members of his tribe. The English Blackbird's merry song is poured forth as richly and not more purely from the white throat than from the dusky one.

This remarkable appearance extends, probably, to all elasses of birds ; although it may not have been witnessed in the rarer specimens, because of the slight opportunities afforded of seeing large numbers of them. In some families of birds the specimens are much less rarely seen than in others. In the Canary family, the largest and most numerous known, I have never seen the true Albino; although pure-white Canaries are sometimes bred. It is, however, on record, that one of the Albino elass was exhibited in England years ago, and created a great deal of comment and argument. Probably in the wild state, before cross-breeding was introduced among them, the Canary family had also its share of Albinos.

In England, Albinos of any class of birds are eagerly sought for; and, when a bird-eateher is fortunate enough to trap one, he may be sure of a large reward. 'The best-known English eage-birds - Goldfinches, Linnets, Blackcaps, 'Thrnslıes, Siskins, Starlings, and Skylarks - all have specinens of the Albino among them. A specimen of the English Nightingale Albino was recently caught, and is exhibited as one of the wonders of the bird family.

In our own eountries the different bird families are represented by specimens of Albinos, the unmistakable white being seen either elear or in specks. In most cases the parents of Albinos breed but one specimen in a brood of birds, the remainder of the nest having the uatural colors of his race. Near Springfield, Mass., a pair of common American Robins reared yearly for several years an entire nest of Albinos; they were beautiful specimens of their class: and, as the pair usually bred near the same spot each year, the nest was eagerly watched: and the young birds, when old enough to be taken from the nest, were eaught, and reared by hand. I have had many of the birds reared by this pair, and in every instance they were exceptionally fine in color and appearance. The feathers were clear white, no spot or blemish being visible to mar the purity of the color. The unmistakable shape of the body, and manners of the bird, and his notes, conld not be concealed by his milky-white plumage and beautiful pink eyes. They were most exeellent songsters, and very tame and unusually affectionate.

It is said that the Albinos are naturally tamer than the common members of the family to which they may belong. Whether this is inferred from the meek appearance which his snowy coat gives him, I do not know ; but it is a fact, that the experience which $I$ have had with the different speeimens that have been in my possession makes me believe that they are not so wild as the common birds.

The appearance of an Albino in a bird-shop results in a series of questions by 
curiosity-loving people, startling in uumber and uature. 'The incredulous look, when told that a White Crow is a Crow, is followed by a string of questions which would aunihilate any but the most patient of bird-men; and the following questions are usually included in the list: "What kind of a White Crow?" "What part of the country did he come from?" "Sure he isn't whitewashed?" "Are his mother" and father white?" All of which, being answered and explained, are followed with advice, to mate him with a black Crow, and raise some octoroons.

'The care of Albinos does not vary in the least from that which should be given to any member of the class to which he may belong.

Owing to the natural weakness of the eyes, they should not be kept in a strong light; as it tends to still further impair the sight. The Albinos are fond of bathing in almost every instance; and the daily bath is an absolute necessity, on account of the color of the plumage. My experience among them does not show any greater weakness of body with them than is common to the natural class. Unfortinately, the price of the Albinos cannot be regulated: the great scarcity of them naturally tends to make them far more valuable than the best specimen of the common birds; and as objects of interest, and curiosities, they are eagerly songht after. Taxidermists willingly pay greatly advanced prices over the common birds of his class for the purpose of adding to rare collections.

Some of the prices known to have been paid are, - English Linnet, £4; English Goldfinch, £5; Skylark, $£ 7$; Nightingale, $£ 10$; Blackbird, $£ 3$ to $£ 5$. In America common American Robin Albino, $\$ 40$ to $\$ 50$; Bluebird, $\$ 15$ to $\$ 20$; English Sparrow, $\$ 10$ to $\$ 15$. 


\section{TOUCANS.}

Ix some species of the Toucan the bill is upward of two inches broad, and seven inches long; and the wonder is, how so small a bird can manage comfortably with such a burden. The question of questions seems to be. "What will he do with it?" 'The medirval naturalists, it is said, who saw the bill only, and not the bird, concluded that the latter belonged to the order of Waders, and lived upon fish: and travellers were soon found to support this erroneous conclusion by travellers tales of the usual romantic eharacter. But later search proved beyond lonbt that he was an arboreal bird, and like the Parrot, the Trogon, and the Barbet, all belonging to the same group, a fruit-eater.

This fact being ascertained, Professor Owen suggested that the great toothed bill was useful in holding and remasticating the food.- Its purpose is explained, however, in a much more satisfactory manner.

"On the erowns of the great forest-trees of South Ameriea the flowers and fruit grow principally toward the extremity of slender twigs. Now, as these are incapable of sustaining any considerable weight, all animals feeding on fruit, or on the insects which dwell in the flowers, must neessarily be provided with some means of reaching their food from a considerable distance. Monkeys employ, as we know, their long arms, and sometimes their tails. Humming-birds are gifted with splendid organs of flight, and a strong muscular development; so that they can sustain themselves on the wing before the blossoms, the treasures of which they seek to plunder. But the wings of the Trogon are feeble, and he is of a lethargic temperament. He cannot take his food on the wing. What he does is, to take his position on a low branch in the forest solitudes, and contemplate the fruits on the surrounding trees, and, when stimulated at last to action by his appetite, darts off to seize a mouthful, and, half-exlausted, returns to his former quiet perch. But the Toucan, on the contrary, remains seated, and employs his enormous bill to counterbalance the disadvantage he would otherwise experience through his awkward and reluctant movements. The Toucan is nineteen inches long; and his beak measures six inches, or nearly one-third of his total length. The beak is orange color on the upper part, and crimson below, with a broad stripe of black separating the two brilliant colors.

It is rendered light by being ehiefly eomposed of a honey-eomb structure of airfilled cells, which are ever buoyant. Its edges are serrated, and they cut like a saw when the bird seizes growing fruit. It seems to be very sensitive, and supplied with nerves; as the bird not only appears to enjoy holding meat or fruits with the tip of his bill, but has been seen to seratch that organ with his foot. plainly proving 
that there must be sensation. When sleeping, the Toucan takes great care of his bill, packing it away, and covering it earefully with the feathers on his back: he then elevates his tail over his back; so that, when roosting, he seems to be merely a round ball of feathers. In addition to his handsome bill the Yellow-breasted Toucan is otherwise beautiful and showy; his back is a greenish black; the cheeks,

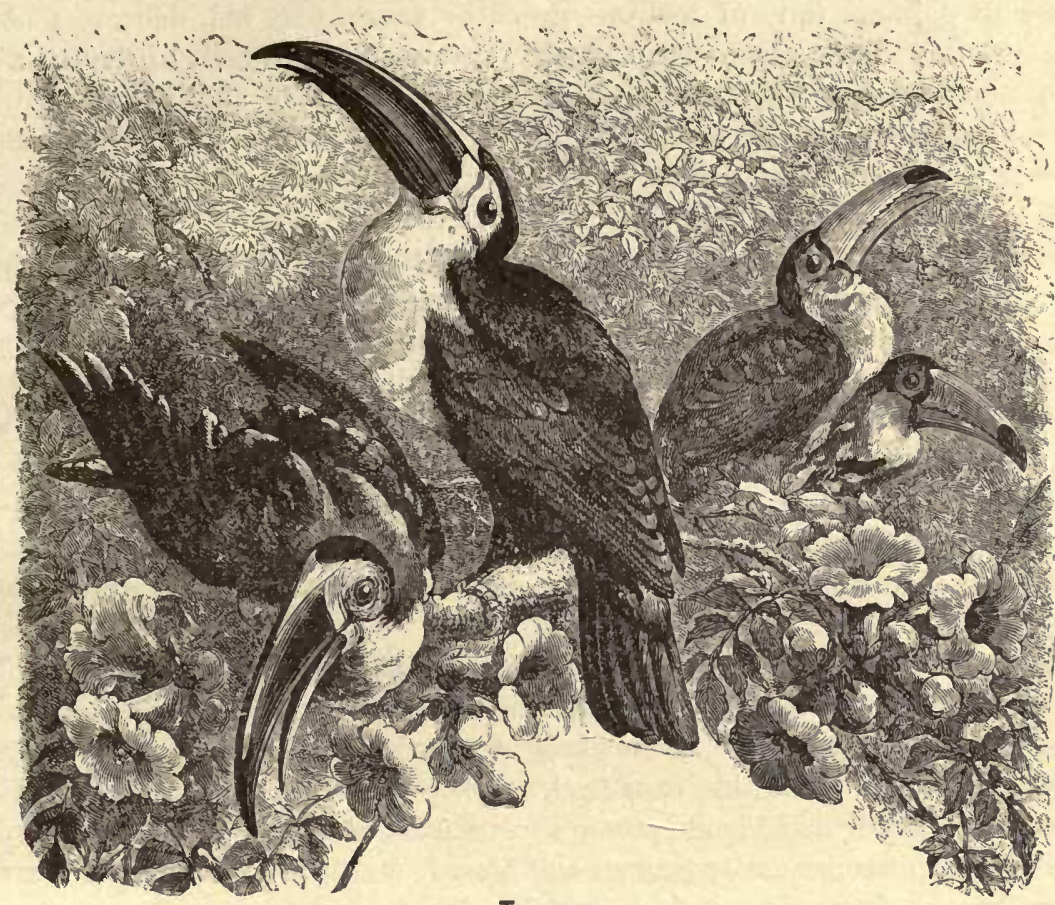

Toucans.

throat, and upper part of the breast, are a deep orange; on the breast is a crimson stripe; the upper part of the belly is a beautiful red; the lower part and the sides are blackish, as are also the quill-feathers and the tail. The upper tail-coverts are sulphur-colored, the under are crimson : the feet and claws are lead-colored. The bird climbs, like a Parrot, witl feet and beak:

There are many varieties of Toucans; but the species imported from South America to the New-York market include the "Yellow-breasted " described above, the "Brazilian," and the "Preacher." These two are even more handsome than the Yellow-breasted.

The Brazilian Toucan's upper mandible is a delicate yellowish green, with orange-colored serrated edges; the lower mandible is a pale blue; both upper and lower, for a space of two inches from the point, are scarlet. The top of the liead, the neck, back, belly, wings, and tail, are black; the sides, throat, and breast are yellowish white; between the breast and belly is a beatiful red erescent. The upper tail-coverts are white, the lower are clear red. The feet are light blue. He is a native of Cayeune and Brazil. 
In the Preacher 'Toucan, the parts which are hlack in the Brazilian have a greenish tinge; the lower part of the back and rump are tinged with ashen gray; the breast is a dleep orange; the belly, sides, thighs, and lower tail-coverts, are bright red ; the feet and elaws are black. He is a native of Brazil and Guiana.

All these varieties, as seen in the dense tropical forests of deep-green rerdure, which furnish charming settings for their beautiful colors, have plumage which shines with glorious tints of lustrous green or azure, rosy red, delicate pink, and golden yellow. They seem, when quietly sitting in the forest, to devote a good real of time to the contemplation of their personal charms; and, in extenuation of this weakness, they may plead high examples. No doubt, they are as handsome as "fine feather's" can make them.

When flying, the 'Toucans' large beaks give them an awkward appearnee; but they show no awkwardness in making use of them. Alighting on a tree, they choose one of their number to act as sentinel; and he proves his vigilance by constantly repeating the loud cry "Tucano." The others disperse about the branches, climbing by aid of their beaks, and seizing the fruit. While they are feeding, they assiduously maintain a hoarse elatter; and at intervals they join their sentry in a screaming concert, which can be heard a mile off. 'Their hunger satisfied, they lumber away into the deeper shades of the forests, and give themselves up to a tranquil siesta. When trained, they may be taught many tricks; and specimens which I have seen would obey the voice of the master, and march and countermarch at command.

The Preacher 'Tonean receives his name from his quite constant cries. 'These birds seem to suppose their beauty can be increased by trimming the tail, which undergoes the same operation as our hair in a barber's shop, only with this difference, that each bird uses his own beak, which is serrated, in lieu of a pair of scissors. Both male and female attempt to beantify their tails in this manner.

The young birds are easily trained and reared, for they will eat any thing which is given them, - fruits, bread, flesh, or fish. They seize the morsels with the point of the beak, toss them up in the air, and, opening the beak wide, receive them down in the gullet.

A 'Toucan dinner, given by a fashionable resident of Rio Janeiro, comprised in its menu only vegetables, fruits, and drinks, in addition to the eight courses of 'Toucan, commencing with 'Toucan soup, and ending with a melting pie made from the same delieate bird.

The menu was inseribed in illuminated text on gorgeous mandibles of the Toucan, and at each guest's place his name was set in rose diamonds in the mandible.

Amerieans who desire to give a most novel and expensive entertainment have only to invite the guests, and duplicate the above menu.

One or two Toueans may be found oeeasionally in the shops in New York. 'They feed, when caged, on the prepared food, bananas, and oranges, and are very hardy, and free from diseases. 


\section{FINCHES AND NUNS.}

\section{AVIARY COLLECTIONS.}

'TnEr: are very many people who take pleasure in keeping birds, whose knowledge of the feathered family is confined to the birds ealled Canaries and Parrots. 'To them a bird that eannot sing, or seream loud enough to start a good headache in ten minutes, seems of no value. Quiet, soft, warbling birds are all called "Sparrows," and eonsidered not worth the keeping. But if we ask those who keep all sorts of birds for pleasure, "Which eage do you like best?" the quick reply is, "The aviary collection."

While both English and American Goldfinches and Linnets, Bullfinches, African Red-face Love-birds, Australian Paroquets, and White and Gray Java Sparrows, are found in the aviaries, the majority of the birds in the collections is small Finches from Afriea, China, Australia, and India, and the tiny Nuns from Japan.

The varieties of these small birds are numbered by the hundreds, and twenty or thirty kinds ean usually be found on sale in the shops in New York.

All these birds are very social; and, when twenty or thirty are kept in a large cage, they will all sit on the same perch, and, what-is singular enongh, will sing in regular succession. 'They are very active, and when singing bow therr bodies up and down, or else, spreading their tails like faus, sway from side to side in a ludierous manner. At night the bird at each end of the long row hops orer towards the centre of the perch, that he may keep both his sides warm: thus the outside birds keep hopping into the middle, and crowding down in between, until darkness leaves some unfortunate on the ends who eannot see elearly enough to jump safely into the middle.

They vary in length from two inches and a half to four inches. Most all kinds. have been bred in eages, but for this purpose should be confined in single pairs; and the temperature of the breeding-room should be eonstantly kept as high as eighty degrees Fahrenheit. Most of the pairs breed from September to Mareh, and sit fourteen days.

In eomparison with the tiny Avadavats, a trifle over two inches long, the Paradise Whydah makes a great show, and might be considered too large for the aviary; but he is a quiet bird, and his sweeping train is seldom moved with force enough to disturb his eompanions. From January to midsummer the Paradise Whyclahs, both male and female, resemble dark Linnets. But when the time of the year comes which in their native country is their breeding season, abont July, a marvellous change takes place in the appearance of the male bird. The head and wings 


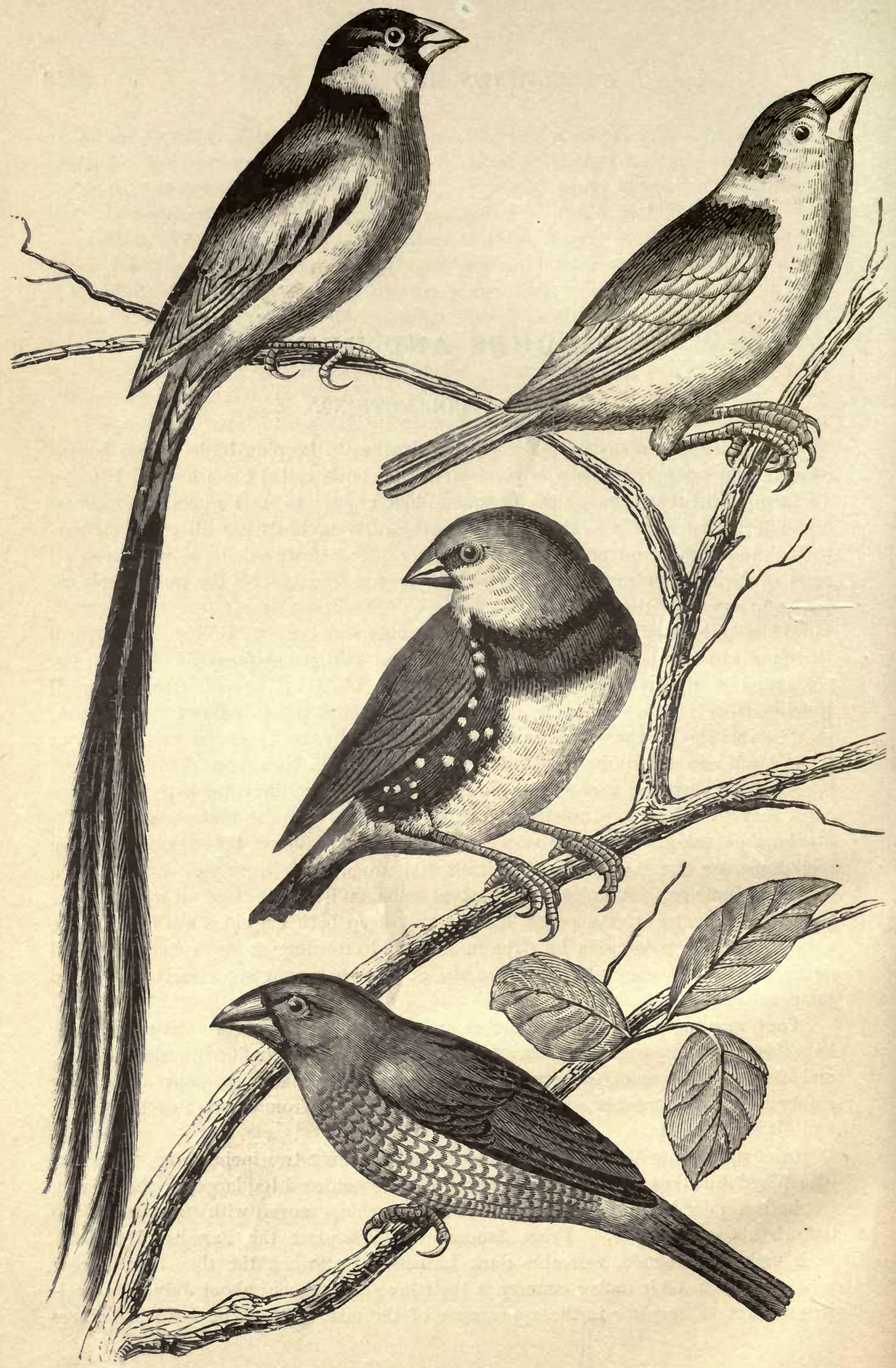

Paradise Whydah.

Diamond Sparrow.

Variegated Manakin.

Chestnut Finch. 
assume a more or less intense black color; a broad collar of rich brown oruaments: the neck; the lower body becomes mealy white; and, with surprising rapidity, four black tail-feathers grow to a great length, the centre feathers being about ten inches long. A small cage will, of eourse, destroy the beauty of this tail within a few hours : but placed in a large aviary, and in perfect plumage, the graceful flight of the bird, with his long, sweeping tail, is a sight of great beauty. At first the smaller inmates will be a little frightened when the Whydah swoops down among them, but about twenty-four hours reconeiles the most timid amongst the small Finehes to the tail of their new friend. When feeding on the ground, the male Whydah carries his tail very carefully in a most graceful curve, the extreme ends just touching the ground. whilst the agile feet scratch in the sand and food-dishes.

The White and Variegated Manakins, sometimes called Bengalese, and commonly known as Japanese Nuns, are bred in cages, and are not trapped birds, like most of the Australian and African Finches.

The Japanese living three thousand years ago, writes Blakston, knew quite as well how to breed birds in cages as we do now. We see the singular result of a breed of perfectly white or mottled little birds being regularly produced, descendect from brown-striped ancestors, - another example how birds through cage-breeding may ehange their colors in the same way our old friend the Canary has done. When and how the ehange of color was brought about is unknown, says Blakston; but other writers state, that the change from the evenly striped brown was obtainect by placing the pair's and the nest, during ineubation, under various color's of glasses, and in strong sunlight. These Nuns are clear white, brown and white, einnamon and white, and nearly clear brown in color's. The White variety is not an Albino, like the White Blackbird ; for the eye is not pink, and his progeny is as certain to be white as the Yellow Canary's offspring is certain to be yellow. All the Nuns are very docile and tame. They will readily build any sort of a nest out of any suitable material in any nest-box or other receptacle; and they will, under favorable cireumstances, prove wonderfully prolifie. Such is the experience of one who has frequently bred them. The male bird is amusing; for lie will take a piece of fibre in his bill, and execute a peculiar sort of dance to please his sweetheart, while he sings a pretty little song.

When several are kept in one eage, they will all sit at night packed in one nestbox, nearly as close as sardines are laid in a tin. When they once begin to breed, they will produce a very numerous progeny; and the young will breed again when: four to six months old.

For food for the young brood give millet and maw seed, both soaked in hot water, and strained, and soaked ants' eggs and boiled egg. The best way to breeck them, quoting Blakston's experience, is, to place only one pair in a regular breeding-cage, without nest-boxes or nesting materials, and feed them on millet and eauary seed, with plenty of green food, such as apple and chickweed. When the pair is in as perfeet condition as possible, and when the weather is genial and warm, then begin by feeding them with egg-food and soaked ants' eggs, and give them a nest-box and nesting material. In the same nest of young birds you will likely find some pure white, and some piebalds of various shades. The young should be removed from the breeding-cage as soon as they can feed themselves; because they" 
will surely creep into the nest of the parent-birds when these want to sit again, and thus disturb the second sitting.

The Diamond Sparrow's plumage is very elegant; but the colors are strong, and the contrasts great. 'The head and back are silver-gray, and the wings and tail somewhat darker brownish gray; the breast and lower part of the body are pure white, with a broad, rich black band extending along the sides, and these bands are ornamented with large, irregular, pure-white spots ; the chest is crossed by a banct of velvet-like black. The end of the back, and root of the tail, are a rich carmine red, which gives the bird a very brilliant appearance when flying. The bird is about three inches and a half long. In the aviary the Dianond Sparrow is peaceable and very showy. A pair will sit for hours quietly on a branch or perch, when the male will slowly rise up on his feet, utter a long-drawn, loud call, warble a moment, and then sink back into his former position. 'The bird is imported from Australia. If breeding is intended, it is advisable to separate the males and the females during the winter, and to keep two or more of each sex in a cage fourteen to eighteen inches long. 'Their jealousy will eause them to exercise enough, so they will not get too fat. The bird is quite indifferent to temperature, and may be kept almost anywhere: in fact, some breeders maintain that very cold weather improves the plumage. About March the birds may be paired, one pair only in a cage. The nest is a huge bundle of sticks, hay, green stuff, grass, or fibre: the pure-white eggs will be hatched in about twelve days. It has been noticed, that the mother is so jealous of the young brood, that, if the male bird comes near the nest, he will be persecuted so vigorously that the brood may be forgotten, or the male parent killed by the chirping family. A separation of this veritable hen-pecked husband from his family is the only remedy. 'The best food for the young Diamond Sparrows is live insects. Give, also, soaked ants' eggs, meal-worms, egg-food, and scalded, soaked, and strained white French millet and canary seeds. The Diamond Sparrows are not at all common, and can only occasionally be found in the shops. Males and females are the same colors.

'The Chestnut Finch, known also as the Nutmeg or Spice-bird, is a curiously marked bird, rich chocolate brown on the back, the lower part of the body being: marked with numerous white crescent-shaped spots, or light brown feathers. By no means delicate, this bird will live a long time in the aviary; and with the smallest Waxbills he will invariably be on good terms, and share their food and treatment. 'The Nutmeg-bird is common in India, and on the islands of the Indian Ocean; but it is very difficult to breed him in a eage. They are kept solely for the sake of their plumage and playful ways : one of their interesting features is the attempts of the male bird to sing. IIe will stand almost upright on the perch, the crop will extend as if the bird were about to make a violent effort, the bill will open and shut, but scarcely a sound will be heard. If other birds happen to be singing, the performance will appear like a dumb-show. The males and females are marked alike.

The Chestnut-breasted Finch from Australia is about the size of the Indian Chestnut Finch, and has, like that bird, many peculiar traits. The colors of the plumage are soft, and form agrecable contrasts of light gray on the head, and cinnamon brown on the back; the face and throat are dark brown; and the chest 
is light chestuut color, with a broad black band across the middle of the breast, the lower part being pure white. Male and female are marked about alike.

The Cinereous Waxbill, from the $\Lambda$ frican coast, is another beautiful small Finch, and probably more difficult to obtain than any heretofore mentioned. He has a delicate soft lavender or pale slate-color all over the body. The lower part of the back and the tail are purple, and the beak crimson. A line of black extends from the beak beyond the eye. His length is about two inches and three-quarters. These birds have been bred in cages in Germany, but successful rearing has been so rare that the birds eannot be commended as good breeders. My experience with the Cinereous Waxbill is, that he is most enjoyable in the aviary; being very pretty, sprightly, and playful, and having a soft, charming little song.

The small African Finches are brought to America principally by captains of barks plying between the West Coast and Boston. Negroes eatch these birds in the interior of the country, perhaps one hundred miles up the river from the coast, and bring them in lots of fifty to one hundred, and barter for "solid gold gentlemen's " watch-chains, "stove-pipe hats," and paper collars.

As many of the negroes wear few or no clothes, the watch-chains cannot, under' these circumstances, be attached to any apparel, but are used as bracelets and necklaces; and a dozen paper collars will adorn each leg as bangles. Sometimes a nude, burly specimen is seen, who considers himself in full dress when wearing a stove-pipe hat perehed on his left ear. His appearance in the village-streets on the coast is apt to have a scattering effect. The captains also carry "Old Medford rum," and trade a pint of it for the first ten birds : then, when the negro is under its influence, they take the other ninety, and drop the seller over the bark's stern, perliaps a mile from shore. As pure Africans cannot be drowned, the bird-trapper, after floating hither and yonder for some hours, too intoxicated to guide himself, is finally tossed on the beach, where the hot sand and a tropic sun overcome the pacifying effects of the liquor, and make him again a perfect savage.

On the bark the Fiuches are put in wooden boxes with wire fronts, three feet long, three feet deep, and ten inches high, having perches arranged closely together in amphitheatrical order; so that any one looking into the wire front sees a solid mass of faces and breasts of the eight bundred small birds packed closely together, tier above tier, - palest turquoise-blue Finches, with the ruby Avadavats on either side; and above and below are the delicate lavender Waxbills, brilliant Fire Finches, and Bishop Finches arrayed in gorgeons orange apparel. If only one bird in every eight is singing, the chorus of a full hundred voices makes the old, sea-battered, rough box rival in sweetness the polished rosewood music-boxes from Geneva. •

Frequently the Finch-boxes are brought over on the upper deck; and at such times, when a luurricane suddenly blows up, box and Finches have been washed overboard, and tossed from erest to crest of the billows for an hour before a boat's crew conld leave the ship for the rescue. Of course, many of the birds perished. When they first arrive in America, they are in rough feather and bad order ; because the boxes are overerowded, and in a filthy condition, and the seed used during the voyage the cheapest grade. Clean brass eages, an abundance of room, and the best quality of white French millet-seeds, soon make them look as finely as when 
first captured in the tropical forests. Each bird is of so slight value in Africa, that, if the trapper should depend on catching Finches in trap-cages, he would die a strict teetotaller before eatching birds enough to obtain the coveted quantity of liquor. 'The trap-cage plan would entail quite a good deal of work too. Our African has a chronic hatred of work, and loves the "Old Medford: " so he strolls about until he finds a piece of forest where hundreds of the Finches roost; then, obtaining a peculiar kind of wood, which, when burning, stupefies the birds, he stretches his sort of blanket made of large leaves, lights the odorous tinder, and catches blankets full of Finches faster than he can transfer them to the boxes.

'There is another method of catching the birds, which still better agrees with the negroes' well kuown-laziness; and, on the score that the plan is "clean gone black," it is entitled to great credence. There may be some sceptics who will say "that style of trapping is all bosh:" it remains for them to prove that. Here is the outline of the second method of trapping birds. An African king, named "Pretty Blue Eyes," called his harem together, and notified them that a bark was in the harbor, having on board various casks of New-England pure spring-water, for which the captain wanted a few little birds. "Get you hence to the forest, all you younger women, whose hair is long and kinky, and pinned on tight by nature; sow on your heads sweet seeds, that the beautiful Cordon Finch loves so well; then lie down, all of you, under the trees, quictly; sleep, but snore not! nor brush the tarantula from your breasts until all the Cordon Bleus and Marechal Neil Yellow-breasted Warblers are tangled in your wavy locks. Caught thus, bring the birds to the lofty ship, whither I precede you, to test whether or no the casks contain the delicious, inspiring, electric tonic mined in those dear old NewEngland bills."

The Finches and Nuns live eight to ten years, and, when acclimated, are subject to few or no diseases. They eat the white French millet-seed and Sicily canary-seeds mixed three parts of millet to one part of canary. As they all are natives of warm countries, care should be taken to keep them out of dranghts of cold air. They enjoy an abundance of coarse gravel to scratch in, and are fond of cayenne pepper once a week : this pepper may be mixed with boiled egg. Green stuff may be given daily in moderate quantities. It is necessary their cages should be close wired, as they are able to fly out through the spaces of an ordinary Canary-cage.

These Finches and Nuns are hardy birds, and are seldom affected by diseases. The Canary and these birds are of the same family, and in ease of sickness they should be treated just as that well-understood bird would be.

The Orange Bishop Finch, one of the Weaver family, from the West Coast of Africa, is a little smaller than the Canary, and a very handsome burd. The male's plumage is a brilliant reddish orange and satin-like black. The eap on the head is black, a wide band of long, orange-colored feathers encircles the neck, the blackest and glossiest of plumage adorns the breast, and the back and tail are of orange hues, so deep as to be dazzling. The female has only a brown color. No aviary collection can be considered complete unless it contains one of these gorgeous and sprightly birds. He is a lively and restless bird, and in order to be kept in good humor, and made to behave, should be furnished with two or three mates. He is 
a constant worker, and, unless he has nests to build for his mates, is liable to use whatever material is furnished him for weaving purposes to "hang up " some of the defenceless smaller Finches. In the breeding-season he will divide lis attention among his numerous mates, and build nests enough so that there will be some for the other Finches to lay in, all of which prefer such to any artificial nests.

Some time ago l'owned a pair of these Bishops, and kept them separate from other birds, in a brass cage $8 \times 10$ inches. They were given varions colored worsteds to weave with, and made a nest, entrance, and diagonal avenues, that completely filled the cage. The gorgeous colors of the worsteds rivalled the bird's own gay coat. The whole structure was very ingeniously made, and the knots and halfhitches were marrels of neatness and strength. The worsted was given in piees measuring from six to twelve inches long, and there were, perhaps, two hundred or more such pieces; but not a loose end conld be seen. All the ends were either spliced, or else carefully tucked in toward the inner walls. The male alone did the work, and used his feet more deftly in the delieate operations than a person could use thumb and forefinger. The male is a singer, though with such beauty and industry you can hardly expect the sweetest music: but he sings, and that, too, quite constantly; my impression is, that the less he sings, the better you would like him. The song consists of a series of harsh, metallic trills, such as might be produced by "gusts" of fine shot on sheet-iron : the tone is so soft it is not at all painful.

The Bishop is very hardy, and may be kept almost anywhere, witlout regard to low temperature. He changes color twice a year, assuming, at times, a sombre garb, after his bright apparel has become "rusty," only to re-appear in more brilliant habiliments. At this time, if I may liken the parts of his plumage to a man's garments, first one sleeve will become, in two or three days, bright orange; then the whole back of the coat the same color; and soon a glossy, satin-like waistcoat appears. Quickly the whole suit is just perfection. The longer orange feathers about the neek can be made to stand out like a ruftle whenever the bird is excited or sings.

The Madagascar Weaver, the Napoleon Weaver, and the Red-headed Wearer, have caidinal and brown, lemon and brown, and cardinal and black, colors, all differing in plumage from the Orange Bishop Wenver, but like lim in respect to weaving, song, and habits in the cage. All of these are kept in ariaries ; but, unless the cage is a large one, only one kind should be confined in it. Not one of them is an affectionate bird, either towards mankind or his own mate: indeed, love for the mate is expressed by giving her a "switching." 'Two male Wearers will ignore the best dinner that ean be offered just for the fun of a good fight.

One may grab the other by the foot, and hurl him the length of the cage repeatedly, without injury, so strong is the peeuliar construetion of the legs of this genus for working purposes.

The White-eapped Nun is a soft seal-brown color all over, except the head and upper part of the neck, which are grayish white or white. The bird was imported from India, but has been bred here in cages. Perhaps not one otler of all the small birds for the aviary will so quietly, easily, and completely gain his keeper's affection as this Nun with large, mild eyes, sweet face, subdued demeanor, and winning ways. He possesses, in a large degree, that kind of loreliness that leads 


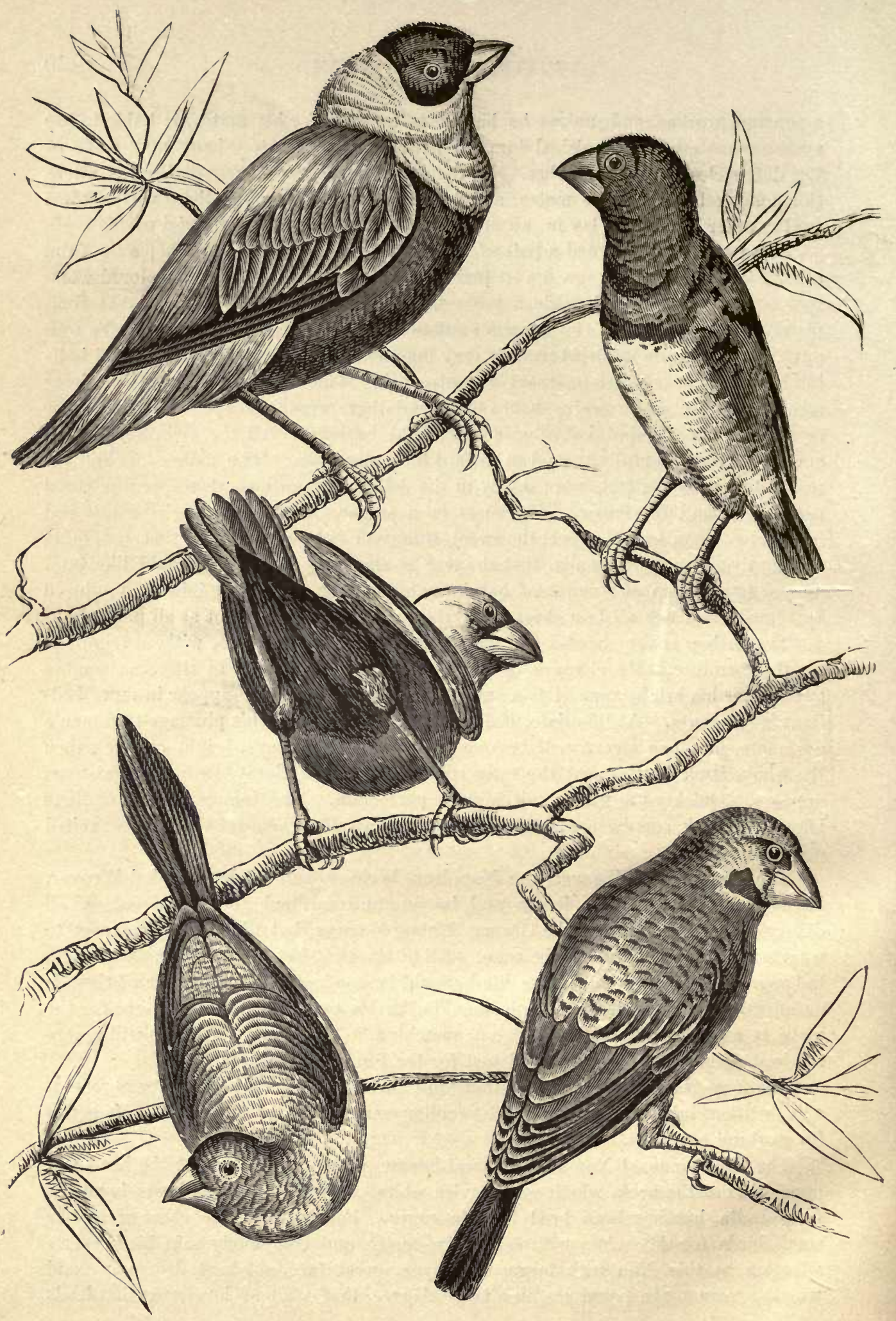

Orange Bishop Finch.

Silver-bill Finch.

White-capped Nun.

Magpie Finch.

Cut-throat Finch. 
many to involuntarily exclaim to him, "I'd just like to hug you!" His song can be described only by stating that it seems like a laughing-song. Good-natured, affectionate, playful, he is a great additional charm to any collection. The bird is about two inches and three-quarters long, very sprightly, and quickly becomes well enough acquainted with his keeper to accept seed from the fingers or lips.

The Black-capped Nun is similar in size and shape to the White Cap; and the only difference in color is, that, where the latter is white, he is black. He has many pretty little ways that make him an interesting addition to the collection. He is a native of India, but thrives well in our colder climate.

The Black-capped Finch; or Three-colored Nun, differs from the two immediately preceding, only in having a white stripe down the breast.

The Cut-throat Finch from Africa is one of the most popular of all the Finch tribe. The red stripe across the throat of the male gives the bird his somewhat appalling name. The plumage is a soft fawn color, delicately mottled on the breast with dark-brown spots. The pairs will breed in cages more readily than any other African Finch. A German bird-breeder mentions in his writings, that a "pair began in his aviary by laying nine eggs, which were lost through an accident. The same pair brought out of their nest two young ones Nov. 8, four on April 2 , five on May 15, and three on June 20. The same pair bred in the following season in even quicker succession; and a lady in Vienna had from one pair in three years forty-five broods, altogether over two hundred and forty eggs, from which one hundred and seventy-six were latched! The young hen-birds were ready to breed at the early age of two to three months."

The nestlings should be fed on the soaked millet-seeds, egg-food, and ants' eggs. The pairs usually mate in November, and a temperature of sixty-five to seventy degrees is warm enough.

When the male throws the brood out of the nest, and leaves them to perish, it is because he wants to mate again. Either he should be put in a separate cage, or a brood or two of eggs may be destroyed, and thus the pair cooled off. These Cutthroats have the peculiar habit of sitting in rows, and resting their bodies on a single stick, regardless of how many unoccupied perches there may be. Suddenly, as though it had just occurred to him that the assemblage was rather quiet, one will rise up on his feet to his greatest height, and sing and warble with many accompanying gesticulations of body and head, then as suddenly drop back to his place, and be silent: while another will jump up, and give his song, dancing, and eurvinghis body into ludicrous shapes; while his face expresses a vacuity that would, if possible, make a ten-inch post-lole smile an envious smile.

The Cut-throat is hardy, thrives on the canary and millet seeds, and lives six or eight years. When bred in cages the birds are, of course, tame; but even those brought wild from Africa soon become attached to him who feeds them, and will eagerly take dainty morsels from the fingers or lips. They may be generally found on sale in the shops.

The Silver-bill Finch, or Quaker Finch, from Africa, is an unpretending little bird, whose presence you would not be apt to notice in first glancing at an aviary collection; but a half-hour's acquaintance would so interest you in his soug, that afterwards the first notes of the prelude would instantly catch your attention. 'The 


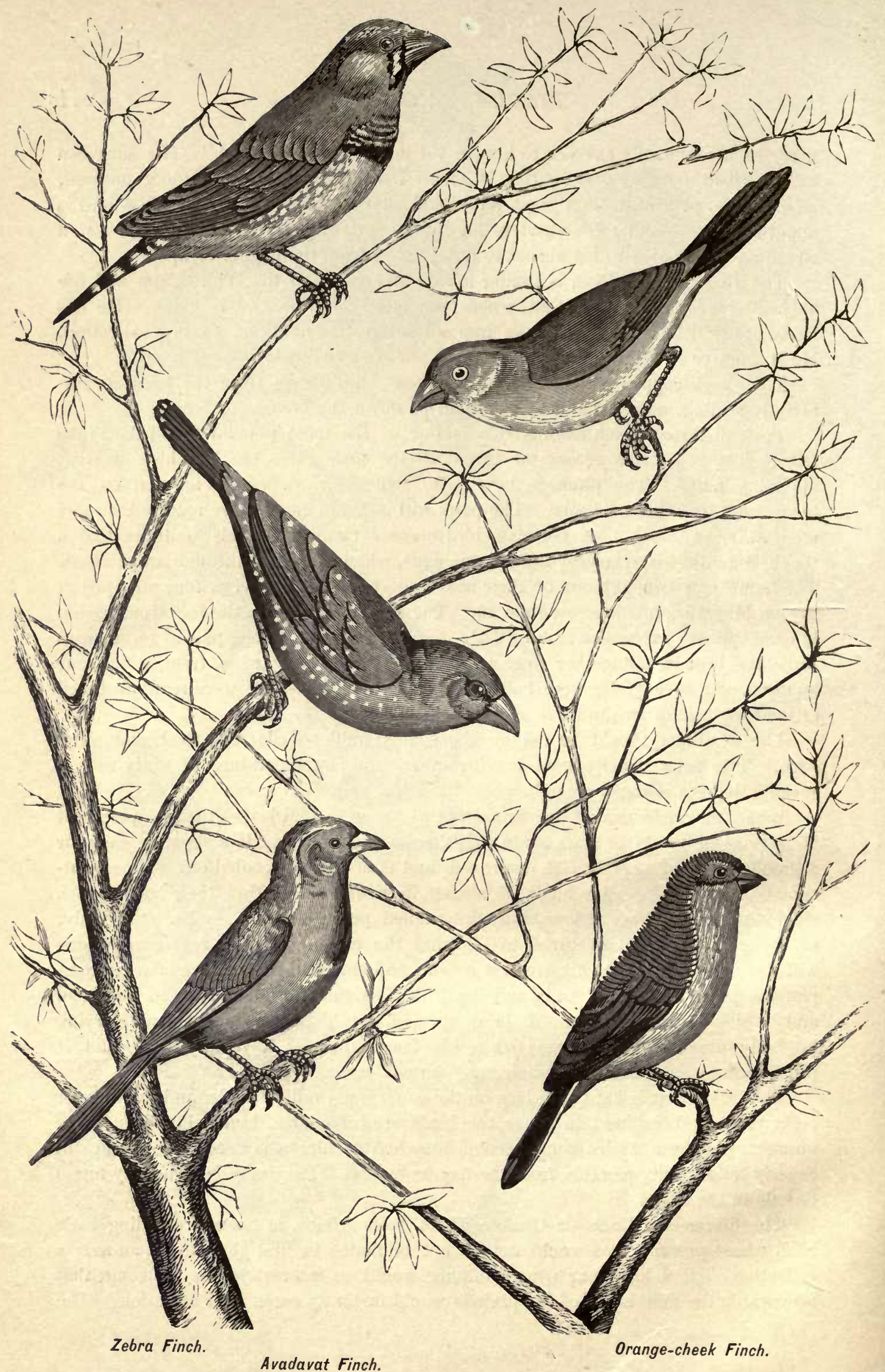

Cordon-bleu Finch.

Waxbill Finch. 
upper part of the bird is fawn color, the wings and tail are a little darker, and the lower part of the body is dull white.

A pair will build the nest in a little wicker cage, or on any projecting ledge, and rear the nestlings on the soaked millet and ants' eggs. 'Though the color of the plumage is not gaudy enough to attract, it is so sleek and smooth, and shows evilence of such care and neatness, as to excite admiration. The bird is about three inches and a half long, slender, and very graceful in flight.

The Magpie Finch, or Bronze Manakin, from Africa, is a sprightly little beauty, who is very courageous and very playful. His head, throat, wings, and back are black, with glossy tinges of purple and violet; and his breast is clear white.

In the aviary he becomes tame, and, though less than three inches long, will defend his mate and his young with a dash and sharpness that put a bird twice his size to flight. Like the Silver-bill, he will build the nest almost anywhere, provided there is food conveniently near. He, too, thrives on the canary and millet, and sings and dances even more than the Cut-throat.

The Grass Finch, from Africa, has the same colors and markings as the Magpie, but is fully a third larger than that bird. He has a pleasing song, will breed in the aviary, and is cared for the same as the above.

The intelligence possessed by these small birds when confined in eages seems all the more strange when one recalls the very different habits of birds in the wild state. 'They soon learn to distinguish individuals, and will instantly recognize with cheerful chirps and flutterings whoever feeds them. Extend your hand, containing seed, into the eage; and as many as can alight in it will feed as long as permitted. If accustomed to being put to bed - that is, covered - at a regular time each evening, they will remind you of any neglect with many dissatisfied calls.

The Orange-cheeked Waxbills are very small and aetive birds, pleasing singers. and have bright and sleek plumage, that seems as if it were just turned out from the loom. The color is mainly a light grayish brown, while the bright orange patches on the eheeks give the bird his name. On the abdomen there is a diffused patch of orange, gradually shaded toward the chest and sides. The tail, which is somewhat longer than usual in Finches of this size, is dark brown, with a crimson patch at the root: the beak is coral red. Male and female are very much alike, but in the latter the orange is a paler hue. The bird is most amiable in the aviary. and usually constitutes himself one of the guardians of the collection. His everwatchful eye is sure to discern the approach of a stranger; and his short, sharp chirp of alarm sounds out clearly above the chatterings of the multitude.

No matter how many varieties of small Finches the aviary may contain, the pair of Orange-cheeks, though social and well disposed towards all, is seldom seen apart; and a case is not known where either a male or a female of this variety ever accepted any other variety for a mate if one of its own was to be had.

These birds are especially desirable for a collection, because they are so gentle and handsome, and have such pleasing songs. Moreover, they are easily acclimated, and live many years.

The Common Waxbill is imported in larger numbers than any other of the small Finches. His color is grayish brown, marked with delicate wavy lines athwart the body. The abdomen has a bright roseate hue, deepest in the centre, and faintest 
towards the chest and sides. The beak is a coral red, and a broud red line passes from the root of the beak through the eyes. The tail is dark brown, rather long, the central feather's being longest, and wedge shaped. When the bird is exeited or singing, the tail is spread fan-like. The male and female are alike in colors. In the aviary the bird is cheerful and lively, keeps in good plumage, and lives many years. He devotes a great deal of time to arranging his own plumage and that of his mate, using his tiny beak so carefully and caressingly on the latter, that she generally takes a nap until the spell is broken by his desire for exercise or food. The pair's are usually industrious nest-builder's if suitable materials - such as the more pliable dried grasses aud deer's hair - are furuished. If given a room for breeding purposes, they will build nests, either on a shrub, in a nest-box, or even on the floor. 'They have often been bred in captivity, and will reall their young on dried and soaked ants' eggs and hard-boiled egg.

The Cordon-bleu Finch is one of the most attractive of the aviary-birds, as 'he possesses showy, unusual color's, and is a delightful singer, tame, sprightly, and playful. The bird is very prettily colored, being pale brownish gray on the back; the face, throat, chest, and tail being pale sky blue; the cheeks of the male are ormamented with a pateh of erimson. The female is similar in color, but the (rimson patch on the eheeks is absent.

The Cordon-bleu, like the other Waxbills, is sociable, and is so fond of his mate, that, if separated from her, he gives utterance to very pathetic, agonizing cries, that cease only when she is re-united to him. Owing to the peculiar marking of the male, the birds are often called the Crimson-eared Waxbill. The pairs seldom will build the nest in a box, but prefer' to construct a nest entirely of their' own, selecting for this purpose a bush, or branches fixecl to the wall of a room or the highest part of an aviary. The young should be fed the same as other Waxbill nestlings.

The male Cordon-bleu will seize any small piece of thread or cotton twine in his beak, fly to the side of his mate, and sing song after song; while she stands almost resting her ear against his beak, so not a note may be lost. Certainly, this is highly commendatory listening; and so the male eontinues to sing his most charming songs, ceasing only when hunger calls him away.

The Double-banded Finch, compared with the brilliant hues of the high-colored Finches, seems at first sight very modestly attired. Blakston describes the bird as follows: "A pure silvery white is the ground-color. The feathers are delicately pencilled with fine black lines or bars, which, when seen at a distance, give the bird a light silver-gray appearance; but, examined more closely, the plumage of this Fincli, one of the smallest of the Australian Finches, is of great beauty and marvellous delicacy. 'The face, throat, breast, and the lower part of the body, are white. A narrow black line, which crosses the throat, extends from ear to ear. A second black line, across the lower breast, runs parallel with the former, and gives the bird the name of Double-banded Finch. 'The wings are black; but the feathers have rows of white square spots, which on the dark ground appear something like a trellis. The Germans have named this bird for this reason, 'Lattice-wing.' The beak is of silver-gray tint, and the tail is black."

The fenale is marked exitetly like the male. Very hard aloe fibre furnished to a 
pair pleased them ; and they quickly busied themselves with it, and soon built a large ball in the crest of a tree. 'The ball was nearly as cleverly constructed as a Weaverbird's nest, had a very small entranee at the side, and formed a capital nest, in which four or five pure-white eggs were laid, and hatched in the usual time of thirteen to fifteen days.

The young brood is easily reared; being fed on millet and maw seed soaked in lot water, and strinined, a little egg-food, and soaked ants' eggs.

The Zebra Finch is a happy bird, contented in the cage alone, or in an aviary. He is pretty, a delieate gray being the prevailing eolor. The lower body is white. A patch of chestnut-color marks the cheeks; and a band of ehestnut-color, dotted witl white spots, ornaments the sides. The throat is gray, shaded with blaek; the black forming a sharply defined collar-like mark where it borders on the white of the breast. 'The black tail is oruamented with white bars across each feather. 'The bill is brick-red: the feet also are brick-red. The female does not have the chestnut-colored patches and bands on the cheeks and sides, and the lower body is a dull grayish tint. The Zebras breed more realily than any other Finelies, and can rear twenty or thirty young birds in a season. Blakston states that his only difliculty in breeding Zebras is their prodigious reproductiveness. This is due to too stimulating food, which will result in the birds building nests, and laying eggs without hatehing them.

If a healthy and apparently strong pair are obtained, it is advisable to keep them for a time without nesting materials, and to feed them only on dry millet and canary seed, with a little fresh meat at times. When the birds lave beeome nsed to their new home and surroundings, and when the perfection of their plumage denotes their perfect health, - and not before, - give them an opportunity to begin to nest. In a cage this opportunity is best given by fixing a roomy nest-box, into which the birds will forthwith carry a mass of aty material they can pick up. Bits of hay and straw, moss, small twigs, wool, fibre, feathers, - notling comes amiss to construct as slovenly a nest as any sparrow ever built. Now is the time to give the Zebra Finclies a little extra food daily. A small quantity each of sponge-eake, boiled egg, maw-seer, and soaked ants' eggs, all mixed together, will be an ample daily allowance for the pair, besides their regular millet and canary seeds. They will soon lay four to seven very small white eggs, and hatch them in about eleven days. In the larger aviary the Zebra Finch is showy and well disposed, has- a pleasing song, and many odd, cunning traits not possessed by any other members of the Finch family.

The st. Helena Waxbill is similar in appearance to the Common Waxbill, but somewhat larger than that tiny specimen. He has the same coral-red beak, the same red line through the eyes, the same soft brown body-eolor, and roseate tint on the breast. But the wavy eross-lines, which are faint on the plumage of the Common Waxbill, slow very elearly on the St. Helena Waxbill. He is a gentle, peaceable bird, graceful in motion, and considered remarkably handsome. In a collection eomprising even many beaties, he is conspicuously attractive. His plumage is always in good order; and, thongh his song consists of only a few notes, he is a most willing and cheerful vocalist. If furnished with suitable material, a pair will build al shabby sort of nest, and hateh out the young in eleven or twelve 
days. The nestlings should be fed the same as other young Finches, referred to above.

The Avadavat, or Strawberry Finch, is imported in large numbers from India, and perhaps is more generally known than any other of the small Finches. His plumage is dark brown, with a carmine-red tint, and covered all over with small pearl-white spots. When the breeding season arrives, the red tints become more brilliant; and the little bird, with its coral-red beak and shining purple hue, is then a sight of rare beauty. Several pairs will live very peaceably together; and towards dusk they will all sit on the same perch, very close together. At that time one, aud then another, will suddenly raise itself, and sing a melodious stanza, settling down to sleep when it is done. The female will sing nearly as well as the male.

The male Strawberry Finch's song is very pleasing, and sounds as though it were produced by a miniature pipe-organ. He is, perhaps, the most delightful singer of all the small Finches.

All of the above Finches thrive on millet and canary seed mixed, two-thirds millet and one-third canary: usually the French, or white, millet and the domestic millet are both mixed with the canary seed. In addition they should have apple or lettuce twice a week, an abundance of flinty gravel, fresh daily, and an opportunity to bathe in shallow, tepid water.

All of the Finches and Nuns will usually be found amiable and charming inmates of the aviary; and, in raising a variety of these beautiful songsters, one forms strong attachments for them, and is surprised to find how many delightful hours can be enjoyed in their eompany.

Those bird-owners who have one or two or half a dozen birds, each in a separate cage, cannot realize how much more pleasure there is in keeping birds in an aviaryeage.

With the small Finches and Nuns, in aviaries, the following birds may be kept: The Goldfinch, Linnet, Bullfineh, Siskin, White and Gray Java Sparrows, Australian Paroquets, Afriean Love-birds, Nonpareils, Indigo-birds, Yellow-birds, or American Goldfinches, and Canary-birds. These are all peaceable, most of them are singers, and all of them have handsome, showy plumage. 


\section{BIRD BUYING AND IMPORTING.}

Few people who own birds, or who are charmed by the sweet voices of the numberless varieties of songsters, are aware of the trials and hardships undergone in obtaining and bringing them from a far-distant country. The men engaged in the business of transporting birds are a tough, hardy lot, who must be capable of enduring a vast amount of exposure and hardship, and must be possessed of shrewdness and intelligence, otherwise success will not be assured. In the busy season, each importing-house employs from thirty to forty travellers, men who travel back and forth, principally between Europe and America. Besides these, there are a great number of pickers, who go from breeding-house to house selecting the singers, and large numbers of men employed in the business at either end of the route. All

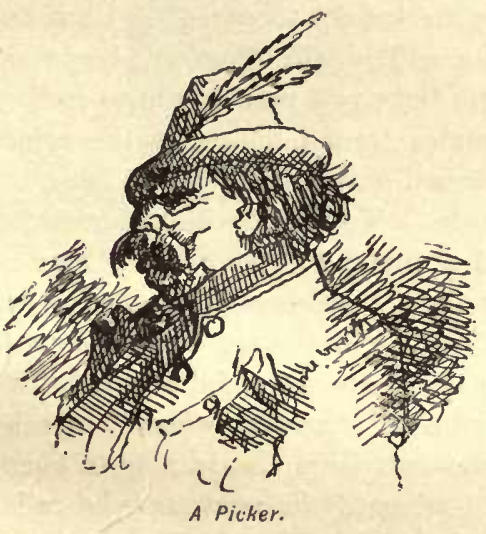
are obliged to serve a certain length of time as apprentices, usually two or three years, in order to accustom them to the different breed: of birds, and that they may become experts in feeding, know the numberless ailments birds: are subject to, and just how to prescribe foreach. Abeve all, they must learn to distingursh the sexes of all kinds of birds. When one has learned this last, he is a master in the trade, and secures a jermanent position. The time for breeding Canaries, the principal birds imported, is from February until August. Germany and England furvish all but a small part of the Canaries raised in the world; and the great exporting-houses are all situated in Germany, with distributing branches in the different cities, New York being the distributing depot for the United States.

The early summer season, from May until the first of July, is the dull one; all business as regards exporting is suspended, for the Canaries are too young to bear a long journey; so in this dull season the different rooms in the large birdhouses are thoroughly cleaned, repainted, and whitewashed, in order to free them from any possible clisease, or from vermm. Each large dealer controls a great number of breeders who raise birds, and deliver them when called for. In certain districts in Germany, notably in the Harz Mountains, each village has its quota of bird-raisers, many being well-to-do. The trouble and expense of raising Canaries there are slight, and the profits are large. The number of Canaries raised by the 
different breeder's varies; each being governed by the amount of money he ean inrest, and the size of room or rooms which ean be spared. In cases where the breeders are too poor to buy the "Heek" or parent birds, such birds are sent him without charge by the exporter, who thus gains the right to purchase all the biris raised. In some cases money is paid in advance to the leading bird-fanciers of a village, which secures for the dealer all the birds raised in that section. The dealer selects his pickers, and assigns each to a certain village or district. In many eases the picker is the only one recognized, - the dealer being known only by name, and never seen in person, - and his coming is usually heralded. His arrival is wamly greeted ; as he bears interesting news from the outside world to the secluded hamlet, and gives information as to the ruling prices in the bird-market. As his conscience might be hurt should he give too high figures, he never quotes above par. He carries the small eages so eommonly seen in the bird-shops. 'These cages, by the way, are an industry by themselves, and consume a deal of time and labor in their construction. They are made by the poorest classes, chiefly miners and woodeutters, who whittle them out by hand: the entire family engage in their manufacture. Tanne (fir), a straight-grained, soft wood, easily split, is used. A finished cage sells for ten pfennig, or about two cents and a half American coin. The average number completed per night - as they are only made during the evening lours, when no outdoor work ean be done - is fifteen. When a case, two hundred and ten eages, is ready, it is sold to the large dealer; the goods are always in remand, and the manufacturer easily finds a ready market for them : still, I am not acquainted with any mannfacturer who has retired a millionnaire from this business:

The picker starts in the morning as soon as the light will permit him to readily distinguish shades: as the Canaries are selected, males from females, by the colors on their heads. This branch of the business is learned only after years of constant practice, and even then mistakes may easily be made. To select without error the males from the females, requires sliarp eyes, and a pretty thorough knowledge of human nature; for the simple bird-raisers are not always guileless, as the following experience will prove: The picker is assured that an old female bird (the most difficult Canary of all to judge) is the male from which the splendid stock before him was raised: he does not wish to quarrel with the breeder, whose birds lie desires to buy ; but still, confident in his own judgment, he is always able to laugh the matter off by telling the breeder to keep the bird until the next time he calls, or that he will send for him by the next mail, as he is looking for a bird of just that sort, but would be sorry to mix so fine a one with the common herd. 'The woman of the house - she is generally the party with whom the bargain is made assures him that the bird is not a female, as he is a beautiful singer. "You are a female, and a fine singer too," he replies. So, flattered and bantered out of it, she retires, muttering, "You vogel fellows vas too shmart." 'Thus it is from house to house he encounters the hard-headed traders who know more of the business than he; but, being suoplied with an inexhaustible amount of good-nature, he goes home not such a bad fellow after all. A good day's work, provided the houses of the village are close together, and the season a prolific one, is, to pick two hundred birds. 'The strongest birds are the ones taken on the first trips, the birds last hatched and the females being left until later in the season. 
In the late summer and early autumn the physieal work connected with pieking is easy, as the weather is delightful and the travelling good; but the amount of care required in separating the males from females is much greater, for the young bircls liave not " colored out" enough so the sexes can be easily distinguished. Later in the season, when snow to the depth of four or six feet is on the ground, and bleak winds howl down the mountain side, the pieker suffers from frost-bites, and gets worn out plunging on foot through deep drifts. Birds are searce then, too, owing

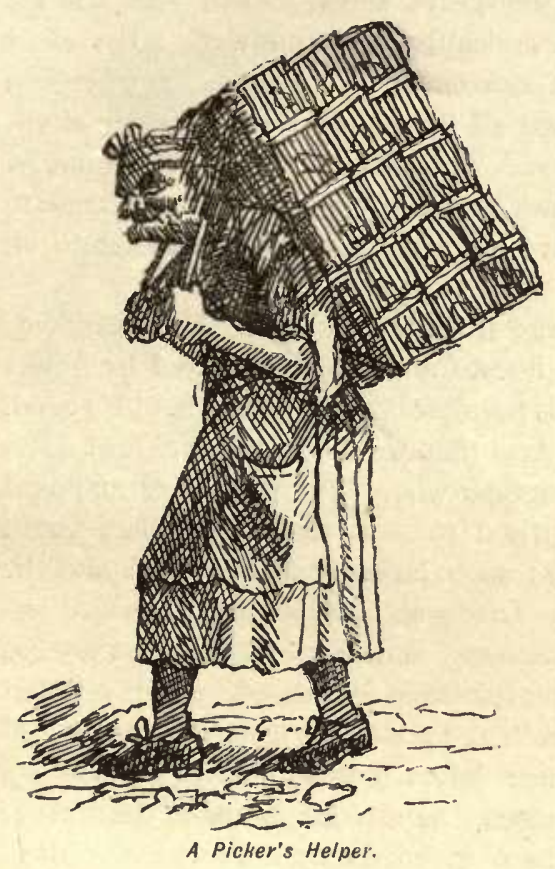

to the draft upon them in the early trips: and this makes long tramps necessary. The pieker must be careful not to diseard males, as every bird counts : competition in New York is sharp, and the demand large: therefore he should pass none. It is then he trudges into the outlying small districts, sorts of branches of the main villages, where the houses are seattered, some lying an hour or two hours' walk apart. Starting early in the morning with a woman (women being used for the more laborious work of earrying birds in this part of Germany) having twelve rows of cages strapped on her back, he proceeds, wallowing through the banks of snow, buffeting the fierce wincls and piercing storm, to seleet for you a soft. sweet, fluffy songster. No matter what he may be suffering, the birds are always his first consideration; they are carefully protected : and, if necessary, he divests himself of his great travelling-coat, and wraps it about the package as an additional protection, trusting to his vigorous eonstitution and an oecasional run to keep up the proper circulation of his blood.

Many villages, notably St. Andreasberg, are situated three hours distant from the railway station. St. Andreasberg lies three thousand feet above the sea level, and is extremely cold. On a trip to this village the pieker packs lis birds carefully in hay, then wraps the cases in double case-covers made from thiek, strong linen, and, ontside of these, wraps thick woollen blankets. These are the costliest of all Canaries, hence precantions are doubled.

The birds are sent in Germany the same as baggage would be here; and the flank movements executed against the railway offieials in getting goods aboard a fast express - where they are not allowed - would do credit to a man with a longer head than a simple bird-picker is supposed to earry.

His trip by rail from the breeding-place to his employers' bird-house occupies eight or ten hours. On arrival, the birds are carefully taken from the railway station, fed, eared for, and put in condition for their long ocean-journey, which may commence within a day or two. 
An inspection of one of these large bird-houses is exceedingly interesting. It contains from forty to fifty rooms, each room being prepared for its special variety of birds; some are kept warm, others at a moderate temperature, and still another suite cold; each bird being kept in the temperature to which it has been aceustomed. In busy times things are very lively; as here are twenty-five thousand birds to be eleaned, fed, and watered daily, and for severil months of each year four thousand received and shipped each week. This number of birds consumes each month all the seed that ean be grown on twenty-five acres. Each man has his special duty to perform: the young beginners clean, feed, and water; the older Inen sort out the different grades, eull out the sick ones, and prepare the travellers for their different destinations. Every morning all the rooms are thoroughly aired, and every precaution taken to prevent sickness. The musie sent forth from one of these large houses, eontaining, as they oftentimes do, twenty-five thousand songsters, is as loud as it is varied, and would easily drive an average opera audienee into an insane asylum.

How the proprietor ean keep track of his large stock is a puzzle to the uninitiated. The trade is not exclusively foreign; for the finest Canaries are selected by homeexperts, - men who are speeially trained for this peeuliar branch, - and kept for retail orders at home. Germans are much better judges than we are of the different notes which a tine Canary should have. And in America, where high prices are supposed to reign supreme, a bird-faneier would be surprised to think that fifty dollars would be given for an extra song Canary in Germany; such, however, is the case : and the very best birds seldom are found in America. Lately an enterprising American importer has had a few of this grade of birds sent over; and, wherever heard, they are always spoken of as being worth fur more than the price asked. The men selected for "hearing-up," as it is called, are "ancients," and are men who have been reared from boyhood in the business, who ean at once detect a false note in a Canary's song. 'This hearer's patience is never exhausted; he sits for hours if the bird is not in humor for singing: and, when the song is given, every note which the bird can utter is heard before there is an aceeptance or rejection. 'The long, low trill, the deep roll (the bighest prized of all notes), the flute, the bell, the turn, the bubble, and many others, are successively heard : if there is a false move in any, the bird is immediately rejeeted. That is indeed a fine Canary which proves acceptable; and when one hears from the ancient's lips, "Dieser ist ein guter vogel" ("This is a fine bird"), he may be sure of a prize. The finest song-birds which ean be proeured are selected as the teachers for broods of young Canaries (I am now writing of the finest grade of Canary obtainable) ; and maybe one pupil in ten or twelve follow the teacher aceurately, and would pass, in Germany, as one of the superfine. It may thus be easily understood how hard it is to procure a singer which would be regarded in Germany as extra fine.

Another exelusively German custom is, sending Canaries by mail : one or a dozen birds may be sent as quickly as a letter, and are handled carefully; the wooden cage is enclosed in a pasteboard box, which is just the proper size to admit it, and with a glass at each end to give the bird light enough to see to eat and drink. It is an excellent idea, and one which should, and may at some future time, be adopted in America. 
In the large bird-house the birds, after being carefully sorted over, are placed in the proper rooms: some are destined for London, others for New York, and some for South Ameriea. The male birds sent to London by the large dealer's are of two grades, the very fine and the refuse: many females also are sent in the early season. 'The men sent to London are an old hand and a young beginner, the latter sent to make a short sea-trip, and learn the business of being able to withstand the attacks

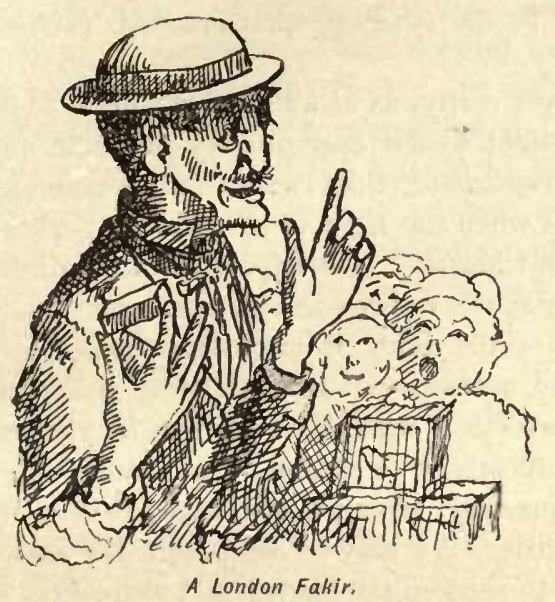
of London sharks. There is one distinet bird-quarter in London to which the German travellers always go; and there they are patronized by both the best elass of bird-dealers, who select fine stock, and hy the "Fakirs," who peddle on the streetcorners, and buy only female Canaries. These females are taken home, and painted, - in London the birds are sold for their color, - and, after the artist's work is finished, they are taken out for sale. The Fakir usually has a stand with patent soap for sale, warranted to wash a negro white, and, as an extra inducement to buy, offers a fine singing cock Canary to the one who draws the lueky paper in any of the packets. In this manner he disposes of an enormous number of silent female Canaries.

The birds selected for America are always the strongest, no matter what the grade of song may be : sickly birds are set aside, and only the strongest and healthiest selected for the trip. 'The men selected for the work of bringing the birds over must also be in prime condition, capable of working twenty hours ont of twentyfour if necessary, and muscular enongh to take their own parts successfully in eases of attempts at stealing, which are ofteri made. 'They must be prime sailors, and, above all, know when to let beer alone. A man combining all of these qualities is a treasure. and is always sure of a permanent position. One man takes charge of five large crates : these crates vary some in size: the usual one has thirty rows of small eages, each row containing seven, which makes two hundred and ten eages of birds to a erate. When sent to America, Fritz is supplied with five hurricane-deckers. - thirty-threerow boxes, - and a large package also. which altogether make about fourteen hundred cages to feed, clean, and water every day. Let the young lady pause and ponder, who grumbles beeause she has the huge task of feeding one Diekie every morning.

'The birds are shipped, either by the way of Bremen, or Hamburg, or London. When all is ready, Fritz takes leave of his family, and starts by train for Bremerhafen, the nearest seaport, which is about twelve hours distant from the eity of Hanover, - the centre of the bird-region.

He always has a man detailed to accompany him to the port, to see to the "bills of lading," to assist in feeding on the day of sailing, and help stow away the eases. seeds, and utensils abourl ship. The trip to the port is made in the night-time in a fourth-class car, - a car that is not encumbered by seats of any kind, - and one is 
at liberty to ehoose the softest part of a hard plank; but Fritz being used to hard knocks, and possessed of a eallous back, is fast asleep in a surprisingly short time. "Change cars" is shouted; and he is up in a second, and out to see that his crates of birds are not landed upside down. An extra mark (twenty-five cents) to the faithful (when paid) railway-man, will insure that his birds are properly handled, and earefully stowed away on the next train.

When Bremerhafen, the seaport from which the North German Lloyd line of steamers sail, is reached, the birds are sent to the steerage quarters, fed, paeked, and made ready for the voyage.

Sharp eyes are required ; as thieves are ever ready, as at all seaport towns, to do their work. A ease-cover is easily slit, the slight wicker eage quickly smashed, and a bird transferred to the coat-pocket : then the spitzbube (thief) wallis off in a mincing, innocent gait, whistling "Where was Moses when the light went out," or perhaps some leading motive from Wagner's "Pilgrim Chorus." The trip, when made direct from Bremerhafen, is comparatively easy as regards railway travel, but, when made via London, the real trouble eommenees: for the route is eireuitous; and many changes, both on ear and by boat, are made necessary before reaching Ameriea. Fritz must ever be on the alert, and has to "wrestle" with three different languages, and as many different sets of custom-house officials, who at times believe the erates are filled with gold watehes instead of live Canaries. He must also take his ehanees for getting spare time enough to feed his birds. As may be supposed, the many changes and eonsequent rongh handling tend to weaken the birds ; and extra eare is required.

The quarters aboard ship vary. Sometimes Fritz and his birds are stowed below in the coal-bunkers, again in the steerage, and sometimes (but how seldom!) are assigned to a room by themselves. In the latter ease he is in his glory, and consider's himself equally as good a man on the ship as the man they eall Captain. He is, however, prepared for the worst. After seeing that seeds, watering-eans, eleaningknives, and other utensils, are safely stowed away, he puts every thing in order for the trip; his first precaution being to see that the crates are made fast; for otherwise, in heavy weather, every thing would break loose, and the effeets be disastrous. 'The erates are six feet high, two feet wide by three feet long, and are made fast by being jammed closely together against the ship's side, and a stout plauk securely fastened from the eeiling to the deck against the outside ease.

Fritz's baggage is not burdensome, consisting of a mattress and blankets; while a small grip-sack contains his personal effects. This grip-sack usually partially conceals a.spare shirt, a pair of Sunday suspenders, and maybe a package of insect powder. 'Toilet articles are dispensed with; as he ean use the fingers of one liand as a comb, and make the other greasy hand act as substitute for a mirror. He is usually put aboard the evening before the steamer is to sail, and his labor of packing and fastening keeps him busy until late at night. $\boldsymbol{\Lambda}$ hasty nap, and he is at work. This first day's labor is easily done, as the ship lies steady at the dock.

The German vessels, which now earry so many emigrants, afford very poor accommodations for the bird-man ; and his quarters are the least thought of. Fritz, at the beginning of the trip, is solitary and alone, but can make friends as fast as any traveller known: for a niee soug Canary is always eonsidered a handsome present; 
and officers, stewards, or anybody who ean render him the least favor, easily obtains the promise of one. Fritz has always an eye on the cabin bill of fare, and generally attains his ends, without the least idea of fulfilling his promise when called upon to make good his wort. 'This special bird promised has either died of eonsumption, been drowned, or devoured by the rats; and, if these various excuses and melancholy events don't allay the wrath of the irate steward, he reluetantly makes the gift of a silent songster in the shape of a female.

After his work is performed, he goes on deek to inspect the greenhorns who are arriving in numbers. 'The noise and bustle do not in the least disturb him : nothing is new to him who has crossed the ocean twenty, thirty, or forty times. No one is on the dock, waving a handkerehief, or bidding him "God-speed: " and he thinks any one who cloes is foolish. Should he espy a blanket which he thinks better than his own, and finds the owner in an abstracted mood, thinking of his liver, or the friends to be left behind, at that partienlar time he quickly transfers it to his bunk, deeming two better than one; and, in ease his own should be stolen, this one would prove acceptable. He is used to the sobbing and earesses always seen when relatives and friends part for a length of time. 'The constant repetition of these scenes render him stony-hearted; and his only cause for regret is, that some of the pretty girls so lavish in their display of affeetion on other and homelier men are not there to bid him adieu.

When at sea, lie must attend strietly to his work: otherwise his neglect will quickly show itself in the health of his charges, and an alarming loss at the end of the trip will be the sure result. He begins his work as early as four o'clock A.s.., to finish in proper season to give his birds a needed rest. A full hour is consumed in eleaning seeds, drawing water, and preparing the different foods; and he has no spare time, even in good weather, if he performs his work thoronghly; and in bad weather his hours of labor are prolonged, consequent on the unsteadiness of the ship, and-the difficulty of moving around.

The feeding and watering cannot be considered heavy work, but is slow and monotonous. It is a labor which cannot be hastened. Each bird must receive its rations of food and water every day, otherwise a long death-list must surely be written. The birds which may become sick must be fed and attended to three and four times every day; as their appetites, during the rum of a disease, are enormonsly developed. Fritz. ehiefly relies on the virtue of hard-boiled egg and maw-seed as a medicine to restore his seed-eating birds to health. Sometimes, during the run of a contagious disease, his labor is doubled, and his best efforts fruitless. Canaries are liable to a disease as contagions and as deadly in its work among them as the small-pox is to the human race. This contagious disease is called the "Schnappen." Cases have been known where only ten birds out of eight hundred were alive in one week's run of this disease. There is no known eure, but it is supposed to come from over-erowded and poorly ventilated rooms in the large bird-louses.

When Fritz once sees this malady at work, his thoughts are bent on suicide; as lifé becomes a burden to him. Every good traveller takes a pride in having the death-list as short as possible; but to work hard. and see his charges die throngh no neglect of his, is certainly not encouraging. His hours of labor are varied. In good weather, with a smooth sea, and every thing favorable, he ean do his work with 
an average lot of eleven hundred birds in ten hours; but in heavy weatleer it may be prolonged to twice that length of time. While the ship is driving before a gale, or trying to fight against one, and performing more anties in her struggles than a clown in the ring, and life is a burden to the poor, seasick passenger, Fritz is obliged to stand up, and do a hard day's work, no matter how great the effort. It is a task in itself to keep one's feet. Then, added to this, is al careful work; as every little box must receive its correct portion of seed, and the nozzle of his

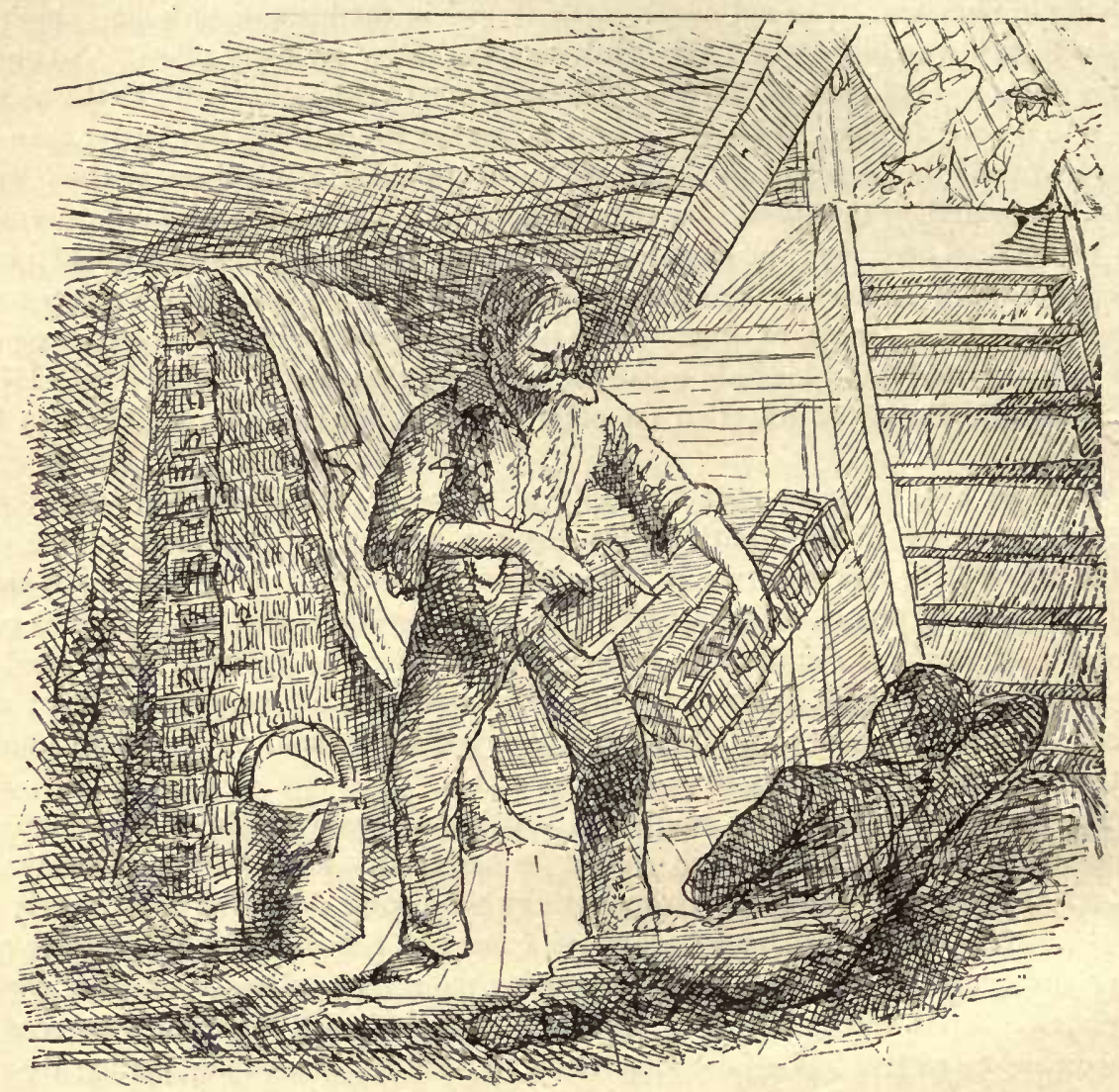

Watering Birds.

peculiar-shaped watering-can must be put through the narrow space into the tiny water-pot. He ean grasp no support: as both hands are engaged, one holding the row of seven birls, and the other the watering-can or seeds ; so his only way is to brace with his feet, and follow the motions of the ship: his body is bent at all the different angles known in geometry; and, when a quick lurch comes, he is oftentimes hurled down among birds. seeds, and watering-cans. It is sometimes serious, and again ludicrous, to witness the effect of some of these disasters, with fifteen or twenty rows of birds capsized, and poor Fritz balanced on his left elbow in the midst of the wreek, with perhaps the bird-seed filling his ears, and the watering. 
can at the angle to pour a large, cold stream just inside of his shirt-collar. But he comes up smiling, as it does not pay to get into bad humor: the capsized rows have to be again fed and watered, as every thing in the seed-boxes and water-pots is spilled ont. When the birds are stowed aft, the work is more severe, as all the water has to be pumped from the forward part of the ship; and in cold weather, when the waves delnge the deck in small oceans, and freeze as fast as they strike, it is oftentimes even a perilous trip. His little eap is tightly pulled over his head;

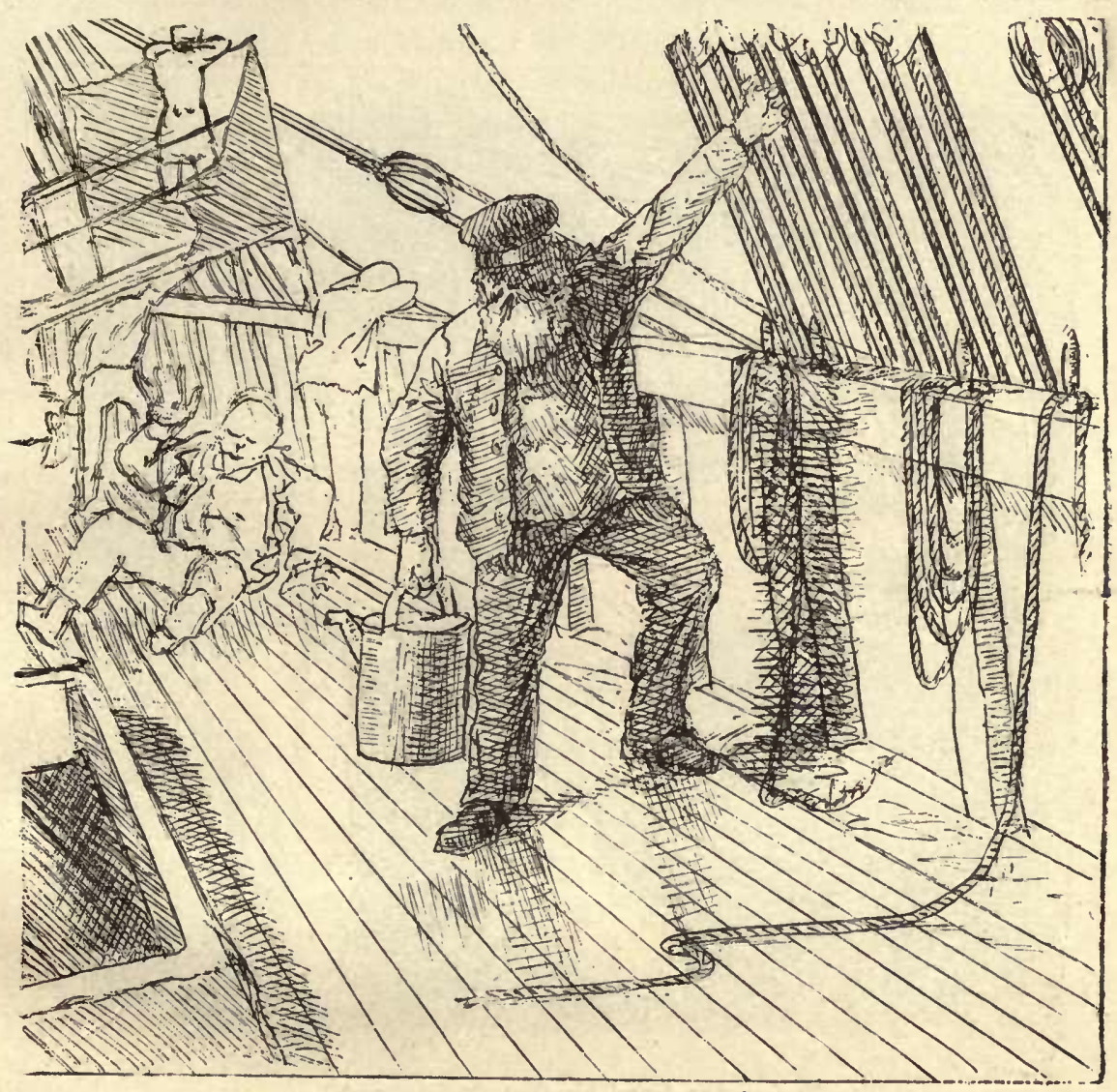

Carrying Water under Difficulties.

and, with teeth shut together with a suap, he slips and struggles over the deck with many a curse on tire raging deep.

Be the waves momntain ligh, he never gets into the eondition of the party who can be seen "looking over the rail, you know."

His first and great eare is his birds : they occupy his every thought, and he sacrifices his own personal comfort for them. If the space assigned him is limited, as it too often is, he tear's away his bunk to give them more room; being willing to spread his mattress on the deck, and sleep there. Fritz must he a man easily 
awakened, so he may guard his tender eharges against their chief enemies, cats and rats : the first are easily disposed of ; as they are readily coaxed into his gift-bearing hands, and port-holes are casy means by which to get rid of them. Dead men tell no tales: dead eats are likewise silent. But rats are his most wily enemies; and, when they make their appearance, many sleepless nights have to be lived through. A constant watch has to be kept on these pests, and even then they do their deadly work so noiselessly that birds are killed under his open eyes. Ship-rats never devour birds, though they are the most voraeious of their race: but the

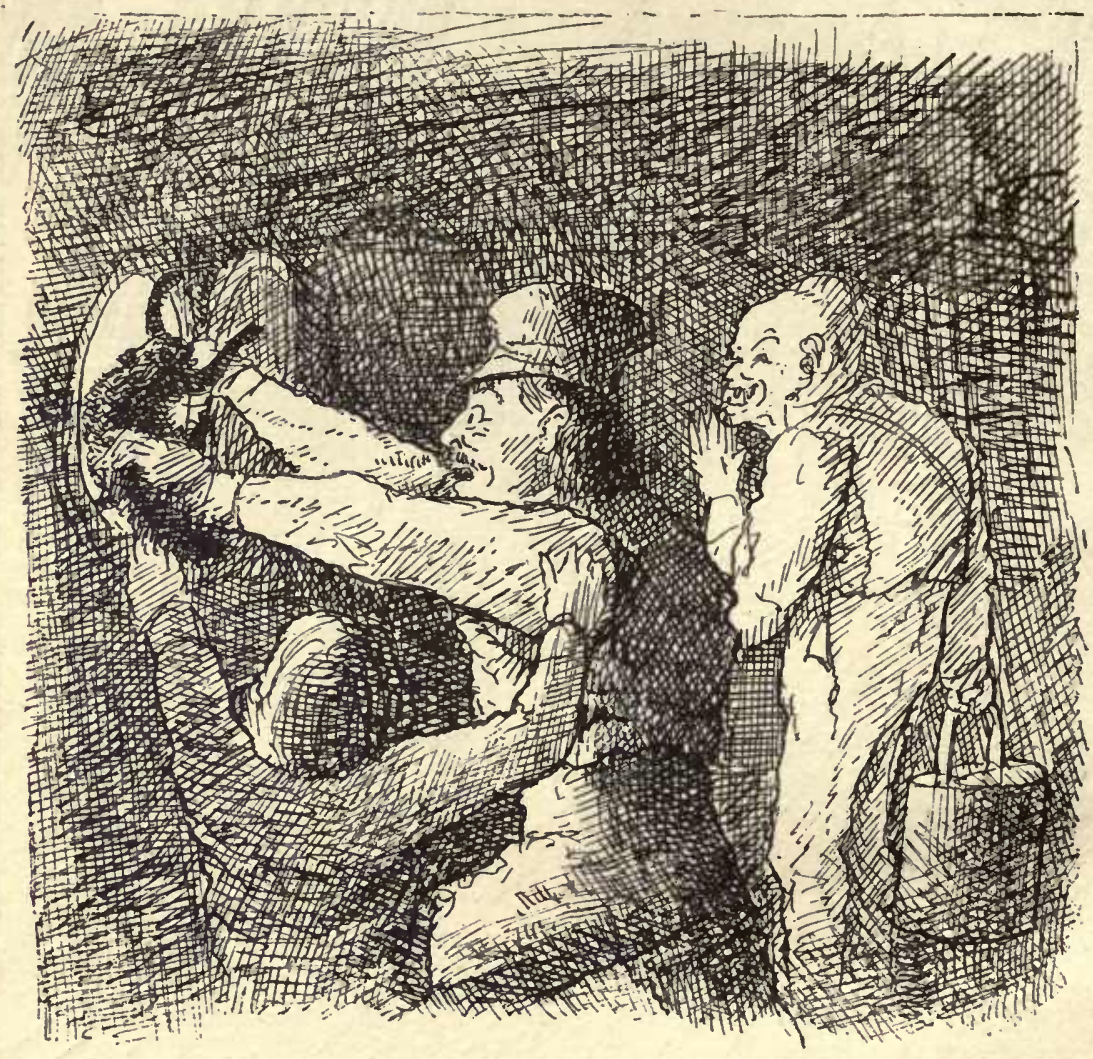

Tommy has killed his Last Bird (already).

absence of fresh water keeps them thirsty; so they are ever on the alert for drink. and bird's blood is their espeeial delight. 'They open a bird's neek, and suek the blood to appease their thirst. I.et one or two once taste the blood, and they return, bringing the entire tribe. Many sehemes are devised to drive them away, but these rarely sueceed. Usually a string is tied behind the eases, and all the arailable tin-ware fastened along the line; and Fritz, at one end, jerks the cord, and makes night hideous in his endeavol's to frighten his plagues away. Fritz and the Old Salt don't agree on the question relating to rats : the Old Salt will not put his foot aboard a craft free from rats, as he feels sure the ship is about to sink: Fritz. on 
the contrary, would gladly take the risk of drowning, if assured that rats are not abostrd.

As may be supposed, Fritz's many travels make him a grand story-teller; and he is regarded among the emigrants as the oracle. Sitting at the dimly lit table after his work is finished, with a well-thumbed pack of eards in his hands, and a nose-warming pipe between his teeth, he relates many a yarn for the benefit of those who have never been in Ameriea. America, the land in which all on board are interested, usually is his subject; and the easy manner in which wealth may be obtained is related free of charge. He tells that chickens run loose in the streets, and anybody may eatch them, bring them to market, and sell them. Everybody is rich ; and, if he did not receive an enormous salary, he would stay there permanently.

'Thus the trip is passed: he makes many friends, and many a poor homesick or seasick passenger is grateful for his little acts of kinduess. He is, by his ready promises, able to procure some of the cabin delieacies, and, smuggling them below, bestows them in the steerage, where they are most needed, giving them, of course, to the old and homely women. The homesick, aged women, who in Germany have bred birls, probably making the long journey to see some of their ehildren, feel the awful effeets of seasickness, and often lie in their miserable quarters, and listen to the eheerful voices of the Canaries. When the bird-man passes around, one says, "God bless the little birds! they make me think of home."

Fritz's life is made up of adventures small and great: nothing astonishes him. His principal cause for anxiety is, that, should the propeller break, his seeds may run short. Cases have oecurred where the steamer, breaking down in mid-ocean, is obliged to make slow headway under sail; it is then that every kernel of seed must be made to last, and the seed once fed must be eleaned and reeleaned, and the birds put on short rations just in the same manner as shipwreeked passengers; but this aecident rarely liappens, thanks to great improvements in the ships of to-day over those of olden times. Fritz may be put aboard of some old boat rendered leaky by hel numerous battles with the waves; and a ease has been known where a ship of this description has arrived with every eage and bird wet, the ease-covers rotten, and every thing soaked by the sea beating through the decks above, and pouring through the battered-in port-holes.

Sometimes Fritz is sent to Australia, where he is intrusted with the entire business of trading and selling the shipment. He usually returns with a valuable stock of the faney feathered tribe, ineluding Cockatoos, and hundreds of gorgeously plumed Paroquets.

Where two men travel together, with double the number of birds given in charge of one man, neither the work nor the risk is so great; as the chances for keeping wateh is better, and, should one man meet with an aceident, the birds would not starve. The chance which a man runs of breaking a limb or an arm on the slippery, billowy decks is not slight; and, if such an aceident should happen to a man when alone with a cargo of birds valued at five thousand dollars, the loss could not be made up in a whole season's business.

The character of Fritz, sketched above, has been taken from the best of the men who travel : to be sure, there are seapegraces among them, who, on account of the numberless temptations in their paths, fall vietims to drink, and other bad 
habits, that too frequently prevail in the steerage, and shirk their responsibilities. But the appearance of the birds at the end of the voyage, and the losses, indicate very plainly whether the man is careful or careless.

A man may, through many of the causes related, have an occasional disastrous trip despite his best efforts; but a constant serics of losses is quickly and rightly laid to neglect, and the ranks are thinned of the bad men. As a rule, Fritz is a hard-working, good-natured, happy-go-lucky chap, who would not change his lot for one less adventurous. His mode of living makes him careless and daring, and thus he lives and dies in the business.

Few ladies while caressing their pets, and bestowing on them their daily delicacies, imagine for a moment the dangers through which the feathered emigrants have passed in their younger days while coming to this country. If, after they peruse the above, Dickie receives more considerate care, the writer will be satisfied. 


\title{
FOOD AND CARE.
}

\author{
MONTHLY SUGGESTIONS RESPECTING ALL KINDS OF BIRDS.
}

\section{OCTOBER - NOVEMBER.}

All birds at this season require extra food. Canaries should have, all through the year, German summer rape, Sicily canary, and millet seeds mixed in equal parts ; and care should be taken to have the seeds fresh, and of best quality. You can usually obtain these best at a bird-store, as a "bird-man" who uses seeds is more particular than is the grocer or druggist. In addition to the seeds, feed Canaries, daily, one-fourth part of a hard-boiled egg, both yolk and white, and mix with it as much cracker-dust as can be taken up on a ten-cent piece. Fresh water, both for drinking and for the bath, and plenty of coarse, washed gravel, daily, will usually keep a bird in health. Twice a week give a small piece of sweet apple or lettuce.

If the bird has not yet finished moulting, keep him in an even temperature of about sixty-five to seventy degrees; and let him lang where there is no possibility of a draught.

If not yet in song, hang a half-inch strip of raw, fat salt pork in the cage, and let him pick at it for a week or so. There are also tonies for loss of roice, and song restorers, that can be used with great benefit. There have been cases where a Canary has not sung for two years, and proper treatment has fully restored his voice.

Iu addition to being fed as above, such a bird should hang where he can hear a fine singer.

When the little red insects so sap a bird's strength that he will not sing, use the German msect-powder; eatch the bird, and dust it through his plumage, and thoroughly wash the cage; if it is a brass eage, have it regilded, - a sure method of destroying the vermin.

Moeking-birds, Blackeaps, Japanese Robins, Thrushes, 'Troopials, and all softbill burds which eat the prepared food, may be fed on the moist food just as it is bought; but they keep in better condition and song if an equal amount of raw earrot, grated, is mixed with the moist food. Carrot must be mixed witli the dry food. Give these birds daily a teaspoonful of ants' eggs soaked, and mixed with the food. A meal-worm or two, and a little lean, raw beef, scraped fine, will also be an aid to renewed song. Prepared-food eups ought to be washed every other day, to prevent the food from souring. " Plenty of gravel, and fresh water for drinking and the bath, should be daily given. 
Parrots do not all eat the same food. One will thrive on hemp-seed, another on unhulled rice and hemp, while a third requires these two and cracked corn : all these may disagree with a fourth. Generally the three seeds are mixed in equal parts, and a parrot allowed to select those he likes. The effects of the food should be watched, and the bird deprived of either that seems harmful. For a drink, coffee is much better than water; but, whichever is used, let most of the liquid be absorbed in cracker or stale bread. Roasted peanuts may be fed, but avoid the rich, oily nuts, and all greasy food and chicken-bones. A bird fed on greasy food, which makes the blood impure, will soon pull out his feathers; and it will take months to restore him to good health. The larger your Parrot-cage, the healthier your bird will keep, and the more freely will he talk. The stands, either with or without swings, are preferable to any cage. A bird should learn to stay on the stand withont being chained, and on it keeps in much better plumage, and, with the greater exercise, in better order. Special cages are used to put over the stands at night.

\section{NOVEMBER - DECEMBER.}

If any male Canary is now out of song, there must be some ailment that requires "heroic" treatment. Catch your silent bird, hold him so that his back is against the palm of your left hand, then lightly blow apart the feathers on his breast: if his breast-bone is sharp, and not well filled on each side with flesh, either you are feeding him poor seed, - in which case he eats almost constantly, and gets in thinner flesh daily, - or else his digestion is poor. A bird in that low condition may also have insects, which fact a white cloth spread over the cage at night, and examined early in the morning, will diselose. In any case make a radical change of food: if the bird has been eating hemp-seed, - though this is not likely, - give him not another grain; if he has been eating the regular proper seeds, one-third each of German summer rape, Sicily canary, and domestic millet, withhold all of them for a week, and feed him only the hemp. Watch and see if he has strength enough to crack it; if not, crush it for him. If possible, let him have a cage fourteen to twenty inches long; strew its whole pan with gravel, and give the bird, daily, besides all the hemp-seed he can eat, one-third of a liard-boiled egg ehopperl fine; also put a piece of sweet apple where he can eat all of it he desires. If necessary, continue this diet of hemp-seed two or four weeks, or until the bird is in fair physieal condition; then return to the regular bill of fare. If a Canary has the asthma, which he shows by hard breathing, and making a squeaky noise, hang a piece of raw, fat salt pork in his eage, first sprinkling it well over with strong cayenne pepper. Feed also plenty of rape-seed, and but little of the other seeds. Frequently, when these homœopathic remedies fail to alleviate, some one of the numerous "birdcures," "tonics," or "restorers," will be found beneficial. If you have conficlence in your bird-dealer, let him see the bird: he can usually decide what ailment the - bird has, and will prescribe proper remedies.

The soft-bill birds are not yet many of them in song, and need extra food, and careful attention. Set it down as a rule never to be deviated from, that, when a male bird is out of song, he requires better food, and more care than usual. Buy the richest, most " meaty" food obtainable, and mix with it raw carrot fresh grated, 
aceording to the bird's taste; ald a thimble or two full of ants' eggrs which have been moistened in tepid water; give daily, also, two or three meal-worms; if the bird seems to require more, mix with the food a teaspoonful of moistened pokeberries, and give him an entrée of raw lean beef, scraped fine. Except under compulsion, birds recognize no fast-clay : on the other hand, my impression is, birds understand well the subject of movable feasts; they feasted yesterday, and want to have another feast moved in to-day.

Birls that are to be used the eoming season for breeding ought now to have a cage separate from other birls, each one in a home of his or her own, where proper food and eare, as is befitting, can be given to one who is to engage in the great labor of rearing five, ten, fifteen, or more, descendants. Birds that are kept alone in a eage will get, with special eare, into good condition, and are more likely to mate, and will certainly produce better stock, than if left to really care for themselves right up to mating time.

Do not forget that good fresh water is of greater importance than food, to any bird.

\section{DECEMBER - JANUARY.}

Many statements that would naturally be placed under this heading are included in other articles which so thoroughly treat the subject that little is left to be written up fresh for this column. For instance, the Parrot article diseusses quite fully all the usual diseases to which that bird is subject, and states the proper remedies. In such a ease, only some uncommon disorder, as shown in a bird brought to me for treatment, perhaps, can be explained.

If we have to deal with disagreeable facts, and the items seem - are - prosy, bear in mind, that while the contemplation of diseases, and suggestion of suitable remedies, many times inspire one with great enthusiasm, the thoughts jotted down do not always make bright, jolly reading. On " hospital clays," - clays when many sick birds are brought in for inspection, suggestion, or, in some cases, immediate cure, 一 the writer's task, recalling an idea from the "Pirates of Penzance," taking one consideration with another, is " not a happy one."

Here comes No. 1, with a sick bird. "Is Mr. H. in?" - "Yes, I am he." "Well, Mrs. M. sent me with this bird, to see what you can do for it. The basement window was open, and a black" - I thought likely the bird wonld die before she would finish even the first chapter; so I took him to another apartment, and, on examination, discovered a leg broken midway between the hip and joint below. I drew the leg out slightly, easily, taking hold just below the break, then, with finger and thumb, pressed the two ends of the break into position, sheared the feathers off for a half-inch each side the break, and-wound a piece of cotton cloth, threequarters of an incli wide, twice around the leg, and seeured it with thread. A halfinch splint of pine, one-sixteenth of an inch thick, and one-eighth of an ineh wide, was placed inside the leg, and another outside, and secured in their places with thread. The perches were remored from the cage, and the seed and water put in shallow dishes on the base, so the bird would not be compelled to exert himself. In three weeks he will be as well and sprightly as ever.

No. 2 comes rushing in. A short man, dark complexion, excited, talks rery 
fast, French: "Monsieur! zis paro", he hang in window, he fall ! Och! Mon Dieu ! up tree steorry. Ze madame will keel me; och ! Mon Dieu : ze paro' do not move, he must be var seek." — "Oh, no, John! a glance tells me the hird is not sick." At that a joyful smile replaces John's look of agony. "He is not sick, John, he is simply dead." I feared for a moment it would be flowers for two; but John revived, and returned the next day to say that the Parrot had a "beautiful funeral." It is daugerous to hang a Parrot out of the window if he ean work the nut loose that holds the hanging-ring to the cage.

The feathers on any kind of a bird sometimes co:ne off in patches, and new cues do not grow : this is usually owing to improper feed, - either too rich, and the blood is out of order; or too poor, and the bird derives little nourishment from it. A bird fed on all sorts of things will have all sorts of diseases. Feed a ragged, seed-eating bird on a mixture two-thirds German summer rape, and the one-third equal parts Sicily eanary and millet seeds. Iíeep him in a eage twelve or sixteen inehes long, with plenty of gravel for a daily bath, but let the bird remain in a dark place - execpt during the bathing-hours - for four to six weeks. At the end of that time the plumage will usually be perfect. If the bird belongs to the softbill family, keep him on a diet of boiled egg and boiled potato mixed; or, if he refuses that, give the dry, or box, prepared food, witl grated raw eariot mixed with it ; confine in darkness - in a large eloset, or room that can be made very dark - for six weeks, or until the plumage is perfeet.

Asthma, or hard breathing, if not cheeked in season, greatly injures the vocal

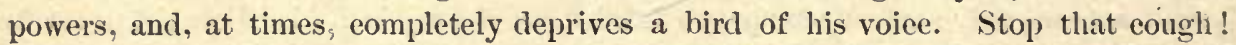
if you let it " run wild," asthma is sure to follow. In asthmatic cases feed nearly plain rape - from which, with a sprinkle of water, you have washed the dust - and a little eanary seed; feed daily, also, bread and milk sprinkled with red pepper, and let a pieee of raw, fat salt pork hang in the eage as long as the astlima continues. Put three drops of the tincture of aconite in a half-gill of water, and let the hird drink as mueh as he will each day; mix a fresh dose every morning. I have known many bad cases alleviated, and some of them eured, by the use of regular bird tonies and cures. In a severe case, probably incurable, it is humane to resort to chloroform, and thus relieve the bird of lis misery.

When a bird gets mangled beyond possible recovery, it is evidence of the kindest heart to administer ehloroform. To do this, make a paper lorn large enough to bold the bird ; let six drops of ellloroform drop into the bottom, put the bird in, and elose the top of the horn. His suffering is ended. Death is painless and instantaneous.

\section{JANUARY - FEBRUARY.}

If I should write an item on dress-eoats, or thirteen columns on the shades of felt hats now worn so extensively, the first suggestion to an intending buyer would be, do not throw away money on a poor artiele. So, too, if you want a diamond, it is better to purehase a small and perfeet white stone, than a larger one that has specks in it, or is off eolor. In regard to ail kinds of live-stock, more than any other line of goods, it is wise to purehase only the best. Above all other kinds of merchandise, it may be truly sairt that cheren-live-stock is dear at any prieé. - Good 
birds require less care than poor ones, and sing better as well as more lours in the day. Some birds that can be bought cheap constantly need tonics, and many extra moments of attention.

Birds are kept for the pleasure they afford, I take it; but if, instead of sprightly songs, there are stupid silences, and, instead of bright eyes and sprightliness, there is heaviness, and a clouded vision, then birds give us only pain; and so the cheap bird is in the end the most costly bird you could buy. I would like to blot out that word "care," whenever it relates to diseases, from our bird-dictionary : "food" sounds pleasantly enough; and though I am now frequently too busy to linger in enjoyment at a festal-board, still there is a sort of mince-pie-peach-preserve aroma about the word that is wafted way up here from boyhood's hours secretly spent behind the pantry-door.

In winter, and especially at the time when the mercury drops lowest, let every bird eat all he will of seeds and foods that are proper for him: if a bird seems to care little for fresh seeds, or prepared food, furnish several good feedings of lettuce or chickweed, celery or apple. It will surprise you to see how much "green stuff" a bird will eat in a day, and how beneficial it is. Birds that are mated will devour - a pair of them - four or five good-sized leaves of lettuce a day, and none will be wasted if it is given at intervals : a good quantity of green stuff is absolutely necessary while the pair are being fed on the egg-paste.

The yellow millet-seed in general use to mix with canary and rape seeds, for Canaries, is better for them than only the canary and rape: it is quite as nutritious as the canary-seed, and not so heating. The white, or French, millet is fed to the small African Finclies, and small Japanese Nuns: its hulls are soft, so these tiny birds can shell it easily. It should be mixed for them with an equal quantity of canary-seed.

The aviary collections of these small birds-should have, oncc a wcek, a good sprinkling of cayenne pepper put in with the gravel on the base of the cage: their bathing-dishes should be wide and shallow, and contain water only to the depth of one inch and a half. A wide and long dish permits a large number to bathe at once, which is evidently greatly enjoyed by them, and a real pleasure to an observer. These birds like a temperature of sixty-five to seventy degrees. If small nests, either of rush, and shaped like a barrel, and open at one end, or of wire, and lined with canton flannel, are furnished, many of the small birds, such as Strawberry Finches, Orange-breasts, Silver-bills, and Cordon-bleus, and the several kinds of Japanese Nuns, will lay, and then hatch and rear the most tiny specimens of the feathered tribe ever seen in cages. When hatched, the young Finches are only onethird the size of a tiny Humming-bird.

When there are young birds of these varieties to be fed, the cage should be supplied with maw-seeds and millet-seeds that have been soaked over night in warm water, and then strained; also yolk of egg, and sponge-cake mixed with dried ants' eggs soaked.

Many varieties of soft-bill birds are now again commencing to sing. Enconrage them with the additi $n$ of a few dairties to the regular bill of fare. A teaspconful of ants' eggs soaked, and mixed with the prepared food, a small quantity of lean, raw beef, scraped fine, and put in a separate dish, a few poke-berries soaked, and 
mixed with the food, will each add many variations to the song; while a lively waterbath, and a long, but not too strong, sun-bath, are sure to have beneficial results. The perches for these larger birls should be about three-quarters of an inch in diameter; and there should be five perches in cages twenty-four inches long, and only three perches in smaller cages.

\section{FEBRUARY - MARCH.}

Canaries, and many other species of birds, are troubled with inflammation of the intestines. The causes most likely to produce this are over-eating, especially of " high" food, like eggs, or partaking of green stuff which is in a state of decomposition. Sometimes the drinking-water, which should be fresh and elean each morning, is left unchanged for several days. The symptoms indicate acute pain in the region affected. The bird is dull, cares little to move about, is silent, and often rests bodily on the perch. There is no desire to eat, and great thirst; and the bowels are usually costive, though sometimes the bird has a diarrhœa. Frequently there is vomiting of the bile and mueus. An examination, condueted rery gently, will reveal a swollen and distorted condition of the lower part of the abdomen, with some change of color, varying, according to the stage of the disorder, from pale to dark red, amounting in very dangerous cases to a very dark hue. This inflammation may be cured if treatment is commenced at once, and a decided course followed. Let the bird be put, if possible, into a clean, dry cage, and hung in a. warm, well-ventilated room, and the food changed, and be entirely non-stimulating, but at the same time nourishing; plain crackers nixed with new milk, to which should be added a little moist sugar. Let the bird have only this food for a clay or two. If the bird, in the commencement, is constipated, the bowels . should be opened witl two or three drops of pure oil; but, if there is much inflammation, purgatives should not be employed.

Counter-irritation will do much good. Paint the lower part of the abdomen, by means of a camel's-hair brush, with warm turpentine. This gives relief, and should be repeated once or twice if necessary. Opium is of great service in this complaint. Place, therefore, every morning in the fresh water, thirty drops of ipecacuanha wine, and fifteen of laudanum, along with a bit of gum-arabic, and two or three grains of the nitrate of potash. But in more severe cases we prefer opium in eonjunction with belladonna, - ten drops of each of the tinctures in the drinking-water, - a little gum, and a little sweetening of glycerine.

Breeding-birds can be fed on. rich food without the danger of evils resulting therefrom that birds not at work might incur. Birds which are in thin physical condition, so as to be enfeebled, or are, through carelessness, moulting, will not usually mate; and in exceptionable cases, where they mate and hatel, it is seldom the young birds live. Only a manual examination - the actual taking of the bird in the hand - will disclose his real condition. Frequently the expression is heard, "My bird is too fat to sing;" and it would seem to be the fact, since he looks so large, because the feathers stand out straight - are puffed up; but snch a bird is usually found to be a mere skeleton, and greatly in need of appetizing food and a change of diet. Feed such a skeleton eracker soaked in as much sweet milk as it 
can absorb, and give twice a day as mueh egg chopped fine as will lay on a twentyfive-cent piece. Let the mated birds have the boiled eggs chopped fine, and a little craeker-dust mixed with it, fresh three or four times a day, plenty of apple or lettuee or chickweed, and an abundance of coarse gravel. Before each laying furnish pounded oyster-shells, or erushed old plastering. 'The German summer rape-seed, Sieily eanary-seed, and the millet-seed, equal parts mixed, should be the regular diet: a small quantity of hemp-seed will also be beneficial.

When young birls are a week old they may be transferred to a new, elean uest, which should be the same style as the old one: if the nest is properly cared for, the birds will selclom be troubled with insects; but, should these pests appear, use the German insect-powder, following strictly the directions on the package.

When a bird is moulting out of season, it is because he has a cold. Follow the suggestions heretofore made for such cases.

\section{MARCH - APRIL.}

Fits claim many birds, that, if judiciously fed, would have lived many years in health. Some birds are naturally so weak as to be subject to the spasms of fainting, and in such a ease the remedy is a sprinkling of cold water.

Another kind of fit has an apoplectie nature; and, besides the usual causes, it is often induced by hanging the bird in the hot sunshine. Many persons hang a eage close to a window in strong sunlight, where the heat is greatly augmented by the glass. It is certainly very desirable, and, indeed, neeessary to health, that a bird should have sunlight; but it is cruel to hang a bird in a position where in half an hour he will drop to the bottom of the eage gasping for breath, or in a fit.

Whatever may cause fits, the Canary, or other small seed-eating birls subject to them, should have carefully regulated plain food, plenty of rape-seed, some milletseed, very little canary, and no hemp, and, occasionally, to aid digestion, a drop or two of eastor-oil.

When soft-bill birds are subject to fits, the same eare must be exercised in regard to the diet. Use, if obtainable, ouly the dry prepared food, and mix with it an abundance of grated fresh earrot. Every third day stale bread soaked in milk may be given, and the other food withheld.

The claws of Canaries, and many other birds, especially Bullfinches, grow very long and hooking, and need to be cut. Hold the bird up to a strong light, and cut the elaws with a sharp pair of scissors, avoiding hitting the vein in the claw.

The bill, or beak, may grow so long, that it is almost impossible for the bird to pick up his food. Usually only the upper mandible needs to be eut back, and should be left of natural length, and, of course, longer than the lower. After being cut with the scissors, the round edge may be scraped off with a knife; and the encl of the bill should not be left blunt, but should be brought, by scraping, to such a point as it naturally would have.

For asthma in birds, a remedy used with great success is a small lump of earbonate of ammonia. Put a fresh piece in the elean drinking-water each morning. In three or four days' time a cure will be effected. 
Pimples, or obstruction of the rump-gland. - This is a gland which forms part of the structural economy of every bird, and is intended for secreting the oily substance required to render the plumage supple, and impervious to wet. The bircl presses this gland, which is sitnated just above the rump, with its bill ; and the oil oozes out: if this is not done frequently, the opening is apt to get clogged; and, there being no vent for the increasing contents of the gland, it gets hard and inflamed. If you see your bird sitting about with its tail bent downwarls, and of ten turning its head to peck at the hinder part, where the feathers will most likely appear ruffled, suspect that this is the case, and if, on examination, you find it so, rub the gland with some fresh butter and sugar mixed together, at the same time clearing and enlarging the aperture with a needle or sharp knife. Some persons cut off the gland altogether, but this is a bad plan; for, although it effects a cure, it deprives the bird of a useful organ, for want of which at the next moult he will probably die. Bechstein recommends a salve of litharge, white lead, and olive-oil, to remove the obstruction; and 'Tscheiner, another German naturalist, states that this evil may be remedied by puncturing the gland, compressing it frequently, batbing the bird with a syringe, and plucking ont some of the tail-feathers: in the renewal of the feathers accumulated fat is absorbed, and the gland sufficiently relieved to resume its functions.

As the heat of summer approaches, every cage should be provided with an awning that may be easily put on wlien the bird has his daily sun-bath. Cageatwnings, for small round and square cages, are now manufactured in large quantities, and can be found in the shops. For the large cages, wires may be bent over the top from side to side, and the plain " duck" to be had at dry-goods stores may be stretched over them, and fastened witl simple wire hooks. The awning should extend two inches or more out from the eage.

\section{APRIL-MAY.}

Nestling Canaries, as soon as they can feed themselves, should be put into flight-cages as large as can be conveniently used : six birds should have. a cage not less than twenty inches long, and twelve birls should have a cage not less than thirty inches long. Not more than twelve song Canaries should be kept together, and even this number is more than many breeders permit in one cage. It is shown, that birds grow faster and stronger, keep in better feather, and learn to sing more sweetly, where not more than six are in one cage.

When you have reared Canarięs of good shape and fine feather, the next point is, to cultivate their voices.

Canary-songs are not entailed: the son inherits little or no voice from the father, and sings his parent's song because he hears it only and no other. And. while his vocal organs are very different in shape from those of Thrush or Nightingale, and his windpipe is so contracted in comparison, that he cannot, by any system of voice-building, utter notes that will comprise a song identical with theirs, still, let him in his youthful weeks hear the silvery trills and plaintive modulations of the Nightingale, the grand aspirations of the Lark, or the charming whistling of the Virginian Nightingale, and you may be sure of having, after three months of such instruction, a Canary with nearly all of the prized tweuty odd notes. 
His attempts to imitate these lirds gradually enlarges his windpipe, and repeated efforts finally enable him to utter their notes.

While the English Nightingale and the English Lark are preferred as instructors, since of all bircls they have the greatest range of notes, tlie scarcity of good songsters has brought the Virginian Nightingale, as master singer, into very general use.

It is, perhaps, unnecessary to state, that he performs the duties of the position well. In a class of six male Canaries, selected at random, and placed under his tuition, four at least will show well-cultivated voices; and if the Canaries, during the months of instruetion, are kept each in a cage by himself, every one will be a good singer.

'The seed given young Canaries while they are learning their songs makes a great difference with the tones of voice.

If only the plain rape is given, the voice will be soft and sweet; and this will be the ease if some millet-seed is mixed with the rape: but canary-seed makes the voice louder and harder; the larger the proportion of canary-seed given, the shriller the voice. A small quantity of hemp-seed may be crushed and given daily. After a bird's voice has been trained, and the style of song is fixed, he may be fed on the regular mixed seeds, one-third each of eanary, rape, and millet.

Green stuff, like lettuce, chickweed, or apple, should be given young birds three or four times a week; and, of course, there slionld be an abundance of coarse gravel furnished, and the usual opportunities daily for water and sun baths. Young Mulebirds, if it is desired they should retain the characteristies of the father bird's song, should liear the song of the same kind of bird only.

'Thus, Goldfinch Mules should hear only a Goldfinch, and Bobolink Mules should hear only a Bobolink's jingle. Young birds, in the flight-cage, may be healthy and strong, and occasionally take naps during the day; but generally they are lively, flying about a great deal. If a bird sits moping, with his feathers all puffed out, catch him ; and if he is in thin condition, and there seems to be inflammation of the abdomen, it is certain his digestion is bad; either sour egg, or else stale green stuff, has been eaten. Drop two or three drops of eastor-oil into his mouth, or remove the water-cup an hour or two, and return it with a goodly supply of codliver oil on the water's surface. Either remedy generally effects a cure.

Most diseases of young birds arise from indigestion, and inflammation of the bowels; and if the breeder watches for these diseases, and treats them promptly, he need have little fear of losses.

Careful attention to clieting, and keeping the invalids near the fire, will do as much as any thing to restore health. Heat is indispensable, and it is astonishing to what an extent sick birds are benefited by it.

When the young birds are about two months old, they commence the first moult, shedding only the body-feathers. The moulting is a natural process, and is not attended with any danger to the birds if reasonable care is given to them. During moulting they are, to a greater or less extent, deprived of a protecting covering, and, in consequence, should not be exposed to draughts : they ought also to have daily a little soft fool - egg and cracker - with some cayenne pepper mixed in it. 


\section{MAY - JUNE.}

Plenty of fresh air is as beneficial to the feathered tribes as to people; and those having regular bird-rooms, where twenty-five or more birds are kept, know how important it is that the ventilation be as perfect as possible. Good ventilation should be secured for five birds, or even one; but draughts should be carefully guarded against. At this season of the year a sort of frenzy seizes us to get out of doors, and roam in the fields; to throw ourselves on the ground beneath a tree. and "enjoy nature." We recline on the ground; and afterwards for the next forty-eight hours we enjoy nature too fully, as many of the most natural aches anc pains seize us in consequence of the indiscretion. In the same way, when the first clear, warm spring days come, we liang the bird outside of the window, regardless of how hot the sun shines, or how chill the wind blows, and are surprised that on the next day the bird's plumage is all rufled, and, afterwards, that he has a fit of sickness which, perhaps, terminates fatally.

Male Canaries, that have not been mated, are apt to act dull, and to sit stupidly on the perch, and refuse to eat much or to sing any. This is generally the ease where only one bird is kept. If possible hang another singer near him, to eheer him up; change his location, giving him considerable sunshine; let him have, each day, some morsels of fresh green stuff, or a small portion of egg, and thus tempt his appetite. If these things fail to arouse his spirits, it is better to get a mate for him than to lose him. The pair may be mated, but it is not necessary to furnish a nest. Young Canaries or Mules may be kept tame by teaching them, when they commence to help themselves to food, to eat from the hand. It is a very simple matter then to teach them to draw up the food in a thimble, to feign death, to fly away and return to the finger, to climb the ladder of fingers, and to do other tricks of a similar nature. In the earlier lessons it will be necessary to appeal to the bird's want of food, but after he has learned a few tricks he will give close attention at any time. Birds under instruction of this kind learn more readily if kept where they do not see any other birds. Reward each step of progress in learning with one or two hemp-seeds.

Our native wild birds that live on seed usually require a mixture of two-thircls canary-seed and one third millet. This mixture is the proper food for Nonpareils, Bobolinks, Linnets, Indigo-birds, and Rose-breast Grosbeaks : the Yellow-bird, or Goldfinch, should have maw or poppy seed in addition to the other two seeds.

These wild birds, when first caged, should be kept in a quiet place, and watched to see that they find the seed and water dishes; as it sometimes happens they are so timid as to constantly flutter about, and, not finding seed or water, die of thirst or hunger.

For the Grosbeak, the proper eage sliould be eighteen to twenty-four inches long; for the other birds mentioned above, the cage should be twelve to twenty inches.

While all of these birds are very timid when first caught, after three or four days some commence to sing; and in four to six weeks any one of then will take food from the hand. 'They should hang seven or' eight feet from the floor.

Young Mocking-birds should be carefully guarded against the ravages of the 
red insects commonly called birl-vermin. Cover the cage at night with a white cloth, and if there are vermin they will be found on the cloth in the morning. Clean the cage, and dust the German insect-powder into the joints; and eatch the bird and sprinkle the powder under his wings and around bis neck. Two thorough applications are usually sufficient.

The food for nestling Mocking-birds is boiled egg and boiled potato mixed in the proportion of half an egg to a medium-sized potato. This will furnish enough for one bird one day. It should not be given all at once, but put in the cage fresh two or three times a day: otherwise it will get soiled or sour.

Spiders and grasshoppers may be given alive, and a few whortleberries may be furnished for dessert. After feeding the egg and potato for three or four weeks, a teaspoonful of the dry prepared food for Mocking-birds should be mixed with it: and the quantity of egg and potato and food can be inereased as the bird seems to demand it. Later on, the grated, raw carrot and the prepared food ean be given in place of the egg and potato. Young birds do not require ants' eggs, meal-worms, and berries; but these should be furnished in small quantities when the birds are four or five monthis old.

The Mocking-bird eage should be not less than twenty-two inches long, and one twenty-four or twenty-eight inches is better still. For other information on these birds, see the article on Mocking-birds.

\section{JUNE - JULY.}

Young birds commence to moult when six weeks old, and it continues for two months. It is a season of special danger to young birds moulting for the first time. 'The symptoms of the approaching moulting may be readily seen. The birds beeome sad and sleepy in appearanee, and sit upon their perehes or the bottoms of their eages, with their heads under their wings, for the greater portion of the day : while the floors of the eages are eovered with small pin-feathers, which they shed during all the time until the new ones appear. They are apt to eat very sparingly, and only that description of food which they most prefer, and which should always be supplied to them. Boiled egg, both white and yolk, with bread-erumbs or cracker-dust mixed with it, should be daily given. Great care must be taken at this time to give them the richest kinds of food, such as hemp-seed and spongecake. One of the worst things that ean happen to a Canary is, to be put at this season in a cold place, or where a draught ean reach him. He should, so far as possible, be kept in an even, warm temperature, and be put every day in the sunlight for at least an hour. Should the moult prove uncommonly bad, give him daily a piece of sponge-cake soaked in sherry wine: this will greatly invigorate him. Every day or two, so long as he seems drooping, blow a little sherry wine over his feathers, and then hang lim in the sunlight, or near the fire.

Coarse gravel is very benefieial in the moulting-season, and care should be taken to daily furnish an abundant supply.

Other seed-eating birds should be treated in the same manner as recommended for the Canary.

Mocking-birds, 'Thrushes, and other soft-bill birds, should also have the same 
careful attention during the moulting-season. Each bird should he fed stronger than usual ; as the shedding of feathers is an exhausting process, and attended with more or less debility. Raw lean beef scraped fine, and an extra supply of ants' eggs and meal-worms, will all be helps to a quick moult that will leave the bird in good order.

Young Canaries may now be taught their songs. Soon after they are able to feed themselves they begin to twitter; and, even at this early period, Bechstein says, the male may be distinguished from the female by the more connected character of his song. 'Then is the time to begin tlie course of musical instruction: the birds to be taught should be put into separate cages of small size, which should at first be covered with a linen cloth, and afterwards with some thicker substance, so as nearly to exclucle the light; place them in a room by themselves, as remote as possible from all discordant and distracting sounds; let a short air be whistled or played to them on a flute, flageolet, or bird-organ, five or six times a day, and repeated on each occasion about that number of times. Especially in the morning and evening, and at feeding-time, should these lessons be given: from two to six months is the time required by the birds to learn the tune perfectiy. The time required varies; some having better memories, and some being more docile and attentive than other's. Should you wish your bird to acquire the strain of any ather feathered performers, you must hang him in the room with them, and let him hear as little else as may be. A well-instructed Canary, Virginian Nightingale, Goldfinch, Sky or Wood Lark, may be the inusic-master. St. Andreasberg Canaries are, most frequently, taught to imitate the warbling of the Nightingale; and in Thuringia, as Bechstein tells us, "the preference is generally given to those birds as teachers, which, instead of a succession of noisy bursts, know how, with a silvery, sonorous voice, to descend regularly through all the notes of the octave, introducing, from time to time, a sound like a trumpet."

13ird-organs are used with great success; a young Mocking-bird or Canary quickly catching an air, and giving it just as expressed by the instrument. These organs are played by turning a crank, and usually have six or eight songs. The list comprises such pieces as "God save the Queen," "Yankee Doodle," "Up in a Balloon," "The Campbells are coming," and waltzes, airs from operas, etc. The price of an organ is ten dollars. We properly box them, and deliver to any express company on receipt of the above amount. Young birds may also be taught to sing and whistle by receiving the daily lessons from the lips of any person who is a good whistler. During most of the time when the instructor is not whistling, his pupil should be kept covered in a quiet place, so his voice will be fresh and sweet, and not worn out by over-use.

\section{JULY - AUGUST.}

During the moulting-season, now close at hand, there are opportunities to so feed a bird as to entirely change the color of his plumage when he again gets into full feather. When feeding for color, the bird should be kept in an even temperature, warm enough so that he will moult quickly, seventy degrees being about right. 'The proper coloring-food is put up in tin cans, each can containing sufficient to color 
one bird. The price per can is one dollar, or, if sent by mail, one dollar and ten cents. Full directions accompany each package. When using the coloring-food, very little seed should be fed: otherwise the food will not act.

Birds well fed become a deep salmon color, very showy; and this lasts for a year, until the next monlting-season, when the bird may again be fed in the same manner.

The food has less effect on green plumage, so only those having elear yellow or slightly mottled eolors should be selected for feeding.

Insects breed rapidly on birds at this season, and a superabundance of them should be guarded against by thorough use of the German inseet-powder. A white clotlı thrown over the enge at dusk, and examined early in the molning, will reveal the true state of affairs in respect to sueh pests.

Parrots erave soft food now in addition to the regular feed of hemp-seed, rough rice, and cracked corn. Pilot-bread, soaked either in water or coffee, whichever the bird prefers, should be given in whatever quantity will be consumed. Young burds in partieular require the soaked bread.

Bobolinks, Limmets, and other wild native birds, are generally overfed when kept eaged. In a wild state, where the birds fly long distances, large quantities of food are eaten without harm resulting; but the same quantity eaten when a bird is caged, and has little exereise, usually results in an attack of epilepsy. All these birds. require is the same amount of seed as is given a Canary, and in addition gravel, and green stuff daily, either lettuce, chickweed, or apple.

At the seashore birds should not liang out after four o'clock in the afternoon. If allowed to hang out later, or if liung where there are strong draughts of air, colds and bowel complaints ensue.

\section{AUGUST - SEPTFMBER.}

Canaries should have hard-boiled egg, and cracker, daily, now until the moulting-period is well passed. Many eareful breeders continue such food for two weeks, at least, after the bird easts any feathers.

Bathing too frequently will eause birds to have cramps, and a third attack is sure to prove fatal. One bath a day, or a bath on alternate days, is frequently enougl.

For cramps give a dose of sherry wine and water, five drops of each mixed.

When spiders are abundant, a erop should be gathered for a soft-bill bird : if the experiment has not been tried, one will be surprised at the inereased amount of song each spuder fed will impel your bird to utter. Three to five spiders a day are as many as one bird should eat.

Young Mocking-birds sometimes eat too leartily, and dangerous eases of surfeit and indigestion follow. In such cases five drops of oil earefully given will nsually effect a cure. 'Then feed more sparingly; and the bird will grow faster, and make greater improvement in song, than when overfed.

Young Mocking-birds now commence to note some; and judicious feeding will cause almost a perceptible daily improvement in voice, plumage, and shape. If it is too much work to feed the dry prepared food mixed with boiled potato or raw 
carrot, every day, give it at least every third day ; for the moist foor that is fully prepared for use is too heary feed to give a young bird constantly. The moist food, too, should have carrot mixed with it.

The prepared dry food. or the moist food, is sent by mail, postage prepaid, for fifty cents.

Brown Thrushes, Cat-birds, Orioles, and all our long-bill or soft-bill native hirds, eat this prepared food ; though, when very young birds are first eaptured, they sliould luve stale bread soaked in fresh milk, for a week or so. $\Lambda$ dish of dry foorl mixed with boiled poiato may be offered as soon as the bird is taken; and, when he eats this, discontinue the bread and milk. A newly captured bird is liable to beat against the bars, and either ruin the plumage for a whole sensen, or so injure the head as to make a recovery doubtful. Keep a new wild bird in a quiet place, where there is not too much light, or keep him covered quite closely, until he becomes somewhat accustomeci to the cage.

The quality of seed is of the utmost importance at this season, when birds are sherlding feathers, and require the first grade of food; and many of our readers who sre travelling find it almost impossible to obtain good seed. Let every one remember, that any quautity up to four pounds ean be sent by mail. We have regular packages of seeds of all kinds, either mixed or separate, which are sent by mail, postage prepaid, on receipt of thirty, fifty, or eighty cents, according to the quantity desired. Only the best quality of fresh seeds is kept. The mixture of equal parts of Sieily canary, German summer rape, and millet seed, is espeenally recommended for Canaries.

Cayenne pepper may be fed with the egg or in the gravel, daily, to all birds during moulting, as a sort of tonic; and Parrots may have, once a reek, the vegetable red peppers.

The African Finches and Japanese Nuns should be very carefully protected against dranghts during the monlting-season. At night, as the temperature begins to fall below its summer range, the aviary-cage should be covered, and the langer from sudden changes guarded against. All of these small birds live many years if properly cared for; and such care comprises regular feeding and bathing, a daily allowance of clean gravel, and fresh chickweed or apple, and exclusion of draughts.

If it is intended to breed Finches, it is the wiser plan, generally, to separate the pair or pairs from other birds about the middle of September, and get them into fresh prime conclition by extra care and attention, which ean be especially givel them when in these separate eages. Some breeders have good luck, even when all the Finches rum together, as is stated in the article on "Finches and Nuns ;' lunt their "luck" comes, it would seem, from a wide experience.

'The plumage of the Finches and Nuns, as well as of the Canaries and other birds that bathe in water, is greatly improved if a teaspoonful of sherry wine is stirred in the bathing-water. The plumage of any bird is greatly injured by keeping the bird in a brilliantly lighted room in the evening. A bird kept quiet in the dark, a part of the daytime, will usually have more glossy plumage. 


\section{SEI'TEMBER - OCTOBER.}

With the issue of this twelfth paper on the above subject, suggestions for the period of a full year will be given. But, though the suggestions have thus been given for each month of the year, the subject of food and care of eage-birds has been by no means exhausted. In the limited space allotted, we have treated as fully as possible the ordinary diseases to which cage-birds are liable, and have tried to give prominence to the old proverb of "An ounce of prevention," ete. Improper care, late hours, luxuries, dissipation, - these kill all animal-life, never once stopping to inquire whether that life be possessed by man or bird.

The prevention of disease is worthy of far greater praise than any possible display of skill can be that attempts to control the flame of fever kindled by sheer carelessness.

To prevent diseases in birds, use the best quality of seeds, clean fresh water for drinking or bathing, coarse, flinty gravel, cuttle-bone, and fresh green stuff. If these are supplemented by light, airy rooms, where the bird may have one or two hours of sunlight each day, and regular attention, your bird, if fairly well bred, will be subject to few diseases. While many diseases have been preseribed for nnder our present heading, special items will be found in the articles on Canaries, Parrots, Mocking-birds, and other birds.

The Pekin Nightingale is at times subject to indigestion. 'This attacks him suddeuly, as it does other birds. He may be as well, and eat his breakfast as greedily, as ever in the early morning; but an hour later finds him in a corner of the cage with plumage ruffled, and an I'm-sure-I'm-going-to-die expression on his countenanee. Three or four drops of sweet-oil, put in his bill, will quiekly transforn him into the long-jumping, sprightly bird of yesterday. In general, birds seem to be quite intelligent; but the songster from Pekin is as liable to eat a harmful quantity, and then suffer for it, as some people are. It is seldom the bird suffers from indigestion when fresh carrot is mixed with his food.

Long-breed Canaries, either Manchesters or those from Antwerp, should have such care as to be kept in prime order during the fall and early winter months. This is more essential in regard to the birds named; since they breed very early in the year, commeneing six to eight weeks earlier than the short breeds. Their food should always include a small quantity of hemp-seed daily; and, from the middle of October to January, birds should have a quarter part of the yolk and white of a hard-boiled egg, mixed with a little cracker-dust, two or three times a week. After the first of January the quantity of egg may be increased, and given daily ; and a thmbleful of hemp, or more if the bird seems to require it, should be offererl in addition to the regular allowance of rape, canary, anc? millet seeds. Of course, it is understood a bird should have some green stuff at least as frequently as every other day.

Eagles, Vultures, Hawks, Owls, and other birds of prey, are not often kept as pet birds; but still we get many letters, during the year, regarding the proper food for them. Every bird of prey, eaged, subsists on fresh raw beef or fish. The large birds will devour two pounds, or more, per day, and should be fed in the morning and at night. The Owls will eat only during the night. Owls and Storks are 
fond of live mice. Clean, fresh drinking and bathing water should be given in abundance. Nestlings of any of the above birds may be reared on bread and milk, and meat in small quantities, chopped fine.

The cage in which a bird is confined should be adapted to the habits and disposition of its occupant. A Canary will appear very restless sometimes in a round cage, flying to the top, and stretching his head backwards until he drops to the bottom. This trick soon becomes a habit; the bird soon ceases to sing; and the time is occupied in nervous, aimless flutterings, that render the bird nearly worthless, and drive his owner to distraction. Usually, if such a bird is put into a cage of different pattern before the trick becomes a confirmed habit, he will be cured, and sing as well as ever. 


\section{SEEDS AND FOODS, RECIPES, DISEASES, MEDICINES.}

THE foods suitable for the different birds have been fully enumerated under the different subjects, but there are other varieties of birds which have not been treated on ; and it is for the purpose of indicating the proper food for them, and for the purpose of referriug more particularly to the best seeds, and mixtures of the foods. which have been heretofore mentioned, that the following article has been written.

The chief consideration, in deciding upon the proper food for the various species of cage-birds, is, to select that which most closely corresponds to their natural diet. In the case of trapped birds, the proper selection must be made with great care : for, if such birds are not sufficiently nourished, a considerable loss of life is sure to follow.

There are birds, it is true, which, as soon as taken from the trap, will eat without hesitation almost any thing that is given them: these include the hardier class of hirds, among them the Mocking-bird, Thrush, Skylark, Chaffinch. Others, however, are more delicate, and at first, partly from grief, and partly from want of their natural fare, will eat nothing. It is a bad sign if such birds as are accounted delicate begin to eat greedily as soon as put into the cage; as it is thought to indicate an unnatural indifference at the loss of freedom, which can only proceed from disease. If, on the contrary, they sulkily hide themselves in a corner for some hours, there is little need to be anxious about them; as, when the sulky fit is allowed to wear off, they usually begin to eat in a natural manner. All birds may be classified generally into two divisions, the hard billed and the soft billed.

The first class consists of those birds which live on seeds, and the second those which live on soft foods and insects. The first class, such as Canaries, Goldfinches, Lnnnets, and Bullfinches, eat seeds only. The soft-billed elass may be subdivided, and includes birds which eat seeds, soft food, and insects, as Larks of all kinds. Quails, Yellow-hammers, etc. ; birds which eat soft food and insects, as Nightingales, Mocking-birds, Thrushes, Blackeaps, ete. ; and birds which subsist on insects only. such as Wagtails, Blue-throated Warblers, and many of the varieties of very small soft-billed birds. These last are the most difficult to rear, and keep in health ; and since, as a rule, their songs are not remarkable for length or pleasing notes, they by no means repay the trouble which must be expended in keeping them. Usually. however, when plenty of live insects are mixed with the Mocking-bird food, such birds may be kept in health for a considerable length of time.

In all classes of cage-birds, it is necessary to change the diet as often as possible. and at the same time to feed only plain fare, reserving the dainties for odd times. or when the health of the bird depends on them. The principal foods used in feeding the hard-billed class of birds are seeds, green food, and fruits. 
The seeds used for all varieties of hard-billed birds are, eanary, hemp, maw, or poppy, millet (domestic and French), plantain, rape, and sunflower seeds, Indian corn (whole aud cracked), oats, and patda, or unhulled rice. The sieily canary-seed and the Spanish are the two best kinds: the Sicily is the smaller and richer seed. Never buy the sbort Dutch seed when either of the two former can be obtained. Canary-seed is a very rich, nomrishing seed, and is used more than any other kind. Great eare should be exereised in the selection of it; as from age, dirt, or damage in transport, it becomes injurious; and its use often proves fatal. See that the shell of the seed is shiny and firm; the interior of a kernel of good canary-seed should be white and hard; when a quantity of canary-seed is tossed in the air, no particles of dust should be seen coming from it ; dust and small particles of foreign matter should be carefully sifted out of all seeds. Old canary-seed is known by the lustreless appearance of the shell, and the honeycombed interior, the work of small parasites. If such seed is fed, slow death is a sure result. It is, therefore, better to always examine the seed when purchasing, and, if possible, to buy of a birtdealer; as he uses the utmost care, selceting only the best for his birds. The Sicily seed is recommended as the best; as it is richer, and more easily cracked.

Hemp-seed is the richest of all seeds, and is more universally used in a whole and a crushed state than any of the others. Its nutritious qualities are unsurpassed, and it is looked upon by all classes of seed-eating birds as a dainty. It should be fed sparingly at all times to the smaller seed-eating birds; but, in the case of the largest birds, it forms one of the principal mixtures. The hemp-seed is one of the largest of bird-seeds ; and in good specimens the outer surface slould be round and smooth, and the interior should be well filled and very sweet.

Maw, or poppy seed, is the smallest of the bird-seeds, and is easily recognized by the grayish-blue color. The best class of maw-seed should have a clear, bright color, and should have a fresh odlor. 'The age of all classes of seeds may be detected by the odor: musty or foul-smelling seerls should be rejected at all times. Maw-seed forms the chief article of diet for such birls as the Goldfinch, Siskin, Crossbill, etc. It is very rich, and is used as a medicine or stimulant for nearly all the smaller birds: it also enters largely, as maw-meal, into mixtures of food for the soft-billed birds.

Millet-seeds consist of two kinds : the domestic, or smaller grade, is round and yellow: it is a very good seed to use in the mixtures for the small seed-eating birds. 'The French millet is a little larger than the domestic, perfectly round, and the best clear white. It is a handsome seed, and very rich. It is used principally for the small African birds, and smallest Paroquets.

Plantain-seed was formerly used as a medicine: it is but rarely called for at the present day.

Rape-seed is one of the principal seeds in use, and in Germany is almost wholly used as the main seed for Bullfinches and Canaries. It is, without doubt, one of the healthiest seeds which can be fed the majority of seed-eating birds. It is not so rich as some of the other seeds meutioned, but its health-giving properties are well known among bird-faneiers. The best grade is the German summer rape, which is the young seed grown in Germany: this kind is distinguished from the other and inferior grades by the peculiar dark reddish color, and the smaller size 
as compared with them. The appearanee of the best rape-seed should be clear and bright. The seed should be mild to the taste, and not withered in appearance. 'The cheaper grades of rape-seed work much harm among all kinds of birds: these grades are mueh darker and larger, and very bitter. Speeial eare slould be exercised when seleeting rape-seed for trained Bullfuches and the best class of German Canaries.

Sunflower-seed is a black, flat, oval seed, and, although seldom used, makes a good addition and pleasant change when fed to the harder-billed seed-eating birds, sueh as all elasses of Cardinals, Grosbeaks, and Parrots.

Indian eorn is used in many ways, and is fed boiled, and in a natural state whole or eracked, in the mixtures for the larger class of Parrots. It should be fed in addition to other seeds, as it is not of sufficient richness when given as the only article of diet.

Oats are usually fed the larger classes of soft-billed birds, such as Quails, Larks, etc., and is mixed with the food of many of the seed-eating elasses.

Padda, or unhulled riee, as its name implies, is riee before the hulls are removed: it forms an excellent addition to the mixtures used for the hardest-billed birds. It should be fresh and elean: the light-colored, full seeds are the young seeds, and the only quality which should be fed.

Any of the above seeds are but rarely fed singly: they are usually given in mixtures, which forms a change for the birds, and at the same time avoids the danger of too rieh or too plain feeding.

The best-known mixture is that usually given the common class of eage-birds, such as the Canary, Linnet, Chaflineh, and numerous other varieties, and consists of equal parts of eanary, rape, and clomestic millet seeds.

For Goldfinches, Siskins, Yellow-birds, Crossbills, the mixture should be equal parts of maw, eanary, and hemp seeds.

For Bulltinches, plain rape-seed, and oceasionally a few grains of hemp in addition.

For Cardinals, Grosbeaks, ete., equal parts of padda, hemp, eracked corn, and sunflower-seeds. Many persons use also some eanary-seed.

Parrots' foods vary, and the variety of seeds used are numerous: the best mixture, if they can be accustomed to it, is, equal parts of hemp, padda, and cracked corn.

The small African Finches and Paroquets live principally on white French millet and plain canary-seeds.

All classes of birds like a change of food; and, when this is given in the form of fresh green food, the delight is dloubled. Green food in its season should be given fresh and almost daily, and may consist of lettuce, water-cress, groundsel, or ehickweed. Fruits may also be freely fed, and in the ease of tropieal birds this is almost a neeessity : any ripe fresh fruit forms an agreeable change of diet.

Egg-mixture is found to be one of the chief articles of diet at the present day for all the common, smaller elasses of seetl-eating birds : it is especially useful in breeding and moulting seasons, and in times of siekness. 'The receipts used for mixing the egg and the other artieles are numerous. One of the best is, To one whole grated hard-boiled egg, add one-half the amount of breacl-erumbs or grated German 
Zwiebaek, and sprinkle the mixture with small quantities of maw-seed, granulated sugar, and cayenne pepper.

The tonies, treats, and medicines used in cases where the seed-eating elasses require them are as numerons as the varieties of birds themselves. It is necessary at times to administer these, but in many eases it is as much overdone as in the case of administering useless patent medicines to the human race. I have always found that birds are kept healthier by good plain food than by numberless daily doses of patent tonics and worthless mixtures. The following list of drugs should be kept in the bird-room, and they will cover about all the cases which require treatment: castor-oil, gum-arabic, glycerine, cod-liver oil, prepared chalk, nitrate of potash, dandelion-juice, paregoric, and laudanum.

Bird-tonies are made for the purpose of restoring the song of a bird; and it is claimed by many manufacturer's of them, that they form a certain eure for any and all diseases to which the bird-race is subject : it is, of course, apparent, that the elaim is sheer nonsense. 'They are, however, excellent stimulants in eąses of weakening of the constitution, and a needed restorer after sicknesses. An excellent tonie is, 'To a wine-glass of water add fifteen grains of tineture of iron, ten grains of the compound tincture of gentian, aud ten drops of glycerine. This is a good general tonic, and may be administered in any ease of debility with usually good results.

Treats of various names, and song-restorers, are palatable compounds of crushed seeds and honey or sirup, and effect good results in some cases, but are usually looked upon in the light of dainties. Gunning's Tonie is commended.

A bird-treat, made of equal portions of erushed hemp, canary, rape, and maw seeds, plentifully sprinkled with cuttle-bone dust, and carefully kneaded with honey in order to unite the mass firmly, may be suspended by means of a wire in the eage.

Song-restorer is a preparation of cruslied seeds, ete., and oftentimes will restore the voices of birds which have been silent for a long period. In cases where birds have always been accustomed to a change and variety of food, it is hardly necessary. It is compounded of powdered hemp, canary, and unaw seeds, mixed with powdered euttle-bone, rock-candy, and Zwieback, all in equal portions.

Various eures in the shape of simple powders are recommended for special diseases, such as asthma, eold, constipation, and diarrhoea. Asthma mixture consists of equal portions of eayenne pepper, crushed hemp, and lettuce-seeds, mixed with $Z$ wieback and grated hard-boiled egg.

Cold or Moulting is treated in the same manner.

Constipation. - For this disease a mixture is compounded of crushed hemp, saffron, rape, and lettuce seeds in equal portions, mixed with grated hard-boiler egg.

Diarrhoec. - A good remedy for this is to mix equal parts of eayeneue pepper, powdered chalk, pulverized charcoal, crushed hemp and maw seeds, and mix with grated hard-boiled egg.

Many more receipts could be compounded for the diseases of the smaller seedeating birds ; but, in cases which require stronger medicines, the remedies and treatment advised in the diseases on Canaries will apply to the smaller classes of hard-billed birds. 
The outward sign of a healthy bird is, that he looks bright, and that not a feather is out of place, rumpled, or dirty. If the bird be "ont of sorts," my advice is, to ferret out the probable eause, remove it if possible, and let nature, proper food, pure water, fresh air, and cleau sand, do the rest. When a disease is first noticed, a few drops of eastor-oil should be administered at once: this always proves an excellent, harmless remedy; as it cleanses the system, and fits the bird to receive proper foods. Parrots, or larger birds, which resent handling, may be given castoroil by pouring just sufficient over the drinking-water to cover the surface, which will oblige them to take it with the water.

Egg-binding is the cause of many deaths in the aviary, but is easily overcome by the introduction, with a camel's-hair brush, of a drop of sweet-oil into the eggpassage.

Birds, when freshly imported in large numbers, frequently pull each other's feathers out, and, when large numbers are erammed together, become dirty, weak, or sickly. With proper eare, a elean eage, good food, fresh water, and pure air, they recover in a very short time; but they should never be put into an aviary or cage with other birds before they are fully recovered, and able to take eare of themselves. If feathers are broken, and the moulting-season be far off, one or two feathers may be earefully pulled out every other day, when nature will replace them at once. But, the process being painful to the bird, the operation onght never to be performed except by very experienced hands.

Parasites or insects are as often due to weak health as to uncleanliness. A healthy bird, with sufficient opportunities to bathe, or dust itself in the sand, will keep itself quite free from vermin. As in the case of tonies and patent medicines, the ways of using the different kinds of insect-powder are numberless : pretty little air guns and bellows are filled with the powder, and the many attraetive forms of putting it up make it far more salable than it is useful. The best powder to use is the German inseet-powder : and the best method of using it is the old-fashioned way of eatching the bird in one hand, and thoroughly dusting every portion of the body under the feathers with the other. The eage should be thoroughly cleansed, the top being unserewed for this purpose: these precautions will stop the plague if eare be taken at the same time to improve the bird's health by suitable and generous diet.

The soft-billed birds are a class distinguished from the hard billed by their inability to erack hard seeds; and although some of the hard-billed varieties are capable of living and thriving on the food given the soft-billed birds, and some of the soft billed are able to crack and live on the softer kinds of seed, they are notably separate elasses. The two elasses are distinguished from one another by the length and formation of the beak. The hard-billed class usually have short conical beaks; and the soft-bill class have, as a rule, long, slender beaks.

In captivity the methods of feeding, and mixtures compounded as foods for the soft-billed class, are very different : at the present time the chief food given this class of birds is ealled Mocking-bird food; and it has so far proved so mueh superior to any mixture which has been compounded, that, whenever it ean be procured, it is universally used as the basis of feeding soft-billed birds.

There are two kinds of this food, - the moist and the dry. The moist food may 
be used without any additional mixture; but the dry, in order to be palatable, must be mixed with grated raw earrot, or hard-boiled egg and potato.

The common receipt for making moist Mocking-bird food is to mix in the following proportions: Eight quarts of maw-meal (which is pulverized maw-seed), four quarts of Zwieback, two pounds of boiled ox-heart, and four pounds of the best lard. All of the above materials should be fresh, and of the best quality. 'The ox-heart must be boiled for several hours, and, when sufficiently hard, should be pulverized in a coffee-mill. When the ingredients are ready, they should be thoroughly mixed.

The above mixture forms a plain food; it may be made richer by the addition of one pint of ground ants' eggs, or the same amount of desiceated egg ; to it may also be added dried flies, grasshoppers, or any other prepared insects. 'The richer the food, the better for the bird; and the necessity of giving daily rations of live insects is lessened.

Dry Mocking-bird food is prepared by mixing eight quarts of maw-meal, four quarts of Zwieback, tivo pounds of boiled ox-heart, and one quart crushed hempseed. This food may also be made richer in the same mamner as the moist food. Before feeding the dry food, it must be thoronghly moistened with raw grated carrot.

Each kind of food has its class of supporters; but, where the slight trouble of grating the carrot is not heeded, I should advise the feeding of the dry food.

These foods are usually sold by bird-dealers throughout the country. Every true bird-lover trusts only to home-made manufacture; and as the many spurious and impure foods, which are sold at a cheaper rate than good foods can be manufactured, result in sad losses, sometimes it is better to manufacture the food at home, or to buy only the best qualities.

The above foods are used solely for birds which have grown accustomed to them through long confinement. At first this prepared food is mixed with boiled egg and potato until the bird seems to thrive on the food alone.

An excellent mixture on which to rear nestling soft-billed birds is, Equal parts of scraped raw beef, soaked bread, boiled potato, hard-boiled egg, and crushed hemp-seeds; mix these together well, and form a paste. The food should be given in small pellets as often as the young birds call for it. As the birds grow older, gradually introduce the prepared food ; and in a short time it may be fed them without mixture.

Food for fresh-trapped soft-billed birds : Mix equal parts of seraped raw beef, grated hard-boiled egg, and bread-crumbs, and add a few scalded ants' eggs ; or three or four meal-worms may be daily given. As the birds become accustomed to confinement, introduce the prepared food, as advised for young birds.

An excellent substitute for the prepared food is the German paste for soft-billed birds: Three-quarters of a pound of pea-meal, a quarter of a pound of oatmeal, one ounce of moist sugar, one ounce of olive-oil, two ounces of honey, half a pint of well-crushed hemp-seed, and half a gill of maw-seed. The meal and sugar should be well rubbed in ; then add the oil and honey, which has been first well mixed ; stir the whole together, so that there be no lumps; then add the hemp and maw seed. 
Change of diet for soft-billed birds should be fresh, ripe, soft fruits of any lind, green food such as lettuee, water-cress, or chickweed. The above, when not in season, may be replaced by dried currants, or ants' eggs which should be scalded before feeding, a piece of split fig, dried flies, grasshoppers, or spiders. Finechopped nuts of rich quality, such as wahnuts, are very good. The above articles, or a number of them, should be kept in the bird-room; as they of ten prevent and cure disease. Meal-worms are a necessity with all of this class of birds.

Method of breeding meal-worms. An earthern jar or tiu box should be used as a receptacle, with a covered top, which should be perforated to admit air. Half fill the jar with bran, oatmeal, flour, or Indian meal, and add a few pieces of old Hannel or old shoe-leather. In this, four or five hundred meal-worms may be placed, and if allowed to renain for three months, being occasionally moistened with a cloth soaked in stale beer, will become beetles, which again lay eggs, and propagate the species with great rapidity.

Tropical soft-billed birds should have, as often as possible, fresh fruits such as bananas, oranges, figs, grapes, etc.

'The remarks on the diseases of the seed-eating class of birds apply to the softbilled birds. An excellent stimulant, or tonic, for the larger birds, in case of sudden sickness, is, to a wineglass of water add a teaspoouful of sherry wine: in severe cases brandy may be substituted for the wine. Or use Gunning's Tonic.

Cramps in the legs and feet often occur among this class of birds, owing to rich food, and may be readily cured by filling the draw-slide of the cage with hot sand; and, when the invalid has recovered, bathe the legs and feet with warm brandy. A simple cure for hoarseness is, to dip some fresh bread in honey, or dissolved rockcandy.

A delicacy, when birds are recovering from weakness, is, to mix scalded ants' eggs, and sponge-cake soaked in sherry wine, and plentifully sprinkle it with cayenne pepper.

Cough-mixture for birds, when suffering from severe colds : To a wineglassful of water add twenty drops of paregoric, a teaspoonful of glycerine, and a lump of rock-candy. 
TWENTY SOYGSTERS COMPARED.

\begin{tabular}{|c|c|c|c|c|c|c|c|c|c|c|}
\hline \multirow[b]{2}{*}{ TWENTY SONG-BIRDS. } & \multicolumn{5}{|c|}{ Voice. } & \multicolumn{5}{|c|}{ ATTRACTIVE QUALITIES. } \\
\hline & 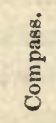 & 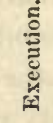 & 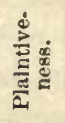 & 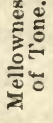 & 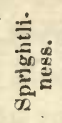 & 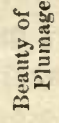 & 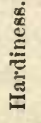 & 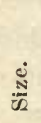 & 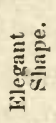 & 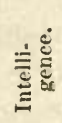 \\
\hline English Nightingale. & 10 & 10 & 10 & 9 & 8 & 5 & 4 & 4 & 6 & 7 \\
\hline Blackeap. . & 8 & 8 & 7 & 7 & 6 & 4 & 4 & 3 & 5 & 6 \\
\hline Skylark . . & 9 & 9 & 5 & 6 & 9 & 4 & 7 & 5 & 4 & 6 \\
\hline Thrusly : . & 8 & 7 & 7 & 7 & 6 & 5 & 8 & 8 & 7 & 7 \\
\hline Blackbird . • & 7 & 5 & 8 & $\mathrm{~s}$ & 5 & 6 & 8 & 9 & 8 & 7 \\
\hline English Starling . & 3 & 2 & 2 & 2 & 5 & 5 & 9 & 7 & 5 & 9 \\
\hline Englisl Robin. & 4 & $\overline{5}$ & 4 & 4 & 5 & 6 & 4 & 3 & 4 & 6 \\
\hline Troopial : : . & อ & 8 & 4 & 8 & 6 & 8 & $\mathrm{~s}$ & 8 & 7 & 9 \\
\hline Pekin Nightingale & 5 & $\mathrm{~s}$ & 4 & 5 & 7 & 7 & 9 & 4 & 6 & 8 \\
\hline Brazilian Cardinal & 4 & 5 & 4 & 5 & 6 & 7 & 6 & 6 & 6 & 5 \\
\hline Mocking-bird & 10 & 10 & 9 & 9 & 10 & 5 & 8 & 8 & 9 & 8 \\
\hline Virginia Cardinal . & 7 & 7 & 5 & 6 & 7 & 9 & 7 & 7 & 7 & 5 \\
\hline Brown Thrasher . . & 8 & 7 & $\check{J}$ & 5 & 6 & 6 & 8 & 9 & 8 & 6 \\
\hline Rose-breasted Grosbeak . & 4 & 5 & 3 & 5 & 6 & 7 & 7 & 6 & 5 & 4 \\
\hline Bobolink . . . . & 5 & 5 & 4 & 4 & 9 & 6 & $\dot{9}$ & $\mathbf{5}$ & 5 & 7 \\
\hline Baltimore Oriole . . . . & 5 & 4 & 4 & 4 & 6 & 7 & 5 & 5 & 5 & 8 \\
\hline Cat-bird . . . . & 6 & 5 & 7 & 8 & 6 & 4 & 5 & 6 & 6 & 6 \\
\hline American Robin . . & 7 & 7 & 4 & 6 & 6 & 5 & 8 & 7 & 6 & 6 \\
\hline Blue Robin . • . • . & 4 & 4 & 5 & 7 & 5 & 8 & 5 & 5 & 5 & 4 \\
\hline Scarlet Tanager . . . . . & 3 & 2 & 2 & 2 & 3 & 10 & 4 & 5 & 6 & 4 \\
\hline
\end{tabular}

This table is arranged with reference to a scale of a hundred points. While, in all probability, no one would agree with me in regard to a large part of these figures, not a unit has been written without most careful consideration; and the whole table has had several thorough revisions, so that, as more names were added to the list. each bird should be given just the total number of points that are justly his, when he is compared with all the others.

This table is given, like all the rest, rather as a guide to intending purchasers who are not thoroughly posted on birds, than as an "exact" authority. 


\title{
HOLDEN'S PRICE-LIST.
}

\section{GEORGE H. HOLDEN,}

\author{
AUTHOR OF "CANARIES AND CAGE-BIRDS," ETC.,
}

BIRD IMPORTER,

6til Avenue, New York, N.Y.; 9 Bowdoin Square, Boston, Mass.; 37 North Main Street, Providence, R.I.; St. Andreasberg, Germany.

TuE prices given below are subject to variations. Any one desiring to buy will be furnished by mail with full information.

Birds and cages can be sent in perfect safety by express, south, as far as Texas, and west, as far as Omaha, Neb., without danger of loss or damage.

Money can be sent by draft on New-York bank, by post-office order, or in a registered letter. Postage-stamps are accepted for any article sold for $\$ 1.00$ or less.

C.O.D. - Goods are sent "collect on delivery" only to known responsible buyers.

GuAIANTYs. - Birds, cages, seeds, etc., are guaranteed to be of the best quality, and just as represented. It is requested, as a favor, that any article not suiting the buyer, after trial, be returned for exchange.

Shipping Directions. - In ordering goods to be sent by express, state clearly the names of the nearest express offices, county, and State; and name the particular express company preferred.

Mailing Directions. - In ordering goods by mail, write plainly the post-office, county, and State.

Special Orders. - Campanini Canaries, extra grade, and extra Piping Bullfinches are now imported to order.

\section{PRICE-LIST OF BIRDS.}

German male Canaries, young, ruaranteed to sing to suit

Females, same kind . . . . . . . . . . . . . . . 1.00 to 1.50

St. Andreasberg German Canaries, trained singers . . . . . . . . . 4.00 to 5.00

Females, same kind . . . . . . . . . . . . . . . 2.00

Campanini German Canaries . . . . . . . . . $\$ 8.00, \$ 10.00,12.00$ to 15.00

Campanini, imported to order, extra grade singers . . . . . 25.00, 30.00 to 50.00

Canary-birds, English, crimson color, singers . . . . . . . 8.00, 10,00 to 12.00

Females, crimson color . . . . . . . . . . . . . 4.00, 5.00 to 6.00

Canary-hirds, English, Gold or Silver Spangled Lizard, singers . $\quad 8.00,10.00$ to 12.00

Females, same kind . . . . . . . . . . . . $4.00,5.00$ to 6.00

Canary-birds from Norwich, England, clear gold color or mottled, in perfect plumage, good singers, usually sell for . . . . . . $\$ 4.00,500$ to 8.00

Females, same breed . . . . . . . . . . . . . . . . 2.00 to 3.50

Canary-birds, Manchester Coppy, the largest breed of Cauary singers, $\$ 10.00,12.00$ to 15.00

Female, same kind, generally crested . . . . . . . . . 600 to 8.00

Canary-birds, Scotch Fancy . . . . . . . . . . . $\$ 10.00,12.00$ to 15.00

Females, same kind . . . . . . . . . . . . . 6.00 to 8.00 
Cinnamon Canary. This lighly prized bird, if clear stock, in perfect plumage and song, sells at prices varying from

PRICE EACII.

Cinnamon Females

$\$ 5.00$ to $\$ 8.00$

2.00 to 3.50

Canary-birds, singers, of an olive-green or golden-brown color, usually sell at .

Females, high colored, either a deep golden color, olive-green, goldenbrown, or any clear stock, sell at prices varying from . . . $\$ 2.00$,

Long-breed Canaries, called Belgian or Antwerp birds, are sold at prices varying from

$\$ 6.00$,

Males and females both sell at the same price.

The above prices refer to imported stock.

Half Long-breed Canaries, males and females, are sold at prices varying from .

Long-breed Canaries, bred in America, males and females

Mule birds, crosses between any two breeds, as named below, vary greatly in price, according to color and song.

Goldfinch-Canary, mules . . . . . . . . . $\$ 3.00, \$ 5.00, \$ 8.00, \$ 10.00$ to $\$ 15$. . ( . .

Linnet-Canary, mules . . . . . . . . . . . . 3.00, 5.00, 8.00 to 10.00

Bullfinch-Canary, mules . . . . . . . . . . . . 8.00, 10.00 to 15.00

Siskin-Canary, mules . . . . . . . . . . . . . . $3.00,5.00$ to 8.00

Bobolink-Canary, mules . . . . . . . . . . . . 5.00, 8.00 to 10.00

Nonpareil-Canary, mules . . . . . . . . . . . . 5.00, 8.00 to 10.00

Indigo-Canary, mules . . . . . . . . . . . . . . . 5.00, 8.00 to 10.00

Yellow-bird-Canary, mules . . . . . . . . . . . 3.00, 4.00 to 6.00

Blackbird, English or German . . . . . . . . . . . . . 8.00 to 10.00

that pipes a tune . . . . . . . . . . . . . 25.00 to 40.00

Blackcap Warbler, European . . . . . . . . . . . . . 5.00 to 6.00

Brazilian Cardinal . . . . . . . . . . . . . . . . . . . . . . . . . . . . . . . . . .

a very choice songster . . . . . . . . . . 8.00

Bullfinch, unlearned . . . . . . . . . . . . \$3.00,

4.00 to 5.00 that pipes part of a tume . . . . . . . . . . . . 10.00 to 15.00

" " one tune. . . . . . . . . . . . . . . 25.00 to 30.00

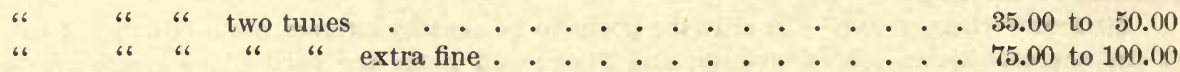

Chaffinch, German . . . . . . . . . . . . . . . . 2.50 to 3.00

" a choice songster . . . . . . . . . . . . . . 5.00 to 10.00

Goldfinch, English . . . . . . . . . . . . . . . . 2.00 to 3.50

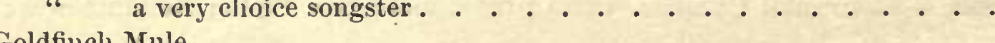

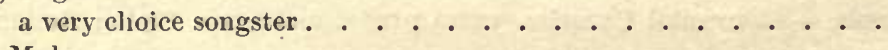

" a very choice songster . . . . . . . . . . . . . . . . . . .

" 6 " " " 6 and high colored or clear white . . .

Japanese Robin, or Pekin Nightingale . . . . . . . . . . . . . .

" " a choice songster . . . . . . . . . . . . . . .

Java Sparrows . . . . . . . . . . . . . . . . . .

" " White . . . . . . . . . . . . . . .

Linnet, Gray or Brown, European . . . . . . . . . . . . .

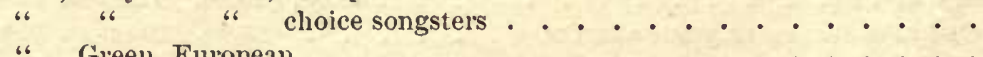

" Green, European • • • • • • • • • • • • • • • • • • •

Mud Minor . . . . . . . . . . . . . . . . . . .

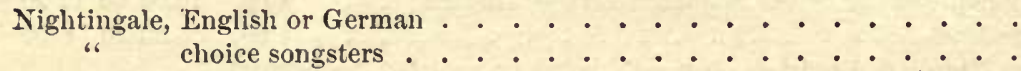

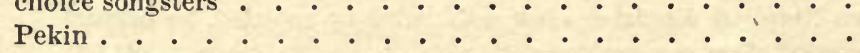

5.00

5.00 to 8.00

10.00

10.00 to 15.00

6.00 to 7.00

10.00

1.50 to 2.00

5.00

2.00 to 4.00

5.00

3.00

5.00

5.00 to 10.00

15.00 to 20.00

25.00

6.00 to 7.00

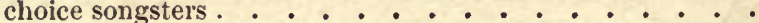

Robin Redbreast, English . . . . . . . . . . . . . . . 3.00 to 4.00

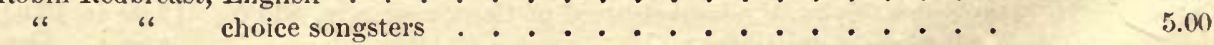

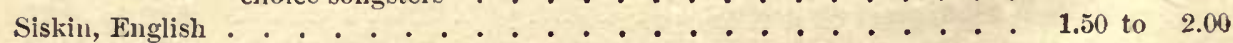


Skylarks, English

PRICE EACH.

English . . . . . . . . . . $\$ 3.00$ to $\$ 5.00$

ehoice songsters . . . . . . . . . $\$ 8.00,10.00$ to 12.00

Starling, English _. . . . . . . . . . . . . . 5.00 to 8.00

" that pipes one tune . . . . . . . . . . 20.00 to 40.00

"Satin . . . . . . . . . . . $\$ 10.00,15.00$ to 20.00

Talking Minor, or Mlusical Grackle, young . . . . . . . . . . 20.00 to 25.00

" " well trained . . . . . . . . . . . $\$ 50.00,75.00$ and 100.00

Thrush, Song, of Europe . . . . . . . . . . 8.00 to 10.00

" choice songsters . . . . . . . . . . . . . . . 15.00

“ Stone, European, males . . . . . . . . . . . . . 10.00 to 15.00

Troopial, South American . . . . . . . . . . 8.00 to 10.00

" choice songsters and tame. . . . . . . . . . . . 15.00

Woodlark, English . . . . . . . . . . . . . . . . . 3.00 to 5.00

" choice songsters . . . . . . . . . . . . . 10.00 to 15.00

All the above are imported birls, and the highest prices quoted should purchase the choicest bird of its kind in any part of America.

\section{FINCHES AND NUNS.}

The following birds are suitable for the aviary: Avadavat, or Amandava, Bishop Finch, Banded Finch, Cordon-bleu Finch, Cut-throat Finch, Celestial Finch, Cuba Finch, Dianond Sparrow, Fire-finch, Fascinated Finch, Indian Sparrow, Indian Silver-bill, Clear-white Japanese Nuns, Brown and White or Cinnamon and White Japanese Nuns, The Little Doctor, Magpie Fincl, Napoleon Finch, Negro, Nun (both black and white capped), Quaker Finch, Rockhampton Finch, Strawberry Finch, Spotted-sided Finch, Saffron Finch, St. Helena Waxbill, Spice-birds.

The preceding birls ringe in price from $\$ 2.00$ to $\$ 5.00$ each, and are imported from Europe, Asia, and Africa.

\section{PARROT FAMILY AND PAROQUETS.}

Cockatoos, Great Iumon-crest

PRICE EACH.

" . . . . . . . . . . $\$ 25.00$ to $\$ 40.00$ all other range from . . . . . . . . . . . 8.00 to 25.00

Macaws, Scarlet-and-Blue . . . . . . . . . . . . . . . . 2000 to 25.00

" " " " talkers . . . . . . . . . . . . 30.00 to 50.00

" Blue-and-Yellow . . . . . . . . . . . . . . 20.00 to 30.00

" " " " $"$ ". . . . . . . . . . . . 30.00 to 40.00

"Green . . . . . . . . . . . . . . . . 15.00 to 20.00

Parrots, African, Gray (young birds) . . . . . . . . . . . 1200 to 15.00

" " " talkers . . . . . . . . . . . . . . . 25.00 to 75.00

" extra fine talkers and whistlers . . . . $\$ 100.00,200.00$ and 300.00

Double Yellow-head, young . . . . . . . . . . . 15.00 to 20.00

" " " talkers and singers . . . . $\$ 40.00,50.00,100.00$ to 250.00

Carthagena, same prices as Double Yellow.

Half Yellow-head, young . . . . . . . . . . . . 10.00 to 15.00

Blue-front Amazon . . . . . . . . . . . . . $\$ 8.50,10.00$ and 12.00

Maracaibo . . . . . . . . . . . . . . $7.00,8.00$ and 10.00

Cuban . . . . . . . . . . . . . . $4.00,5.00$ and 6.00

Dwarf . . . . . . . . . . . . . . . 3.00 to 5.00

" talkers and tame......... . . $\$ 10.00$ to 15.00 and 25.00

PER PAIR.

Paroquets, Australian or sliell . . . . . . . . . . . . . $\$ 50.00,6.00$ to 8.00

Red-face, or African Lore-birds . . . . . . . . . . 6. 60 to 8.00

" I'lum-head, or Madagascar . . . . . . . . . . . . 6.00 to 8.00 
NATIVE BIRDS.

Paroquets, West-Indian

Other varieties average

PRICE EACH.

Bobolink (wild), males

$\$ 5.00$ to $\$ 8.00$

Bobolink (wild), males

5.00 to 8.00

" in solls

females

1.00 to 1.50

2.00 to 3.00

1.00 to 1.50

Cardinal Bird, or Virginia Nightingale, singers . . . . . . . . . 3.00 to 5.00

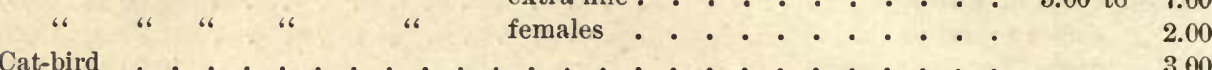
5.00 to 7.00

3.00

5.00 to 10.00

Grosbeak, Rose-breasted (wild)

3.50 to 5.00

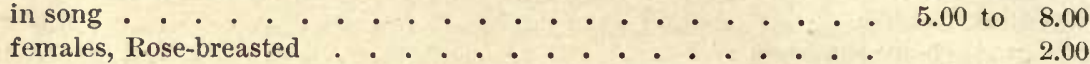

Pine, males . . . . . . . . . . . . . 6.00 to 10.00

Blue " . . . . . . . . . . . . . . . 6.00 to 10.00

Humming-birds . . . . . . . . . . . . . . . . 3.00 to 5.00

Indigo-bird (wild), males . . . . . . . . . . . . . . . 1.50

" " $"$ in song . . . . . . . . . . . . . . . . . . . . . . . 3.00 to 5.00

$"$ females . . . . . . . . . . . . . 1.50 to 2.00

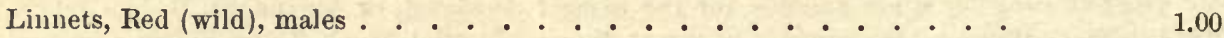

" in song . . . . . . . . . . . . . . . . 2.00 to 3.00

females . . . . . . . . . . . . . . 1.00 to 1.50

Mocking-birds (nestling). . . . . . . . . . . . . 3.50 to 5.00

" " $"$ one-year-old, in song . . . . . . . . . . . . 8.00 to 12.00

"two-year-old, choice songsters . . . . . . . . . 15.00 to 30.00

" three-year-old, choice songsters, finest . . . . . . . 50.00

" females... . . . . . . . . . . 3.00 to 5.00

Nompareils, males . . . . . . . . . . . . . . . 3.00 to 5.00

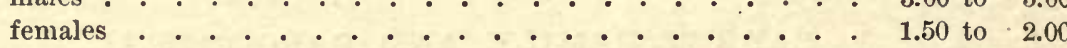

Orioles, Baltimore . . . . . . . . . . . . . . . 1.50 to 3.00

" " choice songsters and tame . . . . . . . . . 5.00

Orchard . . . . . . . . . . . . . 1.50 to 3.00

choice songsters and tame . . . . . . . . . . 5.00

Robins, Redbreast, males . . . . . . . . . . . . 3.00 to 5.00

"Golden, males . . . . . . . . . . . . . . 3.00 to 5.00

"Blue " . . . . . . . . . . . . . . . . 1.00 to 2.50

Redbird, or Virginia Nightingale . . . . . . . . . . . . . 3.50 to 5.00

Scarlet Tanager . . . . . . . . . . . . . . . . 3.00 to 5.00

Snow Buntings . . . . . . . . . . . . . . . . . 2.00 to 5.00

Thrush, or Brown Thrasher . . . . . . . . . . . . . . 3.00

" " " " " 6 choice songsters . . . . . . . . . 5.00 to 8.00

"Wood . . . . . . . . . . . . . . . 3.00 to 5.00

"G Golden-crowned . . . . . . . . . . . . . . . 5.00 to 8.00

"Water . . . . . . . . . . . . . . . 5.00 to 8.00

Woodpeckers, any variety . . . . . . . . . . . . . 5.00 to 10.00

Yellow-birds (American Goldfinch), males . . . . . . . . . . . .75 to 2.00

"6 "6 " 6 females . . . . . . . . . . . . . . 50 to 1.00

MISCELLANEOUS LARGE BIRDS.

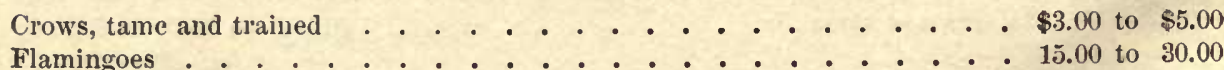

PRICE EACII.

Jackdaws, young . . . . . . . . . . . . . . 5.00 to 8.00 talkers . . . . . . . . . . . . . . 10.00 to 20.00 
Magpies, English or European, young

\section{"6 Australian, young talkers}

talkel's. 10.00 to 25.00

Ostriches

\section{PRICES OF SEEDS, FOODS, ANTS' EGGS, MEDICINES, ETC.}

Seed, canary, Sicily . . . . . . . . . . . . . . . . . . . . . $\$ 0.20$

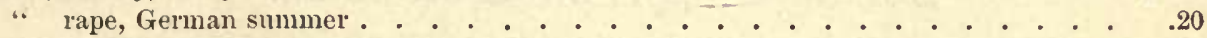

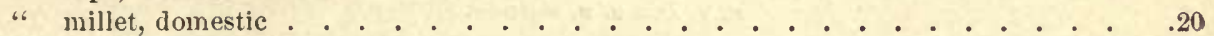

". . French . . . . . . . . . . . . . . . . . . . . . . 40

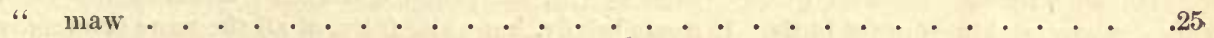

" padda, or unhulled rice . • . . . . . . . . . . . . . . . . . . . . . . . . .

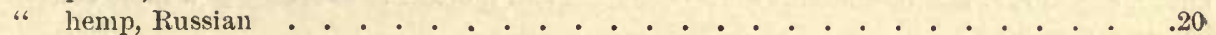

" canary, rape, and millet, mixed for Canaries . . . . . . . . . . . . . . . . . . .

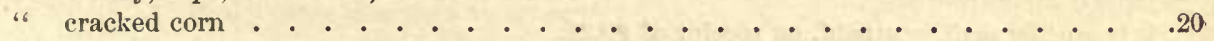

“ hemp, cracked corn, padda, and sunflower mixed for Parrots . . . . . . . . 20

Ants' eggs . . . . . . . . . . . . . . . . . . . . . . . 1.00

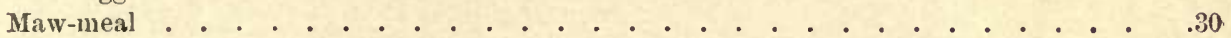

Packages of seeds, ants' eggs, or maw-meal, will be sent by mail, on receipt of $\$ 0.25$ or $\$ 0.50$; largest packages, $\$ 1.00$. Fresh seeds of the best quality call thus always be promptly had, even by those who reside in the Western Territories, where seeds cannot be obtained.

Cuttle-bone, large . . . . . . . . . . . . each, $\$ 0.05$; by mail, $\$ 0.08$ Meal-worms . . . . . . . . per dozen, $\$ 0.06$; per hundred. $\$ 0.40$; by mail, .50 Food, prepared, either moist, ready for use, or dry, requiring grated raw calrot, per quart, .35 " inoist in bottles, or dry in boxes . . . . . . . . . . . . . . . . . 40 " moist or dry, packages, by mail . . . . . . . . . . $\$ 0.25, \$ 0.50$, or 1.00 Red food, for coloring Canaries red . . . . . . . . per box, $\$ 1.00$; by mail, 1.12 Gravel . . . . . . . . . . . . . . pint box, $\$ 0.05$; quart box, 10 Gunning's Tonic, a liquid not mailable, to tone up weak birds . . . . . . . . . . . . . . 5 Sheppard's Song Restorer, a powder . . . . . . . . . . . . . by mail, .25 Bird Treat, or Appetizer . . . . . . . . . . . . per package, by mail, 10 Lime, to use in catching birds . . . . . . . . . . per box, \$0.25; by mall, .35

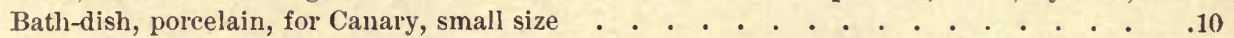

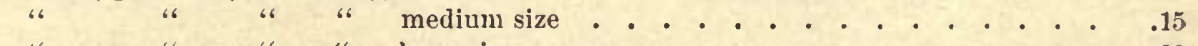

large size . . . . . . . . . . . . . . . . . 20 for Mocking-bird, Thrush, Redbird, etc. . . . . . . . . .25

Nest, wire . . . . . . . . . . . . . . . . unlinerl, $\$ 0.10$; lined, .15

Nest-box of zinc, and nest complete, for hanging in cages . . . . . . . . . . . . 40

Nesting tow or deer's hair . . . . . . . . . . . \$0.05; by mail, .08

Gravel-paper, 12 sheets . . . . . . . . in a package, $\$ 0.25$; by mail, .37

The round gravel-paper is $8,8 \frac{1}{2}, 9,9 \frac{1}{2}$, and 10 inches in diameter.

The square gravel-paper is $7 \times 9,7 \frac{1}{2} \times 10$, and $10 \times 10$. 


\section{HOLDEN'S BIRD-CURES AND INSECT-POWDER.}

Holden's Bird-Cures, carefully prepared after a long experience in the care of all kinds of birds, are recommended for birds which, from various causes, are out of song, either because they are sick, or are infested with vermin. We put these powders up in suitable form for mailing, and send them to any address, with full directions for use with each package, postage prepaid, for $\$ 0.25 \mathrm{per}$ package; or five packages of Cures or Insect-Powder, $\$ 1.00$. The whole seven are sent on receipt of $\$ 1.40$.

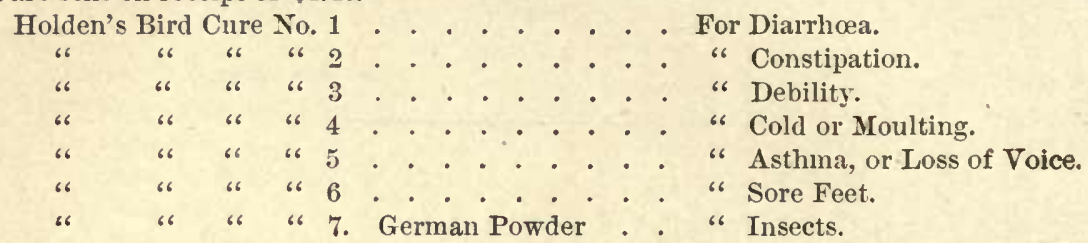

Holden's German Insect-Powder is harmless to birds, and a sure destroyer of bird-vermin.

\section{HOL_DEN'S (NEW) BOOK ON BIRDS.}

C. F. AND G. H. HOLDEN.

Holden's (new) "Book on Birds" (page $4 \frac{1}{2} \times 6 \frac{1}{2}$, 128 pages, illustrated) treats of the food, care, diseases, and breeding of birds. It treats briefly, but quite fully, of all the more commonly known cage-birds; and its contents are so classified and indexed as to render it a most convenient reference-book.

150,000 copies now sold.

It is sent by mail, postpaid, on receipt of $\$ 0.25$. 


\section{PRICE OF CAGES, CUPS, HOOKS, ETC.}

\section{BRASS CAGES, ETC.}

No. 500

Brass cage, cliameter $7_{4}^{3}$ inches

PRICE EACH

. $\$ 1.25$

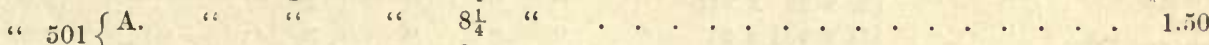

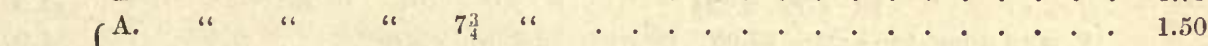

" $502\{$ B. " "

C. "

" 503 "

" 504 "

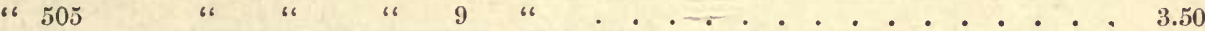

“ $506\{$ А. Brass cage, diameter 10 inches . . . . . . . . . . . . 4.25

B. Same style, solid bronze, very rich color . . . . . . . . . . . 5.00

" $507\{$ A. Brass cage, dianeter 10 inches . . . . . . . . . . . . . 4.25

B. Same style, solid bronze, very rich color . . . . . . . . . . . 5.00

“508\{ A. Brass cage, diameter 10 inches . . . . . . . . . . . . . . 4.25

B. Same style, solid bronze, very rich color . . . . . . . . . . . . 5.00

“ $509\{$ A. Brass cage, diameter 10 inches . . . . . . . . . . . . . . 4.50

B. Same style, solid bronze, very rich color . . . . . . . . . . . 5.25

$\left\{\right.$ A. Brass body, $6 \frac{3}{4} \times 9 \frac{1}{2} \times 12 \frac{1}{2}$ inches high . . . . . . . . . . . . 1.00

“ $510\{$ B. " " $7 \times 10 \times 13$ " 7 . . . . . . . . . . 1.25

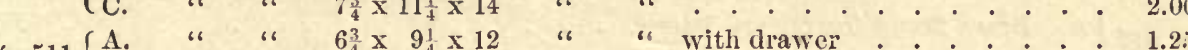

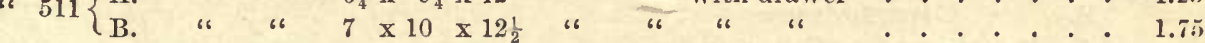

" 512 Fender to fit any canary cage, state dimensions . . . . . . . . . . . .50

" $513\left\{\right.$ A. Brass body, $7 \frac{3}{4} \times 9 \frac{3}{4} \times 13 \frac{1}{2}$ inches higlı . . . . . . . . . . 3.00

B. " " " $8 \times 10 \times 13 \frac{1}{2}$ " " with drawer . . . . . 3.2

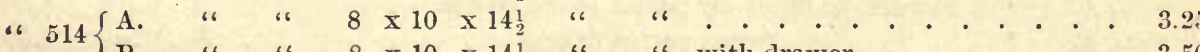

B. " " " $8 \times 10 \times 14 \frac{1}{2}$ " " " witl drawer . . . . 3.50

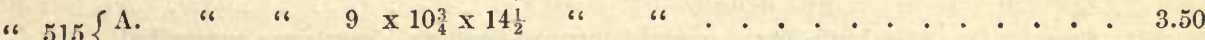

B. " " " $9 \times 10_{4}^{3} \times 14 \frac{1}{2}$ " " with drawer . . . . . . 3.75

4 516 " " " " $7 \frac{3}{4} \times 9 \frac{3}{4} \times 15$ " withont fender, 3.25 ; with fender, 3.75

" 517 " " $7 \frac{3}{4} \times 9 \frac{3}{4} \times 15$ " " with drawer . . . . . 3.50

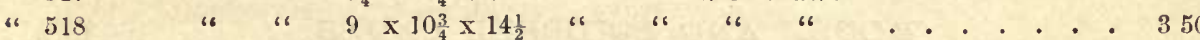

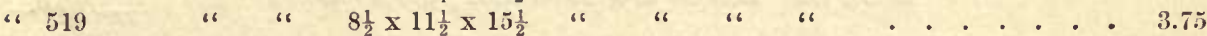

" 520 " " $69 \frac{1}{2} \times 12 \times 16$ " " . . . . . . . . . . . . 425

" 521 " " $9 \times 12 \times 15 \frac{1}{2}$ " " witl clrawer . . . . . . 4.50

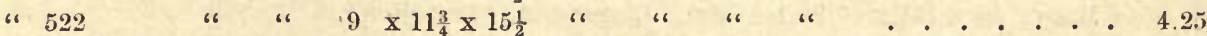

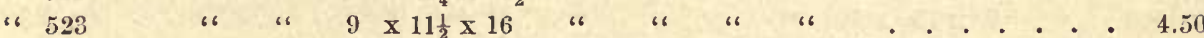

" 524 " " " $7 \times 13 \frac{1}{2} \times 22$ " " " 6 wheel . . . . . . 6.00

" 525 " " $6 \frac{1}{2} \times 9 \frac{1}{4} \times 12 \frac{1}{2}$ " " Close wire, for 4 small birds . . 2.2.

" 526 " " " " " " " $10 \times 13 \times 17 \frac{1}{2}$ " " 10 Finches . 8.00

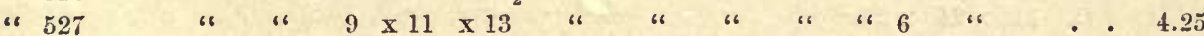

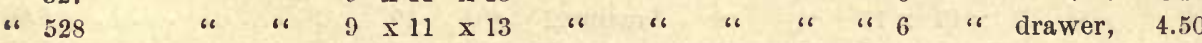

" 529 " " " $10 \frac{1}{2} \times 13 \times 18_{4}^{1}$ " "For breeding, 2 doors . . . . 5.00

" 530 " " " " " $10 \times 13 \times 17 \frac{1}{2}$ " " " 
No. 531

“ 532

6 533

6. 534

“535\{ $\left\{\begin{array}{l}\text { A. } \\ \text { B. } \\ \text { C. }\end{array}\right.$

a $536\left\{\begin{array}{l}\text { A. } \\ \text { B. }\end{array}\right.$

“ 537

“ 538

“ $539\left\{\begin{array}{l}\text { A. } \\ \text { B. }\end{array}\right.$

Brass body, $10 \times 13 \times 17$ PRICE EACH.

"، " " $10 \times 13 \times 17$ " " " " . . 5.50

" " $11 \times 13_{4}^{3} \times 16 \frac{1}{2}$ " " " " " " ". . . 6.00

" " " $13 \frac{1}{4} \times 16 \frac{1}{4} \times 18 \frac{1}{2}$ " " " Cardinal . . . . . 8.50

" " " $14 \frac{1}{2} \times 20 \times 2 I_{\frac{1}{2}}$ " " " " Mocking-bird . . . . 12.00

" " " $14 \frac{1}{2} \times 23 \frac{1}{2} \times 23 \frac{1}{2}$ " " " " " . . . 13.00

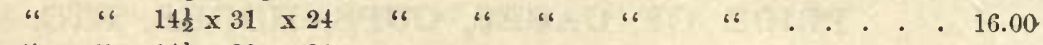

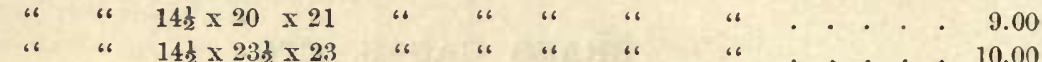

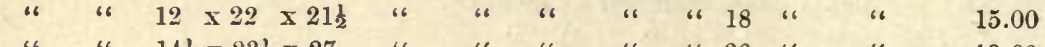

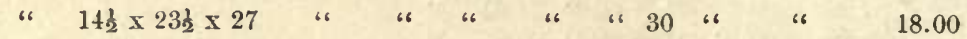

" $20 \times 29 \times 32 \frac{1}{2}$ " " " " " 40 " " 4000

A, with dome-top extra, $\$ 3.00 ; \mathrm{B}$, with dome-top extra . . . . . . . . 5.00

“ 540 Revolving Percll : for No. 539, style A, \$3.00; style B . . . . . . . 3.50

\section{PARROT-CAGES AND PARROT-STANDS.}

(A. Tinned wire, brass bands, and zinc base; close wire for Paroquets $\quad$ PRICE EACH. $\$ 2.50$

B. Same material, diameter 12 inches. For Cuban Parrots . . . . . 2.50

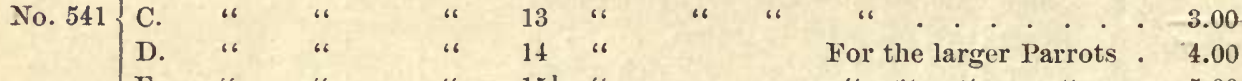
E. " " " $615 \frac{1}{2}$ "

“ 542 All brass, diameter 15 inches, height $26 \frac{1}{4}$ inches.

" 543 Brass body, tinned wire, $14 \times 17 \times 24$ inches high.

" 544

" $15 \times 18 \times 25 \frac{3}{4}$ " " "

" “ "6 "6

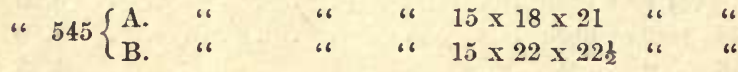

$\therefore 546$

"6 $15 \times 22 \times 26 \frac{1}{2}$

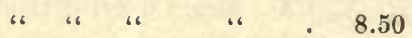

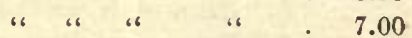

" 6 " 6 " 69.50

"6 "6 "6 610.00

" " " " 1100

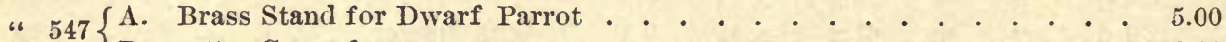

" $548\{$ A. Parrot-stand, with iron foot . . . . . . . . . . . . . . . 6.00

549 Brass Cover, with door, to fit all my parrot-stands . . . . . . . 6.00

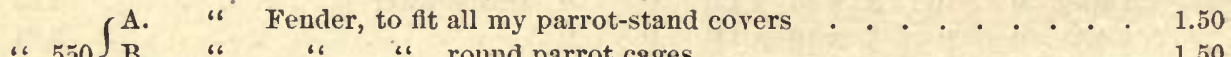

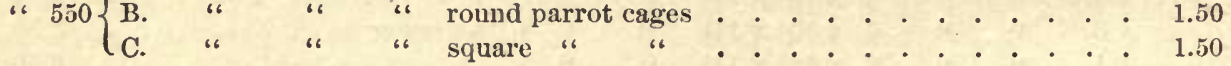

“ 551 Stand $3 \mathrm{ft} .10 \mathrm{in}$. high, brass upright, bronze foot, and iron cups enamelled . 9.50

“ 552 Stand same as above, with branch and swing . . . . . . . . . . . 11.00

\section{MOUSE AND SQUIRREL CAGES.}

No. $553\left\{\right.$ A. Body, $4 \frac{1}{2} \times 9 \frac{1}{2} \times 6$ inches high. Bright tin. For Mice . . . . . $\$ 0.75$

B. Same, japanned . . . . . . . . . . . . . . . . . 1.00

" 554 Body, $5 \frac{1}{2} \times 11 \frac{1}{2} \times 7$ inches high. Japanned. For Mice . . . . . . 2.00

“ 555 " $6 \times 10 \times 10$ " " " 6 . . . . . . 2.50

A. $7 \times 15 \times 17$ inches high. Bright tin. For Squirrels . . . . . 2.00

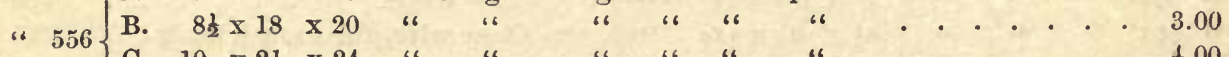

C. $10 \times 21 \times 24$ " " " " " " "

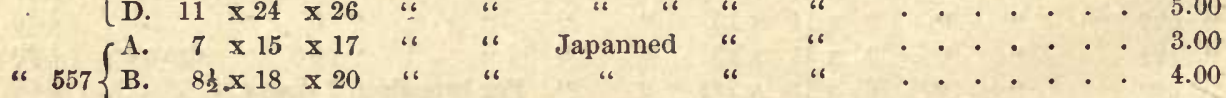


PRICE KACH.

$\left\{\right.$ A. $10 \frac{1}{2} \times 12 \times 14$ inches high. Iron wire. Walnutbase. For Red Squirrels, $\$ 3.00$

No. $558\left\{\right.$ B. $12 \frac{1}{2} \times 14 \frac{1}{2} \times 17 \frac{1}{2}$ " " " " " " " " " " " " " " " 4.00

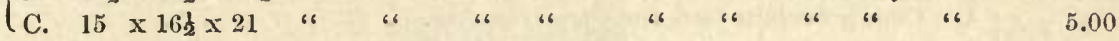

" 559 All Brass, body $15 \times 18 \times 21$ inches higll. Wheel 14 inches." " " " " 10.00

" 560 " " " $15 \times 22 \times 21$ " " 2 wheels 14 " " 13.50

\section{WOOD-FRAME, TINNED-WIRE CAGES.}

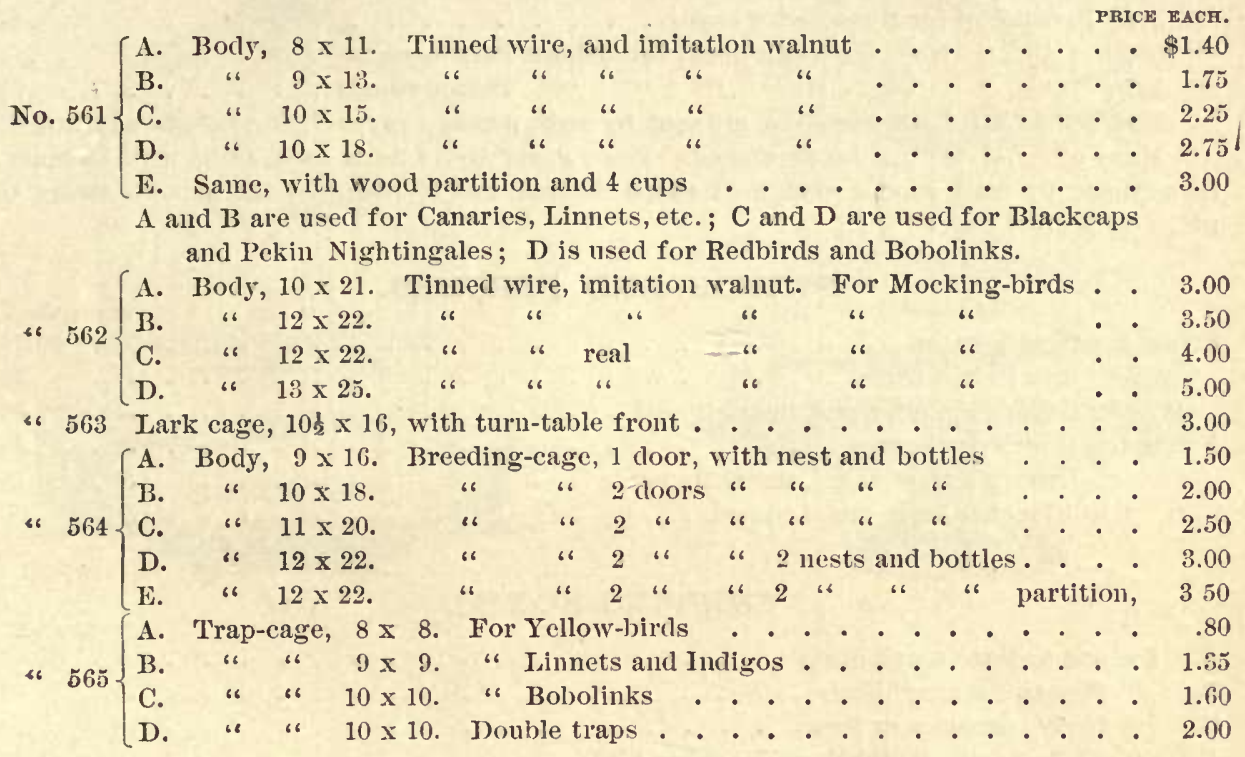

HOOKS, CHAINS, SPRINGS, CUPS, ETC.

PRICE EACH.

No. 566 Hook to suspend cage from ceiling . . . . . . . . . . \$0.05

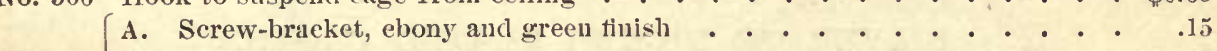

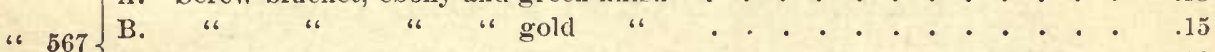

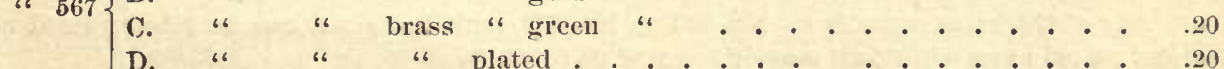

$\cdot \cdot \cdot \cdot \cdot \cdot \cdot \cdot 20$

“ $568\left\{\begin{array}{l}\text { A. Bracket, adjustable to any angle, brass plated . . . . . . . . . } 25 \\ \text { B. }\end{array}\right.$

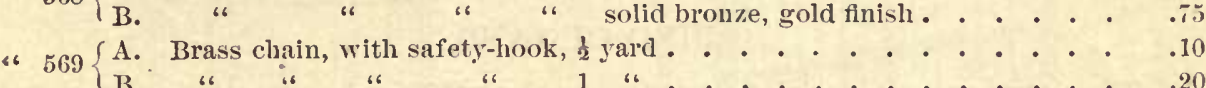

« 570 Brass safety-hook . . . . . . . . . . . . . . . . .03

“ 571 Elevator, to suspend cage at any height . . . . . . . . . . . . . .50

“ 572 Brass spring for suspending cage . . . . . . . . . . . . . . . .15

“ 573 Spring-perch, for any size cage . . . . . . . . . . . . . .25

CUPS.

No. 574 Cup, opal, Osborn cage, shield . . . . . . . . . . . . . \$0.10

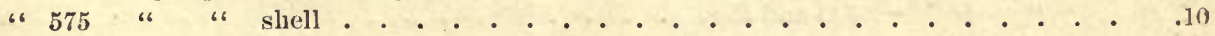

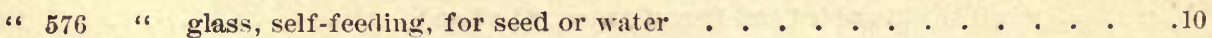

4577 " "6 or opal, 2 xizes, for Gunther and Lindemann cages . . . . . . 10 
No. 578 Bottle, glass, for wood-frame cages $\quad$ PRICE EACH.

“ 579 Cup, glass or porcelain, monogram . . . . 10

“580\{ A. Cup, porcelain star, for Canary-cages . . . . . . . . . . . . . . . . .

B. " " " " " Mocking-bircl cages . . . . . . . . . . . 20

" 581 Cup, glass top, tin sides and back, for wood cages . . . . . . . . . . . . . . . . . . . . . .

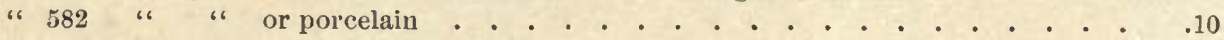

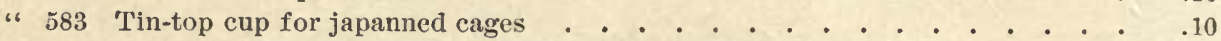

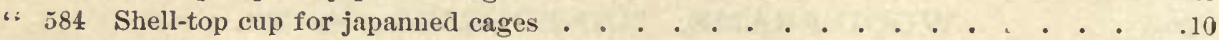

“ 585 Parrot-cup for tinned-wire cages . . . . . . . . . . . . . . . . . . . . . . .

" 586 " " " iron, porcelain lined, for Osbor'n Parrot-cages . . . . . . . .75

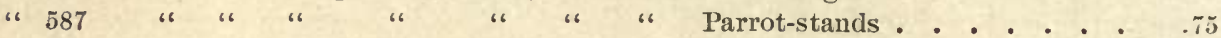

Nos. 566 to 587 , both inclusive, are sent by mail, postage prepaid, for 5 cents additional.

Many other styles can be furnished. Price generally 10 cents each, or by mail 15 cents

In ordering by mail, send a sketch of shape desired, and if possible, the maker's name as given on door of cage.

SWINGS AND PERCHES.

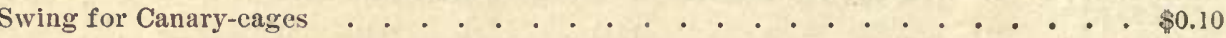

" " iron Parrot-cages . . . . . . . . . . . . . . . . . . . . . 20

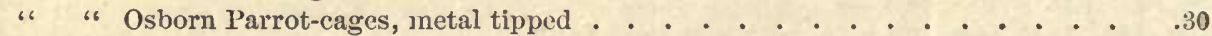

Perch for iron Parrot-cages . . . . . . . . . . . . . . . . . . . . . . . . . . . . . . . .

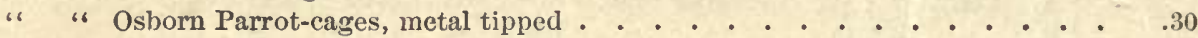

"6 6 to 10 inches long, metal tipped . . . . . . . . . . . . . . . . . .

\section{SHIPPING-BOXES.}

A. For one to three small birds

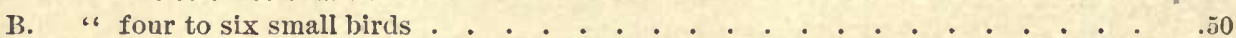

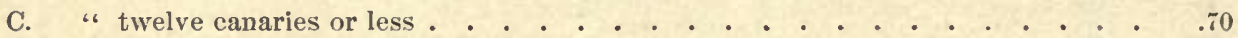

D. "six to twelve Redbirds or Mocking-birds . . . . . . . . . . . . . 1.25

Birds are put in these shipping-boxes when they are to be sent by express over five hundred miles, so that sufficient seed and water may be given to insure they will not die of thirst or starvation.

\section{SILVER OR NICKEL PLATED CAGES.}

Any of the brass cages from No. 500 to No. 532 , both inclusive, can be silver plated or nickel plated at an additional cost of from $\$ 2.00$ to $\$ 3.00$.

\section{BIRD-ORGANS.}

These organs are made to play eight airs, popular ballads and waltzes, in keys that Canaries, Bullfinches, Mocking-birds, and other birds can learn readily. The instrument is operated by a crank. Price $\$ 8.00$.

\section{NEW SEED FENDERS.}

(See Cuts Nos. 512 and 550.)

Fenders, round or square, to fit all regular Canary size of cages

" to fit cages Nos. $526,529,530,531,532$, or any cage that size . . . . . . .50

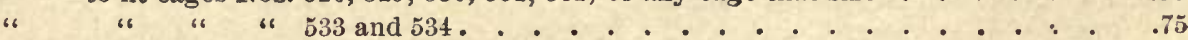

“ " all Mocking-bird and Parrot cages, $\$ 1.25$ and . . . . . . . . . . 1.50

" “ Parrot-stands . . . . . . . . . . . . . . . . 1.50 


\section{- caNaRY CAGES.}
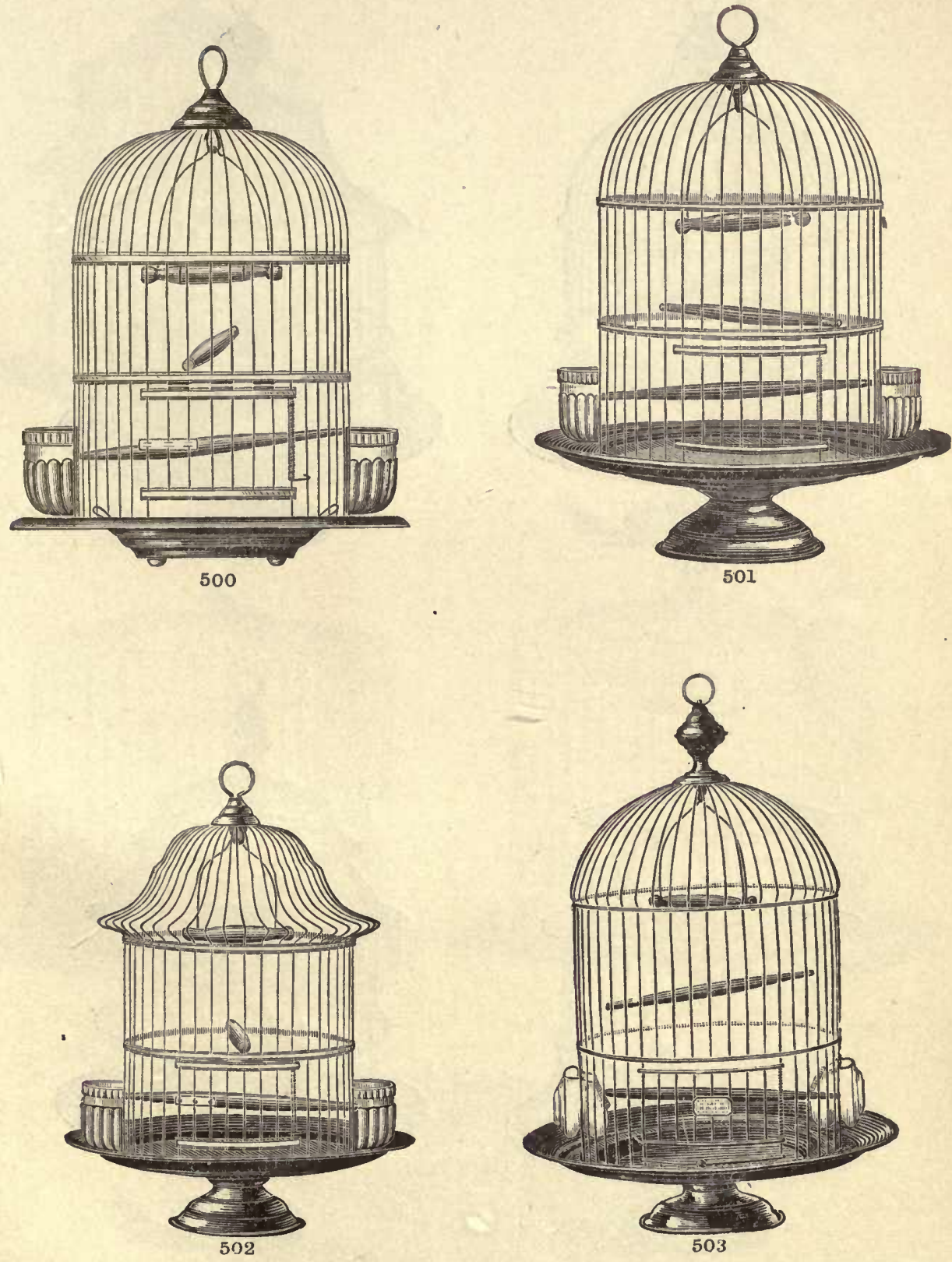

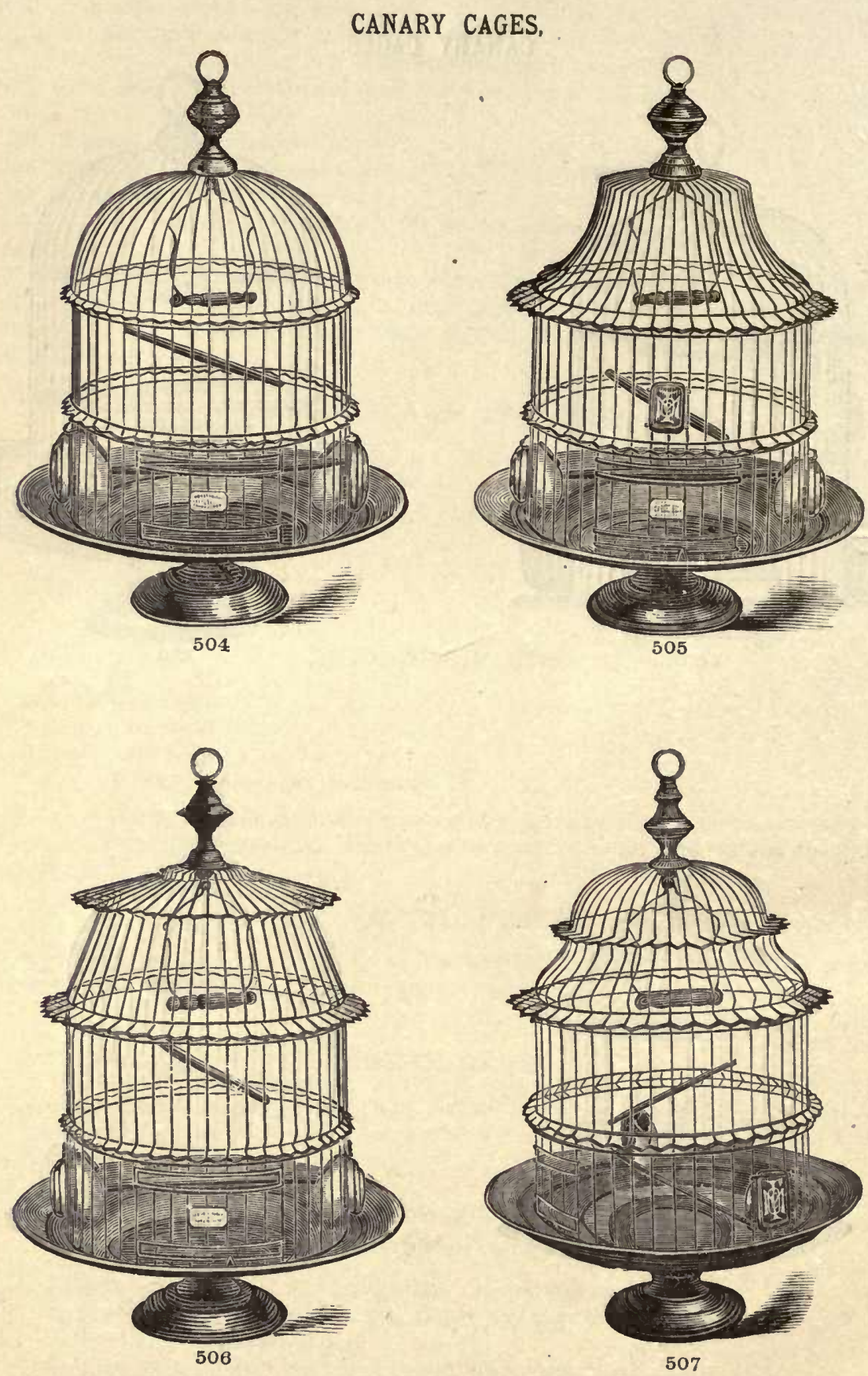

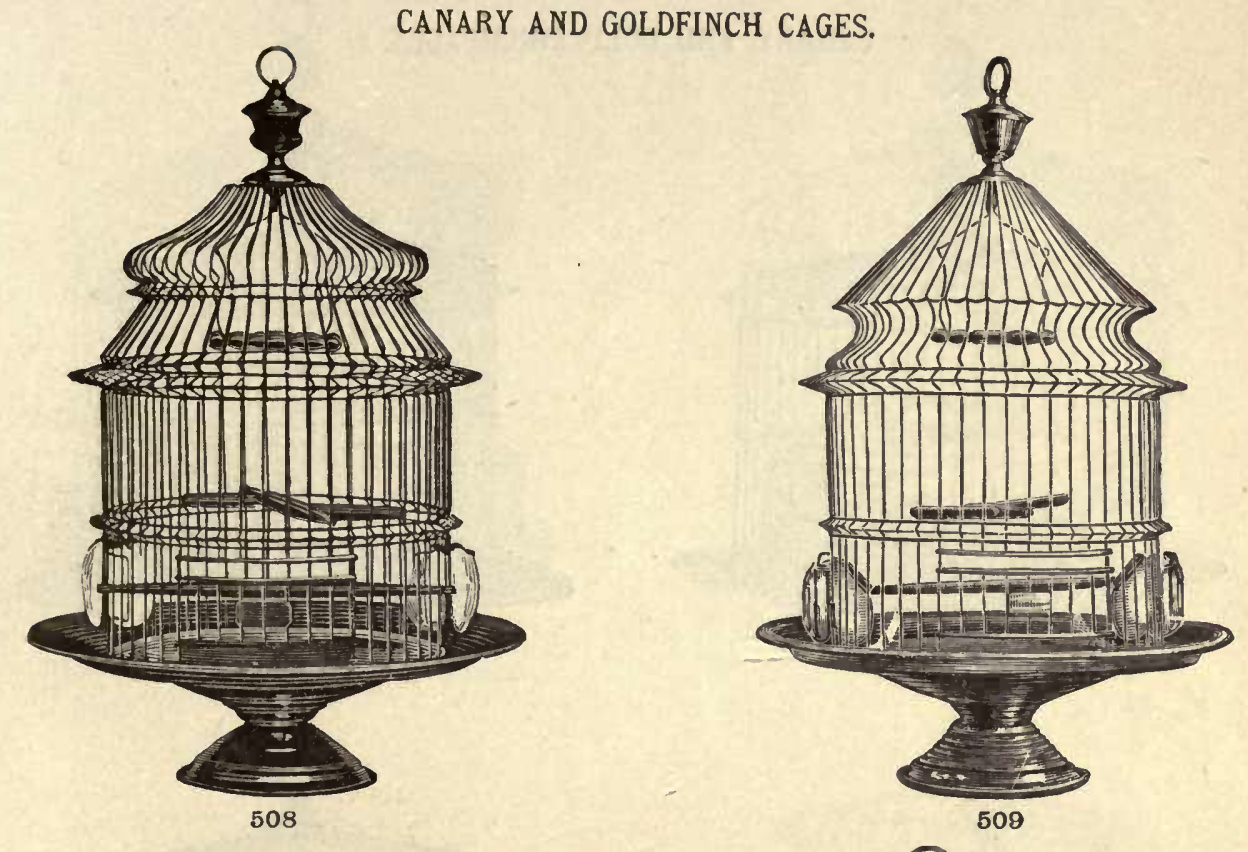

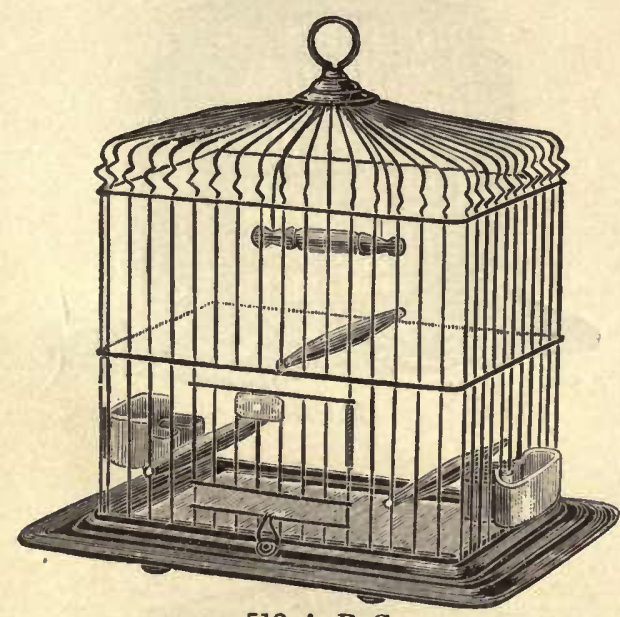

$510 \mathrm{~A}, \mathrm{~B}, \mathrm{C}$

A strong cage at low price.

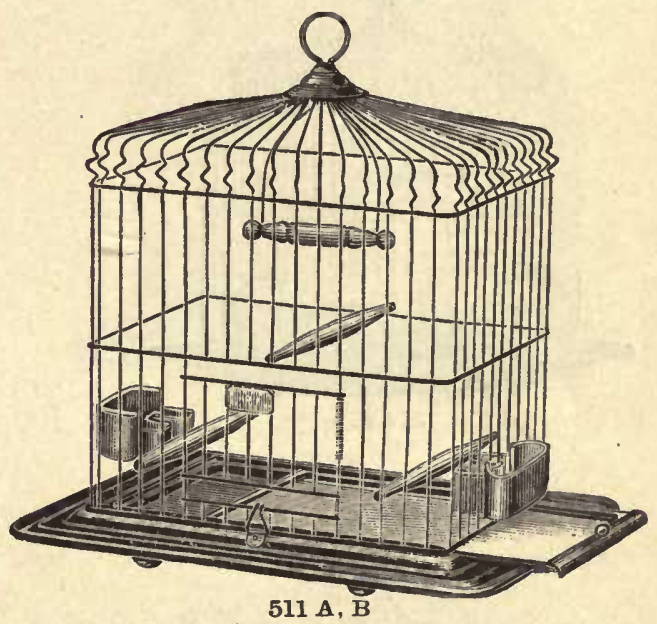

Showing drawer base. A strong cage at low price.

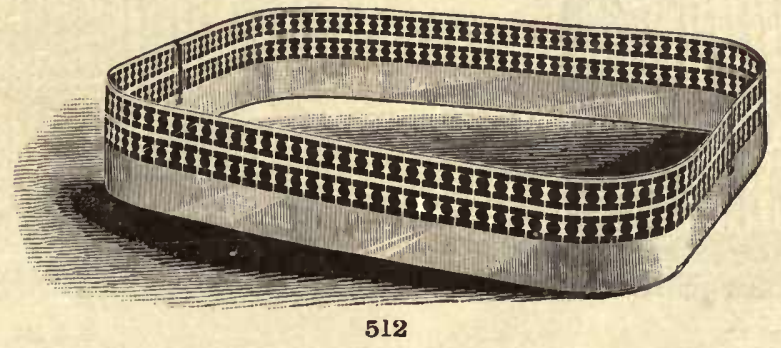

Fender to prevent seed from scaltering. 
CANARY AND GOLD FINCHCAGES.
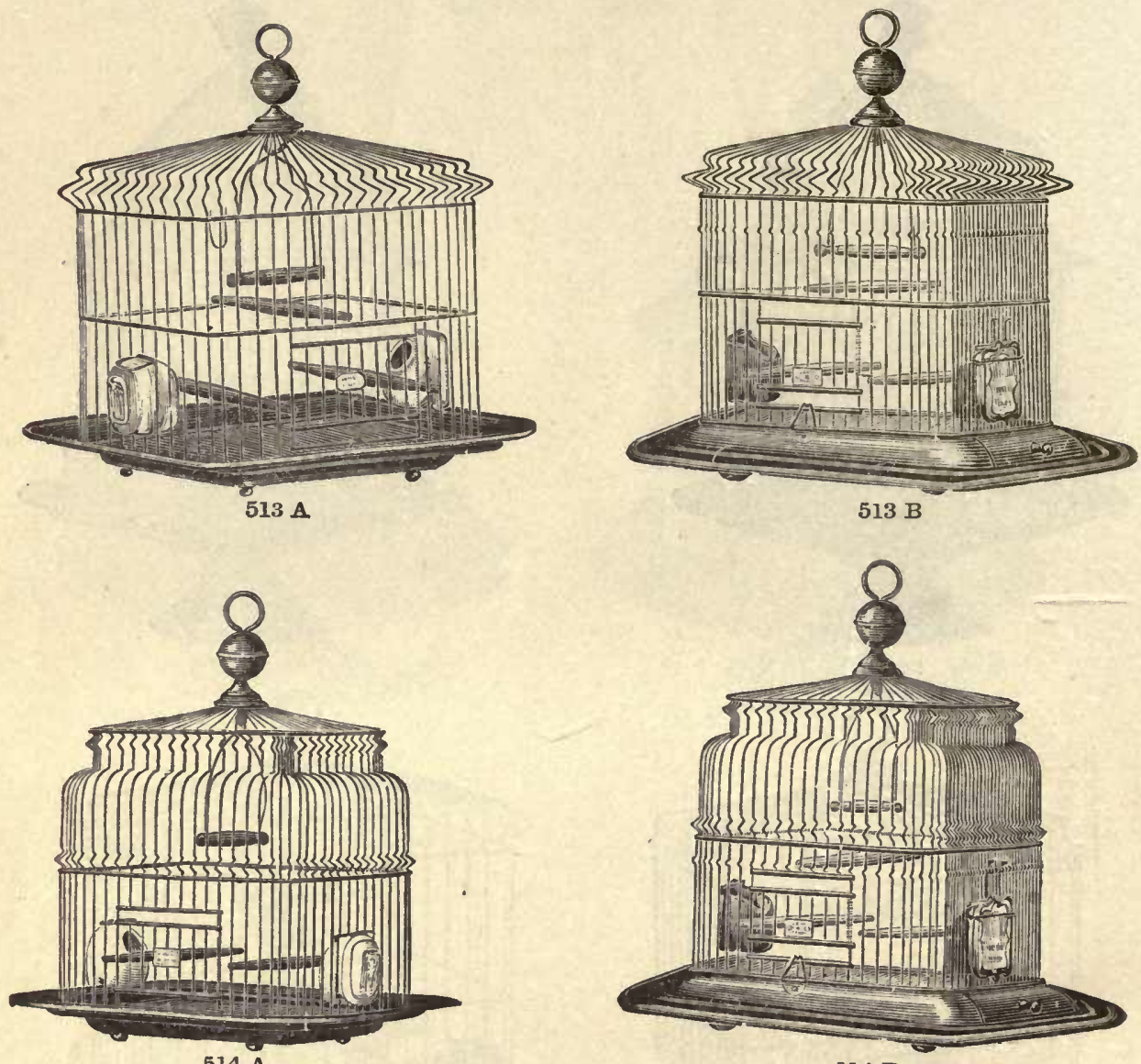

514 A
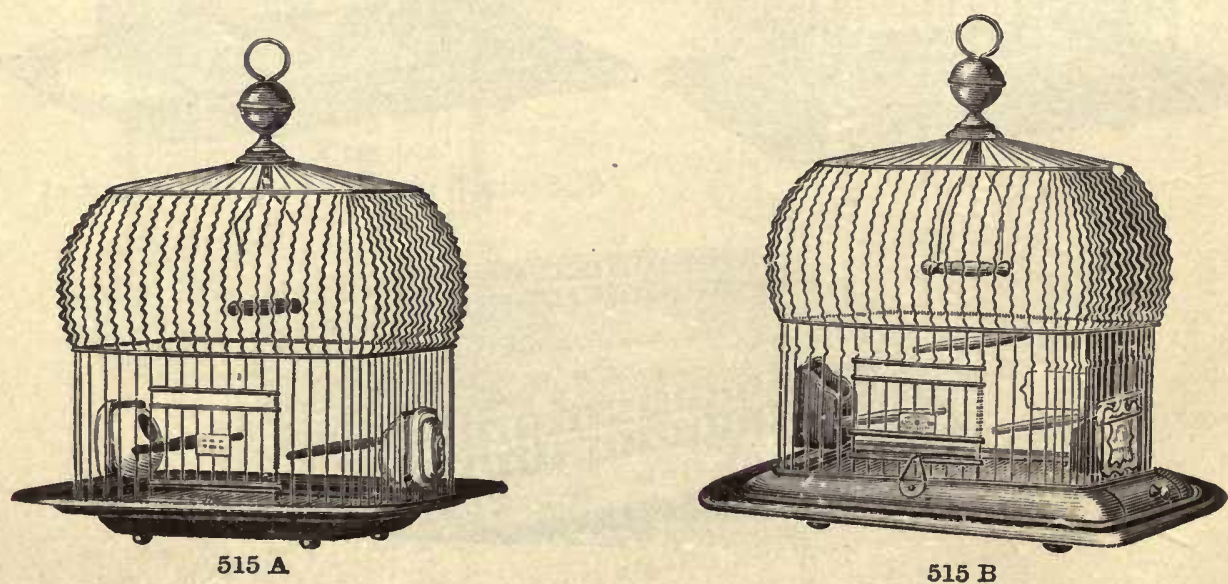


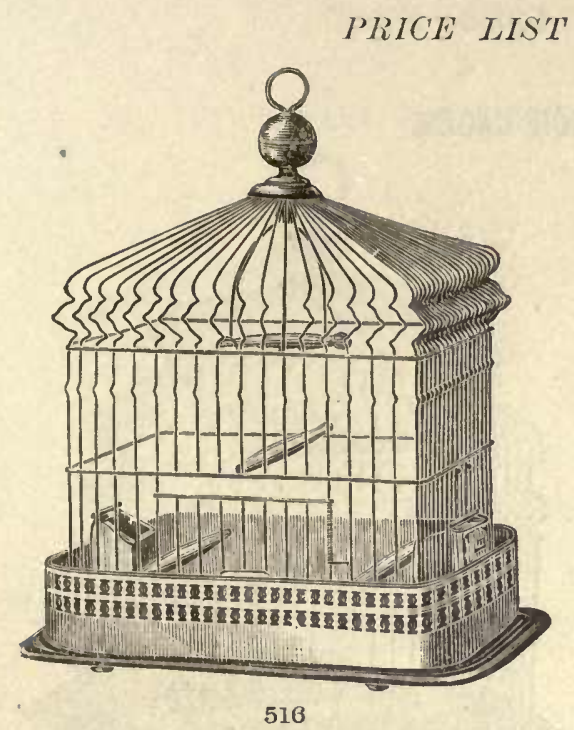

TAGES, ETC.

297

Representing Cage with Fender.
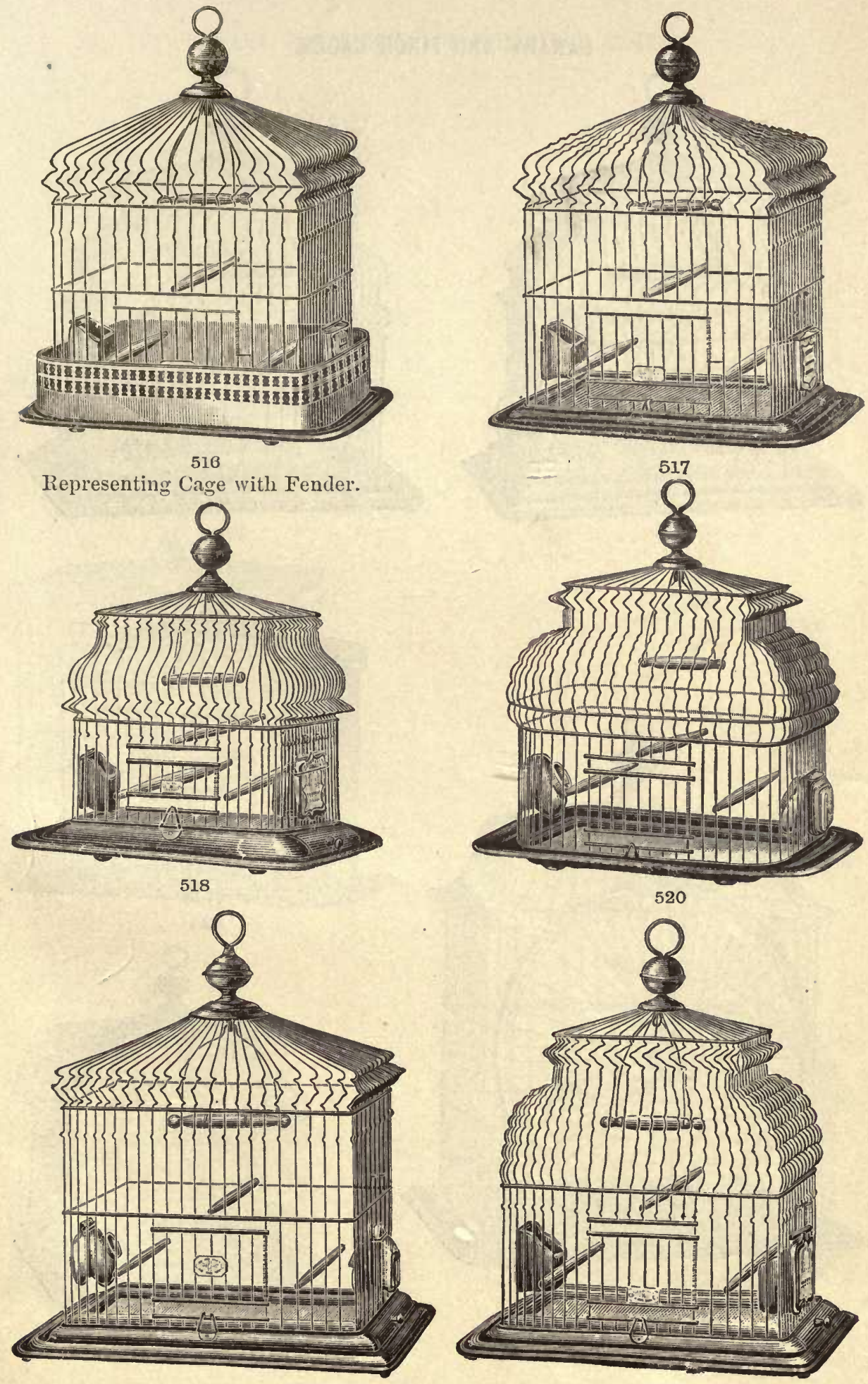

5.9

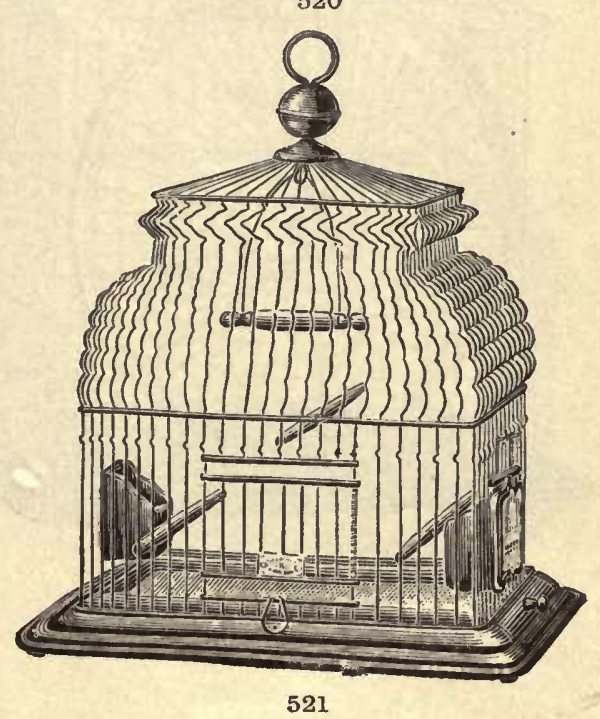



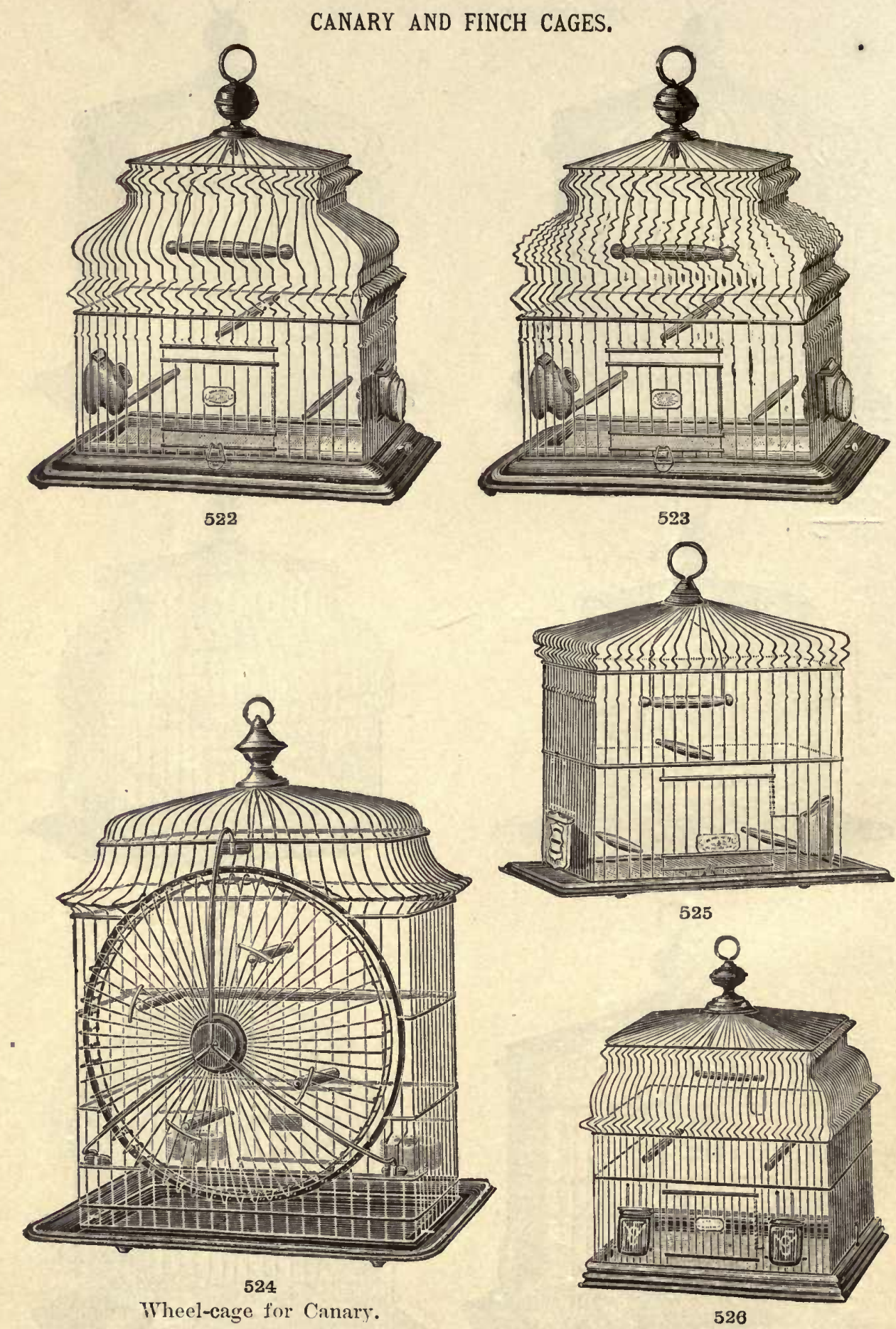
CANARY, GOLDFINCH, AND BULLFINCH CAGES.
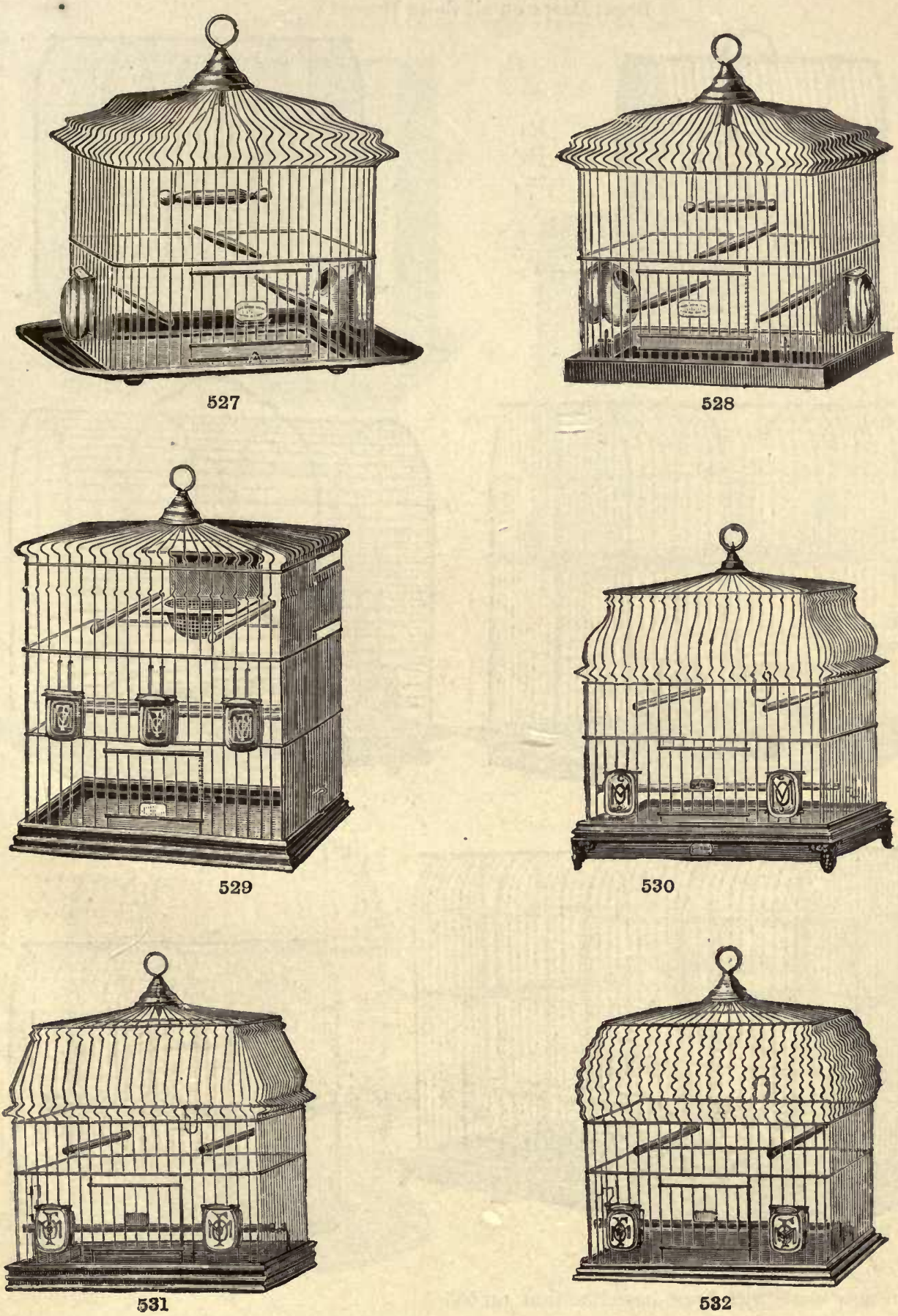
PAROQUET, CARDINAL, MOCKING-BIRD, AND AVIARY CAGES,

Brass Bases on all these Brass Cages.
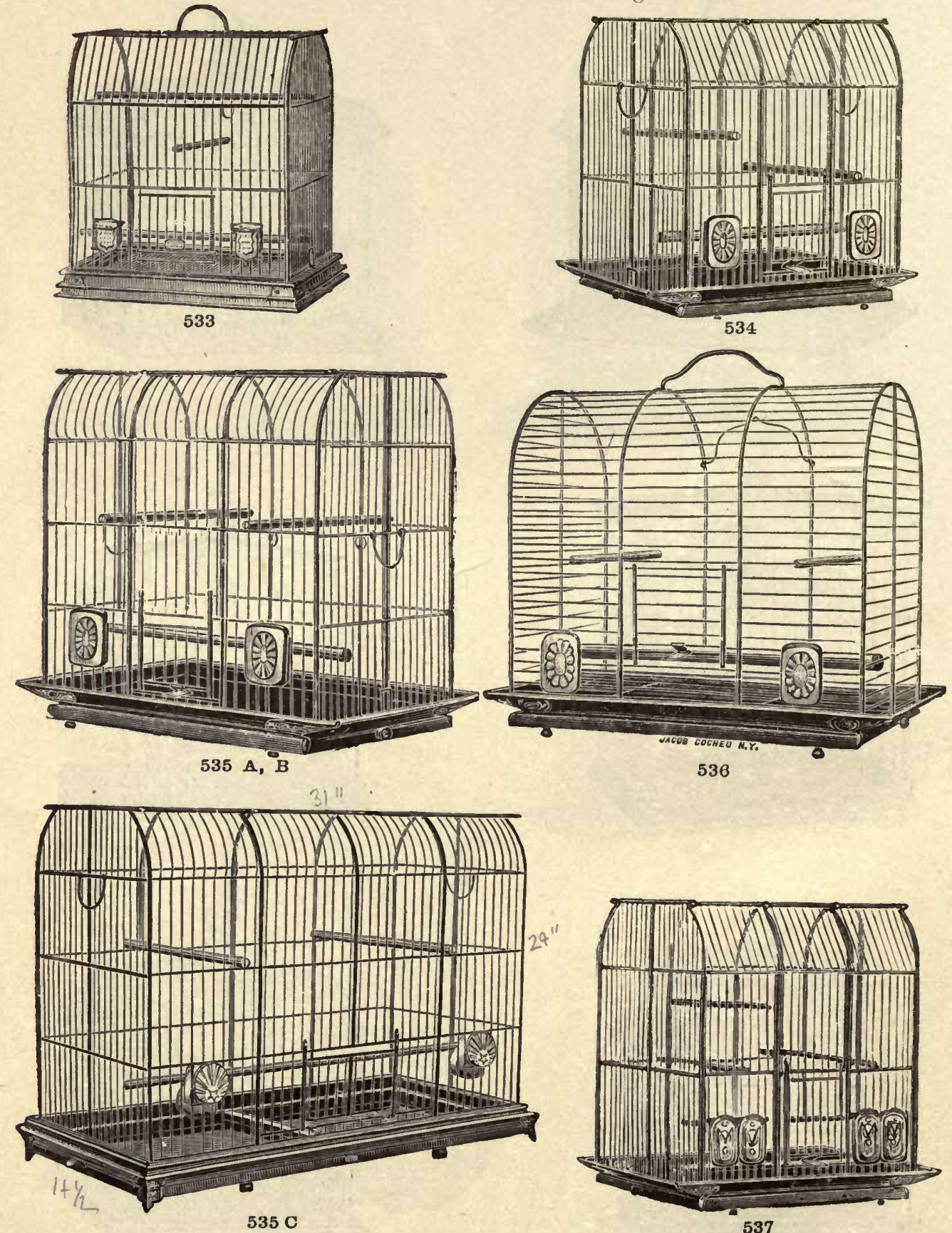

But now made with brass base like that on $53.5 \mathrm{~A}$.

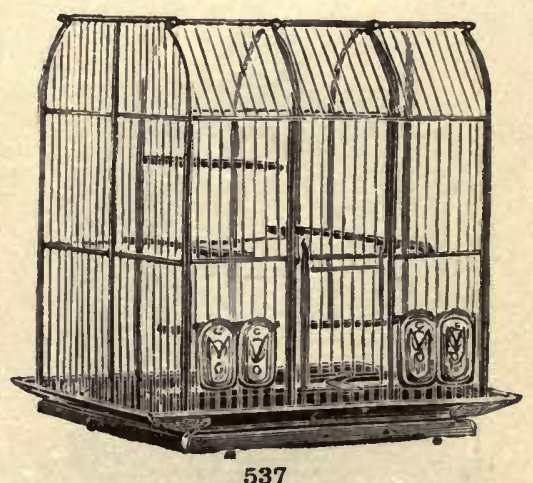




\section{AVIARIES AND PARROT CAGES.}

Brass Bases on all these Cages except No. 541 style.
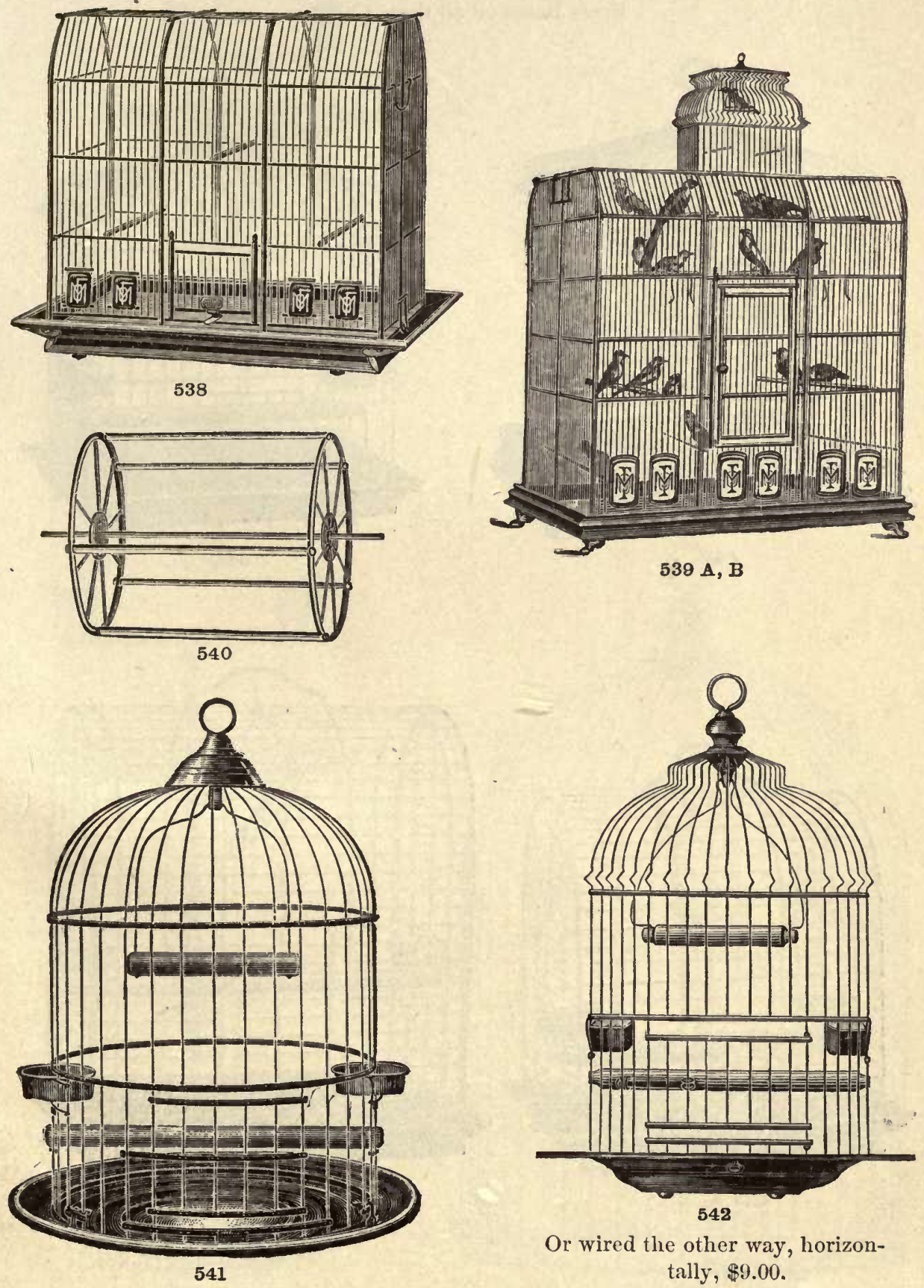

Or wired the other way, horizontally, \$9.00. 
PARROT AND COCKATOO CAGES.

Brass Bases on all these Cages.
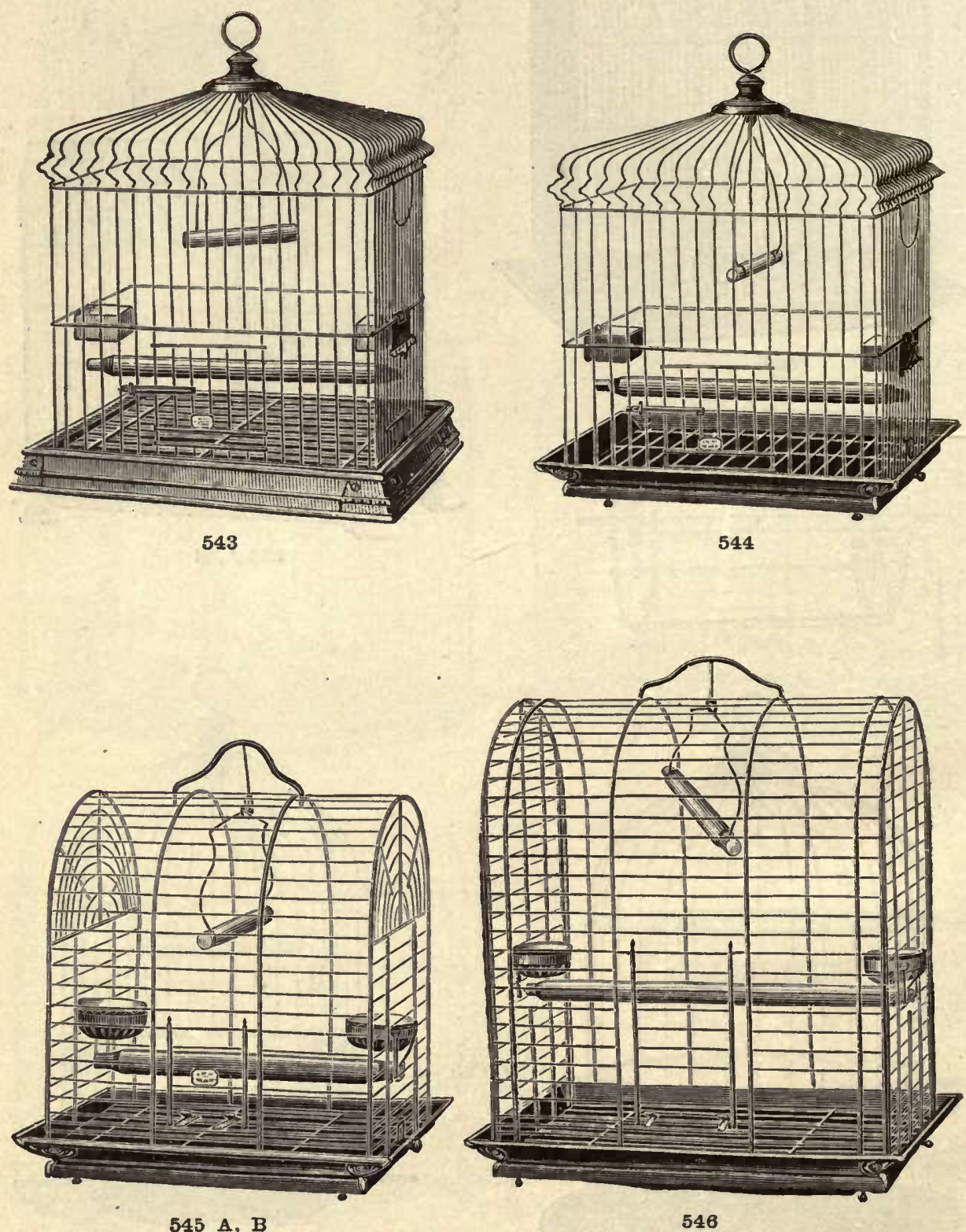
PARROT STANDS AND COVERS.
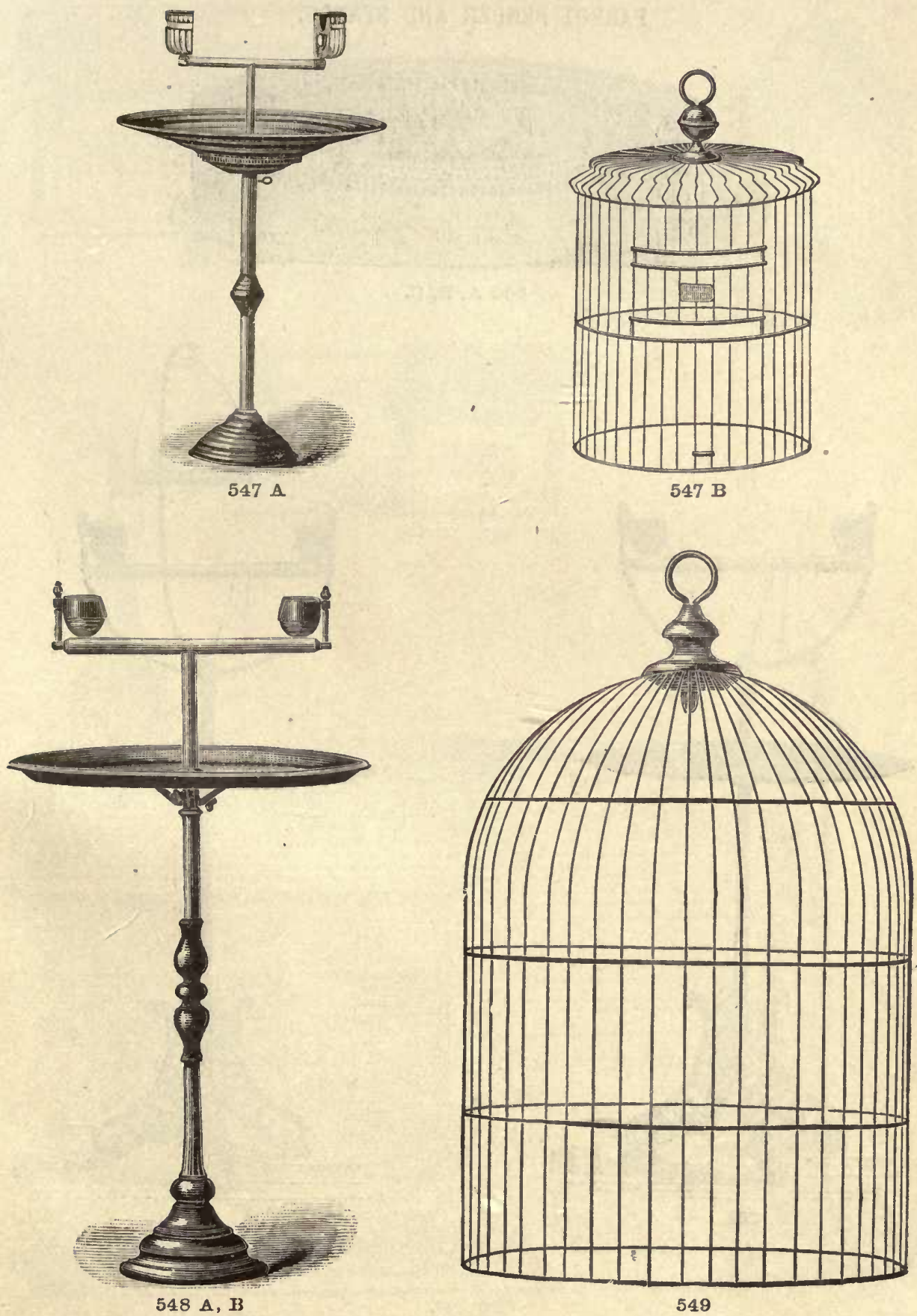
PARROT FENDER AND STANDS.
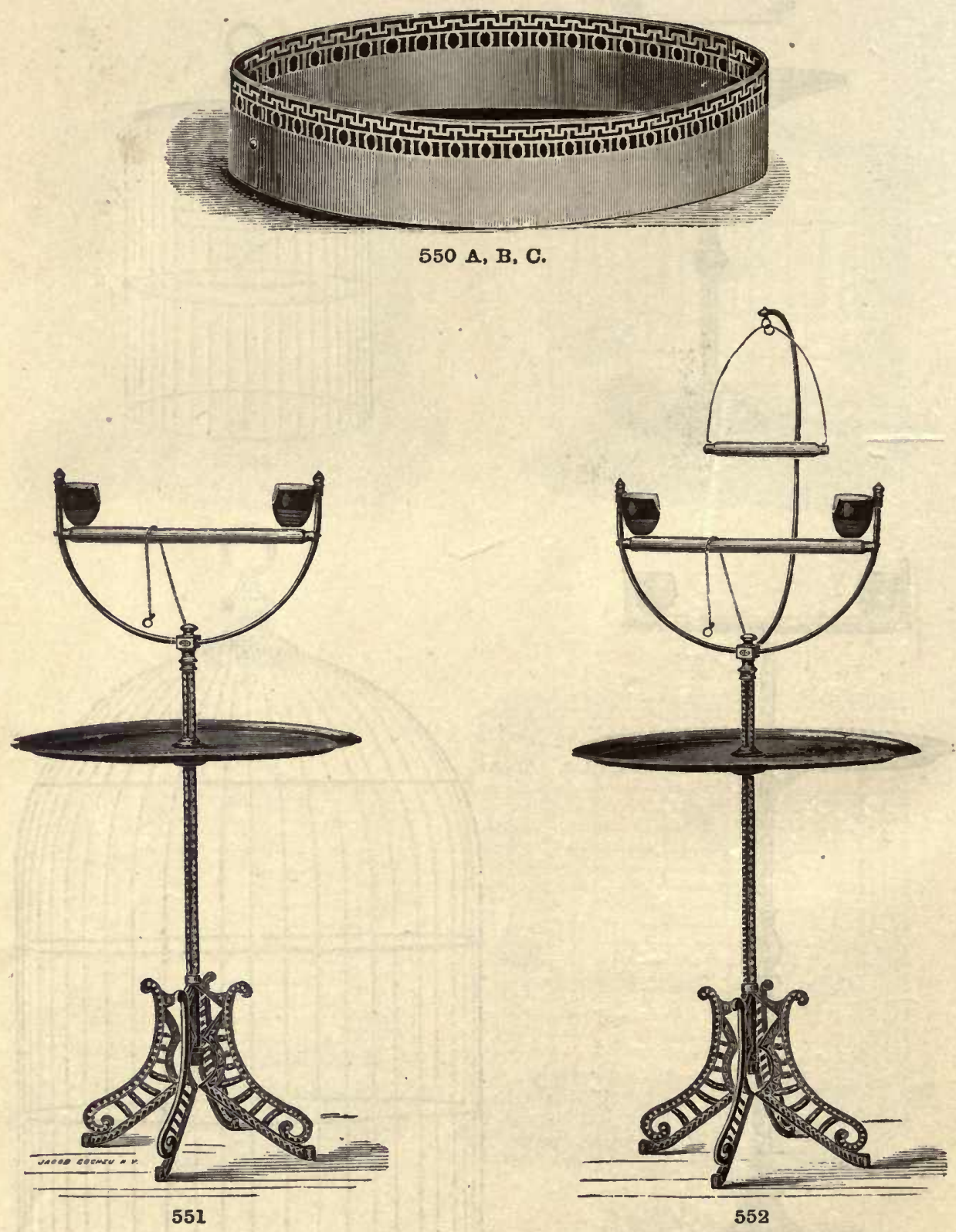
MOUSE AND SQUIRREL CAGES.

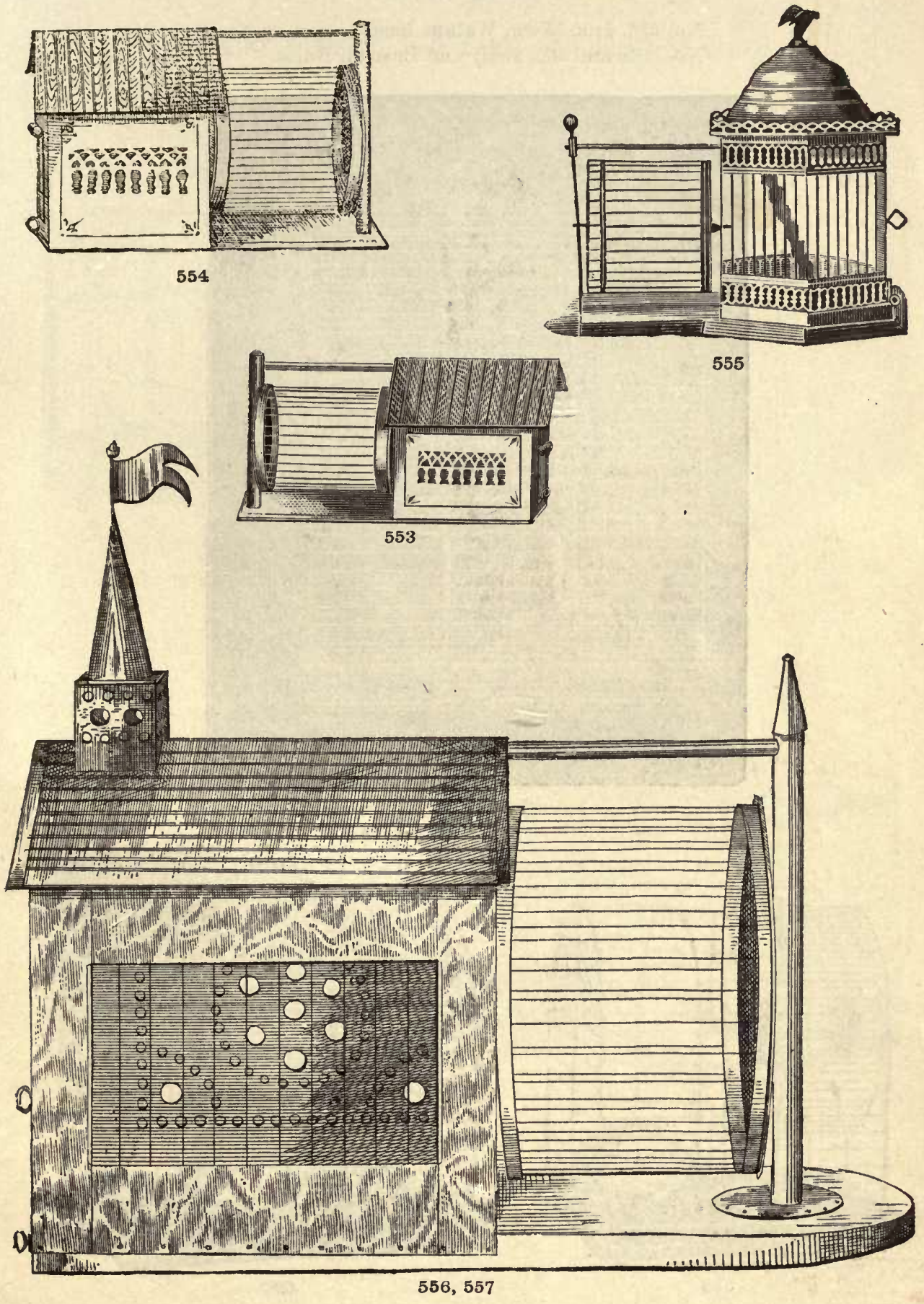


SQUIRREL CAGES.

No. 558, Iron Wire, Walnut Base.

Nos. 559 and 560, Body and J3ase all I3rass.

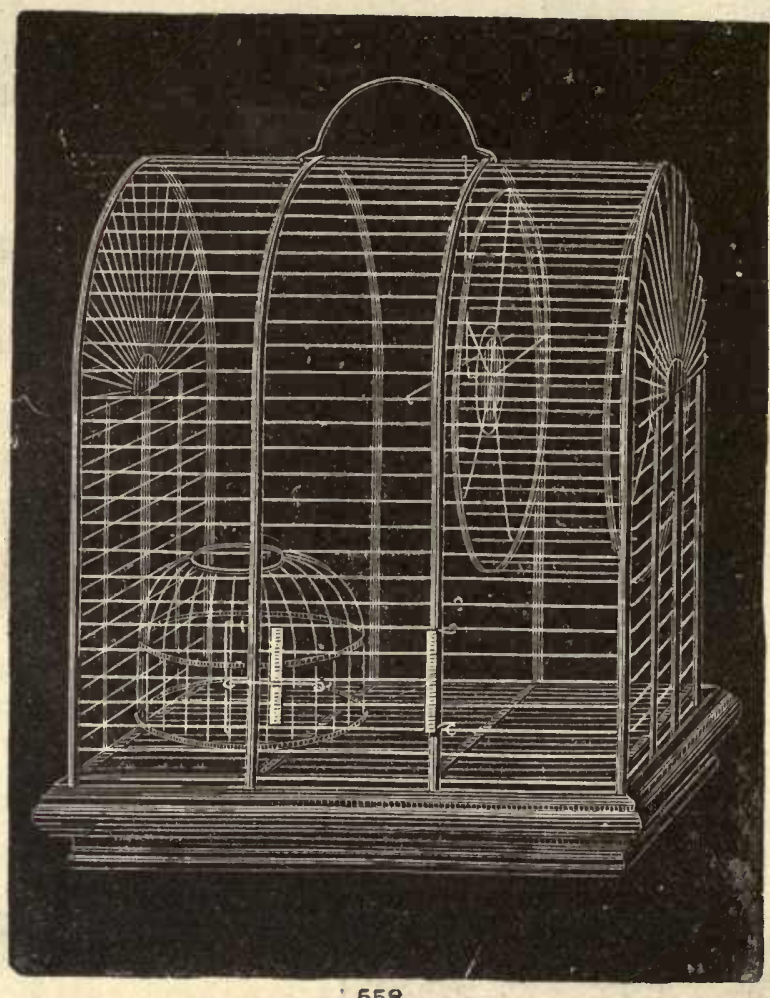

558
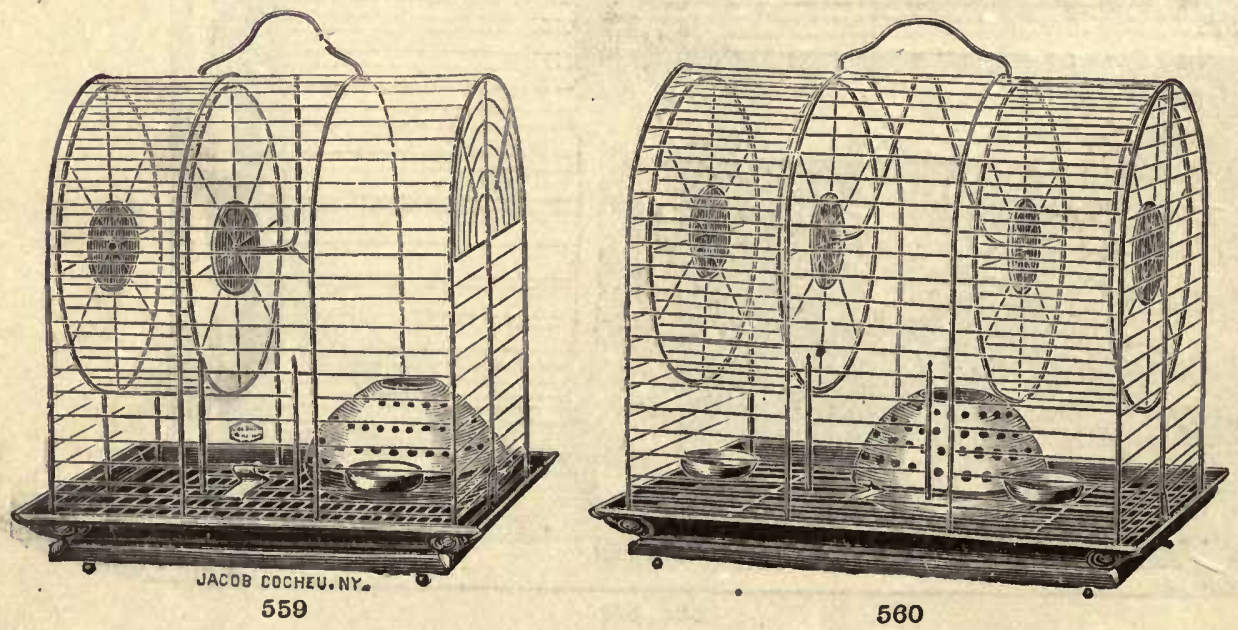
BOBOLINK, MOCKING-BIRD, LARK, AND BREEDING CAGES.
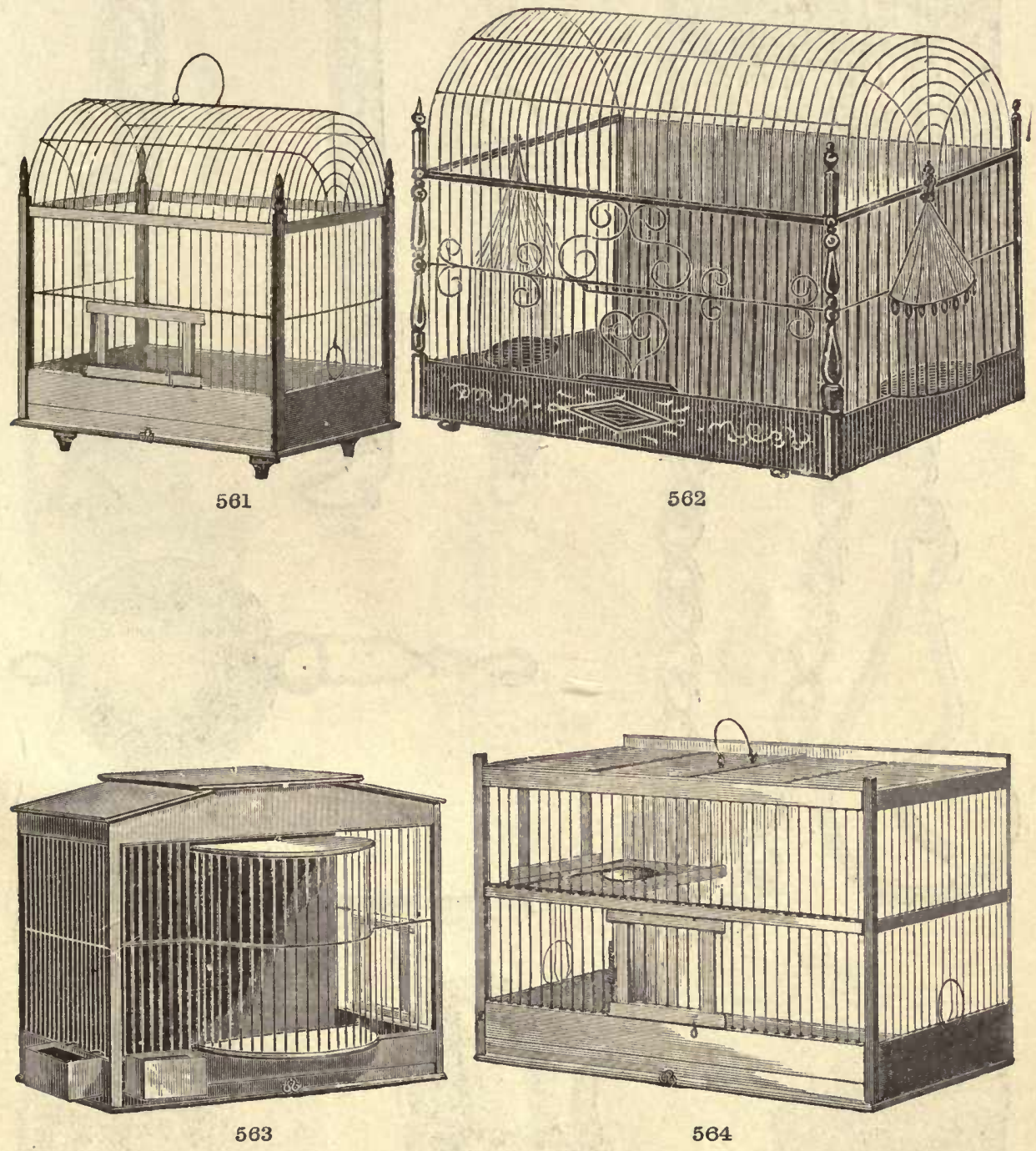
PRICE-LIST OH CAGES, ETC.

TRAP-CAGE, SPRING, HOOKS, ELEVATOR, CHAIN, AND GUARD.
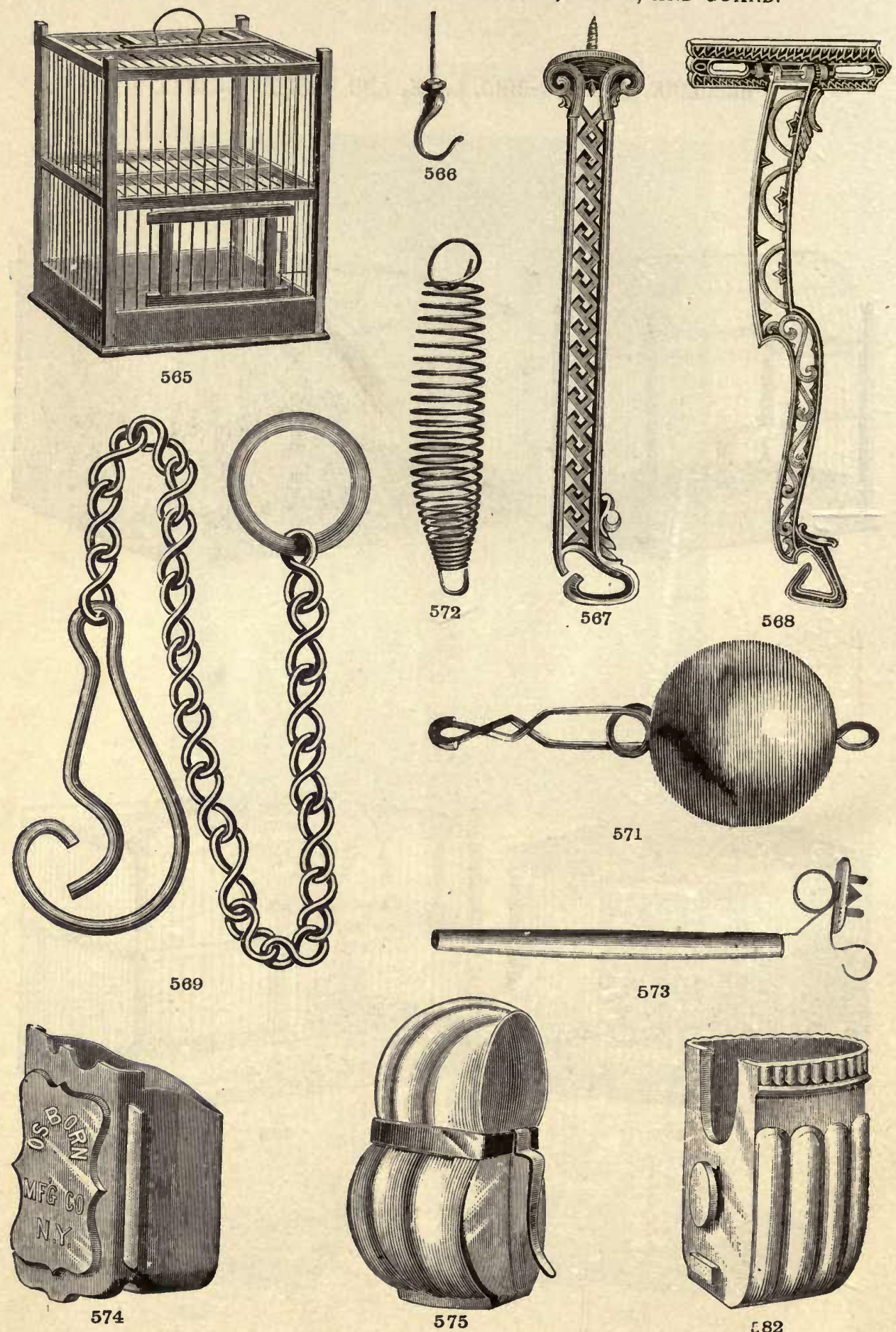

571
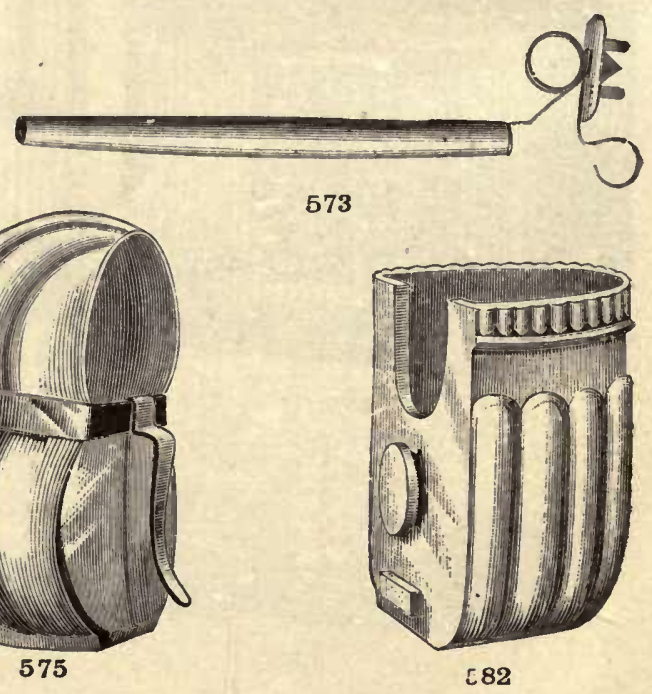


\section{PRICE-LIST OF CAGES, ETCO 309}

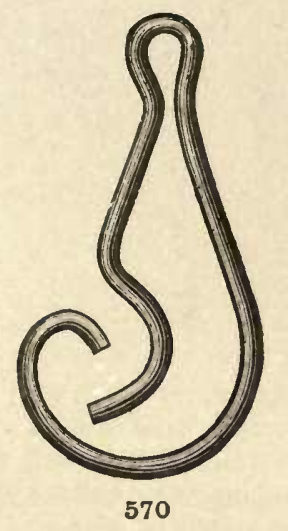

HOOK AND CUPS.
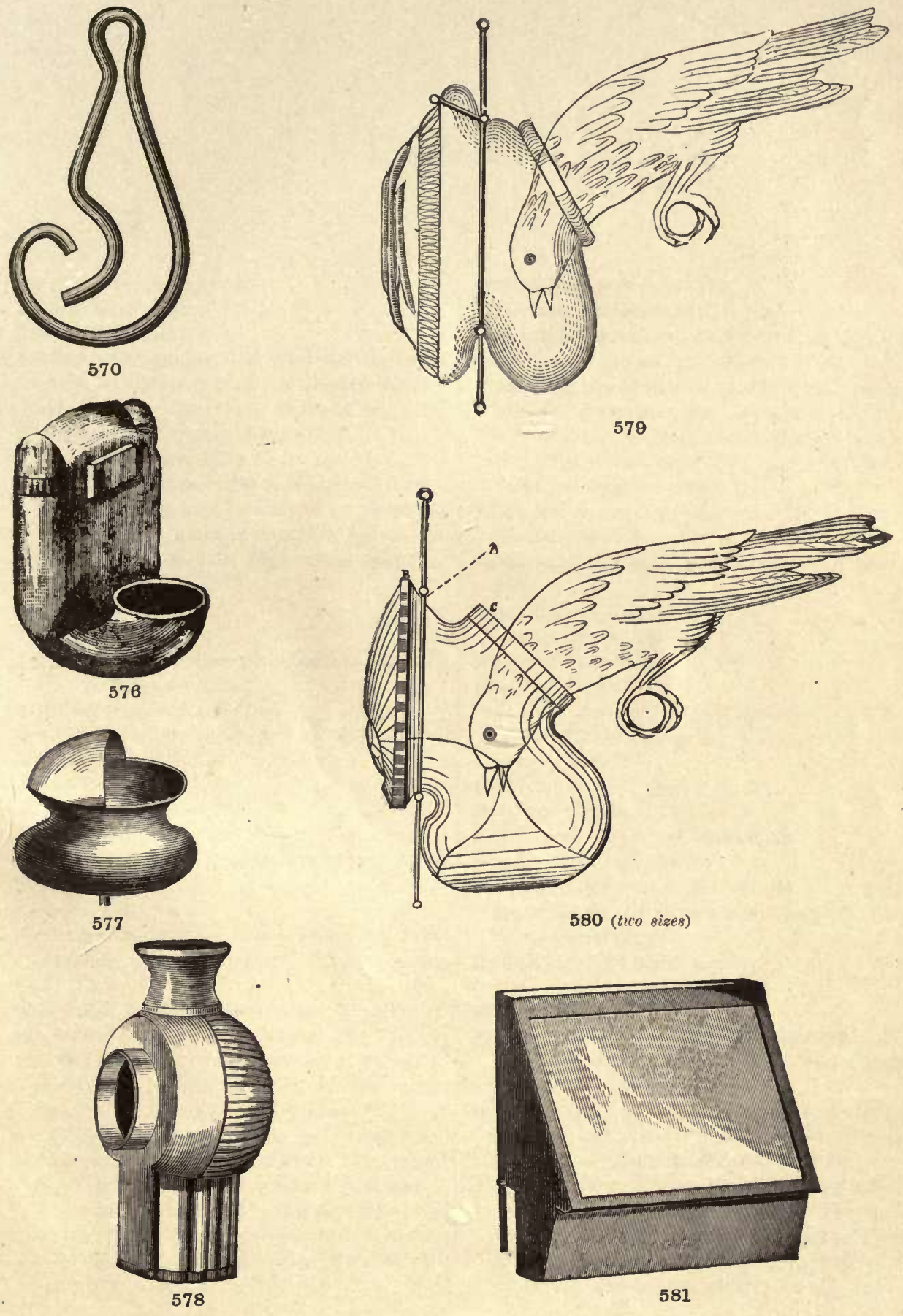



\section{INDEX.}

Accidents to Canaries, 43.

African Gray Parrot, 184.

A frican Love-bird, 212.

African, Madagascar, and West-Indian Paroquets, 211 ; mostly used for beautifying the aviary, 211; food and diseases of, 212 ; "Tommy's" love of butter, 213.

Albino Blackbirds, 142.

Albinos, cause of peculiar appearance of, 227 ; in olden times held as objects of religions worship, 227; most remarkable specimens of, 228 ; care of, 229 ; high prices paid for, 229.

Amazon Parrot, 189.

American Canary, 30.

American Red Linnet, plumage and size of, 103 ; treatment of, 103.

Artificially colored Canaries, 28.

Ass and the Nightingale (poem), 127.

Asthma in Canaries, 39.

Australian Magpie, 222.

Australian Paroquet, 207.

Avadavat, or Strawberry Finch 246.

Aviaries for breeding-birds, 43; indoor, 52.

Aviary, indoor, 52 .

Baltimore Oriole, size and plumage of, 174; ingenuity in nest-building, 174 ; treatment of, 175 .

Bargaining for Bullfincles in Germany, 61 .

Belgian, or Long-breed Canary, 17 ; bronze model of, 19; the blue-blood of the Canary family, 19; careful breeding of, 20 ; cages for, 21,22 ; societies for breeding, 22 .

Bird buying and Importing, 247; travellers employed by inporting-houses, 247 ; experience of pickers. 248; Canary "hearers," 281 ; London fakirs, 251 ; transportation by steamer, 252 ; feeding and watering birds, 257 ; danger from rats, 256 ; "Fritz's" adventurous life, 257 .
Bird-organs, prices of, 292.

Bird-shows in Scotland, 26.

Blackbird, European, size and plumage of, 140; intelligence and devotion of, 140 ; amusing anecdotes of, 140; natural song of, 140; a favorite dish for epicures, 141; a favorite of English bird-lovers, 141; Albino Blackbirds, 142 ; food, care, and treatment for diseases, 142.

Blackcap, size and plumage of, 129 ; food and diseases of, 130.

Black-capped Finch, or Three-colored Nun, 240.

Black-capped Nun, 240.

Black Goldfinch, 88.

Blue-and-Yellow Macaw, 201.

Blue Grosbeak, 118.

Bobolink, destructive to farmers, 119 ; plumage of, 119; song of, 120; activity and gluttony of, 121.

Brass cages, etc., prices of, 289.

Brazilian Cardinal, 113.

Brazilian or Blne-front Parrot, 189.

Brazilian Toucan, 231.

Breeding-birds, 43; cages for, 44; food for, 44 ; color in breeding-birds, 45 ; eggs, 46 ; time of sitting, 46 .

Broken legs of Canaries, 43.

Bronze Manakin, 242.

Brown Linnet, 91.

Brown Thrasher and other American Thrushes, 166; Wood Thrush, 166; Golden-crowned Thrush, 167; Water Thrush, 167.

Bullfinch, the favorite among trained birds, 57 ; size and color of German, 5̃7; Gray, Black, 56; Mottled, Hybrid, English, 58; lightning way of training wild, 58 ; affectionate nature of, 58 ; method of training, 59 ; style of music tanght, 60 ; bargaining for, in Germany, 61; teaching English and American airs to, 62 ; rivalry of, in whis- 
tling, 64; suitable food for, 65 ; proper cages for, 66 ; diseases of, 66 .

Bullfinch songs and music, 72-85.

Cages for breeding-birds, 44 .

Campanini Canary, 14.

Canaries, houschold pets since commencement of sixteenth century, 9 ; when first brought to England, 9; found in a wild state on islands of the coast of Africa, 9 ; inferiority of wild to domesticated birds, 9 ; each breed distinguished by size, shape, color, and song, 9; main classes, 9 ; Germans first give attention to breeding of, 10 ; in the Harz Mountains, 10; training of, at $\mathrm{St}$. Andreasberg, 11; selection of, 15 ; to determine the age of, 15 ; singing of, by gasliglit, 15 ; forced breeding of, 16 ; German mode of feeding, 17; English mode of feeding, 17 ; Belgian, or Long-breed, 17 ; English, 22 ; Norwich, 23; London Fancy, 23 ; Lizard, 23; Scotch Fancy, 25; Yorkshire, 26; Manchester Coppy, 26; French, 27 ; Cayenne-fed, 28; American, 30; $\mathrm{Hy}$ brid, 32 ; trick, 33 ; piping, 34 ; talking, 34 ; diseases of, 35 ; mice a source of torture to, 36 ; insects a pest to, 36 ; nests for, 37 ; chief diseases of, 38 ; breeding-birds, 43 ; treatment of young, 47; Hybrid breeding with, 47 ; fancies of, 49 ; time of mating, 50 ; varieties of Hybrid, 51 ; comparative table of, 55 .

Canary-table, 55.

Cancer in Canaries, 42.

Carclinal, common names of, 110 ; plumage of, 110 ; male used to rear nests of young Canaries, 110 ; disposition of, 111 ; food in continement, 112 ; diseases of, 113.

Cardinal Grosbeak, 110.

Carthagena Parrot, 187.

Cat-bird, size, plumage, and song of, 168; food and treatment of, 169.

Cayenne pepper used to color Canaries, 28.

Chaffinch, size and plumage of, 95; food of, 96.

Chestnut-breasted Finch, 236.

Chestnut Finch, 236.

Cheveral, or King Goldfinch, 88.

Cinereous Waxbill, 237.

Cockatoos, Australia pre-eminently the realm of, 203; mode of catching, 204; Great Lemon-crested, Leadbeater's, Roseate, Nose, Small Iemon-crested, 205.

Common Waxblll, 242.
Contagious Diseases of Canaries, 42.

Constipation in Canaries, 38, 39.

Consumption in Canaries, 38.

Cordon-bleu Finch, 244.

Cramps in Canaries, 41.

Crow, size and plumage of, 224; may be taught numerous tricks, 224.

Cuban Parrot, 189 ; "Two Cubans on toast," 190.

Cut-throat Finch, 240.

Diamond Sparrow, 236.

Diarrhoea in Canaries, 39.

Diseases, 275-282.

Diseases of Canaries, 35 ; indigestion, wasting, temperature, surfeit, constipation, consumption, 38 ; asthma, loss of voice, diarrhoea, 39 ; inflammation of the bowels and liver, 40 ; epilepsy, or tits, 40 ; cramps, pip, 41 ; pimples, or obstruction of the rumpgland, 41; yellow gall, 41; giddiness, cancer, contagious diseases, 42 ; wounds, sore feet, 42; accidents, broken legs, 43.

Domesticated Canaries superior to wild ones, 9.

Double-banded Finch, 244.

Dwarf Parrots, 198.

England, Canaries first brought to, 9.

English mode of fceding Canaries, 17 ; varieties of Canaries, 22 ; training differs from German, 23.

English Nightingale, 123.

English Robin, 150.

English Starling, 145.

Epilepsy, or fits, in Canaries, 40.

Feeding of Canaries, German mode of, 17; English mode of, 17 .

Finch-boxes, 237.

Finches and Nuns, activity of, 234; breeding of, by Japanesc, 235 ; trading for African, 237 ; boxes for, 237 ; age of, 238.

Food and care, monthly suggestions respecting all kinds of birds, 259; November - December, 260; December - January, 261 ; January - February, 262; February March, 264; March-April, 26ŏ ; April -- May, 266; May - June, 268; June July, 269; July $\rightarrow$ August, 270; August - September, 271; September-October, 273.

Food for hreeding-birds, 44.

French Canaries, 27. 
German class of Canaries, 10 ; sime and color of, 14.

German mode of feeling Canaries, 17.

Germans first give attention to breeding of Canaries, 10.

Gildiness of Canaries, 42 .

Glossy Starlings, 14;.

Golden-crowned Trush, 167.

Golden Robin, 174.

Goldflnch, American, 101.

Goldfinch, European, points by which sex is distinguished, 87 ; Cheveral, or King Goldfinch, 88; Black Goldfinch, 88; Hybrid, 88 ; food, song, and intelligence of, 89 ; diseases of, 90 .

Grass Finch, 242.

Grass Paroquets, 210.

Gray Linnet, 103.

Gray, or Brazilian, Cardinal, 113.

Great Lemon-crested Cockatoo, 205.

Greater Redpoll Linnet. 91.

Green Satin Starling, 149 .

Green Macaw, 201.

Grosbeaks, 115 ; Rose-breasted, habits of, 115 ; foor for, 116; diseases of, 117 ; Pine Grosbeak, affection of, size and plumage of, 117 ; song of, 118; Blue Grosbeak, size and plumage of, 118; other varieties of Grosbeak family, 118 .

Harz Mountains, the lome of the German song Canary, 10.

Hill, or Rock, Minor, size, and plumage of, 215 ; resemblance of, to the Starling family, 215 ; a pions Minor, 215; a demoralized Minor, 216; voracity of, 217.

Holden's bird-cures and insect-powders, 287.

Holden's (new) Book on Birds, 288.

Holden's Price-list, 283-286.

Hooks, chains, springs, cups, etc., prices of, 291.

Hybrids, 32.

Indigestion in Canaries, 37.

Indigo-bird, size, plumage, and song of, 100 ; proper food and eage for, 100 .

Iucloor aviary, 52.

Inflammation of the bowels and liver in Canaries, 4J.

Insect-powder, Gerınan, 36.

Insects a pest to Canaries, 36 .

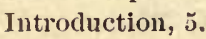

Jacklaw, favorite of the Crow tribe, 225 ; not so destructive as the Rook and Crow, nor so dignifled as the Raven, 226.

Java Sparrow, also called Rice-birds, 105; size and plumage of, 105; amusing tricks of, 105 .

Leadbeater's Cockatoo, 205.

Linnet, European, plumage of, 91; Brown Linnet, Greater Redpoll, Yellow Linnet, 91; beantiful song of, training of, 92 ; Burns's verse on, Hybrids, 93.

Lizard Canary, 23.

London Fancy Canary, 23.

Lories, 203.

Loss of roice in Canaries, 39.

Macaws, remarkable intelligence of, 200; Searlet, 13lue-and-Yellow, Green, 201 ; cage and stand for, 202.

Madagascar Love-bird, 213.

Madagascar Weaver, 239.

Magpie Finch, or Bronze Manakin, 242.

Magpies, the clowns or monkeys of the birdrace, 219 ; size, plumage, and nests of, 219 ; thieving propensities of, 220 ; a bird of ill omen, 221 ; capacity of, to talk, 221; food and care of, 222.

Manchester Coppy Canary, 26.

Maracaibo Parrot, 189.

Mating, time of, among Canaries, 50 .

Medicines, $2 \pi \breve{s}-281$.

Mexican Double Yellow-headed Parrot, intelligence and capability of, $186^{\circ}$; food and diseases of, 187.

Mice a source of torture to Canaries, 36 .

Minor Grackle, 215.

Mocking-bird, size and plumage of, 159 ; mode of eatching, natural song, powers of mimicry, 161 ; prices lower in the Northern than in the Southern States, 162; sex distinguished by markings, 163 ; diseases of, 164 .

Mottled Bullfinch, 58.

Mouse and squirrel cages, prices of, 290.

Mud Minor, 217.

Mules, 32.

Musleal Grackle, 215.

Napoleon Weaver, 239.

Nests for Canaries, 37.

New York Siskin, 101.

Nightingale, English, size and plunage of, 123 ; migrations of, 123 ; nest of, 123 ; song 
of, 124; difference in voices of, 12.) ; food of, 125; diseases of, 126 ; increased sale of, $12 \pi$.

Nonpareil, or Painted Bunting, plumage of, 98; mode of trapping, food, and care of, 99.

Norwich Canary, 23.

Nose Cockatoo, 205.

Orange Bishop Finch, 238.

Orange-cheeked Waxbill, 242.

Orchard Oriole, size ancl plumage of, 175 ; food and care of, 176 .

Paroquets, spread over immense districts in Australia, 207; size and plumage of, 207; the first live pair brought to England in 1840, 20 ; method of taming, 208; conjugal fidelity of, 209 ; Grass Paroquets, 209.

Parrot, African Gray, plumage of, 183 ; talking qualities of, 184; "Jim," a wonderful bircl, 184.

Parrot, Carthagena, 187.

Parrot-cages and Parrot-stands, prices of, 290. Parrot family, table of, 206.

Parrots, Dwarf, habits of, 198 ; stand high as family pets, 199.

Parrots, food, care, and diseases of, 193.

Parrots, liabits and breeding of wild, 179; food and diseases of, 191.

Parrots, methods of taming, 191 .

Parrots, teaching, 192.

Pekin Nightingale, or Japanese Robin, size and plumage of, 1.53; an accomplished gyınnast, 154; food and diseases of, 155.

Perches suitable for Canaries, 36 .

Pine Grosbeak, 117.

Pine Linnet, 103.

Piping Canaries, 34.

Pip, or obstruction of rump-gland, of Canaries, 41.

Preacher Toucan, 231.

Prices of cages, cups, liooks, etc., 289.

Prices of seeds, foods, ants' eggs, medicines, etc., $28 \pi$.

Quaker Finch, 240.

Raven, size, plumage, and nests of, 223 ; held in esteem for his propletic faculty, 224.

Recipes, 275-281.

Rerlbird, 110.

Red Cardinal, 110.

Rerl-headed Weaver, 239.

Redpoll Linnet, 103.
Reerl-bircl, 120.

Rice-bird, 105, 120.

Robin, American, size and plumage of, 170 ; not in deunand as a cage-bird, but a favorite dish, 171; treatment of, 172 .

Robin, Blue, size, plumage, and song of, 173; expert at catching iusects, 173 .

Robin, English, endearing qualities of, 150 ; size and plumage of, 150 ; nest of, 150 ; story of poor Cock Robin, 1.51; Worksworth's verse on, 151 ; song and pugnacity of, 151 ; kindly disposition of, 152.

Robin, Japanese, 153.

Rook, social habits of the, 225 .

Roseate Cockatoo, 205.

Rose-breasted Grosbeak, 115.

Scarlet Macaw, 201.

Scarlet Tanager, size, plumage, and song of, 177 ; food and treatment of, 178.

Scoteh Fancy Canary, 25.

Scotland, bircl-slows in, 26.

Seeds and Foods, IRecipes, I)iseases, Medicines, $275-281$.

Shell Paroquet, 207.

Shiner, 101.

Shippiug-boxes, prices of, 292.

Silver-bill Finch, or Quaker Finch, 240.

Silver or nickel plated caces, prices of, 292.

Siskin, size and plumage of, fool of, 47 .

Skylarks and Woodlarks, 133 ; song and flight of Skylark, 133; nest and fool of, 134; breeding of, 134 ; best cage for, 135 ; size, plumage, and soner of Woollark, 135.

Small Lemon-erested Cockatoo, 205.

Snow Bunting, home of, 104; plumage of, 104; an article of food in cold climates, 104; song of, 104; care of, 105.

Song, 131.

Song from the German of Giebel, 96 .

Sore feet in Canaries, 42.

Starling, English, laughable tricks of, 145; size and plumagre of, 145 ; fondness of, for water, training of, 146.

Starling, Satin, brilliant plumage of, 147 ; four varieties of, 147; Golden-breasted, Superb Satin, 148; Green Satin, 14!.

Stone Tlirusl, 143.

St. Andreasberg Canary, 11; Nightingale notes of, 12 .

St. Helena Waxbill, 245.

Strawberry Finch, 246.

Surfeit in Canaries, 38.

Swings and perches, prices of, 292. 
Table of Bulfinches, folltinches, etc., $10 \mathrm{~s}$. Table of Canaries, 5.5.

Table of talking-birds other than Parrots, 226.

Table of the Parrot Family, 206.

Table of twenty songsters compared, 282.

Talking Canaries, 34.

'Temperature for Canaries, 38.

Thistle-bird, 101.

Three-colored Nun, 240.

Thrush, song, size, and plumage of, 137 ; lines of Tennyson on, 138; sagacity of, 138 ; care of, 139.

Thrush, Stone, home of, 143 ; size, plumage, and natural song of, 143; food of, 144 .

Toucans, large bill of, 230 ; mode of feeding, size, and plumage, 230; varieties of, 231;

Toucan dinner in Rio Janeiro, 232.

Trick Canaries, 33.

Troopial, the best-known of South American song-birds, size and plumage of, 156 ; fond of sweetmeats, and readiness to display his accomplishments, 157 ; a young lacly's pet, 158.

Twenty songsters compared, 282.

Undulated Grass Paroquet, 207.
Virginla Cardinal, 110.

Virginia Niglıtingale, 110.

Wasting in Canaries, 35.

Water Thrush, 167.

Weaver, 239.

West-Inclian Paroquet, 213.

White-capped Nun, 239.

White-headed Paroquet, 213.

White Java Sparrow, eause of cliange of color, $10 \tau$; breeding of, by Japanese, 107.

Wood-frame, tinned-wire cages, prices of, 291.

Wood Thrush, 166.

Woodlark, 135.

Wounds of Canaries, 42.

Yellow-bird, 101 ; known as Amerlcan Goldflnch, Thistle-bird, New-York Siskin, and Shiner, 101; nest and song of, 101; trieks of, and cages for, 102 .

Yellow Gall in Canaries, 41.

Yellow-breasted Toucan, 231 .

Yellow Linnet, 91.

Yorkshire Canary, 26.

Zebra Finch, 245. 
SINGER'S PATENT GRAVEL PAPER,

For the Bottom of Bird Cages,

Is promounced by all to be the greatest con. venience, for those keeping birls, ever offered to the public. It forms an artificial ground for the birl to serateb and plck upou, renders the feet tough and strong, and preventa filth, disease, and vermin. Indorsed by all bird fancierk.

For sale by all druggists, and bird and cage dealers. 25 cents per package of twelve papers.

\section{MAYLFACTURED BY}

J. H. SINGER, 213 West 31st St., NEW YORK.
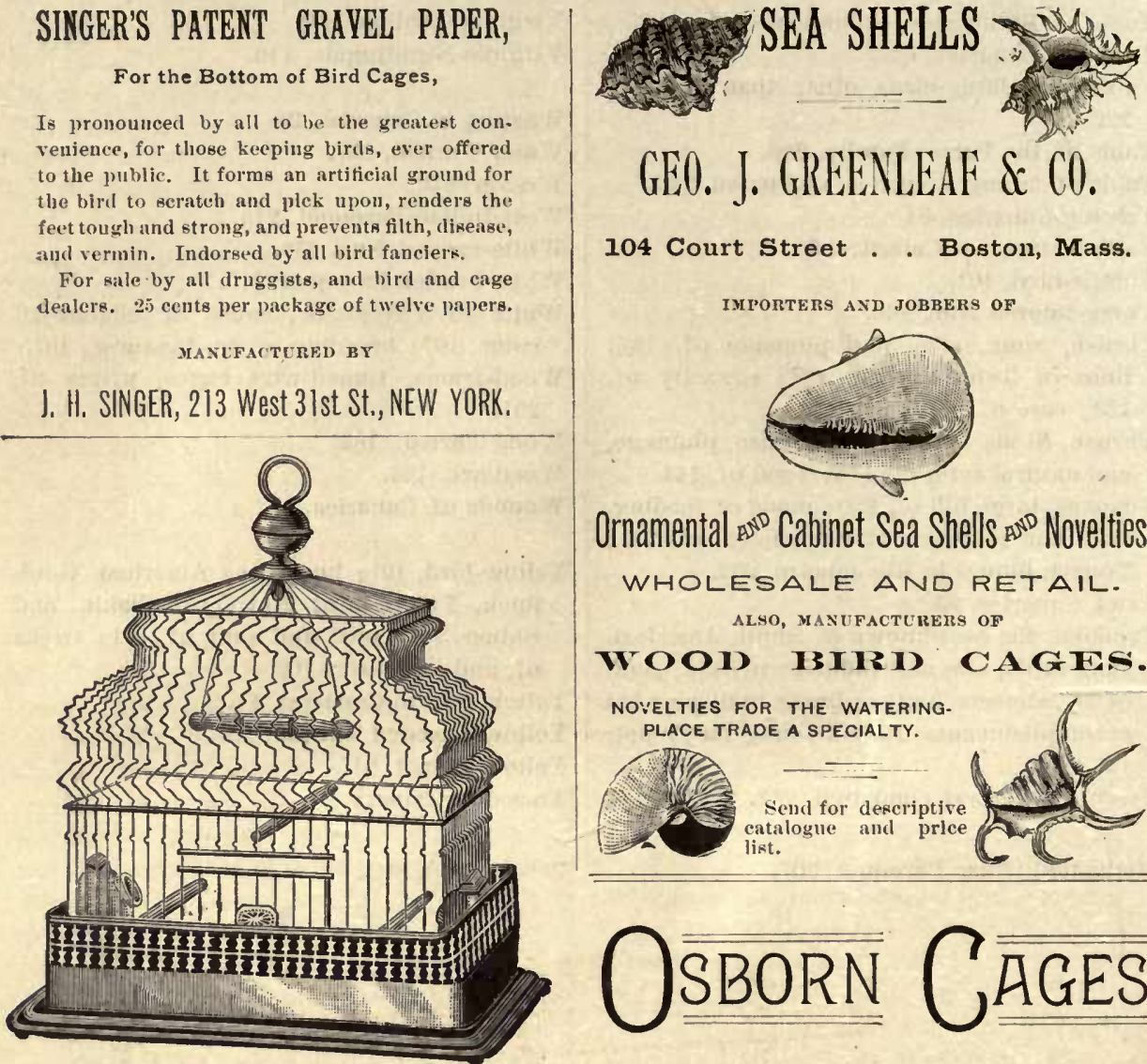

104 Court Street . Boston, Mass.

IMPORTERS AND JOBBERS OF

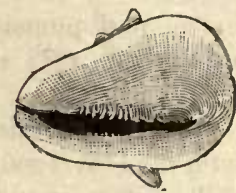

Ornamental wa Cahinet Sea Shells wovelties

WHOLESALE AND RETAIL.

ALSO, MANUFACTURERS OF

\section{WOOD IBITID CAGES.}
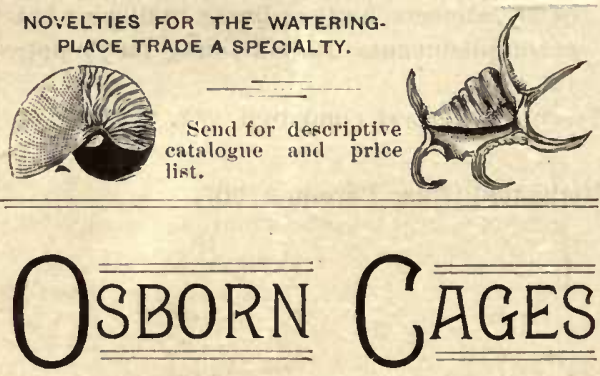

Always receive Diplomas and Medals at all Exhibitions and Fairs where exhibited, for BEAUTY OF DESIGN, ORIGINALITY, THOROUGHNESS OF CONSTRUCTION.

NEW PARROT CAGE FENDER. This effectually prevents any scattering of dirt or food.

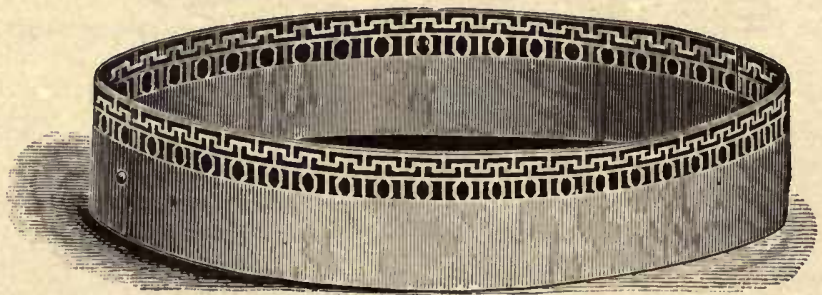

Onr New Combination Seed Fender for Canary Cages. Utllity and beanty combined. It has no equal for prevent Ing the scattering of seed.

ASK FOR THE NEW OSBORN CAGES FOR CANARIES.

Designs new and beautiful. See that "Osborn Mfg. $\mathrm{C}_{0} . "$ is on the door. Sold by the trade generally, N. B. - DON'T BUY POOR IMITATIONS. 


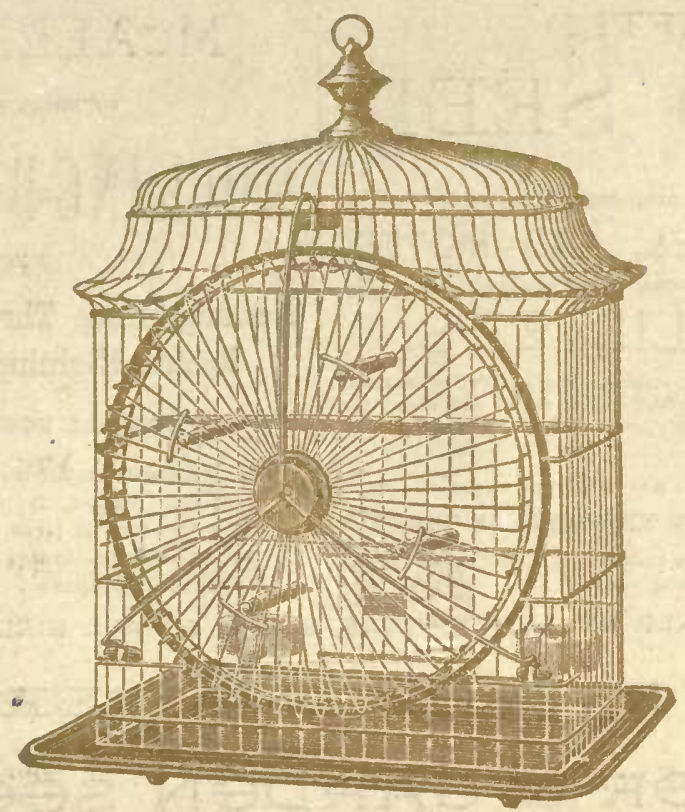

No. 3 รо.

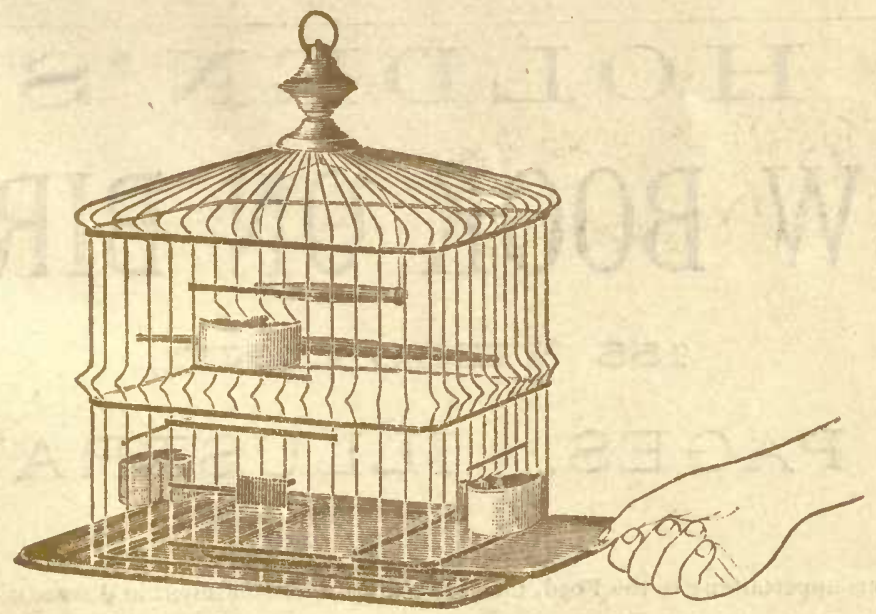

No. 315.

Above illustrates oir Patented improvement in Cages. The Mat or Pan ean be removed from the Cage wlthout detaching the Body from the Base of the Cage, absolutely avolding the danger of losing the bird. It is applied to all our Square Brass, Nickel Plated and Bronze Cages with Netal Bases. No. 350 illustrates our Brass Revolving Wheel Cage for Canary Birds.

\section{ANDREW B. HENDRYX \& CO,}

MANUFACTLRERS OF

BRASS, GOID BRONZE, BRIGHT METAY AND JAPANNED CANARY CAGES.

CAGE SPECIALTIES, PARROT, SQUIRREL AND MOCKING CAGES.

NEW HAVHN, CONN. 


\section{SIFTED \\ BIRD SEED.}

IF YOU WANT BIRD-SEED FREE FROM

DIRT, GRAVEL, AND MOTES, ASK YOUR GROCER OR DRUGiGIST FOR MCALLISTER'S.

This seed is carcfully selected best quality of canary, German rape, and imported millet seeds, and is put np fresh in one-pound boxes.

IF YOUR BIRD HAS LOST HIS VOICE, SHEPPARD'S SONG RESTORER, OR TREAT,

Is an invigorating tonic that is sure to get the hird into song agaln.

FOR SALE BY ALL DRUGGISTS AND AT ALL BIRD STORES.

F. F. MCAIIISTER,

DEALER IN

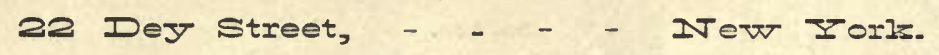

$\mathrm{HO} \mathrm{O} \mathrm{DH} \mathrm{N}$, $\mathrm{S}$

NEW BOOK ON BIRDS,

155 THIOUSAND,

128 PAGES. ILLUSTRATED.

Latest facts appertaining to the Food, Care, Breeding, and Treatment in disease of Cage Birds.

By Mail postpaid for Twenty-five Cents.

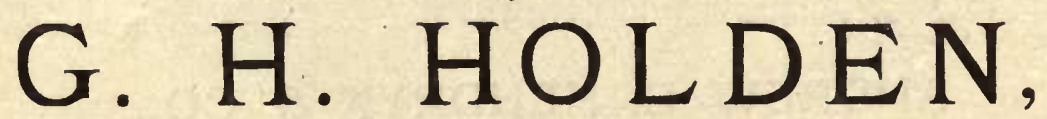

240 6th Avenue, 15th and 16th Streets; New York. 9 Bowdoin Square, Boston, Mass.

37 North Main Street, Providence, I. L 


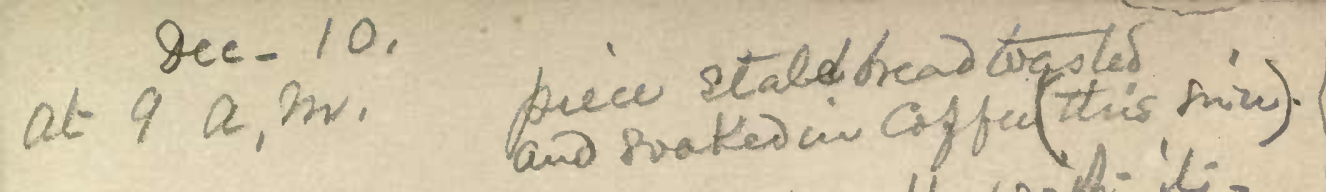
$\frac{1}{4}$ leaspormple coffer mind - it.

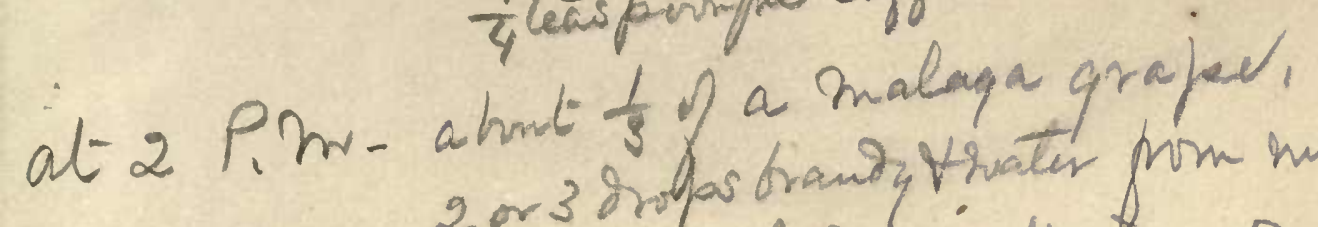

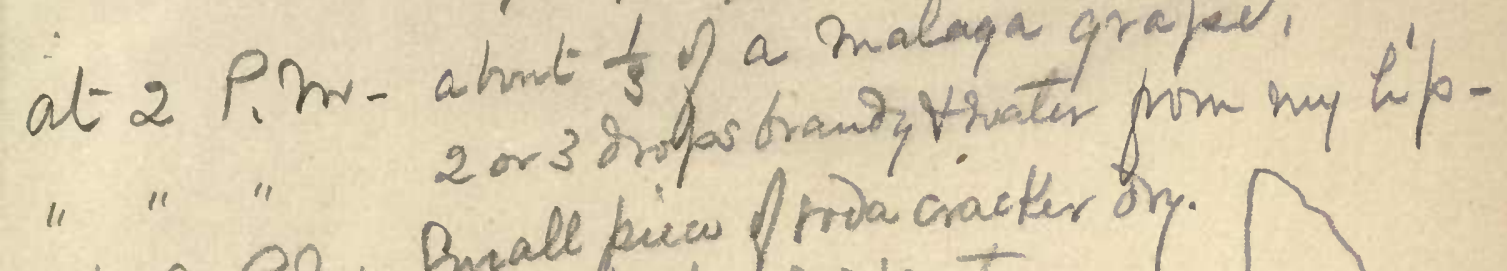

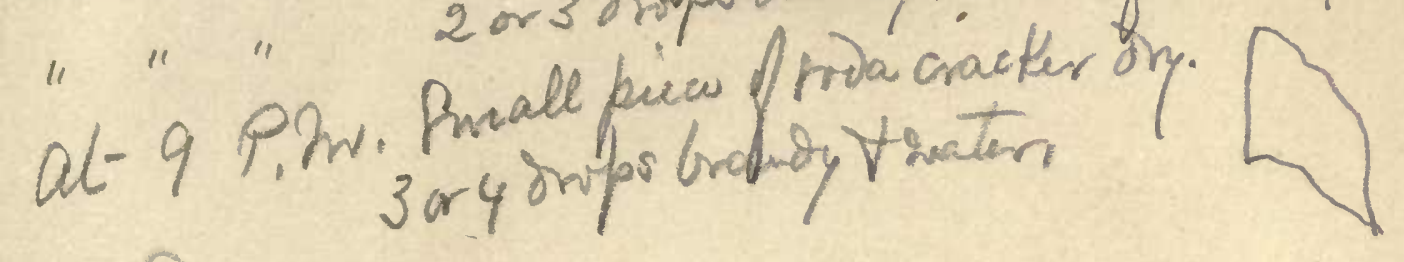

Qee- 11.

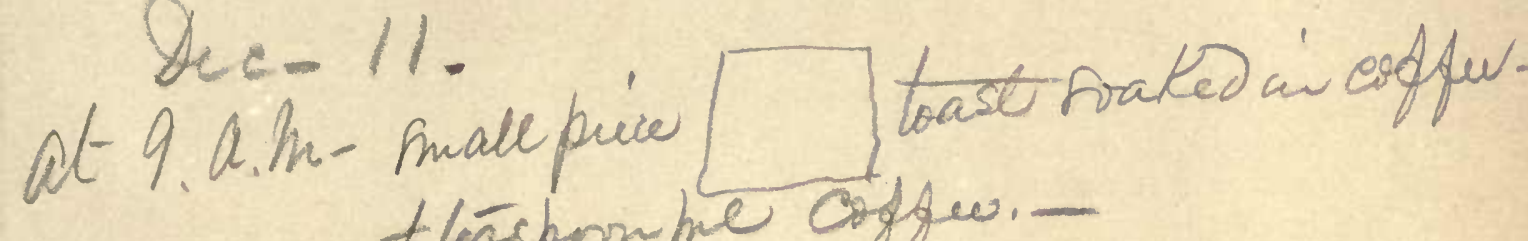
$\frac{1}{2}$ lasspormpic offew.- 


4:

THIS BOOK IS DUE ON THE IAST DATE

STAMPED BELOW

RETURN CIRCULATION DEPARTMENT

TO $\rightarrow 202$ Main Library

LOAN PERIOD
HOME USE

4

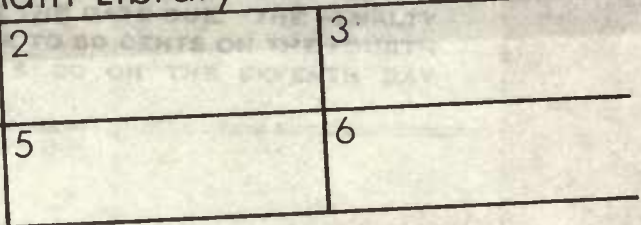

ALL BOOKS MAY BE RECALLED AFTER 7 DAYS

Renewals and Recharges may be made 4 days prior to the due date.

Books may be Renewed by calling $\mathbf{6 4 2 . 3 4 0 5}$

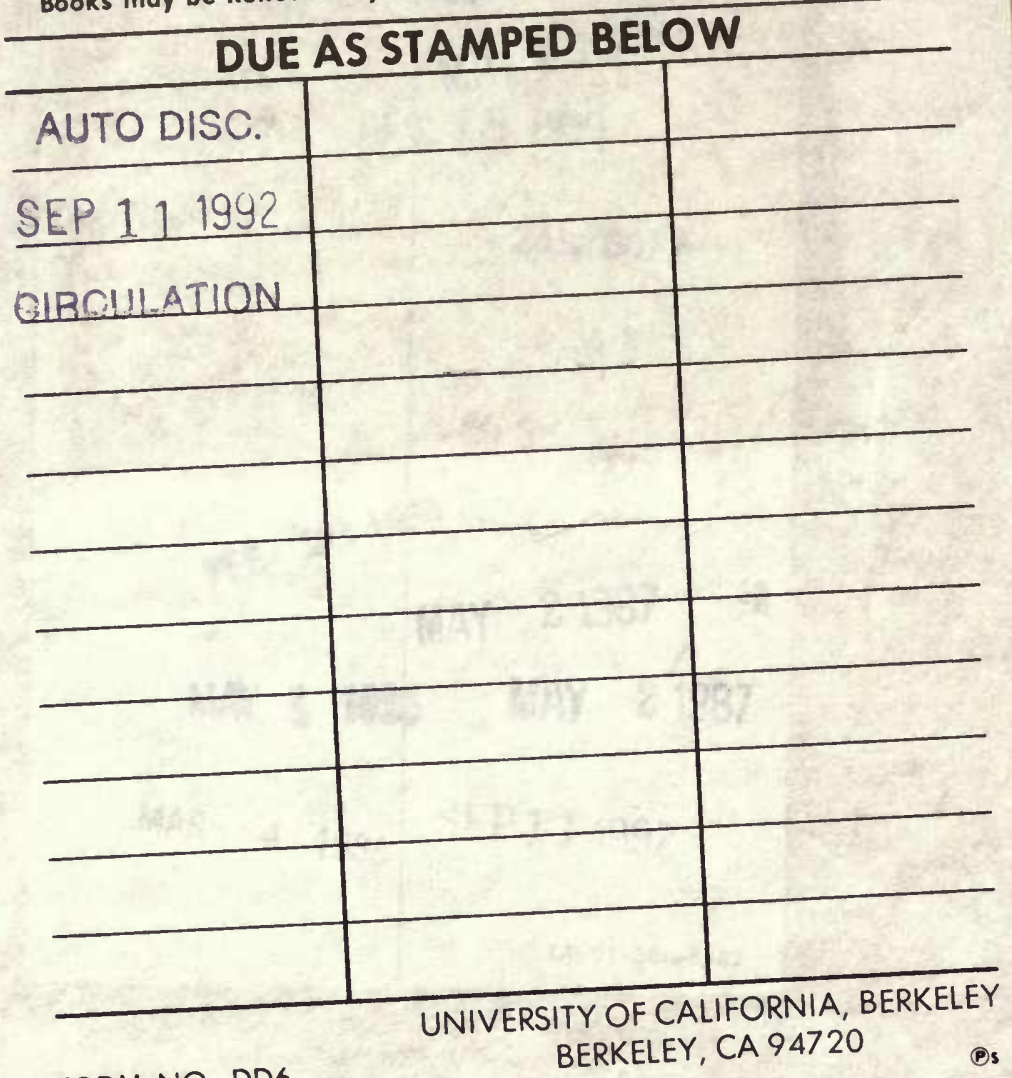

FORM NO. DD6 


\section{U.C. BERKELEY LIBRARIES}

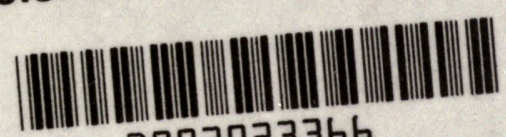
B003023366

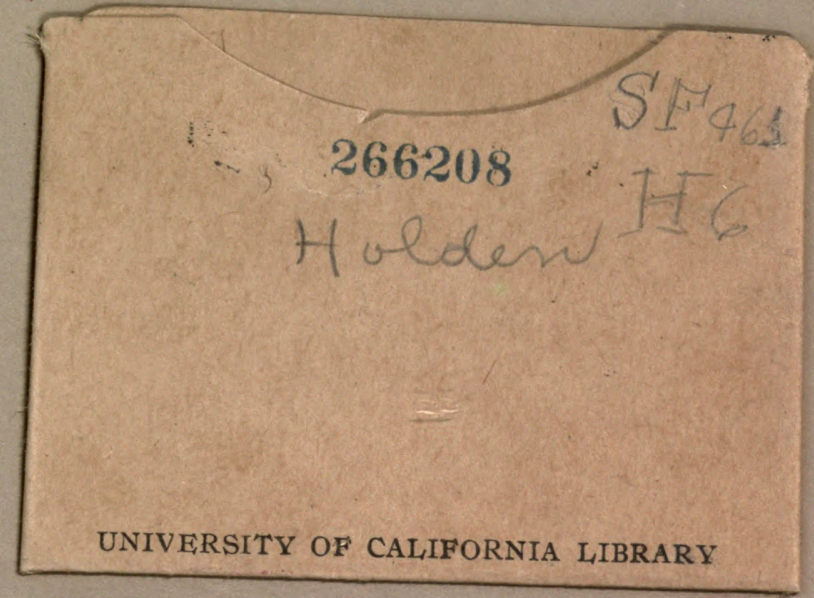

t.

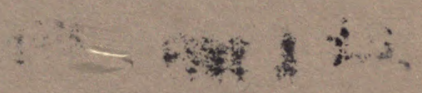


